Aplicação da análise de mutantes no contexto do teste e validação de redes de Petri coloridas 



\title{
Aplicação da análise de mutantes no contexto do teste e validação de redes de Petri coloridas
}

\author{
Adenilso da Silva Simão
}

Orientador: Prof. Dr. José Carlos Maldonado

Tese apresentada ao Instituto de Ciências Matemáticas e de Computação - ICMC-USP, como parte dos requisitos para obtenção do título de Doutor em Ciências - Ciências de Computação e Matemática Computacional.

"Versão Revisada Após a Defesa" 

A Olivia, Geraldo, Selma e Emanoela. 



\section{Agradecimentos}

- A Deus, pois feliz aquele que trilha Seus caminhos.

- À minha esposa Selma, pela paciência, incentivo e apoio ao longo de todos esses anos. E também pelo amor e compreensão em todos os momentos, fáceis e difíceis.

- À minha filha Emanoela, por simplesmente existir e me ensinar o que significa "amar incondicionalmente".

- À minha família, em especial aos meus pais, Geraldo e Olivia, pelo apoio e confiança imprescindíveis para realização deste trabalho.

- Ao Prof. Dr. José Carlos Maldonado, pelo apoio, pela orientação, tanto acadêmica quanto pessoal, e, principalmente, pela amizade.

- Aos amigos do Labes e aos amigos "do" Labes, pelo apoio e pelo ambiente descontraído e sempre estimulante. Mesmo correndo o imperdoável risco de estar esquecendo alguns, citarei (em ordem alfabética) Aline, Andrea, André Maluquinho, André Rocha, Antonielly, Auri e Elaine, Camila e Cláudio (ou Claudia e Camilo), Débora, Dona Vilma, Edilson, Elisa, Ellen, Ernesto, Erika, Fabiano (Falcon), Gawa, Ju, Luciana e Richard, Marco, Maria Istela, Masiero, Mateus e Raquel, Otávio, Osnete, Reginaldo Ré, Rogério, Renata, Rosana, Rosângela, Rosely, Rudinei e Flavia, Sandra, Sandrão (Cantina), Sandro (KLB), Seu Adão, Simone, Simone e Paulo, Tânia (Tonha), Tatiana, Thaise, (U)Bira(jara) e Valter (Wagner).

- Àqueles que, de alguma forma, me ajudaram ao longo desse trabalho. Em especial, a Alessandro Fabrício Garcia, André Luis dos Santos Domingues, Antonio Santana, Auri Marcelo Rizzo Vincenzi, Carlos Lucena, Marco Arthur Candolo, Roberto Bigonha, Sandra Fabbri, Simone do Rocio Senger de Souza, Tatiana Sugeta e Thaise Yano.

- Ao Alessandro, Christina, Elton e Alésio, pela acolhida no Rio de Janeiro naquele chuvoso janeiro de 2002.

- Um agradecimento às pessoas que ajudaram na revisão do texto, em especial a Cagnin, Camargo, Domingues, Ferrari, Hohn, Simão, Sugeta e Vincenzi.

- A todos os funcionários do ICMC, em especial à Ana Paula, Beth, Laura, Carmen, Ângela, Sueli e Tatiana, pelo apoio acadêmico e amizade.

- À FAPESP e à USP, pelo apoio financeiro. 



\section{Sumário}

Resumo $\quad$ Xv

Abstract $\quad$ xvii

1 Introdução 1

1.1 Considerações Iniciais . . . . . . . . . . . . . . . . . . . . . . . . . 1

1.2 Contexto e Motivação . . . . . . . . . . . . . . . . . . . . . 6

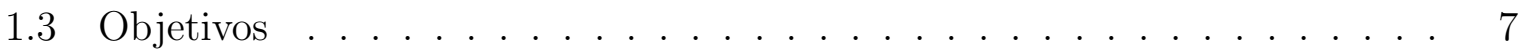

1.4 Organização do Trabalho . . . . . . . . . . . . . . . . . . . 8

2 Revisão Bibliográfica $\quad 11$

2.1 Considerações Iniciais . . . . . . . . . . . . . . . . . . . . . . . . . 11

2.2 Teste de Software: Uma Visão Geral . . . . . . . . . . . . . . . . . . . . . 11

2.2.1 Critérios de Teste . . . . . . . . . . . . . . . . 14

2.2.1.1 Teste Exaustivo . . . . . . . . . . . . . . . 15

2.2.1.2 Teste Aleatório . . . . . . . . . . . . . . . . . . 15

2.2.1.3 Teste Funcional . . . . . . . . . . . . . . . . . . . 15

2.2.1.4 Teste Estrutural . . . . . . . . . . . . . . . 16

2.2.1.5 Teste de Caixa Cinza . . . . . . . . . . . . . . . . 18

2.2.1.6 Teste Baseado em Erros . . . . . . . . . . . . . . . . . . . 19

2.2.2 Comparação entre Critérios de Teste . . . . . . . . . . . . . . . . 21

2.2.2.1 Comparação com base em Estudos Teóricos . . . . . . . . 21

2.2.2.2 Comparação com Base em Estudos Empíricos . . . . . . . 22

2.2.2.3 Comparação do Teste de Subdomínio versus Teste Aleatório 23

2.2.3 Automatização da Atividade de Teste . . . . . . . . . . . . . . 25

2.2.3.1 Ferramentas de Teste . . . . . . . . . . . . . 26

2.2.3.2 Geração de Casos de Teste . . . . . . . . . . . . . . . . . . 28

2.3 Análise de Mutantes . . . . . . . . . . . . . . . . . . . . . . . . . 29

2.3.1 Principais Passos da Análise de Mutantes . . . . . . . . . . . . . . 30

2.3.1.1 Geração dos Mutantes . . . . . . . . . . . . . . . . . 30

2.3.1.2 Execução de $P$. . . . . . . . . . . . . . . . . . 33

2.3.1.3 Execução dos Mutantes . . . . . . . . . . . . . . . 33

2.3.1.4 Análise dos Mutantes . . . . . . . . . . . . . . . 35

2.4 Sistemas Reativos: Técnicas de Especificação . . . . . . . . . . . . . 36 
2.4 .1 Redes de Petri . . . . . . . . . . . . . . . . . . . . 39

2.4.1.1 Representação Gráfica . . . . . . . . . . . . . . . . 41

2.4.1.2 Representação Matricial . . . . . . . . . . . . . . . . 42

2.4.1.3 Propriedades . . . . . . . . . . . . . . . . . 43

2.4.1.4 Classes de Redes de Petri . . . . . . . . . . . . . . . . 44

2.4.2 Redes de Petri Coloridas . . . . . . . . . . . . . . . . . . . 46

2.4.2.1 Definição Formal . . . . . . . . . . . . . . . . . . 52

2.4.2.2 Técnicas de Análise e Validação . . . . . . . . . . . . . . . 57

2.4.2.3 Grafo de Ocorrência . . . . . . . . . . . . . . . 57

2.4.2.4 Ferramentas de Apoio . . . . . . . . . . . . . . . . 59

2.5 Aspectos de Teste e Validação de Especificações . . . . . . . . . . . . . . . 62

2.5.1 Cálculo de Invariantes . . . . . . . . . . . . . . . . . . 65

2.5.2 Árvore de Alcançabilidade . . . . . . . . . . . . . . . . . . . . 66

2.5.3 Simulação . . . . . . . . . . . . . . . . . . . . . . 69

2.5.4 Critério Análise de Mutantes . . . . . . . . . . . . . . . 70

2.5.4.1 A Ferramenta Proteum-RS/PN . . . . . . . . . . 73

2.6 Análise de Risco . . . . . . . . . . . . . . . . . . . . . . . . 76

2.6.1 Técnicas de Análise de Risco . . . . . . . . . . . . . . . . . 77

2.6.1.1 Técnica HAZOP . . . . . . . . . . . . . . 78

2.6.1.2 Análise de Árvore de Falhas . . . . . . . . . . . . . . . . . 79

2.6.1.3 Análise de Modos e Efeitos de Falhas . . . . . . . . . . . . 82

2.6.1.4 Análise de Risco com Redes de Petri . . . . . . . . . . . . 82

2.7 Considerações Finais . . . . . . . . . . . . . . . . . . . . . . . . . 82

3 Análise de Mutantes Aplicada a Redes de Petri Coloridas $\quad 85$

3.1 Considerações Iniciais . . . . . . . . . . . . . . . . . . . . . . . . . . . . . . . . . . . . . . . . .

3.2 Operadores de Mutação . . . . . . . . . . . . . . . . . . . . 86

3.2 .1 Alterações na Marcação Inicial . . . . . . . . . . . . . . . . . . 86

3.2.2 Alterações nos Arcos . . . . . . . . . . . . . . . . . . . . . . . 88

3.2 .3 Alterações nas Variáveis . . . . . . . . . . . . . . . . . . . . 92

3.2.4 Alterações em Constantes . . . . . . . . . . . . . . . . . . . 93

3.2.5 Alterações nas Anotações dos Arcos . . . . . . . . . . . . . . . . . . . 94

3.2.6 Alterações nas Condições de Guarda . . . . . . . . . . . . . . . . . 95

3.2.7 Alterações nos Operadores . . . . . . . . . . . . . . . . . 96

3.3 Execução e Análise dos Mutantes: Relação de Equivalência . . . . . . . . . 97

3.3 .1 Sequência Habilitada . . . . . . . . . . . . . . . . . . . . . 97

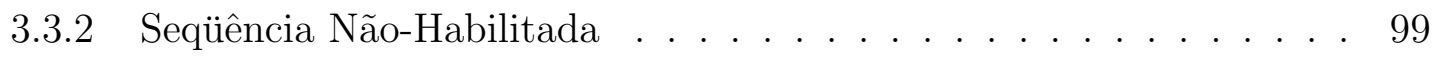

3.4 Complexidade dos Operadores . . . . . . . . . . . . . . . . . . . . . . . . 99

3.4 .1 Alterações na Marcação Inicial . . . . . . . . . . . . . . . . . . . . . 99

3.4 .2 Alterações nos Arcos . . . . . . . . . . . . . . . . . . . . . . 100

3.4 .3 Alterações nas Variáveis . . . . . . . . . . . . . . . . . . . . . 101

3.4.4 Alterações em Constantes . . . . . . . . . . . . . . . . . . . . 101

3.4.5 Alterações nas Anotações dos Arcos . . . . . . . . . . . . . . . . . . 101

3.4.6 Alterações nas Condições de Guarda . . . . . . . . . . . . . . . 102

3.4.7 Alterações nos Operadores . . . . . . . . . . . . . . . . . . . . 102

3.5 Descrição de Operadores de Mutação . . . . . . . . . . . . . . . . . . . . . 103

3.5.1 A Linguagem $\mathcal{M} u \mathcal{D} e \mathcal{L}$. . . . . . . . . . . . . . . . . . . . . . . 104

3.5.1.1 Requisitos ..................... 104 
3.5.1.2 Notação Básica . . . . . . . . . . . . . . . . . . . . 105

3.5.1.3 Casamento de Padrões e Substituições . . . . . . . . . . . 106

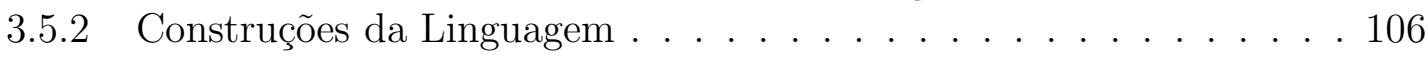

3.5.2.1 Um Exemplo . . . . . . . . . . . . . . . . . . . . . . 111

3.5.2.2 Mutações Sensíveis a Contexto . . . . . . . . . . . . . . . 113

3.5.3 Aplicações . . . . . . . . . . . . . . . . . . . . . . . . . 117

3.5.3.1 Redes de Petri Coloridas . . . . . . . . . . . . . . . . 118

3.5.3.2 C, C++ e Java . . . . . . . . . . . . . . . 118

3.5.3.3 SML . . . . . . . . . . . . . . . . . . . . . . . . . . . 119

3.6 Análise de Risco . . . . . . . . . . . . . . . . . . . . . . . . . . . . . . 119

3.7 Considerações Finais . . . . . . . . . . . . . . . . . . . . . . . . 121

4 Geração de Seqüências de Teste Baseada na Análise de Mutantes 123

4.1 Considerações Iniciais . . . . . . . . . . . . . . . . . . . . . . 123

4.2 Esquema Geral do Algoritmo . . . . . . . . . . . . . . . . . . . . 124

4.3 Geração de Vetores de Caracterização . . . . . . . . . . . . . . . . . . 125

4.3.1 Geração de Seqüências Baseada no Vetor de Caracterização . . . . . 128

4.4 Exemplo . . . . . . . . . . . . . . . . . . . . . . 132

4.5 Aplicação do Algoritmo para Redes de Petri Coloridas . . . . . . . . . . . 135

4.6 Considerações Finais . . . . . . . . . . . . . . . . . . . . . . . 137

5 Ferramentas de Apoio $\quad 139$

5.1 Arquitetura . . . . . . . . . . . . . . . . . . . . 140

5.2 Modelagem . . . . . . . . . . . . . . . . . . . . . . 140

5.2.1 Esquema Conceitual . . . . . . . . . . . . . . . . . . . . 141

5.2 .2 Esquema Navegacional . . . . . . . . . . . . . . . . . . . . . . 142

5.2 .3 Modelo de Interface Abstrata . . . . . . . . . . . . . . . . . . . . . 144

5.3 Aspectos Operacionais . . . . . . . . . . . . . . . . . . . 157

5.3 .1 Acesso . . . . . . . . . . . . . . . . . . . . . . 158

5.3 .2 Criação de Projeto . . . . . . . . . . . . . . . . 160

5.3.3 Inclusão dos Operadores de Mutação . . . . . . . . . . . . . . . . . 162

5.3.4 Inclusão da Rede a Ser Testada . . . . . . . . . . . . . . . . . . . . 162

5.3.5 Definição da Relação de Equivalência . . . . . . . . . . . . . . . . . 163

5.3.6 Finalização de Projeto . . . . . . . . . . . . . . . . . . . . 165

5.3 .7 Criação de Sessão . . . . . . . . . . . . . . . . . . . . . . 165

5.3.8 Inclusão dos Mutantes . . . . . . . . . . . . . . . . . . . . . . 168

5.3.9 Inclusão de Casos de Teste . . . . . . . . . . . . . . . . . . . . . . . 169

5.3 .10 Inclusão Interativa de Casos de Teste . . . . . . . . . . . . . . . . . 170

5.3 .11 Análise dos Mutantes . . . . . . . . . . . . . . . . . . . . . 171

5.3 .12 Configuração de Exibição . . . . . . . . . . . . . . . . . . 173

5.4 Aspectos Relevantes da Implementação . . . . . . . . . . . . . . . . . . . . 175

5.4 mudelgen . . . . . . . . . . . . . . . . . 176

5.4.1.1 Uso de Semântica Denotacional como Oráculo . . . . . . . 178

5.4.1.2 $\mathcal{M} u \mathcal{D} e \mathcal{L}$ Animator . . . . . . . . . . . . . . . . . . . 180

5.4.2 Sim/CPN: Um Simulador para Redes de Petri Coloridas . . . . . . 181

5.5 Considerações Finais ． . . . . . . . . . . . . . . . . . . . 182 
6 Estudos de Caso $\quad 185$

6.1 Considerações Iniciais . . . . . . . . . . . . . . . . . . . . . . . . . . 185

6.2 Estudo de Caso I: Aplicação da Análise de Mutantes a Redes de Petri

Coloridas . . . . . . . . . . . . . . . . . . . 185

6.2 .1 Definição . . . . . . . . . . . . . . . . 186

6.2 .2 Materiais . . . . . . . . . . . . . . . 186

6.2 .3 Procedimento . . . . . . . . . . . . . . . . . . . 187

6.2 .4 Coleta de Dados . . . . . . . . . . . . . . . . . . . . 188

6.2.5 Resultados . . . . . . . . . . . . . . . . . . . 188

6.2.5.1 Número de Mutantes Gerados . . . . . . . . . . . . . . 188

6.2.5.2 Mutantes Equivalentes . . . . . . . . . . . . . . . . 190

6.2.5.3 Conjuntos de Casos de Teste . . . . . . . . . . . . . . . . 191

6.3 Estudo de Caso II: Algoritmo de Geração de Casos de Teste para Redes de

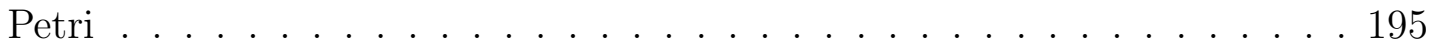

6.3 .1 Definição . . . . . . . . . . . . . . . . . . 195

6.3 .2 Materiais . . . . . . . . . . . . . . . . . 195

6.3 .3 Procedimento . . . . . . . . . . . . . . . . . 196

6.3 .4 Coleta de Dados . . . . . . . . . . . . . . . . . . . 197

6.3.5 Resultados . . . . . . . . . . . . . . . . . . . . . . 197

6.4 Considerações Finais . . . . . . . . . . . . . . . . . . . 198

7 Conclusão 201

7.1 Contribuições . . . . . . . . . . . . . . . . . . . . . 201

7.2 Dificuldades e Limitações . . . . . . . . . . . . . . . . . . . . . . . . . 202

7.3 Trabalhos Futuros . . . . . . . . . . . . . . . . . 203

7.4 Publicações . . . . . . . . . . . . . . . . . . . . . 205

7.4 .1 Periódicos . . . . . . . . . . . . . . . 205

7.4.2 Congressos com Arbitragem . . . . . . . . . . . . . . . 205

7.4.3 Sessões de Ferramenta . . . . . . . . . . . . . . . . . . 206

7.4 .4 Outras Publicações . . . . . . . . . . . . . . . . 207

$\begin{array}{ll}\text { Referências Bibliográficas } & 209\end{array}$

A Gramáticas Formais e Linguagens $\quad 231$

B Definição Formal da Linguagem $\mathcal{M} u \mathcal{D} e \mathcal{L} \quad 235$

B.1 Domínios . . . . . . . . . . . . . . . . . . . . 235

B.2 Sintaxe Formal . . . . . . . . . . . . . . . . . . . . . 237

B.3 Funções de Valoração Semântica . . . . . . . . . . . . . . . . . . . . . 238

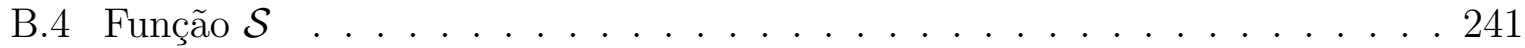

B.5 Funções Auxiliares . . . . . . . . . . . . . . . . . . . . . . . . . 242

C Descrição $\mathcal{M} u \mathcal{D} e \mathcal{L}$ dos Operadores de Mutação para RPCs 245

D Critérios de Cobertura para Redes de Petri Coloridas $\quad 261$

D.1 Considerações Iniciais . . . . . . . . . . . . . . . . . . . . . . . . 261

D.2 A Família de Critérios . . . . . . . . . . . . . . . . . . . . . . . 261

D.2.1 Análise de Propriedades da Coloured Petri Nets Coverage Criteria

Family $(\mathrm{CPNCCF}) \ldots \ldots . \ldots . . \ldots 264$ 
D.2.2 Estabelecimento dos Requisitos de Teste . . . . . . . . . . . . . 265

D.2.3 Análise de Adequação e Geração de Conjuntos de Teste . . . . . . . 267

D.3 Considerações Finais . . . . . . . . . . . . . . . . . . . . . . . . . . 269

E Redes de Petri Coloridas do Estudo de Caso I 271

E.1 Alocador de Recursos (RA) . . . . . . . . . . . . . . . . . . 271

E.2 Sistema Telefônico (TL) . . . . . . . . . . . . . . . . . . 272

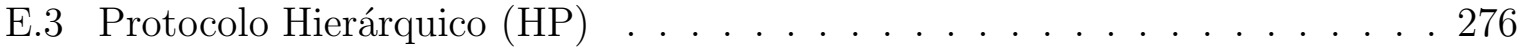

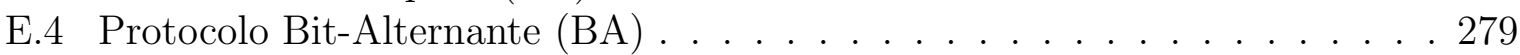

E.5 Protocolo Conferência/Cotê de Resyste $(\mathrm{CP})$. . . . . . . . . . . . . . . 280 


\section{Lista de Figuras}

2.1 Representação Gráfica de uma Rede de Petri. . . . . . . . . . . . . . . . . 41

2.2 Rede da Figura 2.1 após o Disparo de $T_{2} \ldots \ldots \ldots$. . . . . . . . . . . . . 42

2.3 Representação Matricial da Rede de Petri da Figura 2.1. . . . . . . . . . . . 42

2.4 Exemplo de uma Rede de Petri Colorida (Jensen, 1997b). . . . . . . . . . . 48

2.5 Definição em CPN-ML dos Tipos do Modelo DDB. . . . . . . . . . . . . . 50

2.6 A Rede de Petri Colorida da Figura 2.4 Representada com uma Tupla. . . 54

2.7 Grafo de Ocorrência para a Rede da Figura 2.4 para $n=3 \ldots$. . . . . . . 58

2.8 Módulo Editor da Ferramenta Design/CPN. . . . . . . . . . . . . . . . . 62

2.9 Desenvolvimento de Sistemas Baseados em Especificações (Baseada em $($ Desel, 2002)). . . . . . . . . . . . . . . . . . . 63

2.10 Visão Detalhada do Desenvolvimento de Sistemas Baseados em Especificações (extraído de (Desel, 2002)). . . . . . . . . . . . . . . . . 63

2.11 Algoritmo para a Geração da Árvore de Cobertura para Redes de Petri (Macial et al., 1996; Murata, 1984; Peterson, 1981) . . . . . . . . . . . . 68

2.12 Uma Rede de Petri (Peterson, 1981) cujo Conjunto de Marcações Alcançáveis é Infinito. . . . . . . . . . . . . . . . . . . . . . . . 68

2.13 Árvore de Cobertura da Rede da Figura 2.12. . . . . . . . . . . . . . . . . 69

2.14 Visualização de um Mutante durante a Inclusão de um Caso de Teste. . . . 75

2.15 Exemplo de Árvore de Falhas (Leveson e Harvey, 1983). . . . . . . . . . . . 81

3.1 Exemplo de Mutante Gerado pelo Operador InitMarkDel. . . . . . . . . . 88

3.2 Exemplo de Mutante Gerado pelo Operador InitMarkIns. . . . . . . . . . 88

3.3 Exemplo de Mutante Gerado pelo Operador InitMarkExchange. . . . . . . 89

3.4 Exemplo de Mutante Gerado pelo Operador ArcInversion. . . . . . . . . . 89

3.5 Exemplo de Mutante Gerado pelo Operador InputArcDel. . . . . . . . . . 90

3.6 Exemplo de Mutante Gerado pelo Operador InputArcIns. . . . . . . . . . 91

3.7 Exemplo de Mutante Gerado pelo Operador InputArcExchange. . . . . . . . 91

3.8 Exemplo de Mutante Gerado pelo Operador InputArcShift. . . . . . . . . 92

3.9 Exemplo de Mutante Gerado pelo Operador VarExchange. . . . . . . . . . 93

3.10 Exemplo de Mutante Gerado pelo Operador VarSmall. . . . . . . . . . . . 93

3.11 Exemplo de Mutante Gerado pelo Operador AnnotExchange. . . . . . . . . . 94

3.12 Exemplo de Mutante Gerado pelo Operador AnnotSmall. . . . . . . . . . . 95

3.13 Exemplo de Mutante Gerado pelo Operador GuardIns. . . . . . . . . . . . 96 
3.14 O Padrão de Árvore para '( :a ) * :b'. Os Tipos de ':a' e ':b' São Definidos como $\langle A\rangle$ e $\langle B\rangle$, Respectivamente. . . . . . . . . . . . 105

3.15 Processo de Casamento de Padrões. . . . . . . . . . . . . . . . . . 106

3.16 Um Operador de Mutação Simples. Para Cada Comando no Programa, um Mutante é Gerado Removendo-se Tal Comando. . . . . . . . . . . . . . 107

3.17 (a) Um Operador de Mutação que Substitui um Comando while por um Comando do-while. (b) Um Operador de Mutação que Substitui Todos os Comandos while em Qualquer Nível por um Respectivo Comando do-while. 108

3.18 Um Operador de Mutação que Troca cada Comando while em Qualquer Nível por um Comando do-while e Vice-Versa. . . . . . . . . . . . . . . . . 109

3.19 Um Operador de Mutação que Troca a Expressão de Controle de Comandos Do-While por 0. O Caracter \# Marca uma Linha de Comentário. . . . . . . 110

3.20 (a) Um Operador de Mutação que Gera um "Mutante" que Igual ao Produto Original. (b) Um Operador de Mutação que não Gera Nenhum Mutante. 111

3.21 Um Operador de Mutação Multi-Propósito. . . . . . . . . . . . . . . . . . 111

3.22 (a) Programa Original. (b)-(f) Mutantes Gerados pelo Operador da Figura 3.21. As Partes Alteradas Estão em Destaque. . . . . . . . . . . . . 112

3.23 Exemplo de uma Gramática de Atributo para a Expressão '3 * 5 + 4' . . 114

3.24 Síntese e Herança de Atributos. . . . . . . . . . . . . . . . . . . . . 115

3.25 Exemplo de Utilização do Comando consult. . . . . . . . . . . . . . . 116

3.26 Exemplo de Utilização do Comando assert. . . . . . . . . . . . . . . . . . 117

3.27 Reúso das Descrições na Linguagem $\mathcal{M} u \mathcal{D} e \mathcal{L}$ dos Operadores Intra-método para C, C++ e Java (Vincenzi, 2004).

4.1 Uma Rede de Petri para o Nível 3 do Protocolo OSI (Tanenbaum, 1989). . 132

4.2 Árvore de Caracterização para a Rede da Figura 2.1 com o Vetor de Caracterização $\langle 1,0,1, \omega, \omega, \omega, \omega, \omega, 1,1, \omega\rangle \ldots \ldots$. . . . . . . . . . 134

4.3 Rede de Petri Semanticamente Equivalente à Rede da Figura 2.4. . . . . . 136

4.4 Rede de Petri Estruturalmente Similar à Rede da Figura 2.4 . . . . . . . . 136

5.1 Arquitetura da Proteum/CPN. . . . . . . . . . . . . . . . . . . . . 140

5.2 Esquema Conceitual da Proteum/CPN. . . . . . . . . . . . . . . . . . . . . 141

5.3 Esquema Navegacional da Proteum/CPN - Visão do Administrador. . . . . 143

5.4 Esquema Navegacional da Proteum/CPN - Visão do Proprietário de Projeto. 143

5.5 Esquema Navegacional da Proteum/CPN - Visão do Usuário de Sessão. . . 144

5.6 Esquema de Contextos Navegacionais da Proteum/CPN. . . . . . . . . . 145

5.7 ADV da Proteum/CPN. . . . . . . . . . . . . . . . . . . . . 146

5.8 ADVs da Área de Conteúdo Variado da Figura 5.7. . . . . . . . . . . . . . . 148

5.9 ADVs de Mais Baixo Nível da Ferramenta Proteum/CPN. . . . . . . . . . . 149

5.10 ADV Charts Login e Logout. . . . . . . . . . . . . . . . . . . . 150

5.11 ADV Chart Formulário de Registro. . . . . . . . . . . . . . . . . . . . . . 151

5.12 ADV Chart Autorização. . . . . . . . . . . . . . . . . . 151

5.13 ADV Chart Projetos. . . . . . . . . . . . . . . . . . . . . . 152

5.14 ADV Chart Operadores. . . . . . . . . . . . . . . . 153

5.15 ADV Chart Código Fonte. . . . . . . . . . . . . . . . . . . . 153

5.16 ADV Chart Sessões. . . . . . . . . . . . . . . . . . . . . . . 154

5.17 ADV Chart Casos de Teste. . . . . . . . . . . . . . . . . . 155

5.18 ADV Chart Inserir Caso de Teste. . . . . . . . . . . . . . . . . . . 155

5.19 ADV Chart Mutantes. . . . . . . . . . . . . . . . . 156 
5.20 ADV Chart Inserir/Remover Mutantes. . . . . . . . . . . . . . . . 157

5.21 ADV Chart Relatórios. . . . . . . . . . . . . . . . . . . 157

5.22 Página de Acesso à Proteum/CPN. . . . . . . . . . . . . . . . . . 158

5.23 Formulário de Registro de Usuário. . . . . . . . . . . . . . . . . . . . . . 159

5.24 Página de Autorização de Conta de Usuário. . . . . . . . . . . . . . . . . . 160

5.25 Página de Ativação de Conta de Usuário. . . . . . . . . . . . . . . . . . . 160

5.26 Página de Criação de Projeto. . . . . . . . . . . . . . . . . . 161

5.27 Página de Seleção de Operadores de Mutação. . . . . . . . . . . . . . . . . 162

5.28 Página de Inclusão do Código Fonte. . . . . . . . . . . . . . . . . 163

5.29 Visualização do Fonte. . . . . . . . . . . . . . . . . . . . . . . . . . 164

5.30 Definindo a Relação de Equivalência para Lugares. . . . . . . . . . . . . . 164

5.31 Status de Geração de Mutantes. . . . . . . . . . . . . . . . . . . . 165

5.32 Requisição de Autorização. . . . . . . . . . . . . . . . . . . . . . . 166

5.33 Propósito da Requisição de Autorização. . . . . . . . . . . . . . . . . . . 166

5.34 Página de Autorização para Criação de Sessão. . . . . . . . . . . . . . . . 167

5.35 Página de Criação de Sessão. . . . . . . . . . . . . . . . . . . . 168

5.36 Inclusão de Mutantes por Operador. . . . . . . . . . . . . . . . . . . . . 169

5.37 Inclusão de Mutantes por Linha de Código. . . . . . . . . . . . . . . . . . . 170

5.38 Inclusão de Mutantes por Número de Mutantes. . . . . . . . . . . . . . . 170

5.39 Simulação da Rede de Petri Colorida. . . . . . . . . . . . . . . . . 172

5.40 Mutantes de uma Sessão. . . . . . . . . . . . . . . . . . . . . . . . . . . . 172

5.41 Visualização Lado a Lado da Rede Original e da Mutante. . . . . . . . . . . 173

5.42 Página de Configuração de skins. . . . . . . . . . . . . . . . . . . 174

5.43 Outro Modo de Exibição Possível da Proteum/CPN. . . . . . . . . . . . . . . 174

5.44 Modelo Entidade-Relacionamento da Proteum/CPN. . . . . . . . . . . . . 176

5.45 Esquema de Execução do mudelgen. . . . . . . . . . . . . . . . . 177

5.46 Execução de mudel.G. . . . . . . . . . . . . . . . . . . . . . . . . . . . 179

$5.47 \mathcal{M} u \mathcal{D} e \mathcal{L}$ Animator. . . . . . . . . . . . . . . . . . . . . . . . . 180

5.48 Sim/CPN: Esquema Geral de Execução. . . . . . . . . . . . . . . . . 182

6.1 Evolução do Escore de Mutação para a Rede de Petri Colorida DDB. . . . 192

6.2 Evolução do Escore de Mutação para a Rede de Petri Colorida RA. . . . . . 192

6.3 Evolução do Escore de Mutação para a Rede de Petri Colorida TL. . . . . . 193

6.4 Evolução do Escore de Mutação para a Rede de Petri Colorida HP. . . . . . 193

6.5 Evolução do Escore de Mutação para a Rede de Petri Colorida BA. . . . . . 194

6.6 Evolução do Escore de Mutação para a Rede de Petri Colorida CP. . . . . . 194

A.1 (a) Uma Gramática BNF Livre de Contexto para Expressões Simples.(b) Árvore Sintática para ' $(1+a) * a$ '. . . . . . . . . . . . . . . 232

B.1 Sintaxe Abstrata da Linguagem $\mathcal{M} u \mathcal{D} e \mathcal{L} \ldots \ldots \ldots$. . . . . . . . . . 238

B.2 Definição da Funções unify e unifyRec. . . . . . . . . . . . . . . . . . . . . 243

D.1 Grafo de Ocorrência da Rede de Petri Colorida da Figura 2.4. . . . . . . . 266

D.2 Grafo de Ocorrência Reduzido com a Utilização de Classes de Equivalência. 267

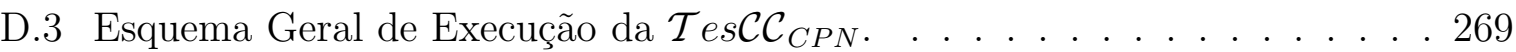

E.1 Rede de Petri Colorida RA. . . . . . . . . . . . . . . . . . . 272

E.2 Rede de Petri Colorida TL - Página Phone. . . . . . . . . . . . . . . . . 273

E.3 Rede de Petri Colorida TL - Página EstabCon. . . . . . . . . . . . . . . . 273 
E.4 Rede de Petri Colorida TL - Página Dialing. . . . . . . . . . . . . . . . . 274

E.5 Rede de Petri Colorida TL - Página BreakEng. . . . . . . . . . . . . . . . 274

E.6 Rede de Petri Colorida TL - Página BreakRec. . . . . . . . . . . . . . . . . 275

E.7 Rede de Petri Colorida TL - Página BreakSen. . . . . . . . . . . . . . . . . 275

E.8 Rede de Petri Colorida HP - Página Top. . . . . . . . . . . . . . . . 276

E.9 Rede de Petri Colorida HP - Página Network. . . . . . . . . . . . . . . . 277

E.10 Rede de Petri Colorida HP - Página Receiver. . . . . . . . . . . . . . . . 277

E.11 Rede de Petri Colorida HP - Página Sender. . . . . . . . . . . . . . . . . 278

E.12 Rede de Petri Colorida BA - Página Top. . . . . . . . . . . . . . . . . . . 279

E.13 Rede de Petri Colorida CP - Página CSAP. . . . . . . . . . . . . 280

E.14 Rede de Petri Colorida CP - Página CPE . . . . . . . . . . . . . . . . 281

E.15 Rede de Petri Colorida CP - Página JoinAnswer. . . . . . . . . . . . . . 281

E.16 Rede de Petri Colorida CP - Página Leave. . . . . . . . . . . . . . . . . . . 282

E.17 Rede de Petri Colorida CP - Página Receive. . . . . . . . . . . . . . . . . . 282

E.18 Rede de Petri Colorida CP - Página Send. . . . . . . . . . . . . . . . 283 


\section{Lista de Tabelas}

2.1 Operadores de Mutação para Redes de Petri. . . . . . . . . . . . . . . . . . 72

2.2 Módulos da Proteum-RS/PN. . . . . . . . . . . . . . . . . . 76

2.3 Palavras-Guia Propostas para Software (McDermid e Pumfrey, 1994). . . . 79

2.4 Símbolos de uma Árvore de Falhas. . . . . . . . . . . . . . . . . . . . 80

3.1 Operadores de Mutação para Redes de Petri Coloridas. . . . . . . . . . . . 87

6.1 Características das Redes de Petri Coloridas. . . . . . . . . . . . . . . 188

6.2 Número de Mutantes Gerados para cada Operador. . . . . . . . . . . . . . . 189

6.3 Número de Mutantes Equivalentes. . . . . . . . . . . . . . . . . . . . . . . 190

6.4 Porcentagem da Causa da Morte dos Mutantes. . . . . . . . . . . . . . . . 191

6.5 Número de Casos de Teste nos Conjuntos Adequados. . . . . . . . . . . . . 191

6.6 Resultados do Estudo de Caso II . . . . . . . . . . . . . . . . . . . . . . 196

6.7 Resultados da Aplicação do Algoritmo de Geração de Casos de Teste para Redes de Petri. . . . . . . . . . . . . . . . . . . . . . . . . 197

D.1 Subconjunto dos Requisitos de Teste para a Rede de Petri Colorida da Figura 2.4. . . . . . . . . . . . . . . . . . . . . 266

D.2 Subconjunto dos Requisitos de Teste para a Rede de Petri Colorida da Figura 2.4 com Classes de Equivalência. . . . . . . . . . . . . . . . . 268 


\title{
Lista de Siglas
}

\author{
AM - Análise de Mutantes \\ CPNCCF - Coloured Petri Nets Coverage Criteria Family \\ DDB - Banco de Dados Distribuído (do inglês, Distributed Data Base) \\ ECCF - Estelle Coverage Criteria Family \\ E-MPT - Estelle-directed Mutation-based Protocol Testing \\ ES - Engenharia de Software \\ GO - Grafo de Ocorrência \\ MEFE - Máquina de Estados Finitos Estendida \\ MEF - Máquina de Estados Finitos \\ MTE - Máquina de Transição de Estados \\ OOHDM - Object-Oriented Hypermedia Design Method \\ Proteum - Product Testing Using Mutation \\ Proteum-RS - Program Testing Using Mutation/Reactive Systems \\ RPC - Rede de Petri Colorida \\ RP - Rede de Petri \\ SCCF - Statechart Coverage Criteria Family \\ SDL - Specification and Description Language \\ SML - Standard Meta-Language \\ SR - Sistema Reativo \\ STR - Sistema de Transições Rotuladas \\ VV\&T - Verificação, Validação e Teste \\ XML - Extensible Markup Language
}




\section{Resumo}

uso de técnicas e métodos formais contribui para o desenvolvimento

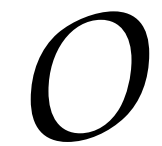
de sistemas confiáveis. No entanto, apesar do rigor obtido, em geral, é necessário que essas técnicas sejam complementadas com atividades de teste e validação. Deve-se ressaltar que o custo para eliminar erros encontrados nas etapas iniciais de desenvolvimento é menor do que quando esses erros são encontrados nas fases posteriores. Dessa forma, é essencial a condução de atividades de VV\&T — Verificação, Validação e Teste — desde as primeiras fases de desenvolvimento. Critérios de teste, como uma forma sistemática de avaliar e/ou gerar casos de teste de qualidade e, dessa forma, contribuir para aumentar a qualidade da atividade de teste, têm sido investigados para o teste de especificação de Sistemas Reativos.

A técnica Redes de Petri Coloridas tem sido constantemente utilizada para a especificação do aspecto comportamental de Sistemas Reativos. Apesar de existirem diversas técnicas de análise, um aspecto não considerado é a cobertura alcançada, visto que, em geral, a aplicação exaustiva não é viável devido ao alto custo. Considerando a relevância do estabelecimento de métodos sistemáticos para o teste e validação dessas especificações, este trabalho propõe a aplicação do critério de teste Análise de Mutantes para o teste de Redes de Petri Coloridas.

Neste trabalho foram almejados três objetivos principais, os quais podem ser divididos em estudos teóricos, estudos empíricos e automatização. No contexto de estudos teóricos, foi realizada a definição e embasamento teórico para possibilitar a aplicação da Análise de Mutantes no contexto de Redes de Petri Coloridas. Além disso, investigaram-se mecanismos genéricos para a descrição e geração de mutantes. Definiu-se um algoritmo para a geração de casos de teste baseado na Análise de Mutantes. No contexto de estudos empíricos, foram conduzidos estudos de caso para avaliar a aplicabilidade e eficácia dos resultados teóricos obtidos. Finalmente, no contexto de automatização, foram desenvolvidas ferramentas de apoio à aplicação da Análise de Mutantes. 


\section{Abstract}

he usage of formal methods and techniques contributes to the development of highly reliable system, but, in spite of the achieved rigour, these techniques must be complemented with testing and validation activities. It should be highlighted that the cost to eliminate errors found in the early phases of development is smaller than when those errors are found in the later phases. Therefore, the accomplishment of VV\&T activities - Verification, Validation and Test - starting at the first development phases is essential. Testing criteria, as a systematic way to evaluate and/or generate test cases, contributing, therefore, to improve the quality of the test activity, have been proposed for testing reactive systems specifications.

A technique that has been steadily employed for specifying the behavioural aspect of reactive systems is the coloured Petri nets. Although there are several analysis and validation techniques, a usually neglected aspect is the achieved coverage, given that, in general, the exhaustive application is not feasible due to its high cost. Considering the relevance of establishing systematic methods for the test and validation of coloured Petri nets based specification, this work proposes the investigation of the viability of applying Mutation Testing to test coloured Petri nets.

In this work three main goals were pursued, which can be grouped in: theoretical studies, empirical studies and tool development. In the context of theoretical studies, it was accomplished the definition of theoretical concepts to enable the application of Mutant Analysis in the context of coloured Petri nets. Moreover, a mutation-based algorithm was defined to generate test sequences for Petri nets. In the context of empirical studies, case studies were carried out to evaluate the applicability and effectiveness of the achieved theoretical results. Finally, in the context of tool development, tools for supporting the application of Mutation Testing were developed. 


\section{Introdução}

\subsection{Considerações Iniciais}

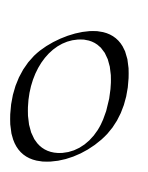

uso cada vez mais intenso de sistemas de computadores em praticamente todas as atividades da sociedade contemporânea tem aumentado a demanda por produtos de software. Somado ao ambiente de grande competitividade, característico dos dias atuais, esse fato determina uma busca crescente por produtos de qualidade. Em linhas gerais, o objetivo principal da Engenharia de Software (ES) é a obtenção de processos, métodos, técnicas e ferramentas eficientes e seguras para desenvolver produtos de software de qualidade, atendendo a restrições de custo e tempo.

Os produtos de software podem ser divididos em: software básico, sistemas de informação, sistemas científicos, sistemas embutidos, sistemas pessoais, sistemas de inteligência artificial e Sistemas Reativos (SRs) (Pressman, 2000). Um SR caracteriza-se por manter uma interação permanente com seu ambiente externo, quer seja esse ambiente um usuário, um dispositivo de entrada, outra parte do sistema, ou mesmo outro sistema (Furbach, 1993). Seu comportamento é baseado na relação entre eventos de entrada e de saída que ocorrem discretamente no tempo. Como exemplos de SRs, pode-se citar sistemas de controle de tráfego aéreo, de controle metroviário e de controle de monitoramento hospitalar (Leveson e Stolzy, 1987; Liu e McDermid, 1996). Deve-se ressaltar que, mesmo com o uso de métodos, técnicas e ferramentas, defeitos podem ser introduzidos no produto durante o processo de desenvolvimento de software. Dessa forma, para que o produto de software, e, em especial, um SR, atinja um grau aceitável de qualidade, é necessário que atividades de garantia de qualidade sejam aplicadas durante todo o processo de desenvolvimento.

A utilização de métodos rigorosos de desenvolvimento assegura que produtos com uma quantidade menor de defeitos sejam desenvolvidos, pois contribui para a redução de inconsistências e ambigüidades (Barroca e McDermid, 1992). Visando a facilitar a especificação do aspecto comportamental de SRs, várias técnicas formais de especificação 
têm sido propostas, as quais tentam conciliar o poder de modelagem com a capacidade de análise de propriedades do sistema. Dentre as técnicas formais, estão as baseadas em modelos de Máquinas de Transição de Estado (MTEs), nas quais o aspecto comportamental é modelado por meio de eventos discretos no tempo. Como exemplos de técnicas dessa categoria, pode-se citar as Máquinas de Estados Finitos (MEFs) (Gill, 1962), os Statecharts (Harel, 1987a) e as Redes de Petri (RPs) (Peterson, 1981). Visto que SRs distinguem-se de outros tipos de sistemas por terem no comportamento sua maior ênfase (Furbach, 1993), deve-se buscar modelos adequados para a especificação do aspecto comportamental, assim como formas apropriadas para testá-los e validá-los.

Segundo Peterson (1981), a técnica RPs foi desenvolvida para modelar sistemas com interação de componentes paralelos e concorrentes, sendo um modelo formal e abstrato do fluxo de informação, representado por meio de um grafo que modela as propriedades estáticas do sistema e que, por meio de sua simulação, permite também representar as propriedades dinâmicas. As RPs podem ser aplicadas a qualquer área ou sistema que possa ser descrito graficamente como um diagrama e que precise de algum mecanismo para representar atividades paralelas ou concorrentes (Murata, 1989; Reisig, 1985; Reisig e Rozenberg, 1998; Zimmermann, 1997).

A simplicidade e força de representação fazem das RPs uma ferramenta adequada para a especificação de SRs. No entanto, as tentativas de usar RPs em situações práticas revelaram duas desvantagens principais. Em primeiro lugar, não existe o conceito de dados e, desse modo, os modelos freqüentemente se tornam muito grandes, uma vez que toda a manipulação de dados deve ser representada diretamente na estrutura da rede. Em segundo lugar, não existe o conceito de hierarquia e, por isso, não é possível construir um modelo grande a partir de um conjunto de submodelos. Para tentar resolver esses problemas, foram propostas diversas extensões às RPs que visam a possibilitar a manipulação direta de tipos e valores de dados, tais como as Redes Predicado/Transição (Genrich, 1987) e as Redes de Petri Coloridas (RPCs) (Jensen, 1986, 1994, 1997b; Mortensen, 2002),

Deve-se ressaltar que, mesmo com a aplicação de métodos rigorosos de desenvolvimento, defeitos podem estar presentes no produto, seja por limitações inerentes a esses métodos, seja por restrições de custo no que se refere a sua completa aplicação. Assim sendo, devem ser introduzidas ao longo de todo o processo de desenvolvimento diversas atividades, genericamente denominadas atividades de Garantia de Qualidade de Software, dentre as quais estão as atividades de Verificação, Validação e Teste (VV\&T). As atividades de VV\&T visam a reduzir a ocorrência de erros e aumentar a confiabilidade do produto de software desenvolvido. Dentre as técnicas de VV\&T, a atividade de teste é aplicada para identificar defeitos por meio da execução do produto de software. Além disso, a atividade de teste pode ser utilizada para fornecer evidências sobre a confiabilidade e qualidade do produto. É importante salientar que, em geral, o teste deve ser conduzido em complemento a outras atividades, tais como inspeções e revisões e técnicas formais 
rigorosas de especificação e desenvolvimento (Maldonado, 1991; Maldonado e Fabbri, 2001; Myers, 1979).

A atividade de teste é geralmente conduzida em três fases, concentrando-se em aspectos diferentes do sistema. No teste de unidade, concentra-se na validação da menor unidade de projeto de software. Dependendo da granularidade escolhida, essa unidade pode ser um módulo, um procedimento, um método ou uma classe do programa. No teste de Integração, concentra-se na validação das interfaces entre as unidades e é aplicado após cada unidade ter sido testada individualmente. No teste de sistema, concentra-se na validação do software integrado em seu ambiente, avaliando requisitos de qualidade, tais como desempenho, segurança, e robustez.

Deve-se observar que os mesmos conceitos, problemas e limitações referentes ao teste em nível de programa aplicam-se ao contexto de teste e validação de especificações, uma vez que defeitos não encontrados na especificação de um sistema podem comprometer todo o processo de desenvolvimento. Além disso, o custo de remoção de um defeito nessa fase é inferior ao custo de removê-lo nas fases posteriores (Kemmerer, 1985; Pressman, 2000). Uma abordagem utilizada para validação de especificações de SRs é a simulação, na qual a especificação é "executada", calculando-se, com base na semântica da técnica de especificação empregada, a seqüência de configurações correspondentes a uma seqüência de eventos. Para o teste de especificações de SRs, existem várias abordagens de simulação, tais como a simulação interativa, a simulação em batch, a simulação programada e a simulação exaustiva (Harel, 1992).

Outra técnica que também tem sido utilizada no contexto de teste de especificações é o model checking, que é uma técnica de verificação estática baseada na exploração de estados. Para a aplicação de model checking não é necessário que os modelos estejam totalmente especificados, porém por ser baseada na exploração de estados, apresenta o problema de explosão de estados, aspecto crítico quando se trata de sistemas complexos (Clarke e Wing, 1996). Além de permitir a verificação de propriedades do software, model checking pode ser aplicada para a avaliação de cobertura do teste (Black et al., 2000b). Nesse caso, um critério de teste deve ser selecionado inicialmente e aplicado na especificação para derivar os requisitos de teste, ou seja, o conjunto de propriedades a serem testadas. Para usar um model checker, esses requisitos são representados como fórmulas em lógica temporal. Para avaliar a cobertura de um conjunto de casos de teste, cada caso de teste é executado e o model checker determina quais requisitos são satisfeitos pela execução [(Ammann e Black, 1999) apud (Sugeta, 2002)].

No entanto, apesar de serem úteis para a verificação do aspecto comportamental da especificação e análise de suas propriedades, tal como a ausência de deadlocks, em geral, a simulação e o model checking não consideram, por si só, o aspecto de cobertura, uma questão relevante que permite que a qualidade da atividade de teste seja quantificada. Diversas iniciativas no sentido de se definirem critérios de teste e validação de 
especificações e de se avaliarem os custos/benefícios associados podem ser identificadas. Em geral, são utilizados conceitos tradicionalmente empregados em nível de unidade para o teste de programas, avaliando-se a adequação desses conceitos no contexto de teste de especificações (Black et al., 2000a; Chung e Sidhu, 1991; Fabbri et al., 1994c, 1995b; Petrenko et al., 1996; Probert e Guo, 1991; Souza et al., 2000a,c; Ural et al., 2000; Ural e Yang, 1991; Wang e Liu, 1993).

Segundo Maldonado (1997), dois pontos cruciais na atividade de teste são (i) a seleção de um conjunto de casos de teste $T$ para o teste de um produto $P$, dado que, em geral, é impraticável utilizar todo o domínio de dados de entrada para avaliar os aspectos funcionais e operacionais de $P$; e (ii) a avaliação da qualidade de um determinado conjunto de casos de teste. O objetivo é utilizarem-se casos de teste que tenham alta probabilidade de encontrar a maioria dos defeitos, porém, com um mínimo de tempo e esforço. Buscando-se sistematizar a atividade de teste e reduzir seu custo, várias técnicas e critérios têm sido propostos para auxiliar sua condução e avaliação. As técnicas e critérios de teste fornecem ao testador uma abordagem sistemática e teoricamente fundamentada para seleção de casos de teste, além de constituírem um mecanismo que auxilia a avaliar a qualidade da atividade de teste (Frankl e Weyuker, 1993; Weyuker e Jeng, 1991; Zhu et al., 1997). Uma grande variedade de critérios têm sido estabelecidos (Alexander et al., 2004; Beizer, 1990; Bieman et al., 2001; Budd, 1981; Coward, 1988; Delamaro, 1997; DeMillo et al., 1978; Goodenough e Gerhart, 1975; Herman, 1976; Howden, 1982; Kovács et al., 2003; Krichen e Tripakis, 2004; Laski e Korel, 1983; Maldonado, 1991; Myers, 1979; Ntafos, 1984; Rapps e Weyuker, 1982, 1985; Ural e Yang, 1988). Tradicionalmente, os critérios podem ser agrupados em três técnicas de teste, cuja diferença básica está na origem da informação que é utilizada para avaliar ou selecionar conjuntos de casos de teste. Na Técnica Funcional, também conhecida como teste de caixa preta, utiliza-se a especificação do software para obter os requisitos de testes. Na Técnica Estrutural, também conhecida como teste de caixa branca, derivam-se os requisitos de teste a partir dos aspectos de implementação do software. Na Técnica Baseada em Erros, os elementos requeridos para caracterizar a atividade de teste são baseados em erros típicos que podem ocorrer durante o desenvolvimento do software.

É importante notar que, em geral, nenhuma dessas técnicas é completa, no sentido de que nenhuma delas é suficiente para garantir a qualidade da atividade de teste. Segundo Maldonado (1991), essas diferentes técnicas se complementam e devem ser aplicadas em conjunto para tentar assegurar um teste de melhor qualidade, o que torna necessária a determinação de estratégias de teste que combinem as vantagens de cada técnica. Com esse propósito, estudos empíricos e teóricos são de vital importância para fornecer subsídios para o estabelecimento de estratégias de baixo custo e alta eficácia (Maldonado, 1997; Maldonado et al., 1998). 
A Análise de Mutantes (AM) (Acree, 1980) é um critério de teste da técnica baseada em erros que tem sido intensamente investigado (Acree, 1980; Acree et al., 1979; Agrawal, 1989; Barbosa et al., 1998; Bieman et al., 2001; Budd, 1981; Daran e Thévenod-Fosse, 1996; Delamaro, 1993, 1997; Delamaro e Maldonado, 1993, 1996; Delamaro et al., 2001; DeMillo, 1980; DeMillo et al., 1988, 1978; DeMillo e Offutt, 1991; Fabbri et al., 1995a, 1993, 1994b,c, 1995b; Kovács et al., 2003; Maldonado et al., 2000; Nakagawa e Maldonado, 2001; Offutt, 1989; Offutt et al., 1996; Offutt e Pan, 1997; Offutt et al., 1993; Probert e Guo, 1991; Ritchey, 2000; Simão, 2000; Simão e Maldonado, 2000a,b, 2001; Simão et al., 2000; Souza, 1996; Souza e Maldonado, 1997; Souza et al., 2000b; Sugeta, 1999b; Sugeta et al., 1999, 2001, 2004; Untch et al., 1993; Vincenzi, 1998; Wah, 2000; Weiss e Fleyshgakker, 1993; Wong et al., 1994, 1997; Wong e Mathur, 1995a; Wong et al., 1995; Yano, 2004; Yano et al., 2003, 2004). Apesar de ter sido inicialmente proposto para o teste de programas, esse critério vem sendo utilizado em diversos outros contextos, tais como no teste de integração (Delamaro, 1997; Delamaro e Maldonado, 1999; Delamaro et al., 2001), no teste de protocolos (Fabbri, 1996; Probert e Guo, 1991), no teste de modelos de segurança de redes (Ritchey, 2000) e no teste de especificações (Fabbri et al., 1999a, 1994b; Simão, 2000; Simão et al., 2000; Souza et al., 2000b; Sugeta, 1999b, 2004). Basicamente, são feitas alterações sintáticas em um programa $P$, gerando um conjunto de programas, denominados mutantes de $P$, e constroem-se casos de teste capazes de mostrar diferenças de comportamento entre $P$ e seus mutantes (Delamaro e Maldonado, 1993).

Por meio de estudos empíricos, tem sido demonstrado que a AM é um critério eficaz em revelar defeitos em programas (Souza, 1996; Wong e Mathur, 1995a). No entanto, a aplicação da AM apresenta um alto custo devido principalmente à grande quantidade de mutantes gerados e à dificuldade em identificar os mutantes equivalentes ao programa original, um problema computacionalmente indecidível. Algumas iniciativas para diminuir esse custo têm sido propostas, tanto para o teste de programas (Barbosa et al., 2001; Offutt et al., 1996, 1993; Wong et al., 1994) quanto para o teste de especificações (Fabbri, 1996), visando a reduzir a quantidade de mutantes utilizados. Outras iniciativas buscam reduzir o custo de aplicação desse critério pela automatização do processo de geração de casos de teste e determinação dos mutantes equivalentes. No teste de programas, pode-se observar os trabalhos de DeMillo e Offutt (1991) e Offutt e Pan (1997).

Por sua vez, a própria atividade de teste também está sujeita a erros e, em geral, sua condução manual é improdutiva, de forma que a aplicação de um critério de teste está fortemente condicionada ao seu grau de automatização. Portanto, é fundamental a existência de ferramentas de teste que apóiem a sua aplicação. A disponibilidade de ferramentas de teste contribui para um desenvolvimento de software de maior qualidade e produtividade. Por parte da indústria, pode-se observar o esforço alocado pela Telcordia (USA), em cooperação com o SERC/Purdue University (USA), para o desenvolvimento das ferramentas xATAC (que apóia a aplicação de critérios baseados na análise de fluxo de controle e de 
dados) e xRegress (que reduz o custo do teste de regressão). Ambas as ferramentas fazem parte do xSuds (Software Understanding System), um pacote para visualização e análise de software (Agrawal et al., 1998; Horgan e Mathur, 1992).

No contexto de teste e validação de especificações, pode-se citar as ferramentas Spin (Holzmann, 1997), que apóia a verificação e validação de sistemas distribuídos e utiliza a linguagem de alto nível denominada PROMELA (PROcess MEta LAnguage) para a descrição de sistemas, e UPPAAL (Pettersson e Larsen, 2000) que consiste de um pacote integrado de ferramentas para modelagem, simulação e verificação de sistemas de tempo real, desenvolvida pelo Department of Computing Systems da Uppsala University em conjunto com Basic Research in Computer Science da Aalborg University. Para apoiar a aplicação no critério AM para a validação de especificações de SRs, o Grupo de Engenharia de Software do Instituto de Ciências Matemáticas e de Computação/Universidade de São Paulo (ICMC/USP) desenvolveu a família de ferramentas Program Testing Using Mutation/Reactive Systems (Proteum-RS), que atualmente inclui as ferramentas Proteum-RS/FSM (Fabbri et al., 1995a), para MEFs, Proteum-RS/ST (Sugeta et al., 1999), para Statecharts, e Proteum-RS/PN (Simão et al., 2000), para RPs.

\subsection{Contexto e Motivação}

O contexto deste trabalho é a investigação de estratégias de teste e validação para o desenvolvimento de SRs baseado em RPCs, com ênfase no critério AM. O Grupo de Engenharia de Software do ICMC/USP vem desenvolvendo atividades de pesquisa no estudo de princípios, estratégias, métodos e critérios de teste e validação na produção de software, assim como na especificação e implementação de ferramentas que apóiem a realização das atividades de teste e viabilizem a avaliação dos aspectos complementares desses critérios, por meio de estudos empíricos.

O teste de software, em conjunto com outras atividades de VV\&T, é de fundamental importância para a garantia da qualidade dos produtos de software desenvolvidos. Uma vez que a especificação do sistema é um documento essencial para possibilitar seu correto desenvolvimento, faz-se necessário que métodos e técnicas sejam identificados para testar e validar tais especificações. Ressalta-se que, quanto mais tarde um defeito for encontrado no processo de desenvolvimento de software, maior é o custo para correção desse defeito (Pressman, 2000). Dessa forma, o ideal é a detecção de defeitos no início do processo, o que motiva o uso de critérios sistemáticos para o teste e validação do sistema durante a fase de especificação (Kemmerer, 1985). Tendo-se em vista que, em geral, a ocorrência de falhas em SRs pode colocar em risco vidas humanas e/ou levar a grandes prejuízos materiais, a atividade de teste nesse contexto deve ser realizada com rigor, mesmo quando isso implique altos custos. Observa-se que várias técnicas e critérios de teste de programas têm sido explorados no contexto de teste e validação de tais sistemas, principalmente no 
que diz respeito a seus aspectos comportamentais (Chow, 1978; Fabbri, 1996; Kovács et al., 2003; Petrenko, 1997; Petrenko et al., 1996; Simão, 2000; Souza et al., 2000b; Sugeta, 1999b, 2004; Sugeta et al., 2004).

As RPs constituem uma técnica formal freqüentemente utilizada para a especificação de SRs. A validação de RPs pode ser conduzida por meio de diversas técnicas apropriadas, tais como a inspeção da Árvore de Alcançabilidade e o cálculo de invariantes (Macial et al., 1996; Reisig, 1985). Entretanto, a aplicação dessas técnicas fica restrita a redes pequenas, devido à complexidade da explosão do espaço de estados (Jensen, 1997c; Murata, 1989; Peterson, 1981), o que caracteriza a dificuldade encontrada na atividade de teste e validação das especificações baseadas nessa técnica. Segundo Harel (1992), uma das formas de validação de SRs em geral, e que conseqüentemente também pode ser utilizada na validação de RPCs, é a simulação da especificação. No entanto, uma questão importante que geralmente não é considerada pela simulação é o aspecto de cobertura da atividade de teste, por meio da qual é possível a quantificação da qualidade dessa atividade. Isso motiva a investigação de outras formas de validação de especificações. Embora a AM seja um critério de teste desenvolvido para o teste de programas, sua aplicação em diferentes contextos é uma alternativa viável, devido à sua flexibilidade. Dessa forma, esse critério foi investigado no contexto do teste e validação de RPs Lugar/Transição (Fabbri, 1996; Fabbri et al., 1994b, 1995b; Simão, 2000; Simão e Maldonado, 2000a,b; Simão et al., 2000). As RPCs estendem as RPs Lugar/Transição com a inclusão de conceitos de tipos e valores de dados, o que aumenta o poder de modelagem, mas diminui o poder de análise, sendo, portanto, ainda mais relevante o desenvolvimento de técnicas para a análise e validação das RPCs. Dessa forma, a AM apresenta-se como uma possibilidade a ser investigada.

Uma vez que as técnicas empregadas para a Análise de Risco estão relacionadas às técnicas utilizadas na especificação do sistema, faz-se necessário o desenvolvimento de mecanismos para a Análise de Risco de SRs especificados com RPCs. Ressalta-se que, apesar de uma iniciativa semelhante poder ser identificada no que se refere à Análise de Risco com RPs Temporais (Leveson e Stolzy, 1987), nenhum trabalho direcionado a RPCs foi encontrado na literatura. Além disso, o trabalho de Leveson e Stolzy (1987) baseia-se na Árvore de Alcançabilidade, a qual, como já mencionado, apresenta o problema da explosão de estados, fazendo-se necessário investigar técnicas alternativas.

\subsection{Objetivos}

Em linhas gerais, este trabalho consiste em investigar os aspectos de validação de sistemas especificados com Redes de Petri Coloridas. O critério de teste Análise de Mutantes é investigado buscando-se avaliar sua adequação e aplicabilidade nesse contexto. Com base nos resultados obtidos com outras técnicas de modelagem, avalia-se a adequação da 
AM para realizar a validação de RPCs de SRs especificados com essa técnica. O objetivo deste trabalho está em consonância com a linha de pesquisa do Grupo de Engenharia de Software do ICMC/USP que investiga critérios para o teste de especificações de SRs, com ênfase no teste e validação dos aspectos comportamentais desses sistemas.

As contribuições deste trabalho podem ser divididas nas três linhas de pesquisa em teste de software apontadas por Maldonado (1997):

Estudos Teóricos: Definição e avaliação de mecanismos para a validação de RPCs. Como contribuições nessa linha, pode-se citar:

- A adequação dos conceitos de mutação a RPCs;

- A definição de operadores de mutação para RPCs; e

- A definição de mecanismos de geração de casos de teste.

Estudos Empíricos: Definição e condução de estudos que visem a fornecer evidências da aplicabilidade dos resultados teóricos alcançados. Como contribuições nessa linha, pode-se citar:

- A avaliação do custo de aplicação da AM; e

- A avaliação da eficácia dos mecanismos de geração de casos de teste.

Automatização: Desenvolvimento de mecanismos de apoio à aplicação da AM, buscando-se estabelecer mecanismos tão genéricos quanto possível, objetivando, dessa forma, facilitar novas aplicações da AM em outros contextos. Como contribuições nessa linha, pode-se citar:

- O desenvolvimento de uma ferramenta para o apoio à aplicação da AM para a validação de RPC; e

- A definição de linguagens de descrição de operadores de mutação e desenvolvimento de ferramentas associadas.

\subsection{Organização do Trabalho}

Neste capítulo foram apresentados o contexto em que se insere este trabalho, as motivações para o seu desenvolvimento e os objetivos a serem alcançados.

No Capítulo 2, é apresentada uma revisão bibliográfica dos temas relacionados a este trabalho. Apresenta-se uma visão geral sobre teste de software, introduzindo-se os conceitos básicos e a terminologia relacionada, com destaque para o critério AM. São apresentadas também técnicas de especificação de SRs, com destaque para as técnicas RPs e RPCs. Ao final, são apresentados os principais aspectos de teste e validação de especificações, assim como da Análise de Risco. 
No Capítulo 3, são caracterizadas as contribuições relacionadas ao critério AM no contexto de RPCs. Definem-se e exemplificam-se os operadores de mutação. Para possibilitar a descrição e geração dos mutantes, é definida uma linguagem para descrição de operadores de mutação. É também discutido sucintamente como a AM pode auxiliar na Análise de Risco, apontando direcionamentos de futuras investigações.

No Capítulo 4, são descritas as contribuições para a geração de casos de teste para RPs e RPCs com base na AM. Apresenta-se um algoritmo que auxilia na identificação de seqüências de casos de teste para matar mutantes específicos e na determinação de mutantes equivalentes. O algoritmo é definido para RPs e abordagens para permitir sua aplicação para RPCs são apresentadas.

No Capítulo 5, discute-se a importância da automatização da atividade de teste e apresentam-se as contribuições deste trabalho no desenvolvimento de ferramentas de apoio.

No Capítulo 6, são apresentados estudos de caso conduzidos para observar a aplicabilidade dos conceitos definidos nesta tese. Os estudos também permitiram avaliar a usabilidade dos mecanismos de automatização desenvolvidos neste trabalho.

Finalmente, no Capítulo 7, são descritas as conclusões desta tese e as perspectivas de trabalho futuro.

No Apêndice A, apresenta-se uma introdução sucinta à teoria de gramáticas e linguagens formais, de modo a apoiar a definição da linguagem de descrição de operadores introduzida no Capítulo 3. A semântica formal dessa linguagem é apresentada no Apêndice B. No Apêndice C, são apresentados os operadores de mutação para RPCs descritos nessa linguagem. No Apêndice D, apresenta-se a definição de critérios de teste para RPCs baseados em cobertura do grafo de ocorrência. No Apêndice E, apresentam-se as RPCs utilizadas nos estudos de caso do Capítulo 6. 


\section{Revisão Bibliográfica}

\subsection{Considerações Iniciais}

este capítulo é apresentada a revisão bibliográfica dos principais conceitos
relacionados a este trabalho, a saber: teste de software, técnicas de espe-
cificação de SRs, automatização da atividade de teste e Análise de Risco. Inicialmente, na Seção 2.2, são apresentadas definições e feitas considerações a respeito da importância do teste durante o processo de desenvolvimento. São ilustrados critérios das técnicas funcional, estrutural e baseada em erros, bem como critérios que utilizam conceitos de mais de uma técnica, tais como o teste de caixa cinza. Na Seção 2.2.2, apresentam-se trabalhos relacionados à comparação entre os diversos critérios de teste. Questões referentes à automatização da atividade de teste, incluindo a geração de casos de teste e disponibilidade de ferramentas de apoio, são consideradas na Seção 2.2.3. Na Seção 2.3, é apresentado o critério de teste AM, discutindo-se os passos principais e as diversas linhas de investigação em cada passo.

Em seguida, na Seção 2.4, apresentam-se os principais conceitos relacionados a técnicas de especificação de SRs. Apresenta-se uma revisão sucinta das técnicas MEFs, Statecharts e Estelle. Por estarem mais diretamente relacionados a este trabalho, apresentam-se com mais detalhes as técnicas RPs e RPCs. Na Seção 2.5, discutem-se as abordagens, motivações e limitações do teste e validação de especificações. A Análise de Risco, como uma forma complementar de aumentar a segurança de sistemas, é descrita na Seção 2.6. Finalmente, na Seção 2.7, são feitas as considerações finais relativas aos assuntos tratados neste capítulo.

\subsection{Teste de Software: Uma Visão Geral}

A meta primária de toda a atividade de teste é a busca pela demonstração de que o programa contém defeitos e a indicação de quais condições o conduzem a um 
comportamento errôneo (Myers, 1979). Assim, uma atividade de teste bem sucedida é aquela que revela (ao menos) um defeito. Caso seja conduzida de forma sistemática e rigorosa, a atividade de teste pode ser utilizada como um dos parâmetros para determinar a confiabilidade do programa, ou seja, a probabilidade de que o programa funcione adequadamente (Harrold, 2000; Weyuker, 1996).

Para a obtenção de qualquer um desses dois objetivos, a saber, a revelação de erros e a determinação da confiabilidade do programa, faz-se, então, necessário que o teste seja conduzido seguindo-se métodos, técnicas e diretrizes bem definidas (Beizer, 1990; DeMillo et al., 1988, 1979; DeMillo e Mathur, 1995; Gutjahr, 1999; Harrold, 2000; Kit, 1995; Myers, 1979).

Normalmente, a atividade de teste está associada à execução do programa resultante da fase de implementação e análise de resultados em conformidade com os requisitos do sistema (em geral, na forma de uma especificação). No entanto, neste documento, o teste será considerado como uma atividade mais genérica, que envolve tanto a execução de programas quanto a simulação de especificações. Dessa forma, será utilizado o termo produto $P$ para designar o item a ser testado (quer seja um programa, quer seja uma especificação). A especificação $S$ será o documento, formal ou informal, que define os requisitos que $P$ deve satisfazer. Caracterizam-se dessa forma dois cenários principais:

- O produto $P$ é um programa que é executado (da forma usual) e os resultados são analisados em conformidade com a especificação $S$, seja $S$ um documento formal, informal ou uma abstração do entendimento do especificador.

- O produto $P$ é uma especificação que é executada (ou seja, simulada) e os resultados são analisados em conformidade com $S$, nesse caso, um documento com os requisitos para $P$.

O paralelo traçado por essa definição entre a execução de programas e a simulação de especificações permitirá a referência a uma atividade genérica de teste de produtos. Quando a distinção for necessária, o termo específico será empregado.

Existe uma considerável divergência na terminologia adotada no Brasil por pesquisadores das áreas de teste e algumas outras áreas (como, por exemplo, por pesquisadores da área de tolerância a falhas) no que se refere aos termos erro, defeito e falha. O padrão IEEE 610.12-1990 (IEEE, 1990) diferencia os termos: defeito (do inglês, fault) — passo, processo ou definição de dados incorreta; engano (do inglês, mistake) - ação humana que produz um resultado incorreto; erro (do inglês, error) — diferença entre o valor obtido e o valor esperado; e falha (do inglês, failure) — produção de uma saída incorreta com relação à especificação. 
Neste documento, serão utilizadas as seguintes definições:

Defeito: Um defeito é uma divergência entre o produto desenvolvido e o produto supostamente correto (esperado).

Erro: Um erro é um estado interno do produto que diverge do estado correto (esperado). É produzido pela execução de um defeito introduzido no produto.

Falha: Uma falha é a manifestação externa de um erro e ocorre quando esse erro interfere nos comandos que produzem a saída do produto.

Dessa forma, pode-se considerar que "uma falha é a manifestação externa de um erro produzido pela execução de um defeito do produto". Ao se executar um produto $P$ com um caso de teste $t$, pode-se verificar se o resultado obtido caracteriza uma falha. Em caso afirmativo, pode-se concluir que um defeito está presente em $P$ (de outra forma, não haveria falha). No entanto, identificar qual defeito deu origem à falha é, em geral, o objetivo da atividade de depuração. Uma conseqüência dessa definição é que o objetivo principal da atividade de teste deve ser o de "expor uma falha" ou "revelar um defeito", e não "encontrar um defeito".

Neste documento será considerado apenas o teste como uma atividade de análise dinâmica. Isto significa que o produto é executado com um ou mais casos de teste (elementos do domínio de entrada do programa) e os resultados produzidos são analisados (Weyuker, 1986). Existem outras formas de validar um programa que não necessariamente envolvem a execução do produto, tais como análises estáticas e verificações formais, tais como o model checking. O teste faz parte de um conjunto de atividades realizadas ao longo do processo de desenvolvimento de software que visam a garantir a qualidade desse processo, assim como do produto desenvolvido (Harrold, 2000), coletivamente chamadas de Atividades de Validação, Verificação e Teste (VV\&T) (Pressman, 2000). O teste verifica por meios empíricos (ou seja, por meio de execuções) se um produto $P$ satisfaz os requisitos para os quais foi construído. Um produto $P$ é tratado como uma função sobre um domínio de entrada específico $D$. Para $x \in D, P(x)$ representa abstratamente o resultado do produto quando executado com a entrada $x$. Os requisitos são apresentados na forma de uma especificação $S$. Uma especificação $S$ também é tratada como uma função sobre o domínio $D$. Um produto $P$ está correto em relação a uma especificação $S$ se $P$ e $S$ concordam nos resultados de qualquer elemento do domínio de entrada. Ou seja, $P$ está correto em relação a $S$ se

$$
\forall x \in D, P(x)=S(x)
$$

Verificar se $P$ e $S$ concordam em todos elementos do domínio de entrada é geralmente impraticável, considerando-se que o número de entradas é, em geral, infinito ou, mesmo quando finito, muito grande para ser exaustivamente analisado. O teste de software consiste em escolher um subconjunto finito do domínio de entrada, $T \subseteq D$. 
Idealmente, $T$ deve ser tal que,

$$
(\forall t \in T, P(t)=S(t)) \Longrightarrow(\forall x \in D, P(x)=S(x))
$$

Ou seja, se $P$ e $S$ concordam em todas as entradas em $T, P$ está correto em relação a $S$. Budd e Angluin (1982) demonstram que um $T$ com essa característica sempre existe, de forma que sempre há um conjunto de teste capaz de provar que um produto está correto. No entanto, os autores também demonstram que não existe uma maneira sistemática de calcular $T$ ou de decidir se um $T$ particular possui essa propriedade, pois, de outra forma, poder-se-ia provar a equivalência entre programas, que é um problema indecidível.

\subsubsection{Critérios de Teste}

De um ponto de vista abstrato, um critério de teste estabelece um processo para a seleção de um subconjunto (relativamente pequeno) $T$ do domínio de entrada $D$. Visto de outra forma, pode-se caracterizar um critério de teste como um processo que descarta, por algum motivo, o complemento $D-T$, não o utilizando para o teste. Um dos métodos mais utilizados para o cálculo de $T$ é definir uma coleção ${ }^{1} \mathcal{D}_{S P}$ de subdomínios de $D$ e selecionar um número $k$ de elementos de cada subdomínio. Assume-se que os elementos de um subdomínio específico são, em alguma forma de abstração, "iguais", e, por isso, são completamente intercambiáveis (Hamlet e Taylor, 1990). Um critério de teste é, portanto, um método para a definição de $\mathcal{D}_{S P}$ e para a seleção dos $k$ elementos de cada subdomínio de $\mathcal{D}_{S P}$. Em geral, assume-se que a seleção dos $k$ elementos de um dado subdomínio é feita de forma aleatória. Na maioria dos critérios, estabelece-se $k=1$.

A qualidade de um critério de teste pode ser medida pela homogeneidade dos subdomínios que define (Weyuker e Ostrand, 1980). Um subdomínio $D_{i}$ é homogêneo se, ou todo elemento de $D_{i}$ revela um defeito, ou nenhum o faz. Dessa forma, selecionando-se um $t$ qualquer de cada $D_{i} \in \mathcal{D}_{S P}$, todos os defeitos, se existirem, serão revelados. No entanto, a existência de um critério de teste que definisse subdomínios perfeitamente homogêneos, implicaria a possibilidade de provar a correção do programa, um problema que, como já mencionado, é indecidível. Portanto, critérios de teste que sempre selecionem subdomínios homogêneos não podem ser obtidos na prática, e deve-se buscar as melhores aproximações possíveis (Goodenough e Gerhart, 1975; Gutjahr, 1999; Weyuker, 1986).

Budd e Angluin (1982) definem, para um critério $C$, dois procedimentos associados: Avaliador: Um procedimento $A_{C}(P, S, T)$ é um avaliador (do inglês, acceptor) se responder "sim" se o conjunto de casos de teste $T$ é adequado para o produto $P$ e a especificação $S$ com relação ao critério $C$, e responder "não", caso contrário.

\footnotetext{
${ }^{1}$ Uma coleção, ou multi-conjunto, é uma entidade matemática semelhante a um conjunto, exceto que uma coleção pode ter elementos repetidos.
} 
Gerador: Um procedimento $G_{C}(P, S)$ é um gerador se produzir um $T$ adequado para $P$ e $S$ com relação a $C$.

Os autores provam, em seguida, que a existência de um procedimento avaliador para um critério $C$ implica a existência de um gerador para $C$, e vice-versa. Assim, pode-se considerar um critério de teste tanto como uma forma de avaliar um conjunto de casos de teste quanto como uma forma de gerar tal conjunto.

Os critérios de teste podem ser agrupados em três categorias: teste funcional (ou de caixa preta), teste estrutural (ou de caixa branca) e teste baseado em erros. O enquadramento de um dado critério em um dos grupos acima nem sempre é possível, visto que existem critérios que utilizam conceitos de mais de um grupo, tal como o teste de caixa cinza. Além disso, os critérios de teste exaustivo e aleatório não se encaixam adequadamente em nenhuma das características desses grupos. A seguir são descritos esses grupos, assim como os principais critérios de cada um. Descrevem-se também o teste exaustivo e o teste aleatório.

\subsubsection{Teste Exaustivo}

O teste exaustivo consiste em selecionar $T=D$. Em outras palavras, todo o domínio de entrada é utilizado para o teste. Em geral, o teste exaustivo é impraticável, seja porque o domínio de entrada é infinito, seja porque sua cardinalidade é muito grande. No entanto, existem casos críticos em que o custo de testar cada possível entrada, quando factível, é menor do que o custo ocasionado pela ocorrência de uma falha, e, nesse caso, o teste exaustivo, não pode ser desconsiderado.

\subsubsection{Teste Aleatório}

O teste aleatório consiste em selecionar aleatoriamente um $T \subseteq D$. Contudo, o teste aleatório não deve ser confundido com o teste ad hoc. Ao contrário deste, o teste aleatório é feito de forma sistemática, levando-se em consideração as características do domínio e a distribuição da probabilidade de cada entrada. Segundo Marick (2002), o teste aleatório deve ser sempre aplicado como um último passo da atividade de teste, para revelar possíveis erros que não foram evidenciados pelos critérios até então aplicados.

\subsubsection{Teste Funcional}

No teste funcional, ou teste de caixa preta, os casos de teste são selecionados a partir das funcionalidades que o sistema deve apresentar, tomando como base apenas sua especificação. A coleção de subdomínios $\mathcal{D}_{S P}$ é definida inteiramente a partir de $S$ e, idealmente, pode ser utilizada para qualquer possível implementação. 
Particionamento em Classes de Equivalência $\mathrm{O}$ domínio de entrada é dividido em classes, a partir das quais os casos de teste são derivados. As classes devem ser definidas de tal forma que os erros revelados por seus elementos sejam iguais, ou seja, os erros revelados por um caso de teste sejam os mesmos revelados pelos demais elementos da(s) classe(s) a que pertence. Dessa forma, basta selecionar um caso de teste de cada classe para cobrir o domínio de entrada.

Análise de Valor Limite A análise de valor limite pode ser considerada uma especialização do particionamento em classes de equivalência. São selecionados elementos que estejam, de alguma forma, nos "limites" das classes. Essa heurística baseia-se no fato empiricamente constatado de que a incidência de erros é maior nos limites das classes do que no seu interior. Além disso, o domínio de saída também é particionado e são exigidos casos de teste que produzam resultados nos limites dessas classes de saída. Como apontado por Howden (1989), apesar de ser tradicionalmente classificado como um critério de teste funcional, a análise de valor limite é um tipo de teste baseado em erros, uma vez que toma como base a ocorrência de erros para orientar a seleção de casos de teste.

\subsubsection{Teste Estrutural}

O teste estrutural, ou teste de caixa branca, utiliza-se de informações provenientes do programa $P$ a ser testado para derivar os casos de teste. A coleção de subdomínios é definida em função de $P$ e é utilizada sem se levar em consideração a especificação que deve ser satisfeita.

Teste Baseado em Caminhos O teste baseado em caminhos é uma denominação genérica que pode ser aplicada a diversos critérios de teste que envolvem a análise dos possíveis caminhos de execução do programa para derivar os casos de teste. Um conceito importante quando se considera o teste baseado em caminhos é o de bloco de comandos. Um bloco é uma seqüência de comandos que sempre são executados de forma consecutiva em um programa. Dessa forma, os desvios de controle só ocorrem para o começo ou a partir do final de um bloco. Em outras palavras, quando o primeiro comando de um bloco é executado, todos os demais também o são. Definido o conceito de bloco de comandos, pode-se definir o que é um grafo de programa. $G=(N, E)$ é um Grafo de Programa de um programa $P$ se para cada bloco de comandos de $P$ existe um nó $n \in N$ e para cada possível transferência de controle entre um bloco representado por $n_{i}$ e um bloco representado por $n_{j}$ existe um arco $\left(n_{i}, n_{j}\right) \in E$. Em um grafo, o nó correspondente ao bloco cujo primeiro comando é o comando inicial do programa é denominado nó inicial e o nó correspondente ao bloco cujo último comando é o comando final do programa é denominado nó final. 
A seqüência $K=\left\langle n_{1}, n_{2}, \ldots, n_{k}\right\rangle$ é um caminho completo de $G$ se $\left(n_{i}, n_{i+1}\right) \in$ $E$, para $1 \leq i<k$, e $n_{1}$ e $n_{k}$ são, respectivamente, o nó inicial e o nó final de $G$. Se um nó $n$ ocorre em um caminho $K$, então $n$ pertence a $K$, indicado por $n \in K$. Analogamente, um arco $\left(n_{1}, n_{2}\right)$ pertence a $K$, indicado por $\left(n_{1}, n_{2}\right) \in K$, se $n_{1}$ e $n_{2}$ aparecem consecutivamente em $K$. Para um caminho completo $K$, seja uma função $f_{K}$, que resulta da composição funcional do resultado da execução de cada bloco do caminho e seja $D_{K} \subseteq D$ o conjunto de elementos de entrada que fazem com que $K$ seja executado. Uma vez que, assumindo-se programas determinísticos, um elemento de entrada só pode levar à execução de um caminho, para dois caminhos completos $K^{\prime}$ e $K^{\prime \prime}$, tem-se que

$$
K^{\prime} \neq K^{\prime \prime} \Longrightarrow D_{K^{\prime}} \cap D_{K^{\prime \prime}}=\emptyset
$$

Observe também que $D_{K}$ pode ser vazio, para algum caminho $K$, o que implica que não existe elemento do domínio de entrada que fará com que $K$ seja executado. Tais caminhos são denominados caminhos não-executáveis. De forma análoga, se $D_{K} \neq \emptyset, K$ é um caminho executável. O problema de determinar se um caminho é executável é, em geral, indecidível.

No teste baseado em caminhos, os caminhos completos são agrupados segundo algum critério e casos de teste são selecionados de forma a executar um caminho de cada grupo. A seguir, alguns exemplos de critérios são apresentados.

Teste Baseado em Fluxo de Controle Os critérios de teste baseados em fluxo de controle agrupam os caminhos com base no grafo de programa. Dentre os critérios dessa categoria, pode-se citar:

Critério Todos-Nós O critério Todos-Nós exige que cada nó seja executado ao menos uma vez. Ou seja, para cada nó $n \in N$, define-se um conjunto de caminhos $C T N_{n}=\{K \mid n \in K\}$.

Critério Todos-Arcos O critério Todos-Arcos exige que cada arco seja executado ao menos uma vez. Ou seja, para cada arco $\left(n_{1}, n_{2}\right) \in E$, define-se um conjunto de caminhos $C T A_{\left(n_{1}, n_{2}\right)}=\left\{K \mid\left(n_{1}, n_{2}\right) \in K\right\}$.

Critério Todos-Caminhos Todos os possíveis caminhos do programa devem ser exercitados. Em geral, esse critério é impraticável, pois, na presença de laço, o número de caminhos é infinito.

Teste Baseado em Fluxo de Dados Critérios de teste baseados em fluxo de dados utilizam informações sobre a definição e uso de variáveis, utilizando técnicas geralmente 
empregadas em compiladores (Herman, 1976; Korel e Laski, 1985; Maldonado, 1991; Ntafos, 1988; Rapps e Weyuker, 1985).

Rapps e Weyuker (1985) definem critérios de teste que estabelecem requisitos de teste com base nas computações realizadas pelo programa e como as variáveis do programa são utilizadas. Assim, uma variável é definida quando lhe é atribuído um valor. Uma variável é usada quando seu valor é referenciado, havendo uma distinção entre o uso da variável em uma computação e em uma expressão de decisão, tal como a condição de um laço. A idéia que motiva essa abordagem é de que, se um conjunto de casos de teste não utiliza o valor de uma variável definido em uma computação, não há evidências de que essa computação foi feita adequadamente. Os critérios de teste são então definidos em função da definição e do uso de variáveis, podendo-se citar os seguintes critérios.

Critério Todas-Definições Para cada definição de uma variável deve-se selecionar ao menos um caso de teste que induza um caminho livre de definição até um uso dessa variável (Rapps e Weyuker, 1985). Ou seja, cada computação de valor deve ser utilizada pelo menos uma vez. Um caminho $K=\left\langle n_{1}, n_{2}, \ldots, n_{i}\right\rangle$ é livre de definição para uma variável $x$ se $x$ não for definida em $K$, exceto possivelmente nos nós $n_{1}$ e $n_{i}$.

Critério Todos-Usos Para cada definição de uma variável deve-se selecionar ao menos um caso de teste que induza um caminho livre de definição até cada uso dessa variável (Rapps e Weyuker, 1985). Ou seja, cada possível uso de uma computação de valor deve ser exercitado pelo menos uma vez.

\subsubsection{Teste de Caixa Cinza}

Existem abordagens que buscam uma integração das informações da especificação e da implementação para determinar os casos de teste. Jalote (1989) discute um método para o teste de completitude de especificações algébricas de tipos abstratos de dados. Especificações algébricas definem as propriedades e os relacionamentos entre as diversas operações que podem ser aplicadas aos elementos de um tipo abstrato de dados. O autor propõe um método para a derivação de sequiências de operações para verificar se todas as operações e combinações válidas possuem um valor definido segundo a especificação.

Gall e Arnould (1996) apresentam um framework para o teste de programas baseados em especificações algébricas, e salientam que, em geral, a semântica da especificação e a semântica do programa possuem fundamentos matemáticos diferentes, o que dificulta a verificação da correção dos resultados obtidos frente aos esperados. Faz-se necessário, acrescentam os autores, a utilização de uma "semântica intermediária" que incorpore o papel de oráculo.

Outra abordagem é proposta por Howden (1989) em sua Análise de Sabores (do inglês, flavor analysis). O autor propõe uma forma de anotar no próprio programa 
propriedades (chamadas de sabores pelo autor) que entidades abstratas devem possuir em pontos específicos. A estratégia é similar à inclusão de assertivas executáveis (von Staa, 2000), exceto que as entidades abstratas não são necessariamente elementos (variáveis, objetos, etc) do programa. As anotações permitem registrar (em uma linguagem própria) quais suposições foram feitas em um ponto específico do código e das propriedades válidas em tal ponto. Então, em tempo de execução, as suposições podem ser automaticamente verificadas e eventuais discrepâncias podem ser relatadas.

\subsubsection{Teste Baseado em Erros}

Segundo Binder (1999), pessoas podem cometer erros na criação e/ou desenvolvimento de muitas formas, mas os meios utilizados para expressar o que se tem em mente, bem como o que se utiliza para a construção, limitam os tipos de erros que se podem cometer. Assim, diferentes linguagens de programação permitem que determinados tipos de erros possam ocorrer com maior ou menor freqüência. Por exemplo, Binder afirma que não é possível, incorreta e transparentemente, alterar o contador de programa para um endereço ou instrução diferente na maioria das linguagens de programação de alto-nível. Ainda como exemplo, a linguagem Pascal não permite que valores do tipo caracter sejam usados em locais onde valores inteiros são esperados, enquanto que na linguagem $\mathrm{C}$ isso é possível. Com base nesse fato, o teste baseado em erros utiliza-se de informações sobre erros que podem estar presentes em um produto para derivar os casos de teste. Em geral, essas informações variam em função da linguagem, técnica ou método utilizado para o desenvolvimento do software, impactando, dessa forma, no critério de teste empregado. Dessa forma, um conjunto de diretrizes podem ser definidos para guiar a atividade de teste, levando em consideração o conjunto de erros típicos da linguagem que se está utilizando ou de outras características relevantes. Nesta seção são apresentados alguns critérios de teste baseados em erro.

Análise de Mutantes A AM (Acree et al., 1979; DeMillo et al., 1978) é um critério que avalia a adequação de um conjunto de casos de teste em revelar erros específicos. Para isso, utiliza-se um conjunto de operadores de mutação, os quais geram produtos semelhantes ao produto que está sendo testado (chamado de produto original), mas nos quais foi incluído um defeito (gerando os produtos mutantes). Em seguida, os produtos mutantes são executados com os casos de teste e seus resultados são comparados com os resultados obtidos pelo produto original. A adequação dos casos de teste é definida por meio do escore de mutação, calculado como a razão entre o número de mutantes que apresentaram resultados diferentes do resultado do produto original e o número de mutantes gerados não-equivalentes ao produto original. O critério AM será discutido mais detalhadamente na Seção 2.3. 
Teste de Defeitos de Predicados Kuhn (1999) apresenta um método para calcular as condições que precisam ser satisfeitas por um conjunto de casos de teste para garantir que uma classe particular de defeitos seja detectada em expressões booleanas. Para um predicado $\theta$, o método calcula as condições que farão com que um predicado defeituoso $\theta^{\prime}$ produza um valor diferente de $\theta$, ou seja, quais condições satisfazem $\theta \oplus \theta^{\prime}$, onde $\oplus$ é o ou-exclusivo. As classes de defeitos consideradas são:

Referência de Variável: uma variável booleana $x$ é trocada por outra variável $y$, com $x \neq y$.

Negação de Variável: uma variável booleana $x$ é trocada por $\neg x$.

Negação de Expressão: uma expressão booleana $p$ é trocada por $\neg p$.

Deslocamento Associativo: uma expressão é trocada por outra na qual a associação entre as variáveis está incorreta, tais como $x \wedge(y \vee z)$ por $x \wedge y \vee z$.

Referência de Operador: um operador booleano por outro, tais como $x \wedge y$ por $x \vee y$.

Teste Algébrico de Defeitos Morell (1990) apresenta uma abordagem de teste baseado em erros, na qual se procura identificar não que o programa está correto, mas sim quais programas não podem estar corretos com base nos casos de teste já utilizados. Para isso, para cada programa, é considerado um conjunto de elementos (por exemplo, expressões, comandos, etc) e um conjunto de elementos alternativos. Após a execução de um caso de teste, determinam-se quais programas alternativos ainda poderiam estar corretos sabendo que o programa original se comportou adequadamente para esse caso. Os elementos alternativos são representados algebricamente. Dessa forma, a expressão $z:=x+F$ é uma expressão alternativa de $z:=x+y$, onde $F$ representa as possíveis expressões que incluiriam um defeito em $y$. Suponha-se que o valor $z$ foi corretamente calculado em $z:=x+y$ para um caso de teste com $x=3$ e $y=4$. Pode-se concluir que qualquer programa alternativo para o qual $F \neq 4$ não estará correto.

Teste de Perturbação Segundo Zeil (1983), para algumas classes de programas é possível caracterizarem-se os tipos de defeitos (chamados pelo autor de perturbações) que não podem ser evidenciados por um determinado caso de teste. Dessa forma, o autor apresenta uma estratégia de teste que avalia as perturbações que não são percebidas por um conjunto de casos de teste. Os erros que não são descobertos por um caminho do programa são descritos como cegueiras (do inglês, blindness). Segundo o próprio autor, "A maior limitação do método é exigir que o testador afirme que a forma funcional da expressão aritmética 'correta' está dentro de um espaço vetorial." 


\subsubsection{Comparação entre Critérios de Teste: Aspectos Teóricos e Empíricos}

Uma questão fundamental para a condução efetiva da atividade de teste é a determinação da relação de custo/benefício entre os diversos critérios existentes. Os critérios de teste podem ser comparados de diversas maneiras, tanto teóricas quanto empíricas. As vantagens e desvantagens de critérios de teste de software também podem ser avaliadas por meio de estudos teóricos e empíricos sob três aspectos (Wong, 1993):

custo: O fator custo reflete o esforço necessário para que o critério seja utilizado; existem diversas formas de medir o esforço requerido por um critério, tais como o número de casos de teste necessários para satisfazer o critério e a quantidade de recursos computacionais utilizados, tais como tempo de execução e espaço de armazenamento.

eficácia: A eficácia refere-se à capacidade que um critério possui de revelar defeitos.

força: (do inglês, strength) A força refere-se à probabilidade de satisfazer-se um critério tendo sido satisfeito outro critério.

Uma questão também muito importante e que tem recebido muita atenção da comunidade de teste é a determinação de se é ou não eficiente o uso de critérios de teste quando comparada ao teste aleatório. Em outras palavras, dado o custo de aplicação de um determinado critério, investiga-se sob quais condições é mais eficiente aplicá-lo, em vez de selecionar os casos de teste aleatoriamente.

\subsubsection{Comparação com base em Estudos Teóricos}

No contexto de estudos teóricos, o custo de aplicação de um critério é geralmente investigado pelo estabelecimento da complexidade do critério (Maldonado, 1991; Rapps e Weyuker, 1982), definido como o número mínimo de casos de teste necessários para satisfazer o critério, ou, como no caso da AM, como o número de mutantes gerados. A eficácia, por sua vez, é investigada em termos da probabilidade de que um conjunto de casos de teste que satisfaça o critério revele um defeito. Já a força é, em geral, investigada em termos da relação de inclusão (Frankl e Weyuker, 1985; Zhu, 1996) entre os critérios.

Uma relação de inclusão (do inglês, subsumption) estabelece quando conjuntos de casos de teste adequados a um critério $C_{1}$ também são adequados a outro critério $C_{2}$ (Frankl, 1987; Zhu, 1996). Visto que, segundo Frankl e Weyuker (1993), o fato de um critério $C_{1}$ incluir um critério $C_{2}$ não garante que $C_{1}$ é melhor que $C_{2}$ em revelar a presença de erros, outras relações foram propostas, de modo que, se um determinado critério $C_{1}$ satisfaz uma dada relação com respeito a um critério $C_{2}$, seja possível afirmar que $C_{1}$ é melhor que $C_{2}$ em revelar a presença de erros. Frankl e Weyuker (1993) definem cinco 
novas relações que comparam a capacidade em revelar a presença de erros dos critérios de teste de acordo com três medidas probabilísticas.

Zhu (1996) contesta os resultados obtidos por Frankl e Weyuker (1993) sobre o fato de que a relação de inclusão não reflete a capacidade em revelar erros dos critérios. Dois cenários de teste são apresentados: um cenário em que os casos de teste são construídos com base no critério de adequação utilizado, e outro em que os casos de teste são gerados sem que se tenha conhecimento sobre qual critério está sendo considerado. De acordo com Zhu, os resultados obtidos por Frankl e Weyuker (1993) são válidos para o primeiro cenário de teste. No entanto, considerando-se o segundo cenário, mostrou-se que a relação de inclusão implica também em maior capacidade em revelar erros dos critérios (Zhu, 1996).

Frankl e Weyuker (2000) estenderam os resultados obtidos em (Frankl e Weyuker, 1993) por meio da definição de medidas de eficácia relacionadas à gravidade de falhas no programa em teste. Duas métricas foram introduzidas, relacionando o risco detectado e a redução dos riscos proporcionada pela utilização de um dado critério de teste. Com base nessas métricas, os critérios de teste foram comparados analiticamente considerando o aspecto de eficácia.

\subsubsection{Comparação com Base em Estudos Empíricos}

No contexto de estudos empíricos, o custo de aplicação de um critério de teste é, em geral, determinado pela coleta de informações sobre os recursos (número de casos de teste, tempo computacional, esforço humano, espaço de armazenamento, etc) necessários para a obtenção de um conjunto adequado. A eficácia é avaliada verificando-se a quantidade (ou porcentagem) dos defeitos encontrados durante a aplicação do critério. Em geral, isso requer que os defeitos sejam conhecidos previamente. A força é avaliada comparando-se o quanto um conjunto adequado a um critério é adequado a outro.

Mathur e Wong (1994) comparam a adequação de conjuntos de casos de teste em relação aos critérios AM e Todos-Usos. O objetivo do experimento foi verificar a força entre os dois critérios, bem como seus custos. Nesse estudo, os conjuntos de casos de teste adequados para o critério AM também se mostraram adequados para o critério Todos-Usos. No entanto, os conjuntos de casos de teste adequados para o critério Todos-Usos não se mostraram, em muitos dos casos, adequados para o critério AM. Esses resultados demonstram que é mais difícil satisfazer o critério AM do que o critério Todos-Usos e que, na prática, a AM inclui Todos-Usos (Mathur e Wong, 1994).

Souza (1996) realizou um estudo empírico com a finalidade de avaliar a força e o custo do critério AM, empregando, para efeito comparativo, os critérios Potenciais Usos (Maldonado, 1991), os quais incluem o critério Todos-Usos. Os resultados demonstraram que o custo de aplicação do critério AM, estimado pelo número de casos de teste necessário para satisfazer o critério, apresentou-se maior do que o custo dos critérios 
Potenciais-Usos. Em relação à força observou-se que, de uma maneira geral, os critérios AM e Todos-Potenciais-Usos são incomparáveis mesmo do ponto de vista empírico.

No trabalho de Wong et al. (1994) foram comparadas seis diferentes classes de mutação restrita quanto à eficácia em revelar erros. Analisou-se a eficácia das classes de mutação obtidas a partir dos operadores de mutação da ferramenta Product Testing Using Mutation (Proteum) (Delamaro, 1993; Delamaro e Maldonado, 1996). Nesse experimento pôde-se observar quais classes de mutação eram mais econômicas (baixo custo de aplicação) e eficazes. Com isso, foi possível o estabelecimento de uma ordem incremental para o emprego dessas classes de mutação, com base na eficácia e custo de cada uma. Desse modo, os conjuntos de casos de testes podem ser construídos inicialmente de forma a serem adequados à classe com melhor relação custo×eficácia.

Entre os estudos empíricos que visam a estabelecer alternativas viáveis para a aplicação do critério AM pode-se destacar os trabalhos de Offutt et al. (1996) e Vincenzi (1998). O objetivo do estudo conduzido por Offutt et al. (1996) era determinar um conjunto essencial de operadores de mutação ${ }^{2}$ para o teste de programas FORTRAN-77, a partir dos 22 operadores de mutação utilizados pela MOTHRA. Os resultados obtidos demonstraram que apenas 5 operadores de mutação eram suficientes para aplicar eficientemente o teste de mutação.

Vincenzi (1998) investigou qual o relacionamento entre os critérios AM e Mutação de Interface (Delamaro, 1997; Delamaro et al., 2001) — cuja idéia básica é viabilizar o teste da interface entre as unidades que compõem o software, ao contrário da AM, que explora somente as características das unidades separadamente - e como utilizar tais critérios de forma complementar na atividade de teste, estabelecendo uma estratégia de teste incremental (Vincenzi et al., 1999).

No contexto do teste de especificações, Souza (2000) conduziu um estudo para avaliar a relação de custo/benefício entre critérios para o teste de Statecharts. Foram considerados o critério AM (Fabbri et al., 1999b) e critérios FCCS (Família de Critérios de Cobertura para Statecharts) (Souza et al., 2000c), nos quais são utilizados conceitos de fluxo de controle com base na Árvore de Alcançabilidade de Statecharts (Masiero et al., 1994). Os resultados desse estudo mostraram que esses critérios são incomparáveis.

\subsubsection{Comparação do Teste de Subdomínio versus Teste Aleatório}

Segundo Gutjahr (1999), poucos tópicos na área de teste parecem ser mais controversos do que a questão se é eficiente o uso de casos de teste gerados com base em critérios que particionam o domínio de entrada, conhecidos genericamente como teste de

\footnotetext{
${ }^{2}$ Entende-se por conjunto essencial de operadores de mutação aquele formado por um subconjunto do total de operadores de mutação, capaz de modelar a maioria dos erros que se objetivam revelar durante a atividade de teste. Ainda, a utilização desse conjunto deve proporcionar sensível redução de custo, em termos do número de mutantes gerados, preservando alto escore de mutação em relação ao critério AM (Barbosa et al., 1998).
} 
subdomínio. Central a esse ponto está a questão de que o teste aleatório possa ser tão bom quanto o teste de subdomínio, com um custo relativamente menor. Diversos estudos têm sido publicados nessa linha de pesquisa (Chen e Yu, 1996; Duran e Ntafos, 1984; Frankl e Weyuker, 2000; Gutjahr, 1999; Hamlet e Taylor, 1990; Jeng e Weyuker, 1989; Weyuker e Jeng, 1991).

Duran e Ntafos (1984) apresentam um estudo teórico no qual o problema da comparação é definido em bases estatísticas. Considerando diversas suposições, a probabilidade de detectar ao menos um defeito foi estimada tanto para o teste de subdomínio quanto para o teste aleatório por meio de experimentos simulados e os resultados foram comparados. Apesar de o teste de subdomínio geralmente requerer um esforço maior para a geração de casos de teste, seu resultado mostrou-se apenas marginalmente superior ao teste aleatório. Dessa forma, os autores sugerem que o teste aleatório possa ser mais compensador, balanceando-se o custo de aplicação e eficiência. Hamlet e Taylor (1990) consideraram os resultados de Duran e Ntafos (1984) como contra-intuitivos, uma vez que o teste de subdomínios aparenta ser mais rigoroso e sistemático. No entanto, Hamlet e Taylor conduziram experimentos similares e seus resultados essencialmente confirmaram os resultados obtidos por Duran e Ntafos.

Frente a tais resultados, Chen e Yu (1996) sugerem que o número de casos de teste a ser selecionado de cada subdomínio deva ser proporcional ao tamanho do subdomínio. Sob essa estratégia, o teste de subdomínio possui uma probabilidade maior de revelar mais defeitos do que o teste aleatório. Observe que o teste aleatório também tende a alocar casos de teste proporcionalmente ao tamanho do subdomínio. A diferença é que o teste aleatório faz isso apenas "em média". Na verdade, a seleção proporcional faz com que o teste de subdomínio "imite" o teste aleatório, no sentido de que à medida que mais casos de teste são selecionados, mais os resultados de ambas as estratégias se aproximam. No entanto, a aplicabilidade dessa estratégia é limitada pela dificuldade de determinar a proporção dos subdomínios, principalmente na presença de subdomínios finitos frente a subdomínios infinitos. Além disso, a eficácia dessa estratégia é contestada por Ntafos (1998), que afirma, baseado em um estudo empírico, que a vantagem obtida é, em geral, desprezível. O autor ainda acrescenta que a seleção proporcional reduz a vantagem relativa do teste de subdomínio sobre o teste aleatório, forçando a estratégia "mais forte" a comportar-se como a "mais fraca".

Weyuker e Jeng (1991) avaliam analiticamente os critérios de teste de subdomínios e investigam quais condições afetam sua eficiência. Uma comparação com o teste aleatório também é realizada. Conclui-se que o teste de subdomínio pode ter uma eficiência maior, menor, ou igual ao teste aleatório, dependendo da forma com que os subdomínios são definidos (Jeng e Weyuker, 1989). Em suma, as observações comprovam analiticamente os resultados empíricos obtidos por Duran e Ntafos (1984) e Hamlet e Taylor (1990) e ressaltam que a homogeneidade dos subdomínios é o fator primordial para a superioridade 
do teste de subdomínio. Dessa forma, um critério de teste deve idealmente dividir o domínio de entrada em subdomínios tais que, ou todos os seus elementos são processados corretamente, ou todos são processados incorretamente (Weyuker e Ostrand, 1980).

Gutjahr (1999) compara o teste de subdomínio e o teste aleatório sob a suposição de que a taxa de defeitos não é conhecida com certeza antes do teste e são, dessa forma, modelados por variáveis aleatórias segundo uma dada distribuição estatística. (Apesar de considerar apenas a distribuição normal em seu artigo, Gutjahr afirma que os resultados são válidos para outras distribuições.) É demonstrado que quando a quantidade de defeitos não é conhecida com certeza, o teste de subdomínio sistematicamente supera o teste aleatório. A restrição a taxas de defeitos conhecidas favorece o teste aleatório.

\subsubsection{Automatização da Atividade de Teste}

A qualidade da atividade de teste é dependente dos critérios de teste utilizados. No entanto, como a quantidade de informações que deve ser manipulada é geralmente grande, a automatização da aplicação de um critério é fator determinante da produtividade da atividade de teste e, em última análise, também de sua qualidade.

Uma forma de automatizar a atividade de teste é a criação de ferramentas de apoio. Ferramentas de apoio aumentam a produtividade por realizarem tarefas "mecânicas" de forma sistemática. De forma análoga, aumentam a qualidade por potencialmente reduzir os erros decorrentes da própria realização do teste (Marick, 2002). No entanto, a automatização completa da atividade de teste é um objetivo inalcançável, visto que existem problemas inerentemente indecidíveis que a permeiam (Frankl, 1987; Harrold, 2000; Howden, 1987; Ntafos, 1988; Rapps e Weyuker, 1985):

- dados dois programas, se eles são equivalentes;

- dados duas seqüências de comandos (caminhos) de um programa, ou de programas diferentes, se eles computam a mesma função; e

- dado um caminho, se ele é executável ou não, ou seja, se existe um conjunto de dados de entrada que leva à execução desse caminho.

Outro ponto em que se pode buscar a automatização da atividade de teste é a geração de um conjunto de casos de teste que satisfaça um determinado critério. Essa tem sido uma linha de pesquisa intensamente investigada (Bergadano e Gunetti, 1996; Bueno e Jino, 2001; Cohen et al., 1996; DeMillo e Offutt, 1991; Denney, 1991; Desel et al., 1997; Gotlieb et al., 1998; Gutjahr, 1999; Herbert e Price, 1997; Howden, 1975; Kotik e Markosian, 1989; Lindquist e Jenkins, 1988; Maurer, 1990; Michael e McGraw, 1997; Nemhauser e Wolsey, 1988; Ritchey, 2000; Simão e Maldonado, 2000a; Vergílio et al., 1993). 


\subsubsection{Ferramentas de Teste}

Sem a existência de uma ferramenta, a aplicação de um critério torna-se uma atividade propensa a erros e limitada a produtos simples (Horgan e Mathur, 1992). A disponibilidade de ferramentas de teste permite a transferência de tecnologia para a indústria e contribui para uma contínua evolução de tais ambientes, fatores indispensáveis para a produção de software de alta qualidade (Binder, 1999). Além disso, a disponibilidade de ferramentas de teste oferece recursos para a condução de estudos empíricos que visem a avaliar e a comparar os diversos critérios de teste existentes.

Diversos esforços na direção do desenvolvimento de ferramentas de teste podem ser observados (Agrawal et al., 1998; Barbosa et al., 2004; Borges et al., 1995; Chaim, 1991; Delamaro, 1993; Delamaro et al., 2001; Fonseca, 1993a; Frankl e Weyuker, 1985; Hamlet, 1988; Korel e Laski, 1985; Leitão, 1992; Lindquist e Jenkins, 1988; Maldonado et al., 1989, 2000; Martins et al., 2000; Oliveira e Andrade, 2003; Sharon e Anderson, 1997; Simão, 2000; Sugeta, 1999a; Sugeta et al., 2004; Sze, 2000; Telcordia Technologies - USA, 2002; Vincenzi et al., 2003).

A ferramenta Asset (A System to Select and Evaluate Tests), desenvolvida na New York University por Frankl e Weyuker (1985), figura como um dos primeiros esforços no sentido de automatizar a aplicação dos critérios de teste baseados em análise de fluxo de dados. Esta ferramenta testa programas escritos em Pascal, apoiando a aplicação dos critérios baseados em fluxo de dados definidos por Rapps e Weyuker (1982).

A ATAC (Automatic Test Analysis for $C$ ), desenvolvida pela Telcordia Technologies (Horgan e Mathur, 1992), apóia a aplicação de critérios estruturais de fluxo de controle e de fluxo de dados no teste de programas escritos nas linguagens $\mathrm{C}$ e $\mathrm{C}++$. Uma extensão da $A T A C$, denominada $A T A C O B O L$, que apóia a aplicação de critérios baseado em fluxo de dados em programas COBOL foi desenvolvida (Sze, 2000). Em linhas gerais, a ferramenta permite verificar a adequação de um conjunto de casos de teste, visualizar código não coberto pelos casos de teste, auxiliar na geração de casos de teste e reduzir o tamanho do conjunto de teste, por meio da eliminação de casos de teste redundantes. Atualmente a $A T A C$ está integrada ao xSuds (Telcordia Software Visualization and Analysis Toolsuite), um ambiente de apoio às atividades de teste, análise e depuração (Agrawal et al., 1998; Telcordia Technologies - USA, 2002).

A ferramenta PokeTool (Potential Uses Criteria Tool for Program Testing) (Chaim, 1991; Maldonado et al., 1989), desenvolvida no DCA/FEEC/UNICAMP em colaboração com o ICMC/USP, apóia a aplicação dos critérios Potenciais-Usos e também outros critérios estruturais como Todos-Nós e Todos-Arcos. Inicialmente a ferramenta foi desenvolvida para o teste de programas escritos em C. No entanto, a PokeTool também foi configurada para o teste de programas em COBOL (Leitão, 1992) e Clipper (Fonseca, 
1993b). Ainda, a PokeTool trabalha de forma integrada à ferramenta ViewGraph (Vilela, 1994), que possibilita a visualização de grafos de programa.

A MOTHRA é uma ferramenta de apoio ao critério AM para o teste de programas na linguagem FORTRAN-77 que foi desenvolvida na Purdue University e no Georgia Institute of Technology (Choi et al., 1989a,b; DeMillo et al., 1988). Além disso, a ferramenta apresenta interface baseada em janelas e possui funcionalidades que permitem a incorporação de diversos módulos, tais como, gerador de casos de teste, verificador de equivalência e oráculo.

As ferramentas Proteum (Delamaro, 1993; Delamaro e Maldonado, 1996) e Proteum/IM (Delamaro, 1997; Delamaro e Maldonado, 1999) foram desenvolvidas no ICMC/USP e apóiam a aplicação dos critérios AM e Mutação de Interface (Delamaro et al., 2001), respectivamente, para programas em C.

Considerando-se o teste de especificações, a disponibilidade de ferramentas de apoio também é importante, propiciando maior qualidade e produtividade para essa atividade. Deve-se ressaltar que, em geral, várias das ferramentas de apoio às técnicas de especificação também apóiam a simulação e, dessa forma, auxiliam na validação dos modelos.

A ferramenta Spin (Holzmann, 1997), desenvolvida pelo grupo de métodos formais e verificação da Bell Labs, apóia a verificação formal de sistemas distribuídos. Essa ferramenta utiliza uma linguagem de alto nível denominada PROMELA para descrever os sistemas. A Spin verifica a consistência lógica de uma especificação e tem sido usada em projetos de sistemas tais como protocolos de comunicação de dados, sistemas operacionais, sistemas de switching e algoritmos concorrentes.

A UppaAl (Pettersson e Larsen, 2000) consiste em um ambiente integrado de ferramentas para modelagem, simulação e verificação de sistemas de tempo real, e foi desenvolvida pelo Department of Computing Systems da Uppsala University em conjunto com Basic Research in Computer Science da Aalborg University. Essa ferramenta é composta por três partes principais: uma linguagem de descrição, um simulador e um model checker. O simulador permite a validação do modelo pela análise de possíveis execuções de um sistema durante fases iniciais de projeto. O model checker analisa o comportamento do sistema de modo exaustivo, verificando propriedades de alcançabilidade e invariantes pela exploração do espaço de estados do sistema.

Utilizando os conceitos da AM em nível de especificação, foram desenvolvidas no ICMC/USP as ferramentas Proteum-RS/FSM (Fabbri et al., 1994a, 1995a, 1999a), Proteum-RS/ST (Sugeta, 1999b; Sugeta et al., 1999, 2001) e Proteum-RS/PN (Simão, 2000; Simão e Maldonado, 2000b), que apóiam a validação de especificações baseadas em MEFs, Statecharts e RPs, respectivamente. Por estar diretamente relacionada a este trabalho, a ferramenta Proteum-RS/PN é descrita em mais detalhes na Seção 2.5.4.1. 


\subsubsection{Geração de Casos de Teste}

Um critério de teste define requisitos que devem ser satisfeitos por um conjunto de casos de teste. Esses requisitos podem ser utilizados para guiar a geração automática de casos de teste. Por exemplo, dado um conjunto de caminhos, pode-se buscar casos de teste que os executem.

Em geral, a geração de casos de teste é dificultada por uma série de limitações inerentes à própria atividade de teste (Frankl, 1987; Harrold, 2000; Howden, 1987; Ntafos, 1988; Rapps e Weyuker, 1985). Dessa forma, as propostas para a geração automática de casos de teste utilizam-se de heurísticas que procuram contornar essas limitações. A seguir, são apresentadas algumas técnicas para geração de casos de teste com base nos critérios baseados em caminhos e na AM.

O teste de domínio busca identificar possíveis defeitos nas expressões predicativas do programa [(White e Cohen, 1980) apud (Jeng e Weyuker, 1989)]. As expressões predicativas, tais como a expressão de controle de um comando condicional ou iterativo, são utilizadas para determinar qual, dentre dois ou mais possíveis próximos arcos, será selecionado. Observe-se que uma expressão predicativa define uma borda que separa o domínio de entrada de dois (ou mais) caminhos. A estratégia busca garantir que as bordas de um dado caminho $p$ não estão deslocadas em relação às bordas "corretas". Para isso, a estratégia estabelece que para cada borda de $p$ sejam selecionados casos de teste distintos, tanto que satisfaçam a expressão predicativa quanto que não a satisfaçam. Pode-se notar que essa estratégia segue as mesmas idéias do critério análise de valor limite, diferenciando-se desse por considerar os limites de cada expressão predicativa de um caminho, e não cada classe funcional de entrada.

DeMillo e Offutt (1991) apresentam uma técnica para a geração de casos de teste baseada em restrições, que usa conceitos da técnica AM. Os casos de teste são gerados de forma a matar os mutantes gerados para um programa específico. Para cada mutante, um conjunto de restrições é gerado para caracterizar sob quais valores de entradas o delta do mutante (ou seja, a diferença entre o mutante e o programa original) é exercitado e produz um estado diferente do programa original. Um caso de teste é selecionado entre as entradas que satisfazem esse conjunto de restrições. Deve-se observar que a técnica baseada em restrição apresenta limitações devido a alguns problemas indecidíveis, não tratados pela técnica, tal como decidir se o delta do mutante é alcançável ou se a diferença no estado influencia na saída do programa.

Bergadano e Gunetti (1996) apresentam um método para derivar um conjunto $T$ de exemplos por meio da indução de um programa Prolog $P$ a partir de um conjunto $\Phi$ de programas alternativos. O método busca, começando com um conjunto vazio de exemplos, identificar um exemplo $i$ que possa eliminar um programa $P^{\prime}$ de $\Phi$ e incluir $i$ em $T$. Caso contrário (ou seja, caso não seja possível encontrar tal exemplo) $P^{\prime}$ é equivalente a $P$ 
e deve ser desconsiderado (eliminando-o de $\Phi$ ). Um paralelo pode ser traçado com a AM, considerando-se $\Phi$ como o conjunto de mutantes ${ }^{3}$. Dessa forma, a indução pode ser considerada como uma técnica de geração de casos de teste baseada em mutação.

Gupta et al. (1998) utilizam um método similar ao método de programação linear conhecido como Simplex (Nemhauser e Wolsey, 1988) para gerar casos de teste que executem um determinado caminho no programa. Uma entrada é inicialmente selecionada e, após a execução do programa, caso o caminho não tenha sido executado, calcula-se o ajuste necessário para que isso aconteça. O processo continua iterativamente até que se obtenha uma entrada que execute o caminho ou se atinja um limite máximo de tentativas.

Uma abordagem similar apresentada por Gupta et al. (1998) é utilizada por Bueno e Jino (2001) para a geração de casos de teste, no entanto, aplicando-se algoritmos genéticos para identificar uma entrada que execute um caminho. Elementos de uma população de entradas são combinados, eliminados ou favorecidos por uma função de fitness. A função de fitness deve ser tal que penalize elementos com baixa probabilidade de produzir o resultado esperado (ou seja, executar o caminho).

\subsection{Análise de Mutantes}

O critério AM possui um forte relacionamento com um método clássico para deteç̧ão de defeitos lógicos em circuitos digitais, conhecido como modelo de teste de falha única (Acree, 1980; Delamaro e Maldonado, 1993). Segundo Delamaro e Maldonado (1993), a AM é um critério para medir a adequação dos casos de teste, sendo que um conjunto de casos de teste é dito adequado se o produto funciona corretamente quando executado com os casos de teste e se todos os produtos incorretos têm um comportamento não esperado para algum caso de teste. Dessa forma, o objetivo inicial da AM é servir como um meio de medir o quanto um conjunto de casos de teste é adequado a um determinado produto. Também foi demonstrada sua eficácia para detectar defeitos (Souza, 1996; Souza e Maldonado, 1997; Wong et al., 1994). Além disso, a AM pode ser utilizada para a geração de conjuntos de casos de teste adequados por construção (DeMillo e Offutt, 1991; Simão e Maldonado, 2000a).

Nesta seção, a AM é apresentada por meio do detalhamento dos principais passos envolvidos em sua execução, destacando-se em cada passo os principais problemas e iniciativas de pesquisa. Em seguida, descreve-se a aplicação da AM no contexto da validação de RPs Lugar/Transição, cujos resultados motivaram este trabalho. A ferramenta Proteum-RS/PN desenvolvida para a apoiar essa aplicação também é sucintamente descrita.

\footnotetext{
${ }^{3}$ No método proposto por Bergadano e Gunetti, os programas alternativos não estão limitados a mutações simples.
} 


\subsubsection{Principais Passos da Análise de Mutantes}

Basicamente, dados um produto $P$ e um conjunto de casos de teste $T$ cuja qualidade se deseja avaliar, deve-se seguir os seguintes passos para aplicar o critério AM:

- Geração do conjunto de mutantes $M$;

- Execução de $P \operatorname{com} T$;

- Execução dos mutantes $M \operatorname{com} T$ e

- Análise dos mutantes.

A seguir, apresenta-se a descrição de cada um desses passos.

\subsubsection{Geração dos Mutantes}

Constrói-se um conjunto de produtos, obtidos pela inclusão de alterações, ou desvios sintáticos, em $P$. Cada produto gerado dessa forma é denominado um mutante de $P$ (Acree, 1980) e o conjunto $M$ de mutantes é denominado a vizinhança de $P$ (Budd e Angluin, 1982), denotado por $\Phi(P)$. Esse é o passo chave na AM. O sucesso da aplicação do critério depende, em sua maior parte, da escolha adequada da vizinhança selecionada, a qual deve ter as seguintes características:

- ser abrangente, de modo que um conjunto de casos de teste que satisfaça a AM ou, em outras palavras, que seja adequado para $P$ em relação a sua vizinhança, consiga revelar a maior parte dos defeitos de $P$; e

- ter cardinalidade pequena, para que o problema de gerar os mutantes ou de verificar se um conjunto de casos de teste é ou não adequado seja tratável.

Duas hipóteses são utilizadas para guiar a geração de mutantes de modo a tentar atingir esses dois objetivos: a hipótese do programador competente e a hipótese do efeito de acoplamento. A hipótese do programador competente assume que os produtos a serem testados estão corretos ou próximos do correto (DeMillo et al., 1978). Dessa forma, a vizinhança de $P$ pode ser restringida aos produtos que são (sintaticamente) próximos de $P$. Essa hipótese baseia-se no fato de que um produto é fruto de um trabalho, que foi desenvolvido buscando-se satisfazer sua especificação. De outra forma, ou seja, se $P$ não foi desenvolvido de forma a estar próximo de sua especificação, os defeitos presentes em $P$ serão de certo modo triviais e facilmente identificados por casos de teste adequados mesmo para critérios mais fracos.

A hipótese do efeito de acoplamento assume que casos de teste que são capazes de revelar defeitos simples, também são capazes de revelar defeitos mais complexos. Nesse documento, um defeito é considerado simples quando uma alteração sintática simples (não decomponível) for suficiente para removê-lo, e é considerado complexo caso contrário. Sob 
esse aspecto, um defeito complexo pode ser considerado como uma composição de defeitos simples. Um corolário da hipótese do efeito de acoplamento é que se cada defeito simples for considerado e descartado (ou seja, se esse defeito não estiver presente no produto testado), pode-se assumir que os defeitos complexos também podem ser descartados. Contudo, a hipótese do efeito de acoplamento é, sobretudo, probabilística, no sentido de que eventualmente existem situações nas quais dois ou mais defeitos simples se anulam para algumas entradas do sistema, diferindo em outras. No entanto, a probabilidade de que isto ocorra é relativamente pequena, podendo ser negligenciada. Diversos trabalhos têm sido realizados com o objetivo de confirmar a hipótese do efeito de acoplamento, e os resultados parecem corroborá-la. Offutt (1992), por exemplo, apresenta um experimento no qual o efeito de acoplamento é empiricamente investigado ${ }^{4}$. Os principais resultados obtidos indicam que casos de teste $100 \%$ adequados para mutantes de primeira ordem são, em geral, mais que $99.9 \%$ adequados para mutantes de segunda ordem e, o autor sugere que sejam ainda mais adequados para mutantes de mais alta ordem. Além disso, os mutantes de segunda ordem que não foram mortos não possuíam padrão específico. Casos de teste que os matariam seriam alternativas viáveis para os casos de teste escolhidos originalmente, o que indica que permaneceram vivos por uma "combinação probabilística".

Com base nessas duas hipóteses, as características, até certo ponto conflitantes, que são esperadas de uma vizinhança apropriada são conciliadas escolhendo-se apenas mutantes nos quais defeitos simples são incluídos. Esses mutantes são denominados mutantes de ordem 1 ou, alternativamente, mutantes de primeira ordem. Em geral, mutantes de mais alta ordem, obtidos pela inclusão de mais de um defeito por vez, não são considerados. Pela hipótese do programador competente, existe uma alta probabilidade que os defeitos relevantes estejam sendo tratados. Além disso, pela hipótese do efeito de acoplamento, mutantes de ordem mais alta não contribuiriam para melhorar a qualidade dos casos de teste obtidos, e, no entanto, aumentariam exponencialmente a quantidade de mutantes gerados. Essa suposição tem sido comprovada por estudos teóricos (Wah, 2000) e empíricos (Offutt, 1989, 1992). Além disso, Daran e Thévenod-Fosse (1996) apresentam um estudo que compara defeitos reais e defeitos introduzidos por mutação. Os resultados indicam que os defeitos introduzidos por mutação, apesar de não serem necessariamente representativos dos defeitos reais (estes não estão contidos naqueles), comportam-se de forma similar a defeitos reais.

Para modelar as alterações sintáticas, utilizam-se operadores de mutação (do inglês, mutant operators), os quais geram o conjunto de mutantes de $P$. Em geral, a aplicação de um operador de mutação gera mais de um mutante, pois se $P$ contém várias entidades que estão no domínio do operador, esse operador é aplicado a cada uma dessas entidades.

\footnotetext{
${ }^{4}$ Offutt discute o efeito de acoplamento de mutação (mutantes de primeira ordem sobre mutantes de ordem superior) e não o efeito geral de acoplamento (defeitos simples sobre defeitos complexos). No entanto, os defeitos de mutantes de ordem superior são um subconjunto dos defeitos complexos e os resultados tendem a indicar que o efeito geral também é válido.
} 
Além dos tipos de defeitos que se desejam revelar e da cobertura que se quer garantir, a escolha de um conjunto de operadores de mutação depende também da linguagem em que os produtos a serem testados estão escritos. Em geral, a definição dos operadores de mutação é uma das partes mais importantes da aplicação da AM. Dado o seu impacto na eficácia e na eficiência da técnica, diversos esforços podem ser observados para a definição, refinamento e aprimoramento de conjuntos de operadores para linguagens específicas (Barbosa et al., 1998; Offutt et al., 1996).

Kim et al. (1999) propõem o uso da técnica HAZOP (McDermid e Pumfrey, 1994) para derivar os operadores de mutação. Essa técnica é baseada em dois conceitos. Primeiramente, identificam-se na gramática da linguagem alvo os pontos nos quais podem ocorrer as mutações. Em seguida, as mutações são definidas utilizando-se palavras-guia (do inglês, Guide Word). Os autores aplicaram sua técnica para a linguagem Java. Apesar de os operadores resultantes não diferirem significantemente de trabalhos passados, a metodologia proposta é um passo importante na direção de uma disciplina mais rigorosa na criação de operadores de mutação.

Um dos maiores problemas para a utilização do critério AM é o alto custo computacional exigido na execução do grande número de mutantes gerados. Na tentativa de solucionar o problema de custo, algumas abordagens vêm sendo propostas, as quais procuram reduzir a quantidade de mutantes utilizados:

\section{Mutação Aleatória (do inglês, Randomly Selected X\% Mutation)}

Na Mutação Aleatória (Acree et al., 1979), seleciona-se aleatoriamente uma porcentagem dos mutantes gerados por cada operador. Segundo DeMillo et al. (1988), em geral, mesmo utilizando uma pequena porcentagem do total de mutantes é possível construir bons casos de teste. Esse aspecto foi investigado experimentalmente, apresentando resultados que comprovam essa hipótese (Mathur e Wong, 1993; Wong et al., 1997).

\section{Mutação Restrita (do inglês, Constrained Mutation)}

Na Mutação Restrita (Mathur e Wong, 1993), apenas alguns operadores de mutação são selecionados para a geração dos mutantes. Segundo Wong e Mathur (1995b), com a escolha de um bom subconjunto de operadores de mutação é possível obter uma sensível redução no custo de execução dos mutantes sem reduzir de forma significativa a capacidade em revelar defeitos.

Mutação Seletiva (do inglês, Selective Mutation)

Na Mutação Seletiva (Offutt et al., 1993), os operadores de mutação responsáveis por gerar o maior número de mutantes não são utilizados.

Conjuntos Essenciais de Operadores de Mutação A determinação de Conjuntos Essenciais de Operadores de Mutação (Offutt et al., 1996) refere-se a seleção de um 
subconjunto do total de operadores que permita reduzir significativamente o custo de aplicação do critério, mantendo praticamente a mesma cobertura e a mesma eficácia que seria obtida pelo conjunto total de operadores (Barbosa et al., 2001, 1998; Offutt et al., 1996; Wong et al., 1997).

\subsubsection{Execução de $P$}

$\mathrm{Na}$ AM, assim como em outros critérios de teste, esse passo consiste em executar o produto $P$ usando os casos de teste de $T$ e verificar se seu comportamento é o esperado. Se não for, ou seja, se o produto apresenta resultados incorretos para algum caso de teste, então um defeito foi detectado. Caso contrário, a aplicação do critério AM continua no passo seguinte.

Como na maioria das técnicas e critérios de teste, a tarefa de decidir se o resultado produzido está correto é desempenhada por um oráculo (Weyuker, 1982), geralmente o próprio testador.

\subsubsection{Execução dos Mutantes}

Nesse passo, cada um dos mutantes é executado usando os casos de teste de $T$. Se um mutante $m$ apresenta resultado diferente de $P$, conclui-se que os casos de teste utilizados são sensíveis e conseguiram expor a diferença entre $P$ e $m$; neste caso, $m$ está morto e é descartado. Por outro lado, se $m$ apresenta comportamento igual a $P$, isto indica ou uma baixa qualidade de $T$ (pois não conseguiu distinguir $P$ de $m$ ) e diz-se que $m$ continua vivo, ou que $P$ e $m$ podem ser equivalentes.

Para que um caso de teste $t \in T$ mate um mutante $m$ com relação a $P$, três condições estão relacionadas, sendo elas usualmente denominadas de alcançabilidade, necessidade e suficiência (DeMillo e Offutt, 1991):

$C_{1}$ Alcançabilidade: $\mathrm{O}$ elemento $e$ no qual ocorreu a mutação deve ser exercitado (alcançado) quando $M$ for executado com $t$.

$C_{2}$ Necessidade: Após alguma execução de $e$, o estado de $M$ deve diferir do estado de $P$. Ou seja, além de executado, $e$ deve influenciar de alguma forma no estado do mutante.

$C_{3}$ Suficiência: A saída de $M$ deve diferir da saída de $P$. Ou seja, a diferença de estado ocasionada pela execução de $e$ deve propagar até a saída observável de $P$.

Essas três condições apresentam-se de forma hierárquica, de forma que quando a condição $C_{i}$ é satisfeita, a condição $C_{j}$, com $j<i$ também o é.

A execução dos mutantes e a comparação dos resultados podem ser totalmente automatizadas, não requerendo a intervenção do testador. Os resultados obtidos com a execução dos mutantes são comparados com aqueles produzidos pelo produto original no 
passo anterior e o próprio sistema de mutação pode marcar como mortos os mutantes que apresentam resultados diferentes. Se apenas a condição $C_{1}$ for utilizada como critério de distinção de mutantes, a AM equiparar-se-ia ao critério Todos-Nós. Duas abordagens alternativas relacionam-se à escolha entre a condição $C_{2}$ ou $C_{3}$. Caso $C_{2}$ seja escolhida, obtém-se o que se denomina Mutação Fraca (Howden, 1982), na qual o resultado da mutação é avaliado imediatamente após a execução do componente mutado. Caso $C_{3}$ seja escolhida, obtém-se o que se denomina Mutação Forte, na qual apenas a saída é comparada. Em geral, por questões de ordem pragmática, além dessas condições, leva-se em consideração o tempo de execução de um mutante com um caso de teste. Assim, se um mutante não concluir sua execução após um certo período (estabelecido em função do tempo de execução do programa original), a execução do mutante é interrompida e o mutante é considerado morto. Isso é feito para evitar problemas com mutantes que tenham possivelmente entrado em loop.

Após a execução dos mutantes, pode-se ter uma medida da adequação dos casos de teste utilizados por meio do escore de mutação ("mutation score"). O escore de mutação é um valor no intervalo (0..1) e fornece uma medida de quanto o conjunto de casos de teste analisado aproxima-se da adequação. Dado o produto $P$ e o conjunto de casos de teste $T$, calcula-se o escore de mutação $m s(P, T)$ da seguinte maneira:

$$
m s(P, T)=\frac{D M(P, T)}{M(P)-E M(P)}
$$

Sendo:

$D M(P, T)$ : número de mutantes mortos pelos casos de teste em $T$.

$M(P)$ : número total de mutantes gerados.

$E M(P)$ : número de mutantes equivalentes a $P$.

Devido ao alto custo computacional, a execução dos mutantes é, em geral, um empecilho à aplicação prática da AM. Por isso, diversas abordagens têm sido investigadas buscando-se reduzir esse custo. Considerando-se programas, Untch et al. (1993) apresentam uma abordagem para acelerar a compilação e execução dos mutantes, utilizando-se o que o autor denominou de Mutant Schemata. Um conjunto de mutantes $\left\{m_{0}, m_{1}, \ldots, m_{k}\right\}$ é embutido em um único meta-mutante, que é compilado, gerando um programa que recebe um parâmetro adicional $j$, com $0 \leq j \leq k$ que indica que o meta-mutante deve se comportar como o mutante $m_{j}$. Uma abordagem similar foi empregada por Delamaro (1997) na ferramenta Proteum/IM.

Weiss e Fleyshgakker (1993) propõem um algoritmo melhorado que visa diminuir o tempo de execução da AM, o qual se baseia em uma estrutura de dados que armazena informações sobre todos os estados internos do programa (inicial e final, bem 
como intermediários). Essa estrutura é então analisada para verificar se um mutante específico precisa ser executado. A análise é dividida em três partes, as quais se relacionam respectivamente às condições de alcançabilidade, necessidade e suficiência para que um caso de teste mate um mutante. Observe-se que, apesar de o algoritmo ser ótimo em relação ao número de execuções de mutantes, o custo para monitorar os estados internos da execução (principalmente os estados internos intermediários) e armazená-los é altamente proibitivo. Uma alternativa simplificada de algoritmo é adotada por Delamaro et al. (2001) para melhorar o tempo de execução dos mutantes, na qual apenas a condição de alcançabilidade é considerada. Como resultado, um compromisso entre a redução do tempo de execução e das necessidades de armazenamento e monitoramento é alcançado.

\subsubsection{Análise dos Mutantes}

Esse é o passo que requer mais intervenção humana. Primeiramente é preciso decidir se o teste deve continuar ou não. Se o escore de mutação já estiver próximo de 1 , pode-se decidir por encerrar o teste e considerar $T$ como um conjunto "suficientemente bom" de casos de teste para $P$. Caso decida-se por continuar o teste, é preciso analisar os mutantes que sobreviveram à execução com os casos de teste e decidir se esses mutantes são ou não equivalentes ao produto original. Novos casos de teste devem ser gerados para matar os mutantes vivos não-equivalentes.

Deve-se ressaltar que, segundo DeMillo e Offutt (1991), não é muito clara a relação entre a distância sintática e a distância semântica ${ }^{5}$. Ou seja, é difícil prever como uma mutação influenciará na saída do programa. No entanto, uma propriedade que parece ser válida em referência à $\mathrm{AM}$ é que, se um dado operador de mutação gera mutantes cuja distância semântica do programa original seja muito grande, tais mutantes seriam facilmente mortos, pois a seleção de um caso de teste que o mate seria simples. Além disso, a probabilidade de gerar um mutante equivalente é baixa. Os melhores operadores seriam então os que geram mutantes semanticamente próximos do programa original, pois induzirão a selecionar casos de teste mais elaborados. No entanto, a probabilidade de um mutante gerado ser equivalente (ou seja, um mutante cuja distância semântica é nula) será maior. Conclui-se que, operadores melhores tendem a gerar mais mutantes equivalentes.

Em geral, o problema de determinar a equivalência de um mutante ao programa original é indecidível. Dessa forma, não é possível a automatização completa dessa tarefa. No entanto, alguns métodos e heurísticas têm sido propostos para determinar a equivalência de programas em uma grande porcentagem dos casos de interesse (Budd, 1981; DeMillo e Offutt, 1991; Offutt e Pan, 1997; Simão e Maldonado, 2000a; Vincenzi

\footnotetext{
${ }^{5}$ Em (Offutt e Haeys, 1996), são propostas as seguintes definições de distância sintática e distância semântica. Distância sintática é a quantidade mínima de modificações que devem ser feitas para transformar um produto $M$ em um produto $P$ (supostamente correto). Distância semântica entre os programas $P$ e $M$ pode ser definida como a razão entre o domínio de entrada e o subconjunto desse domínio para o qual a saída de $P$ e $M$ diferem.
} 
et al., 2001). Algumas vezes, esses métodos e heurísticas estão relacionados a técnicas de geração de casos teste (DeMillo e Offutt, 1991; Simão e Maldonado, 2000a). Por exemplo, a técnica de geração de casos de teste baseada em restrições (DeMillo e Offutt, 1991; Offutt e Pan, 1997) é capaz de identificar alguns casos em que as restrições relacionadas a um mutante específico são contraditórias, indicando que se trata de um mutante equivalente. Em outras abordagens, busca-se estimar a probabilidade de um mutante ser equivalente. Por exemplo, Vincenzi et al. (2001) utilizam aprendizado Bayseano para definir essa probabilidade com base nos casos de teste já utilizados.

\subsection{Sistemas Reativos: Técnicas de Especificação do As- pecto Comportamental}

A especificação de um sistema é um documento que define as características funcionais e/ou não-funcionais que o sistema deve atender (Hoare, 1996). Considerando-se SRs, sua característica particular de envolver interação com o ambiente externo ou interno faz com que seu aspecto comportamental seja de fundamental importância para definir os requisitos do sistema e métodos adequados devem ser utilizados para representá-lo (Bochmann e Petrenko, 1994; Furbach, 1993; Gall e Arnould, 1996). Existem várias técnicas que apóiam a especificação do aspecto comportamental de SRs. Por exemplo, pode-se utilizar a linguagem natural durante a fase de especificação dos requisitos para detalhar o comportamento esperado do sistema. Porém, em geral, a linguagem natural é ambígua, resultando em uma documentação também ambígua e potencialmente inconsistente (Barroca e McDermid, 1992; Furbach, 1993; King et al., 2000; Wing, 1990), motivando o estabelecimento de métodos rigorosos para especificação de SRs.

Segundo Wing (1990), alguns métodos possuem também o aspecto visual, ou seja, sua linguagem inclui elementos gráficos e podem ser divididos em métodos formais e semiformais. Entre os métodos visuais formais, pode-se citar RPs, Statecharts e MEFs. Entre os métodos visuais semiformais, pode-se citar o método Jackson (Jackson, 1983), o HIPO (Hierarchy Input Processing Output) (Corporation IBM, 1974) e o SD (Structured Design) (Gane e Sarson, 1979). Esses métodos semiformais têm a vantagem de facilitar a comunicação entre projetista e cliente, pois se assume que podem ser compreendidos com relativa facilidade. No entanto, por combinarem vários tipos de notações (diagramas e textos), esses métodos podem contribuir para a elaboração de especificações ambíguas.

Em muitos casos, os métodos apóiam a execução (simulação) das especificações. Assim, a especificação pode ser usada pelo projetista para fornecer feedback e permitir a elaboração de protótipos. Segundo Wing (1990), dentre esses métodos estão MEFs, Statecharts, OBJ (Gerrard et al., 1990) e RPs. Como exemplificação de técnicas visuais formais e executáveis, que contextualizam este trabalho, a seguir, são descritas sucintamente as 
técnicas MEFs, Statecharts e Estelle. Em seguida, apresentam-se mais detalhadamente as técnicas RPs e RPCs.

\section{Máquinas de Estados Finitos}

Uma MEF (Gill, 1962) é uma máquina hipotética composta por estados e transições. Cada transição liga um estado $a$ a um estado $b$ ( $a$ e $b$ podem ser o mesmo estado). A cada instante, uma máquina pode estar em apenas um de seus estados. Em resposta a um evento de entrada, a máquina gera um evento de saída e muda de estado. Tanto o evento de saída gerado quanto o novo estado são definidos unicamente em função do estado atual e do evento de entrada (Davis, 1988). Uma MEF pode ser representada tanto por um diagrama de transição de estados quanto por uma tabela de transição. Em um diagrama de transição de estados, os estados são representados por círculos e as transições são representadas por arcos direcionados entre estados. Cada arco é rotulado com a entrada que gera a transição e a saída que é produzida, usando o formato entrada:saída. Em uma tabela de transição, os estados são representados por linhas e as entradas, por colunas (Davis, 1988).

Uma vez que, por definição, o conjunto de estados atingíveis em uma MEF é finito, é possível responder a quase todas as questões sobre o modelo, o que permite a automatização do processo de validação. No entanto, a classe de sistemas que podem ser efetivamente modelados por uma MEF é limitada. Mesmo para os casos nos quais a modelagem é possível, o modelo resultante pode ser excessivamente grande. Por exemplo, a impossibilidade da representação explícita da concorrência leva à explosão combinatória do número de estados. Com o propósito de aumentar o poder de modelagem, foram propostas várias extensões às MEFs, tais como Statecharts (Harel, 1987b), SDL (Specification and Description Language) (ITU, 1993), MEFs Comunicantes (Özdemir e Ural, 1997; Peng, 1997) e Estelle (Budkowski e Dembinski, 1987; Lopes, 1989).

\section{Statecharts}

Statecharts consistem em uma técnica de especificação de SRs proposta por Harel (1987b), a qual estende as MEFs adicionando-lhes as características de decomposição, ortogonalidade, broadcasting e história.

A decomposição permite que vários estados sejam agrupados e tratados como um superestado ou que um estado seja "explodido" em subestados. Essa característica permite que uma especificação seja criada de forma modularizada, tanto top-down quanto bottom-up. Existem dois tipos de superestados: tipo AND e tipo OR. Em um superestado do tipo $O R$, somente um subestado pode estar ativo a cada instante. Por outro lado, em um superestado do tipo $A N D$, todos os subestados são ativados simultaneamente e agem 
como máquinas independentes. A essa independência entre subestados dá-se o nome de ortogonalidade.

Quando um evento ocorre, cada transição rotulada com esse evento é ativada e sua saída é gerada. Essa saída pode ser um evento externo ou interno. Um evento interno pode desencadear ações nos componentes ortogonais, por meio do mecanismo chamado broadcasting.

A história é a capacidade de lembrar a configuração anterior de um superestado do tipo $O R$. Normalmente, quando um superestado do tipo $O R$ torna-se ativo, o seu subestado default é ativado. No entanto, se um símbolo de história estiver associado à transição, o último estado ativado anteriormente será ativado, o que é denominado entrada por história.

\section{Estelle $^{6}$}

Estelle foi desenvolvida pela ISO (International Standard Organization) para especificação de sistemas distribuídos, protocolos de comunicação e serviços, sendo publicado em 1987 o material ISO 9074 (ISO/TC97/SC21/WG1/DIS9074, 1987) que descreve a sintaxe e a semântica formal dessa técnica.

A estrutura de um sistema especificado em Estelle é uma hierarquia de módulos que se comunicam por meio de trocas de mensagens. O comportamento de cada módulo é descrito por meio de Máquinas de Estados Finitos Estendidas (MEFEs). As máquinas comunicam-se trocando mensagens por meio de canais de comunicação bidirecionais. Mensagens recebidas são armazenadas em filas do tipo FIFO (do inglês, First In First Out) e são processadas de acordo com as condições, prioridades e atrasos associados às transições da máquina. As ações das máquinas são especificadas por meio de comandos da linguagem Pascal. Estelle permite descrever o paralelismo síncrono, assíncrono e a execução seqüencial dos módulos do sistema. Essas diferentes possibilidades de comunicação e sincronização são definidas por meio do atributo de cada módulo: systemprocess, systemactivity, process e activity. Os módulos com atributo systemprocess ou systemactivity são chamados system e ocorre paralelismo assíncrono entre eles. Dentro de um módulo systemprocess, pode ocorrer paralelismo síncrono ou execução seqüencial, dependendo do atributo de seus módulos filhos, que pode ser process ou activity. Os filhos de um módulo process podem ser process ou activity e são executados de forma síncrona e em paralelo, significando que uma transição de cada módulo é selecionada em cada passo e essas transições são executadas em paralelo. Por outro lado, os filhos de um módulo activity podem somente possuir o atributo activity e são executados seqüencialmente, ou seja, uma transição de um dos módulos é selecionada aleatoriamente para execução em cada passo. Já para os módulos systemactivity, seus módulos filhos podem somente ter o

\footnotetext{
${ }^{6}$ Esta seção foi parcialmente extraída de (Souza, 2000).
} 
atributo activity e assim só pode ocorrer execução seqüencial (Budkowski e Dembinski, 1987).

A semântica de Estelle descreve o comportamento global do sistema, definindo as regras para o disparo de transições e como essas transições são selecionadas a partir dos módulos. O comportamento global de um sistema especificado em Estelle é definido pelo conjunto de todas as possíveis seqüências de situações globais geradas a partir de uma situação inicial, sendo que o disparo de uma transição faz com que o sistema mude de uma situação global para outra.

\subsubsection{Redes de Petri}

Redes de Petri (Cardoso e Valette, 1997; Murata, 1984, 1989; Peterson, 1977, 1981; Reisig, 1985) consistem em uma linguagem visual de especificação desenvolvida para sistemas nos quais a comunicação e a sincronização entre processos e o compartilhamento de recursos desempenham papéis importantes. A técnica RPs foi proposta em 1962 por Carl A. Petri e é muito utilizada para modelar sistemas com interação de componentes assíncronos e concorrentes. Segundo Reisig (1985), na proposta original de Petri, os sistemas são organizados por meio da enumeração de suas condições e eventos e da inter-relação entre condições e eventos. Posteriormente, essa definição foi ampliada de forma a permitir que as condições pudessem conter uma ou mais marcas. Nessa nova definição, as condições passaram a ser chamadas de lugares da rede e os eventos, de transições da rede. Esse contraste deu origem a uma classe de redes conhecida como Redes Lugar/Transição, ao passo que as redes anteriores passaram a serem denominadas Redes Condição/Evento. As Redes Lugar/Transição, por serem mais utilizadas e estudadas, acabaram recebendo a denominação genérica de Redes de Petri. Uma Rede Condição/Evento é uma Rede Lugar/Transição cujos lugares podem possuir, no máximo, uma marca.

A seguir é apresentada uma definição de RPs baseada em (Reisig, 1985).

Definição 1. Seja $N=\left(P, T, F, W, \mu_{0}\right)$. $N$ é uma rede de Petri se:

- $P \neq \emptyset$. $P$ é o conjunto finito de lugares da rede.

- $T \neq \emptyset$. $T$ é o conjunto finito de transições da rede.

- $P \cap T=\emptyset$.

- $F \subseteq((P \times T) \cup(T \times P))$. $F$ é o conjunto de arcos da rede. Os arcos podem ligar um lugar a uma transição ou vice-versa. Logo, uma rede de Petri é um grafo bipartido (Peterson, 1981). $(P \times T) \cup(T \times P)$ representa o conjunto de arcos possíveis da rede, sendo que $F$ é um subconjunto dos arcos possiveis. Os arcos pertencentes a F são chamados arcos efetivos, ao passo que os arcos possíveis que não pertencem a F são chamados de arcos não-efetivos e são representados por $\bar{F}$, ou seja, $\bar{F}=(P \times T) \cup(T \times P)-F$. Os arcos pertencentes a $(P \times T)$ são chamados 
arcos de entrada $e$, analogamente, os arcos pertencentes $a(T \times P)$ são chamados arcos de saída.

- $W:(P \times T) \cup(T \times P) \mapsto \boldsymbol{N}$. W é uma função que indica o peso de cada arco possível da rede. O peso de arcos não-efetivos da rede, ou seja, de arcos que não pertencem a $F$, são, por definição, igual a 0 .

Dada uma rede de Petri $N$, $\mu$ é uma marcação de $N$ se $\mu$ é uma função que leva cada lugar da rede a um número natural.

$$
\mu: P \mapsto N
$$

A expressão $\mu(p)$ indica a quantidade de marcas que p possui na marcação $\mu$. Uma marcação representa uma configuração particular do conteúdo de cada lugar.

- $\mu_{0}: P \mapsto N . \mu_{0}$ é a marcação inicial da rede.

Segundo Murata (1984), os três primeiros conjuntos da rede $(P, T, F)$ formam o grafo da estrutura estática da rede. Em uma dada marcação $\mu$, uma transição $t$ pode estar habilitada, o que é usualmente expresso pela notação $\mu[t\rangle$. A notação $\mu \nmid t\rangle$ é usada para indicar que $t$ não está habilitada em $\mu$. A habilitação de uma transição $t$ em uma marcação $\mu$ é definida da seguinte forma:

$$
\mu[t\rangle \Leftrightarrow \mu(p) \geq W(p, t) \quad \forall p \in P
$$

Se $t$ está habilitada em $\mu$, então $t$ pode disparar e gerar uma nova marcação $\mu^{\prime}$, o que é representado por $\mu[t\rangle \mu^{\prime}$ e é definido como:

$$
\mu[t\rangle \mu^{\prime} \Leftrightarrow \mu^{\prime}(p)=\mu(p)+W(t, p)-W(p, t) \quad \forall p \in P
$$

O conjunto de transições habilitadas em uma marcação $\mu$ é indicado por $\mu[\rangle$. Se várias transições estão habilitadas em uma mesma marcação, qualquer uma delas pode disparar de forma não-determinística.

Em certos casos, é conveniente a definição da habilitação e execução de seqüências de transições, em vez da habilitação e execução de transições individuais. Uma seqüência de transições $s q=t_{1}, t_{2}, \ldots, t_{n}$ está habilitada em $\mu_{0}$ (denotado por $\mu_{0}[s q\rangle$ ) e a marcação atingida é $\mu_{n}$ (denotado por $\mu_{0}[s q\rangle \mu_{n}$ ), se, e somente se, para $1 \leq k \leq n$ :

$$
\mu_{k-1}\left[t_{k}\right\rangle \mu_{k}
$$

Pode-se também definir uma função que relaciona uma marcação $\mu$ e uma seqüência de transições $s q$ à marcação atingida após o disparo de $s q$ em $\mu$. Essa é a função de próximo 
estado e é normalmente representada por $\delta$ :

$$
\begin{gathered}
\delta:\left(\text { Marking } \times T_{\mathrm{seq}}\right) \mapsto \text { Marking } \\
\delta(\mu, s q)=\mu^{\prime} \Longleftrightarrow \mu[s q\rangle \mu^{\prime}
\end{gathered}
$$

sendo Marking $=P \mapsto \mathbf{N}$ o conjunto de todas as marcações e $T_{\text {seq }}$ o conjunto de todas as seqüências formadas com as transições de $T$.

Uma marcação $\mu^{\prime}$ é dita alcançável a partir de $\mu$ se existe uma seqüência $s q$ tal que $\mu[s q\rangle \mu^{\prime}$.

\subsubsection{Representação Gráfica}

As RPs possuem uma representação gráfica, o que facilita a sua visualização. Na representação gráfica, os lugares são usualmente representados por círculos e as transições, por barras. Cada arco $(x, y) \in F$ é representado por uma aresta direcionada que liga $x$ e $y$. O peso de cada aresta $a$ é indicado pela rotulação da aresta. No caso de $W(a)=1$, a rotulação de $a$ é opcional. Uma marcação $\mu$ é representada colocando-se $\mu(p)$ marcas no círculo que representa $p$, para todo $p \in P$.

Na Figura 2.1 é apresentado um exemplo de uma RP, tal que

- o conjunto $P=\left\{A_{1}, B_{1}, R, A_{2}, B_{2}\right\}$;

- o conjunto $T=\left\{T_{1}, T_{2}, T_{3}, T_{4}\right\}$;

- o conjunto $F=\left\{\left(A_{1}, T_{1}\right),\left(T_{2}, A_{1}\right),\left(B_{1}, T_{2}\right),\left(T_{1}, B_{1}\right),\left(R, T_{2}\right),\left(R, T_{4}\right),\left(T_{1}, R\right)\right.$, $\left(T_{3}, R\right),\left(A_{2}, T_{3}\right),\left(T_{4}, A_{2}\right),\left(B_{2}, T_{4}\right),\left(T_{3}, B_{2}\right)$;

- a função $W$ está definida de forma que $W(a)=1, \forall a \in F$; e

- a marcação inicial $\mu_{0}$ é definida de forma que

$$
\mu_{0}(p)= \begin{cases}0 & \text { se } p \in\left\{A_{1}, A_{2}\right\} \\ 1 & \text { se } p \in\left\{B_{1}, R, B_{2}\right\}\end{cases}
$$

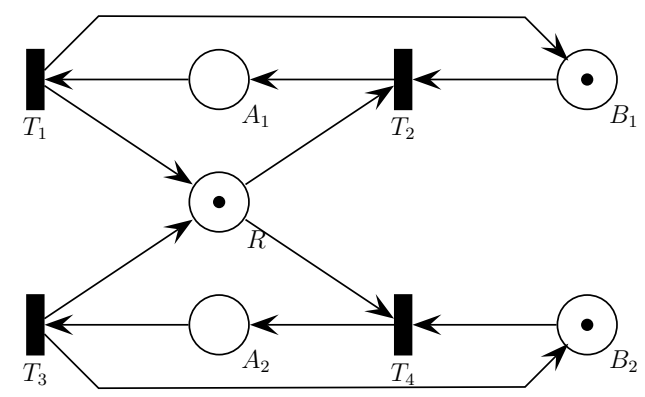

Figura 2.1: Representação Gráfica de uma Rede de Petri. 
Pode-se observar que as transições $T_{2}$ e $T_{4}$ estão habilitadas em $\mu_{0}$, podendo ser disparadas. Na Figura 2.2 é representada a marcação resultante, caso a transição $T_{2}$ seja disparada na marcação inicial.

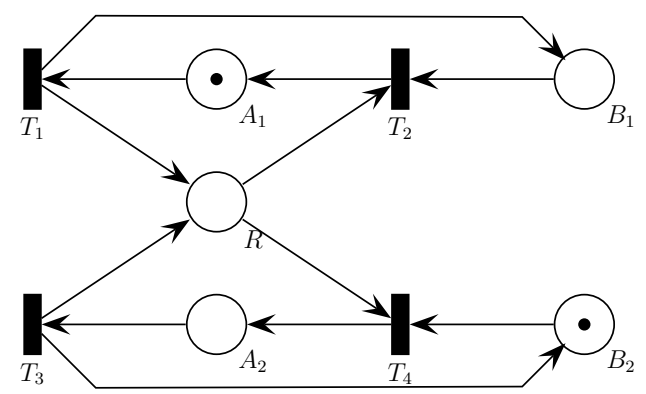

Figura 2.2: Rede da Figura 2.1 após o Disparo de $T_{2}$.

Nessa nova marcação, apenas a transição $T_{1}$ está habilitada e o disparo dessa transição leva a rede à marcação inicial (Figura 2.1).

\subsubsection{Representação Matricial}

A partir de uma $\operatorname{RP} N=\left(P, T, F, W, \mu_{0}\right)$, é possível criar uma representação baseada em matrizes (Reisig, 1985). Para a definição das matrizes que representam $N$, é necessário atribuir-se uma ordenação tanto ao conjunto $P$ quanto ao conjunto $T$. Dessa forma, $p_{i}$ representa o $i$-ésimo lugar da rede e $t_{j}$ é a $j$-ésima transição da rede. Assim, dada uma RP $N$ com $m$ lugares e $n$ transições, uma matriz $I_{m \times n}$ é uma matriz de entrada de $N$ se $I_{i j}=W\left(p_{i}, t_{j}\right)$. Analogamente, uma matriz $O_{m \times n}$ é uma matriz de saída de $N$ se $O_{i j}=W\left(t_{j}, p_{i}\right)$. A matriz de incidência de $N$, representada por $C$, é definida de tal forma que $C=O-I$. Uma marcação $\mu$ é representada como um vetor de $m$ inteiros no qual a $i$-ésima posição é igual a $\mu\left(p_{i}\right)$.

Na Figura 2.3 mostram-se as matrizes $I, O$ e $C$ e o vetor da marcação inicial da rede apresentada na Figura 2.1, considerando $A_{1} \prec B_{1} \prec R \prec A_{2} \prec B_{2}$ como a ordenação dos lugares da rede e $T_{1} \prec T_{2} \prec T_{3} \prec T_{4}$ como a ordenação das transições.

$$
\begin{gathered}
I=\left(\begin{array}{cccc}
1 & 0 & 0 & 0 \\
0 & 1 & 0 & 0 \\
0 & 1 & 0 & 1 \\
0 & 0 & 1 & 0 \\
0 & 0 & 0 & 1
\end{array}\right) \quad O=\left(\begin{array}{cccc}
-1 & 1 & 0 & 0 \\
1 & -1 & 0 & 0 \\
1 & -1 & 1 & -1 \\
0 & 0 & -1 & 1 \\
0 & 0 & 1 & -1
\end{array}\right) \quad \mu_{0}=\left(\begin{array}{llll}
0 & 1 & 0 & 0 \\
1 & 0 & 0 & 0 \\
1 & 0 & 1 & 0 \\
0 & 0 & 0 & 1 \\
0 & 0 & 1 & 0
\end{array}\right) \\
C=\left(\begin{array}{l}
0 \\
1 \\
1 \\
0 \\
1
\end{array}\right)
\end{gathered}
$$

Figura 2.3: Representação Matricial da Rede de Petri da Figura 2.1. 
Seja $s q$ uma seqüência de transições de $T$. O vetor $s(s q)$, com cardinalidade $|T|$, é o vetor de caracterização de $s q$ se a $i$-ésima posição de $s(s q)$ é igual ao número de ocorrências da transição $t_{i}$ em $s q$. Por exemplo, considerando-se a rede da Figura 2.1, o vetor de caracterização da seqüência $s q=\left\langle T_{2}, T_{1}, T_{2}\right\rangle$ é $s(s q)=\langle 1,2,0,0\rangle$. O vetor de caracterização de uma transição $t$ é o vetor de caracterização de uma seqüência de comprimento 1 que contenha essa transição, ou seja, $s(t)=s(\langle t\rangle)$.

Dada uma seqüência de transições $s q$ e uma marcação $\mu$, a habilitação de $s q$ em $\mu$ pode ser definida em função da matriz $I$ como segue.

$$
\mu[s q\rangle \Leftrightarrow \mu \geq I . s(s q)
$$

Dada uma seqüência de transições $s q$, habilitada em uma marcação $\mu$, a marcação $\mu^{\prime}=\delta(\mu, s q)$ atingida a partir de $\mu$ após o disparo de $s q$ pode ser definida em função da matriz $C$ da seguinte forma:

$$
\mu^{\prime}=C . s(s q)+\mu
$$

A Equação 2.1 é, geralmente, denominada como a equação fundamental das redes (Macial et al., 1996).

Dada uma marcação $\mu$ e um vetor de caracterização $v, S E Q(\mu, v)$ representa o conjunto de seqüências que estão habilitadas em $\mu$ e que podem ser representadas por $v$. Ou seja,

$$
S E Q(\mu, v)=\{s q \mid \mu[s q\rangle \wedge s(s q)=v\}
$$

\subsubsection{Propriedades}

Em geral, as técnicas de análise de RPs são tradicionalmente usadas para inferir determinadas propriedades da rede, as quais podem ser usadas tanto para verificação como para a validação da especificação. Na validação da especificação, as propriedades esperadas são derivadas a partir do sistema real e comparadas com as obtidas com a análise da rede. Dessa forma, se a especificação não possui a propriedade esperada do sistema, conclui-se que a especificação não está correta. No entanto, em geral, a presença dessas propriedades na especificação não garante que ela esteja correta. Deve-se observar que as propriedades analisadas da rede precisam ser interpretadas para serem usadas na validação. Por exemplo, um deadlock encontrado no modelo pode ser tanto um estado final válido do sistema quanto um problema a ser evitado. Nesta seção, apresentam-se as principais propriedades das RPs, divididas em Comportamentais e Estruturais.

Propriedades Comportamentais As propriedades comportamentais são aquelas que dependem da marcação inicial. As principais propriedades comportamentais são:

Alcançabilidade A alcançabilidade é utilizada para o estudo de propriedades dinâmicas de um sistema. A alcançabilidade indica a possibilidade de se atingir uma determi- 
nada marcação pelo disparo de um número finito de transições, a partir da marcação inicial.

Limitação A propriedade de limitação está relacionada com a existência de uma quantidade máxima de marcas que os lugares de uma RP podem conter em qualquer marcação alcançável. Se todos os lugares da rede são limitados, então a rede é limitada.

Segurança O conceito de segurança (do inglês, safeness) é uma restrição do conceito de limitação (Peterson, 1981). Uma RP é segura se, e somente se, todos os seus lugares forem limitados a uma marca.

Liveness Essa propriedade está relacionada à ausência de marcações alcançáveis que estejam em deadlock. Uma marcação está em deadlock se nenhuma transição estiver habilitada a disparar e não for uma marcação final.

Reversibilidade Em sistemas computacionais é comum existir uma configuração tal que deve ser possível atingi-la a partir de qualquer ponto da execução. Essa pode ser a configuração inicial, mas não necessariamente. A propriedade de reversibilidade tem relação com a capacidade de alcançar uma marcação específica a partir de qualquer outra marcação alcançável.

Justiça $\mathrm{O}$ conceito de justiça (do inglês, fairness) está relacionado com a idéia de que nenhuma transição (ou conjunto de transições) da rede possa disparar indefinidamente a despeito das outras transições. Para que uma rede seja justa, é necessário que toda seqüência infinita de transições tenha cada transição da rede aparecendo um número infinito de vezes.

Propriedades Estruturais As propriedades estruturais são aquelas que não dependem da marcação inicial. As principais propriedades estruturais são:

Limitação Estrutural Uma rede é estruturalmente limitada se ela é limitada para qualquer marcação inicial.

Conservação Uma RP é conservativa se a quantidade total de marcas não varia nas marcações alcançáveis, apenas sua distribuição entre os lugares. A conservação é uma importante propriedade das RPs permitindo, por exemplo, a verificação da não-destruição de recursos.

\subsubsection{Classes de Redes de Petri}

Desde sua concepção, diversas extensões e/ou restrições das RPs vêm sendo propostas. As pesquisas nessa linha caminham em duas direções complementares. Algumas 
propostas buscam definir um subconjunto de redes que compartilhem determinadas características úteis para aumentar o poder de decisão sobre propriedades do modelo. No entanto, a expressividade do modelo é reduzida, limitando o número de sistemas que podem ser modelados. Esse é o caso, por exemplo, de Redes de Escolha Livre e Redes Elementares (Rozenberg e Thiagarajan, 1986). Em outras propostas, busca-se aumentar a expressividade do modelo com a inclusão de recursos para representar e manipular tipos abstratos de dados, tais como as RPCs (Jensen, 1997c) e as Redes Predicado/Transição (Genrich, 1987), bem como a inclusão da noção de tempo, tais como as RPs Temporais (Kumar e Harous, 1994). Contudo, o poder de decisão sobre propriedades do modelo é reduzido.

Trompedeller (2002) propõe uma classificação dos modelos de RPs levando em conta o nível de detalhes que os lugares (e suas marcas) podem representar. Três níveis são propostos:

Nível 1 As RPs do nível 1 são caracterizadas por lugares que podem representar valores booleanos, isto é, um lugar pode conter no máximo uma marca não estruturada. As principais representantes deste nível são:

Redes Condição/Evento (C/E) (Bernardinello e Cindio, 1992; Reisig, 1985) As Redes Condição/Evento correspondem ao modelo de rede básico proposto por Petri (1962). Os lugares podem conter no máximo uma marca, comportando-se como condições que podem estar satisfeitas (com marcas) ou não (sem marca).

Redes Elementares (Rozenberg e Thiagarajan, 1986) Uma rede Elementar é uma rede Condição/Evento que satisfaz as restrições de que i) nenhuma condição é ao mesmo tempo pré- e pós-condição de um evento; ii) dados dois eventos distintos, ou suas pré-condições ou suas pós-condições são distintas; e iii) não existem eventos isolados.

Nível 2 As RPs do nível 2 são caracterizadas por lugares que podem representar valores inteiros, isto é, um lugar pode conter um número de marcas não-estruturadas. Essas redes são genericamente denominadas de RPs Lugar/Transição ou redes ordinárias (Jantzen e Valk, 1980) e foram apresentadas anteriormente na Definição 1. As principais representantes deste nível são:

Redes de Escolha Livre (Bernardinello e Cindio, 1992) Uma rede de escolha livre é uma RP Lugar/Transição tal que cada arco é o único arco de um lugar a uma transição ou o único arco de uma transição a um lugar.

Máquinas de Estado (Peterson, 1981) Uma Máquina de Estado é uma RP Lugar/Transição na qual cada transição possui apenas um arco de entrada e apenas um arco de saída. 
Grafo Marcado (Peterson, 1981) Um Grafo Marcado é uma RP Lugar/Transição na qual cada lugar possui apenas um arco de entrada e apenas um arco de saída.

Nível 3 As RPs do nível 3 são caracterizadas por lugares que podem representar valores de alto nível, isto é, um lugar pode conter um multi-conjunto de valores estruturados. As principais representantes deste nível são:

Redes Predicado/Transição (Genrich, 1987) Basicamente, os arcos da rede são marcados com predicados sobre o conteúdo de seus respectivos lugares antes e depois do disparo de uma transição.

Redes de Petri Coloridas (Jensen, 1997b) Os arcos da rede são marcados com funções que definem quantas e quais marcas serão eliminadas ou adicionadas aos respectivos lugares. De um ponto de vista abstrato, a diferença básica entre as redes Predicado/Transição e as redes coloridas é que essas utilizam uma abordagem inspirada no paradigma funcional, enquanto aquelas se baseiam no paradigma lógico. Uma discussão mais detalhada sobre RPCs, sua definição formal e aspectos de validação são apresentados na Seção 2.4.2.

Além da complexidade da informação carregada pelas marcas, diversas extensões têm sido propostas, incluindo outros conceitos às RPs. Por exemplo, algumas extensões adicionam o conceito de tempo, tais como as RPs Temporais (Kumar e Harous, 1994) (que associam um tempo de latência às transições, permitindo a modelagem do tempo de disparo de uma transição) e as RPs Estocásticas (Chiola, 1991) (que associam tempo aos lugares, permitindo modelar o tempo consumido por uma atividade representada por um lugar), enquanto outras incluem conceitos de orientação a objetos, tais como as Redes Orientadas a Objetos (Lakos, 2001) (nas quais as marcas são objetos).

\subsubsection{Redes de Petri Coloridas}

RPCs consistem em uma técnica formal com embasamento matemático para a descrição de sistemas, especialmente apropriada para a modelagem de sistemas de eventos discretos (Jensen, 1986). Dentre suas principais características, pode-se citar:

- Descrição distribuída das condições. Diferentemente do que ocorre com algumas técnicas (por exemplo, MEFs), as condições que controlam o aspecto comportamental do modelo estão distribuídas pelos diversos elementos do sistema;

- Representação explícita da dependência ou independência causal;

- Representação gráfica do sistema e de seus aspectos dinâmicos; e 
- Disponibilidade de técnicas de análise.

As RPCs estendem as RPs adicionando-lhes recursos para a definição e manipulação de tipos de dados. Historicamente, convencionou-se designar os tipos em uma RPC como "cores", em contraste com as redes originalmente propostas, nas quais todas as marcas são iguais, ou seja, sem cor. De um ponto de vista abstrato, as RPCs estão para as redes Lugar/Transição, assim como as linguagens de programação estão para a linguagem de máquina (Jensen, 1986).

Nesta seção, é utilizada como exemplo a especificação de um Banco de Dados Distribuído (DDB) simplificado, extraída de (Jensen, 1997b), apresentando informalmente a técnica RPC. A definição formal é apresentada na Seção 2.4.2.1. As principais características do exemplo são:

- O banco é composto por $n$ sites ( $\operatorname{com} n \geq 3)$;

- Cada site possui uma cópia de todos os dados e um controlador local $d_{i}$, (com $1 \leq i \leq n) ; \mathrm{e}$

- Cada controlador pode alterar sua cópia dos dados. Contudo, após uma alteração, o controlador $d_{i}$ do site deve enviar uma mensagem para todos os outros controladores para que eles atualizem suas respectivas cópias. Após ser avisado da atualização por $d_{i}$, o controlador $d_{j}$ atualiza sua cópia e envia uma mensagem de acknowledgement para $d_{i}$. Após receber todos os acknowledgements, $d_{i}$ volta ao estado original à espera de outra atualização. Nesse exemplo, o conteúdo da mensagem não é considerado, e sim somente o cabeçalho da mensagem, que contém o emissor e o receptor.

Na Figura 2.4 é apresentada a RPC que modela o DDB. Os elementos que constituem esse modelo serão explicados posteriormente, quando forem introduzidos os conceitos relacionados. No entanto, pode-se observar que os elementos com tracejado claro controlam o estado dos bancos, podendo ser ativo (qualquer banco pode alterar sua cópia dos dados) ou passivo (nenhuma alteração é possível). Os elementos com traço contínuo claro representam os estados em que uma mensagem pode estar, podendo ser: não-usada, enviada, recebida e respondida. Os elementos com traço contínuo escuro representam os estados em que cada banco pode estar, podendo ser inativo, esperando (que os demais bancos atualizem suas cópias de dados) ou trabalhando (para atualizar sua cópia de dados porque outro banco alterou os dados).

Multi-conjuntos Para a definição de RPCs é necessário o conceito de multi-conjuntos de elementos. Um multi-conjunto é uma entidade matemática semelhante ao conjunto, exceto pelo fato de que múltiplas ocorrências de um elemento são permitidas. Também são denominados como bags, suites ou coleções. Formalmente, um multi-conjunto sobre 


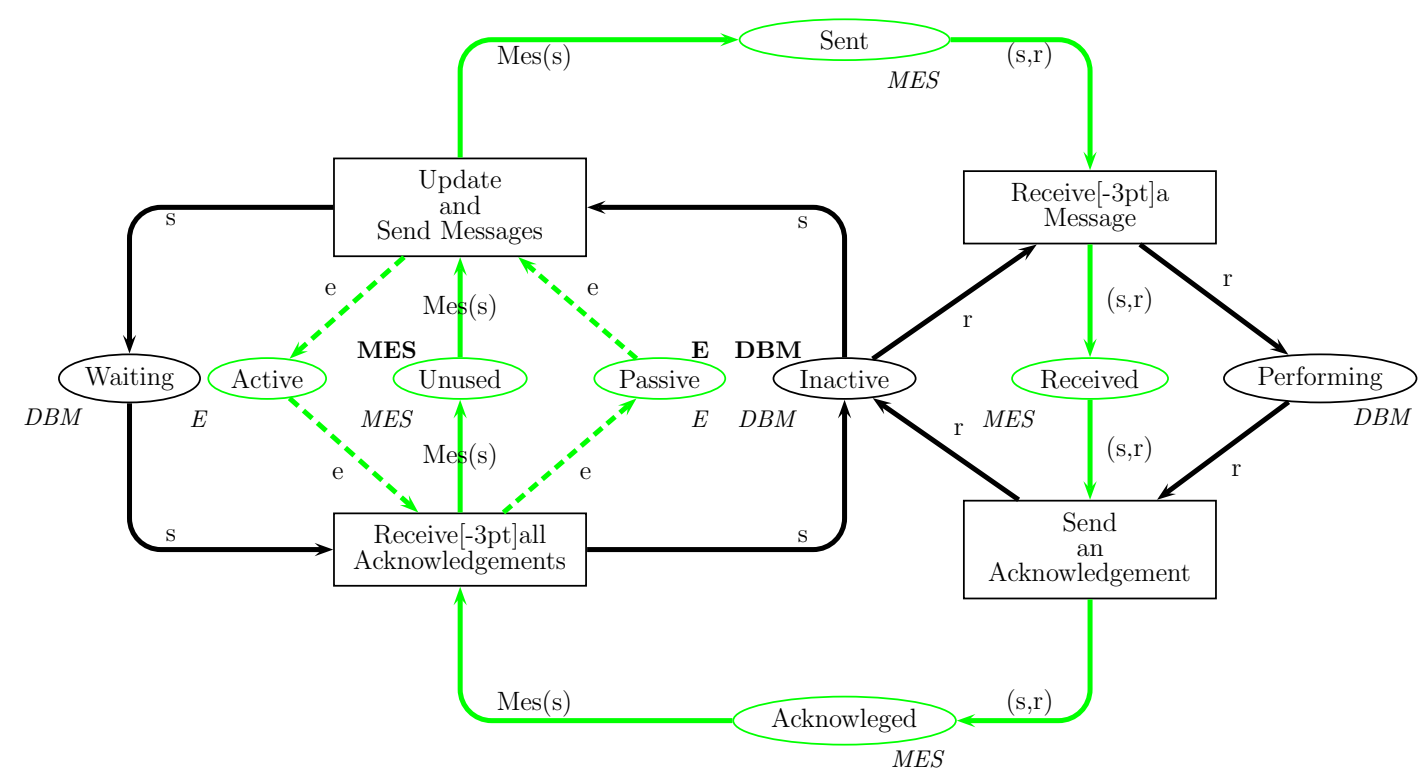

Figura 2.4: Exemplo de uma Rede de Petri Colorida (Jensen, 1997b).

um conjunto $A$ é uma função $m: A \rightarrow\{0,1, \ldots\}$, sendo que $m(a)$ representa o número de ocorrências do elemento $a \in A$ em $m$.

A notação usual para representar um multi-conjunto é como uma soma de termos no formato $m=k_{1}{ }^{6} e_{1}++k_{2}{ }^{6} e_{2}++\cdots$ onde $k_{i}$ é número de ocorrência do elemento $e_{i}$ em $m$, ou seja $m\left(e_{i}\right)=k_{i}$. Dessa forma, no multi-conjunto $m=2^{\natural} a++3^{\natural} b$, o elemento $a$ ocorre 2 vezes, enquanto que $b$ ocorre 3 vezes.

Operações sobre multi-conjuntos de um conjunto $A$ são definidas da seguinte forma:

Adição: $m_{c}=m_{a}++m_{b}$ se

$$
m_{c}(x)=m_{a}(x)+m_{b}(x) \quad \forall x \in A
$$

Multiplicação por escalar: $m_{b}=k * m_{a}$ se

$$
m_{b}(x)=k * m_{a}(x) \quad \forall x \in A
$$

Comparações: Os operadores relacionais para multi-conjuntos são definidos da seguinte forma:

- A relação $m_{a} \leq m_{b}$ é verdadeira se

$$
m_{a}(x) \leq m_{b}(x) \quad \forall x \in A .
$$

- A relação $m_{a} \geq m_{b}$ é verdadeira se

$$
m_{a}(x) \geq m_{b}(x) \quad \forall x \in A .
$$


- A relação $m_{a}<m_{b}$ é verdadeira se $m_{a} \leq m_{b}$ e

$$
m_{a}(x)>m_{b}(x) \quad \text { para algum } x \in A .
$$

- A relação $m_{a}>m_{b}$ é verdadeira se $m_{a} \geq m_{b}$ e

$$
m_{a}(x)<m_{b}(x) \quad \text { para algum } x \in A \text {. }
$$

Igualdade: A relação $m_{a}=m_{b}$ é verdadeira se

Desigualdade: A relação $m_{a} \neq m_{b}$ é verdadeira se a relação $m_{a}=m_{b}$ é falsa.

Subtração: A operação de subtração $m_{c}=m_{a^{--} m_{b}}$ está definida apenas se $m_{a} \geq m_{b}$. Nesse caso,

$$
m_{c}(x)=m_{a}(x)-m_{b}(x) \quad \forall x \in A
$$

Cores Como mencionado anteriormente, dentro do contexto de RPCs o termo cor é utilizado como sinônimo de tipo de dados. Formalmente, uma cor $C$ é um conjunto não vazio, possivelmente com infinitos elementos. Uma RPC possui um conjunto finito não vazio de cores $\Sigma$.

No exemplo do DDB, existem três cores:

- A cor $D B M$ representa o conjunto dos gerenciadores de banco de dados. Formalmente, $D B M$ é definida como

$$
D B M=\left\{d_{1}, d_{2}, \ldots, d_{n}\right\} \quad \text { para } n \geq 3
$$

- A cor MES representa o conjunto das mensagens. Formalmente, MES é definida como

$$
M E S=\{(s, r) \mid(s, r) \in D B M \times D B M \wedge s \neq r\}
$$

Deve-se observar que $M E S$ contém todas as mensagens que podem ser eventualmente enviadas de um gerenciador de banco de dados a outro.

- A cor $E$ representa um conjunto de controle. Formalmente, $E$ é definida como

$$
E=\{e\}
$$

Esse conjunto unitário é freqüentemente utilizado em partes do modelo que necessitam apenas indicar algum fluxo de controle. 
Linguagem de Anotação de Arcos De forma análoga ao que ocorre com linguagens de programação em geral, para a definição das cores de uma especificação e para a manipulação de seus elementos é necessária a utilização de uma linguagem concreta. A escolha dessa linguagem não altera a semântica e a expressividade da técnica. No entanto, a linguagem impacta de forma decisiva no desempenho das técnicas de análise, e procura-se utilizar linguagens que possuam semântica bem definida.

Ao propor as RPCs Jensen (1986, 1997b) utiliza a linguagem CPN-ML, a qual é derivada da linguagem Standard Meta-Language (SML), uma linguagem funcional e fortemente tipada (Hansen e Rischel, 1999). SML é uma sintaxe concreta para o Cálculo Lambda Tipado (Barendregt, 1992). Isso implica que é possível definir todos os tipos de funções matemáticas computáveis. Uma descrição completa da CPN-ML pode ser encontrada em (Jensen, 2002).

Na Figura 2.5 é apresentada a definição em CPN-ML das cores do exemplo DDB. A Linha 1 define $\mathrm{n}$ como o valor constante 4 , que representa o número de bancos no sistema. Na Linha 2 define-se a cor DBM, a qual representa o conjunto de bancos de dados. As Linhas 3, 4 e 5 definem a cor MES, que contém todas as possíveis mensagens que podem ser enviadas no sistema. Observe que a cor PR e a função diff são utilizadas apenas para auxiliar a definição da cor MES ${ }^{7}$. Na Linha 6 é definida a cor E com um único elemento. Na Linha 7 define-se a função Mes, a qual, dado um banco de dados s, retorna um conjunto com mensagens de s para todos os demais bancos ${ }^{8}$. Observe que na Linha 8 são definidas duas variáveis s e r, que podem ser utilizadas no modelo para representar um elemento da cor DBM, ou seja, podem representar um gerenciador de banco de dados.

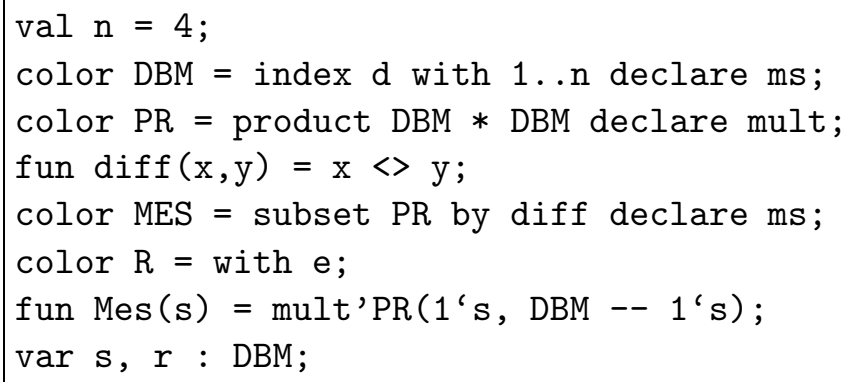

Figura 2.5: Definição em CPN-ML dos Tipos do Modelo DDB.

Elementos Estruturais Uma RPC é formada por elementos que representam os aspectos estruturais e elementos que definem os aspectos dinâmicos. Os elementos estruturais definem os componentes estáticos do sistema, e são eles: os lugares, as transições e os $\operatorname{arcos}$

\footnotetext{
${ }^{7} \mathrm{~A}$ expressão color MES = subset PR by diff declare ms; na linguagem CPN-ML corresponde à definição matemática $M E S=\{x \in P R \mid \operatorname{diff}(x)\}$.

${ }^{8} \mathrm{~A}$ expressão fun $\operatorname{Mes}(\mathrm{s})=\operatorname{mult}$ 'PR $\left(1^{\prime} \mathrm{s}, \mathrm{DBM}-1^{\prime} \mathrm{s}\right)$; na linguagem CPN-ML corresponde à definição matemática $\operatorname{Mes}(s)=s \times(D B M-s)$.
} 
Em geral, os lugares modelam os elementos passivos do sistema, tais como condições, recursos, repositórios de dados, etc. A cada lugar é associada uma cor. Um lugar pode conter um multi-conjunto de elementos de sua respectiva cor. Graficamente, lugares são representados por elipses e o nome da cor associada é posicionado próximo à respectiva elipse (Figura 2.4). No modelo do DDB, pode-se observar os seguintes lugares: Waiting, Active, Unused, Passive, Inactive, Received, Performing, Sent e Acknowleged.

Em geral, as transições modelam os elementos ativos do sistema, tais como eventos, ações e atividades, etc. Graficamente, uma transição é representada por um retângulo. No modelo do DDB, são exemplos de transições: Update and Send Messages, Receive a Message, Send an Acknowledgement e Receive all Acknowledgements. Para facilitar a referência, no restante deste documento, essas transições serão abreviadas para $S M, R M$, $S A$ e $R A$, respectivamente.

Os arcos representam os relacionamentos entre os elementos do sistema. Um arco pode relacionar:

- um lugar $p$ a uma transição $t$. Neste caso, o arco $(p, t)$ é um arco de entrada. Analogamente, $p$ é um lugar de entrada para $t$ e $t$ é uma transição de saída para $p$. Os arcos de entrada de um modelo podem representar pré-condições, valores de entradas, recursos necessários, etc. No modelo do DDB, um exemplo de arco de entrada é o arco que liga Unused a $S M$.

- uma transição $t$ a um lugar $p$. Neste caso, o arco $(t, p)$ é um arco de saída. Analogamente, $p$ é um lugar de saída de $t$ e $t$ é uma transição de entrada de $p$. Os arcos de saída de um modelo podem representar pós-condições, valores de saída, recursos produzidos, etc. No modelo do DDB, um exemplo de arco de saída é o arco que liga $S M$ a Sent.

Elementos Dinâmicos Os elementos dinâmicos de um modelo são conceitos diretamente relacionados à execução da rede, e são eles: anotações de arcos, expressões de guarda e expressões de inicialização.

Uma anotação de arco é uma expressão que, quando avaliada, representa um multi-conjunto de elementos da cor do lugar associado a esse arco e é utilizada para quantificar e qualificar a relação entre os lugares e as transições. Anotações de arcos podem ser formadas por valores constantes, variáveis, funções, etc. Quando não especificada, a anotação de arco assume, como valor default, o multi-conjunto vazio. Graficamente, a anotação é posicionada próxima ao respectivo arco. No modelo do DDB, por exemplo, a anotação do arco de entrada que liga $S M$ a Waiting é s.

Expressões de guarda são associadas às transições e, quando avaliadas, representam valores booleanos. Em geral, as expressões de guarda utilizam as variáveis dos arcos de entrada e saída da transição. Uma expressão de guarda é uma condição que deve ser satisfeita para que a transição possa ocorrer. Caso a expressão de guarda não seja 
explicitamente declarada, assume-se o valor default verdadeiro. Graficamente, a expressão de guarda é posicionada, entre colchetes, próxima à respectiva transição. Deve-se observar que no modelo do DDB, não existem expressões de guarda. No entanto, uma possível expressão de guarda poderia ser incluída, por exemplo, na transição $R M$, tal como $[r<>d(1)]$, que estabeleceria que, para estar habilitada a disparar, uma ligação deveria associar a $\mathrm{r}$ um valor diferente de $\mathrm{d}(1)$.

Expressões de inicialização são valores associados aos lugares que representam um multi-conjunto de elementos da cor do respectivo lugar. Uma expressão de inicialização informa o conteúdo de um lugar quando o sistema é inicializado (o estado inicial). Quando não especificada, a expressão de inicialização assume, como valor default, o multi-conjunto vazio. Graficamente, a expressão de inicialização é posicionada próxima ao respectivo lugar em itálico. No modelo do DDB, por exemplo, a expressão de inicialização do lugar Waiting é DBM.

\subsubsection{Definição Formal}

Nesta seção, é apresentada uma definição formal de uma RPC, baseada em (Jensen, $1997 b)$.

Definição 2. Uma $\boldsymbol{R P C}$ é um tupla $C P N=(\Sigma, P, T, A, N, C, G, E, I)$ que satisfaz os seguintes requisitos:

(i) $\Sigma$ é um conjunto finito não vazio de tipos não vazios, chamado de conjunto de cores.

(ii) P é um conjunto finito de lugares.

(iii) T é um conjunto finito de transições, tal que:

- $P \cap T=\emptyset$.

(iv) A é um conjunto finito de arcos, tal que:

- $P \cap A=T \cap A=\emptyset$.

(v) $N$ é uma função de nós, tal que:

- $N: A \rightarrow P \times T \cup T \times P$.

(vi) C é uma função de coloração, tal que:

- $C: P \rightarrow \Sigma$.

(vii) $G$ é uma função de guarda que associa a cada $t \in T$ uma expressão do tipo booleano: 
(viii) E é uma função de anotações de arcos que associa a cada a $\in$ A uma expressão do tipo do lugar relacionado.

(ix) I é uma função de inicialização que associa a cada $p \in P$ uma expressão do tipo $C(p)$.

Deve-se observar que:

- O conjunto $\Sigma$ de cores determina os tipos, operações e funções que podem ser usadas nas anotações da rede (ou seja, anotações de arcos, expressões de guarda, expressões de inicialização, etc.).

- Os lugares, as transições e os arcos são descritos por três conjuntos $P, T$ e $A$ que são finitos e disjuntos par-a-par. Em contraste com as RPs Lugar/Transição, a estrutura da rede pode ser vazia (ou seja, $P \cup T \cup A=\emptyset$ ).

- A função de nós $N$ mapeia cada arco em um par de elementos da rede de espécies diferentes. Em contraste com as RPs Lugar/Transição, uma RPC pode ter vários arcos entre o mesmo par ordenado de nós. Por isso, define-se $A$ como um conjunto separado e não como um subconjunto de $P \times T \cup T \times P$.

- A função de coloração $C$ mapeia cada lugar $p \in P$ em uma cor $C(p)$. Isso significa que cada marca em $p$ deve ser da cor $C(p)$.

- A função de guarda $G$ mapeia cada transição $t \in T$ em uma expressão booleana, ou seja, em um predicado. Além disso, todas as variáveis em $G(t)$ devem ter tipos que pertençam a $\Sigma$.

- A função de anotação de arco $E$ mapeia cada arco $a \in A$ em uma expressão que deve ser do tipo do lugar associado. Isso significa que cada avaliação da expressão do arco deve gerar um multi-conjunto da cor associada ao lugar correspondente.

- A função de inicialização $I$ mapeia cada lugar $p$ em uma expressão fechada que deve ser um multi-conjunto de $C(p)$.

Na Figura 2.6 é apresentado o exemplo da Figura 2.4 utilizando a definição formal. Observe que os nomes das transições estão abreviados da forma indicada anteriormente. Além disso os nomes dos lugares Sent, Received, Acknowledged, Unused, Passive, Active, Waiting, Inactive e Performing foram abreviados, respectivamente, para SNT, $R C V, A C K, U N S, P S S, A C T, W T G, I N C$ e PRF. Esse exemplo ilustra que, apesar de ser extremamente útil para auxiliar a análise formal de propriedades da especificação, a definição formal não é adequada para a manipulação manual, sendo que, sem a possibilidade da representação gráfica do modelo, sua aplicabilidade seria muito prejudicada. Segundo Jensen (1997b), a habilidade de conciliar tanto uma representação formal rigorosa 
e uma representação gráfica, até certo ponto intuitiva, faz das RPCs uma técnica muito utilizada.

(i) $\Sigma=\{D B M, M E S, E\}$.

(ii) $P=\{S N T, R C V, A C K, U N S, P S S, A C T, W T G, I N C, P R F\}$.

(iii) $T=\{S M, R M, S A, R A\}$.

(iv) $A=\{S M t o S N T, S N T t o R M, R M t o R C V, R C V$ toSA, SAtoACK, ACKtoRA, RAtoUNS, UNStoSM, RAtoPSS, PSStoSM, SMtoACT, ACTtoRA, SMtoWTG,WTGtoRA, RAtoINC, SAtoI NC, INCtoSM, INCtoRM, RMtoPRF, PRFtoSA\}.

(v) $N(a)=(S O U R C E, D E S T)$ se a está na forma SOURCEtoDEST.

(vi) $C(p)= \begin{cases}D B M & \text { se } p \in\{\text { Waiting, Inactive, Performing }\} \\ E & \text { se } p \in\{\text { Active, Passive }\} \\ M E S & \text { caso contrário }\end{cases}$

(vii) $G(t)=$ true

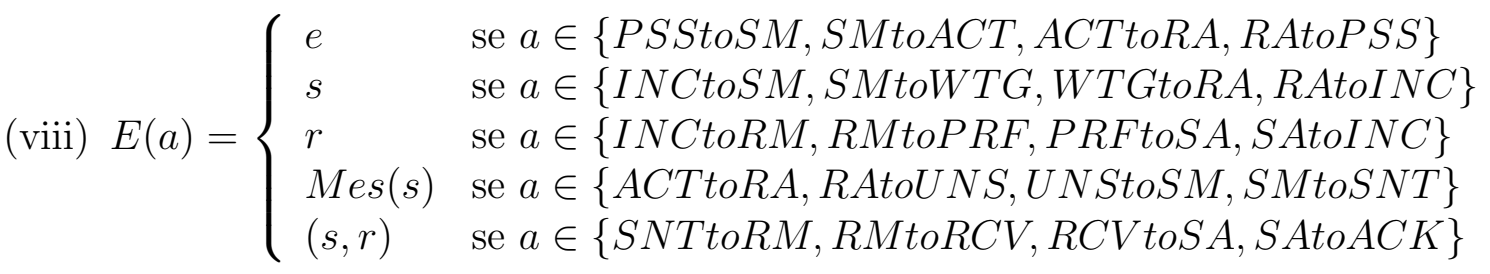

(ix) $I(p)= \begin{cases}M E S & \text { se } p=U N S \\ D B M & \text { se } p=I N C \\ e & \text { se } p=P S S \\ \emptyset & \text { caso contrário. }\end{cases}$

Figura 2.6: A Rede de Petri Colorida da Figura 2.4 Representada com uma Tupla.

Execução de uma Rede de Petri Colorida Uma das vantagens de se utilizar uma técnica formal para a descrição de sistemas, em especial SRs, é o fato de a semântica das especificações geradas nessa técnica ser rigorosa e sistematicamente definida. Em geral, quando os aspectos dinâmicos da especificação são importantes para a análise de propriedades, é necessário que a semântica seja estabelecida pela definição das regras de como a especificação pode ser simulada. Dada uma seqüência de entradas, a simulação consiste em calcular a seqüência de configurações nas quais a especificação resultará.

No contexto de RPCs, a simulação da especificação é controlada pela regra de execução, a qual se baseia nos conceitos de marcas, marcações (ambos relacionados às configurações), ligações e disparos (ambos relacionados às transições entre configurações). 
Uma marca (do inglês, token) é um item mínimo de informação em uma especificação baseada em RPCs. Uma marca está associada a um lugar da rede e deve ser um elemento da cor associada a esse lugar. Portanto, um lugar pode estar associado a um multi-conjunto de marcas de seu respectivo tipo.

Uma marcação é caracterizada pelo conteúdo de todos os lugares da rede. Formalmente, uma marcação $\mu$ é uma função que mapeia um lugar $p$ da rede em um multi-conjunto de elementos de sua respectiva cor. Dessa forma, uma marcação é uma configuração particular de uma RPC. A marcação inicial $\mu_{0}$ é o conteúdo dos lugares no estado inicial do sistema, e é calculada pela avaliação da expressão de inicialização de cada lugar.

A execução de uma RPC é definida pelo relacionamento entre transições e lugares, representado pelos arcos, ou, mais precisamente, por suas anotações. No entanto, como dito anteriormente, uma anotação de arco é uma expressão que pode conter valores constantes, operadores, funções e variáveis. Na presença de variáveis, a anotação de arco somente representará um multi-conjunto de elementos concreto se valores forem atribuídos a essas variáveis. Assim, sendo v uma variável da cor $C$, para que uma anotação de arco que envolve algum cálculo com v seja utilizada é necessário que um elemento de $C$ seja ligado (do inglês, bound) a v. Uma ligação é formada por uma transição $t$ e uma associação de cada variável do modelo a um valor do tipo apropriado. Além disso, a avaliação da expressão de guarda de $t$ com relação a essa associação de valores deve resultar no valor booleano verdadeiro.

Para representar uma ligação, utiliza-se a seguinte notação

$$
\left(t,\left\langle v_{1}=e_{v_{1}}, v_{2}=e_{v_{2}}, \ldots\right\rangle\right)
$$

onde $t$ é uma transição da especificação, $v_{i}$ é uma variável do modelo e $e_{v_{i}}$ é um elemento da cor de $v_{i}$. Deve-se observar que, em geral, apenas as variáveis do modelo que tenham alguma relação com a transição $t$ (ou seja, as variáveis que estão envolvidas na anotação de algum arco de entrada ou saída de $t$ ) são incluídas na ligação. Sejam $(t, b)$ uma ligação e $e$ uma expressão. A notação $e[b]$ representa a expressão $e$ na qual as variáveis foram substituídas pelos respectivos valores de acordo com $b$.

Considerando-se o DDB, as variáveis definidas na especificação são r e s. Dessa forma, uma vez que nenhuma transição possui expressões de guarda, têm-se os seguintes exemplos de ligações:

- $\left(R M,\left\langle s=d_{1}, r=d_{1}\right\rangle\right)$

- $\left(S A,\left\langle s=d_{1}, r=d_{2}\right\rangle\right)$

- $\left(S M,\left\langle s=d_{1}\right\rangle\right)$. Deve-se observar que, como a variável $r$ não está envolvida com a transição $S M$, essa variável não precisa ser citada na descrição da ligação. 
A execução do modelo relaciona uma seqüência de entrada com uma seqüência de configurações. No contexto de RPCs, as configurações são as marcações da rede. Já a seqüência de entrada é uma seqüência de ligações. Dadas uma marcação em particular $\mu$ e uma ligação $y$, calcula-se a próxima marcação $\mu^{\prime}$ por meio do disparo de $y$, da forma descrita a seguir.

Uma ligação $y=(t, b)$ está habilitada em uma marcação $\mu$, se para cada arco de entrada de $t$ o conteúdo do lugar correspondente for maior ou igual ao multi-conjunto resultante da avaliação da anotação do arco. Formalmente, y está habilitada se

$$
\mu(p) \geq E(p, t)[b] \quad \forall p \in P
$$

Por exemplo, considerando-se o DDB, pode-se verificar que as ligações habilitadas na marcação inicial $\mu_{0}$ são:

- $\left(S M,\left\langle s=d_{1}\right\rangle\right)$

- $\left(S M,\left\langle s=d_{2}\right\rangle\right)$

- $\left(S M,\left\langle s=d_{3}\right\rangle\right)$

- $\left(S M,\left\langle s=d_{4}\right\rangle\right)$

Uma ligação habilitada pode disparar. O disparo de uma ligação remove marcas dos lugares de entrada da transição correspondente e adiciona marcas aos lugares de saída dessa transição. A quantidade de marcas removidas ou adicionadas é calculada com a avaliação da anotação do respectivo arco. Formalmente, uma ligação $y=(t, b)$ habilitada em $\mu$ pode disparar e resultar em uma marcação $\mu^{\prime}$, calculada da seguinte forma:

$$
\mu^{\prime}(p)=(\mu(p)-E(p, t)[b])++E(t, p)[b] \quad \forall p \in P
$$

Por exemplo, considerando a marcação inicial $\mu_{0}$ da especificação do DDB, o disparo da ligação $\left(S M,\left\langle s=d_{1}\right\rangle\right)$ resulta em uma marcação $\mu_{1}$, na qual as seguintes ligações estão habilitadas:

- $\left(R M,\left\langle s=d_{1}, r=d_{2}\right\rangle\right)$

- $\left(R M,\left\langle s=d_{1}, r=d_{3}\right\rangle\right)$

- $\left(R M,\left\langle s=d_{1}, r=d_{4}\right\rangle\right)$

O disparo de, por exemplo, $\left(R M,\left\langle s=d_{1}, r=d_{3}\right\rangle\right)$ resulta em uma marcação $\mu_{2}$, na qual as seguintes ligações estão habilitadas:

- $\left(R M,\left\langle s=d_{1}, r=d_{3}\right\rangle\right)$

- $\left(R M,\left\langle s=d_{1}, r=d_{4}\right\rangle\right)$

- $\left(S A,\left\langle s=d_{1}, r=d_{2}\right\rangle\right)$ 
Redes Hierárquicas Para facilitar a definição e a manipulação de RPCs maiores, a rede pode ser organizada em uma árvore de páginas, cada uma contendo uma página RPC. Uma página pode ser considerada como uma RPC simples, cuja semântica depende de outras subpáginas e/ou superpáginas. A associação entre uma página e suas subpáginas é feita por meio de transições hierárquicas e lugares-porta. Uma transição hierárquica é associada a outra página. Cada lugar ligado a uma transição hierárquica é um lugar-porta. A cada lugar-porta, uma transição hierárquica deve associar um lugar compatível (com a mesma cor) na subpágina (denominado, lugar-soquete). A semântica de uma RPC hierárquica é a mesma de uma rede não hierárquica, fazendo-se com que cada par de lugares-porta/soquete se comportem como se ambos fossem o mesmo lugar. Em outras palavras, o conteúdo de ambos os lugares será sempre o mesmo. Isso implica que, sempre que um elemento é adicionado a qualquer um dos lugares, o mesmo elemento é adicionado ao respectivo par. Analogamente, sempre que um elemento é removido de qualquer dos lugares, o mesmo elemento é removido do respectivo par.

\subsubsection{Técnicas de Análise e Validação}

As técnicas de análise desenvolvidas para RPCs são, em geral, adaptações de técnicas utilizadas para RPs Lugar/Transição. Dessa forma, para a análise e validação de uma RPC, pode-se empregar a simulação, o grafo de ocorrência, que é uma representação alternativa da Árvore de Alcançabilidade apresentada na Seção 2.5.2, e o cálculo de invariantes.

A simulação consiste em executar a rede, interativa ou automaticamente, e avaliar o comportamento do sistema modelado, possibilitando visualizar o resultado de uma seqüência de eventos. A simulação automática também permite investigar questões sobre o desempenho do sistema, tais como a identificação de gargalos de desempenho e a predição do espaço de buffer requerido (Jensen, 1997a).

O cálculo de invariantes é empregado para calcular relacionamentos entre o conteúdo dos lugares da rede que são válidos em qualquer marcação alcançável ou seqüências de ligações que, quando disparadas, levam a rede à mesma marcação original. O cálculo de invariantes para RPCs é, em geral, indecidível, visto que é necessária a manipulação das anotações de arco, as quais podem consistir em funções arbitrárias.

Assim sendo, uma das técnicas mais utilizadas para a análise de RPCs é o grafo de ocorrência, descrito a seguir.

\subsubsection{Grafo de Ocorrência}

Um grafo de ocorrência (Jensen, 1997a) é um grafo $G=(V, E)$, tal que $V$ é o conjunto de vértice, representando o conjunto de marcações alcançáveis, e $E$ é o conjunto 
de arestas rotuladas, representando o conjunto de ligações. Para uma rede $N, G=(V, E)$ é definido (implicitamente) pela seguinte regra de formação:

- A marcação inicial $\mu_{0}$ de $N$ pertence a $V\left(\mu_{0} \in V\right)$.

- Para todo $\mu \in V$, tem-se que a ligação y está habilitada em $\mu$ e a marcação resultante do disparo de $y$ em $\mu$ é $\mu^{\prime}$ se, e somente se, $\mu^{\prime} \in V$ e $\left(\mu, y, \mu^{\prime}\right) \in E$.

Deve-se observar que o grafo correspondente pode ser infinito.

A mérito de ilustração, considere-se o exemplo DDB da Figura 2.4 para $n=3$.

Na Figura 2.7 é apresentado o grafo de ocorrência correspondente. Por simplicidade, é utilizada a convenção de representar uma marcação pelo número de mensagens para cada banco de dados que está em Sent, Received, e Acknowledged. Por exemplo, (12,-,-) indica que mensagens foram enviadas para os controladores $d_{1}$ e $d_{2}$, ao passo que $(-, 3,1)$ indica que uma mensagem foi recebida pelo controlador $d_{3}$ e uma foi respondida pelo controlador $d_{1}$. São utilizadas as seguintes abreviações para as ligações:

$S M, i \quad$ O banco $i$ enviou mensagens. Ou seja, a ligação é igual a $\left(S M,\left\langle s=d_{i}\right\rangle\right)$

$R M, i, j$ O banco $j$ recebe uma mensagem do banco $i$. Ou seja, a ligação é igual a $\left(R M,\left\langle s=d_{i}, r=d_{j}\right\rangle\right)$

$S A, i, j$ O banco $j$ enviou um acknowledgement (acusando o recebimento da mensagem) ao banco $i$. Ou seja, a ligação é igual a $\left(R M,\left\langle s=d_{i}, r=d_{j}\right\rangle\right)$

$R A, i$ O banco $i$ recebeu os acknowledgements. Ou seja, a ligação é igual a $\left(R M,\left\langle s=d_{j}\right\rangle\right)$

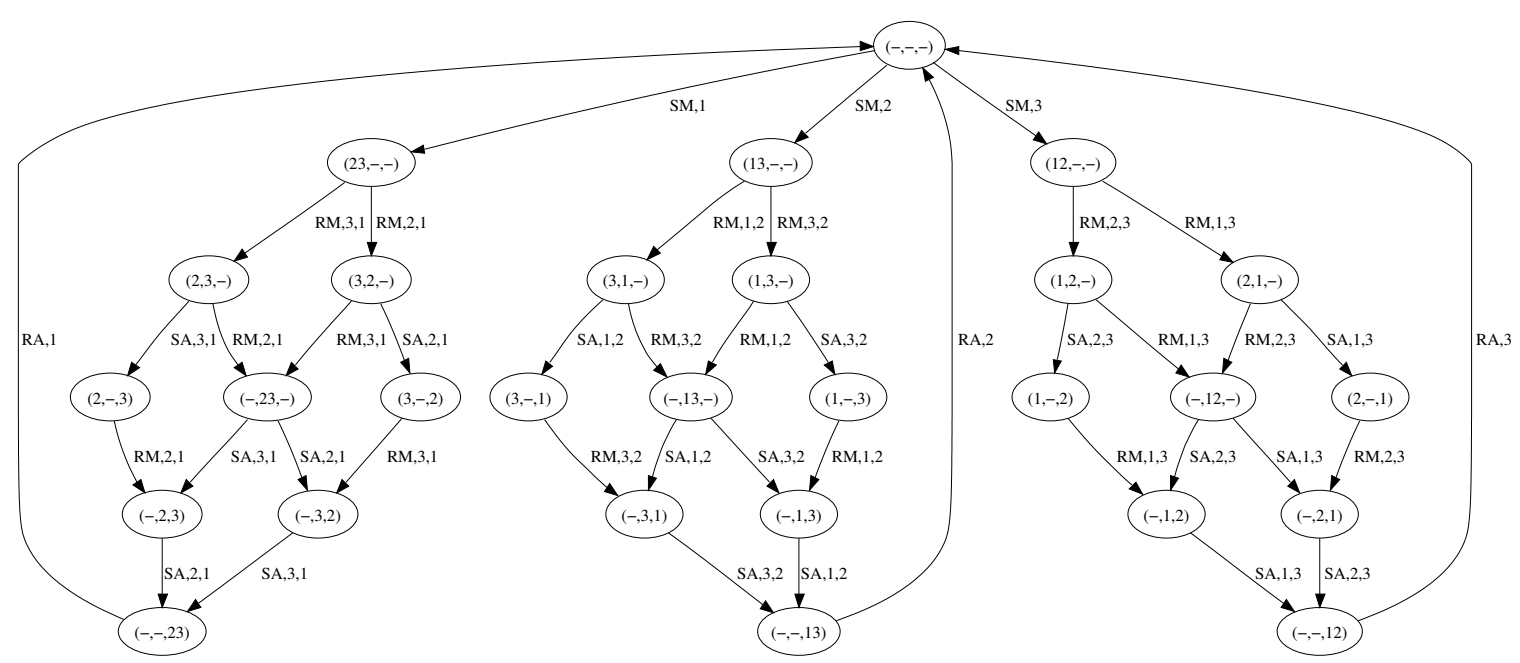

Figura 2.7: Grafo de Ocorrência para a Rede da Figura 2.4 para $n=3$.

A partir do grafo de ocorrência, pode-se analisar diversas propriedades da rede, tais como a inexistência de deadlock, reversibilidade e alcançabilidade de uma marcação especifica. 


\subsubsection{Ferramentas de Apoio}

Devido à grande atenção dada às RPs pela comunidade científica e por iniciativas da indústria, diversas ferramentas que apóiam a edição, simulação e análise de RPs podem ser encontradas. Nesta seção, é apresentada uma visão geral de ferramentas de apoio às técnicas RPs e RPCs, destacando-se a ferramenta Design/CPN.

\section{INA}

A ferramenta INA (Integrated Net Analyzer) (Roch e Stark, 1999) é uma ferramenta especializada na análise de RPs. Ela oferece diversos recursos para analisar as propriedades estruturais e comportamentais da rede, tais como limitação de lugares e alcançabilidade de marcações. A interação com a ferramenta é feita por meio de arquivos texto no formato ASCII, não possuindo interface gráfica.

\section{PED}

A ferramenta PED (Petri Net Editor) (Heiner, 2000) é um editor genérico de RPs que foi desenvolvido para servir como interface para ferramentas de análise e simulação que não possuam seu próprio editor gráfico. A PED apóia a construção de Redes Lugar/Transição Hierárquicas com atribuição de tempo. A comunicação com outras ferramentas é feita por meio de funções de exportação, que podem ser definidas pelo usuário. Atualmente estão disponíveis funções de exportação para INA, PEP e PROD.

\section{ARP e ASPeN}

A ferramenta ARP (Analisador de Redes de Petri) [(Barbosa, 1990) apud (Baroni et al., 1999)] é um analisador e simulador para Redes Lugar/Transição, podendo manipular também Redes Temporais. Dentre as análises disponíveis na ferramenta, pode-se citar a geração do grafo de alcançabilidade, a verificação de propriedades (por exemplo, presença de deadlocks), a análise de variantes e a análise de performance. A versão original da ARP foi desenvolvida para o ambiente DOS. Buscando-se a portabilidade e a inclusão de recursos de edição, foi desenvolvida em Java a ferramenta ASPeN (Baroni et al., 1999).

\section{PEP}

A ferramenta PEP (Programming Environment based on Petri Nets) (Grahlmann, 1997) é formada por um conjunto de componentes para a modelagem, compilação, simulação e análise de RPs. Ela permite que um sistema seja modelado em uma RP ou uma especificação SDL (que é então convertida em uma RP) e simulada. Existem diversos recursos para a análise da rede, tais como a verificação de propriedades de alcançabilidade 
e a ausência de deadlock. A PEP funciona de forma integrada com a ferramenta INA, aproveitando-se dos recursos de análise dessa ferramenta.

\section{PNK}

A PNK (Petri Net Kernel) (Kindler e Weber, 2000) é um pacote com funcionalidades básicas para o desenvolvimento de ferramentas para RPs. Ele implementa funções para carregar, salvar, acessar e modificar a estrutura da rede. A PNK pode ser utilizada como base para a implementação de ferramentas, reduzindo o custo da implementação. A PNK é implementada em Python e pode ser usada em qualquer ambiente que possua essa linguagem.

\section{Visual Object Net++}

A Visual Object Net ++ (Drath, 2000) é uma ferramenta para a edição e simulação de RPs que apresenta uma interface bem elaborada. Ela permite a construção de Redes Lugar/Transição Híbridas, as quais, além do tipo usual de transição discreta, possuem o tipo de transição contínua. Com as transições contínuas, é possível a modelagem do fluxo contínuo de dados. Uma transição contínua não é disparada da mesma forma que uma transição discreta. Em vez disso, o comportamento do disparo é controlado por um fluxo contínuo cuja velocidade é determinada por uma constante ou uma função. Apesar de não possuir recursos de análise, a ferramenta permite visualizar graficamente o conteúdo de um lugar, apresentando-se como uma boa ferramenta para a modelagem e visualização de sistemas dinâmicos.

\section{PROD}

PROD (Varpaaniemi et al., 1995) é uma ferramenta para a verificação de propriedades baseadas na Árvore de Alcançabilidade. Para evitar a explosão de estados, a PROD utiliza uma técnica que analisa as marcações conforme a árvore está sendo criada. A linguagem de descrição das redes é uma linguagem de pré-processamento para C, estendida com diretivas de descrição da rede. A descrição da rede é convertida e compilada em um programa executável que gera a Árvore de Alcançabilidade. A PROD é composta de um pré-processador da linguagem de descrição, do programa gerador da Árvore de Alcançabilidade e de um programa de consulta à árvore.

\section{CPN-AMI}

CPN-AMI (Kordon e Paviot-Adet, 1999) é um ambiente CASE baseado em RPCs desenvolvido na Universidade de P.\&M. Curie, na França. O ambiente oferece funcionali- 
dades para edição, simulação e verificação de propriedades estruturais do modelo de RPC por meio de uma interface de usuário única.

\section{Maria}

Maria (Mäkelä, 1999) é uma ferramenta desenvolvida na Universidade de Tecnologia de Helsinki, na Finlândia. A ferramenta permite a simulação e análise de alcançabilidade para RPs de Alto-Nível. Segundo Mäkelä (1999), uma linguagem front-end é empregada para que os usuários não precisem utilizar o formalismo usado internamente pela ferramenta.

\section{Design/CPN}

Design/CPN (Jensen, 1997b) é uma ferramenta (ou, melhor dizendo, um pacote de ferramentas) que apóia o uso de RPCs desenvolvida na Universidade de Aarhus, na Dinamarca. A ferramenta é distribuída gratuitamente mediante a concessão de licença de uso.

A ferramenta é composta por quatro módulos integrados:

- Um editor, que apóia construção, edição e análise sintática de RPCs. O editor possui as funcionalidades básicas de um editor genérico de figuras vetoriais, permitindo a criação de diversos objetos e sua manipulação. Além disso, durante a construção da RPC, a Design/CPN faz a verificação para garantir que a rede criada seja sintaticamente correta. Por exemplo, a Design/CPN impede que um arco seja criado ligando-se dois elementos que representem transições. O editor permite que atributos gráficos, tais como cor e estilo de linha, sejam alterados para facilitar a identificação de elementos que se relacionam.

Na Figura 2.8 é apresentado o módulo de edição da Design/CPN com a rede da Figura 2.4.

- Um simulador, que apóia a simulação tanto interativa quanto automática de RPCs. São oferecidos dois modos de simulação: a simulação iterativa e a simulação automática. Na simulação iterativa, a Design/CPN destaca as transições que possuem ligações habilitadas. Pode-se, então, selecionar uma ligação e solicitar que seja disparada. Na simulação automática, a ferramenta seleciona aleatoriamente uma ligação habilitada para disparar até que alguma condição de parada pré-definida seja satisfeita ou que não existam ligações habilitadas. Como exemplos de condições de parada, pode-se citar a definição de um número máximo de passo ou a observação de uma marcação com características particulares.

- Uma ferramenta de grafo de ocorrência, que apóia a construção e análise do grafo de ocorrência de uma RPC. Essa ferramenta permite que sejam definidas funções para 


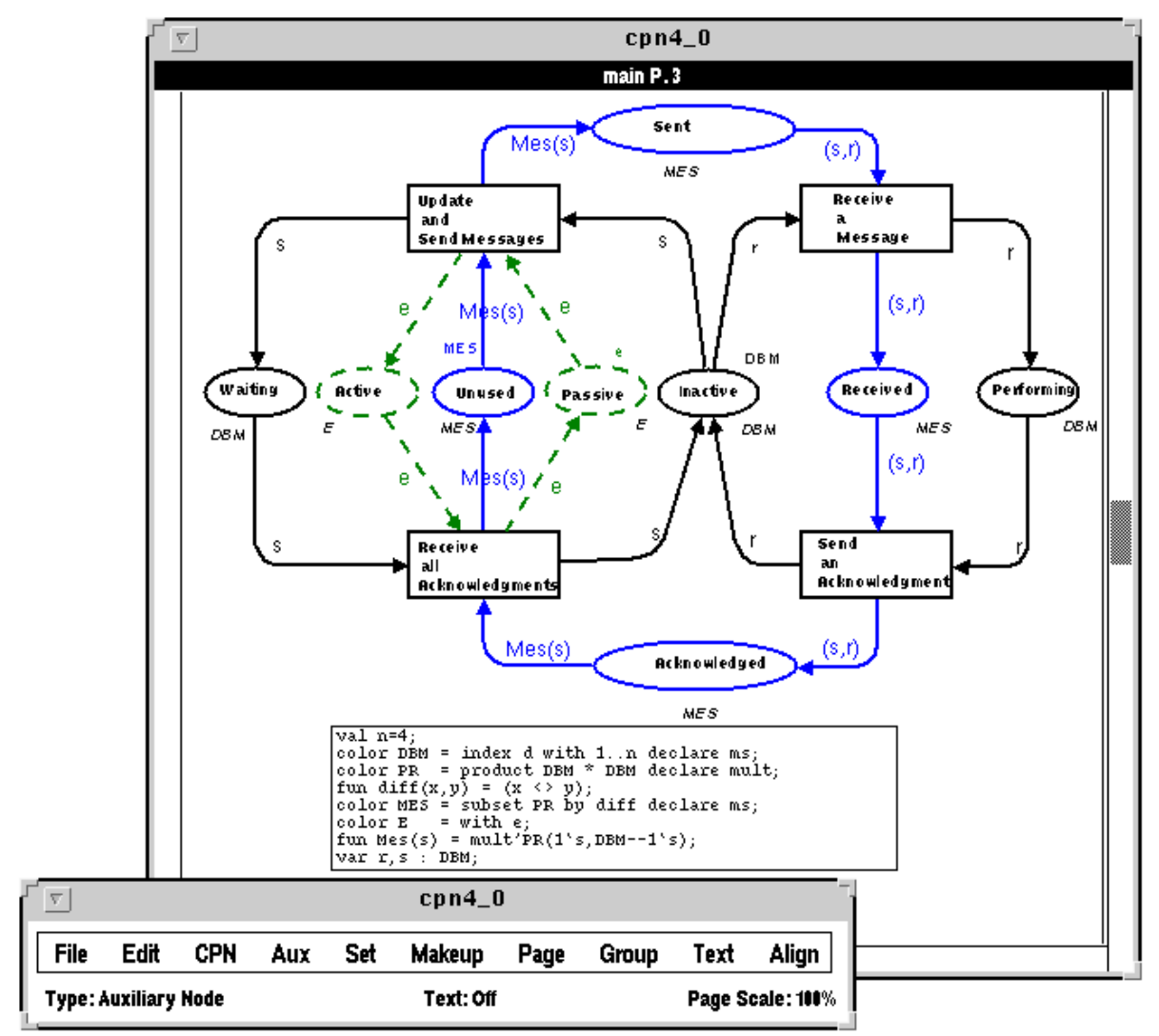

Figura 2.8: Módulo Editor da Ferramenta Design/CPN.

converter as marcações em cadeias de caracteres. Pode-se também definir critérios para limitar o tamanho do grafo de ocorrência. Mecanismos para a consulta do grafo permitem que propriedades formuladas em CPN-ML sejam verificadas.

- Uma ferramenta para analisar o desempenho de modelos baseados em RPCs por meio de simulação. Esse módulo permite que informações referentes ao desempenho simulado da rede sejam visualizadas. Por exemplo, pode-se verificar com que freqüência as ligações de uma determinada transição são disparadas em relação às demais, identificando possíveis gargalos do sistema modelado.

\subsection{Aspectos de Teste e Validação de Especificações}

O desenvolvimento de Sistemas Reativos grandes e complexos traz vários problemas, especialmente no que diz respeito à sua especificação e ao seu projeto. A dificuldade encontra-se na descrição do comportamento desses sistemas de maneira clara, formal e rigorosa (Harel, 1992). Também é necessário que essa descrição seja validada e testada para aumentar a confiabilidade na sua corretitude.

Segundo Desel (2002), na Figura 2.9 é apresentada uma visão geral do processo de desenvolvimento de sistemas baseados em especificações. A especificação é uma re- 
presentação abstrata tanto da parte relevante do "mundo real" quanto da implementação do sistema, ignorando os detalhes irrelevantes do sistema. A verificação geralmente se preocupa com a relação entre a especificação e a implementação do sistema, ao passo que a validação se preocupa com a relação entre o modelo e o "mundo real".

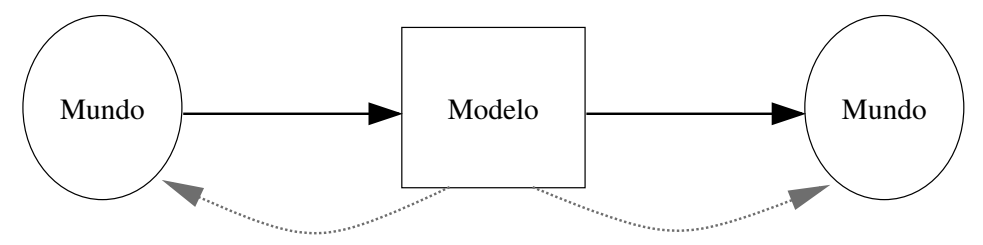

Figura 2.9: Desenvolvimento de Sistemas Baseados em Especificações (Baseada em (Desel, 2002)).

Essa visão ignora o fato de o sistema a ser implementado ter que funcionar dentro de um ambiente, o qual pertence ao "mundo real". Portanto, na Figura 2.10 é apresentada uma visão mais fiel a essa situação. Ambos os lados da figura estão ligados por meio do "mundo real".

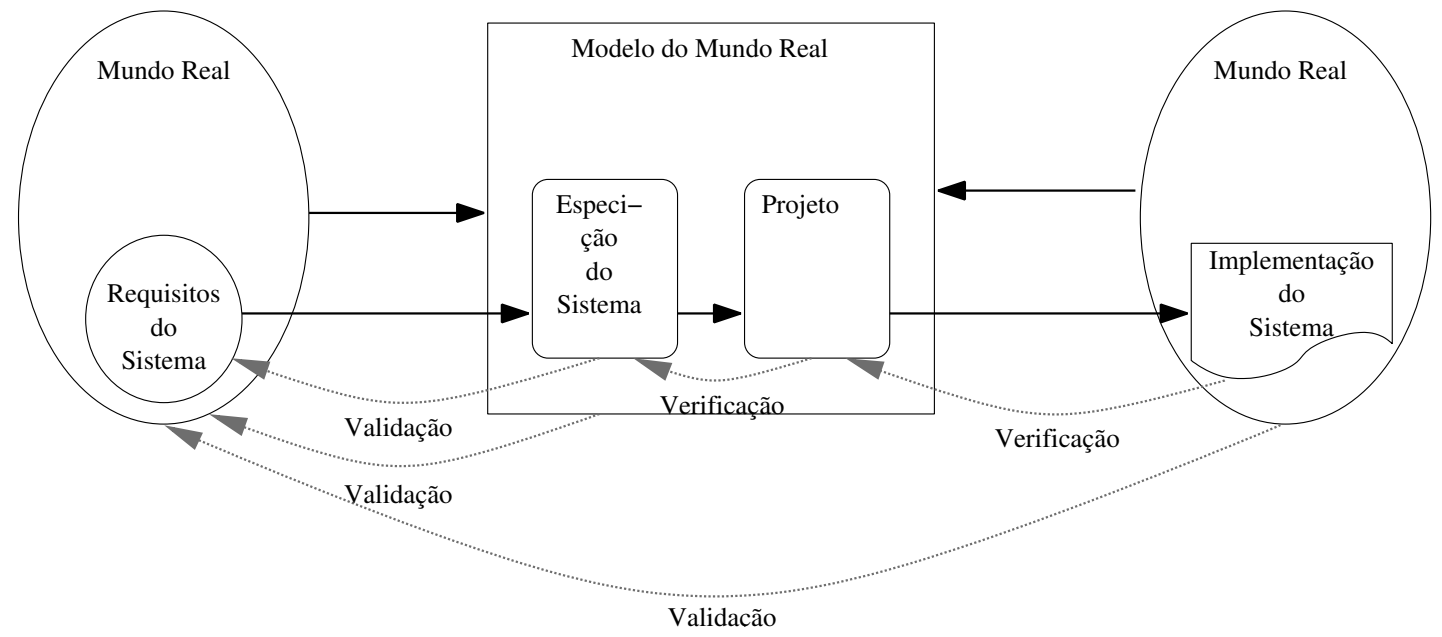

Figura 2.10: Visão Detalhada do Desenvolvimento de Sistemas Baseados em Especificações (extraído de (Desel, 2002)).

Uma visão mais detalhada do modelo distingue a especificação dos requisitos da especificação do projeto. O modelo do mundo real é obtido pela análise do domínio e pela formalização dos aspectos relevantes. A especificação dos requisitos modela as características relevantes do sistema e é obtida pela formalização dos requisitos que existem no "mundo real". A especificação do projeto pode ser vista como o modelo da implementação do sistema, sem, contudo, considerar detalhes de implementação. Ela deve satisfazer todas as propriedades formuladas pela especificação dos requisitos. A transformação da especificação dos requisitos na especificação do projeto não é uma tarefa trivial, uma vez que, existe uma distância semântica entre os dois níveis que deve ser preenchida por meio do detalhamento da especificação dos requisitos. 
A verificação deve avaliar se a implementação do sistema reflete a especificação do projeto. Como o processo de formalização parte de uma descrição não formal do sistema, a corretitude desse processo somente pode ser avaliada pela validação. Kemmerer (1985) ressalta que a validação de especificações é muito importante para reduzir o custo de desenvolvimento, uma vez que é capaz de identificar problemas em suas primeiras fases. O autor ressalta que uma especificação formal é um produto intelectual do especificador. Como tal, ele foi primeiramente concebido (em pensamento) e depois transferido para a especificação concreta. Dessa forma, enganos podem ser cometidos e defeitos podem ser introduzidos na especificação. Deve-se, portanto, testar a especificação mesmo quando métodos formais são empregados. Uma vantagem das especificações formais é que a semântica bem-definida de tais linguagens permite verificar e identificar vários defeitos, de forma análoga ao que um bom compilador é capaz de fazer para programas em linguagens de alto nível (Jalote, 1989). No entanto, defeitos que não são identificados por esses métodos podem permanecer.

A maioria dos trabalhos sobre a verificação de modelos considera o seguinte problema:

"Dado um modelo formal e algumas propriedades formuladas de maneira adequada, verifica-se ou prova-se que o modelo satisfaz essas propriedades."

As propriedades podem ser genéricas, tais como liveness e limitação, ou podem ser específicas para o modelo em questão e formuladas em uma linguagem de propósito geral, tais como as lógicas temporais. Contudo, em complemento à análise de propriedades, a validação de especificações e do processo de formalização subjacente deve ser conduzida e apoiada por métodos, técnicas e ferramentas adequadas. Dessa forma, neste trabalho, o foco de atuação é deslocado para o seguinte problema:

"Dado um modelo formal, como validar que esse reflete corretamente o sistema real?"

A validação de uma especificação pode ser conduzida de quatro formas principais: Análise Visual: Para cada técnica de especificação particular, um conjunto de características de uma especificação pode ser analisado visualmente, tais como a vizinhança de seus elementos, de seus componentes e das primitivas de comunicação. Essa capacidade é especialmente importante em técnicas que possuem uma representação gráfica do modelo, apesar de poder ser utilizada de forma limitada mesmo quando a representação gráfica não está disponível. No entanto, a visualização pode apenas ajudar a evitar erros de modelagem.

Análise Estrutural: A análise estrutural pode ajudar a encontrar erros de modelagem. Um exemplo típico é cálculo de invariante de lugar para RPs (Reisig, 1985). Se um lugar não é coberto por uma invariante de lugar, então é possível que esse lugar seja 
não-limitado. Em algumas situações, isso pode caracterizar um erro de modelagem. Por exemplo, se uma variável de um algoritmo distribuído é representado por um conjunto de lugares, então esses lugares devem formar uma invariante de lugar.

Análise Comportamental: Existem diversas propriedades comportamentais genéricas, tais como liveness, safety e reversibilidade (Macial et al., 1996). Em geral, a especificação deve ter algumas ou todas essas propriedades, apesar de não fazerem parte dos requisitos do sistema.

Simulação: A simulação consiste em "executar" a especificação. Para uma especificação válida, a cada execução da especificação deve corresponder uma execução do sistema e a cada execução do sistema deve corresponder uma execução da especificação. A validação por simulação implica na geração e inspeção de execuções da especificação com relação às execuções correspondentes do sistema.

Nas seções seguintes, exemplificam-se abordagens para a condução dessas formas de validação. Na Seção 2.5.4, é apresentada a aplicação da AM nesse contexto.

\subsubsection{Cálculo de Invariantes}

Outra técnica muito utilizada para a análise de RPs é o cálculo de invariantes da rede (Reisig, 1985), divididas entre invariantes de lugar e invariantes de transição. Uma invariante de lugar relaciona, por meio de uma equação linear, o conteúdo de um conjunto de lugares em qualquer marcação alcançável. Por exemplo, considerando-se a rede da Figura 2.1, pode-se derivar diversas invariantes de lugar, tais como $A_{1}+B_{1}=1$, $A_{2}+B_{2}=1$ e $A_{1}+R+A_{2}=1$. Em geral, invariantes de lugar para uma rede são obtidos entre as soluções positivas $v$ da equação

$$
0=C^{T} \cdot v
$$

onde $C^{T}$ é matriz de incidência transposta.

Uma invariante de transição relaciona, por meio de uma expressão, a quantidade de vezes que cada transição da rede deve disparar de modo que a marcação alcançada seja igual à original. Por exemplo, considerando-se novamente a rede da Figura 2.1, pode-se derivar diversas invariantes de transição, tais como $T_{1}+T_{2}$ e $T_{3}+T_{4}$. Em geral, invariantes de transição para uma rede são obtidas entre as soluções $t$ da equação

$$
0=C . t
$$

Observe que para verificar se uma dada invariante é válida para uma rede, é suficiente verificar se essa invariante é uma solução da respectiva equação. 


\subsection{2 Árvore de Alcançabilidade}

A análise da Árvore de Alcançabilidade é uma técnica muito utilizada para verificação e análise de propriedades de especificações baseadas em MTEs, tais como RPs (Murata, 1984), MEFs Comunicantes (Özdemir e Ural, 1997; Peng, 1997), Statecharts (Masiero et al., 1994) e Estelle (Huang e Hsu, 1994; Jirachiefpattana e Lai, 1997; Souza, 2000).

As técnicas baseadas no modelo de MTEs caracterizam-se por alterarem sua configuração ${ }^{9}$ por meio da ocorrência de eventos discretos no tempo e pela existência de uma configuração inicial. A partir da configuração inicial, eventos podem ocorrer, levando a outras configurações. Por sua vez, em cada uma dessas configurações, outros eventos podem ocorrer e levar a outras configurações, e assim sucessivamente. Pode-se, então, caracterizar essas seqüências de eventos e configurações em uma árvore (a Árvore de Alcançabilidade), cujos nós são as configurações e cujas arestas são rotuladas com os eventos. A raiz da árvore é a configuração inicial. Se um nó $n_{1}$ está ligado a um nó $n_{2}$ por uma aresta com o rótulo $e$, então a ocorrência do evento $e$ na configuração $n_{1}$ leva a máquina à configuração $n_{2}$. Por outro lado, se em uma configuração $n_{1}$ alcançável (ou seja, que pode ser alcançada a partir da configuração inicial com a ocorrência de uma seqüência de eventos), ocorrer um evento $e$ que leva a uma configuração $n_{2}$, então existem na árvore os nós $n_{1}$ e $n_{2}$ e eles são ligados por uma aresta com o rótulo $e$. A seguir é apresentado um algoritmo genérico para a geração da Árvore de Alcançabilidade.

(1) Faça da configuração inicial o nó raiz da árvore e o marque como novo

(2) Enquanto houver nós marcados como novos

(3) Selecione um nó $n_{1}$, tal que $n_{1}$ está marcado como novo

(4) Marque $n_{1}$ como velho

(5) Para todo evento $e$ que pode ocorrer em $n_{1}$ faça:

(6) Seja $n_{2}$ a configuração obtida após a ocorrência do evento $e$ em $n_{1}$

(7) Inclua na árvore o nó $n_{2}$ e uma aresta que liga $n_{1}$ a $n_{2}$ com o rótulo $e$

(8) Marque $n_{2}$ como novo

Em geral, a Árvore de Alcançabilidade pode ser muito grande, devido ao problema da explosão exponencial no número de configurações, também conhecido como problema da explosão de estados. Além disso, a menos que a especificação sempre leve a uma configuração terminal, ou seja, a uma configuração na qual nenhum evento pode ocorrer, a Árvore de Alcançabilidade é infinita. Por isso, o que é geralmente utilizado é uma

\footnotetext{
${ }^{9}$ Apesar de o termo estado ser geralmente utilizado para descrever os conceitos referentes às árvores de alcançabilidade, o termo configuração será utilizado para evitar o conflito com o conceito de estado, presente, por exemplo, nas técnicas MEFs Comunicantes, Statecharts e Estelle.
} 
subárvore da Árvore de Alcançabilidade, definida de forma a manter determinadas características, ao mesmo tempo em que reduz o tamanho da árvore. Por exemplo, pode-se definir uma subárvore de forma que os caminhos entre a raiz e algum nó não possuam nós ou eventos repetidos. A forma como essa subárvore é definida depende da aplicação à qual está destinada. Deve ser observado que qualquer definição de uma subárvore faz com que informações sejam perdidas. Portanto, deve-se definir a subárvore de forma a preservar as informações de relevância para a aplicação.

Para ilustrar como a Árvore de Alcançabilidade pode ser aplicada para uma técnica particular, a seguir é apresentada a Árvore de Alcançabilidade para RPs. Além disso, ilustra-se como se pode evitar o problema das árvores de tamanho infinito utilizando-se uma subárvore da Árvore de Alcançabilidade.

Na Árvore de Alcançabilidade para RPs, os nós são rotulados com marcações e as arestas, com transições. A raiz da árvore é rotulada com a marcação inicial e para cada par de nós $\mu^{\prime}$ e $\mu^{\prime \prime}$ ligados por uma aresta com rótulo $t$, tem-se que $\mu^{\prime}[t\rangle \mu^{\prime \prime}$ e toda marcação alcançável da rede está representada por um nó na árvore. Uma vez que todas as possíveis seqüências de eventos estão direta ou implicitamente representadas, a inspeção da Árvore de Alcançabilidade equivale a um teste exaustivo. Contudo, nos casos em que a rede não é limitada, a Árvore de Alcançabilidade é infinita (Murata, 1984). Para contornar esse problema, define-se a árvore de cobertura, a qual introduz o símbolo $\omega$ para representar lugares que podem conter um número arbitrário de marcas. Para $\omega$, são definidas as seguintes operações sobre os números naturais:

- $\omega+n=\omega$

- $\omega-n=\omega$

- $\omega>n$

sendo $n \in \mathbf{N}$. Em outras palavras, $\omega$ é maior do que qualquer número natural e a adição ou subtração de um número natural a $\omega$ resulta no próprio $\omega$.

Sejam duas marcações $\mu^{\prime}$ e $\mu^{\prime \prime}$ tal que $\mu^{\prime \prime} \geq \mu^{\prime}$ e uma seqüência de transições $s q$ tal que $\mu^{\prime}[s q\rangle \mu^{\prime \prime}$. Seja $p$ um lugar tal que $\mu^{\prime \prime}(p)>\mu^{\prime}(p)$. Tem-se que $s q$ também está habilitada em $\mu^{\prime \prime}$, portanto, $s q$ pode ser disparada um número arbitrário de vezes, fazendo com que o número de marcas em $p$ seja tão grande quanto o desejado. Dessa forma, o símbolo $\omega$ é utilizado para representar o número de marcas de $p$. O algoritmo para o cálculo da árvore de cobertura, extraído de (Macial et al., 1996), é apresentado na Figura 2.11. Deve-se observar que esse algoritmo é uma instanciação mais detalhada do algoritmo apresentado anteriormente. Para ilustrar a aplicação desse algoritmo, nas Figuras 2.12 e 2.13 são apresentados, respectivamente, um exemplo de uma rede de Petri, extraída de (Peterson, 1981), e a árvore de cobertura correspondente.

Apesar de resolver o problema das árvores de tamanho infinito, a árvore de cobertura ainda sofre do chamado problema de explosão exponencial no número de estados, que 
1: $n e w \leftarrow\left\{\mu_{0}\right\}$

2: old $\leftarrow \emptyset$

3: while new $\neq \emptyset$ do

4: $\quad$ Seja $\mu$ uma marcação tal que $\mu \in$ new

5: $\quad$ new $\leftarrow$ new $-\mu$

6: $\quad$ old $\leftarrow$ old $\cup \mu$

7: $\quad$ Seja enabled $=\{t \mid \mu[t\rangle\} \quad \triangleright$ enabled é o conjunto de transições habilitadas em $\mu$

8: $\quad$ for all $t \in$ enabled do

9: $\quad$ Seja $\mu^{\prime}$, tal que $\mu[t\rangle \mu^{\prime}$

10: $\quad$ Seja $P$ o caminho da raiz até $\mu$

11:

12:

13:

14:

15 :

16:

17:

18:

19:

20:

21:

22:

23: $\triangleright$ Inicialmente, somente a marcação $\mu_{0}$ é nova

$\triangleright$ E nenhuma marcação é velha

$\triangleright$ Enquanto houver marcações novas if Existe $\mu^{\prime \prime}$ uma marcação em $P$, tal que $\mu^{\prime} \neq \mu^{\prime \prime}$ e $\forall p \in P, \mu^{\prime}(p) \geq \mu^{\prime \prime}(p)$ then

for all $p \in P$ do

if $\mu^{\prime}(p)>\mu^{\prime \prime}(p)$ then $\mu^{\prime}(p)=\omega$

end if

end for

end if

Introduza $\mu^{\prime}$ na árvore e crie uma aresta rotulada com $t$ ligando $\mu$ a $\mu^{\prime}$

if $\mu^{\prime} \notin$ old then

new $\leftarrow$ new $\cup \mu^{\prime}$

end if

end for

end while

Figura 2.11: Algoritmo para a Geração da Árvore de Cobertura para Redes de Petri (Macial et al., 1996; Murata, 1984; Peterson, 1981).

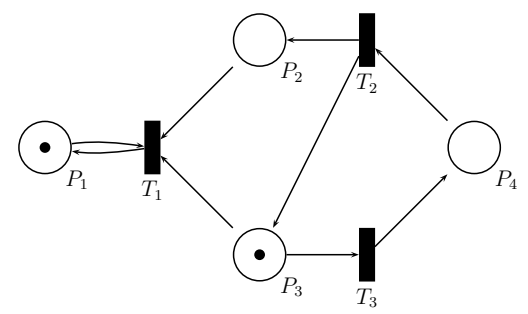

Figura 2.12: Uma Rede de Petri (Peterson, 1981) cujo Conjunto de Marcações Alcançáveis é Infinito.

ocorre freqüentemente quando a rede possui componentes independentes (Peterson, 1981). Nesse caso, o número de nós da árvore torna proibitiva a geração completa. Uma proposta para a redução do número de nós da árvore é considerar os conjuntos Stubborn (Barnard, 1998; Kristensen e Valmari, 1998), os quais são formados por transições habilitadas que são independentes umas das outras de forma que essas transições podem ser disparadas em qualquer ordem obtendo-se a mesma marcação. A Árvore de Alcançabilidade então não inclui todas as possíveis combinações das transições que formam um conjunto stubborn, mas apenas o próprio conjunto, reduzindo-se o número de nós. 


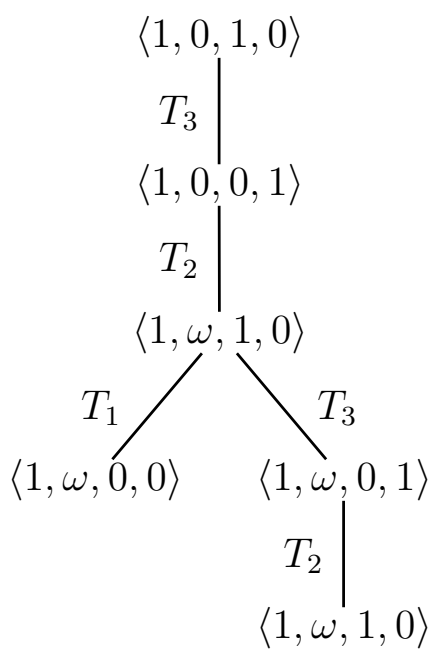

Figura 2.13: Árvore de Cobertura da Rede da Figura 2.12.

Outras propostas para contornar o problema da explosão de estados na Árvore de Alcançabilidade incluem a divisão da rede em componentes e a geração da árvore para cada um desses componentes. No entanto, em geral, não é possível deduzir propriedades globais a partir das propriedades individuais de cada componente (Peterson, 1981).

\subsubsection{Simulação}

Segundo Harel (1992), uma das principais formas de validação de especificações é a simulação. No entanto, para que uma especificação possa ser simulada, é preciso que a semântica esteja formalmente definida. Dessa forma, todas as conseqüências de um evento no sistema podem ser calculadas na especificação e o estado atingido pode ser avaliado. Sob esse aspecto, a simulação comporta-se como uma execução da especificação. Devido à complexidade das informações envolvidas, a simulação deve ser apoiada por ferramentas, que, em geral, podem oferecer diferentes modos de utilização, tais como:

Simulação Interativa: A especificação é executada passo a passo e o usuário emula o ambiente gerando interativamente os eventos. A ferramenta, por sua vez, calcula o próximo estado da especificação e o apresenta ao usuário.

Simulação em batch: A simulação em batch se comporta de forma parecida com a simulação interativa exceto que a seqüência de eventos gerada pelo usuário é armazenada em um arquivo e a ferramenta lê os eventos a partir desse arquivo.

Simulação Programada: Por meio de alguma linguagem apropriada, programam-se diversas características, tais como a geração automática de eventos de forma probabilística, a interrupção da simulação ao atingirem-se determinadas condições, etc.

Simulação Exaustiva: Geram-se todas as possíveis configurações da especificação. Com isso, consegue-se assegurar a ausência de quaisquer situações imprevistas. 
O ideal seria que a Simulação Exaustiva fosse aplicada à especificação, o que, no entanto, nem sempre é praticável, visto que a quantidade de configurações possíveis, em geral, é intratável, quando não infinita. Dessa forma, apenas um conjunto finito de simulações é possível de ser realizado e um problema não considerado pela simulação é a cobertura obtida. Exceto para a Simulação Exaustiva, a qual, por definição, garante que qualquer critério possível de cobertura foi satisfeito, os outros tipos de simulação não avaliam o quanto da especificação já foi coberto pela simulação. Nesse contexto, critérios de teste vêm sendo investigados para auxiliar na avaliação da qualidade dos conjuntos de simulações utilizados. Na seção seguinte, é apresentada a aplicação da Análise de Mutantes na validação de especificações, com ênfase especial na validação de RPs.

\subsubsection{Critério Análise de Mutantes}

Como dito anteriormente, embora a AM seja um critério de teste desenvolvido para o teste de programas, sua aplicação em diferentes contextos pode ser uma alternativa bastante viável, devido à sua flexibilidade. No contexto das técnicas de especificação de SRs, a AM pode facilitar a atividade de teste, pois este critério é baseado em um modelo de erros que pode ser definido de forma adequada para retratar tipos de erros que explorem todas as características dessas técnicas.

Petrenko et al. (1996) usam conceitos semelhantes aos da AM no teste e validação de protocolos de comunicação, baseando-se em um modelo de erros correspondente a um conjunto restrito e preestabelecido dos erros a serem explorados durante essas atividades. Os autores comentam que a abordagem de teste baseada em um modelo de erros é prática, pois captura a intenção do testador para detectar erros de implementação. Em seu trabalho, discutem-se aspectos de cobertura no teste de especificações de modelos de protocolos baseadas em MEFs e faz-se uma análise dos problemas nesse contexto.

Probert e Guo (1991) propõem uma técnica de teste para especificações de protocolos escritas em Estelle baseada na AM, chamada E-MPT (Estelle-directed Mutation-based Protocol Testing). A aplicação desta técnica pode ser sintetizada nos seguintes passos:

1. A especificação original é convertida em código C.

2. Trechos de códigos são adicionados para completar o código gerado.

3. O código completo é compilado e executado com os casos de teste.

4. Os mutantes da especificação Estelle são gerados pelos operadores de mutação apropriados.

5. As especificações mutantes são convertidas em código C.

6. Os códigos dos mutantes são completados de acordo com o que é feito com o código da especificação original. 
7. Os códigos mutantes completos são compilados e executados.

8. Os resultados dos mutantes são comparados.

Souza (2000) também explorou a AM no teste de especificações baseadas em Estelle. O conjunto de operadores de mutação foi definido com base nos aspectos como hierarquia dos módulos, comunicação entre módulos, arquitetura do sistema, interface entre os módulos e paralelismo da especificação, sendo, mais abrangente do que os operadores utilizados por Probert e Guo (1991). Além disso, Probert e Guo (1991) não aplicam o critério AM diretamente na especificação Estelle, mas transformam a especificação e seus mutantes em programas C e estes são executados com os casos de teste, enquanto que no trabalho de Souza (2000) geram-se os mutantes a partir da especificação Estelle e os casos de teste são simulados com a própria especificação e seus mutantes, evitando-se erros que podem ser cometidos durante a transformação da especificação e dos mutantes em programas.

Ammann et al. (1998) utilizam a Análise de Mutantes e a técnica model checking para produzir automaticamente casos de teste a partir de especificações baseadas em Máquinas de Estados Finitos (Ammann et al., 1998) e para medir a cobertura de teste (Ammann e Black, 1999). No primeiro caso, cada transição da máquina de estado é representada como uma cláusula em lógica temporal. Para gerar os testes, os operadores de mutação são aplicados a todas as cláusulas em lógica temporal, resultando em um conjunto de cláusulas mutantes. O model checker compara a especificação original com os mutantes. Com base nas cláusulas inconsistentes, o model checker produz, se possível, os casos de teste. No segundo caso, para medir a cobertura de um conjunto de teste, cada caso de teste é transformado em uma MEF que representa a seqüência de execução daquele caso de teste. Cada MEF é comparada pelo model checker ao conjunto de mutantes produzidos. A métrica de cobertura de adequação à mutação utilizada é o número de mutantes mortos dividido pelo número total de mutantes gerados. Black et al. (2000b) refinaram o conjunto de operadores definidos por Ammann et al. (1998) e propuseram novos operadores para serem aplicados nesse contexto.

Chung e Sidhu (1991) propuseram uma técnica para geração de seqüências de teste probabilísticas para o teste de conformidade de protocolos. Os protocolos são definidos como um conjunto de MEFs que se comunicam por canais full duplex. A forma utilizada para avaliar a cobertura dessas seqüências é um procedimento que se assemelha aos passos da AM. A maior distinção está na forma como são gerados os mutantes, os quais são denominados Máquinas Aleatoriamente Geradas pelos autores. Um mutante é composto por meio de uma combinação aleatória de alterações nos estados de destino e na saída gerada.

Sugeta et al. (2004) exploraram a AM no teste de especificações baseadas em Specification and Description Language (SDL). Foi definido um conjunto de operadores 
de mutação que exploram erros no comportamento dos processos SDL, na comunicação entre os processos SDL e na estrutura da especificação. Também foi estabelecida uma estratégia de teste incremental para auxiliar a exploração das características abordadas pelos operadores de mutação.

Fabbri (1996) utilizou os conceitos da AM na validação de especificações de SRs. Em seu trabalho, foram consideradas as técnicas MEFs, Statecharts e RPs Lugar/Transição. Fabbri definiu o conjunto de operadores para cada uma dessas técnicas e conduziu um estudo no qual aplicou manualmente a AM, obtendo evidências de que este critério pode ser considerado uma forma complementar na validação do aspecto comportamental de SRs.

A seguir, são apresentados mais detalhes sobre a aplicação referente da AM à técnica RPs Lugar/Transição, diretamente relacionada a este trabalho. Os operadores definidos para RPs Lugar/Transição (Fabbri, 1996) são descritos na Tabela 2.1. Baseado no trabalho de Chow (1978) para MEFs, foram considerados dois tipos de alterações na rede: alteração nos arcos e alterações na marcação inicial. As alterações de arcos são subdividas considerando-se o tipo do arco em questão, ou seja, se é um arco de entrada (prefixo Inp) ou um arco de saída (prefixo Out).

Tabela 2.1: Operadores de Mutação para Redes de Petri.

\begin{tabular}{|c|c|c|}
\hline Tipo da Alteração & Operador & Descrição \\
\hline \multirow{2}{*}{ Arco Faltando } & InpDel & \multirow{2}{*}{ exclusão de um arco } \\
\hline & OutDel & \\
\hline \multirow{2}{*}{ Arco Extra } & InpIns & \multirow{2}{*}{ inserção de um arco } \\
\hline & OutIns & \\
\hline \multirow{2}{*}{ Arco Trocado } & InpAlt & \multirow{2}{*}{$\begin{array}{l}\text { troca um arco que liga uma transição a um lugar por } \\
\text { outro arco que liga essa transição a outro lugar }\end{array}$} \\
\hline & OutAlt & \\
\hline \multirow{2}{*}{ Arco Deslocado } & InpShift & \multirow{2}{*}{$\begin{array}{l}\text { troca um arco que liga uma transição a um lugar por } \\
\text { outro arco que liga outra transição a esse lugar }\end{array}$} \\
\hline & OutShift & \\
\hline Marcas Faltando & MarkDel & exclusão de todas as marcas de um lugar \\
\hline Marca Extra & MarkIns & $\begin{array}{l}\text { inclusão de uma marca em um lugar que não contenha } \\
\text { marcas }\end{array}$ \\
\hline Marca Trocada & MarkAlt & Iusao \\
\hline
\end{tabular}

Estes operadores foram analisados em bases teóricas, considerando-se a relação de inclusão (Simão, 2000). Concluiu-se que o conjunto de operadores $O P=\{$ InpIns, InpDel, InpShift, OutIns, OutDel, OutShift, MarkDel $\}$ inclui o conjunto $O P_{\text {all }}$ formado por todos os operadores, ou seja, todo conjunto $T$ de casos de teste que for adequado para $O P$ também é adequado para $O P_{\text {all }}$. Isto implica que os operadores InpAlt, OutAlt, MarkIns e MarkAlt são incluídos por algum outro operador e podem ser desconsiderados, reduzindo o custo de aplicação. 
Equivalência de Comportamento Para definir a equivalência entre o mutante e a rede original, considerou-se o conteúdo dos lugares da rede na marcação final, de forma que um lugar pode estar em duas condições (Fabbri, 1996): com marca ou sem marca. O comportamento da rede mutante é equivalente ao comportamento da rede original, para uma seqüência de teste específica, se todos os lugares estão na mesma condição na marcação atingida após o disparo da seqüência de teste. Além disso, caso a seqüência de teste não possa ser executada pela rede mutante, ou seja, caso ela não esteja habilitada, considera-se o comportamento como não-equivalente.

Formalmente, a condição de uma marcação é definida pela função Sign, como segue:

$$
\begin{gathered}
\text { Sign }: \mathbf{N} \mapsto\{0,1\} \\
\operatorname{Sign}(n)= \begin{cases}0 & \text { se } n=0 \\
1 & \text { se } n>0\end{cases}
\end{gathered}
$$

Definição 3. Dados uma $R P N$, um mutante $N^{\prime}$ e uma seqüência de teste sq, tal que $\mu_{0}[s q\rangle$, define-se que $s q$ distingue $N^{\prime}$ de $N$, ou seja, sq mata $N^{\prime}$, se ocorrer uma das seguintes alternativas:

- $\mu_{0}^{\prime} \chi\langle s q\rangle$

- $\mu_{0}^{\prime}[s q\rangle$ e existe um $p \in P$, tal que $\operatorname{Sign}\left(\delta\left(\mu_{0}, s q\right)(p)\right) \neq \operatorname{Sign}\left(\delta^{\prime}\left(\mu_{0}^{\prime}, s q\right)(p)\right)$

\subsubsection{A Ferramenta Proteum-RS/PN}

Para apoiar a aplicação da AM no teste de especificações, Fabbri (1996) especificou a ferramenta Proteum-RS, a qual deve ser instanciada para as técnicas de especificação em questão. No contexto do teste de MEFs, Fabbri instanciou a ferramenta Proteum-RS/FSM (Fabbri et al., 1994a, 1995a, 1999a). No contexto do teste de Statecharts, Sugeta instanciou a ferramenta Proteum-RS/ST (Sugeta, 1999b; Sugeta et al., 1999, 2001). No contexto do teste de RPs Lugar/Transição, instanciou-se a ferramenta Proteum-RS/PN (Simão, 2000; Simão e Maldonado, 2000b), a qual é descrita a seguir.

A ferramenta Proteum-RS/PN foi desenvolvida em duas fases. Na primeira fase, desenvolveu-se no sistema Mathematica (Wolfram, 1996), um pacote que fornece as funcionalidades da ferramenta em um nível de abstração mais alto. Esse pacote foi utilizado para refinar a especificação da ferramenta a ser desenvolvida, bem como definir estratégias de implementação. Na segunda fase, a Proteum-RS/PN foi desenvolvida em $\mathrm{C}++$ e TCL/TK. Nessa fase de desenvolvimento o pacote desenvolvido na primeira fase foi utilizado durante a validação como um oráculo, a mesma linha discutida em (Weyuker, 1982).

A Proteum-RS/PN está disponível em dois modos de execução: por meio de interface gráfica e por meio de scripts. O modo interface gráfica é mais adequado para a aquisição dos conceitos básicos da técnica de mutação e da ferramenta, porém esse modo 
requer constante interação com o testador. Usuários mais avançados podem, no entanto, realizar operações por meio de chamadas aos módulos que constituem a ferramenta, podendo compor scripts de teste e utilizar a ferramenta de forma programada. Os módulos são programas que realizam operações básicas sobre as bases de dados que compõem uma sessão de teste.

A seguir são sucintamente descritas as principais funcionalidades oferecidas pela ferramenta.

Sessão de Teste. A Proteum-RS/PN utiliza a noção de sessão de teste. Dessa forma, pode-se interromper uma sessão e retomá-la posteriormente. Além disso, pode-se realizar mais de uma sessão para o teste de uma mesma rede.

Edição/Simulação de RPs. Para permitir a criação e edição de RPs, um editor e simulador de RPs foram desenvolvidos e encontram-se acoplados à ferramenta.

Casos de Teste. No contexto de RPs, os casos de teste são caracterizados pela seqüência de transições a ser disparada. Os casos de teste podem ser incluídos em uma sessão de diversas formas. Por exemplo, um caso de teste pode ser incluído interativamente por meio do simulador de RPs. O testador pode disparar as transições habilitadas da rede com um duplo clique sobre ela. Caso o comportamento da rede esteja de acordo com o esperado, pode-se então incluir o caso de teste. A ferramenta também oferece opções para a importação de casos de teste a partir de outra sessão ou de um arquivo ASCII.

Mutantes. A ferramenta implementa todos os operadores de mutação para RPs definidos por Fabbri em (Fabbri, 1996). Para apoiar a estudos empíricos, é possível escolherem-se quais operadores aplicar e qual a porcentagem de mutantes de cada operador que será gerada. Os mutantes podem então ser executados com os casos de teste e pode-se calcular o escore de mutação. Apenas os mutantes e os casos de teste selecionados são considerados durante a execução e o cálculo do escore de mutação. Os mutantes que permanecem vivos devem ser analisados para determinar se são ou não equivalentes à rede original. Caso um mutante seja equivalente, ele é marcado como tal e pode ser descartado. Caso não, deve-se incluir um novo caso de teste para matar esse mutante.

Relatórios. Além do escore de mutação, a ferramenta oferece relatórios mais detalhados sobre a sessão de teste. Por exemplo, pode-se solicitar um relatório sobre os casos de teste, com diversas informações, tais como quantos mutantes foram executados e quantos foram mortos com cada caso de teste. Outro relatório importante é o que informa o status dos mutantes agrupados por operador de mutação. 


\section{Modo Interface Gráfica}

Na Figura 2.14 é apresentado um exemplo da interface gráfica da Proteum-RS/PN, na qual se pode observar a inclusão interativa de um caso de teste. A rede que está sendo testada é apresentada à esquerda e as transições habilitadas a disparar são apresentadas em cor mais clara. Uma rede mutante é apresentada à direita e os elementos que foram alterados são destacados (o lugar $C$ e a transição T1). Ao centro apresenta-se um histórico da execução com todas as transições disparadas até o momento e que permite retroceder a qualquer ponto anterior da execução. A ferramenta permite que um ou mais mutantes sejam visualizados durante a inclusão de um caso de teste, o que facilita identificar quando o caso de teste efetivamente mata o(s) mutante(s) em questão.

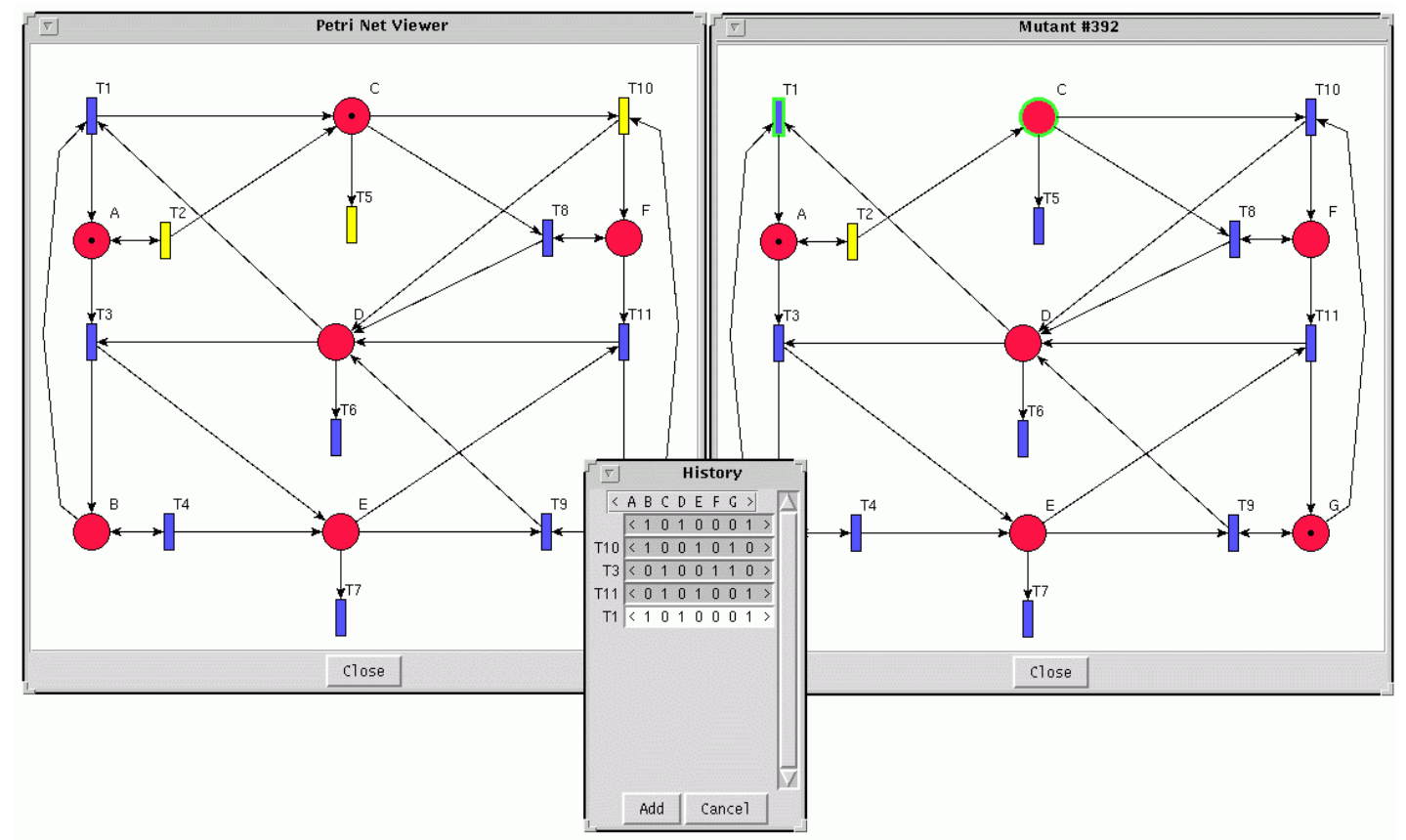

Figura 2.14: Visualização de um Mutante durante a Inclusão de um Caso de Teste.

\section{Modo Script}

As mesmas operações disponíveis na interface gráfica podem ser obtidas por meio de chamadas aos módulos que compõem a ferramenta ou por meio de scripts, oferecendo uma forma programada de conduzir uma sessão de teste. Esses módulos são fornecidos na forma de programas executáveis. Tais programas realizam tarefas simples de manipulação das bases de mutantes e das bases de casos de teste e são chamados programas básicos. Existem também os programas utilitários, que usam os programas básicos para realizar tarefas específicas sobre uma sessão de teste. Na Tabela 2.2 são apresentados os programas que compõem a Proteum-RS/PN. 
Tabela 2.2: Módulos da Proteum-RS/PN.

\begin{tabular}{|r||l|}
\hline \multicolumn{2}{|c|}{ Programas Básicos } \\
\hline \hline ptest & $\begin{array}{l}\text { cria e manipula arquivos de teste, os quais descrevem as } \\
\text { características gerais da sessão de teste }\end{array}$ \\
\hline tcase & cria e manipula a base de dados de casos de teste \\
\hline muta & cria e manipula a base de dados dos mutantes \\
\hline exemuta & $\begin{array}{l}\text { constrói o código fonte dos mutantes e executa os mutan- } \\
\text { tes; é também utilizado para ativar/desativar mutantes }\end{array}$ \\
\hline opmuta & $\begin{array}{l}\text { aplica operadores de mutação na rede original, criando } \\
\text { descritores de mutação }\end{array}$ \\
\hline report & cria um relatório sobre a efetividade dos casos de teste \\
\hline \hline \multicolumn{2}{|c|}{ Programas Utilitários } \\
\hline \hline test-new & cria uma nova sessão de teste \\
\hline muta-view & permite visualizar e analisar os mutantes \\
\hline
\end{tabular}

\subsection{Análise de Risco}

Como dito anteriormente, questões de segurança de software tornam-se cada vez mais importantes à medida que sistemas de software são utilizados para controlar atividades críticas e de tempo real. Isso induz a introdução de métodos rigorosos de desenvolvimento e a condução de uma atividade de teste mais rigorosa. Além disso, de forma análoga ao que ocorre no desenvolvimento de sistemas críticos de hardware e equipamentos em geral, caracterizou-se uma área de pesquisa, denominada Análise de Risco, voltada ao estabelecimento de métodos e técnicas para a análise, identificação e eventual eliminação dos riscos na utilização de um produto de software (Leveson, 1986). A Análise de Risco, como disciplina, tem o objetivo de identificar, avaliar e remover riscos de um sistema de software. Para isso, existem algumas técnicas de análise que visam a auxiliar nesse processo.

O conceito de segurança utilizado está relacionado à "ausência de condições que podem causar mortes, prejuízos à saúde, ou danos/perdas de equipamentos ou propriedade" (Leveson, 1986). Ressalta-se que o que é considerado um dano depende do sistema em particular, podendo ser danos monetários, de vidas humanas, etc.

Quase todos os sistemas que produzem benefícios pessoais, sociais ou industriais contêm elementos de risco que são indispensáveis ao seu funcionamento, [(Browning, 1980) apud (Leveson, 1986)]. Dessa forma, um sistema não pode ser declarado "seguro" e sim "mais seguro". Por exemplo, nenhum avião voaria, nenhum automóvel se moveria e nenhum navio seria colocado em alto mar se todos as condições de risco tivessem que ser eliminadas [(Hammer, 1972) apud (Leveson, 1986)]. Esse problema é ainda mais dificultado pelo fato de que tentativas de se eliminarem riscos resultam apenas 
em uma migração do risco para outro lugar. Por exemplo, a utilização de nitrato em alimentos aumenta o risco de desenvolver câncer, mas previne mortes por botulismo. Benefícios e riscos freqüentemente apresentam trade-offs, tais como entre os benefícios de um diagnóstico médico detalhado e os riscos da exposição a Raios-X.

Deve-se observar que, em geral, questões referentes à Análise de Risco não estão diretamente ligadas a questões de corretitude funcional (Leveson e Harvey, 1983). Por exemplo, um sistema pode estar correto (ou seja, estar de acordo com sua especificação) e não ser seguro. Em geral, a concordância com a especificação pode ser abandonada (ao menos temporariamente) na tentativa de não causar danos. De acordo com essas considerações, Leveson e Stolzy (1987) definem um sistema como "seguro" se esse for livre de situações de risco, mesmo se ele não atender a seus requisitos, funcionais ou não.

Com base na reação esperada de um sistema perante uma falha, um sistema pode ser classificado em:

Sistemas Tolerantes a falhas: O sistema continua a fornecer todas as funcionalidades e a apresentar um desempenho satisfatório na presença de falhas operacionais.

Sistemas Fail-soft: O sistema continua operando, mas fornece apenas um desempenho degradado ou um conjunto reduzido de funcionalidade até que a falha seja removida.

Sistemas Fail-safe: O sistema procura limitar a quantidade de prejuízo causado por uma falha. Nenhuma tentativa é feita para satisfazer os requisitos funcionais, exceto aqueles que forem necessários para a segurança do sistema.

Um sistema em particular pode ser classificado de formas diferentes em função da falha que está sendo considerada. Por exemplo, um sistema pode ser tolerante a falhas com relação a uma determinada falha e ser fail-safe com relação a outra.

É importante notar que, em geral, o software em si não pode causar prejuízos; apenas os instrumentos controlados (físicos ou não) podem danificar, ferir, destruir, etc. Acidentes freqüentemente resultam de seqüências múltiplas de falha que envolvem hardware, software e seres humanos. Dessa forma, procedimentos para a segurança de software não podem ser realizados isoladamente, e sim com uma visão global do sistema.

\subsubsection{Técnicas de Análise de Risco}

Muitas das técnicas utilizadas para a realização da Análise de Risco de Software são derivadas de técnicas utilizadas em outras áreas, tais como a indústria química e de equipamentos bélicos. Nesta seção serão apresentadas as seguintes técnicas: HAZOP (McDermid e Pumfrey, 1994), Árvore de Falhas (Liu e McDermid, 1996), Análise de Modos e Efeitos de Falhas (Leveson, 1986) e baseada em RPs (Leveson e Stolzy, 1987). 


\subsubsection{Técnica HAZOP}

A técnica HAZOP (do inglês, Hazard and Operability) (McDermid e Pumfrey, 1994) é muito utilizada nas indústrias químicas, nucleares e processamento de alimentos, e procura identificar modos de falha previamente não considerados pela sugestão de falhas hipotéticas e, quando necessário, pela sugestão de meios para evitar as situações de risco identificadas. A técnica pode ser considerada como um procedimento qualitativo que envolve uma busca sistemática por hazards pela geração de questões considerando os efeitos do desvio de parâmetros normais.

Dois conceitos que caracterizam a técnica HAZOP são a análise baseada em fluxos e o uso de palavras-guia. A análise baseada em fluxos, no contexto do planejamento de indústrias químicas, significa que o foco principal da análise está nas propriedades e no comportamento dos fluxos nos dutos conectando os componentes principais. Para cada fluxo, um conjunto de palavras-guia é utilizado para levantar considerações sobre falhas hipotéticas, conhecidas como desvios a partir das características e comportamento desejados. Se uma falha hipotética possuir, ao mesmo tempo, causas plausíveis e conseqüências desastrosas, essa é considerada um modo de falha significativo e considerações devem ser feitas para remover suas causas e/ou limitar seus efeitos. Segundo McDermid e Pumfrey (1994), as palavras-guia fornecem a estrutura da análise e, se um conjunto adequado de palavras-guia for selecionado e corretamente aplicado, pode-se obter confiança na cobertura atingida.

Uma característica crucial da técnica HAZOP aplicada na indústria é que se trata de uma atividade de grupo, e uma grande ênfase é atribuída à seleção dos membros apropriados da equipe envolvida. A diversidade de conhecimento e experiências ajuda a garantir uma investigação minuciosa e a abordagem interdisciplinar ajuda a evitar que uma pessoa ou grupo resolva um problema de uma forma que gere novos problemas em outras áreas.

McDermid e Pumfrey (1994) apresentam uma proposta de extensão e aplicação da técnica HAZOP para a Análise de Risco de software. Nesse contexto, os fluxos considerados são os fluxos de controle e dados do sistema e as falhas hipotéticas são consideradas nos fluxos entre os componentes. Um conjunto de palavras-guia é proposto, considerando-se principalmente o fornecimento de serviços entre os componentes do sistema. As palavras-chaves são divididas em três categorias, apresentadas na Figura 2.3. Os autores ressaltam que esse conjunto de palavras-guia deve ser analisado e desenvolvido, a exemplo do que ocorreu com as palavras-guia para a indústria química, que foram refinadas ao longo do tempo e, dessa forma, possuem uma semântica bem estabelecida. 
Tabela 2.3: Palavras-Guia Propostas para Software (McDermid e Pumfrey, 1994).

\begin{tabular}{|c||l|}
\hline Fornecimento do Serviço: & OMISSÃO \\
\cline { 2 - 2 } & COMPROMETIMENTO \\
\hline Tempo do Serviço: & MUITO CEDO \\
\cline { 2 - 2 } & MUITO TARDE \\
\hline Valor do Serviço: & GROSSEIRAMENTE INCORRETO \\
\cline { 2 - 2 } & SUTILMENTE INCORRETO \\
\hline
\end{tabular}

\subsubsection{Análise de Árvore de Falhas}

A Análise de Árvore de Falhas é uma técnica que tem sido freqüentemente utilizada para a análise de segurança de sistemas, sendo geralmente aplicada para a análise de hardware (Liu e McDermid, 1996). Além disso, essa técnica tem sido aplicada para a Análise de Risco de software (por exemplo, Leveson e Harvey (1983)). Na aplicação para Análise de Risco de hardware, as árvores de falha são tradicionalmente derivadas diretamente do modelo físico do sistema para refletir as potenciais causas de uma falha específica (chamada de "top event"). O modelo físico inclui a estrutura, os princípios de operação, as propriedades e os inter-relacionamentos dos componentes do sistema. Cada evento em uma árvore de falha descreve alguma falha envolvendo componentes físicos, e eventos de alto-nível podem ser causados por eventos de baixo-nível, ligados por conectores lógicos, chamados de portas AND, portas OR, portas EXCLUSIVE-OR, portas PRIORITY-AND (que geram o valor verdadeiro apenas se os eventos de entrada ocorrem na ordem especificada na condição associada) e portas INHIBIT (que geram o valor verdadeiro apenas se um evento de entrada ocorre quando alguma condição externa específica estiver satisfeita). Na Tabela 2.4 é apresentado um sumário dos símbolos que podem aparecer em uma árvore de falha. Um exemplo com alto nível de abstração de um árvore de falha, extraído de (Liu e McDermid, 1996), é apresentado na Figura 2.15. Pode-se observar que, por exemplo, o evento de mais alto nível é "Válvula falha para Abrir", o qual pode ser ocasionado por ao menos um dos subeventos "RI $I_{1}$ está fora de controle", "RI $\mathrm{I}_{2}$ está fora de controle" e "RI $\mathrm{I}_{3}$ está fora de controle". 
Tabela 2.4: Símbolos de uma Árvore de Falhas.

\begin{tabular}{|c|c|c|}
\hline \multicolumn{3}{|r|}{ Símbolos de Eventos } \\
\hline & Eventos Básicos & $\begin{array}{l}\text { Uma falha básica que não requer desenvolvimento } \\
\text { posterior }\end{array}$ \\
\hline & $\begin{array}{l}\text { Eventos } \\
\text { Não-Desen- } \\
\text { volvido }\end{array}$ & $\begin{array}{l}\text { Um evento que não requer desenvolvimento posterior, } \\
\text { quer porque apresenta conseqüências insuficientes, } \\
\text { quer porque a informação não está disponível }\end{array}$ \\
\hline & $\begin{array}{l}\text { Eventos Condi- } \\
\text { cionais }\end{array}$ & $\begin{array}{l}\text { Condições ou restrições específicas que se aplicam a } \\
\text { uma porta lógica (geralmente, associadas a portas } \\
\text { PRIORITY AND e INHIBIT }\end{array}$ \\
\hline & $\begin{array}{l}\text { Eventos } \\
\text { Intermediários }\end{array}$ & $\begin{array}{l}\text { Um evento de falha que ocorre porque uma ou mais } \\
\text { causas atuam por meio de portas lógicas }\end{array}$ \\
\hline & $\begin{array}{l}\text { Eventos } \\
\text { Externos }\end{array}$ & Um evento que é normalmente esperado que ocorra \\
\hline \multicolumn{3}{|r|}{$\overline{\text { Símbolos de Portas }}$} \\
\hline & $A N D$ & $\begin{array}{l}\text { A falha de saída ocorre se todas as falhas de entrada } \\
\text { ocorrerem }\end{array}$ \\
\hline & OR & $\begin{array}{l}\text { A falha de saída ocorre se ao menos uma falha de } \\
\text { entrada ocorrer }\end{array}$ \\
\hline & $\begin{array}{l}\text { EXCLUSIVE } \\
\text { OR }\end{array}$ & $\begin{array}{l}\text { A falha de saída ocorre se exatamente uma das falhas } \\
\text { de entrada ocorrer }\end{array}$ \\
\hline & $\begin{array}{l}\text { PRIORITY } \\
A N D\end{array}$ & $\begin{array}{l}\text { A falha de saída ocorre se todas a falhas de entrada } \\
\text { ocorrem em uma ordem específica (a seqüência é } \\
\text { representada por um evento condicional desenhada ao } \\
\text { lado da porta) }\end{array}$ \\
\hline & INHIBIT & $\begin{array}{l}\text { A falha de saída ocorre se a (única) falha de entrada } \\
\text { ocorre na presença de uma condição de habilitação (a } \\
\text { condição de habilitação é desenhada ao lado da porta) }\end{array}$ \\
\hline \multicolumn{3}{|r|}{ Símbolos de Transferência } \\
\hline & TRANSFER IN & $\begin{array}{l}\text { Indica que a árvore é desenvolvida em outra página na } \\
\text { ocorrência do símbolo TRANSFER OUT correspon- } \\
\text { dente }\end{array}$ \\
\hline$\Delta$ & $\begin{array}{l}\text { TRANSFER } \\
\text { OUT }\end{array}$ & $\begin{array}{l}\text { Indica que nesta parte da árvore deve ser anexada o } \\
\text { símbolo TRANSFER IN correspondente }\end{array}$ \\
\hline
\end{tabular}




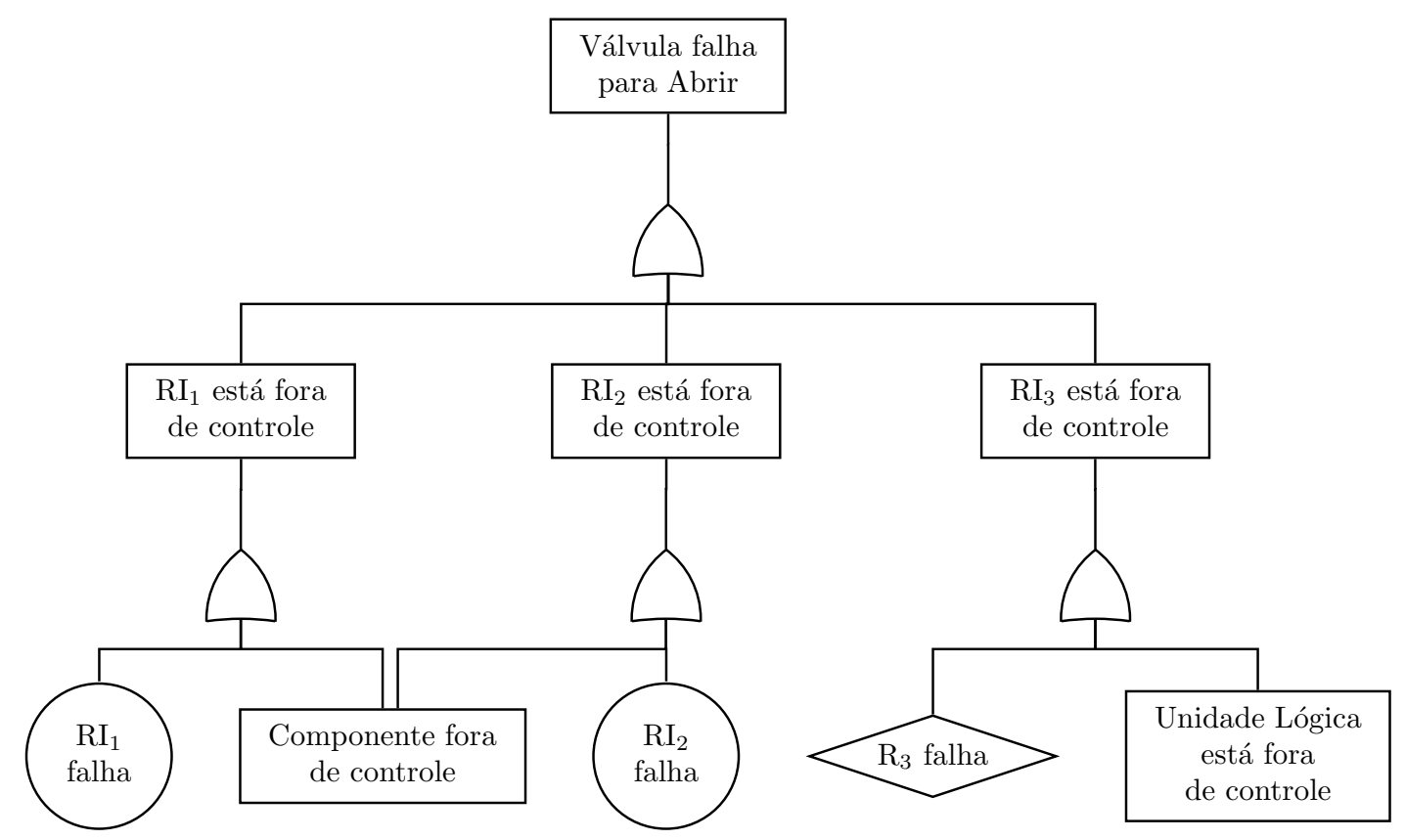

Figura 2.15: Exemplo de Árvore de Falhas (Leveson e Harvey, 1983). 


\subsubsection{Análise de Modos e Efeitos de Falhas}

A Análise de Modos e Efeitos de Falhas (do inglês, Failure Modes and Effects Analysis) é uma técnica de análise de confiabilidade freqüentemente utilizada para Análise de Risco (Leveson, 1986). A técnica examina os efeitos de todos os modos de falha de um sistema ou de seus subsistemas. Uma de suas principais vantagens é poder ser aplicada sem a identificação prévia das possíveis situações de risco e, conseqüentemente, poder auxiliar na identificação de catástrofes ainda não percebidas. No entanto, a técnica é muito onerosa, uma vez que todas as falhas, incluindo as falhas não catastróficas, são consideradas. Além disso, a Análise de Modos e Efeitos de Falhas é eficaz em identificar desastres com causa única, mas geralmente não considera múltiplas falhas. Para levar em conta a gravidade do efeito de uma falha, assim como sua probabilidade e freqüência de ocorrência, a técnica de Análise de Modos, Efeitos e Criticalidade de Falhas foi proposta como uma extensão.

\subsubsection{Análise de Risco com Redes de Petri}

Leveson e Stolzy (1987) apresentam um exemplo de aplicação de técnicas de modelagem e análise de RPs Temporais em sistemas críticos. Os autores discutem como falhas podem ser modeladas no sistema e como o seu nível de segurança pode ser avaliado. A técnica envolve basicamente 2 etapas:

- Primeiramente, deve-se identificar quais as situações de perigo em que o sistema pode estar. Em uma RP, tais situações podem ser modeladas por marcações específicas.

- O grafo de alcançabilidade é construído, buscando identificar se as marcações correspondentes às situações de risco são alcançáveis a partir da marcação inicial. Além disso, as marcações que podem conduzir às marcações de riscos são identificadas. Caso sejam alcançáveis, o modelo deve ser reconsiderado e o risco deve ser eliminado levando-se em conta a probabilidade de que a situação ocorra, por meio da inclusão de mecanismos para evitar ou atenuar as conseqüências.

Uma vez que a construção do grafo de alcançabilidade apresenta, em geral, um custo computacional muito alto, Leveson e Stolzy (1987) sugerem que o grafo seja construído em ordem reversa, isto é, partindo-se das marcações de risco e identificando quais marcações podem alcançá-las. No entanto, mesmo dessa forma o problema de construção do grafo é exponencial em relação ao número de elementos da rede.

\subsection{Considerações Finais}

O propósito deste capítulo foi abordar os principais conceitos relacionados ao contexto em que este trabalho se insere. 
Os principais aspectos relacionados à atividade de teste foram apresentados. Observou-se a necessidade de sistematizar a condução dessa atividade. Diversos critérios de teste foram propostos com esse propósito, visando a fornecer medidas quantitativas da qualidade do teste realizado. Em geral, isso é feito pela determinação de características que devem estar presentes nos conjuntos de casos de teste utilizados. Foram também apresentados diversos estudos que visam a comparar os diversos critérios, buscando identificar os pontos fortes e fracos de cada um. São apresentados também estudos que comparam o desempenho de critérios de teste em geral com o teste aleatório.

O critério AM foi apresentado com mais detalhes. Pôde-se observar que, devido à sua flexibilidade, o critério tem sido utilizado em diversos contextos, incluindo no teste de especificações. Evidenciou-se a importância dos operadores de mutação para a qualidade do critério. Dessa forma, neste trabalho, é proposta uma linguagem para a definição de operadores de mutação, a qual é um primeiro passo na investigação de mecanismos genéricos para o apoio ao teste baseado na AM.

Foi destacada a importância de se utilizarem métodos formais para aumentar o rigor do desenvolvimento. Técnicas de especificação do aspecto comportamental de SRs foram apresentadas, destacando-se e descrevendo-se sucintamente as técnicas MEFs, Estelle e Statecharts. Foram apresentadas em mais detalhes as técnicas RPs e RPCs, destacando-se suas propriedades e técnicas de análise e ferramentas de apoio. Contudo, apesar do rigor proporcionado com o uso de técnicas formais na fase de especificações, a presença de defeitos não é evitada. Para auxiliar a garantia da qualidade, a atividade de teste deve ser conduzida desde as fases iniciais do processo de desenvolvimento de software, pois quanto mais cedo os erros são encontrados, menor é o custo para eliminá-los. Foi enfatizado que, em complemento às técnicas de análise tradicionais, a validação de especificações deve ser conduzida e apoiada por métodos, técnicas e ferramentas adequadas, uma vez que o processo de formalização dos requisitos está sujeito a erros.

No caso de RPCs, as técnicas de análise permitem propriedades genéricas, tais como liveness e limitação, ou específicas para o modelo em questão sejam verificadas. Contudo, foi enfatizado que, ainda dispondo dessas técnicas, é necessário que a RPC seja simulada e que o comportamento seja confrontado com o comportamento esperado do sistema. Em outras palavras, que a RPC seja testada. Assim, a exemplo do que ocorre com o teste de programas em geral, é relevante a investigação de critérios de teste para RPCs.

Pôde-se também perceber a necessidade de estudos teóricos e empíricos que investiguem os critérios de teste utilizados no teste de especificações, de forma a demonstrar a importância dos critérios de teste na prática. Também se destacou que a existência de ferramentas de apoio é indispensável para a realização da atividade de teste de forma produtiva e para o auxílio na condução de estudos empíricos. 
O grupo de Engenharia de Software do ICMC-USP/São Carlos tem investigado critérios estruturais e baseados em mutação no teste de especificações. Esses trabalhos motivam a investigação de critérios de teste no teste de especificações baseadas em outras técnicas formais, como é o caso de RPCs, para fornecer evidências da qualidade do teste da especificação. Em especial, apresentaram-se os resultados da aplicação da AM no teste de RPs, que serviram de base e motivação para a realização deste trabalho.

Foram apresentados também trabalhos relacionados à Análise de Risco, destacando-se que a corretitude do sistema não implica que o mesmo seja seguro. Nesse sentido, estudos que busquem estabelecer técnicas para identificar e eliminar os riscos de um sistema são importantes. De especial interesse para esse trabalho é a iniciativai, apresentada neste capítulo, de se utilizar RP temporais nesse contexto, motivando a investigação de mecanismos para a Análise de Risco com outras modalidades de redes, tais como as RPCs.

Visando a contribuir no escopo de teste de especificações, neste trabalho investiga-se o critério AM no teste de especificações baseadas em RPCs. No próximo capítulo apresentam-se os resultados teóricos dessa investigação. Os conceitos do critério AM são analisados e aplicados no contexto de RPCs. Apresenta-se também a linguagem para descrição de operadores de mutação. Ao final, discute-se como a AM pode ser utilizada para auxiliar na Análise de Risco de sistemas especificados com RPCs. 


\section{Análise de Mutantes Aplicada a Redes de Petri Coloridas}

\subsection{Considerações Iniciais}

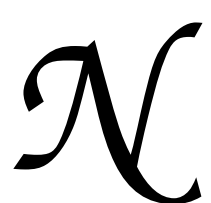

este capítulo, é apresentada a definição dos conceitos do critério AM aplicados no teste de especificações baseadas em RPCs. Como dito anteriormente, o objetivo da AM é testar a corretitude de um produto com base nos defeitos mais comuns que podem ser cometidos ao longo do processo de desenvolvimento. Para modelar esses defeitos, um conjunto de operadores de mutação é definido. Um operador de mutação pode ser considerado como regras que definem como um produto deve ser sintaticamente alterado. A definição dos operadores de mutação é de fundamental importância para a eficácia da aplicação do critério. A partir de um conjunto inicial de operadores, estudos teóricos e empíricos devem ser conduzidos para ajustá-los e melhorá-los, de forma a tornar mais eficaz a atividade de teste. Na Seção 3.2, são apresentados e ilustrados os operadores de mutação definidos para RPCs. Outro ponto importante para a definição da aplicação da análise de mutantes é o estabelecimento da relação de equivalência de resultados, ou seja, o estabelecimento de quando o comportamento da rede mutante com uma seqüência de teste será considerado equivalente ao comportamento da rede original ou quando o mutante pode ser considerado morto pela seqüência de teste. Esse ponto é abordado na Seção 3.3. A análise da complexidade, em termos do número de mutantes gerados, dos operadores definidos é apresentada na Seção 3.4.

Dada a importância dos operadores de mutação, motiva-se a busca por mecanismos que possibilitem a definição precisa de um conjunto de operadores, assim como facilitem a geração dos mutantes. Dessa forma, neste trabalho, definiu-se uma linguagem para a descrição de operadores de mutação. Essa linguagem foi definida de maneira a poder ser utilizada não somente para operadores para RPCs, mas também para outras técnicas de especificação e linguagens de programação. A definição dessa linguagem é apresentada na Seção 3.5. 
Motivado pelo trabalho de (Leveson e Stolzy, 1987), no qual apresenta-se como as RPs temporais podem ser utilizadas na Análise de Risco, neste trabalho, investigou-se como a AM pode ser aplicada para auxiliar na Análise de Risco. Assim, na Seção 3.6, apresentam-se as propostas iniciais nesse contexto e apontam-se direções para investigação futura.

\subsection{Operadores de Mutação}

Para a definição dos operadores propostos neste trabalho para RPCs, foram levadas em consideração as características particulares dessa técnica. Além disso, os operadores propostos em trabalhos anteriores foram analisados nesse contexto. Os operadores propostos para RPs em (Fabbri et al., 1994b) e (Simão, 2000) foram adaptados para serem aplicados a RPCs. Uma vez que a linguagem CPN-ML é baseada na linguagem funcional SML, os operadores propostos para essa linguagem em (Yano, 2004) também foram considerados. Ao todo, são propostos 27 operadores de mutação, os quais podem ser divididos em 7 categorias: Marcação Inicial (com 3 operadores), Arcos (com 10 operadores), Variáveis (com 2 operadores), Constantes (com 1 operador), Anotações (com 2 operadores), Condições de Guarda (com 3 operadores) e Operadores (com 6 operadores de mutação). Na Tabela 3.1 é apresentado um resumo de todos os operadores definidos.

A seguir, são descritos os operadores de mutação de acordo com as respectivas categorias.

\subsubsection{Alterações na Marcação Inicial}

Os operadores dessa categoria têm o objetivo de modelar erros na marcação inicial da RPC.

Remoção de Marcação Inicial O operador InitMarkDel remove a expressão de inicialização, caso seja diferente do multi-conjunto vazio, de cada lugar que não é uma porta ou soquete. Isso corresponde a definir a expressão de inicialização como sendo igual ao multi-conjunto vazio.

Na Figura 3.1 é apresentado um mutante gerado pelo operador InitMarkDel quando aplicado à RPC da Figura 2.4. Pode-se observar que foi removida a expressão de inicialização do lugar Unused.

Inserção de Marcação Inicial O operador InitMarkIns insere uma expressão de inicialização a cada lugar que não é uma porta ou um soquete. As expressões a serem usadas são aquelas expressões não vazias associadas aos lugares da mesma cor. 
Tabela 3.1: Operadores de Mutação para Redes de Petri Coloridas.

\begin{tabular}{|c|c|}
\hline \multicolumn{2}{|r|}{ Marcação Inicial } \\
\hline InitMarkDel & Remoção de Marcação Inicial \\
\hline InitMarkIns & Inserção de Marcação Inicial \\
\hline InitMarkExchange & Troca de Marcação Inicial \\
\hline \multicolumn{2}{|r|}{ Arcos } \\
\hline InputArcInversion & Inversão de Arco de Entrada \\
\hline OutputArcInversion & Inversão de Arco de Saída \\
\hline InputArcDel & Remoção de Arco de Entrada \\
\hline OutputArcDel & Remoção de Arco de Saída \\
\hline InputArcIns & Inserção de Arco de Entrada \\
\hline OutputArcIns & Inserção de Arco de Saída \\
\hline InputArcExchange & Troca de Arco de Entrada \\
\hline OutputArcExchange & Troca de Arco de Saída \\
\hline InputArcShift & Deslocamento de Arco de Entrada \\
\hline OutputArcShift & Deslocamento de Arco de Saída \\
\hline \multicolumn{2}{|r|}{ Variáveis } \\
\hline VarExchange & "Substituição de Variáveis \\
\hline VarSmall & Substituição de Variáveis por Constantes \\
\hline \multicolumn{2}{|r|}{ Constantes } \\
\hline ConstExchange & Substituição de Constantes \\
\hline \multicolumn{2}{|r|}{ Anotações } \\
\hline AnnotExchange & "Substituição da Anotação de Arco \\
\hline AnnotSmall & Substituição de Anotação por Constante \\
\hline \multicolumn{2}{|r|}{ "Condições de Guarda } \\
\hline GuardIns & "Inserção de Condições de Guarda \\
\hline GuardExchange & Troca de Condições de Guarda \\
\hline GuardInv & Inversão da Condição de Guarda \\
\hline \multicolumn{2}{|r|}{ Operadores } \\
\hline OpRelRel & Troca de Operadores Relacionais \\
\hline OpMultRelRel & Troca de Operadores Relacionais para Multi-Conjuntos \\
\hline OpArithArith & Troca de Operadores Aritméticos \\
\hline OpLogLog & Troca de Operadores Lógicos \\
\hline OpIf Inv & Troca de Expressões if-then-else \\
\hline OpMultArithArith & Troca de Operadores Aritméticos para Multi-Conjuntos \\
\hline
\end{tabular}

Na Figura 3.2 é apresentado um mutante gerado pelo operador InitMarkIns quando aplicado à RPC da Figura 2.4. Pode-se observar que foi inserida a expressão de inicialização do lugar Sent como sendo MES.

Troca de Marcação Inicial O operador InitMarkExchange troca a expressão de inicialização de dois lugares distintos. Ambos os lugares devem possuir a mesma cor. 


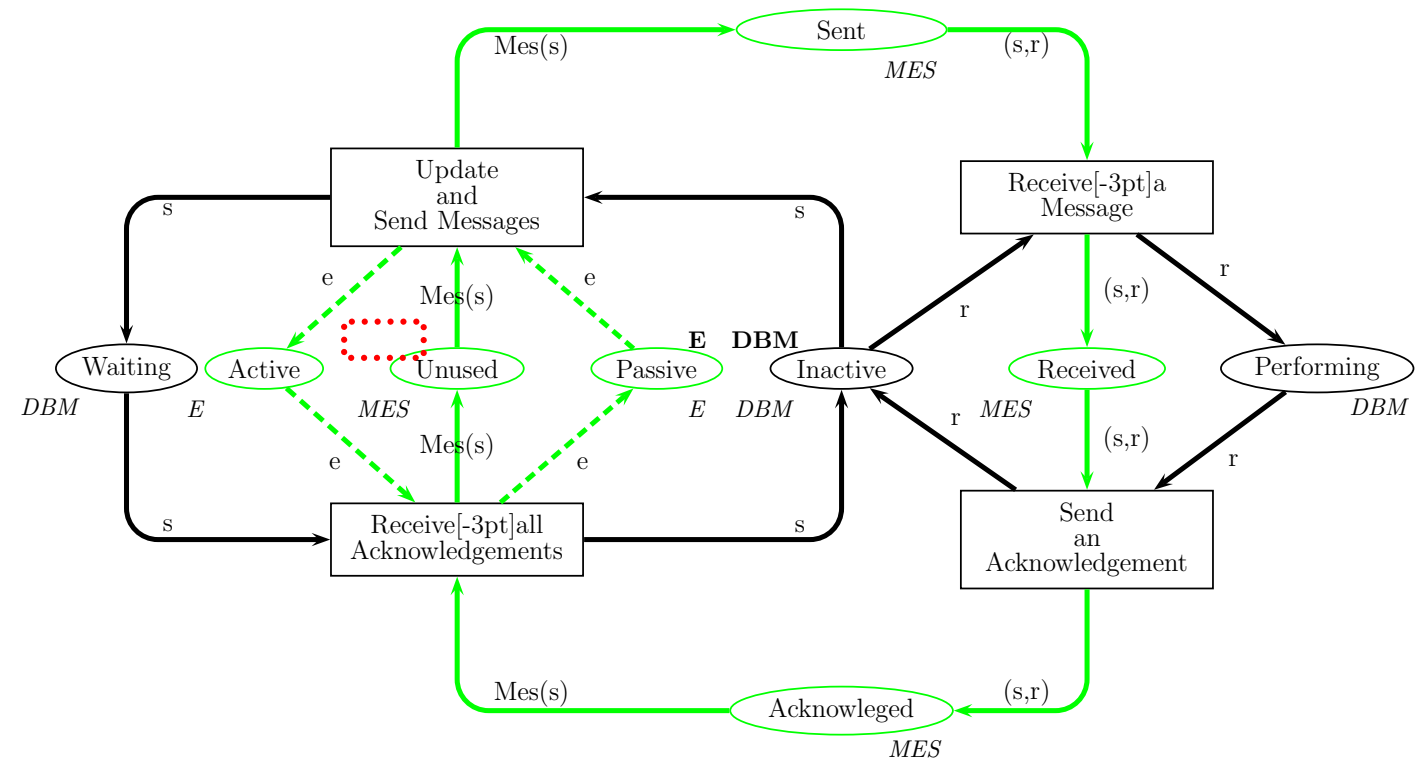

Figura 3.1: Exemplo de Mutante Gerado pelo Operador InitMarkDel.

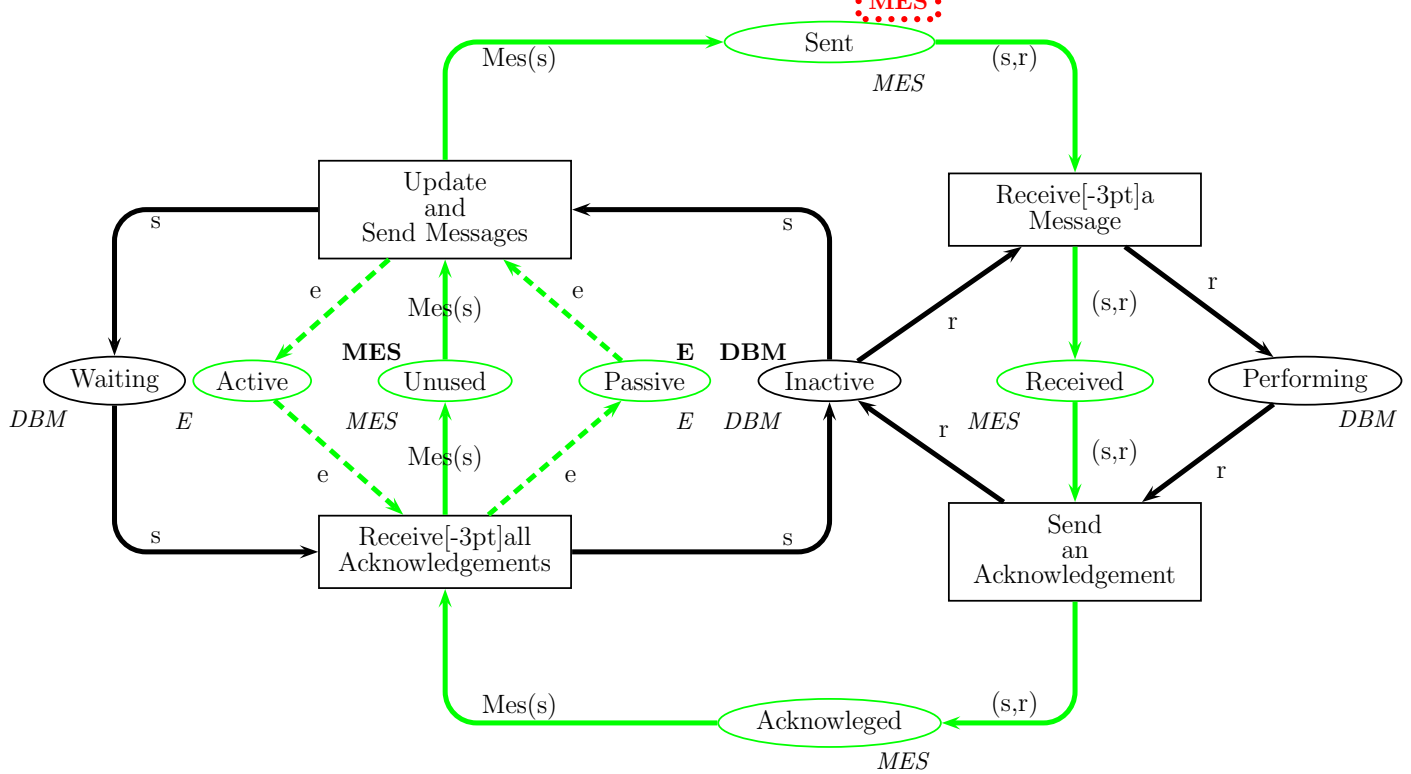

Figura 3.2: Exemplo de Mutante Gerado pelo Operador InitMarkIns.

Na Figura 3.3 é apresentado um mutante gerado pelo operador InitMarkExchange quando aplicado à RPC da Figura 2.4. Pode-se observar que as expressões de inicialização dos lugares Unused e Received foram trocadas.

\subsubsection{Alterações nos Arcos}

Os operadores dessa categoria modelam defeitos nos relacionamentos entre os elementos de uma RPC. Os arcos não-hierárquicos ${ }^{1}$ de uma RPC são alterados. Para cada tipo de alteração foram definidos dois operadores distintos, um para arcos de entrada e um para arcos de saída. Os operadores para arcos de entrada são prefixados com Input, ao passo que os operadores para arcos de saída são prefixados com Output.

\footnotetext{
${ }^{1}$ Um arco é não-hierárquico se a transição à qual ele está ligado não é uma transição hierárquica.
} 


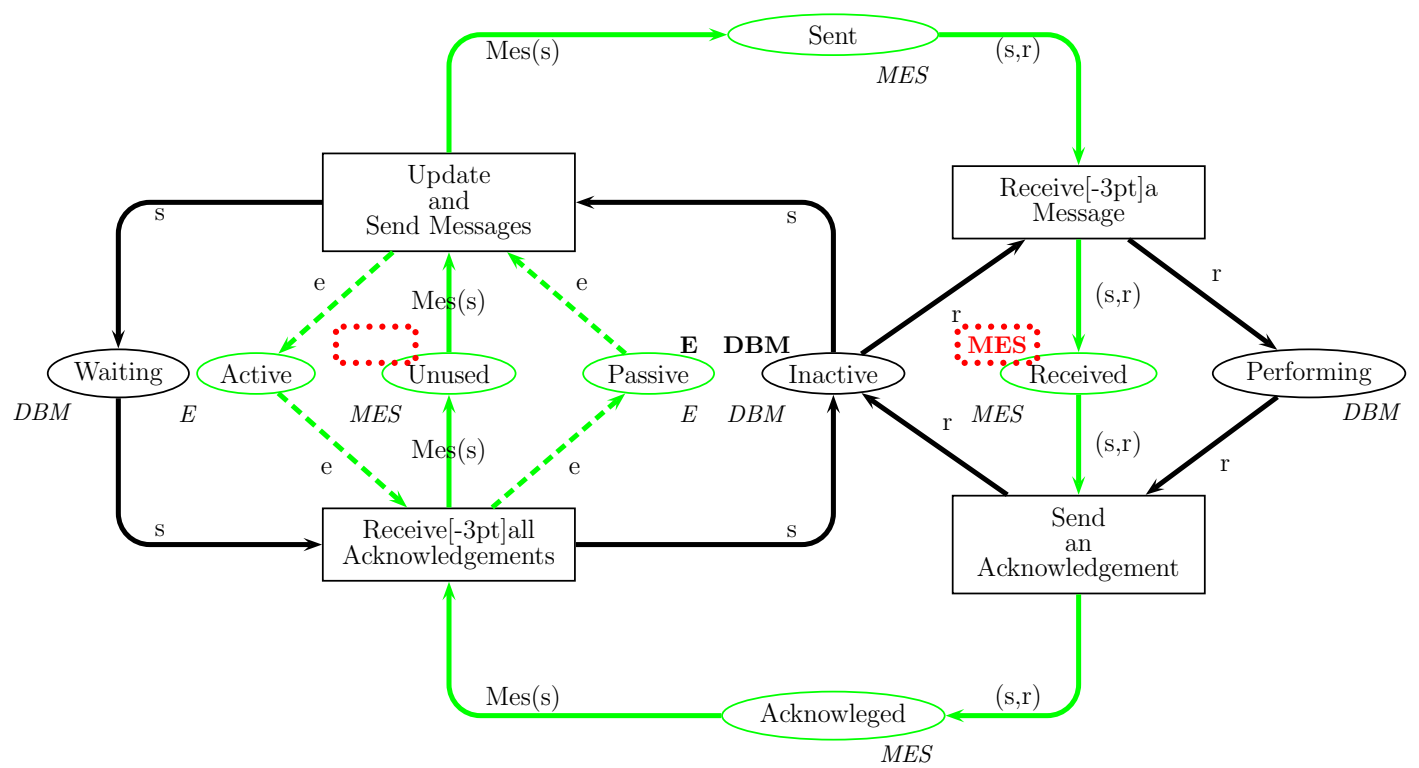

Figura 3.3: Exemplo de Mutante Gerado pelo Operador InitMarkExchange.

Inversão de Arco Os operadores InputArcInversion e OutputArcInversion invertem a direção dos arcos não-hierárquicos. Por exemplo, um arco de entrada entre o lugar $p$ e a transição $t$ será convertido em um arco de saída de $t$ a $p$ pelo operador InputArcInversion.

Na Figura 3.4 é apresentado um mutante gerado pelo operador InputArcInversion quando aplicado à RPC da Figura 2.4. Pode-se observar que a direção do arco entre Inactive e $S M$ foi invertida.

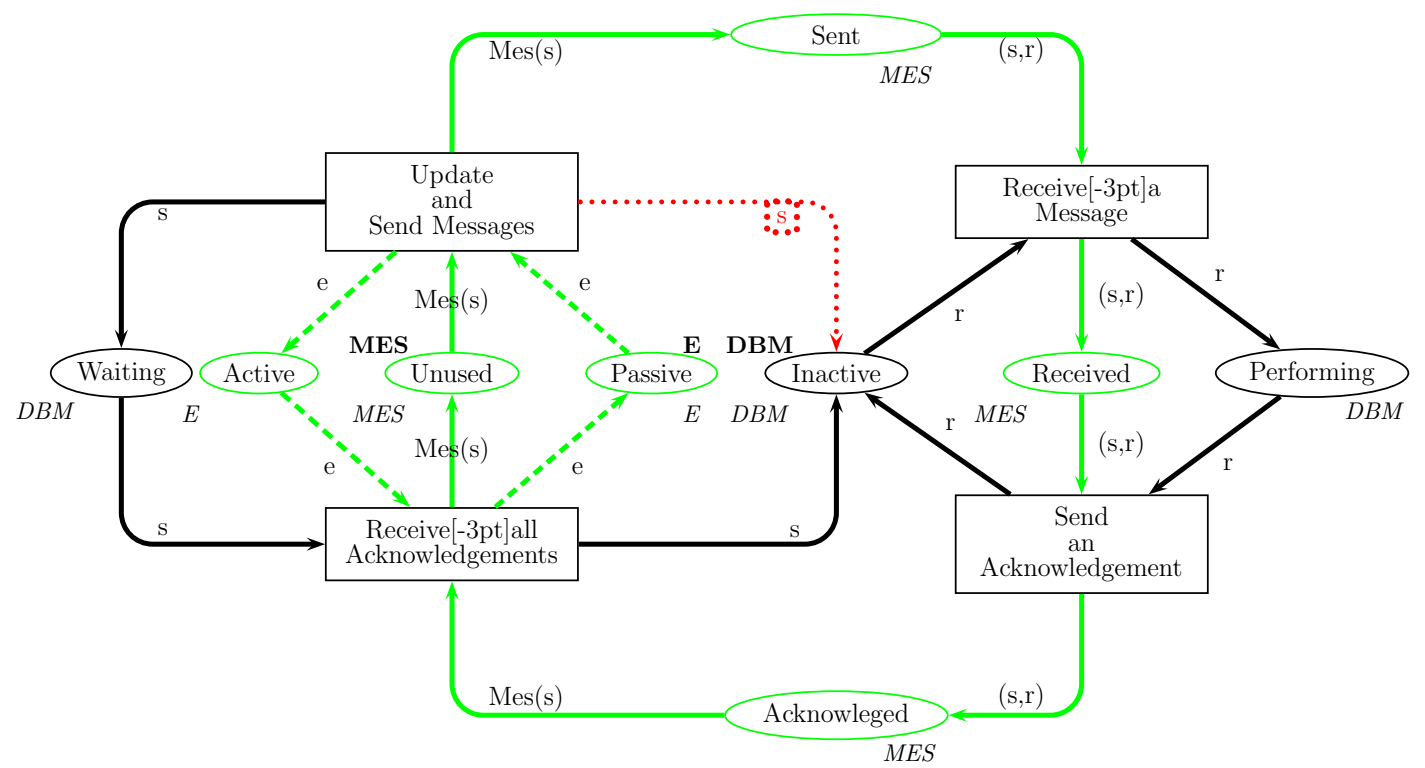

Figura 3.4: Exemplo de Mutante Gerado pelo Operador ArcInversion.

Remoção de Arco Os operadores InputArcDel e OutputArcDel removem cada arco da RPC. 
Na Figura 3.5 é apresentado um mutante gerado pelo operador InputArcDel quando aplicado à RPC da Figura 2.4. Pode-se observar que o arco entre Inactive e $S M$ foi removido.

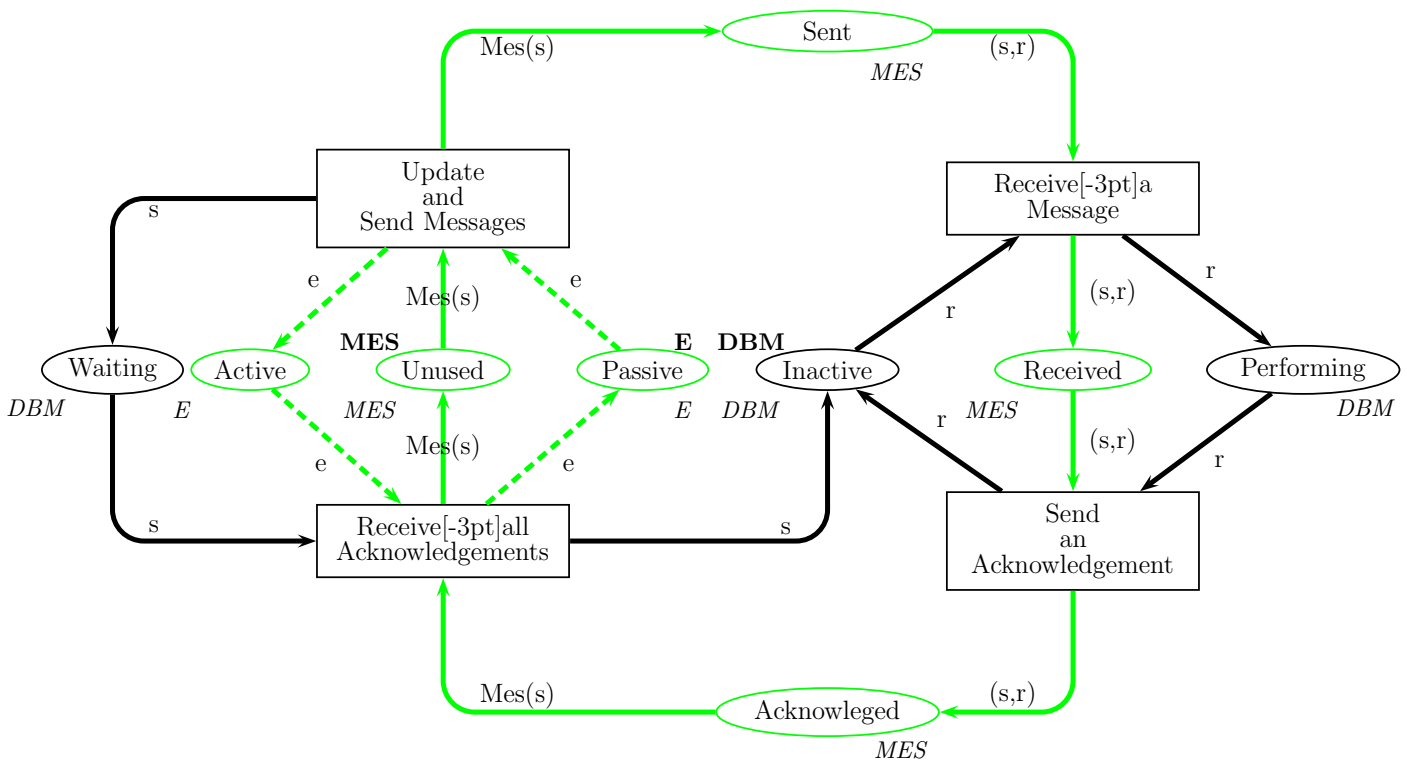

Figura 3.5: Exemplo de Mutante Gerado pelo Operador InputArcDel.

Inserção de Arco Os operadores InputArcIns e OutputArcDel inserem um novo arco na RPC. Considerando-se o operador InputArcIns, para cada par distinto de um lugar e uma transição $(p, t) \in(P \times T)$ de uma determinada página, e para cada anotação de arco distinta $e$ que é associada a um lugar com a mesma cor de $p$, um mutante é gerado por meio da inclusão de um arco que liga $p$ a $t$ com a anotação $e$. Analogamente, considerando-se o operador OutputArcIns, para cada par distinto de um lugar e uma transição $(t, p) \in(T \times P)$ de uma determinada página, e para cada anotação de arco distinta $e$ que é associada a um lugar com a mesma cor de $p$, um mutante é gerado por meio da inclusão de um arco que liga $t$ a $p$ com a anotação $e$.

Na Figura 3.6 é apresentado um mutante gerado pelo operador InputArcIns quando aplicado à RPC da Figura 2.4. Pode-se observar que foi incluído um arco entre Waiting e $R M$ com a anotação $s$.

Troca de Arco Os operadores InputArcExchange e OutputArcExchange trocam o lugar de cada arco da RPC. Considerando-se o operador InputArcExchange, para um arco que liga o lugar $p_{1}$ à transição $t$, o operador gerará um mutante substituindo $p_{1}$ por cada lugar $p_{2}$, tal que $p_{1} \neq p_{2}$ e tanto $p_{1}$ quanto $p_{2}$ possuem a mesma cor, preservando-se a anotação do arco. Analogamente, considerando-se o operador OutputArcExchange, para um arco que liga a transição $t$ a um lugar $p_{1}$, o operador gerará um mutante substituindo $p_{1}$ por cada lugar $p_{2}$, tal que $p_{1} \neq p_{2}$ e tanto $p_{1}$ quanto $p_{2}$ possuem a mesma cor, preservando-se a anotação do arco. 


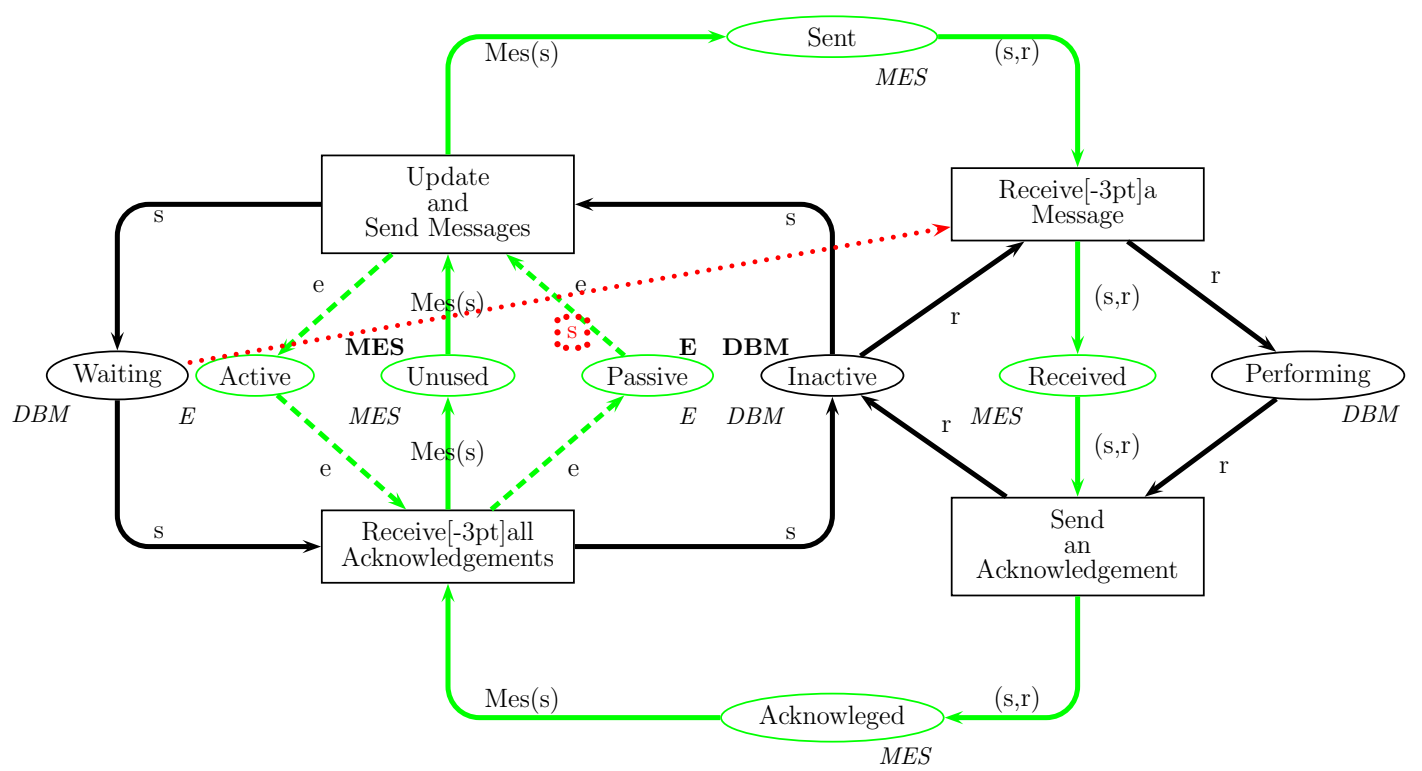

Figura 3.6: Exemplo de Mutante Gerado pelo Operador InputArcIns.

Na Figura 3.7 é apresentado um mutante gerado pelo operador InputArcExchange quando aplicado à RPC da Figura 2.4. Pode-se observar que o arco entre Sent e $R M$ foi trocado pelo arco entre Unused e $R M$, com a mesma anotação $(s, r)$.

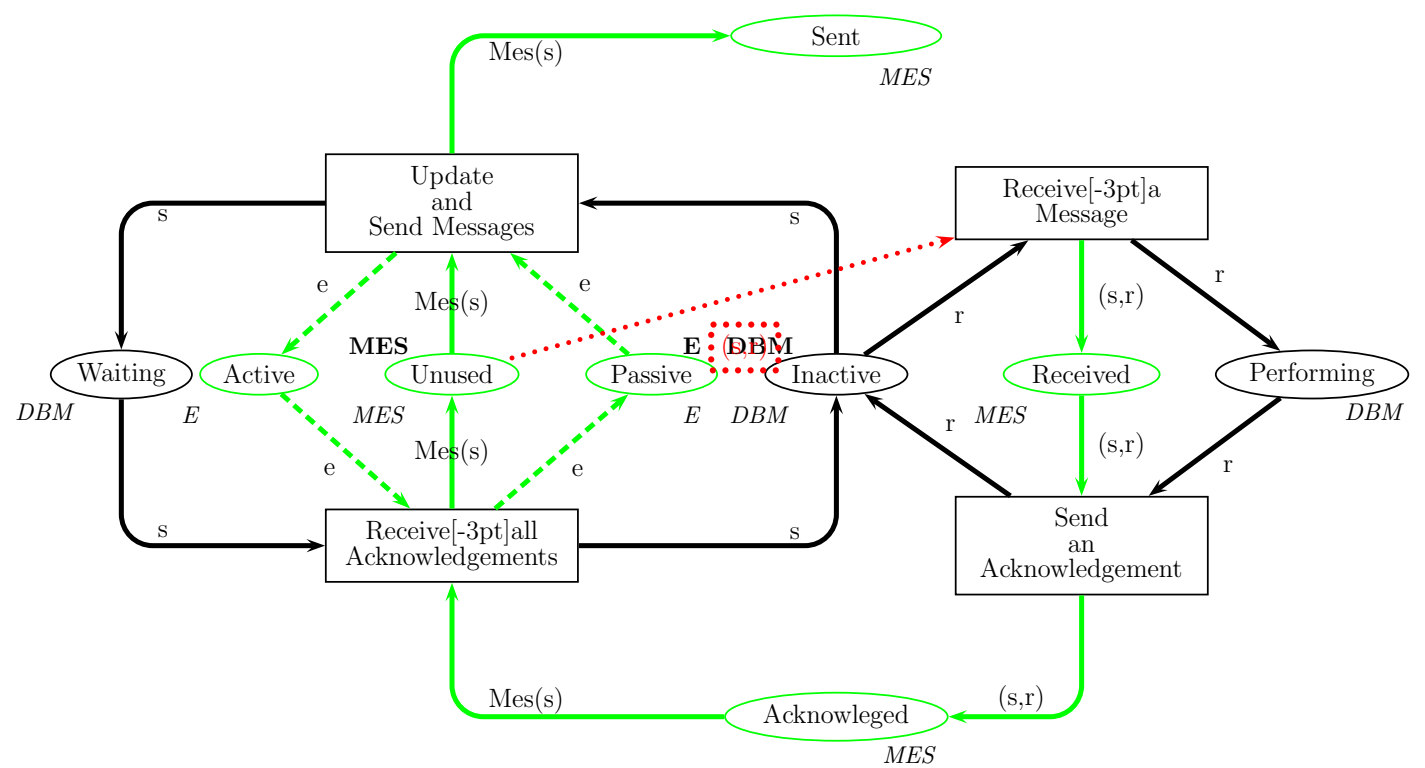

Figura 3.7: Exemplo de Mutante Gerado pelo Operador InputArcExchange.

Deslocamento de Arco Os operadores InputArcShift e OutputArcShift deslocam² a transição de cada arco da RPC. Considerando-se o operador InputArcShift, para cada arco que liga o lugar $p$ à transição $t_{1}$ com uma anotação de arco $e$, o operador gerará um

\footnotetext{
${ }^{2} \mathrm{~A}$ distinção entre esses operadores e os operadores InputArcExchange e OutputArcExchange está no fato de que, nos operadores InputArcShift e OutputArcShift, mantém-se o mesmo lugar, trocando-se a transição, enquanto que nos operadores InputArcExchange e OutputArcExchange, mantém-se a mesma transição, trocando-se o lugar. A escolha entre os termos "trocar" e "deslocar" foi arbitrária, buscando-se fazer uma distinção meramente para fins descritivos.
} 
mutante substituindo $t_{1}$ por cada transição $t_{2}$, tal que $t_{1} \neq t_{2}$ e o conjunto de variáveis em $e$ é um subconjunto da variáveis em $t_{2}$. Analogamente, considerando-se o operador OutputArcShift, para cada arco que liga a transição $t_{1}$ ao lugar $p$ com uma anotação de arco $e$, o operador gerará um mutante substituindo $t_{1}$ por cada transição $t_{2}$, tal que $t_{1} \neq t_{2}$ e o conjunto de variáveis em e é um subconjunto da variáveis em $t_{2}$.

Na Figura 3.8 é apresentado um mutante gerado pelo operador InputArcShift quando aplicado à RPC da Figura 2.4. Pode-se observar que o arco entre Unused e $S M$ foi deslocado para o arco entre Unused e $R M$, com a mesma anotação $M e s(s)$.

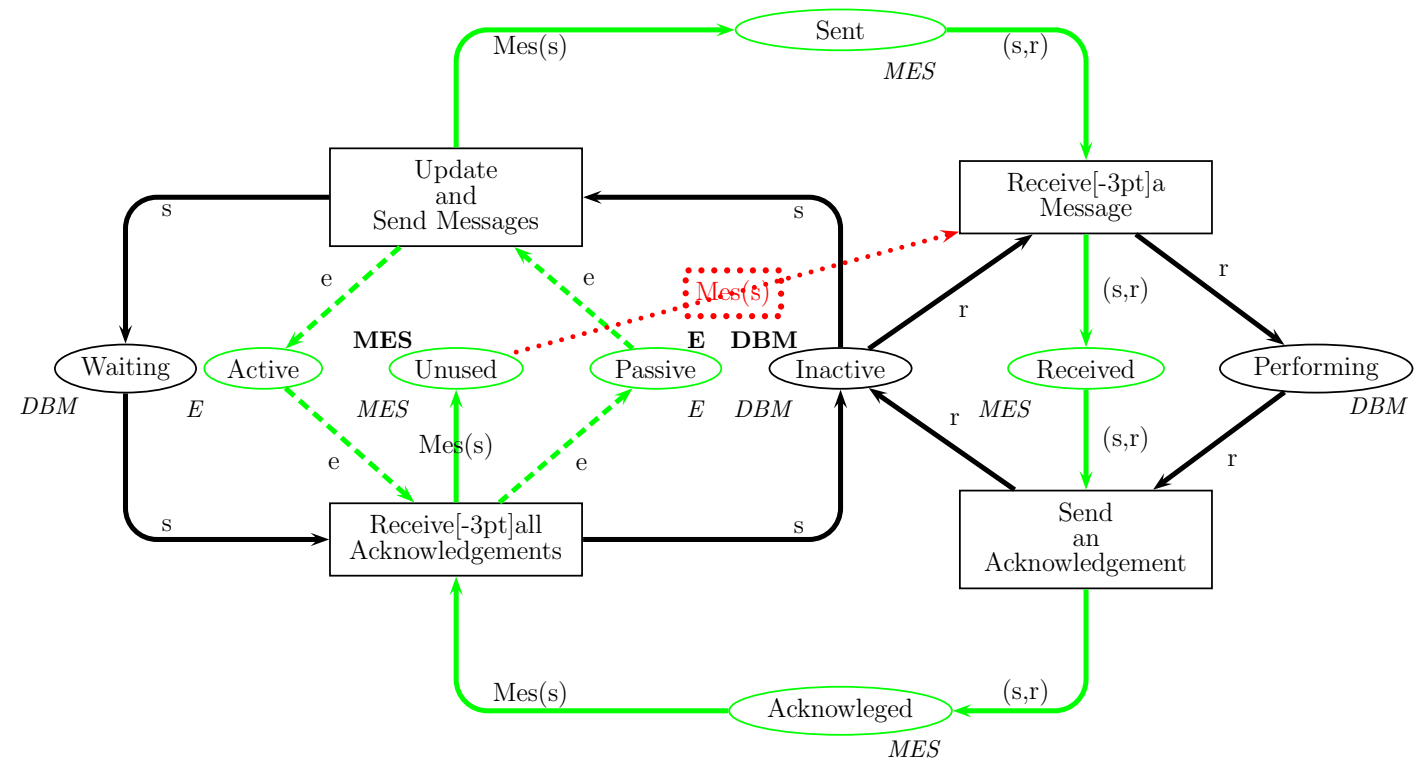

Figura 3.8: Exemplo de Mutante Gerado pelo Operador InputArcShift.

\subsubsection{Alterações nas Variáveis}

Os operadores dessa categoria trocam uma variável que aparece em uma anotação de arco por outra variável da cor correspondente ou por um valor dessa cor.

Substituição de Variáveis O operador VarExchange substitui cada variável que aparece em uma anotação de um arco que liga a uma transição $t$ por outras variáveis da mesma cor, contanto que a nova variável já apareça na anotação de algum arco ligado a $t$.

Na Figura 3.9 é apresentado um mutante gerado pelo operador VarExchange quando aplicado à RPC da Figura 2.4. Pode-se observar que a variável $r$ do arco entre Inactive e $R M$ foi trocado pela variável s.

Substituição de Variáveis por Constantes O operador VarSmall substitui cada variável de uma cor totalmente ordenada com um número finito de elementos pelo primeiro elemento e pelo último. 


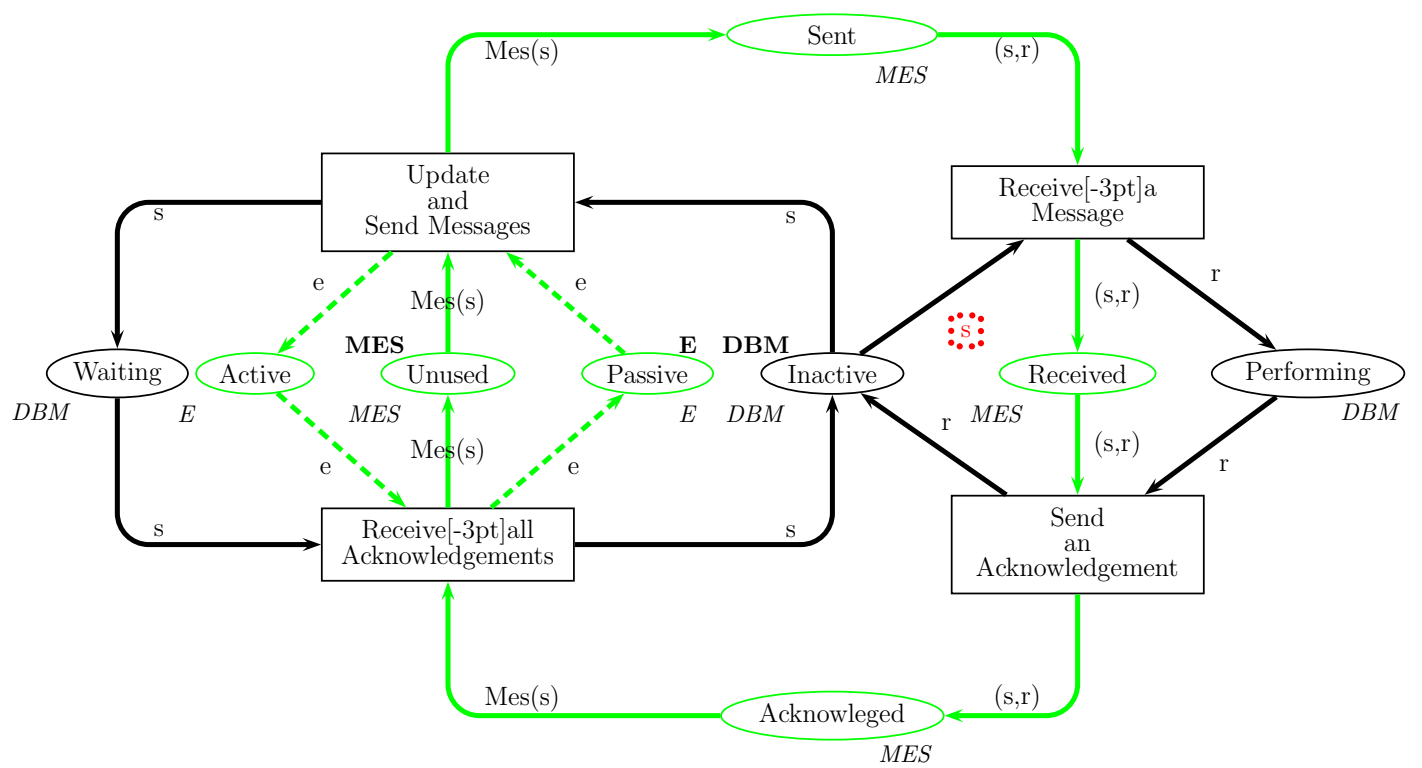

Figura 3.9: Exemplo de Mutante Gerado pelo Operador VarExchange.

Na Figura 3.10 é apresentado um mutante gerado pelo operador VarSmall quando aplicado à RPC da Figura 2.4. Pode-se observar que a variável s do arco entre Sent e $R M$ foi trocado por CPN'last'DBM, que representa o último elemento da cor DBM.

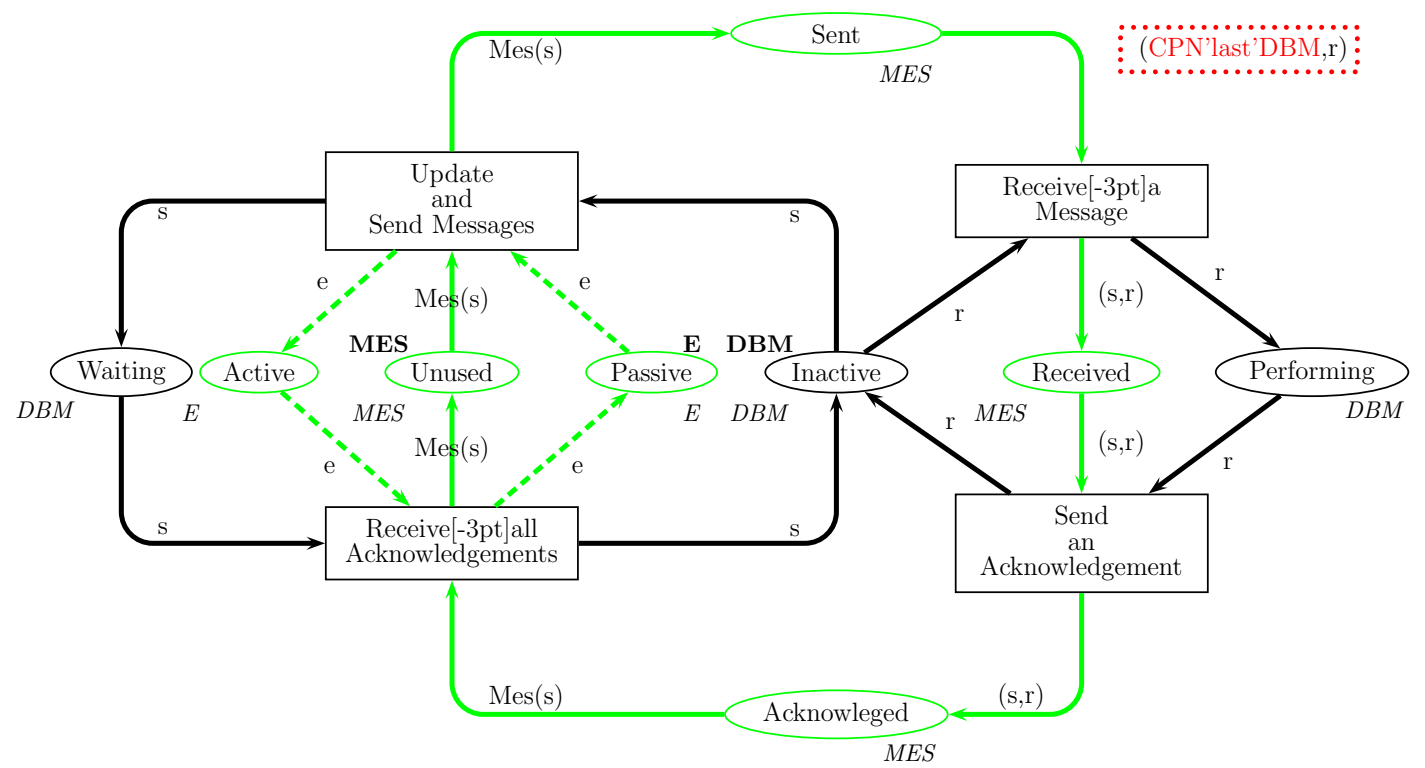

Figura 3.10: Exemplo de Mutante Gerado pelo Operador VarSmall.

\subsubsection{Alterações em Constantes}

Nessa categoria, foi definido um operador, o qual altera os valores contantes que aparecem na RPC. 
Substituição de Constantes O operador ConstExchange troca um valor constante por outro valor constante que aparece na RPC, contanto que ambos os valores sejam da mesma cor. As trocas são realizadas apenas nas anotações dos arcos.

Esse operador não gera mutantes para a RPC da Figura 2.4, uma vez que essa rede não possui valores constantes em anotações de arco.

\subsubsection{Alterações nas Anotações dos Arcos}

Os operadores dessa categoria trocam as expressões dos arcos da RPC.

Substituição da Anotação de Arco O operador AnnotExchange substitui cada anotação de arco por outra do conjunto de anotações da mesma cor. Para evitar a criação de mutantes anômalos, o operador toma o cuidado de não incluir novas variáveis nas transições. Isto é, seja $a$ um arco e seja $t$ a transição à qual $a$ está ligada. Seja $\mathcal{V}$ o conjunto de variáveis que aparecem em qualquer arco ligado a $t$. Assim, uma expressão $e$ pode ser usada para substituir a anotação de arco de $a$ se, e somente se, o conjunto de variáveis em $e$ está contido em $\mathcal{V}$.

Na Figura 3.11 é apresentado um mutante gerado pelo operador AnnotExchange quando aplicado à RPC da Figura 2.4. Pode-se observar que a anotação $(s, r)$ do arco entre Sent e $R M$ foi trocada por $M e s(s)$.

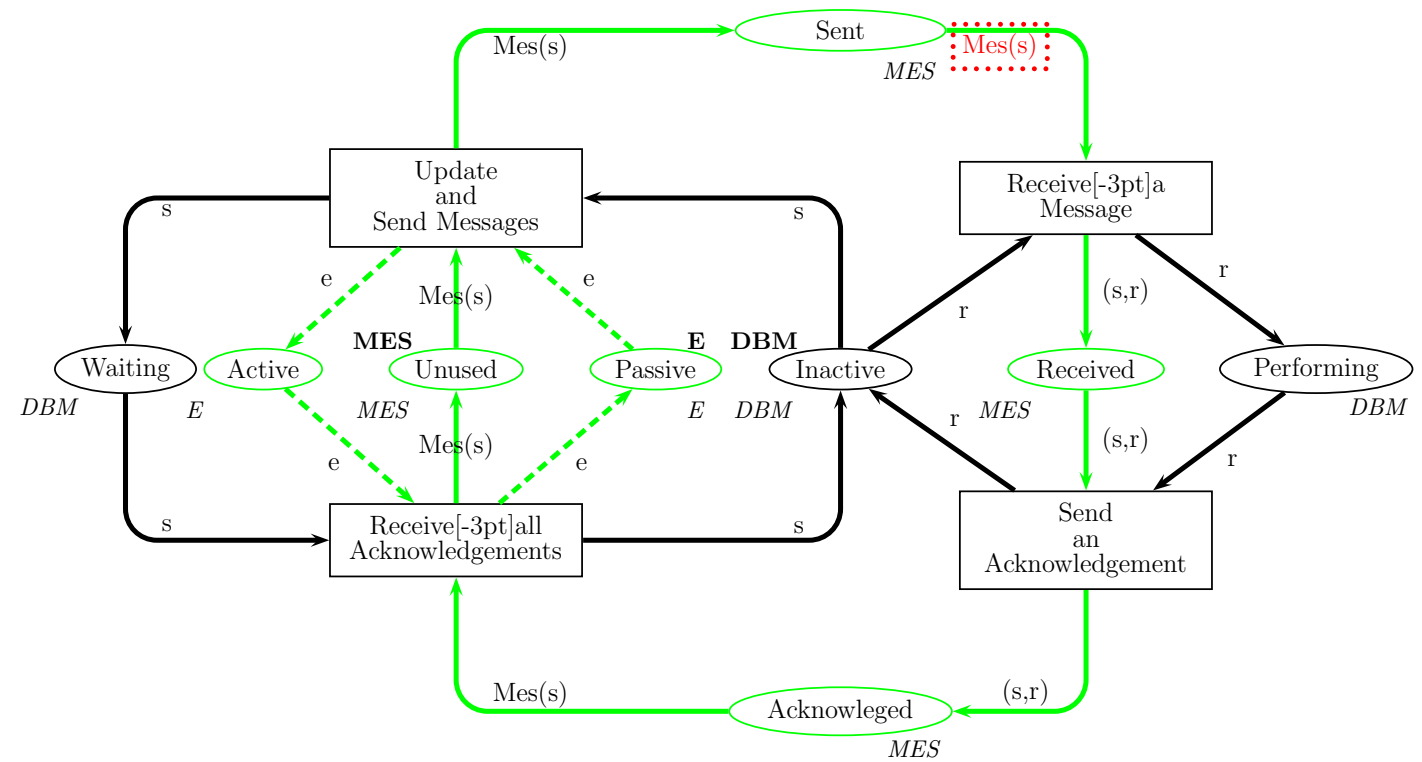

Figura 3.11: Exemplo de Mutante Gerado pelo Operador AnnotExchange.

Substituição de Anotação por Constante O operador AnnotSmall troca cada anotação de arco ligado a uma cor totalmente ordenada e finita pelo primeiro elemento e pelo último elemento dessa cor.

Na Figura 3.12 é apresentado um mutante gerado pelo operador AnnotSmall quando aplicado à RPC da Figura 2.4. Pode-se observar que a anotação $\operatorname{Mes}(s)$ do 
arco entre Acknowleged e $R A$ foi trocado por CPN' last'MES, que é o último elemento da cor $M E S$.

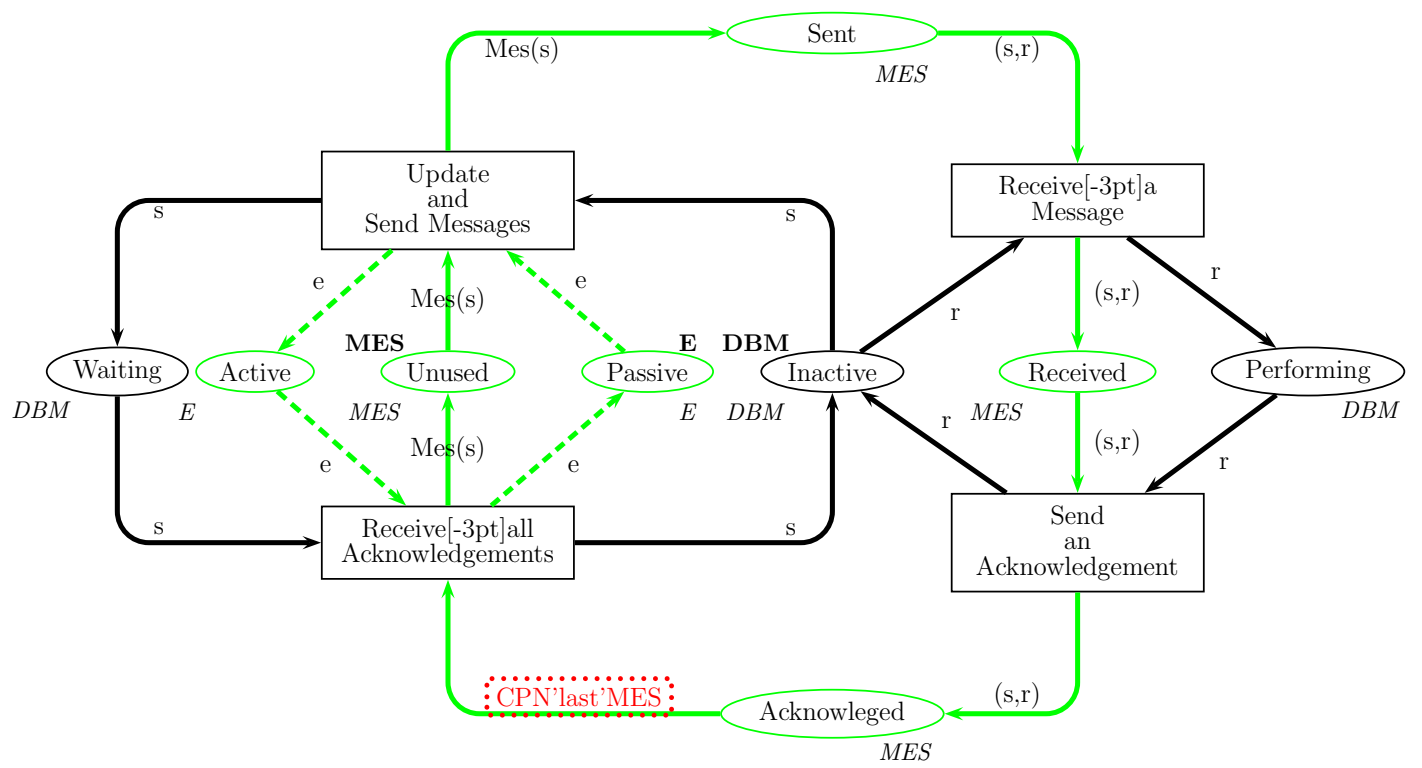

Figura 3.12: Exemplo de Mutante Gerado pelo Operador AnnotSmall.

\subsubsection{Alterações nas Condições de Guarda}

Os operadores dessa categoria trocam a condição de guarda, alterando, dessa forma, o conjunto de transições habilitadas.

Inserção de Condição de Guarda O operador GuardIns insere uma condição de guarda constante para cada transição não-hierárquica da RPC. O valor inserido é igual a false, o que implica que a transição correspondente nunca ficará habilitada.

Na Figura 3.13 é apresentado um mutante gerado pelo operador GuardIns quando aplicado à RPC da Figura 2.4. Pode-se observar que a condição de guarda [false] foi inserida na transição $R M$.

Troca de Condições de Guarda O operador GuardExchange troca a condição de guarda de cada transição não-hierárquica pela condição de guarda das demais transições.

Esse operador não gera mutantes para a RPC da Figura 2.4, uma vez que essa rede não possui condições de guarda.

Inversão da Condição de Guarda O operador GuardInv troca cada condição de guarda por sua negação lógica.

Esse operador não gera mutantes para a RPC da Figura 2.4, uma vez que essa rede não possui condições de guarda. 


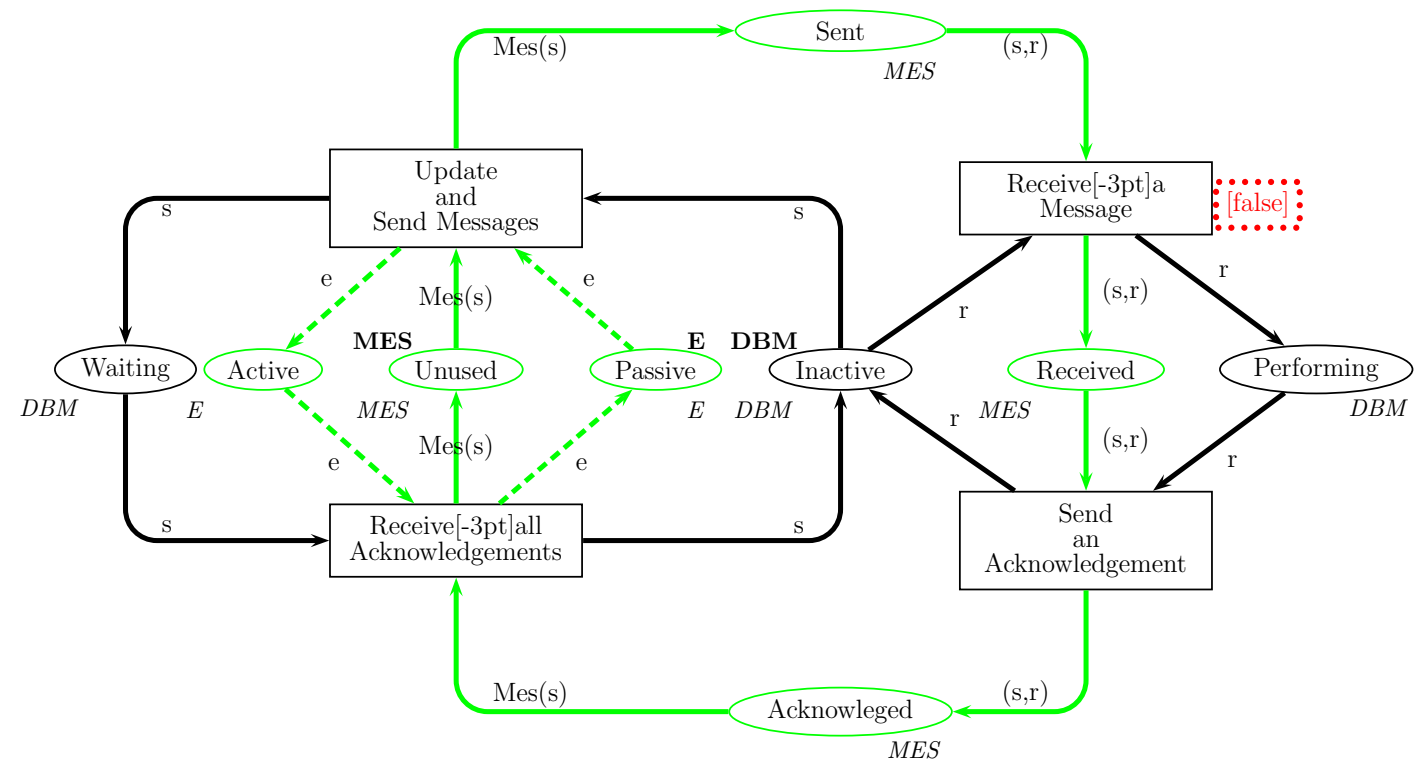

Figura 3.13: Exemplo de Mutante Gerado pelo Operador GuardIns.

\subsubsection{Alterações nos Operadores}

Os operadores dessa categoria trocam os operadores encontrados nas expressões da RPC. São consideradas as expressões que aparecem nas anotações dos arcos, nas expressões de inicialização e nas condições de guarda.

Esses operadores não geram mutantes para a RPC da Figura 2.4, uma vez que essa rede não possui expressão envolvendo operadores.

Troca de Operadores Relacionais O operador OpRelRel troca um operador relacional por outro. Devido às regras de tipagem da linguagem CPN-ML, os operadores de igualdade/desigualdade (isto é, os operadores $=$ e $<>$ ) são substituídos apenas um pelo outro, ao passo que os demais operadores (isto é, os operadores $<,<=$, $>$ e $>=$ ) são trocados por todos os demais, incluindo os de igualdade/desigualdade.

Troca de Operadores Relacionais para Multi-Conjuntos O operador OpMultRelRel troca cada operador relacional de multi-conjunto (isto é, os operadores $==,\langle>\langle>\rangle\rangle\rangle,\rangle=$, $<<$ e $<<=)$ pelos demais.

Troca de Operadores Aritméticos $\mathrm{O}$ operador OpArithArith troca cada operador aritmético (isto é, os operadores +, -, /, *, div e mod) pelos demais.

Troca de Operadores Lógicos O operador OpLogLog troca cada operador lógico (isto é, os operadores andalso e orelse) pelo outro.

Troca de Expressões if-then-else O operador OpIfInv troca a expressão de controle da uma expressão if-then-else por sua negação lógica. 
Troca de Operadores Aritméticos para Multi-Conjuntos O operador OpMultArithArith troca cada operador de adição/subtração de multi-conjuntos (isto é, os operadores ++ e --) pelo outro.

\subsection{Execução e Análise dos Mutantes: Relação de Equi- valência}

Após executar a RPC original com uma seqüência de teste $s q$ e aceitar o comportamento da RPC para essa seqüência, deve-se executar cada uma das redes mutantes e analisar se o resultado obtido por cada uma delas é equivalente ao resultado obtido pela rede original. Dessa forma, um ponto importante as ser definido para permitir a aplicação da AM nesse contexto é o estabelecimento do conceito de equivalência de resultados.

Ao se dispararem as ligações de uma seqüência $s q$ em uma RPC, podem ocorrer duas situações:

orig.1 A seqüência é habilitada na marcação inicial $\mu_{0}$ e, após a execução, obtém-se uma marcação resultante $\mu_{f}$.

orig.2 A seqüência não é habilitada na marcação inicial.

Se não estiver habilitada na marcação inicial, uma seqüência não poderá ser utilizada na simulação. Portanto, somente serão consideradas como casos de teste as seqüências que estão habilitadas na marcação inicial (correspondente ao primeiro caso). Por outro lado, ao se disparar a mesma seqüência de teste $s q$ em uma rede mutante $M$, pode-se igualmente obter dois resultados, tratados a seguir.

\subsubsection{Seqüência Habilitada}

Considerando-se que a seqüência é habilitada na marcação inicial $\mu_{0}^{M}$ e, após a execução, obtém-se uma marcação resultante $\mu_{f}^{M}$, a forma mais simples de comparação seria verificar se, para cada $p \in P, \mu_{f}(p)=\mu_{f}^{M}(p)$. Ou seja, se o conteúdo de cada lugar é o mesmo para cada lugar da rede. No entanto, podem existir casos nos quais um lugar não é relevante para comparar o comportamento da rede, como, por exemplo, quando se trata de um lugar incluído apenas para representar algum estado interno do sistema, sem refletir uma condição externa do sistema. Assim, outras formas de comparação podem ser utilizadas.

Na proposta apresentada neste trabalho, o conteúdo de cada lugar nas marcações resultantes pode ser mapeado antes da comparação. Dessa forma, as marcações serão equivalentes se, para cada $p \in P$, tem-se que

$$
\delta_{p}\left(\mu_{f}(p)\right)=\delta_{p}\left(\mu_{f}^{M}(p)\right)
$$


As funções $\delta_{p}$ podem ser definidas de forma a refletir a relação de equivalência desejada. Propõem-se cinco possibilidades para $\delta_{p}$, apresentadas a seguir:

Equality: Corresponde à função identidade.

Ao se utilizar essa relação de equivalência, os multi-conjuntos serão comparados diretamente, sem alterações.

Contents: Os multi-conjuntos são mapeados em uma forma padrão, na qual as múltiplas ocorrências de elementos são ignoradas.

Por exemplo, tanto $1^{\prime} a++3^{\prime} b$ quanto $2^{\prime} a++2^{\prime} b$ serão mapeados em $1^{\prime} a++1^{\prime} b$. Assim, Contents $\left(1^{\prime} a++3^{\prime} b\right)=$ Contents $\left(2^{\prime} a++2^{\prime} b\right)$.

Essa relação de equivalência pode ser utilizada, por exemplo, quando um lugar representa um recurso do sistema modelado e se está interessado apenas na natureza de recurso presente, não importando a quantidade de cada um.

Cardinality: Os multi-conjuntos são mapeados no número de elementos que possuem.

Por exemplo, tanto $1^{\prime} a++3^{\prime} b$ quanto $2^{\prime} a++1^{\prime} b++1^{\prime} c$ serão mapeados em 4 . Assim, Cardinality $\left(1^{\prime} a++3^{\prime} b\right)=$ Cardinality $\left(2^{\prime} a++1^{\prime} b++1^{\prime} c\right)$.

Essa relação de equivalência pode ser utilizada, por exemplo, quando se está interessado apenas na quantidade de elementos que está presente em um lugar, não importando a natureza de cada elemento.

Emptiness: Um multi-conjunto é mapeado em 0, se não possuir elementos (isto é, se for vazio), ou em 1, caso contrário.

Dessa forma, apenas compara-se se os multi-conjuntos são ambos vazios ou ambos não-vazios.

Essa relação de equivalência pode ser utilizada, por exemplo, quando um lugar representa uma condição do sistema modelado e se está interessado apenas em saber se a condição está ou não satisfeita.

Ignore: Qualquer multi-conjunto é mapeado em 1.

Assim, o conteúdo do lugar é ignorado.

Essa relação de equivalência pode ser utilizada para indicar que o conteúdo de um lugar não deve influenciar na decisão sobre se o mutante continuará ou não vivo.

A utilização de uma ou outra função depende de considerações as serem feitas para cada sistema em particular. Além disso, para alguns sistemas, pode ser necessária a definição de outras funções que capturem detalhes importantes do domínio. Outro ponto a destacar é que funções distintas podem ser utilizadas para cada lugar da RPC. 


\subsubsection{Seqüência Não-Habilitada}

Considerando-se que a seqüência não está habilitada na marcação inicial $\mu_{0}^{M}$, pode-se adotar três alternativas:

1. Considerar que o mutante foi morto pelo caso de teste.

Assume-se que, quando a seqüência não está habilitada a disparar, o comportamento do mutante é diferente da rede original. Deve-se observar que a utilização dessa alternativa equivale a Mutação Fraca (Howden, 1982), pois o mutante é considerado morto independentemente de o efeito da mutação propagar-se ou não até a marcação final.

2. Ignorar a ligação que não está habilitada e continuar com a execução das demais ligações da seqüência.

Dessa forma, sempre se obtém uma marcação resultante para o mutante, a qual é comparada com a marcação resultante da rede original. Formalmente, deve-se alterar a regra de execução da seguinte forma. Sejam $\mu$ uma marcação e $b$ uma ligação. Se $b$ está habilitada em $\mu$, então a marcação resultante será $\mu^{\prime}$, tal que $\mu[b\rangle \mu^{\prime}$. Se $b$ não está habilitada em $\mu$, então a marcação resultante será a própria $\mu$.

3. Considerar que o mutante permanece vivo.

Nesse caso, um mutante só será morto se a sequiência também estiver habilitada e as marcações resultantes não forem equivalentes (no sentido discutido anteriormente).

Novamente, a utilização de uma ou outra alternativa depende de considerações sobre as particularidades de cada sistema.

\subsection{Complexidade dos Operadores}

Nesta seção, os operadores definidos para RPCs são analisados com relação a complexidade de cada um. A complexidade foi determinada em função do número máximo de mutantes que podem ser gerados para uma RPC particular.

\subsubsection{Alterações na Marcação Inicial}

Seja $P_{v}$ o conjunto de lugares cujas expressões de inicialização são vazias. Seja $P_{n v}$ o conjunto de lugares cujas expressões de inicialização não são vazias. Deve-se observar que esses dois conjuntos particionam o conjunto de lugares da rede, ou seja, $P_{v} \cup P_{n v}=P$ e $P_{v} \cap P_{n v}=\emptyset$.

Remoção de Marcação Inicial: O operador InitMarkDel gerará um mutante para cada lugar $p \in P_{n v}$. Assim, esse operador gerará $\left|P_{n v}\right|$ mutantes. 
Inserção de Marcação Inicial: $O$ operador InitMarkIns gerará um mutante para cada lugar $p \in P_{v}$. Assim, esse operador gerará $\left|P_{v}\right|$ mutantes.

Observa-se que os operadores InitMarkDel e InitMarkIns geram, quando aplicados conjuntamente, um mutante para cada lugar da rede, ou seja, geram $|P|$.

Troca de Marcação Inicial: O operador InitMarkExchange gerará um mutante para cada lugar $p \in P_{n v}$ e para cada expressão de inicialização distinta de lugares $p^{\prime} \in P_{v}$. Esse operador gerará no máximo $\left|P_{v}\right| *\left|P_{n v}\right|$ mutantes. A quantidade máxima de mutantes é obtida quando todas as expressões de inicialização são distintas entre si e $\left|P_{v}\right|=\left|P_{n v}\right|=\frac{|P|}{2}$. Assim, o limite superior no número de mutantes é $\frac{|P|^{2}}{4}$.

Dessa forma, os operadores dessa categoria gerarão no máximo $\frac{|P|^{2}}{4}+|P|$ mutantes.

\subsubsection{Alterações nos Arcos}

Os operadores dessa categoria foram subdivididos entre operadores sobre os arcos de entrada e operadores sobre os arcos de saída. Nas análises a seguir, é considerado cada par de operador. Por comodidade, agrupa-se cada par de operador utilizando-se um * para representar tanto Input como Output. Por exemplo, *ArcInversion representa os operadores InputArcInversion e OutputArcInversion.

Seja $E$ o conjunto de anotações de arcos da rede. Deve-se observar que o número máximo de anotações distintas da rede é o número de arcos da rede. Ou seja, $|E| \leq|A|$.

Inversão de Arco: Os operadores *ArcInversion gerarão um mutante para cada arco da rede. Assim, esses operadores gerarão, conjuntamente, $|A|$ mutantes.

Remoção de Arco: Os operadores *ArcDel gerarão um mutante para cada arco da rede. Assim, esses operadores gerarão, conjuntamente, $|A|$ mutantes.

Inserção de Arco: Os operadores *ArcIns gerarão dois mutantes para cada transição $t \in T$, para cada lugar $p \in P$ e para cada anotação de arco $e \in E$ que seja da mesma cor de $p$. Assim, esses operadores gerarão no máximo $2 *|T| *|P| *|E|$ mutantes. A quantidade máxima de mutantes é obtida quando todos os lugares possuem a mesma cor. Pode-se então verificar que serão gerados no máximo $2 *|T| *|P| *|A|$ mutantes.

Troca de Arco: Os operadores *ArcExchange gerarão um mutante para cada arco $a \in$ $A$, para cada lugar $p \in P$ e para cada anotação de arco $e \in E$. Assim, esses operadores gerarão no máximo $|A| *|P| *|E|$ mutantes. A quantidade máxima de mutantes é obtida quando todos os lugares possuem a mesma cor. Pode-se então verificar que serão gerados no máximo $|A|^{2} *|P|$ mutantes. 
Deslocamento de Arco: Os operadores *ArcShift gerarão um mutante para cada arco $a \in A$, para cada transição $t \in T$ e para cada anotação de arco $e \in E$. Assim, esses operadores gerarão no máximo $|A| *|T| *|E|$ mutantes. Pode-se então verificar que serão gerados no máximo $|A|^{2} *|T|$ mutantes.

Dessa forma, os operadores dessa categoria gerarão no máximo $|A| *(2+2 *|T| *$ $|P|+|A| *|T|+|A| *|P|)$ mutantes.

\subsubsection{Alterações nas Variáveis}

Seja $V$ o conjunto de variáveis da rede. Seja $V_{s}$ o conjunto de variáveis cuja cor é finita e totalmente ordenada.

Substituição de Variáveis: O operador VarExchange gerará no máximo $|V| *(|V|-1)$ mutantes. A quantidade máxima de mutantes é obtida quando todas variáveis possuem a mesma cor.

Substituição de Variáveis por Constantes: O operador VarSmall gerará no máximo $2 *\left|V_{s}\right|$ mutantes. A quantidade máxima de mutantes é obtida quando todas variáveis possuem uma cor finita e totalmente ordenada.

Dessa forma, os operadores dessa categoria gerarão no máximo $|V| *(|V|+1)$ mutantes.

\subsubsection{Alterações em Constantes}

Seja $C$ o conjunto de valores constantes de uma rede.

Substituição de Constantes: O operador ConstExchange gerará no máximo $|C| *$ $(|C|-1)$ mutantes.

\subsubsection{Alterações nas Anotações dos Arcos}

Seja $|E|$ o conjunto de anotações de arcos de uma rede. Seja $\left|E_{s}\right|$ o conjunto de anotações de arcos de uma rede cujas cores são finitas e totalmente ordenadas.

Substituição da Anotação de Arco: O operador AnnotExchange gerará no máximo $|E| *(|E|-1)$ mutantes. A quantidade máxima de mutantes é obtida quando todos os lugares (e, conseqüentemente, todas as anotações de arco) possuem a mesma cor.

Substituição de Anotação por Constante: O operador AnnotSmall gerará $2 *\left|E_{s}\right|$ mutantes. A quantidade máxima de mutantes é obtida quando os lugares (e, conseqüentemente, todas as anotações de arco) possuem uma cor finita e totalmente ordenada. 
Dessa forma, os operadores dessa categoria gerarão no máximo $|E| *(|E|+1)$ mutantes.

\subsubsection{Alterações nas Condições de Guarda}

Seja $T_{g}$ o conjunto de transições com condição de guarda. Seja $T_{n g}$ o conjunto de transições que não possuem condição de guarda. Deve-se observar que $T_{g}$ e $T_{n g}$ particionam o conjunto de transições, ou seja, $T_{g} \cup T_{n g}=T$ e $T_{g} \cap T_{n g}=\emptyset$.

Inserção de Condição de Guarda: O operador GuardIns gerará um mutante para cada transição $t \in T_{n g}$. Assim, esse operador gerará $\left|T_{n g}\right|$ mutantes.

Troca de Condições de Guarda: O operador GuardExchange gerará um mutante para cada transição $t \in T_{g}$ e para cada transição $t^{\prime} \in T_{n g}$. Assim, esse operador gerará $\left|T_{g}\right| *\left|T_{n g}\right|$ mutantes. A quantidade máxima de mutantes é gerada quando $\left|T_{g}\right|=\left|T_{n g}\right|=\frac{|T|}{2}$. Portanto, esse operador gerará, no pior caso, $\frac{|T|^{2}}{4}$.

Inversão da Condição de Guarda: O operador GuardInv gerará um mutante para cada transição $t \in T_{g}$. Assim, esse operador gerará $\left|T_{g}\right|$ mutantes.

Dessa forma, os operadores dessa categoria gerarão no máximo $|T|+\frac{|T|^{2}}{4}$ mutantes.

\subsubsection{Alterações nos Operadores}

O número de mutantes gerados pelos operadores de mutação dessa categoria é determinado pela quantidade de vezes que os respectivos operadores aparecem na rede. Contudo, esse número é sempre linear em função da quantidade de operadores.

Troca de Operadores Relacionais: O operador OpRelRel gerará $5 *$ numOpRel mutantes, onde numOpRel é o número de operadores relacionais existentes na rede.

Troca de Operadores Relacionais para Multi-Conjuntos: Sendo numMultOpRel o número de operadores relacionais de multi-conjuntos existentes na rede, o operador OpMultRelRel gerará $5 *$ numMultOpRel mutantes.

Troca de Operadores Aritméticos: Sendo numOpArith o número de operadores aritméticos existentes na rede, o operador OpArithArith gerará $5 *$ numOpArith mutantes.

Troca de Operadores Lógicos: O operador OpLogLog gerará numOpLog mutantes, onde numOpLog é o número de operadores lógicos existentes na rede.

Troca de Expressões if-then-else: O operador OpIfInv gerará numITE mutantes, onde numITE é o número de expressões if-then-else existentes na rede. 
Troca de Operadores Aritméticos para Multi-Conjuntos: O operador OpMultArithArith gerará numMultOpArith mutantes, onde numMultOpArith é o número de operadores aritméticos para multi-conjuntos existentes na rede.

Dessa forma, os operadores dessa categoria gerarão $5 *$ (numOpRel + numMultOpRel +numOpArith $)+$ numOpLog + numITE + numMultOpArith mutantes.

Considerando-se todos os operadores de todas as categorias, pode ser observado que a complexidade dos operadores é, no máximo, quadrática em função dos elementos da rede. Dessa forma, do ponto de vista teórico, o número de mutantes gerados é tratável. Contudo, é necessário a avaliação empírica com diversas RPCs para observar como os operadores comportam-se na prática. Um estudo de caso nessa direção é apresentado no Capítulo 6.

\subsection{Descrição de Operadores de Mutação}

Uma vez definido um conjunto de operadores de mutação, o passo seguinte é a implementação de uma forma que permita a geração dos mutantes para um produto particular. Além disso, o conjunto de operadores de mutação deve ser avaliado e evoluído para melhorar sua adequação em relação à linguagem em questão. Outra questão importante a ser considerada nesse contexto é que, dado o já mencionado impacto na eficácia da AM, os operadores de mutação devem ser definidos de forma precisa.

Neste trabalho, propõe-se a linguagem $\mathcal{M} u \mathcal{D} e \mathcal{L}$ (MUtant DEscription Language), desenvolvida para descrever operadores de mutação. A linguagem foi projetada com conceitos dos paradigmas de programação transformacional e lógico. Seu projeto possui três motivações:

1. fornecer uma maneira precisa e não ambígua para descrever mutantes, possibilitando, dessa forma, o compartilhamento de operadores de mutação entre diferentes trabalhos;

2. fornecer uma maneira de compilar as descrições em mutantes efetivos na linguagem alvo, possibilitando que o projetista do operador possa validar a descrição e, potencialmente, melhorá-la. Para apoiar esse aspecto, foi implementado o sistema mudelgen, descrito na Seção 5.4.1. Dada uma descrição de operador de mutação e um produto original, o sistema mudelgen compila a descrição e gera os mutantes, com base em uma gramática livre de contexto do produto original; e

3. facilitar o reúso de operadores de mutação definidos para diferentes linguagens, fornecendo uma visão abstrata das mutações. Por exemplo, apesar de possuírem gramáticas concretas distintas, linguagens como C e Java apresentam construções similares, e, por meio da definição cuidadosa de suas gramáticas e dos operadores de mutação, esses podem ser reusados. 
Deve-se observar que, apesar de ter sido motivada pela necessidade de descrição de operadores para RPCs, a $\mathcal{M} u \mathcal{D} e \mathcal{L}$ foi definida buscando-se criar um mecanismo genérico que possa ser utilizado para outras linguagens alvo. De fato, a $\mathcal{M} u \mathcal{D} e \mathcal{L}$ foi utilizada para a descrição de operadores de mutação para as linguagens Java, C, C++ e SML.

Nesta seção, é apresentada uma introdução informal à linguagem, ilustrando-se as construções que a compõem. No Apêndice $\mathrm{B}$, a semântica da linguagem $\mathcal{M} u \mathcal{D} e \mathcal{L}$ é descrita usando Semântica Denotacional (Allison, 1986; Stoy, 1977).

\subsubsection{A Linguagem $\mathcal{M} u \mathcal{D} e \mathcal{L}$}

\subsubsection{Requisitos}

Como dito anteriormente, a AM tem sido aplicada em diversos contextos e para diversas linguagens. Em cada caso, os defeitos a serem modelados pelos operadores de mutação são dependentes do contexto/linguagem em questão. A linguagem $\mathcal{M} u \mathcal{D} e \mathcal{L}$ foi projetada com o objetivo de satisfazer a três requisitos básicos:

- O número de mutantes que pode ser gerado é infinito. Considerando um produto original, quase qualquer outro produto na mesma linguagem pode ser considerado como um mutante, devido à definição ampla e informal de "pequenas alterações sintáticas" necessárias para gerar um mutante. Para manter o número de mutantes em um nível computacionalmente tratável, apenas mutantes com alterações simples são consideradas. Uma alteração é considerada simples se ela não pode ser decomposta em alterações mais simples e menores. Por essa razão, para descrever um operador de mutação, somente uma alteração é, em geral, definida. Contudo, em alguns casos, uma única alteração lógica implica alterar mais de um lugar do produto. Por exemplo, um operador de mutação para intercambiar duas constantes em um programa em $\mathrm{C}$ precisa indicar duas alterações distintas, ainda que relacionadas, sendo uma em cada local em que as constantes ocorrem.

- Existem várias similaridades entre diferentes linguagens (por exemplo, entre os modelos de controle das linguagens $\mathrm{C}$ e $\mathrm{C}++$ ), e os defeitos que lidam com porções similares podem ser modelados abstratamente pelo mesmo operador conceitual. Apesar de existirem diferenças entre os tipos de defeitos representados pelo operador de mutação, características comuns podem ser identificadas. Uma linguagem projetada para descrever operadores de mutação deve, dessa forma, incorporar essas características comuns e fornecer meios para indicar as características particulares.

- Em geral, a partir de um único produto original, um operador de mutação gera vários mutantes. Por exemplo, um operador de mutação que troca a estrutura de controle do tipo for em outra estrutura gerará tantos mutantes quantos forem o número de comandos for que existirem no produto original. Dessa forma, o 
comportamento "default" de um operador de mutação é aplicar as trocas em todos os pontos aplicáveis.

\subsubsection{Notação Básica}

A linguagem $\mathcal{M} u \mathcal{D} e \mathcal{L}$ utiliza conceitos da Teoria de Gramáticas Livres de Contexto. Uma descrição sucinta desses conceitos é incluída no Apêndice A. Uma discussão aprofundada pode ser encontrada em (Salomaa, 1973).

É introduzido um conjunto de meta-variáveis $\mathcal{M}$ e as árvores sintáticas são estendidas para permitir que os nós folhas possam ser, além de símbolos terminais, meta-variáveis. Além disso, nessa extensão, o nó raiz pode ser qualquer símbolo não-terminal (não apenas o símbolo inicial). Essa extensão é denominada de padrões de árvore, ou, se não houver ambigüidade no contexto, somente padrões. A cada meta-variável está associado um símbolo não-terminal, que caracteriza seu tipo. Uma meta-variável pode estar livre ou ligada. Toda variável ligada está associada a uma subárvore que pode ser produzida a partir de seu tipo. Dessa forma, uma árvore sintática pode ser considerada como um caso especial de padrão de árvore, no qual todas as meta-variáveis (se houver) estão ligadas. Na Figura 3.14 é apresentado um exemplo de um padrão de árvore. Como uma forma para distingui-las de identificadores usuais, as meta-variáveis são prefixadas com dois pontos “:". Mesmo na presença de meta-variáveis, os nós filhos de um nó precisam estar de acordo com suas regras de produção. Em outras palavras, uma meta-variável pode ocorrer somente em pontos nos quais um não-terminal do seu tipo também pudesse.

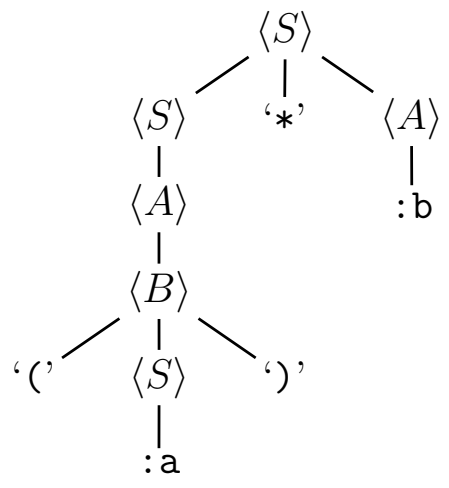

Figura 3.14: O Padrão de Árvore para '( :a ) * :b'. Os Tipos de ':a' e ':b' São Definidos como $\langle A\rangle$ e $\langle B\rangle$, Respectivamente.

Para especificar padrões, é utilizada a seguinte notação. O padrão mais simples é formado por uma meta-variável anônima como sua raiz. Esse padrão é expresso pelo símbolo não-terminal entre colchetes. Por exemplo, $[\mathrm{A}]$ é um padrão cujo nó raiz é uma meta-variável anônima do tipo $\langle A\rangle$. Alternativamente, pode-se expressar um padrão mais complexo colocando-se o símbolo raiz entre colchetes, como anteriormente, mas seguido de uma seqüência de símbolos terminais e meta-variáveis entre " $<$ " e ">", a qual deve ser analisada para gerar o padrão de árvore. Por exemplo, o padrão de árvore da Figura 3.14 é 
denotada por $[S<(: a) *: b>]$. Deve ser observado que, dentro da seqüência que caracteriza o produto, a gramática do produto, e não a gramática da linguagem $\mathcal{M} u \mathcal{D} e \mathcal{L}$, é que deve ser respeitada. Contudo, as meta-variáveis vêm da própria $\mathcal{M} u \mathcal{D} e \mathcal{L}$ e, dessa forma, o padrão anterior apenas será válido se as meta-variáveis :a e :b são declaradas com os tipos adequados.

\subsubsection{Casamento de Padrões e Substituições}

Existem duas operações principais na linguagem $\mathcal{M} u \mathcal{D} e \mathcal{L}$ : casamento de padrões e substituições. Para o casamento de padrões, tenta-se unificar dois padrões de árvore $c$ e $m$, usando-se um algoritmo de unificação semelhante ao utilizado em Prolog (Bratko, 1990). Um casamento de padrões pode resultar em falha ou sucesso. No caso de sucesso, as meta-variáveis nos padrões de árvore são unidas a outras árvores ou a outras meta-variáveis, de uma maneira que faz com que sejam irrestritamente intercambiáveis. No caso de falha, nenhuma unificação ocorre. O processo de casamento de padrões é ilustrado na Figura 3.15.

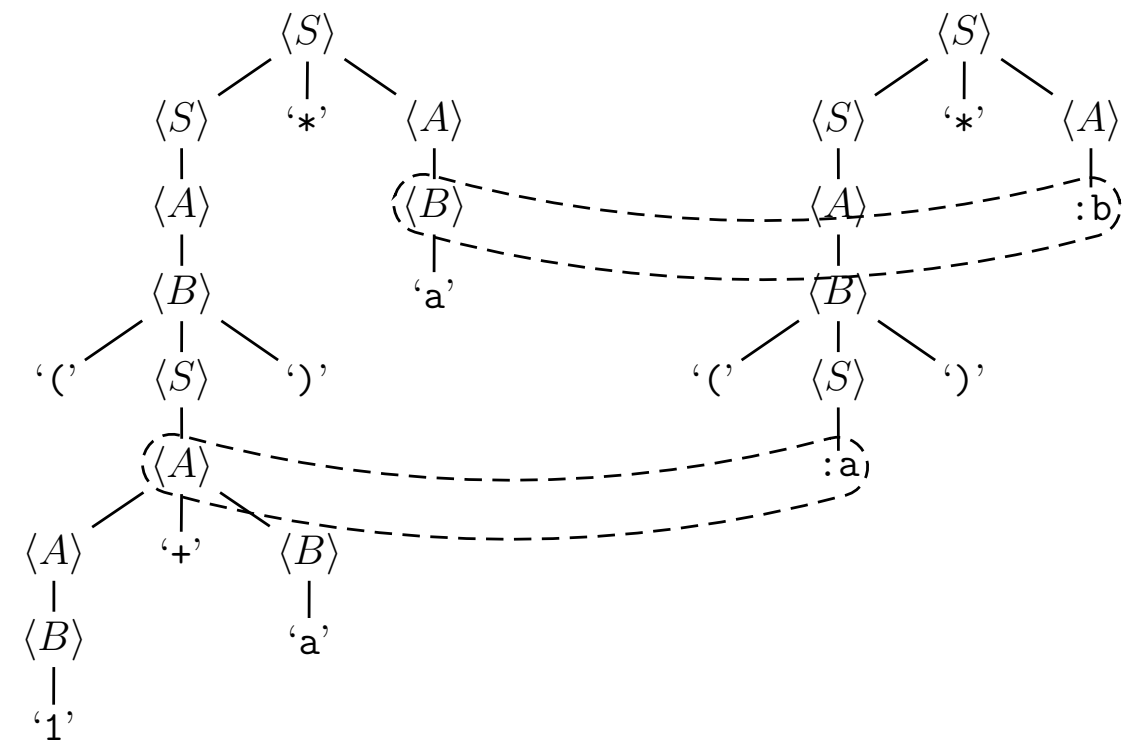

Figura 3.15: Processo de Casamento de Padrões.

Pode-se observar que é realizado o casamento entre a expressão '( $1+a$ ) * a' e o padrão $[S<($ :a $)$ * :b>], unificando a meta-variável :a com '1 + a' e :b com 'a'.

Para a operação de substituição, são utilizados três padrões $c, r$ e $b$. Primeiramente, tenta-se unificar $c$ e $r$. No caso de sucesso, $c$ é substituído por $b$. A substituição é realizada após a unificação de $c$ e $r$. Assim, meta-variáveis em $b$ podem se referir a partes de $c$ e/ou $r$.

\subsubsection{Construções da Linguagem}

Para gerar mutantes, as operações de casamento de padrões e substituições discutidas devem ser expressas em uma sintaxe concreta. Além disso, deve existir alguma forma 
de combinar operações simples em outras mais complexas. Nesta seção, será introduzida a sintaxe da linguagem $\mathcal{M} u \mathcal{D} e \mathcal{L}$ para expressar as operações e para combiná-las. Serão apresentados alguns exemplos simples de operadores de mutação para a linguagem $\mathrm{C}$ e CPN-ML.

Uma descrição de operador de mutação na linguagem $\mathcal{M} u \mathcal{D} e \mathcal{L}$ é composta por três partes. Na primeira parte, é declarado o nome do operador. Esse nome é incluído apenas para propósitos de documentação e não tem impacto nas demais partes da descrição. A segunda parte é opcional e, quando presente, representa a seção de declaração de meta-variáveis. O início dessa seção é marcado pela palavra chave var, seguida por uma lista de uma ou mais declarações de meta-variáveis. Uma declaração de meta-variável é formada por um nome (composto por ':' e um identificador) seguido de um padrão de árvore. Na última parte, apresenta-se uma operação, possivelmente composta, entre as palavras chave begin e end operator. Essa operação será executada na árvore sintática do produto original e gerará os mutantes.

Na Figura 3.16 é apresentada uma descrição de operador de mutação, ilustrando a estrutura geral. Esse operador, cujo nome é STDL, declara uma meta-variável :s com tipo 〈statement〉, e possui uma operação simples, que, como será esclarecido posteriormente, gera mutantes trocando nós com o tipo 〈statement〉 por um ponto e vírgula ";", que corresponde a um comando nulo da linguagem $\mathrm{C}$.

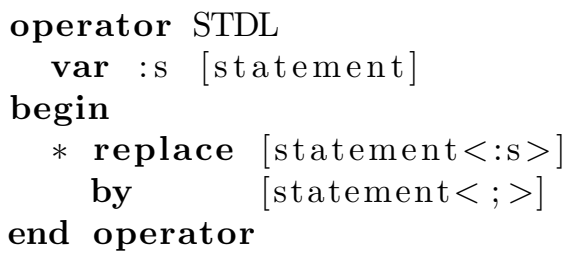

Figura 3.16: Um Operador de Mutação Simples. Para Cada Comando no Programa, um Mutante é Gerado Removendo-se Tal Comando.

A operação de substituição é codificada com a construção replace $r$ by b, na qual r é o padrão a ser encontrado e b é o padrão que o substituirá. Esse tipo de construção possui um padrão de contexto implícito contra o qual r será unificado. Por default, o padrão de contexto de uma operação é o contexto declarado mais interno ou, caso nenhum contexto seja declarado, toda a árvore sintática do produto original. Na Figura 3.17(a) é apresentado o operador de mutação _SWDD, que exemplifica a operação de substituição. Esse operador troca um comando while por um comando do-while. No entanto, o operador _SWDD não faz o que geralmente se esperaria de um operador desse tipo. Como o padrão de contexto default é a árvore do produto original inteira, esse operador geraria um mutante se, e somente se, todo o programa original fosse igual a um único comando while. O que, em geral, seria esperado é que todos os comandos while, em qualquer nível, sejam trocados por comandos do-while. 
Para obter esse efeito, pode-se adicionar o modificador * (leia-se, em profundidade) à substituição. O modificador * denota que a operação modificada será aplicada à árvore de contexto e, recursivamente, a todas as suas subárvores. Dessa forma, uma operação com o modificador * gerará um conjunto de mutantes, uma vez que cada subárvore potencialmente gerará um mutante. Na Figura 3.17(b) é apresentado operador SWDD, que ilustra a utilização do modificador * .

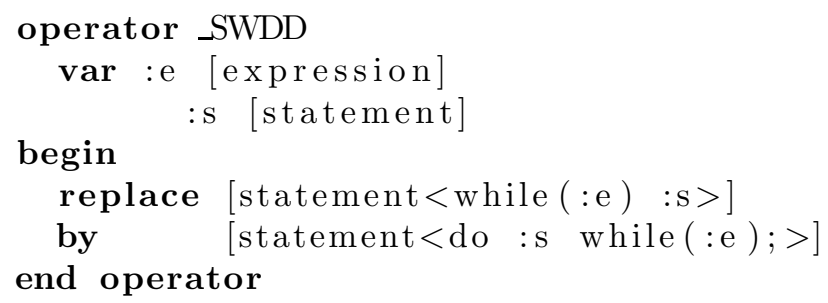

(a)

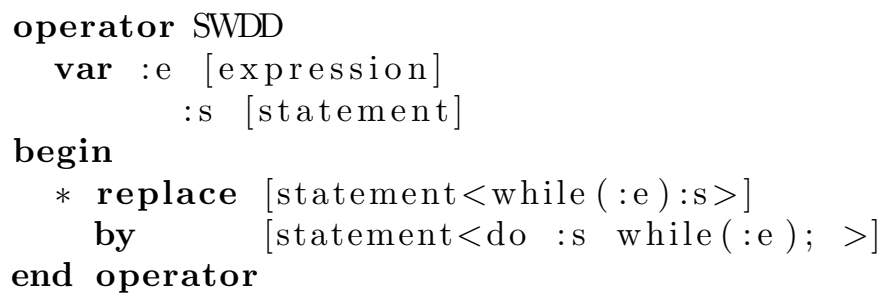

Figura 3.17: (a) Um Operador de Mutação que Substitui um Comando while por um Comando do-while. (b) Um Operador de Mutação que Substitui Todos os Comandos while em Qualquer Nível por um Respectivo Comando do-while.

Supondo que se deseja projetar um operador de mutação que troque um comando while por do-while, como o operador_SWDD, mas também troque os comandos do-while por while ${ }^{3}$. Substituir um comando do-while por um comando while pode ser facilmente realizado invertendo-se os padrões no operador SWDD. É necessário, então, uma forma de combinar essas duas operações. Para esse propósito, foi projetado o combinador || (leia-se como alternativa). O combinador alternativa toma uma seqüência de operações e denota que cada uma dessas operações pode ser tentada, na ordem, para gerar mutantes. Duas ou mais operações pode ser incluídas, separando cada par com o combinador, como por exemplo a $\|b\| c$. A seqüência de operações separadas pelo combinador alternativa é chamada de lista de alternativas. Para cada operação, o estado global será o mesmo, ou seja, após uma operação ter sido concluída, o estado é restaurado e qualquer eventual alteração é desfeita. Em outras palavras, em um dado mutante, apenas os efeitos de uma dessas operações estarão presentes. Dessa forma, o conjunto de mutantes gerados por uma lista

\footnotetext{
${ }^{3}$ Geralmente, esse objetivo é realizado projetando-se dois operadores de mutação distintos, como, por exemplo, em (Agrawal, 1989). Esse operador foi projetado dessa forma apenas com ilustração.
} 
de alternativas é a união dos mutantes gerados por cada operação individual. A habilidade de combinar diferentes operações dessa forma é útil em situações nas quais o operador de mutação requer alterações em elementos sintaticamente diferentes da linguagem do produto. Como exemplo, pode-se citar o operador SMTC definido por Agrawal (1989) para linguagem $\mathrm{C}$, o qual troca as expressões de controle dos comandos de iteração, ou seja, de comandos for, while e do-while. Na Figura 3.18 é apresentada a descrição de um operador de mutação que troca comandos while por um comando do-while e vice-versa.

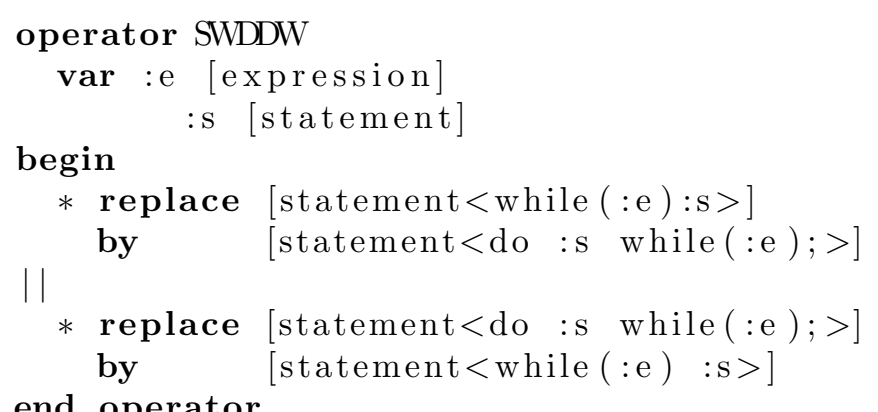

Figura 3.18: Um Operador de Mutação que Troca cada Comando while em Qualquer Nível por um Comando do-while e Vice-Versa.

Outra característica do combinador de alternativas é o seu comportamento quando da presença de uma operação primitiva cut. A operação cut faz com que todas as alternativas seguintes em uma lista de alternativas sejam evitadas. Tanto o objetivo quanto a semântica da operação cut são baseados no predicado cut da linguagem Prolog (Bratko, 1990). Ela foi projetada e incluída na linguagem $\mathcal{M} u \mathcal{D} e \mathcal{L}$ para aumentar o controle sobre o número de vezes que uma operação é aplicada.

Algumas vezes é necessário executar mais de uma operação no mesmo mutante. Nesse caso, utiliza-se o combinador ;; (leia-se, seqüência), que toma uma seqüência de operações e denota que cada uma delas será aplicada para se gerar o mutante. Mais de duas operações podem ser incluídas separando-se cada par com um ;;, como, por exemplo, $\mathbf{a} ; ; \mathbf{b} ; ; \mathbf{c}$. O combinador ;; possui uma precedência maior do que o combinador $\|$ e, assim, a expressão a;;b\|c;;d é interpretada como uma lista de alternativas com duas operações compostas iguais a a;;b e c;;d. Parênteses duplos podem ser utilizados para agrupar operações e sobrescrever a precedência, como, por exemplo, em a;;((b\|c));;d. Entretanto, de uma maneira distinta do que ocorre com a maioria das linguagens de programação e de forma semelhante à linguagem Prolog, a expressão $((a ; ; b)) \| c$ não é equivalente a a;;b\|c, uma vez que, para esta última, se a ou b for igual à operação cut, a operação c será evitada, ao passo que para a primeira, a operação c será executada de qualquer forma. Em outras palavras, o agrupamento com parênteses delimita o escopo da operação cut.

A operação de casamento de padrões é codificada com a construção match m. Como na operação de substituição, $m$ é unificado contra o padrão de contexto. Se a 
unificação ocorre com sucesso, a geração continua, mantendo o efeito de qualquer ligação de variável que tenha ocorrido. Entretanto, se a unificação ocorre com falha, a geração é interrompida nesse ponto e uma alternativa é tentada.

Na Figura 3.19 são ilustrados tanto o combinador ;; quanto a operação de casamento de padrões, apresentando um operador de mutação que troca a expressão de controle de um comando do-while pela expressão constante 0 , a menos que essa expressão de controle já seja sintaticamente igual a 0 .

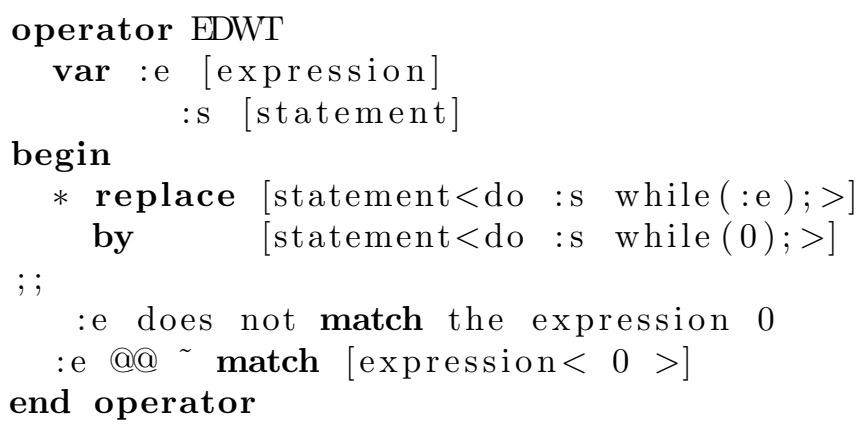

Figura 3.19: Um Operador de Mutação que Troca a Expressão de Controle de Comandos Do-While por 0. O Caracter \# Marca uma Linha de Comentário.

No operador EDWT existem dois novos modificadores: o especificador de contexto @@ e o modificador de negação . O especificador de contexto é usado para declarar explicitamente qual padrão de contexto deve utilizado para a operação modificada. A construção :v@@op declara que a operação op deve ser executada utilizando-se a meta-variável :v como padrão de contexto. O modificador de negação é utilizado para "inverter" o resultado da operação modificada. A construção op falha se a operação op for bem sucedida, e resulta em sucesso com nenhuma unificação se a operação op falha.

Existem duas outras operações primitivas na linguagem $\mathcal{M} u \mathcal{D} e \mathcal{L}$, as quais não envolvem operações de casamento de padrões ou substituições: a operação donothing e a operação abort. A operação donothing na realidade não altera a árvore sintática e é utilizada principalmente como um recurso sintático para preencher um local no qual uma operação é necessária. Dessa forma, o operador de mutação mais simples possível na linguagem $\mathcal{M} u \mathcal{D} e \mathcal{L}$ é apresentado na Figura 3.20(a). Em realidade, esse operador gera um único "mutante" que é idêntico ao produto original. De forma complementar à operação donothing, existe a operação abort, que impede que o mutante seja gerado. Em outras palavras, sempre que uma operação abort é executada, a alternativa em questão é abandonada. Essa operação foi projetada para impedir que mutantes indesejados sejam gerados. Por exemplo, o operador de mutação da Figura 3.20(b) não gera nenhum mutante. 


\section{operator DONOT \\ begin \\ donothing \\ end operator}

(a)

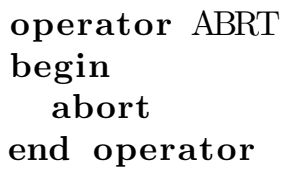

operator ABRT

begin

abort

end operator

(b)

Figura 3.20: (a) Um Operador de Mutação que Gera um "Mutante" que Igual ao Produto Original. (b) Um Operador de Mutação que não Gera Nenhum Mutante.

\subsubsection{Um Exemplo}

Nesta seção, é apresentado um exemplo para ilustrar os principais conceitos da linguagem $\mathcal{M} u \mathcal{D} e \mathcal{L}$ apresentados até esse ponto. Na Figura 3.21 é apresentado o operador de mutação SDWE, que troca um comando while por um comando do-while e troca a expressão de controle por 0 ou por 1.

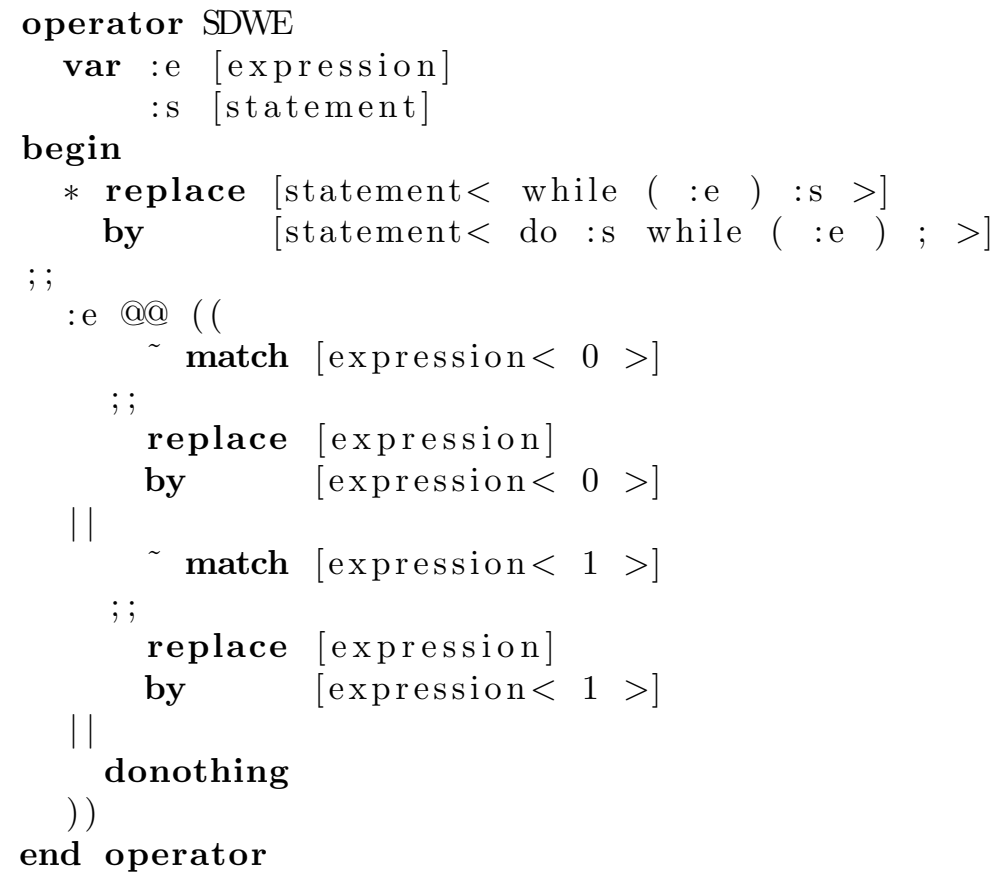

Figura 3.21: Um Operador de Mutação Multi-Propósito.

A operação de substituição nas Linhas 5 e 6 troca cada comando while por um comando do-while, em qualquer nível. A meta-variável :e representa a expressão de controle do comando while. O grupo de operações nas Linhas 8-20 faz a alteração na expressão de controle. Deve-se observar que a declaração de padrão de contexto na Linha 8 afeta todo o grupo e, conseqüentemente, todos os comandos internos.

O casamento de padrões na Linha 9 é negado e garante que o padrão de contexto (nesse caso, a subárvore a qual a meta-variável :e está unificada) não é igual a 0. Se o casamento de padrões falha (e, conseqüentemente, a operação negada resulta em sucesso), o padrão de contexto será substituído por 0 pela operação de substituição nas 
while interno. A operação de substituição (Linhas 5 e 6) e o agrupamento de operações nas Linhas 8-20 formam uma seqüência e, dessa forma, cada mutante gerado conterá os efeitos tanto da substituição como do agrupamento. Esse agrupamento, por sua vez, é composto por uma lista de três alternativas: a primeira alternativa está nas Linhas 9-12, a segunda alternativa está nas Linhas 14-17, e a última alternativa está na Linha 19. Apenas o efeito de uma dessas alternativas será incluído em um mutante particular. Por exemplo, os mutantes \#1 e \#2 nas Figuras 3.22(b)-(c) são gerados pela substituição do comando while externo e a aplicação da primeira e da terceira alternativa, respectivamente. Deve-se observar que a segunda alternativa não gera mutantes, uma vez que a operação na Linha 14 falha. Por outro lado, os mutantes \#3, \#4 e \#5 nas Figuras 3.22(d)-(f) são gerados pela substituição do comando while interno e pela aplicação de cada uma das alternativas.

\subsubsection{Mutações Sensíveis a Contexto}

A sintaxe da maioria das linguagens utilizadas em computação é definida por meio de gramáticas livres de contexto. No entanto, em geral, essas linguagens são, em realidade, sensíveis ao contexto. Por exemplo, uma expressão como " $\mathrm{x}=1$ " será aceita ou não como uma expressão válida da linguagem $\mathrm{C}$ dependendo do contexto no qual ela aparece, em especial, o contexto das declarações de variáveis. Dessa forma, a linguagem C é claramente sensível ao contexto. Contudo, existem duas importantes razões para se utilizar gramáticas livres de contexto para descrever tais linguagens:

1. gramáticas sensíveis ao contexto são mais difíceis de especificar e mais onerosas de se reconhecer; e

2. os detalhes que são sensíveis ao contexto podem ser adequadamente tratados usando-se lookup tables.

De forma similar, mutações podem ser classificadas em livres de contexto e sensíveis ao contexto. Mesmo para linguagens sensíveis ao contexto, pode haver mutações livres de contexto. Um exemplo de mutação livre de contexto é a troca da expressão " $\mathrm{x}=1$ " por " $\mathrm{x}+=1$ ", uma vez que onde quer que a primeira expressão seja válida, a segunda também o será. Entretanto, a troca da expressão " $\mathrm{x}=1$ " por " $\mathrm{y}=1$ " é sensível ao contexto, uma vez que a segunda expressão somente será válida se y tiver sido declarada de forma compatível com a declaração de $\mathrm{x}$.

Para lidar com as mutações sensíveis ao contexto, estenderam-se os conceitos utilizados na definição da linguagem $\mathcal{M} u \mathcal{D} e \mathcal{L}$ para incorporar gramáticas de atributos. Com as gramáticas de atributos, pode-se associar aos nós da árvore sintática um conjunto de atributos. Esses atributos são utilizados para armazenar informações de contexto (Aho et al., 1985). 
Os atributos podem ser de dois tipos: atributos herdados e atributos sintetizados. Um atributo herdado é aquele cujo valor é calculado em função dos atributos dos nós ascendentes do nó ao qual está associado. Assim, por exemplo, pode-se armazenar no nó raiz de um programa atributos referentes aos tipos de variáveis globais, e, definir esses tipos como sendo atributos herdados em todos os nós descendentes. Com isso, consegue-se resolver o problema do escopo de declarações.

Um atributo sintetizado é aqueles cujo valor é calculado em função dos atributos dos nós descendentes ou irmãos do nó ao qual está associado. Assim, por exemplo, pode-se calcular o atributo referente ao tipo de uma expressão a partir dos tipos de suas subexpressões.

Na Figura 3.23 é apresentado um exemplo de uma gramática de atributos. O atributo val de um nó é sintetizado a partir dos atributos correspondentes de seus nós-filho.

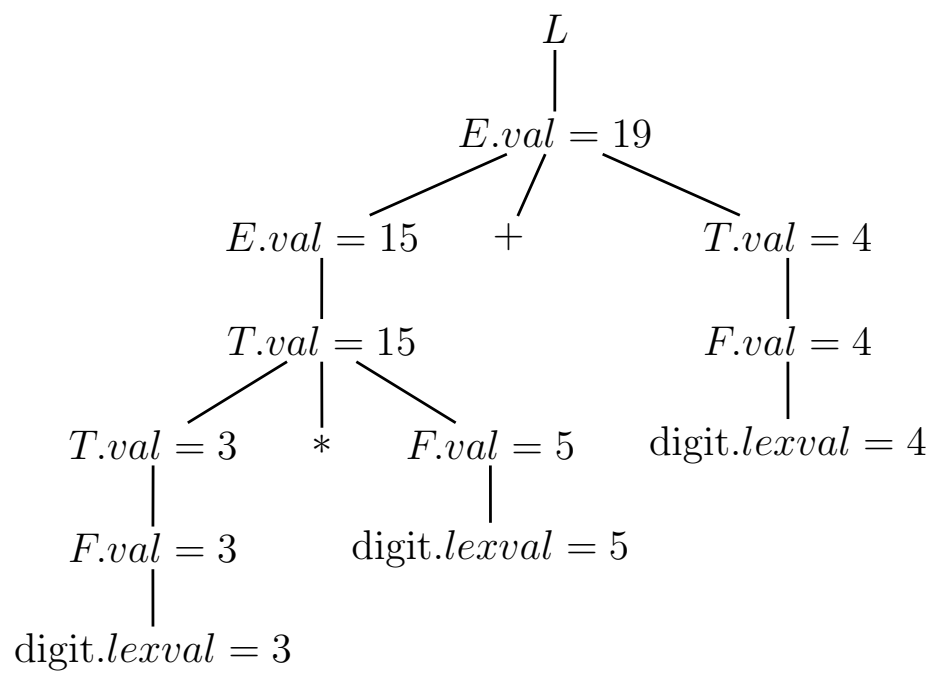

Figura 3.23: Exemplo de uma Gramática de Atributo para a Expressão ' $3 * 5+4$ '.

Para incorporar os conceitos das gramáticas de atributos na linguagem $\mathcal{M} u \mathcal{D} e \mathcal{L}$, faz-se necessário agora definir uma maneira para representar os atributos na árvore sintática, calcular os atributos herdados e sintetizados e deixá-los disponíveis na descrição dos operadores de mutação. Linguagens para a construção de compiladores, tais como YACC, utilizam-se de ações semânticas para o cálculo de atributos. Uma abordagem semelhante foi adotada na linguagem $\mathcal{M} u \mathcal{D} e \mathcal{L}$. Foram assumidas as seguintes hipóteses:

1. a maneira como os atributos dos nós são calculados depende, em sua maior parte, da gramática da linguagem, não sendo dependente do operador de mutação; e

2. os atributos mais importantes que são necessários em uma descrição de operadores de mutação estão relacionados a elementos controlados por escopos de declaração, tais como o tipo de variáveis.

Assim, estendeu-se a linguagem $\mathcal{M} u \mathcal{D} e \mathcal{L}$ para a definição da gramática de entrada para permitir que atributos sejam calculados. Estabeleceu-se que os atributos serão 
conjuntos de strings. As operações relacionadas aos atributos são operações de conjuntos. Além disso, pode-se definir um atributo como um mapeamento de strings em conjuntos de strings.

Os atributos são automaticamente herdados e sintetizados. Isso é feito da seguinte forma. Para cada atributo, pode-se definir quais não-terminais devem ser considerados como escopo. Ao se definir um atributo, ele não é armazenado no nó em que o cálculo é realizado. Em vez disso, ele é armazenado no seu ascendente mais interno que foi registrado como tendo uma relação de escopo para o atributo em questão. Assim, o atributo será sintetizado automaticamente nos seus ascendentes. Da mesma forma, ao se usar o atributo de um nó, é utilizado o atributo que for encontrado no descendente mais interno. Assim, o atributo é herdado automaticamente por todos os descendentes de um nó.

O processo de síntese e herança automática é ilustrado na Figura 3.24. São definidos dois atributos, ids e type, ambos com o símbolo $\langle C S\rangle$ como escopo. Nesse exemplo, a produção

$\langle D\rangle::=\langle T\rangle\langle I D\rangle^{\prime} ;$

determina que o valor de $\langle I D\rangle$ seja adicionado ao atributo ids e que o valor de $\langle I D\rangle$ seja associado ao valor de $\langle T\rangle$ no atributo type. Considerando-se um operador que substitui um identificador por outro de tipo compatível, ao encontrar o identificador 'a' (marcado com um círculo), esse operador pode consultar tanto o tipo de 'a' como também o conjunto de identificadores definidos nesse escopo.

$$
\begin{aligned}
& \text { int } a ; \\
& \text { int } b ; \\
& \text { a }=1 ;
\end{aligned}
$$

(a)

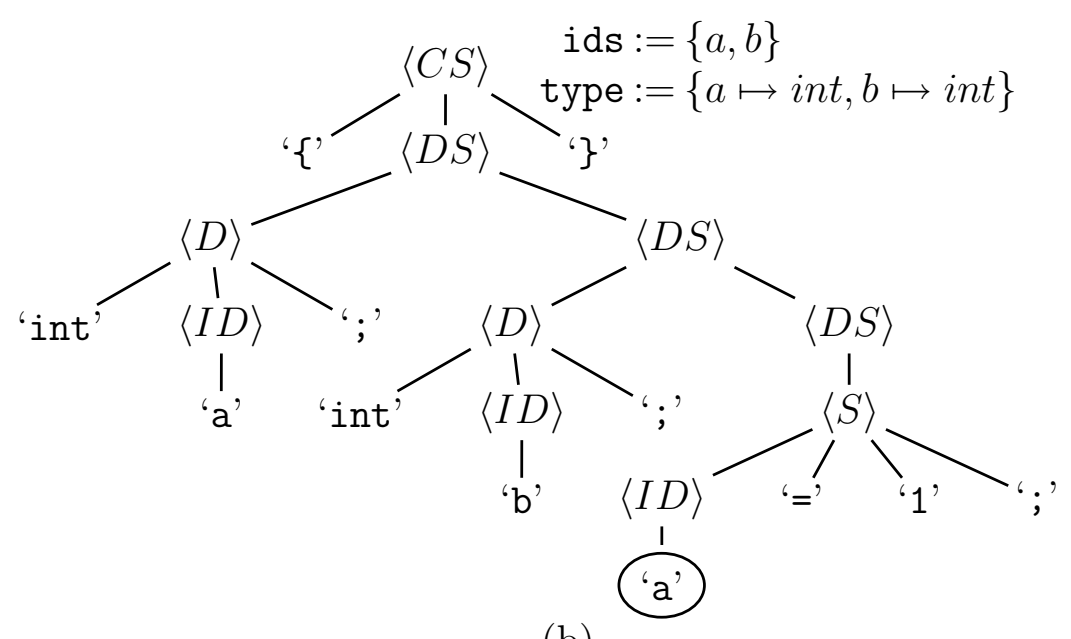

(b)

A linguagem $\mathcal{M} u \mathcal{D} e \mathcal{L}$ incorpora duas construções para lidar como os atributos da árvore: consult e assert. A construção consult permite que os atributos da árvore sejam consultados. Deve-se informar qual o nome do atributo e, opcionalmente, uma meta-variável (para a consulta de atributo simples) ou duas meta-variáveis (para a consulta de atributos de mapeamento). Se nenhuma meta-variável é fornecida, a operação 
será bem sucedida se o atributo estiver definido para a árvore de contexto, não importando o conteúdo. As meta-variáveis podem estar ligadas ou livres. No caso da meta-variável estar livre, ela será ligada a um dos elementos do conjunto de strings que está associado à árvore de contexto. Quando esse conjunto possui mais de um elemento, a meta-variável será ligada ao primeiro elemento e, se alternativas forem solicitadas, será ligada a cada um dos demais elementos. No caso da meta-variável estar ligada, a operação de consulta simples será bem sucedida se a string correspondente aos não-terminais da árvore à qual a meta-variável está ligada estiver presente no conjunto associado ao atributo.

Na Figura 3.25 é apresentado o operador VVRP1 que substitui um identificador por outro, considerando-se o tipo do identificador. A operação da Linha 6 unifica a meta-variável :id1 com cada ocorrência de um identificador no programa original. A operação da Linha 8 consulta o atributo type associado a essa meta-variável. O resultado é unificado com a meta-variável :t. A operação replace das Linhas 10-16, troca todas os identificadores que unificam com a meta-variável :id2 e que satisfazem os critérios expressos nas operações das Linhas 12-14. A operação da Linha 12 garante que a substituição será realizada apenas se os idenficadores unificados às meta-variáveis :id1 e :id2 não forem idênticos. A operação da Linha 14 consulta o atributo type associado à meta-variável :id2. Como a meta-variável :t já foi unificada pela operação da Linha 8, essa operação será bem sucedida se o atributo possuir o mesmo valor, ou seja, se ambas as variáveis forem do mesmo tipo.

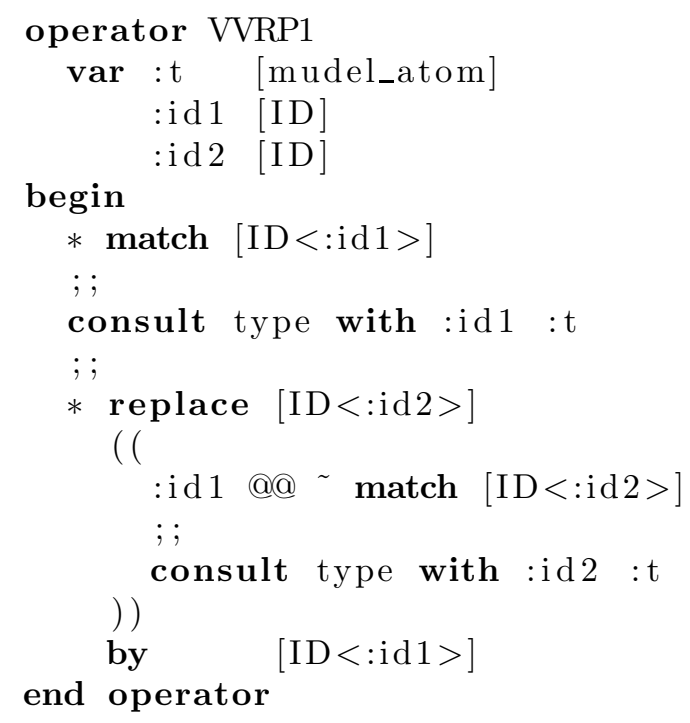

Figura 3.25: Exemplo de Utilização do Comando consult.

A construção assert permite registrar um atributo na árvore. Os parâmetros são similares aos da operação consult. Um parâmetro adicional pode ser incluído para definir qual é o escopo a ser utilizado para esse atributo. 
Na Figura 3.26 é apresentado um exemplo de utilização da operação assert em conjunto com a operação consult. Deve-se observar que se trata do mesmo operador apresentado na Figura 3.25, exceto que foram adicionadas as Linhas 8-10. Com a adição dessas operações, o comportamento do operador é alterado de tal forma que não são utilizadas todas as ocorrências de identificadores que unificam com :id1 na Linha 6, mas apenas uma ocorrência de cada identificador distinto. Por exemplo, considerando-se uma situação em que o identificador a ocorre em três pontos do programa original, o operador VVRP1 gerará mutantes correspondentes a cada uma das três ocorrências, enquanto que o operador o VVRP2 gerará mutantes correspondentes apenas à primeira ocorrência.

A operação da Linha 8 garante que o identificador unificado à meta-variável :id1 não está presente no atributo processed. Na Linha 10 registra-se o identificador :id1 no atributo processed. Como não é informado um escopo na operação, é considerado o nó raiz da árvore. Dessa forma, quando a próxima ocorrência do mesmo identificador for encontrada e unificada com :id1, a operação da Linha 8 garantirá que o processamento não continue para essa unificação.

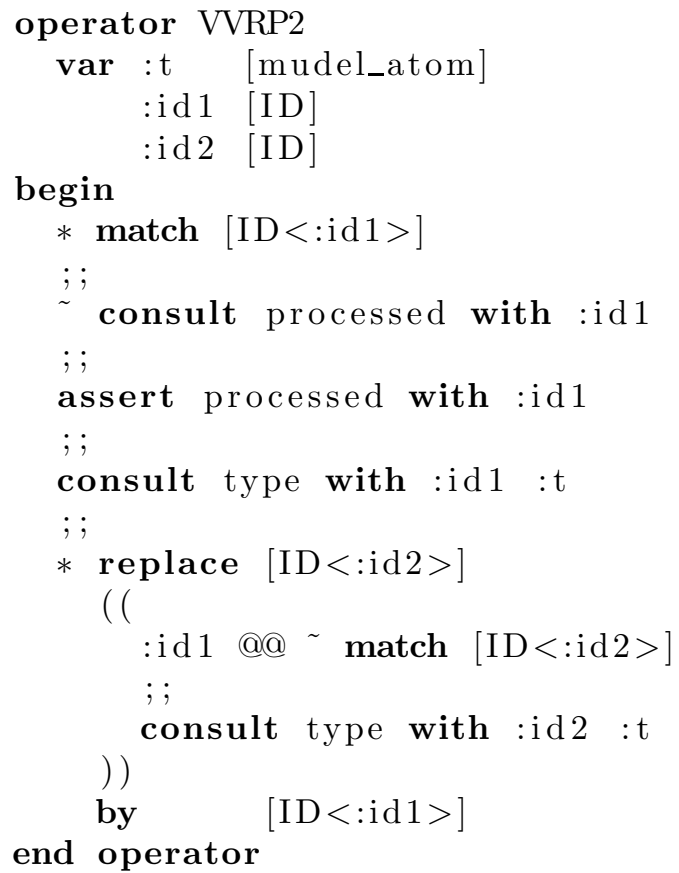

Figura 3.26: Exemplo de Utilização do Comando assert.

\subsubsection{Aplicações}

Nesta seção são apresentadas algumas aplicações da linguagem $\mathcal{M} u \mathcal{D} e \mathcal{L}$. Especificamente, são discutidas as aplicações para RPCs e para as linguagens de programação $\mathrm{C}, \mathrm{C}++$, Java e SML. 


\subsubsection{Redes de Petri Coloridas}

A necessidade de descrever operadores para RPCs foi a principal motivação para o desenvolvimento da linguagem $\mathcal{M} u \mathcal{D} e \mathcal{L}$. Foram descritos todos os operadores definidos na Seção 3.2. A descrição de cada um desses operadores pode ser encontrada no Apêndice C. O sistema mudelgen foi utilizado como gerador de mutantes na ferramenta Proteum/CPN, descrita no Capítulo 5. Dessa forma, permite-se que operadores sejam incluídos, removidos ou modificados no sistema apenas manipulando-se as descrições dos operadores.

\subsubsection{C, C++ e Java}

Vincenzi (2004) explorou a aplicação da AM no contexto de programas Orientados a Objeto. Como parte desse trabalho, foram investigados operadores de mutação intra-unidades para as linguagens $\mathrm{C}++$ e Java, utilizando-se a linguagem $\mathrm{C}$ como base. Todos os operadores obtidos foram descritos na linguagem $\mathcal{M} u \mathcal{D} e \mathcal{L}$. Devido à similaridade sintática entre as linguagens de programação C, C++ e Java em diversas estruturas de controle, durante a implementação dos 80 operadores de mutação de unidade definidos por Agrawal (1989), foram identificados diversos operadores para os quais a mesma descrição na linguagem $\mathcal{M} u \mathcal{D} e \mathcal{L}$ poderia ser reutilizada indistintamente para a geração de mutantes nas três linguagens de programação.

Na Figura 3.27 é ilustrado um diagrama que sintetiza os resultados obtidos da avaliação desses operadores. No centro do diagrama estão os operadores de mutação cuja descrição na linguagem $\mathcal{M} u \mathcal{D} e \mathcal{L}$ pode ser utilizada indistintamente para a geração de mutantes nas três linguagens consideradas. Eles correspondem a 31 dos 80 operadores intra-método, o que representa uma porcentagem de reutilização de 38,75\%. Considerando somente as linguagens $\mathrm{C}$ e $\mathrm{C}++$ observa-se que outras 34 descrições de operadores de mutação na linguagem $\mathcal{M} u \mathcal{D} e \mathcal{L}$, o que corresponde a $42,50 \%$ dos operadores, podem ser reutilizadas. Obviamente, existem também operadores de mutação cuja descrição na linguagem $\mathcal{M} u \mathcal{D} e \mathcal{L}$ é distinta para as três linguagens, tais operadores correspondem a $18,75 \%, 18,75 \%$ e $35 \%$ para as linguagens C, C++ e Java, respectivamente.

Com isso, observa-se que além de a linguagem $\mathcal{M} u \mathcal{D} e \mathcal{L}$ e o sistema mudelgen viabilizarem a construção de ferramentas de teste multi-linguagens, indiretamente, dependendo da característica da estrutura sintática das linguagens sendo consideradas, é possível reutilizar descrições de operadores de mutação, facilitando a implementação da ferramenta de teste e da validação da descrição do operador de mutação. 


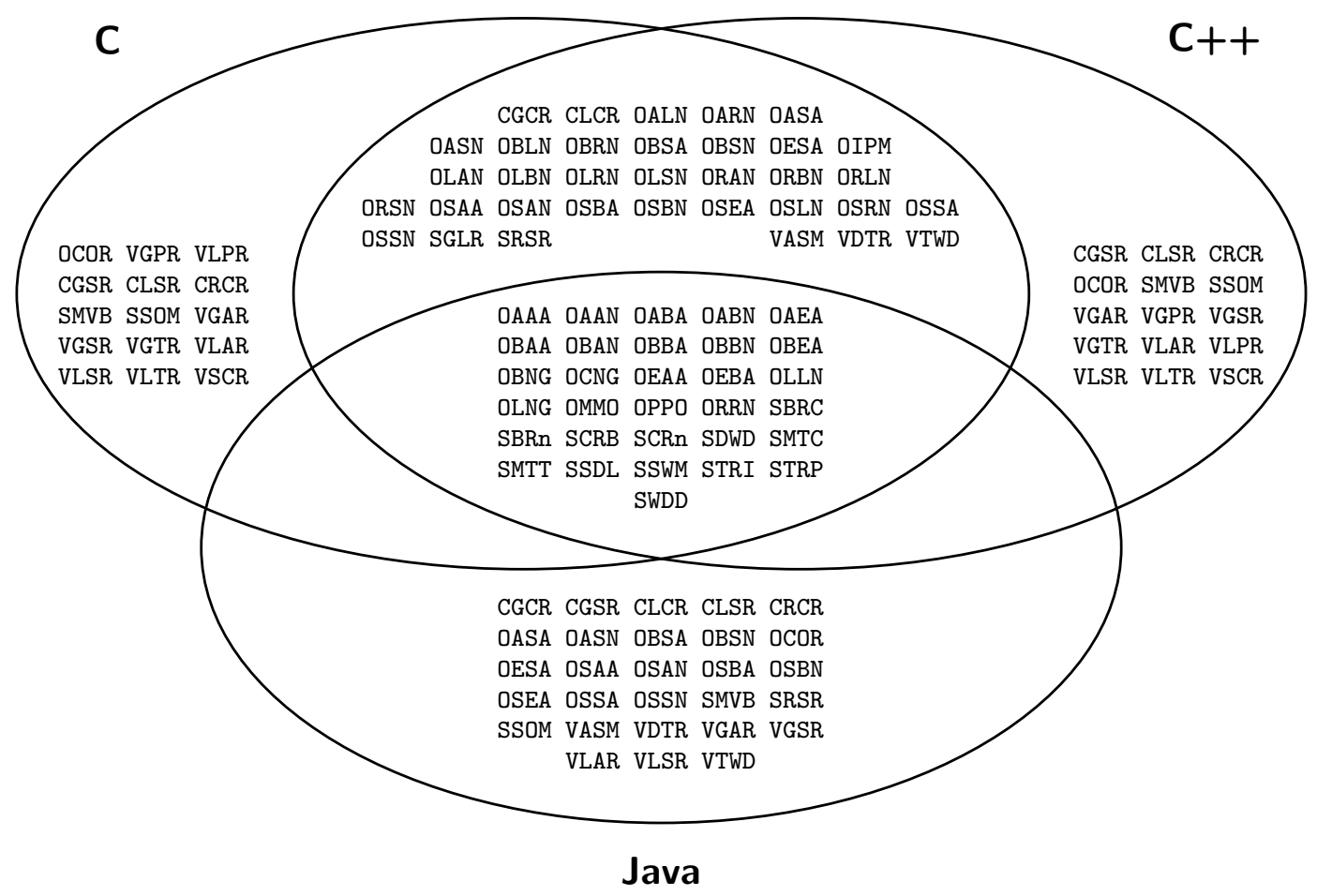

Figura 3.27: Reúso das Descrições na Linguagem $\mathcal{M} u \mathcal{D} e \mathcal{L}$ dos Operadores Intra-método para C, C++ e Java (Vincenzi, 2004).

\subsubsection{SML}

Yano (2004) investigou a aplicação da AM no contexto de programas funcionais, mais especificamente para programas escritos na linguagem SML. Foram desenvolvidos 16 operadores de mutação. Esses operadores foram descritos na linguagem $\mathcal{M} u \mathcal{D} e \mathcal{L}$. Demonstrou-se, dessa forma, a possibilidade de utilizar-se a linguagem $\mathcal{M} u \mathcal{D} e \mathcal{L}$ em linguagens de programação do paradigma funcional.

\subsection{Análise de Risco}

Um dos objetivos iniciais deste trabalho era a investigação de como a AM pode auxiliar na Análise de Risco (Simão, 2002). Apesar de esse ponto não ter sido devidamente explorado, foi identificada uma abordagem para a aplicação da AM na Análise de Risco (Simão et al., 2003b). Contudo, essa abordagem deve ser refinada e avaliada empiricamente. A seguir, essa abordagem é delineada. Como dito anteriormente, os conceitos de corretitude e segurança são de naturezas distintas. Dessa forma, os problemas que 
se busca identificar são também distintos. Assim, pode-se dividir os mutantes em duas classes:

Mutantes Orientados a Corretitude $\mathcal{M}_{\mathcal{C}}$ : Esses são os mutantes no sentido usual que refletem os possíveis erros que podem ser cometidos no modelo.

Mutantes Orientados a Segurança $\mathcal{M}_{\mathcal{S}}$ : Esses mutantes refletem possíveis imprecisões no modelo, assim como falhas no comportamento de alguma de suas partes.

Deve-se observar que, enquanto os mutantes em $\mathcal{M}_{\mathcal{C}}$ podem ser gerados de forma automática usando os operadores de mutação definidos neste capítulo, o conjunto $\mathcal{M}_{\mathcal{S}}$ depende das características da aplicação e dos objetivos de segurança. Os operadores de mutação para gerar $\mathcal{M}_{\mathcal{S}}$ devem refletir os tipos de falhas que podem ocorrer no sistema a ser testado. Dessa forma, não há um conjunto universal de operadores de mutação que será suficientemente geral para modelar as falhas de todos os sistemas. Na realidade, as características específicas de cada sistema são as maiores fontes de problemas na Análise de Risco. O projeto de operadores de mutação que são específicos para um dado sistema deve ser conduzido por um analista de risco. Nesse contexto, a linguagem $\mathcal{M} u \mathcal{D} e \mathcal{L}$ pode colaborar, facilitando a definição de operadores específicos para o sistema em questão e permitindo, por meio do mudelgen, que os mutantes sejam gerados.

A aplicação da AM pode, então, ser dividida em duas fases. Na primeira fase, o conjunto de mutantes $\mathcal{M}_{\mathcal{C}}$ é usado para guiar a geração de um conjunto $T$ de casos de teste adequado. Essa fase é a aplicação usual da AM, como descrito na Seção 2.3.

Na segunda fase, o conjunto de mutantes $\mathcal{M}_{\mathcal{S}}$ é executado com os casos de teste em T. Nessa fase, os mutantes não serão analisados com relação à equivalência no comportamento da RPC original. Em vez disso, o comportamento é analisado com relação à sua segurança. Deve ser verificado se alguma condição de perigo foi alcançada durante a execução de cada mutante $m \in \mathcal{M}_{\mathcal{S}}$ com os casos de teste. Caso isso ocorra, um problema de segurança foi identificado. O analista de risco deve avaliar as conseqüências e as probabilidades (ou seja, o risco) e tomar as medidas necessárias para eliminar o problema ou reduzir o impacto de sua ocorrência. O conjunto de condições de perigo deve ser definido pelo analista de risco, potencialmente com a aplicação de técnicas tradicionais de Análise de Risco, tais como HAZOP e Árvores de Falha. Deve-se observar que, em geral, a análise de se as condições de perigo foram satisfeitas ou não durante a execução nem sempre pode ser automatizada. Entretanto, no caso em que elas podem ser formalmente expressas em termos dos elementos da RPC, sua verificação pode ser realizada automaticamente. 


\subsection{Considerações Finais}

Neste capítulo foi apresentada uma proposta para aplicação do critério AM no teste de especificações baseadas em RPCs. A proposta foi motivada pelos indícios apresentados em outros trabalhos da viabilidade da aplicação desse critério no teste de especificações. Um conjunto de operadores de mutação foi definido. Buscou-se considerar as características próprias das RPCs.

O número de mutantes gerados pode ser um obstáculo para aplicação da AM. Dessa forma, uma análise da complexidade dos operadores de mutação, em relação ao número de mutantes que podem ser gerados no pior caso, também foi conduzida. Pôde-se observar que, no pior caso, os operadores têm complexidade quadrática em relação aos elementos da rede. Na maioria dos casos, porém, a complexidade é linear. Uma avaliação empírica do número de mutantes gerados para um conjunto de RPCs pode ser encontrada no Capítulos 6. É indispensável a existência de ferramentas que apóiem a aplicação da AM. Dessa forma, investigaram-se mecanismos de automatização da aplicação. Foi desenvolvida a ferramenta Proteum/CPN, a qual será apresentada no Capítulo 5.

Dada a importância dos operadores para a eficácia do critério AM, o conjunto apresentado neste trabalho deve ser encarado como uma proposta a ser refinada por estudos teóricos e empíricos futuros. Para facilitar a definição de operadores e a experimentação teórica e empírica, foi definida a linguagem $\mathcal{M} u \mathcal{D} e \mathcal{L}$. Apesar de ter sido motivada pela necessidade de descrever e gerar mutantes para RPCs, a $\mathcal{M} u \mathcal{D} e \mathcal{L}$ foi projetada para ser utilizada em outros contextos. Esse é um primeiro passo na direção do desenvolvimento de mecanismo gerais de apoio a AM.

Apresentou-se também uma proposta preliminar de como a AM pode ser utilizada para auxiliar na Análise de Risco. Apesar de essa linha de pesquisa não foi investigada profundamente, fica clara a relevância de pesquisas nesse contexto. A disponibilidade de uma linguagem para a descrição dos operadores de mutação, como a $\mathcal{M} u \mathcal{D} e \mathcal{L}$, permite que trabalhos futuros busquem explorar o potencial da AM em evidenciar situações de risco.

A AM pode ser utilizada para auxiliar a geração e a avaliação de conjuntos de casos de teste. Dessa forma, no próximo capítulo é apresentado um algoritmo para a geração de casos de teste baseado na AM. O algoritmo foi definido para RPs com base em trabalhos anteriores (Fabbri et al., 1994b; Simão, 2000). Ao final, discute-se como o algoritmo pode ser aplicado a RPCs. 


\section{Capítulo 4}

\section{Geração de Seqüências de Teste Baseada na Análise de Mutantes}

\subsection{Considerações Iniciais}

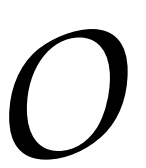

grande número de mutantes que precisam ser analisados é um dos fatores de maior impacto negativo na produtividade da aplicação da AM. Geralmente, são gerados centenas, às vezes milhares, de mutantes. Como apresentado no Capítulo 2, após serem executados com um conjunto de casos de teste, os mutantes que permanecem vivos devem ser analisados para que se possa determinar se o mutante é ou não equivalente ao produto original. Caso o mutante seja equivalente, ele é descartado de forma a não influenciar no escore de mutação. Caso o mutante não seja equivalente, ele indica uma fraqueza no conjunto de casos de teste e, para melhorá-lo, deve-se incluir um caso de teste que mate esse mutante.

A tarefa de determinar se o mutante é equivalente e, se não for, gerar um caso de teste para matá-lo é trabalhosa e requer muita intervenção por parte do testador. Têm-se buscado alternativas para diminuir o custo dessa tarefa. Uma forma de se obter isso é diminuir o número de mutantes gerados, descartando-se a priori alguns mutantes. Apesar de conceitualmente simples, essa alternativa é difícil de ser praticada, pois é um problema complexo definir quais mutantes descartar. Idealmente, deve-se manter os mutantes com alta probabilidade de revelar erros. Algumas abordagens têm sido pesquisadas para atingir esse objetivo, tais como a Mutação Aleatória (Acree et al., 1979) e a Mutação Seletiva (Offutt et al., 1993).

Uma alternativa para diminuir o custo da AM é a automatização do processo de geração de casos de teste e de determinação de mutantes equivalentes (DeMillo e Offutt, 1991; Offutt e Pan, 1997). Dessa forma, o número de mutantes que precisarão ser manualmente analisados é menor. Apesar de essa alternativa não reduzir o custo computacional, uma vez que a quantidade de mutantes que deve ser gerada, armazenada e executada é a mesma, ela reduz a necessidade de interação do testador. 
Neste trabalho, investigaram-se alternativas para automatizar a geração de casos de teste e a determinação de mutantes equivalentes. Desenvolveu-se um algoritmo para a realização dessas tarefas para RPs Lugar/Transição, com base em trabalhos anteriores (Fabbri et al., 1994b; Simão, 2000), os quais motivaram a realização deste trabalho. Buscou-se, posteriormente, estender o algoritmo para permitir a aplicação para RPCs.

O algoritmo utiliza-se do fato de as RPs poderem ser representadas na forma de matrizes para a geração de seqüências de teste. Além disso, é capaz de determinar alguns casos de equivalência de mutantes. Esse algoritmo não é completo, no sentido de que não é capaz de gerar seqüências que matem todos os mutantes. No entanto, ele reduz consideravelmente o número de mutantes que precisam ser manualmente analisados.

Neste capítulo descreve-se o algoritmo e apresenta-se um exemplo de sua aplicação. Em seguida, apresenta-se uma discussão das possibilidades e limitações da aplicação do algoritmo para RPCs. Um estudos de caso com a aplicação do algoritmo para RPs é apresentado no Capítulo 6.

Uma abordagem complementar de geração de casos de teste para RPCs é a utilização de informações provenientes do Grafo de Ocorrência (GO), na linha dos trabalhos conduzidos para Estelle (Souza et al., 2001), Statecharts (Souza et al., 2000c) e SDL (Sugeta, 2004). Ao longo do desenvolvimento deste trabalho, realizou-se a aplicação desses conceitos para RPCs (Simão et al., 2003a), derivando a família de critérios de cobertura CPNCCF. Apesar de não estar diretamente relacionada ao tema central desta tese, a CPNCCF é uma contribuição relevante, que trará desdobramentos na continuação deste trabalho. Uma descrição dos critérios da família CPNCCF pode ser encontrada no Apêndice D.

\subsection{Esquema Geral do Algoritmo}

O algoritmo descrito a seguir toma como argumentos uma RP $N$ e uma rede mutante $N^{\prime}$. A execução do algoritmo pode produzir três resultados alternativos:

Resultado $1 \mathrm{O}$ algoritmo gera uma seqüência que mata $N^{\prime}$;

Resultado $2 \mathrm{O}$ algoritmo determina que $N^{\prime}$ é um mutante equivalente a $N$;

Resultado 3 O algoritmo não é capaz de gerar uma seqüência para matar $N^{\prime}$ nem de determinar sua equivalência.

O algoritmo é divido em duas partes. Na primeira parte, um conjunto de condições necessárias para que uma seqüência de teste mate $N^{\prime}$ é definido na forma de inequações lineares, caracterizando um problema de programação linear inteira. Esse problema é então resolvido, resultando em um vetor de caracterização $v$. Caso o problema seja inconsistente, ou seja, caso o espaço de soluções seja vazio, conclui-se que nenhuma seqüência 
de transições será capaz de matar o mutante, e, portanto, $N^{\prime}$ é equivalente a $N$ (Resultado 2). Contudo, como se trata um sistema de inequações, podem existir infinitas soluções para o problema. Uma vez que não é possível investigar todos os elementos do espaço de soluções, optou-se por selecionar apenas um, utilizando-se uma ordenação parcial desse espaço de forma a privilegiar a solução que possivelmente conduzirá às menores seqüências de teste.

Na segunda parte do algoritmo, uma seqüência $s q \in S E Q\left(\mu_{0}, v\right)$ é calculada por meio da construção da Árvore de Caracterização para a solução $v$ encontrada na primeira parte. Uma Árvore de Caracterização é uma subárvore da Árvore de Alcançabilidade, construída com base em vetores de caracterização. Todas as seqüências em $S E Q\left(\mu_{0}, v\right)$ matam o mutante $N^{\prime}$. Caso consiga-se encontrar uma tal seqüência, obtém-se o Resultado 1. Salienta-se que, uma vez que nem todo espaço de soluções da primeira parte é investigado, não encontrar uma seqüência $s q \in S E Q\left(\mu_{0}, v\right)$ não implica que o mutante seja equivalente. Portanto, caso não se consiga encontrar $s q \in S E Q\left(\mu_{0}, v\right)$, obtém-se o Resultado 3.

Visando a simplificar a descrição do algoritmo, somente os mutantes gerados pelos operadores InpDel, InpIns, InpShift, OutDel, OutIns, OutShift e MarkDel são considerados nesse documento. Tais operadores constituem o conjunto suficiente de operadores de mutação para RPs, como demonstrado em (Simão, 2000). No entanto, com as devidas considerações, o algoritmo pode ser aplicado aos mutantes dos demais operadores, bem como a diferentes alternativas de operadores.

\subsection{Geração de Vetores de Caracterização}

Neste passo, procura-se calcular um vetor $v$ de caracterização tal que toda $s q \in$ $S E Q\left(\mu_{0}, v\right)$ mate o mutante $N^{\prime}$. Isto é feito modelando-se o problema de geração de vetores de caracterização em um problema de programação linear inteira e, então, resolvendo-se esse novo problema. Um problema de programação linear encontra uma solução que minimiza (ou maximiza) o valor de uma função objetivo $f$ sobre um conjunto de variáveis, respeitando-se um conjunto de restrições impostas na forma de inequações lineares. Um problema de programação linear inteira é um problema de programação linear no qual todas as variáveis da solução devem assumir valores inteiros (Plane, 1971). Modelar um problema como um de programação linear é definir a função objetivo $f$ e o conjunto de inequações. Existem diversos métodos na literatura que resolvem problemas de programação linear inteira, entre os quais, pode-se citar a Enumeração Explícita (Woiler, 1968), Algoritmo All-Integer (Hu, 1969), Branch and Bound (Plane, 1971) e Planos de Corte (Nemhauser e Wolsey, 1988). No caso da programação linear inteira, as inequações devem ser formadas com os operadores relacionais $\geq, \leq \mathrm{e}=$ (Plane, 1971). As inequações que não satisfazem esse formato podem ser convertidas por meio dos seguintes esquemas, que 
são válidos para quaisquer valores inteiros de $a$ e $b$ :

$$
\begin{aligned}
& a<b \Leftrightarrow a+1 \leq b \\
& a>b \Leftrightarrow a \geq b+1
\end{aligned}
$$

A escolha da função objetivo $f$ não influencia no conjunto de soluções. No entanto, $f$ estabelece qual solução será gerada por meio de uma ordenação parcial das soluções possíveis. Para a geração de seqüências de teste, considerou-se $f$ de tal forma que as soluções sejam ordenadas em função do tamanho dos vetores, como segue:

$$
f\left(v_{1}, v_{2}, \ldots, v_{n}\right)=\sum_{i=1}^{n} v_{i}
$$

Para determinar o conjunto de restrições, a equação fundamental das redes (Equação 2.1 apresentada no Capítulo 2) é convertida em uma inequação, na qual se apresenta a condição mínima para que uma seqüência de transições esteja habilitada. Tem-se que, para que uma seqüência esteja habilitada, é necessário que a marcação final seja válida, isto é, que seja maior ou igual a zero. Dessa forma, obtém-se a inequação matricial abaixo:

$$
0 \geq \mu_{0}+C . v
$$

a qual pode ser reescrita como:

$$
-\mu_{0} \geq C . v
$$

A inequação matricial pode ser decomposta em um conjunto de inequações denominadas inequações de consistência, sendo uma inequação para cada lugar da rede. Como resultado, obtêm-se as seguintes inequações:

$$
\mu_{i} \leq \sum_{k=1}^{|T|} C_{i k} v_{k} \quad \text { para } 1 \leq i \leq|P|
$$

Inequações adicionais são criadas de forma a restringir as soluções da Equação 4.1 àquelas que matem $N^{\prime}$. Para os operadores considerados, todos os mutantes sofrem alterações em alguns arcos de exatamente um lugar $p_{i}$ ou na quantidade de marcas de $p_{i}$. Como, pela regra de execução, apenas os arcos de um lugar influenciam nas marcas desse lugar durante a execução de uma seqüência de transições, pode-se concluir que para qualquer seqüência de transições $s q$, a quantidade de marcas em $p_{k}$ (para $k \neq i$ ) é igual na rede original e na rede mutante. Portanto, apenas o lugar $p_{i}$ é capaz de apresentar a alteração de resultados necessária para que $s q$ mate $N^{\prime}$. Por isso, a Definição 3 (Página 73) pode ser modificada para capturar esse aspecto. 
Definição 4. Dada uma $R P N$, uma rede mutante de $N^{\prime}$ cuja mutação ocorreu no lugar $p_{i}$, e uma seqüência sq de transições, sq mata $N^{\prime}$ se $\mu_{0}[s q\rangle \mu$ e

$$
\begin{aligned}
& \text { ou } \left.\mu_{0}^{\prime} \chi s q\right\rangle \\
& \text { ou } \mu_{0}^{\prime}[s q\rangle \mu^{\prime} e
\end{aligned}
$$

- ou

$$
0=\mu_{i} \text { e } 0<\mu_{i}^{\prime}
$$

- ou

$$
0<\mu_{i} \text { e } 0=\mu_{i}^{\prime}
$$

A partir de $N^{\prime}$, constrói-se a matriz de incidência $C^{\prime}$, que é utilizada na Equação 4.1. Contudo, apenas a inequação referente ao lugar $p_{i}$ é diferente das inequações obtidas para a rede original. Portanto, basta calcular a inequação de $C^{\prime}$ referente a $p_{i}$ e aplicar a restrição expressa na Definição 4. Dessa forma, dois conjuntos de inequações, cada qual com duas inequações, são definidos a partir de (4.2) e (4.3), como segue (observe-se que as inequações com o operador $<$ foram convertidas para $\leq)$ :

- a partir de (4.2)

$$
\begin{gathered}
-\mu_{i}=\sum_{k=1}^{|T|} C_{i k}^{\prime} v_{k} \\
1-\mu_{i} \leq \sum_{k=1}^{|T|} C_{i k} v_{k}
\end{gathered}
$$

- a partir de (4.3)

$$
\begin{gathered}
1-\mu_{i} \leq \sum_{k=1}^{|T|} C_{i k}^{\prime} v_{k} \\
-\mu_{i}=\sum_{k=1}^{|T|} C_{i k} v_{k}
\end{gathered}
$$

A união do conjunto de inequações de consistência com um dos conjuntos de inequações adicionais, somada à função objetivo, forma um problema de programação linear inteira, cuja solução é um vetor de caracterização $v$. Na verdade, são obtidos dois problemas distintos, sendo um para cada par de inequações adicionais. Como dito anteriormente, se nenhum desses problemas possuir solução, conclui-se que não existe tal vetor $v$ e, conseqüentemente, não existe seqüência de transição que seja capaz de matar $N^{\prime}$. Nesse caso, $N^{\prime}$ é equivalente a $N$. 


\subsubsection{Geração de Seqüências Baseada no Vetor de Caracterização}

Uma vez obtido um vetor de caracterização $v$, o próximo passo é encontrar uma seqüência $s q$, tal que $s q \in S E Q\left(\mu_{0}, v\right)$. Isso é feito pela geração de uma Árvore de Caracterização para $v$, da maneira definida a seguir. Na construção da Árvore de Caracterização, um nó é considerado terminal tão logo possa ser determinado que ele não poderá gerar um nó solução.

Para matar o mutante $N^{\prime}$, tem-se que algumas transições podem ocorrer livremente. Tais transições, chamadas de transições livres, são as que não estão diretamente ligadas ao lugar que sofreu a mutação. O conjunto $\operatorname{livre}\left(p_{i}\right)$ é formado pelas transições livres de $p_{i}$ e é definido como segue:

$$
\operatorname{livre}\left(p_{i}\right)=\left\{t_{k} \mid\left(t_{k}, p_{i}\right) \notin\left(F \cup F^{\prime}\right) \wedge\left(p_{i}, t_{k}\right) \notin\left(F \cup F^{\prime}\right)\right\}
$$

Define-se, então, um símbolo especial $\omega$ que é utilizado para marcar as posições de $v$ correspondentes às transições livres. A exemplo do que ocorre com a Árvore de Cobertura, apresentada na Seção 2.5.2, as operações sobre $\omega$ são definidas de forma a permitir que tais transições possam ocorrer livremente, como segue:

- $\omega-1=\omega$

- $\omega>0$

Dessa forma, dado um vetor de caracterização $v$, cria-se o vetor $v^{*}$ como sendo igual a $v$ exceto que as posições correspondentes às transições livres cujo valor é igual a 0 são substituídas por $\omega$. Assim, tem-se que

$$
v_{k}^{*}= \begin{cases}\omega & \text { se } t_{k} \in \operatorname{livre}\left(p_{i}\right) \text { e } v_{k}=0 \\ v_{k} & \text { caso contrário }\end{cases}
$$

Outro conceito importante durante a execução do algoritmo é a demanda de um lugar, que é o maior peso entre os arcos que ligam as transições a esse lugar. A demanda de $p_{i}$ é definida como segue:

$$
\operatorname{demanda}\left(p_{i}\right)=\max _{t \in T}\left(W\left(p_{i}, t\right)\right)
$$

Se, em uma marcação $\mu$, tem-se que $\mu\left(p_{i}\right) \geq \operatorname{demanda}\left(p_{i}\right)$, pode-se concluir que nenhum acréscimo no número de marcas de $p_{i}$ contribuirá para aumentar o conjunto de transições habilitadas. Assim, dadas as marcações $\mu^{\prime}$ e $\mu^{\prime \prime}$, tais que para todo $p_{k} \in P$ para o qual $\mu_{k}^{\prime} \geq \mu_{k}^{\prime \prime}$, tem-se que $\mu_{k}^{\prime \prime} \geq \operatorname{demand} a\left(p_{k}\right)$, tem-se que todas as transições habilitadas em $\mu^{\prime}$ estão habilitadas em $\mu^{\prime \prime}$. Formalmente,

$$
\left(\forall p_{k} \in P, \mu_{k}^{\prime} \geq \mu_{k}^{\prime \prime} \Longrightarrow \mu_{k}^{\prime \prime} \geq \operatorname{demanda}\left(p_{k}\right)\right) \Longrightarrow\left(\forall t \in T, \mu^{\prime}[t\rangle \Longrightarrow \mu^{\prime \prime}[t\rangle\right)
$$


Para o cálculo da seqüência de teste, é gerada uma subárvore da Árvore de Alcançabilidade, a Árvore de Caracterização. Essa árvore é construída com base no vetor de caracterização $v^{*}$. Cada nó da Árvore de Caracterização é formado por um par $(\mu, v)$ no qual $\mu$ é uma marcação e $v$ é um vetor de caracterização e as arestas são rotuladas com transições. Se dois nós $n^{\prime}=\left(\mu^{\prime}, v^{\prime}\right)$ e $n^{\prime \prime}=\left(\mu^{\prime \prime}, v^{\prime \prime}\right)$ são ligados por uma aresta $t_{k}$, tem-se que:

$$
\mu^{\prime}\left[t_{k}\right\rangle \mu^{\prime \prime}
$$

e

$$
v^{\prime \prime}=v^{\prime}-s\left(t_{k}\right)
$$

Se, em um vetor de caracterização $v$ de um nó $n$, para todas as transições $t_{k} \notin$ livre $\left(p_{i}\right)$, tem-se que $v_{i}=0$, então $n$ é um nó "solution" e as transições do caminho que liga a raiz a $n$ formam uma seqüência de teste procurada. A Árvore de Caracterização para um vetor $v^{*}$ pode ser construída por meio do algoritmo a seguir:

Entrada: Uma $\operatorname{RP} N=\left(P, T, F, W, \mu_{0}\right)$ e um vetor de caracterização $v^{*}$

Saída: A Árvore de Caracterização

$\operatorname{GeraArvore}\left(N, v^{*}\right)$

(1) $\operatorname{root} \leftarrow \operatorname{node}\left(\mu_{0}, v^{*}\right)$

(2) $\quad t r \leftarrow$ NewTree $($ root $)$

(3) Unprocessed $\leftarrow\{$ root $\}$

(4) while Unprocessed $\neq \emptyset$

(5) Seja $n=(\mu, v)$ um nó tal que $n \in$ Unprocessed

(6) Unprocessed $\leftarrow$ Unprocessed $-\{n\}$

(7) if $v_{i}=0$ or $v_{i}=\omega$ para todo $t_{i} \in T$ then

(8) $\quad$ label $(n) \leftarrow$ solution

(9) else

(10) $\quad e \leftarrow\left\{t_{k} \mid \mu\left[t_{k}\right\rangle\right.$ and $\left.v_{k}>0\right\}$

(11) if $e=\emptyset$ then

$$
\text { label }(n) \leftarrow \text { dead }
$$

else

$$
\text { foreach } t_{k} \in e \text { do }
$$

$$
\begin{aligned}
& v_{\text {new }} \leftarrow v-s\left(t_{k}\right) \\
& \mu_{\text {new }} \leftarrow \delta\left(\mu, t_{k}\right)
\end{aligned}
$$$$
n_{\text {new }} \leftarrow \operatorname{node}\left(\mu_{\text {new }}, v_{\text {new }}\right)
$$$$
t r_{\text {new }} \leftarrow \operatorname{AddNode}\left(t r, n, n_{\text {new }}, t_{k}\right)
$$$$
\text { if member }\left(n_{\text {new }}, t r\right) \text { then }
$$$$
\operatorname{label}\left(n_{\text {new }}\right)=\text { old }
$$

else

include $\leftarrow$ false

$$
\begin{aligned}
& n_{\text {cover }} \leftarrow \text { CoveringNode }\left(\operatorname{tr}_{\text {new }}, n_{\text {new }}\right) \\
& \text { if } n_{\text {cover }} \neq \text { nil then }
\end{aligned}
$$$$
u p \leftarrow\left\{p \mid \mu_{\text {new }}(p)>\mu_{\text {cover }}(p)\right\}
$$$$
\text { enough } \leftarrow\left\{p \mid p \in \text { up and } \mu_{\text {cover }}<\operatorname{demanda}(p)\right\}
$$

if enough $=\emptyset$ then

$$
\text { label }\left(n_{\text {new }}\right) \leftarrow \text { covered }
$$


(29)

$$
\begin{aligned}
& \text { else } \\
& \quad \text { include } \leftarrow \text { true } \\
& \text { else } \\
& \text { include } \leftarrow \text { true } \\
& \text { if } \text { include then } \\
& \text { Unprocessed } \leftarrow \text { Unprocessed } \cup\left\{n_{\text {new }}\right\} \\
& t r \leftarrow t r_{\text {new }}
\end{aligned}
$$

Como dito anteriormente, construída a árvore, as seqüências de teste desejadas são aquelas formadas pelos rótulos do caminho que liga a raiz a um nó marcado como "solution".

Algumas funções e estruturas de apoio são necessárias para o funcionamento do algoritmo e apresentadas a seguir:

label(node) Atribui um rótulo aos nós da árvore, bem como retorna o rótulo de um nó específico.

NewTree(node) Cria uma árvore usando node como raiz.

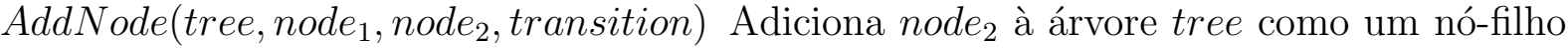
de node $_{1}$, ligando-os com um arco rotulado como transition.

CoveringNode(tree, node) Retorna o último nó no caminho que liga a raiz da árvore ao pai de node cuja marcação associada seja maior ou igual à marcação associada a node. Caso nenhum nó atenda a esse requisito, a função retorna nil. A seguir, é apresentado o algoritmo para CoveringNode. Assume-se a existência de uma função father(node), que retorna o nó pai de node ou retorna nil se node é a raiz da árvore.

CoveringNode (tree, node)

Seja $\mu$ a marcação de node

$n \leftarrow$ father (node)

while $n \neq$ nil

Seja $\mu_{\text {aux }}$ a marcação de $n$

if $\mu_{\text {aux }} \geq \mu$ then

return $n$

$n \leftarrow$ father $(n)$

return nil

member $(n, t r)$ Retorna true se o nó $n$ já está presente na árvore $t$, e false, caso contrário.

A seguir, é demonstrado que o algoritmo apresentado acima sempre pára. Para isso, é necessário o estabelecimento de alguns teoremas auxiliares.

Teorema 1. Cada nó da Árvore de Caracterização é processado no máximo uma vez. 
Prova. Os nós processados são escolhidos no Passo (5) entre os membros de Unprocessed. Os nós pertencentes a Unprocessed são inseridos pelos Passos (3) e (34). Em ambos os casos, esse nó também é adicionado à árvore. Nesse caso, o nó será impedido de ser novamente incluído em Unprocessed pela condição do Passo (20). Portanto, um nó é incluído apenas uma única vez em Unprocessed e, portanto, todo nó é processado no máximo uma vez.

Teorema 2. O número de nós-filho de um nó da Árvore de Caracterização é finito.

Prova. Todos os nós-filho de um nó $n$ são adicionados por meio do Passo (15) que é executado $|e|$ vezes. Como, $e \subseteq T$, cada nó pode possuir no máximo $|T|$ nós-filho, ou seja, um número finito de nós-filho.

Teorema 3. Todo caminho da árvore é finito.

Prova. Por absurdo, assume-se que exista um caminho infinito $L$ na árvore. Seja $U$ uma subsequiência de nós de $L$ cujas marcações são não-decrescentes. Como $L$ é infinito, $U$ também é infinito (Peterson, 1981)[Lema 4-3, pg. 98]. Sejam $n^{\prime}$ e $n^{\prime \prime}$ dois nós consecutivos em $U$, cujas marcações são $\mu^{\prime}$ e $\mu^{\prime \prime}$, respectivamente. Seja $s q$ o caminho que liga $n^{\prime}$ a $n^{\prime \prime}$ em $L$. Dois casos podem ocorrer: $\mu^{\prime}=\mu^{\prime \prime}$ ou $\mu^{\prime} \geq \mu^{\prime \prime}$.

Caso 1. $\mu^{\prime}=\mu^{\prime \prime}$.

Se para toda transição $t_{k}$ em $s q$, tem-se que $t_{k} \in \operatorname{livre}\left(p_{i}\right)$, então $v^{\prime}=v^{\prime \prime}$, pois apenas posições nas quais $v^{\prime}$ é igual a $\omega$ foram subtraídas, e pela definição da operação de subtração de $\omega$, o resultado continua sendo $\omega$. Dessa forma, segue que $n^{\prime}=n^{\prime \prime}$ e, conseqüentemente, $n^{\prime \prime}$ já pertence à árvore e é marcado como "old", no Passo (20). Como as transições não-livres podem disparar somente um número finito de vezes, apenas um número finito de nós iguais ao $n^{\prime \prime}$ para os quais o caso 1 se aplica será incluído em Unprocessed.

Caso 2. $\mu^{\prime} \geq \mu^{\prime \prime}$.

Seja $U p=\left\{p_{k} \mid \mu_{k}^{\prime}>\mu_{k}^{\prime \prime}\right\}$, ou seja, $U p$ é o conjunto de lugares nos quais houve um acréscimo no número de marcas. Para $n^{\prime \prime}$ ser incluído em Unprocessed, é preciso que exista um lugar em $U p$ que tenha menos marcas do que sua demanda. Como a demanda de um lugar é sempre finita, o número de vezes que o caso 2 se aplica, considerando-se um conjunto $U p$ fixo, é finito. Uma vez que existe apenas um número finito de conjuntos $U p$ possíveis (uma vez que $U p \subseteq P$ ), apenas um número finito de nós $n^{\prime \prime}$ para os quais o caso 2 se aplica será incluído em Unprocessed.

Pelos casos 1 e 2, conclui-se que apenas um número finito de nós de $U$ é incluído em Unprocessed e, conseqüentemente, existem infinitos nós de $U$ que não o são. Contudo, se um nó não é incluído em Unprocessed, ele não será escolhido pelo Passo (5) do algoritmo e não terá filhos, sendo um nó terminal. Dessa forma, $U$ é finito. Conseqüentemente, $L$ é finito, o que contradiz a hipótese inicial. 
Teorema 4. O algoritmo de geração da Árvore de Caracterização sempre pára.

Prova. Pelo Teorema 1 cada nó da rede é processado apenas uma vez. Como todo caminho da árvore é finito (Teorema 3) e cada nó possui um número finito de filhos (Teorema 2), o número de nós da árvore é finito. Portanto, o algoritmo pára após ter, no máximo, processado todos os nós da rede.

\subsection{Exemplo}

Nesta seção é apresentado um exemplo da aplicação do algoritmo. O algoritmo é aplicado a RP apresentada na Figura 4.1(a), extraída de (Tanenbaum, 1989). Essa rede é a representação do Nível 3 do protocolo de comunicação OSI. Na Figura 4.1(b) é apresentado um mutante para essa rede, gerado pelo operador InpIns (definido na Seção 2.5.4). O algoritmo é aplicado para gerar uma seqüência de teste que mate esse mutante.

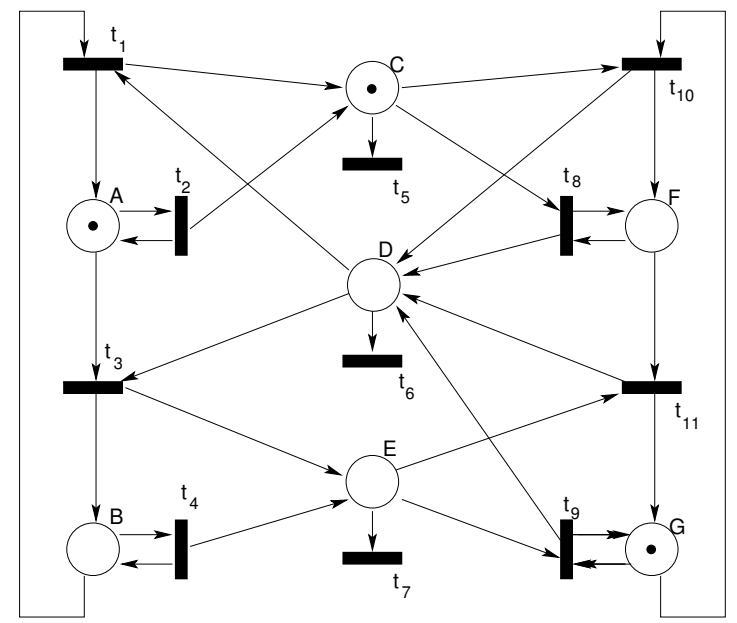

Sender's state
Channel

(a)

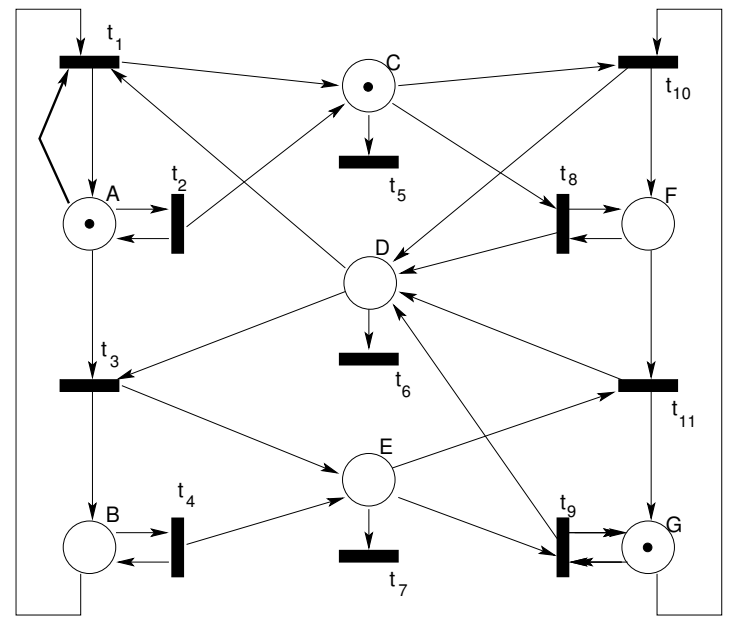

Channel

(b)

Figura 4.1: Uma Rede de Petri para o Nível 3 do Protocolo OSI (Tanenbaum, 1989). 
A inequação matricial de consistência da rede é:

$$
-\left(\begin{array}{l}
1 \\
0 \\
1 \\
0 \\
0 \\
0 \\
1
\end{array}\right) \leq\left(\begin{array}{ccccccccccc}
1 & 0 & -1 & 0 & 0 & 0 & 0 & 0 & 0 & 0 & 0 \\
-1 & 0 & 1 & 0 & 0 & 0 & 0 & 0 & 0 & 0 & 0 \\
1 & 1 & 0 & 0 & -1 & 0 & 0 & -1 & 0 & -1 & 0 \\
-1 & 0 & -1 & 0 & 0 & -1 & 0 & 1 & 1 & 1 & 1 \\
0 & 0 & 1 & 1 & 0 & 0 & -1 & 0 & -1 & 0 & -1 \\
0 & 0 & 0 & 0 & 0 & 0 & 0 & 0 & 0 & 1 & -1 \\
0 & 0 & 0 & 0 & 0 & 0 & 0 & 0 & 0 & -1 & 1
\end{array}\right) \bullet\left(\begin{array}{l}
v_{1} \\
v_{2} \\
v_{3} \\
v_{4} \\
v_{5} \\
v_{6} \\
v_{7} \\
v_{8} \\
v_{9} \\
v_{10} \\
v_{11}
\end{array}\right)
$$

A inequação matricial pode ser convertida em um conjunto de inequações, sendo uma para cada lugar da rede. Assim, o conjunto de inequações de consistência da rede é:

$$
\begin{aligned}
& 1 \leq v_{1}-v_{3} \\
& 0 \leq-v_{1}+v_{3} \\
& 1 \leq v_{1}+v_{2}-v_{5}-v_{8}-v_{10} \\
& 0 \leq-v_{1}-v_{3}-v_{6}+v_{8}+v_{9}+v_{10}+v_{11} \\
& 0 \leq v_{3}+v_{4}-v_{7}-v_{9}-v_{11} \\
& 0 \leq v_{10}-v_{11} \\
& 1 \leq-v_{10}+v_{11}
\end{aligned}
$$

A função objetivo é definida como:

$$
f\left(v_{1}, v_{2}, v_{3}, v_{4}, v_{5}, v_{6}, v_{7}, v_{8}, v_{9}, v_{10}, v_{11}\right)=\sum_{i=1}^{11} v_{i}
$$

Tomando-se a rede mutante da Figura 4.1(b), tem-se que a mutação ocorreu no lugar $A$. Calculando-se a representação matricial do mutante, obtêm-se as seguintes inequações adicionais:

$$
\begin{aligned}
& -1=-v_{3} \\
& 0 \leq v_{1}-v_{3}
\end{aligned}
$$

e

$$
\begin{aligned}
& 0 \leq-v_{3} \\
& -1=v_{1}-v_{3}
\end{aligned}
$$


Solucionando-se a união das inequações de consistência com cada par de inequações adicionais, são obtidos os vetores de caracterização. Nesse caso apenas o segundo par de inequações possui solução, apresentada a seguir:

$$
\langle 1,0,1,0,0,0,0,0,1,1,0\rangle
$$

O conjunto das transições que não estão ligadas a $A$ nem na rede original nem na rede mutante é

$$
\operatorname{livre}(A)=\left\{t_{4}, t_{5}, t_{6}, t_{7}, t_{8}, t_{9}, t_{10}\right\}
$$

Portanto, os vetores de caracterização podem ser transformados de forma a adicionar a informação de que tais transições podem disparar quantas vezes forem necessárias por meio da inclusão de $\omega$.

$$
\langle 1,0,1, \omega, \omega, \omega, \omega, \omega, 1,1, \omega\rangle
$$

Na Figura 4.2, a Árvore de Caracterização para esse vetor é apresentada esquematicamente. Deve-se observar que, por questões de espaço, incluem-se apenas os nós da árvore que conduzem a solução. O nó marcado com o retângulo tracejado é um nó solução e a seqüência de teste correspondente é $\left\langle t_{10}, t_{3}, t_{11}, t_{4}, t_{1}, t_{9}\right\rangle$.

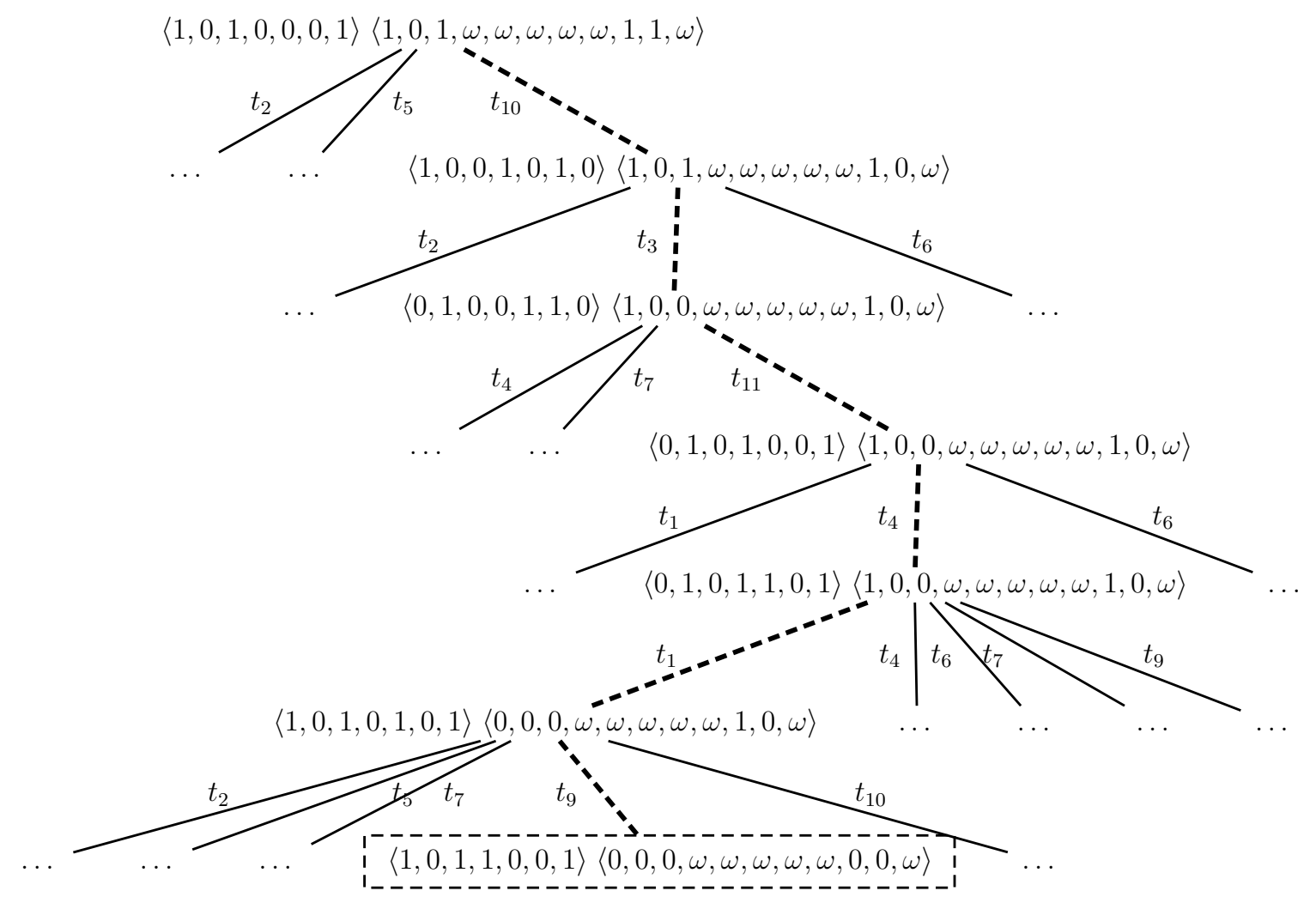

Figura 4.2: Árvore de Caracterização para a Rede da Figura 2.1 com o Vetor de Caracterização $\langle 1,0,1, \omega, \omega, \omega, \omega, \omega, 1,1, \omega\rangle$. 


\subsection{Aplicação do Algoritmo para Redes de Petri Coloridas}

As RPCs estendem as Redes de Petri Lugar/Transição adicionando-lhes conceitos relativos a linguagens de programação de alto nível, tais como tipos de dados, variáveis, etc. Além disso, os arcos das RPCs podem ser rotulados com qualquer função envolvendo constantes, variáveis e operações.

Essas características fazem com que uma RPC não possa ser representada por uma matriz de inteiros, como ocorre com uma RP. Em vez disso, uma RPC deve ser representada por uma matriz de funções. Assim, a aplicação direta do algoritmo para o caso mais geral fica impossibilitada, uma vez que envolveria a resolução de um sistema de inequações cujos coeficientes são funções e não existe um método geral que possa ser aplicado com esse propósito. Contudo, pode-se identificar casos particulares nos quais a RPC pode ser convertida em uma RP para permitir a aplicação do algoritmo. Existem basicamente duas abordagens de conversão e aplicação:

1. Criar uma RP que seja semanticamente equivalente à RPC.

No caso de uma RPC cujas cores são todas finitas, é possível definir uma RP que seja semanticamente equivalente. Esse processo é denominado de unfold (Jensen, 1997b). Em linhas gerais, o processo de unfold pode ser resumido da seguinte forma:

- Para cada lugar $p \in P$ de uma cor $C$ e para cada elemento $v \in C$, cria-se um lugar $p_{v}$.

- Para cada transição $t \in T$ e para cada elemento $v \in C$, tal que $C$ é a cor de algum lugar de entrada ou de saída de $t$, cria-se um lugar $t_{v}$.

- Para cada arco ligando um lugar $p \in P$ de uma cor $C$ e uma transição $t \in T$ e para cada elemento $v \in C$, cria-se um arco ligando $p_{v}$ a $t_{v}$.

Deve-se observar que, em geral, a RP obtida por esse esquema pode ser reduzida, eliminando-se elementos que, apesar de poderem existir, não são efetivamente utilizados na RPC original.

Na Figura 4.3 é apresentada uma RPC semanticamente equivalente à da Figura 2.4, considerando-se $n=3$.

\section{Criar uma RP que seja estruturalmente similar à RPC.}

Nesse caso, as cores da RPC são ignoradas. Assim, as marcas são consideradas como sendo indistintas. Os arcos são convertidos levando-se em conta apenas o número de marcas removidas/adicionadas. Em casos nos quais o número de marcas manipuladas não pode ser determinado (por exemplo, quando a anotação do arco é uma expressão que pode denotar um número diferente de elementos), deve-se considerar o número máximo. 


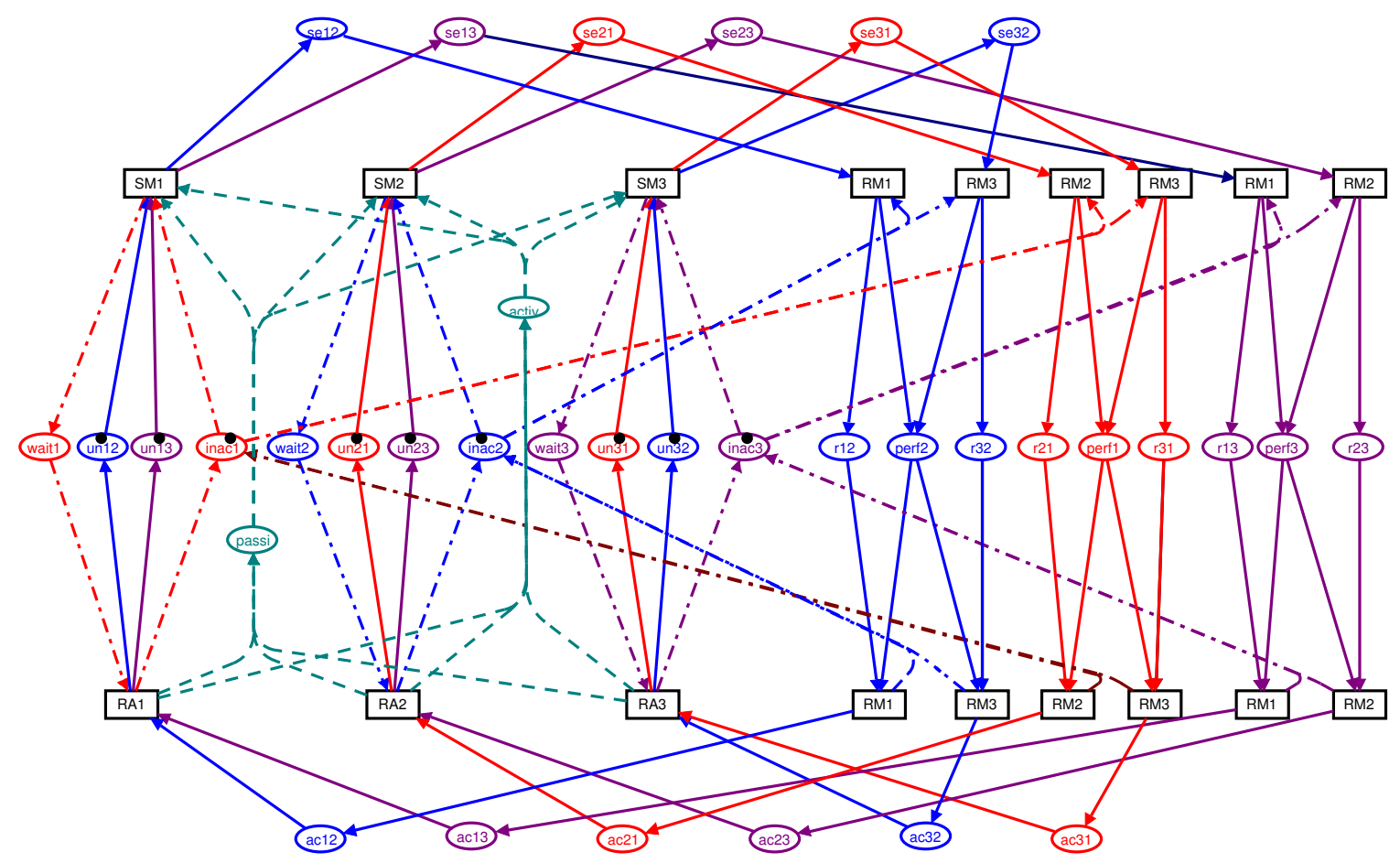

Figura 4.3: Rede de Petri Semanticamente Equivalente à Rede da Figura 2.4.

NA Figura 4.4 é apresentada uma RPC estruturalmente similar à da Figura 2.4.

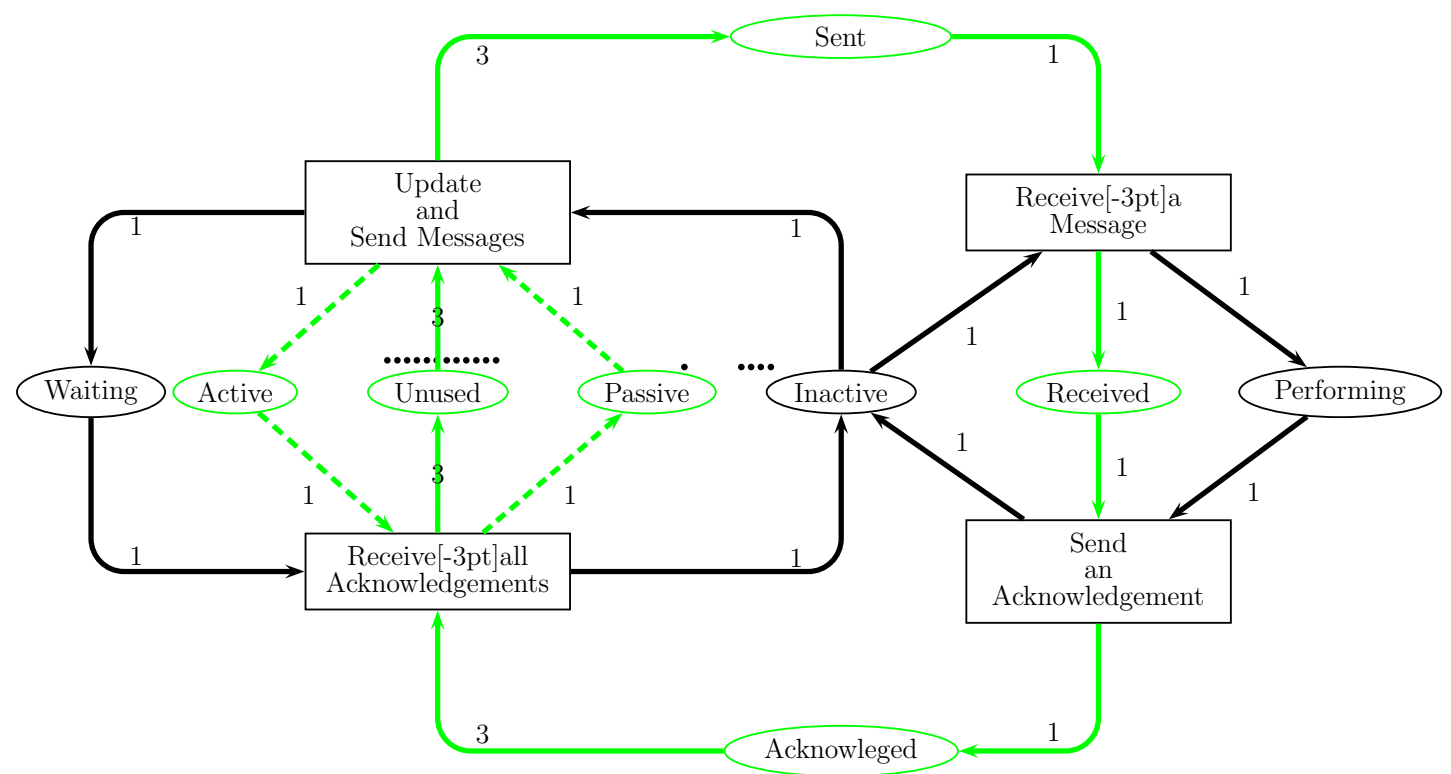

Figura 4.4: Rede de Petri Estruturalmente Similar à Rede da Figura 2.4.

Um ponto a ser destacado é que, as seqüências de teste encontradas para uma RP estruturalmente equivalente à RPC devem ser mapeadas nas seqüências de ligações correspondentes.

Ambas as abordagens possuem vantagens e limitações. Como pode ser observado nas Figuras 4.3 e 4.4, o unfold produz RPs, em geral, maiores do que a segunda abordagem. 
Por refletir mais adequadamente o comportamento da RPC original, a aplicação do algoritmo obtém melhores resultados. Contudo, o unfold apenas pode ser utilizado para RPCs cujas cores são finitas.

A segunda abordagem produz RPs menores e pode ser aplicada a quaisquer RPCs, mesmo as que possuem cores com infinitos elementos. No entanto, como a RP ignora as diferenças entre as marcas, pode ocorrer que as seqüências de teste geradas não sejam necessariamente válidas para a RPC.

\subsection{Considerações Finais}

Neste capítulo apresentou-se um algoritmo para a geração automática de casos de teste e para a identificação automática de mutantes equivalentes. Com o auxílio desse algoritmo, reduz-se consideravelmente a quantidade de mutantes que precisam ser analisados manualmente. Evidências da eficácia do algoritmo podem ser observadas nos resultados apresentados em um estudo de caso descrito no Capítulo 6. O algoritmo baseia-se na representação matricial das RPs para gerar um conjunto de inequações que representam as condições necessárias para que uma seqüência de teste mate um mutante específico. Se esse conjunto de inequações não puder ser satisfeito, conclui-se que o mutante é equivalente à rede original. A partir de uma solução para esse conjunto, procura-se encontrar uma seqüência de teste que corresponda a essa solução, o que é feito por meio da construção e análise da Árvore de Caracterização, uma subárvore da Árvore de Alcançabilidade. O algoritmo para a geração da Árvore de Caracterização também foi apresentado. Deve-se ressaltar que nem sempre o algoritmo apresenta um desses resultados (geração de seqüência de teste ou determinação de equivalência), uma vez que, no caso de não se conseguir encontrar uma seqüência de teste que corresponda a solução encontrada para o conjunto de inequações, não se pode concluir que se trata de um mutante equivalente.

Discutiu-se também a aplicação do algoritmo para RPCs. A aplicação direta não é possível, por envolver a manipulação de sistemas de inequações de alto-nível (cujos coeficientes são funções), os quais não podem ser resolvidos para o caso geral. Foram apresentadas duas abordagens de como converter uma RPC em uma RP e possibilitar a aplicação do algoritmo. Com isso, pode-se obter um conjunto de seqüências de teste para a RP, as quais devem ser mapeadas para obter o conjunto de seqüências para a RPC original.

No próximo capítulo apresentam-se as contribuições deste trabalho no desenvolvimento de ferramentas de apoio e na automatização da atividade de teste. 


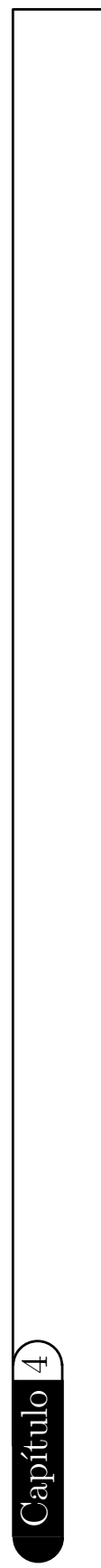




\section{Capítulo 5}

\section{Ferramentas de Apoio}

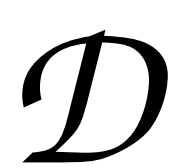

evido ao grande volume de informações que estão envolvidas na aplicação do critério AM, em que, geralmente, um grande número de mutantes deve ser gerado, executado e comparado, a existência de ferramentas de apoio é essencial para a aplicação desse critério. O desenvolvimento de ferramentas para o apoio à atividade de teste é de grande importância, uma vez que sua condução manual é propensa a erros, improdutiva e limitada a produtos muito simples (Harrold, 2000; Horgan e Mathur, 1992).

Neste trabalho, visando a apoiar a aplicação do critério AM para especificações baseadas em RPCs (como descrito no Capítulo 3), foi desenvolvida a ferramenta web Proteum/CPN. A ferramenta oferece um conjunto mínimo de operações que satisfaz os requisitos básicos de uma ferramenta de teste baseada em mutação, os quais são (Delamaro, 1993):

- Tratamento de casos de teste: execução, inclusão/exclusão e habilitação/desabilitação;

- Tratamento de mutantes: geração, seleção, execução e análise; e

- Análise de adequação: escore de mutação e relatórios.

Neste capítulo, a Proteum/CPN é apresentada. Inicialmente, apresentam-se a arquitetura e a modelagem da ferramenta, a qual foi baseada na metodologia Object-Oriented Hypermedia Design Method (OOHDM) (Rossi, 1996). Apresentam-se os aspectos operacionais da ferramenta, exemplificando-se suas principais funcionalidades. Em seguida, são apresentados os aspectos relevantes da implementação da Proteum/CPN. Uma vez que os operadores de mutação foram descritos em $\mathcal{M} u \mathcal{D} e \mathcal{L}$, o sistema mudelgen foi utilizado para gerar os mutantes. Dessa forma, uma descrição desse sistema é também apresentado. 


\subsection{Arquitetura}

A arquitetura da Proteum/CPN é apresentada na Figura 5.1. As funcionalidades da ferramenta encontram-se divididas entre módulos independentes e dependentes. Os módulos independentes são compostos pelas funcionalidades comuns a qualquer ferramenta de mutação. Buscou-se, dessa forma, identificar e isolar as funcionalidades de uma ferramenta de apoio ao critério AM que sejam independentes da linguagem/especificação alvo, visando a promover o reúso de código em outras ferramentas de apoio ao critério AM. Por sua vez, os módulos dependentes possuem as funcionalidades que são estritamente relacionadas às RPCs.

A interação da ferramenta é realizada por meio de interface web. O módulo gerenciador de exibição é responsável pela formatação das páginas, separando os demais módulos de detalhes específicos de exibição. Dessa forma, pode-se alterar toda a aparência das páginas que compõem a ferramenta sem a necessidade de modificar os códigos referentes às funcionalidades. Além disso, é possível personalizar a interface para se adequar às necessidades de uma linguagem/especificação específica.

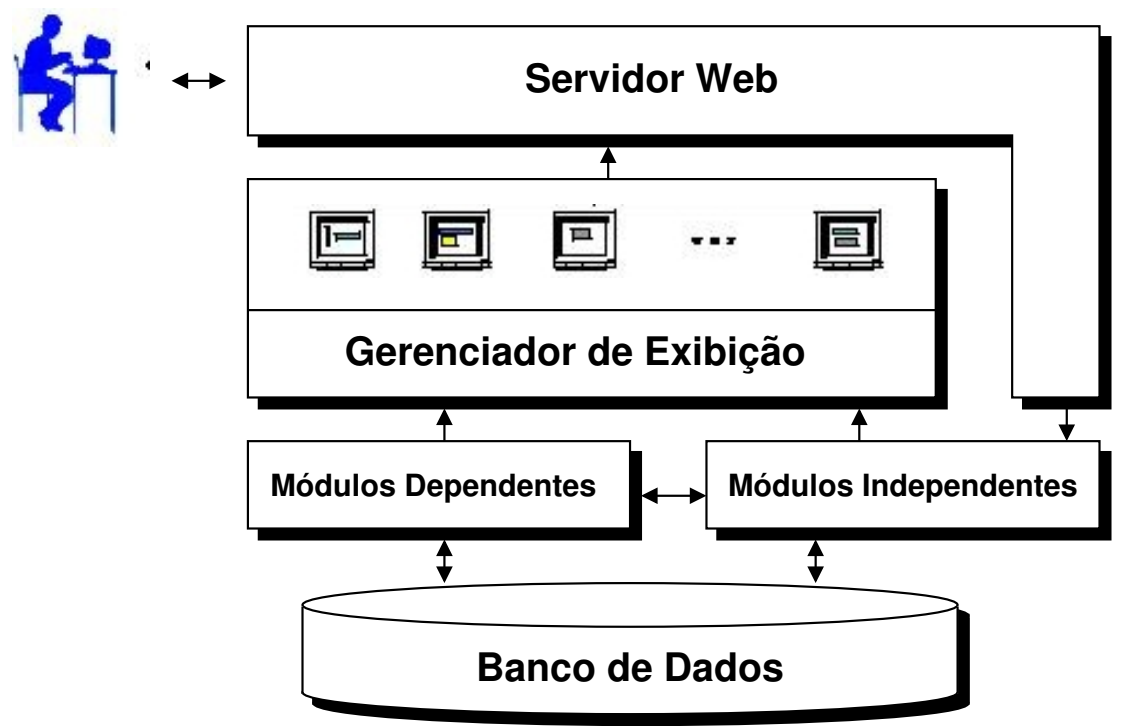

Figura 5.1: Arquitetura da Proteum/CPN.

\subsection{Modelagem}

A modelagem da ferramenta Proteum/CPN é baseada na metodologia OOHDM (Rossi, 1996). Nessa metodologia, são propostas quatro atividades para a construção de uma aplicação hipermídia orientada a objeto: projeto conceitual, projeto navegacional, projeto de interface abstrata e implementação. Em cada uma dessas atividades são gerados alguns produtos. Em particular, para a Proteum/CPN, foram elaborados: o 
esquema conceitual (projeto conceitual), os esquemas navegacionais e de contextos navegacionais (projeto navegacional), os ADVs e ADVcharts (projeto de interface abstrata) e a aplicação em execução (implementação).

\subsubsection{Esquema Conceitual}

O esquema conceitual é um diagrama composto por classes representativas da ferramenta, seus relacionamentos (associação, generalização, composição, agregação, entre outros) e pelos subsistemas que as agrupam. Na Figura 5.2 é apresentado o esquema conceitual da Proteum/CPN. As linhas tracejadas dessa figura estabelecem uma divisão entre as classes relacionadas ao gerenciador de exibição, módulos independentes e módulos dependentes apresentados na arquitetura da ferramenta (Figura 5.1).

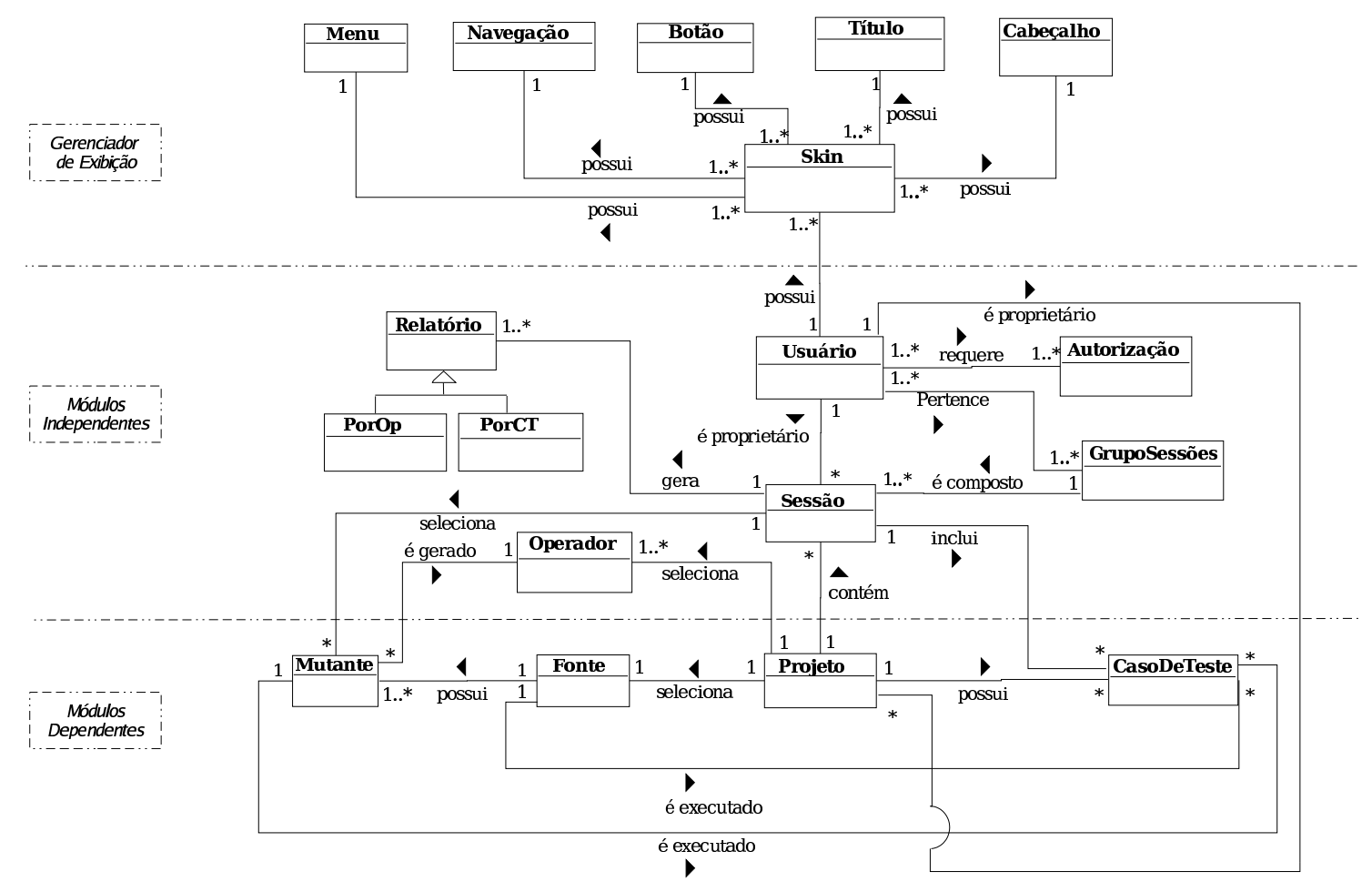

Figura 5.2: Esquema Conceitual da Proteum/CPN.

O usuário da Proteum/CPN tem a opção de escolher um determinado skin para exibir a ferramenta. Para cada skin, varia-se o modo de exibição do menu, dos botões, do título, do cabeçalho e dos navegadores de tabelas.

$\mathrm{O}$ acesso à ferramenta Proteum/CPN é controlado por contas protegidas por senhas. Cada usuário deve requerer a autorização do administrador para possuir uma conta.

A organização na Proteum/CPN é feita por projetos e sessões, a qual permite minimizar o número de gerações de mutantes e execuções de casos de teste. Isso é de grande importância para a condução de estudos empíricos que utilizam um produto a ser 
testado com o mesmo conjunto de mutantes (ou um subconjunto desse) e/ou com casos de teste similares.

Cada projeto determina a RPC a ser testada e o conjunto de operadores que será utilizado para a geração dos mutantes. Um projeto pode possuir uma ou mais sessões de teste. Uma sessão pode importar qualquer subconjunto dos mutantes gerados no projeto ao qual pertence.

Existe também a noção de grupo de sessões que facilita o trabalho cooperativo entre um grupo de testadores. Um grupo é formado por usuários de várias sessões de um mesmo projeto, sendo que os mutantes são particionados entre as sessões do grupo conforme o número máximo de mutantes que cada um pode possuir.

Em uma sessão de teste, antes de se incluir um caso de teste, RPC original é simulada para verificar se o resultado obtido está correto. Caso afirmativo, pode-se incluir o caso de teste para executar os mutantes. Como um caso de teste pode ser inserido em outra sessão do projeto e a fim de se evitar a execução dos mutantes com o mesmo caso de teste, todos os casos de teste são pertencentes ao projeto e todos os mutantes são executados. Assim, quando um caso de teste já existente em projeto for inserido em outra sessão, apenas é necessário consultar as informações sobre sua execução.

Com o objetivo de possibilitar a análise das informações de uma sessão de teste, na Proteum/CPN são disponibilizados dois tipos de relatórios: por operador e por caso de teste. No primeiro, é apresentada a quantidade de mutantes vivos, mortos e equivalentes referente a cada operador. No segundo, resumem-se informações sobre a execução de cada caso de teste.

\subsubsection{Esquema Navegacional}

No esquema navegacional, é definida a visão navegacional do esquema conceitual. Cada visão navegacional corresponde a uma aplicação em OOHDM, que é construída considerando-se os tipos de usuários e o conjunto de tarefas que deverão ser desempenhadas. Assim, diferentes esquemas navegacionais podem ser definidos para o mesmo esquema conceitual, dependendo do perfil de cada usuário e das tarefas da aplicação, expressando-se, dessa maneira, visões diferenciadas do mesmo domínio.

Nas Figuras 5.3, 5.4 e 5.5 são apresentados os esquemas navegacionais da Proteum/CPN, sendo que cada um representa uma visão navegacional correspondente a um tipo de usuário da ferramenta. Na Proteum/CPN, existem três tipos de usuário:

(i) administrador, que é responsável por autorizar a inclusão de outros usuários ao sistema;

(ii) proprietário de projeto, que possui permissão para criar/excluir projetos, para determinar quais usuários podem participar de um projeto, como também, para criar/excluir sessões em seus projetos; e 
(iii) usuário de sessão, que possui apenas permissão para criar/excluir sessões em um projeto já existente.

Todos os usuários podem escolher um dos skins disponíveis da ferramenta como modo de exibição.

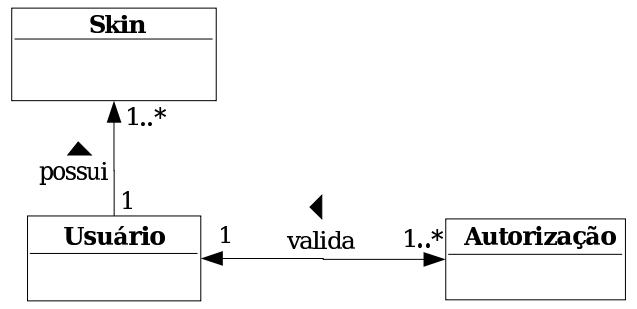

Figura 5.3: Esquema Navegacional da Proteum/CPN - Visão do Administrador.

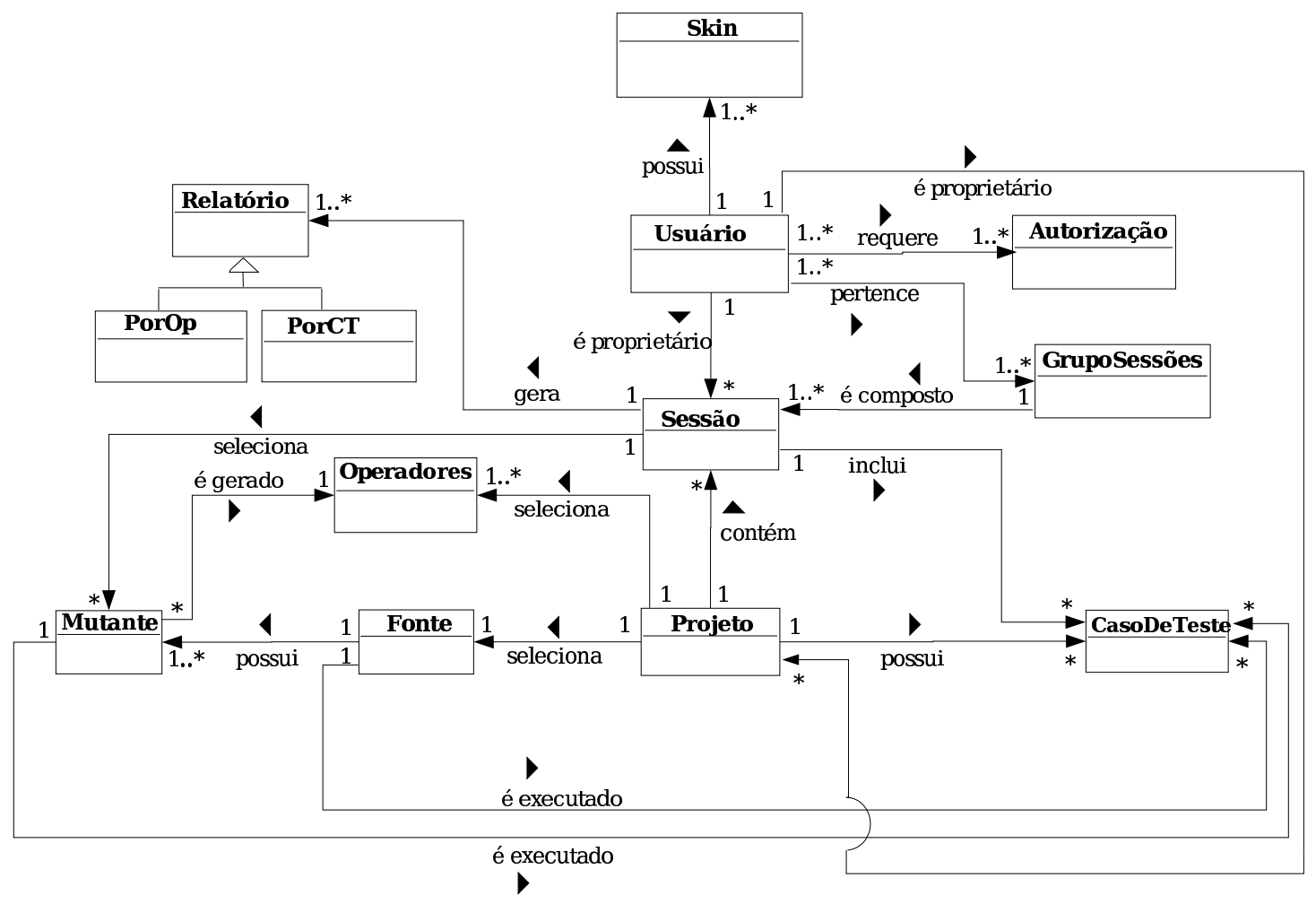

Figura 5.4: Esquema Navegacional da Proteum/CPN - Visão do Proprietário de Projeto.

Após a elaboração dos esquemas navegacionais, define-se em quais contextos será permitida a navegação entre as informações e quais informações serão apresentadas. Isso é representado por meio do esquema de contextos de navegação. Na Figura 5.6 é mostrado esse esquema para a ferramenta Proteum/CPN, apresentando seus contextos de navegação e as estruturas de acesso. Pelo esquema de contextos de navegação, pode-se observar que o usuário, após a validação de sua conta, tem acesso às informações contidas 


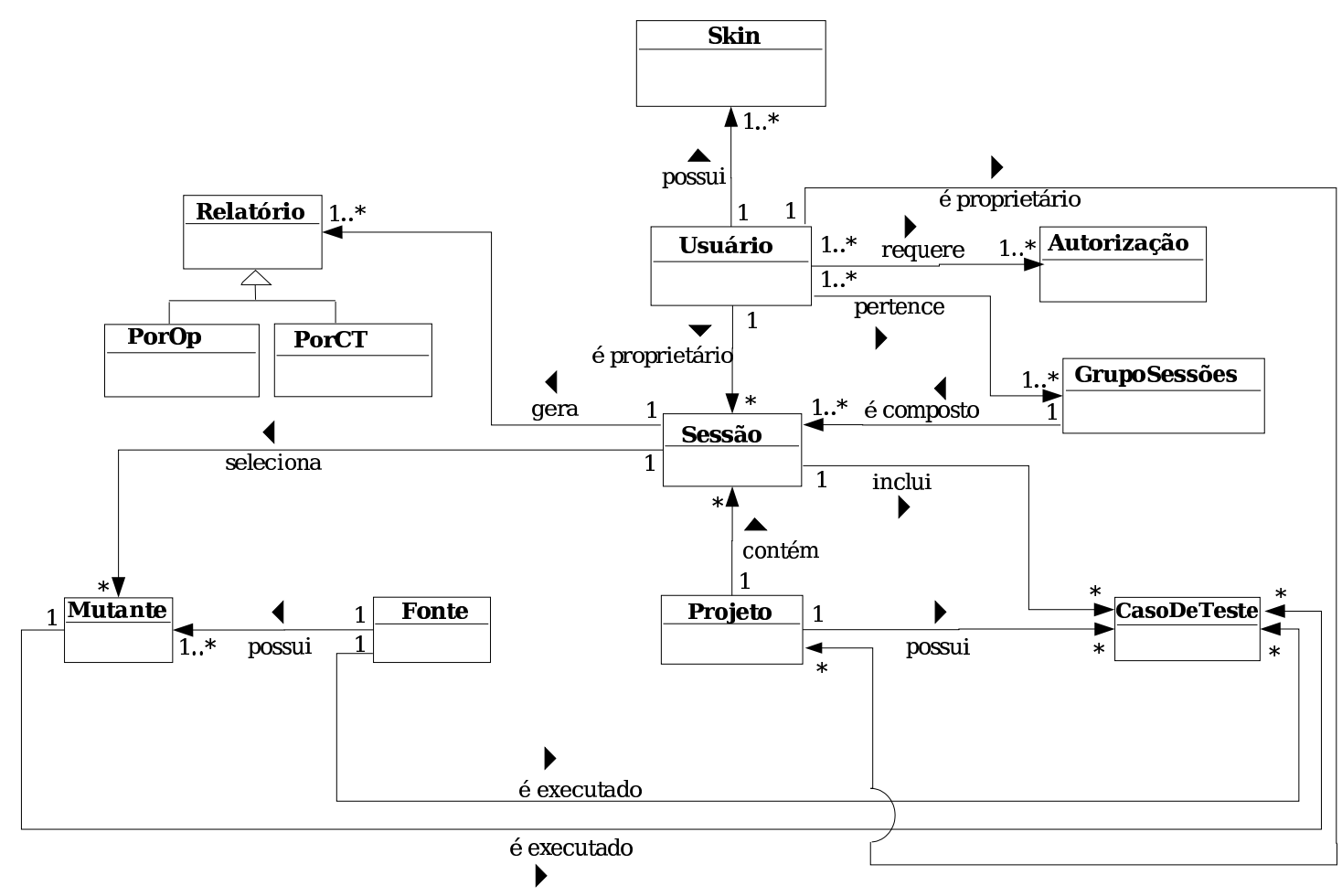

Figura 5.5: Esquema Navegacional da Proteum/CPN - Visão do Usuário de Sessão.

na ferramenta. Se o usuário for o administrador, são apresentadas as informações correspondentes a pedidos de autorização de conta. O administrador pode aceitar ou negar o pedido. Se o usuário for um proprietário de projeto ou sessão, o acesso é iniciado pela lista de projetos e a partir da escolha de um projeto tem-se acesso à lista de sessões. Além disso, no caso de o usuário ser um proprietário do projeto, pode-se excluir ou inserir novos projetos.

Após a criação de um projeto, esse é inserido na lista de projetos e seu status é marcado como inicial. Em seguida, deve-se selecionar o código fonte, o conjunto de operadores de mutação do projeto e a relação de equivalência a ser utilizada. Feito isso, o status do projeto torna-se finalizado e, dessa maneira, pode-se criar sessões de teste no mesmo. Em uma sessão, pode-se determinar seu grupo e o número máximo de mutantes que possuirá, inserir/remover/visualizar mutantes, inserir/remover/habilitar/desabilitar casos de teste e analisar as informações da sessão pelos relatórios por operador ou por caso de teste.

\subsubsection{Modelo de Interface Abstrata}

No projeto de interface abstrata, define-se como serão os objetos de interface, tais como objetos navegacionais, barras de menu e botões de controle, suas propriedades e transformações, obtendo-se um modelo de interface. Esse modelo especifica quais e como 


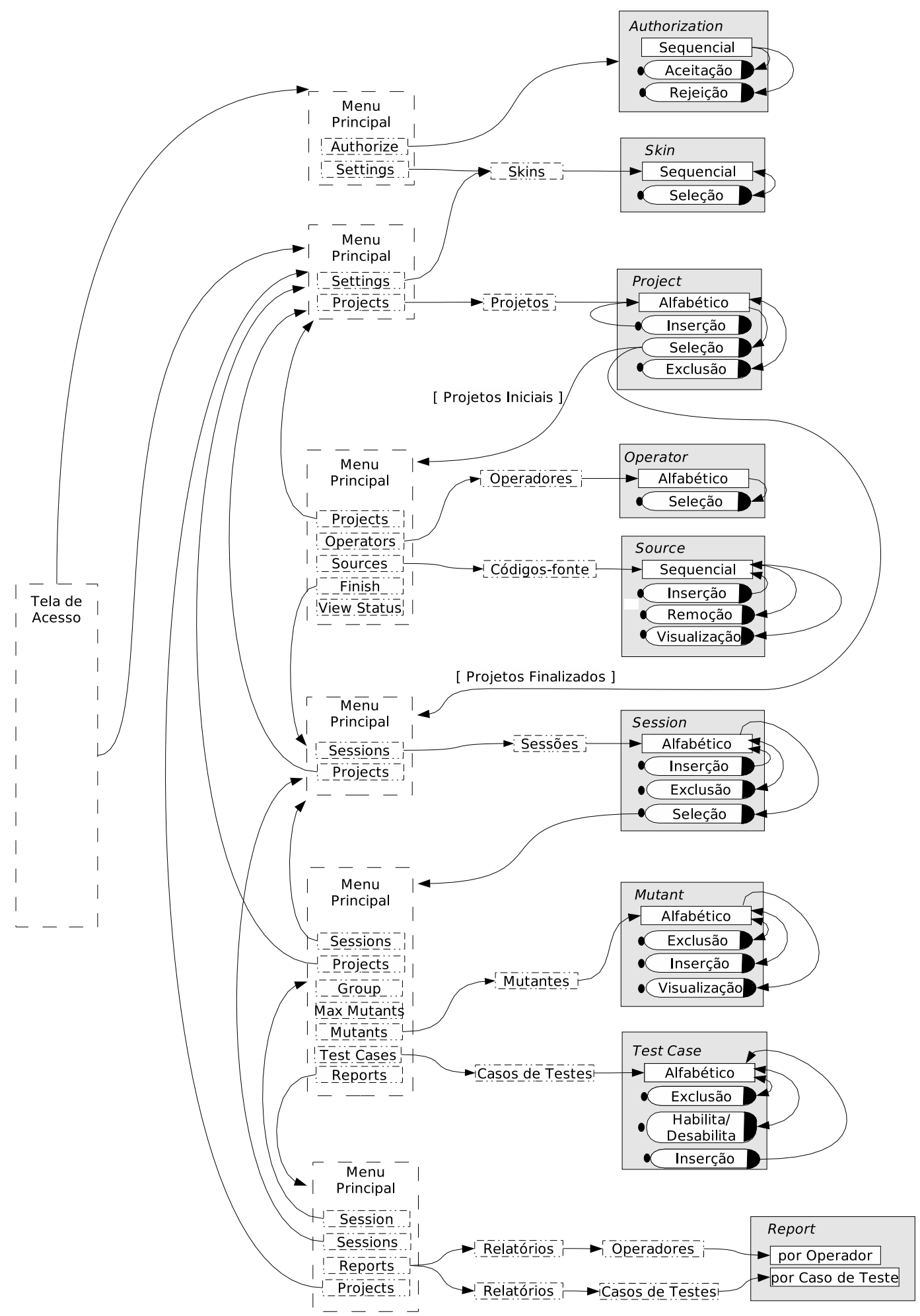

Figura 5.6: Esquema de Contextos Navegacionais da Proteum/CPN.

os objetos de interface são visualizados pelo usuário, quais objetos ativam a navegação, como os objetos são sincronizados e quais transformações ocorrem na interface. Segundo Rossi (1996), a separação entre a interface abstrata e a modelagem navegacional permite 
a construção de diferentes interfaces para o mesmo modelo de navegação, tornando o projeto mais flexível em relação às necessidades ou preferências dos usuários e também à tecnologia utilizada para a construção da interface.

No OOHDM, utilizam-se ADVs (Abstract Data View) para especificar o modelo de interface abstrata. Nos ADVs são definidos os aspectos estáticos dos objetos de interface e o modo como esses objetos estão relacionados aos objetos navegacionais. Os ADVs são utilizados para determinar a aparência dos objetos da ferramenta sem se preocupar com sua implementação. Na Figura 5.7 é apresentado o ADV de mais alto nível da Proteum/CPN. Nessa figura é apresentado o ADV da tela principal da Proteum/CPN composta pelo Menu Principal, Área de Status do Usuário, Rodapé e por uma área com conteúdo variado. O Menu Principal é sensível ao contexto da informação que está sendo apresentada, conforme pode-se observar na Figura 5.6 pela sobreposição parcial dos diversos contextos (Login, Autorização, etc). Na Área de Status do Usuário é mostrado o nome do usuário, além das informações obtidas ao longo da navegação, como o nome e código do projeto atual e o nome e código da sessão atual. Na área com conteúdo variado são exibidas informações de acordo com as opções do usuário, as quais são apresentadas nos próximos ADVs.

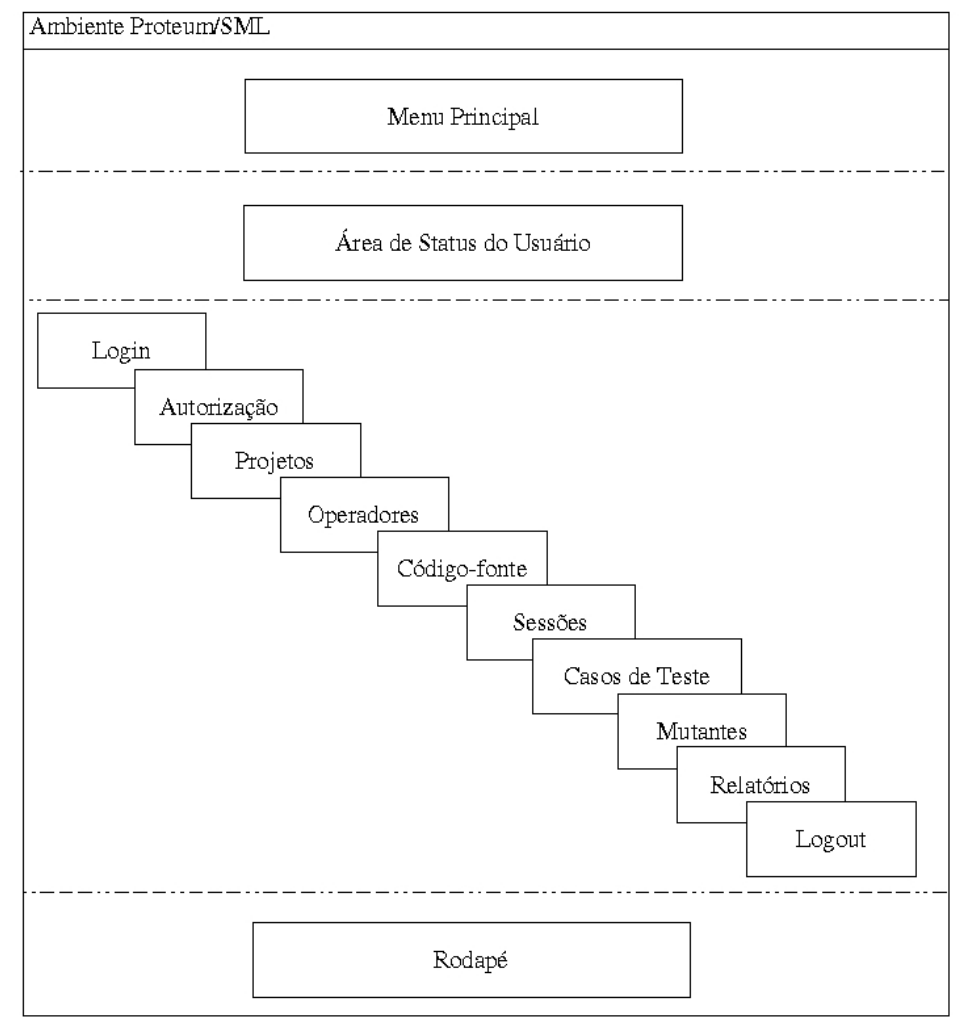

Figura 5.7: ADV da Proteum/CPN.

Na Figura 5.8 são apresentados os ADVs da área com conteúdo variado da Figura 5.7. Os ADVs de mais baixo nível da ferramenta Proteum/CPN são mostrados na Figura 5.9. 
O ADV Login (Figura 5.8(a)) é composto por uma área de formulário, onde o usuário informa o nome e senha da sua conta, por um botão para efetuar o acesso à ferramenta e por um botão que se obtém o formulário de registro de pedidos de novas contas de usuário. Esse formulário é mostrado no ADV Formulário de Registro (Figura 5.9(a)), que contém os campos para preencher as informações sobre a conta, um botão para efetuar o pedido e um texto descrevendo cada campo do formulário. O ADV Logout (Figura 5.8(b)) possui uma área de texto, que mostra uma mensagem de finalização do uso da ferramenta, e um botão para efetuar novamente o acesso à ferramenta. No caso do usuário administrador, existe o ADV Autorização (Figura 5.8(c)) que possui botões para aceitar ou rejeitar pedidos de novas contas além da lista de pedidos. Esse mesmo ADV também é utilizado pelos usuários proprietários de projetos para autorizar outros usuários a participarem de seu projeto.

O ADV Projetos (Figura 5.8(d)) é dividido em duas partes: criação e seleção de projeto. Para a criação, existe um formulário e um botão para criar o projeto. $\mathrm{O}$ formulário é composto por um campo no qual informa-se o nome do projeto a ser criado e por uma opção de projeto privado. Para a seleção, existe uma lista dos projetos existentes e os respectivos botões de exclusão. Em um projeto, selecionam-se os operadores de mutação e o código fonte a ser testado, além da relação de equivalência a ser utilizada. No ADV Operadores (Figura 5.8(e)) há uma lista de operadores selecionados e outra de disponíveis, botões para fazer a inclusão e exclusão de operadores. No ADV Código fonte (Figura 5.8(f)) existe um botão que abre uma janela de diálogo para selecionar o arquivo do código fonte a ser testado e botões para inserir o arquivo selecionado, para visualizar e para remover o código fonte.

O ADV Sessões (Figura 5.8(g)), como o ADV Projetos, também é dividido em duas partes: criação e seleção de sessão. Para a criação, existe um formulário e um botão para criar a sessão. O formulário é composto por campos nos quais se informam o nome da sessão a ser criada, o nome do grupo de sessão, o número máximo de mutantes e o nome do proprietário da sessão. Informa-se também se a sessão é privada e se possui permissão para incluir/remover mutantes. Para a seleção, existe uma lista das sessões existentes no projeto atual e os respectivos botões de exclusão. Além disso, há uma tabela que resume as informações das sessões do projeto, tais como o número de sessões, de grupo de sessões, de mutantes e de casos de teste do projeto. Em uma sessão, selecionam-se mutantes, inserem-se casos de teste e geram-se relatórios. O ADV Mutantes (Figura 5.8(h)) é composto por um botão para inserir/remover mutantes, por uma lista dos mutantes incluídos, por botões que marcam mutantes como equivalente e por botões para se visualizar a RPC original e o mutante lado a lado. A inserção e remoção de mutantes são apresentadas no ADV Incluir/Remover Mutantes (Figura 5.9(c)). Tanto a inserção quanto a remoção podem ser realizadas selecionando-se mutantes por meio de três critérios: (i) por operador, (ii) pelo número do mutante ou (iii) pela linha da especificação 


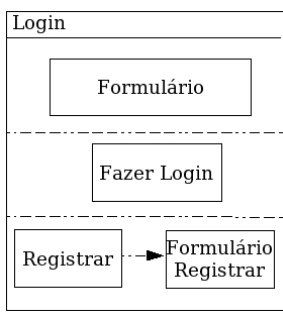

(a) Login

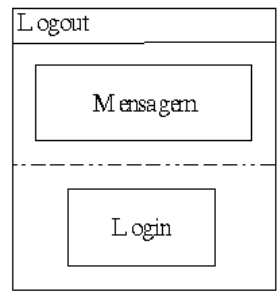

(b) Logout

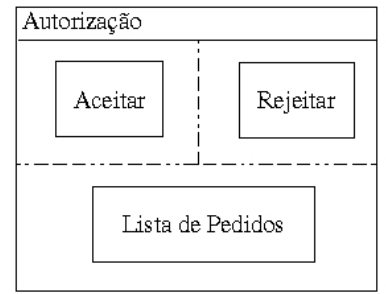

(c) Autorização

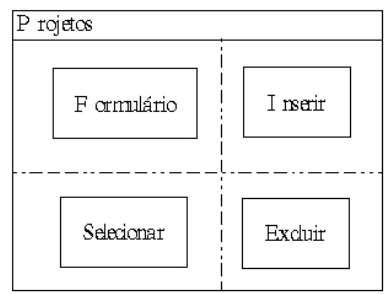

(d) Projetos

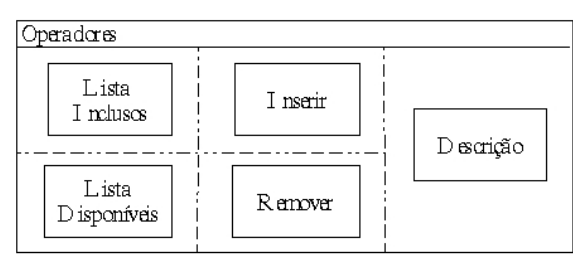

(e) Operadores

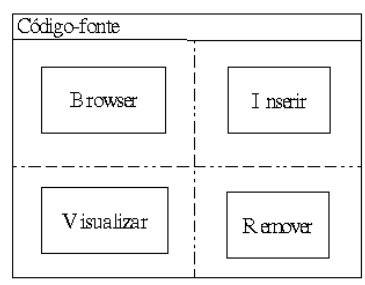

(f) Código Fonte

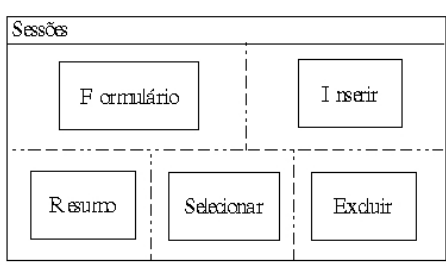

(g) Sessões

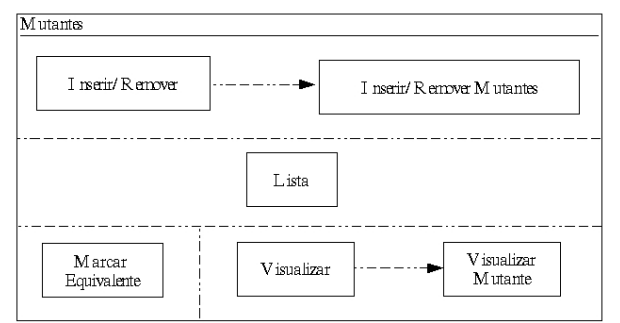

(h) Mutantes

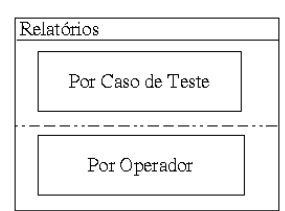

(i)

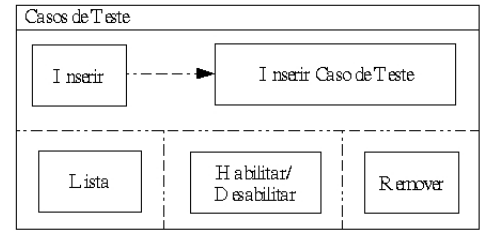

(j) Caso de Teste

Relatórios

que foi mutada. A visualização da RPC original e de um mutante é apresentada no ADV Visualizar Mutante (Figura 5.9(d)). No ADV Casos de Teste (Figura 5.8(j)) encontram-se um botão para inserir casos de teste, uma lista dos casos de teste inseridos e os respectivos botões de exclusão e habilitação/desabilitação de casos de teste. A inserção de casos de teste, que pode ser feita de modo iterativo ou por importação, é apresentada no ADV Inserir Caso de Teste (Figura 5.9(b)). A ferramenta Proteum/CPN disponibiliza dois tipos de relatórios: por operador e por caso de teste, conforme é mostrado no ADV Relatórios (Figura 5.8(i)).

Complementando o projeto de interface, são utilizados ADVs Charts para a especificação dos aspectos dinâmicos da aplicação. Os ADVs Charts expressam transformações no nível de interface de usuário e seu impacto nos objetos navegacionais. Os ADVs Charts são uma generalização de Statecharts (Harel, 1987a), apoiando o aninhamento de estados 


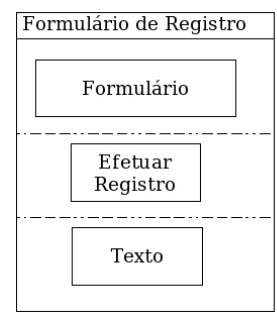

(a)

Formulário de Registro

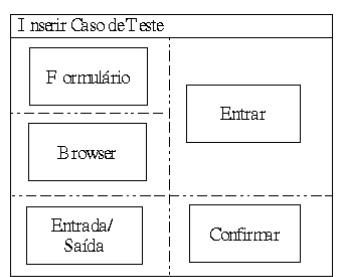

(b) Inserir Caso de Teste

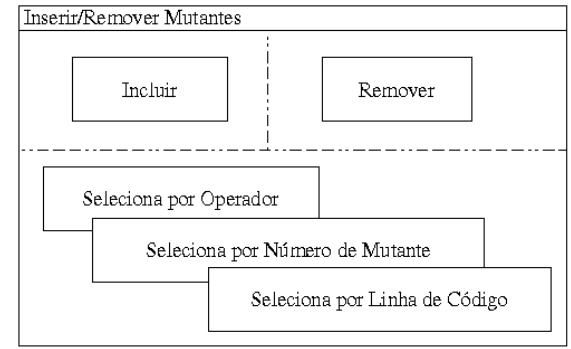

(c) Incluir/ Remover Mutantes

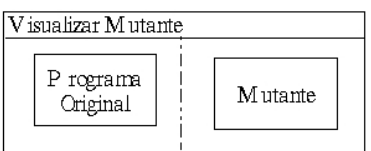

(d) Visualizar Mutante

Figura 5.9: ADVs de Mais Baixo Nível da Ferramenta Proteum/CPN.

e ADVs e permitindo expressar a associação entre eventos externos e ADVs. Por exemplo, no ADV Chart Login (Figura 5.10(a)) é definido o encadeamento de eventos/ações que são disparados instantaneamente, por meio da transição rotulada por 2/3 do estado Conecta em Botão, que ao ocorrer o evento 2 dispara a transição rotulada por 3 do estado paralelo Formulário. Nas próximas figuras são apresentados os ADVs Charts da Proteum/CPN, sendo que em cada figura são descritos os eventos, pré- e pós-condições das transições.

Pode-se observar no ADV Chart Login (Figura 5.10(a)) que após a transição do estado Exibir Desligado para Exibir Ligado, exibi-se um formulário que deve ser preenchido pelo usuário, além do botão Login e Register Form. Quando é pressionado o botão Login, os dados do formulário são autenticados e, caso estejam corretos, a tela volta ao estado Exibir Desligado e a navegação segue pela ferramenta. No caso da autenticação não ser estabelecida, o formulário volta a ser exibido. Pelo botão Register Form obtém-se a tela com o formulário de pedido de nova conta na ferramenta. O pedido é feito pelo ADV Chart Formulário de Registro (Figura 5.11), em que preenche-se um formulário com as informações necessárias para requerer uma conta e, ao pressionar o botão Register, o nome da conta é validado. Se for válido, o pedido é enviado para o administrador. 
O ADV Chart Logout (Figura 5.10(b)) possui um comportamento simples. Quando o usuário pressiona o botão Logout do menu principal, o estado Exibir Ligado passa a ser ativo, mostrando uma mensagem e um botão que conduz à tela de acesso da ferramenta.
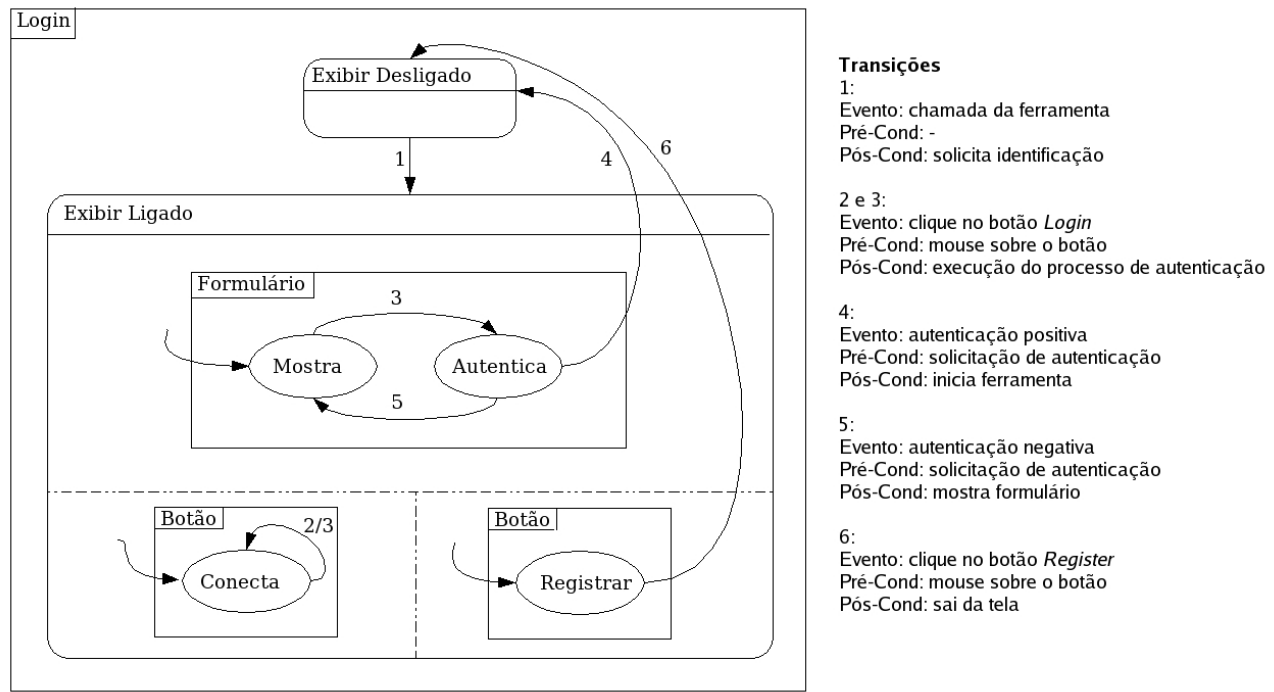

(a) Login

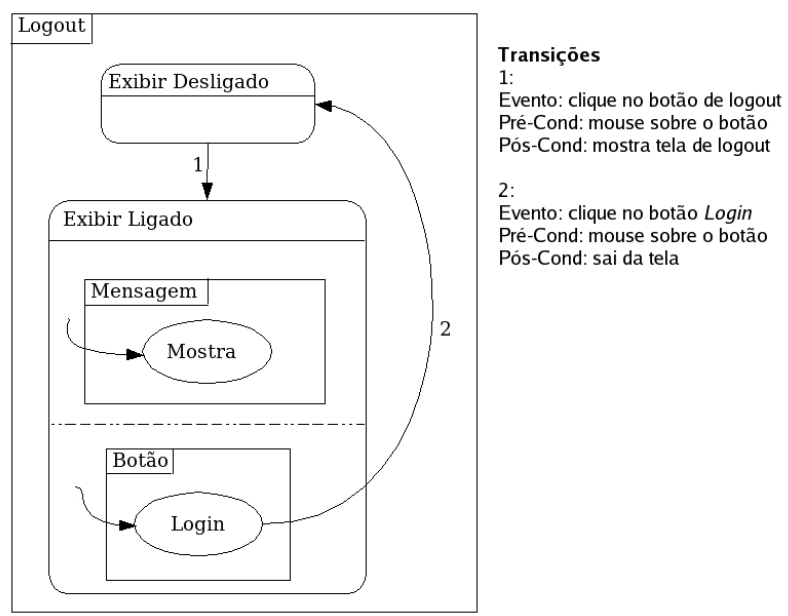

(b) Logout

Figura 5.10: ADV Charts Login e Logout.

Quando o usuário administrador pressiona o botão Authorize do menu principal, o ADV Chart Autorização (Figura 5.12) passa do estado Exibir Desligado para Exibir Ligado. Ao selecionar os pedidos de contas, pressiona-se o botão Grant ou Deny para, respectivamente, aceitar ou rejeitar os pedidos e, em seguida, é atualizada a lista de pedidos. Analogamente, no caso do usuário proprietário de projeto, essa situação está 


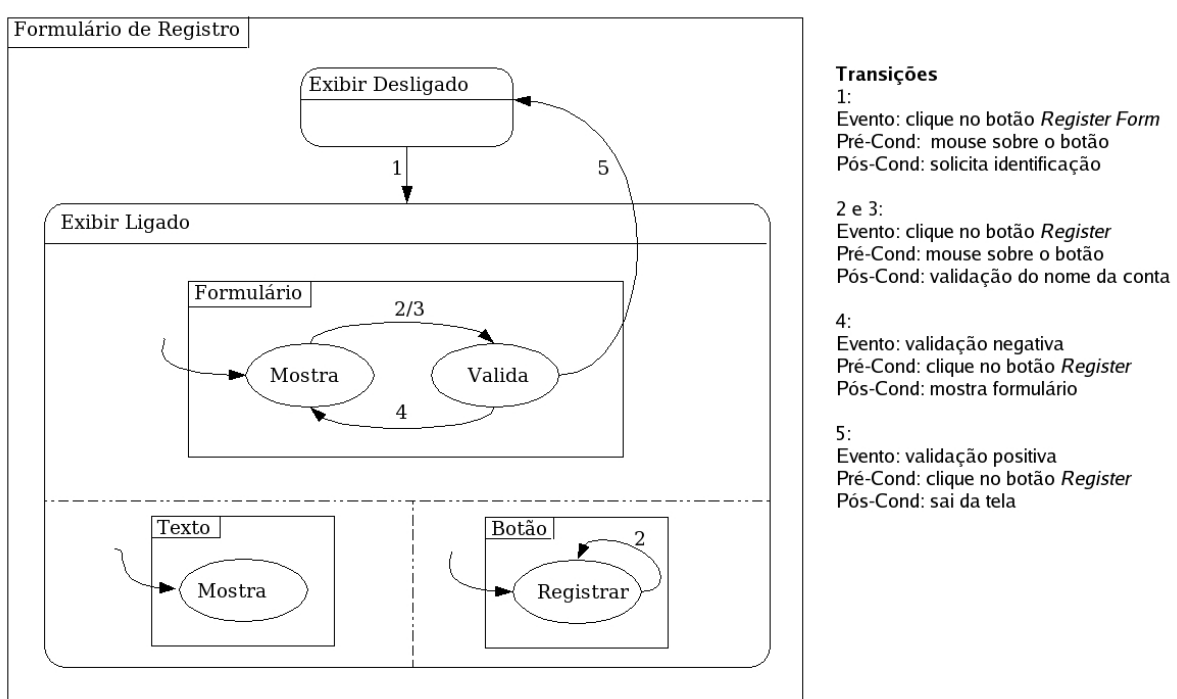

Figura 5.11: ADV Chart Formulário de Registro.

relacionada a autorizar usuários a participarem de seu projeto. Ao pressionar qualquer botão do menu principal, passa-se ao estado Exibir Desligado.

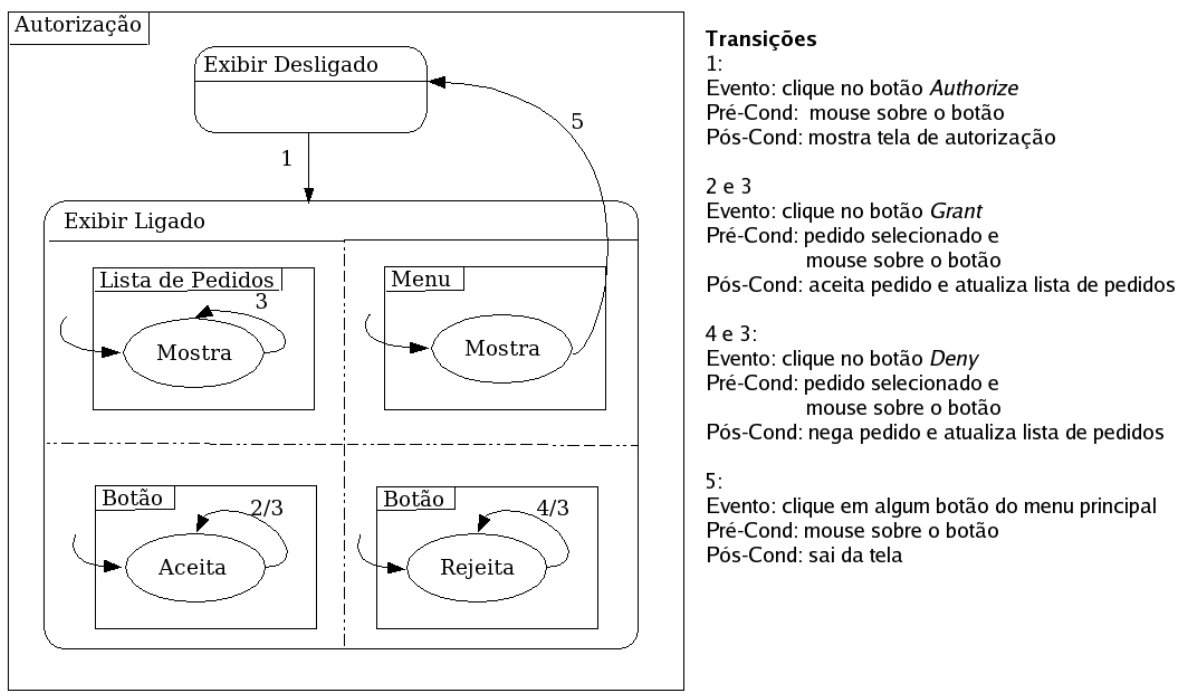

Figura 5.12: ADV Chart Autorização.

Ao pressionar o botão Projects do menu principal, o ADV Chart Projetos (Figura 5.13) passa do estado Exibir Desligado para Exibir Ligado. Nesse ADV Chart é ilustrado o processo de criação, seleção e remoção de um projeto. Ao preencher o formulário para a criação e pressionar o botão Create Project, verifica-se se o nome do projeto é válido. No caso afirmativo, cria-se o projeto e atualiza-se a lista de projetos existentes. No caso negativo, retorna-se ao formulário para nova tentativa de criação. A seleção de um projeto é feita pela lista de projetos. Se o status do projeto selecionado é inicial, mostra-se a tela de seleção de operadores e código fonte. Se o status é finalizado, 
mostra-se a tela de sessões desse projeto. Ao pressionar o botão Delete de um projeto, realiza-se a remoção do projeto e a lista de projetos é atualizada.
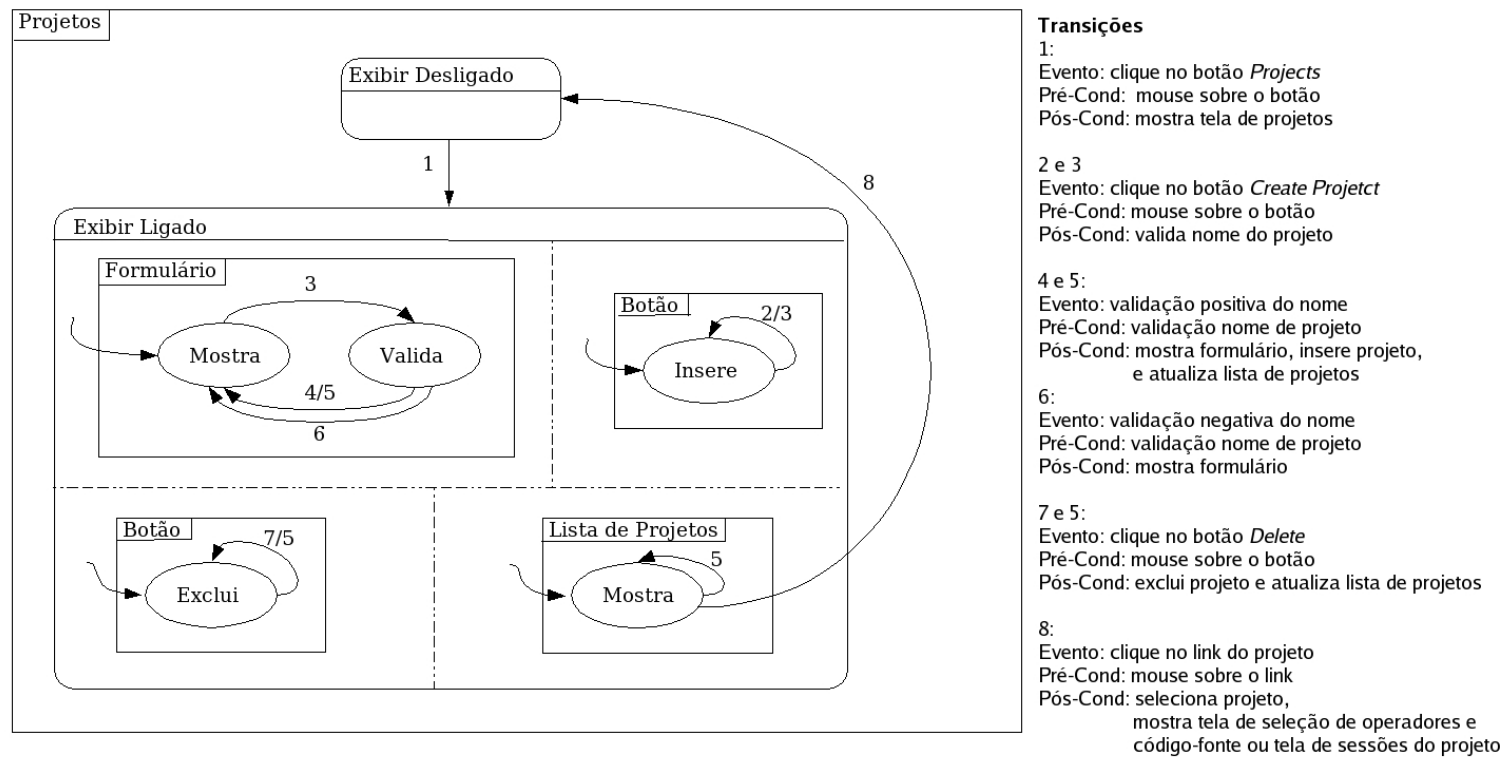

Figura 5.13: ADV Chart Projetos.

Quando um projeto com status inicial é selecionado, no menu principal aparece a opção Operators para seleção dos operadores de mutação do projeto em questão. Ao pressionar esse botão, o ADV Chart Operadores (Figura 5.14) passa do estado Exibir Desligado para Exibir Ligado. Existem duas listas de operadores: a lista de disponíveis, que contém os operadores de mutação que ainda podem ser incluídos no projeto e a lista de operadores selecionados, que contém os operadores já pertencentes ao projeto. Ao selecionar operadores da lista de disponíveis e pressionar o botão "<<", tais operadores de mutação são incluídos no projeto e as listas são atualizadas. Inversamente, ao selecionar operadores da lista de operadores selecionados e pressionar o botão ">>", tais operadores de mutação são removidos do projeto e as listas são atualizadas.

Além da seleção de operadores de mutação, em um projeto com status inicial seleciona-se o código fonte a ser testado. No menu principal aparece o botão Source que, ao ser pressionado, ativa o estado Exibir Ligado do ADV Chart Código Fonte (Figura 5.15). Inicialmente, são exibidos o botão Browser, que abre uma janela de diálogo para selecionar o arquivo com código fonte e o botão Add para a inserção do código fonte no projeto. Ao inserir, são exibidos os botões View e Remove que mostra e remove o código fonte, respectivamente. Após a remoção do código fonte, os botões View e Remove tornam-se novamente desativados.

Ao selecionar um projeto com status finalizado, o ADV Chart Sessões (Figura 5.16) passa do estado Exibir Desligado para Exibir Ligado, sendo exibidas as informações referentes ao projeto selecionado. Analogamente ao ADV Chart Projetos, no ADV Chart Sessões é apresentado o processo de criação, seleção e remoção de uma sessão. Ao 


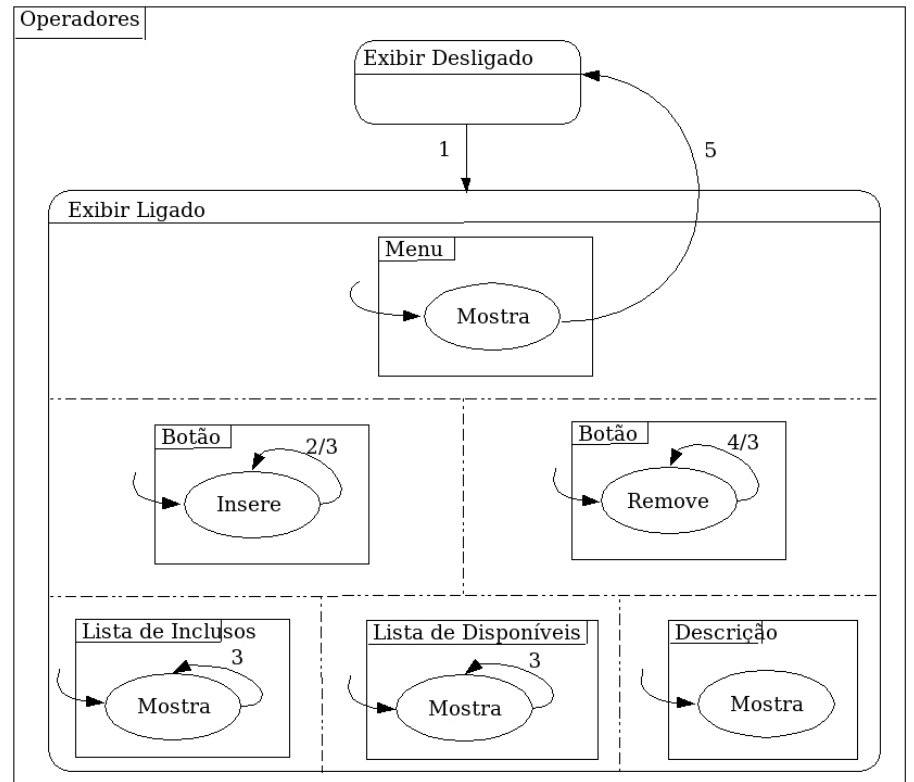

Transiçōes

Evento: clique no botão Operators

Pré-Cond: mouse sobre o botão

Pós-Cond: mostra tela de operadores

2 e 3

Evento: clique no botão <<

Evento: clique no botáo $<<$
Pré-Cond: operador selecionado e

mouse sobre o botão

Pós-Cond: insere operador e atualiza lista de operadores inclusos e disponiveis

4 e 3:

Evento: clique no botão >>

Pré-Cond: operador selecionado

mouse sobre o botão

Pós-Cond: remove operador e atualiza lista de operadores inclusos e disponiveis

Evento: clique em algum botão do menu principal Pré-Cond: mouse sobre o botão

Pós-Cond: sai da tela

Figura 5.14: ADV Chart Operadores.

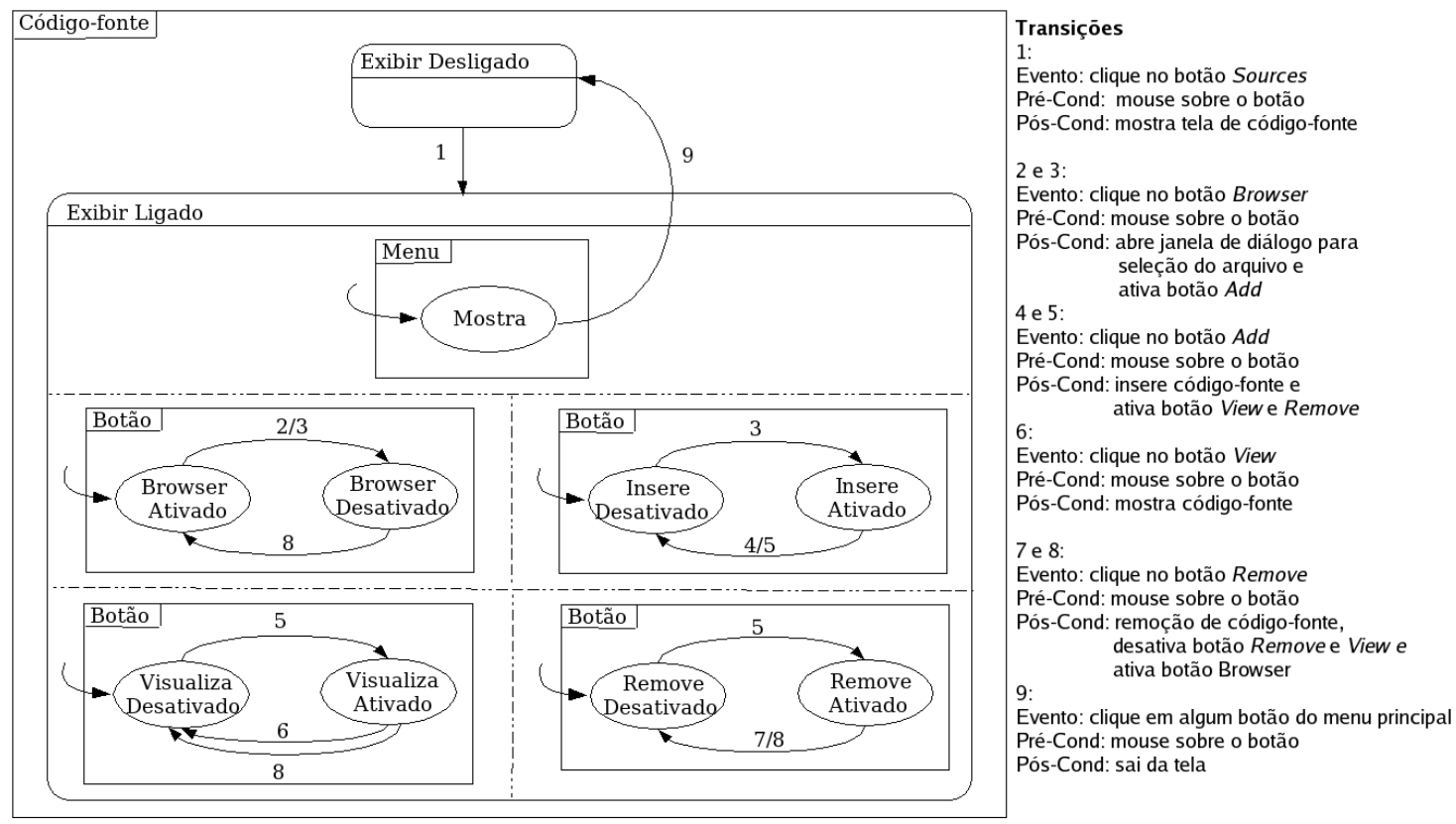

Figura 5.15: ADV Chart Código Fonte.

preencher o formulário para a criação e pressionar o botão Create Session, verifica a validade do nome da sessão. No caso afirmativo, cria-se a sessão e atualizam-se a lista de sessões e a tabela resumo. No caso negativo, retorna-se ao formulário para nova tentativa de criação. Ao selecionar uma sessão na lista de sessões, são mostradas as informações correspondentes a essa sessão, tais como casos de testes, mutantes e relatórios. Ao pressionar o botão Delete de uma sessão, realiza-se a remoção da sessão e atualizam-se a lista de sessões e a tabela resumo. 


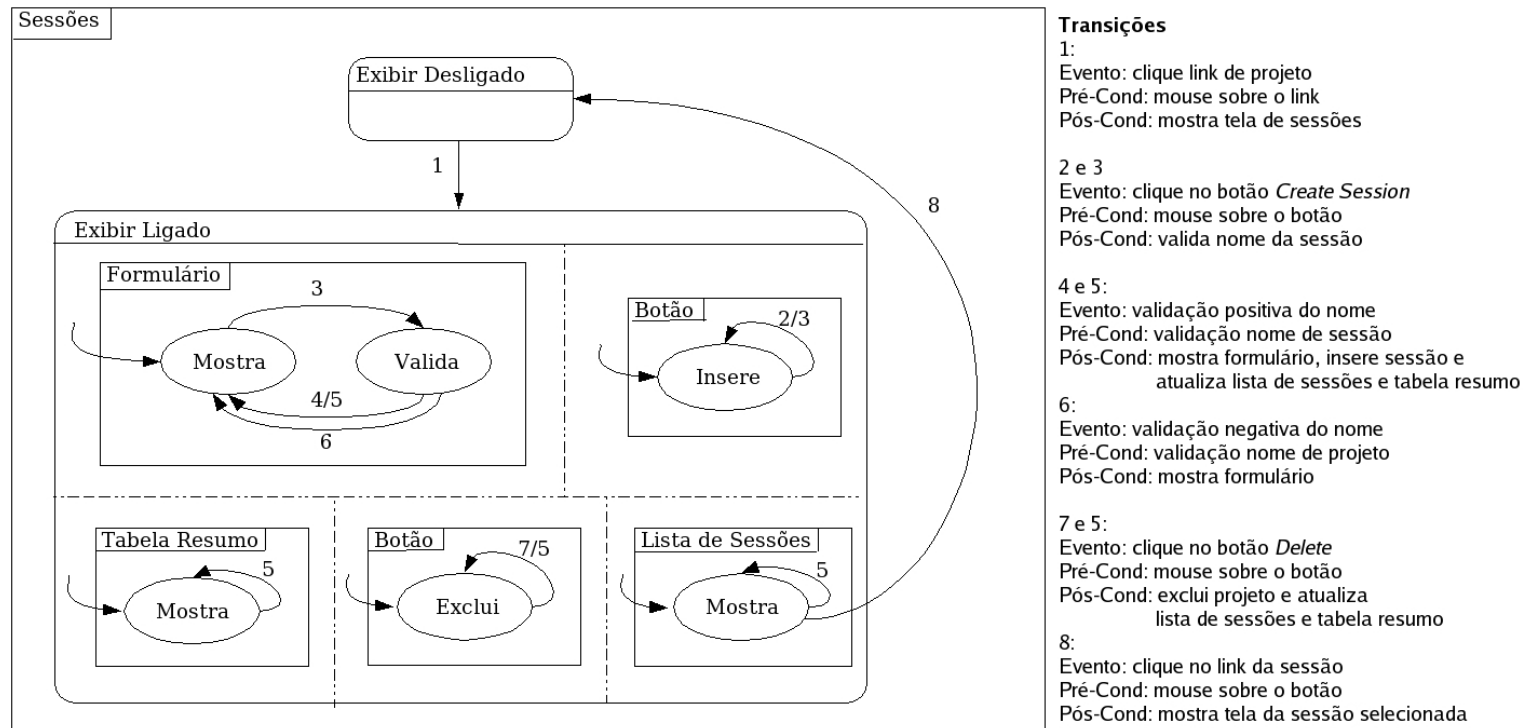

Figura 5.16: ADV Chart Sessões.

Ao selecionar uma sessão de teste, no menu principal é exibido o botão Test Cases para a visualização da lista de casos de testes inseridos na sessão e para a inserção dos mesmos. Ao pressionar esse botão, ativa-se o estado Exibir Ligado do ADV Chart Casos de Teste (Figura 5.17) que exibe um botão para a inserção de caso de teste e a lista de casos de teste. Para cada caso de teste, existe um botão Remove que ao ser pressionado remove o caso de teste e, atualizando-se a lista de casos de teste. Além disso, para cada caso de teste, existe um botão de habilitação/desabilitação que por default é rotulado como Disable para desabilitar o caso de teste e se for pressionado, o rótulo do botão torna-se Enable para habilitar o caso de teste. A fim de inserir um caso de teste, pressiona-se o botão Include Test Case encontrado na tela de casos de teste, ativando assim o estado Exibir Ligado do ADV Chart Inserir Caso de Teste (Figura 5.18). Pode-se inserir um caso de teste de duas formas: por interação e por importação. Na inclusão interativa, o usuário fornece o caso de teste por meio da simulação dos disparos das ligações (mais detalhes são apresentados na Seção 5.3.10). Na importação, o usuário escolhe os casos de teste entre os disponíveis nas sessões às quais ele tem acesso. 


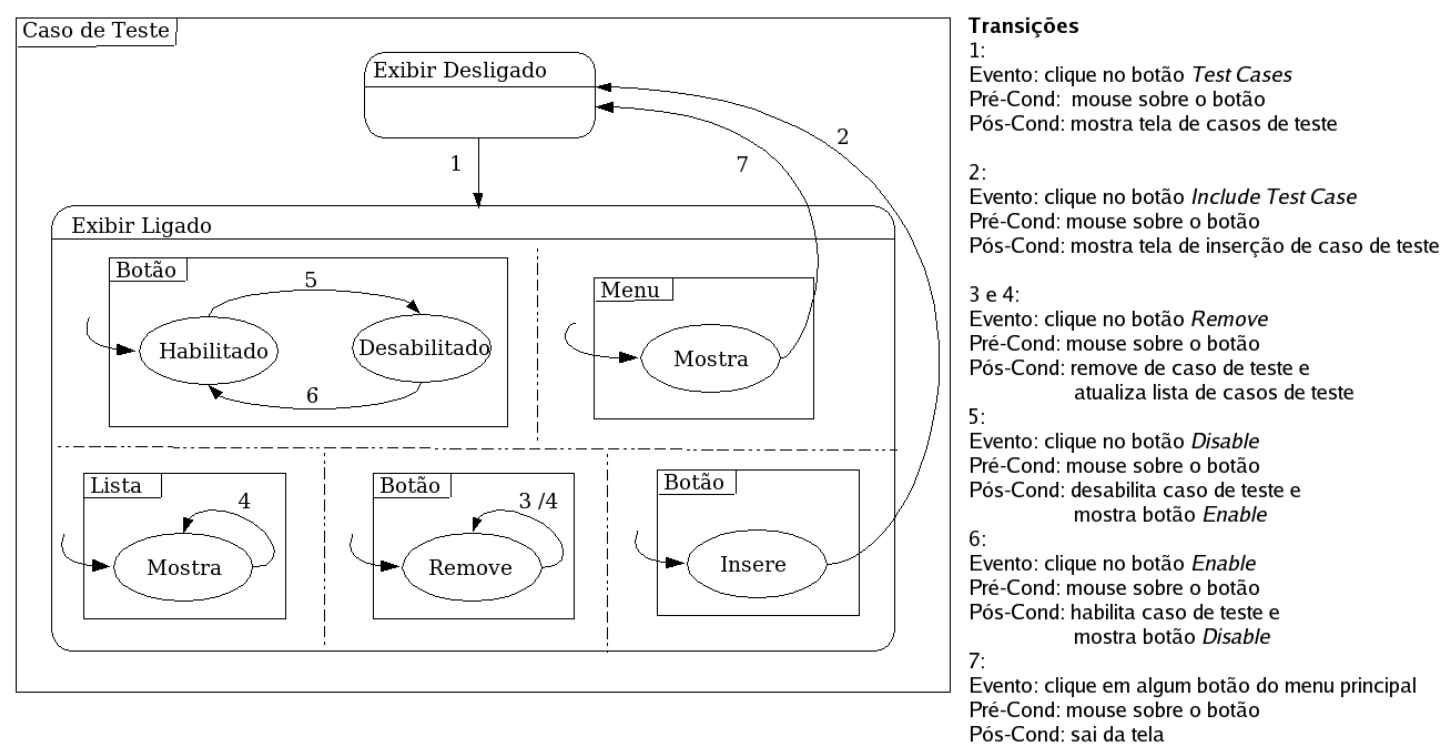

Figura 5.17: ADV Chart Casos de Teste.

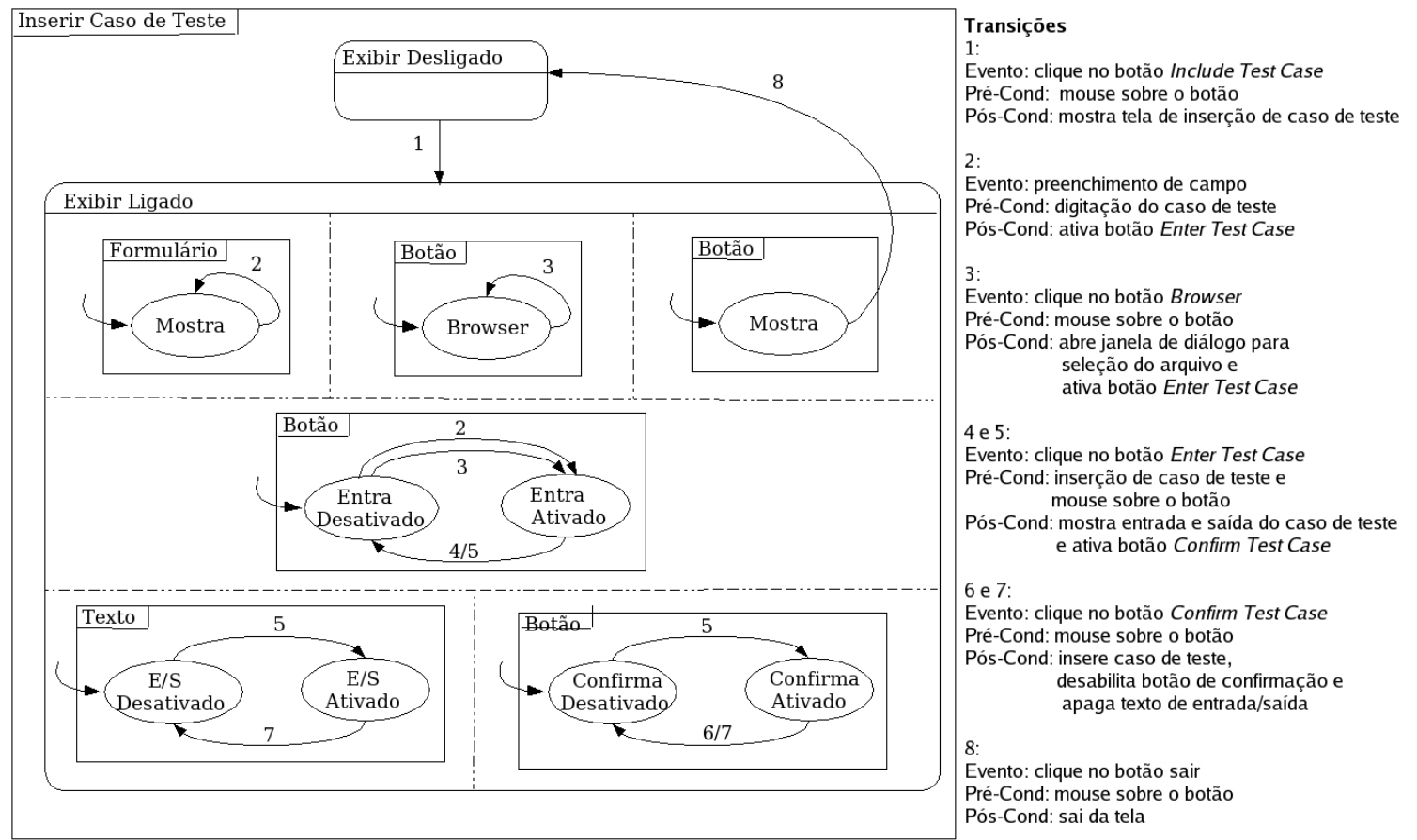

Figura 5.18: ADV Chart Inserir Caso de Teste.

Os mutantes de uma sessão são visualizados pressionando-se o botão Mutants do menu principal, ativando o estado Exibir Ligado do ADV Chart Mutantes (Figura 5.19). Os mutantes são exibidos em uma lista, sendo que cada um possui os botões Mark Equiv e View. Ao pressionar o primeiro, o mutante é marcado como equivalente e o rótulo do botão passa a ser Unmark Equiv para poder desfazer a marcação de equivalência. Ao pressionar o segundo, é aberta uma janela que mostra RPC original e o mutante lado a lado. O processo de inserção de mutantes é ilustrado no ADV Chart Inserir/Remover Mutantes (Figura 5.20). O estado Exibir Ligado desse ADV Chart é ativado quando 
pressiona-se no botão Include/Remove Mutants encontrado na tela de mutantes. Os mutantes podem ser selecionados de três maneiras: por operador, por linha de código e por número de mutante. Feita a seleção, pode-se pressionar o botão Include para inserir os mutantes selecionados, ou Remove para remover.
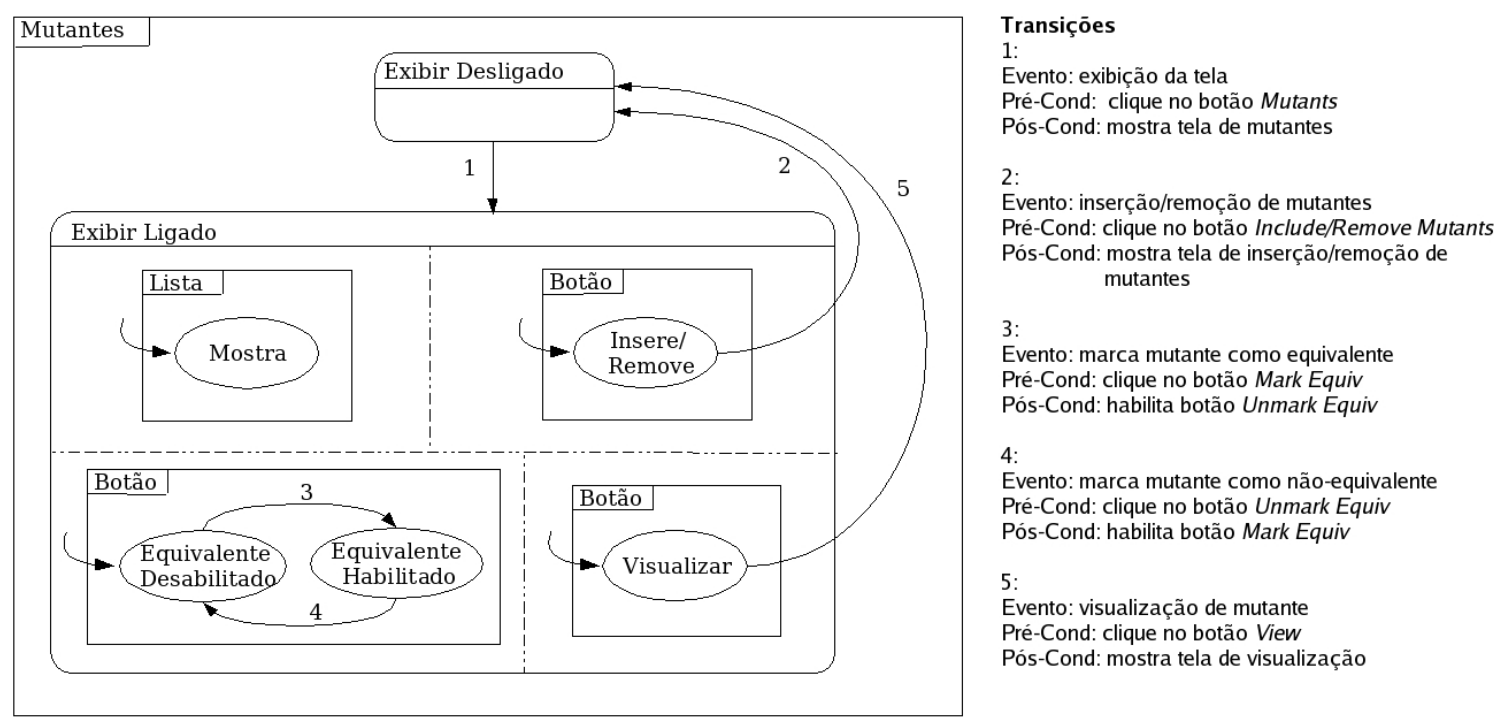

Figura 5.19: ADV Chart Mutantes.

A ferramenta Proteum/CPN disponibiliza dois tipos de relatórios de uma sessão de teste: por caso de teste e por operador. Tais relatórios podem ser visualizados pressionando-se o botão Reports do menu principal. Ao pressionar esse botão, ativa-se o estado Exibir Ligado do ADV Chart Relatórios (Figura 5.21), que mostra os botões para visualização de cada relatório. 


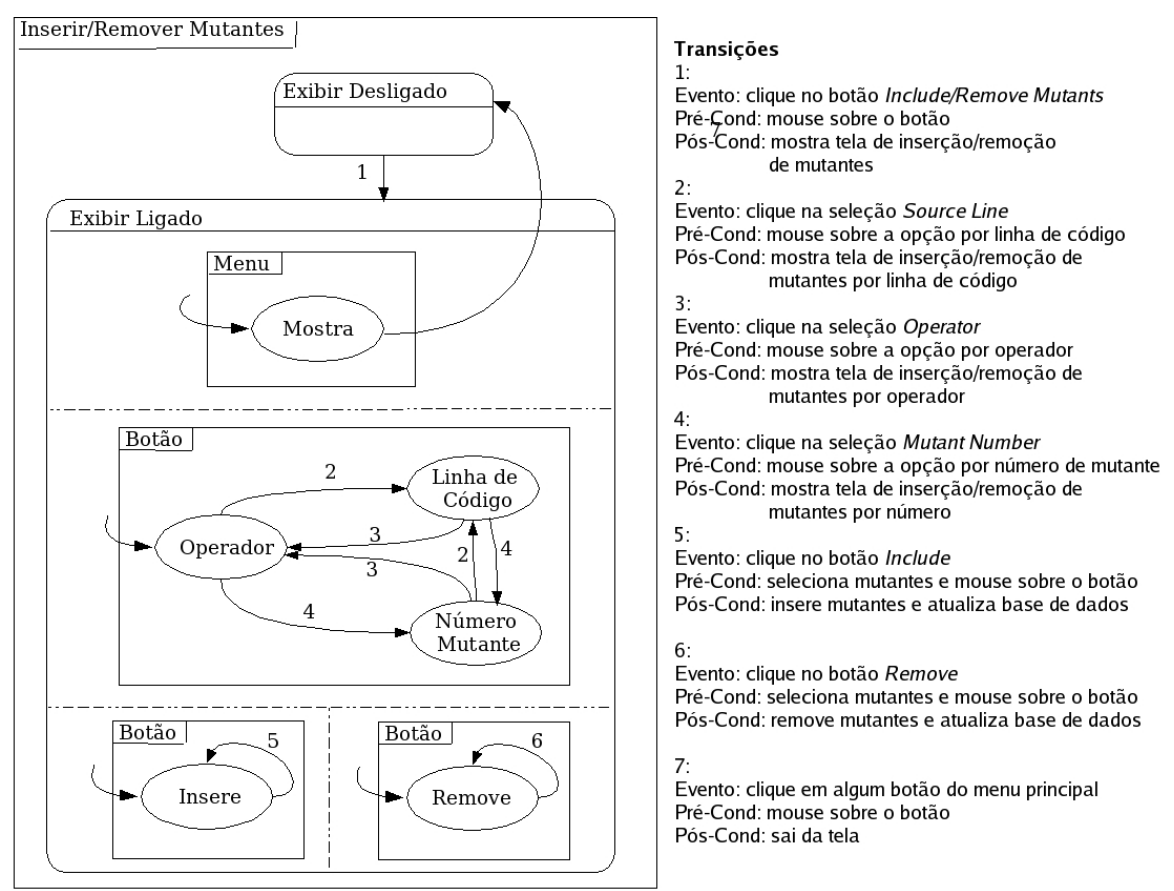

Figura 5.20: ADV Chart Inserir/Remover Mutantes.

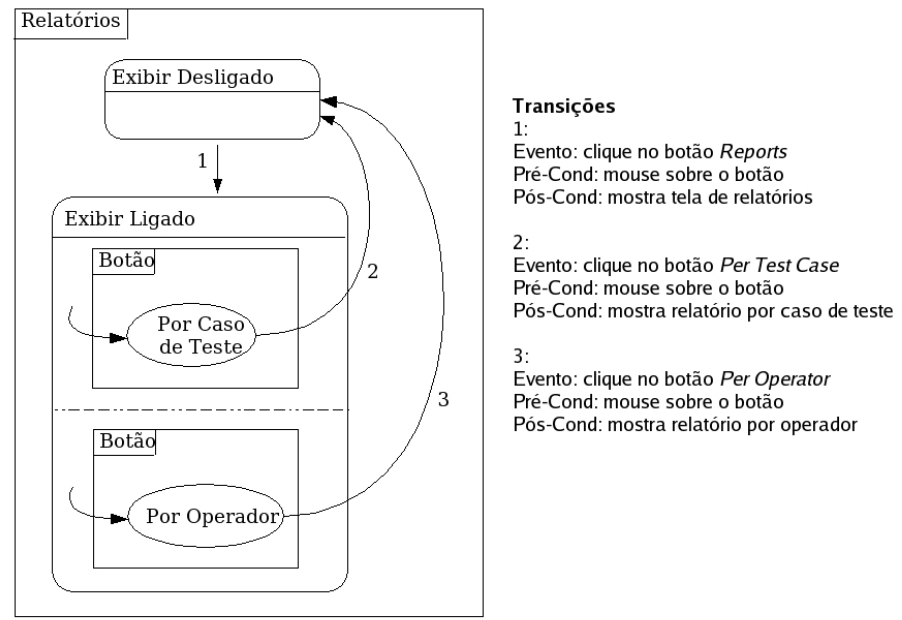

Figura 5.21: ADV Chart Relatórios.

\subsection{Aspectos Operacionais}

A seguir são apresentados os principais aspectos operacionais da ferramenta: esquema de controle de acesso, criação de projeto e sessão, geração de relatórios e configuração do modo de exibição da Proteum/CPN. Simultaneamente, é descrita a condução de uma sessão de teste com a RPC do Banco de Dados Distribuído (do inglês, Distributed 
Data Base) (DDB) (Jensen, 1994, 1997b), exemplificando-se as principais páginas da ferramenta.

\subsubsection{Acesso}

A Proteum/CPN tem um controle de acesso, no qual cada usuário possui uma conta protegida por senha, como apresentado na Figura 5.22. Assim, para se ter acesso à ferramenta, deve-se ter uma conta. Existem três tipos de conta:

Administrador: O usuário administrador (denominado root) é criado na instalação da Proteum/CPN e é responsável por autorizar a entrada de outros usuários ao sistema.

Proprietário de Projeto: Um proprietário de projeto tem permissão para criar novos projetos e sessões e determina quais usuários podem participar de seu projeto.

Usuário de Sessão: O usuário de sessão tem permissão para criar sessões em um projeto já existente.

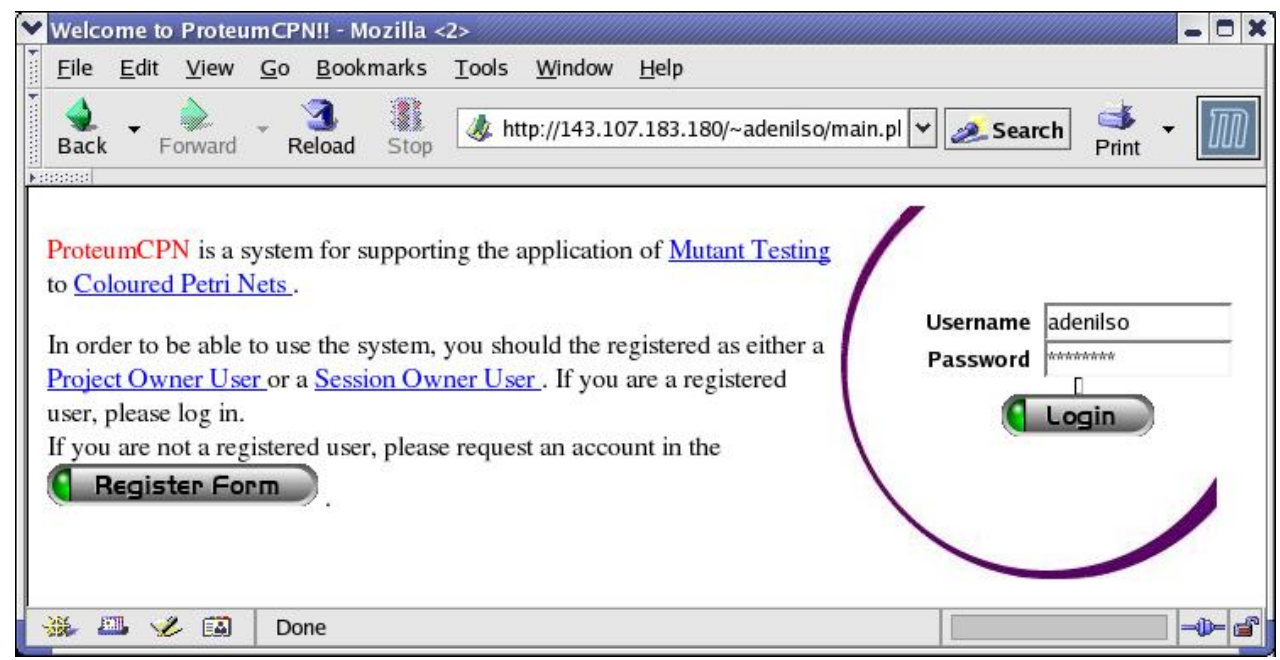

Figura 5.22: Página de Acesso à Proteum/CPN.

Considere, por exemplo, que um indivíduo queira requisitar uma conta do tipo proprietário de projeto e que o nome da conta seja adenilso. Para solicitar uma conta, é necessário preencher um formulário de registro (Figura 5.23). Esse pode ser obtido por meio do botão Register Form, localizado na página inicial da Proteum/CPN (Figura 5.22). Os campos que devem ser preenchidos no formulário são:

Username: Nome da conta do usuário, que deve ser uma seqüência de letras e dígitos, iniciando-se por uma letra e ter no mínimo 3 e no máximo 16 caracteres. Caso já exista uma conta com o mesmo nome, a ferramenta mostra um aviso e outro nome deve ser escolhido;

Full Name: Nome do usuário. Não precisa ser único e tem apenas propósito descritivo; 
Contact e-mail: E-mail de contato utilizado para receber o aviso de que a conta foi aceita ou não. Caso afirmativo, é enviada uma mensagem com um endereço para o usuário inserir uma senha na sua conta;

Purpose: Propósito pelo qual se deseja uma conta. Embora não seja obrigatório, sua descrição pode ser útil no julgamento do administrador sobre autorizar ou não o acesso.

Status: Escolher o tipo de conta que se deseja: proprietário de projeto ou usuário de sessão.

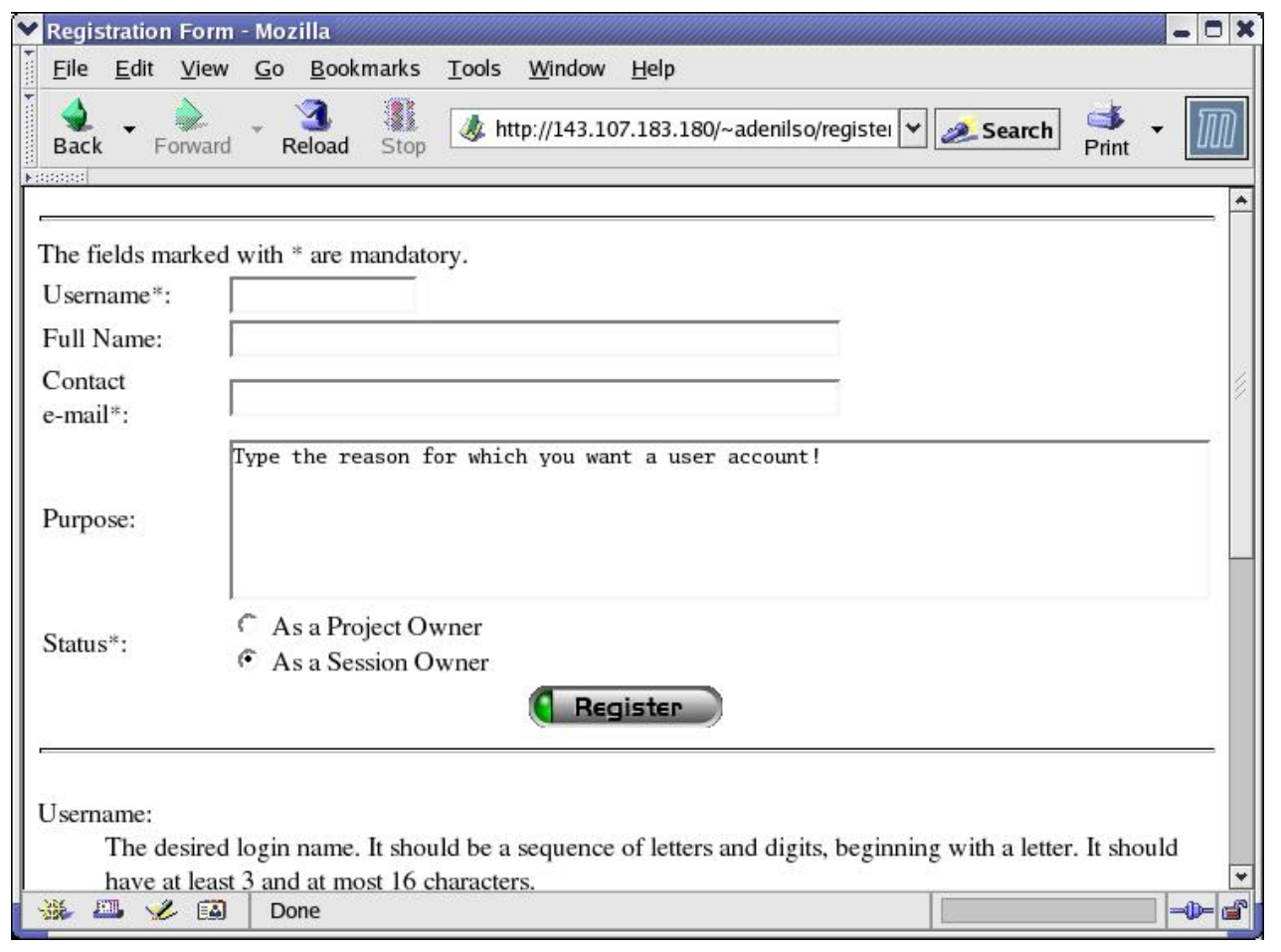

Figura 5.23: Formulário de Registro de Usuário.

A autorização de novas contas é analisada pelo administrador, que recebe um e-mail informando que existe uma requisição de conta aguardando para ser analisada. Após analisar o pedido, pode-se conceder ou negar a autorização. A página de autorização é mostrada na Figura 5.24.

Assim que o pedido é analisado, o usuário que requisitou a conta recebe um e-mail informando se foi aceito ou não. Caso seja recusado, o e-mail contém uma justificativa do administrador. Caso seja aceito, o e-mail contém um endereço no qual o usuário deve acessar para ativar sua conta. Isso é feito, informando-se uma senha e clicando-se no botão Activate (Figura 5.25). 


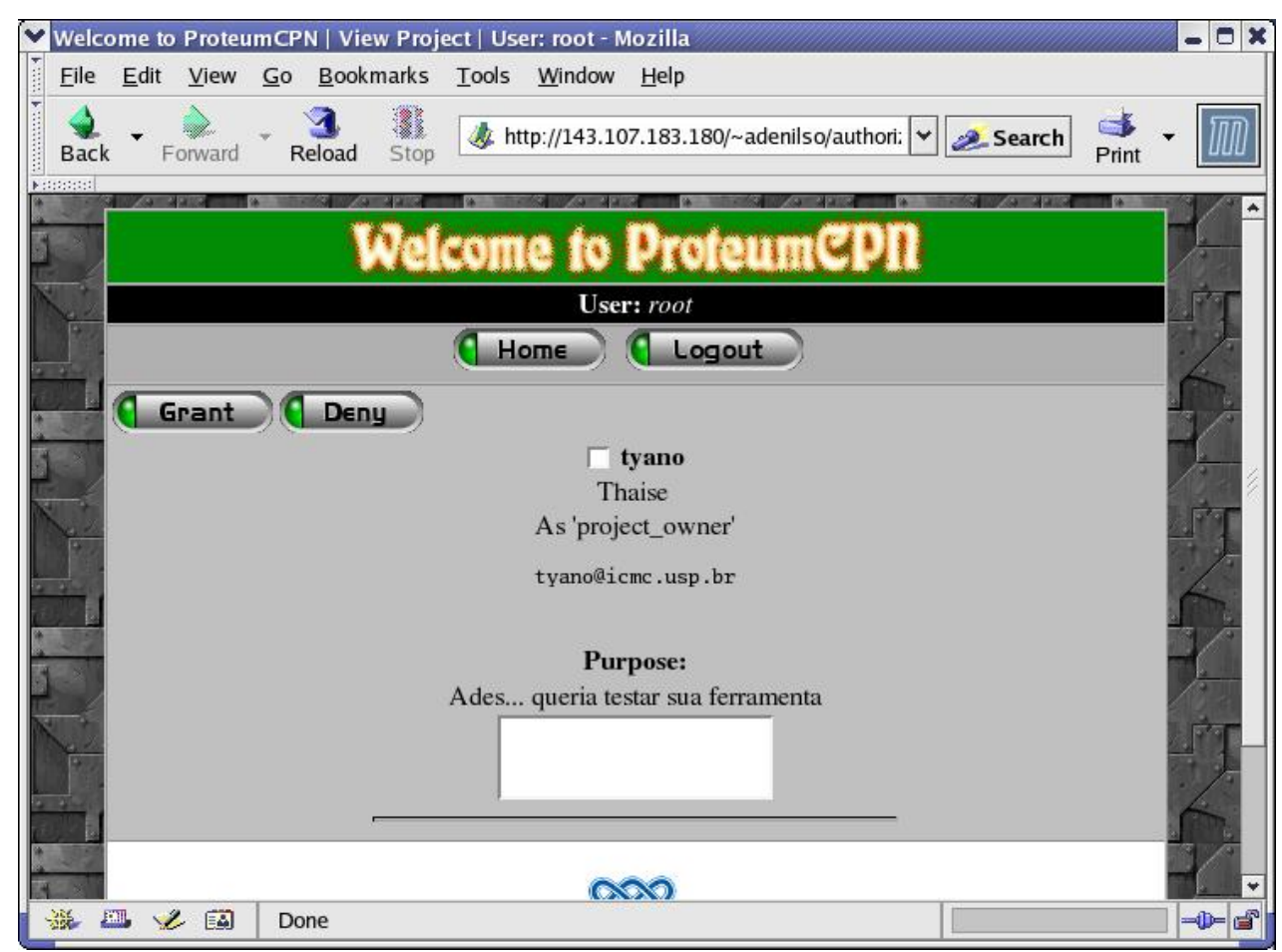

Figura 5.24: Página de Autorização de Conta de Usuário.

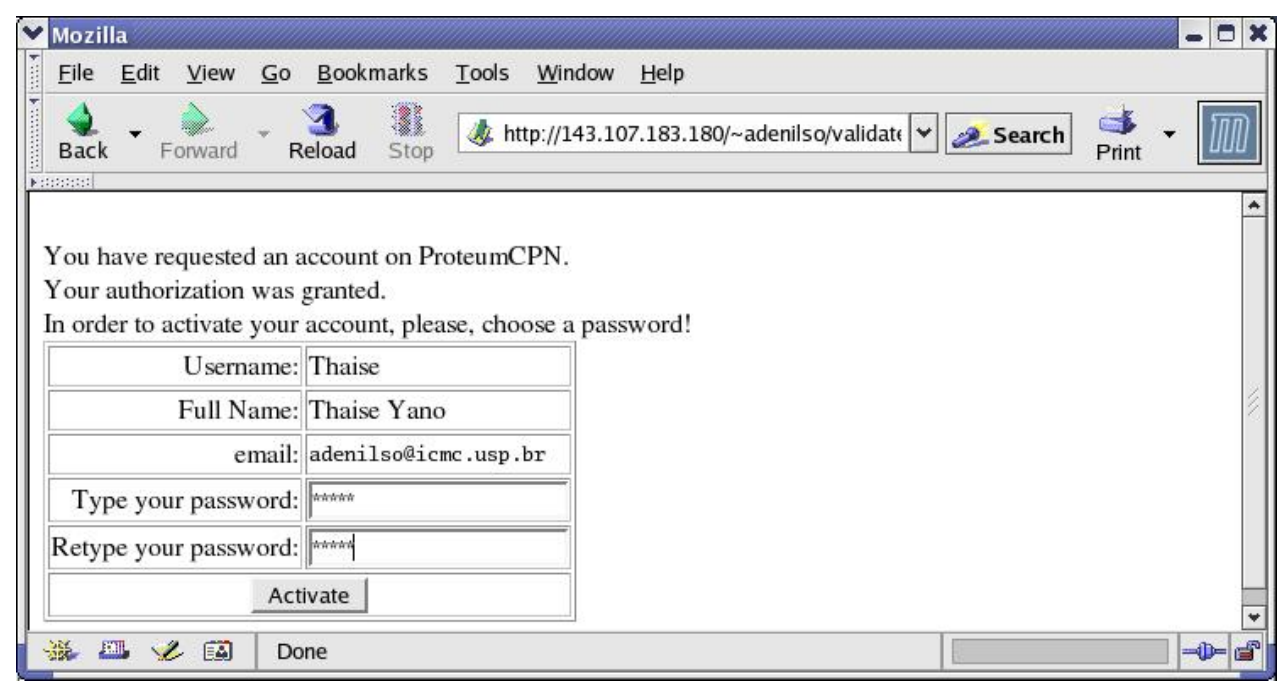

Figura 5.25: Página de Ativação de Conta de Usuário.

\subsubsection{Criação de Projeto}

Na Figura 5.26 é mostrada a página para criação de projetos, na qual é informado o nome do projeto a ser criado, indicando se é um projeto privado ou não. Um projeto privado aparecerá apenas na listagem do usuário que o criou. Por outro lado, um projeto que não é marcado como privado aparecerá na listagem de todos os usuários, os quais poderão solicitar autorização para participar do projeto. Por default, o projeto não é privado. Considere que a conta adenilso do tipo proprietário de projeto tenha sido aceita. Dessa maneira, o usuário cria um projeto chamado ad-DDB e não o marca como 
privado. Ao clicar em Create Project, aparecerão as opções Operators e Sources no menu principal, nas quais selecionam-se os operadores de mutação e o código fonte do projeto, respectivamente.

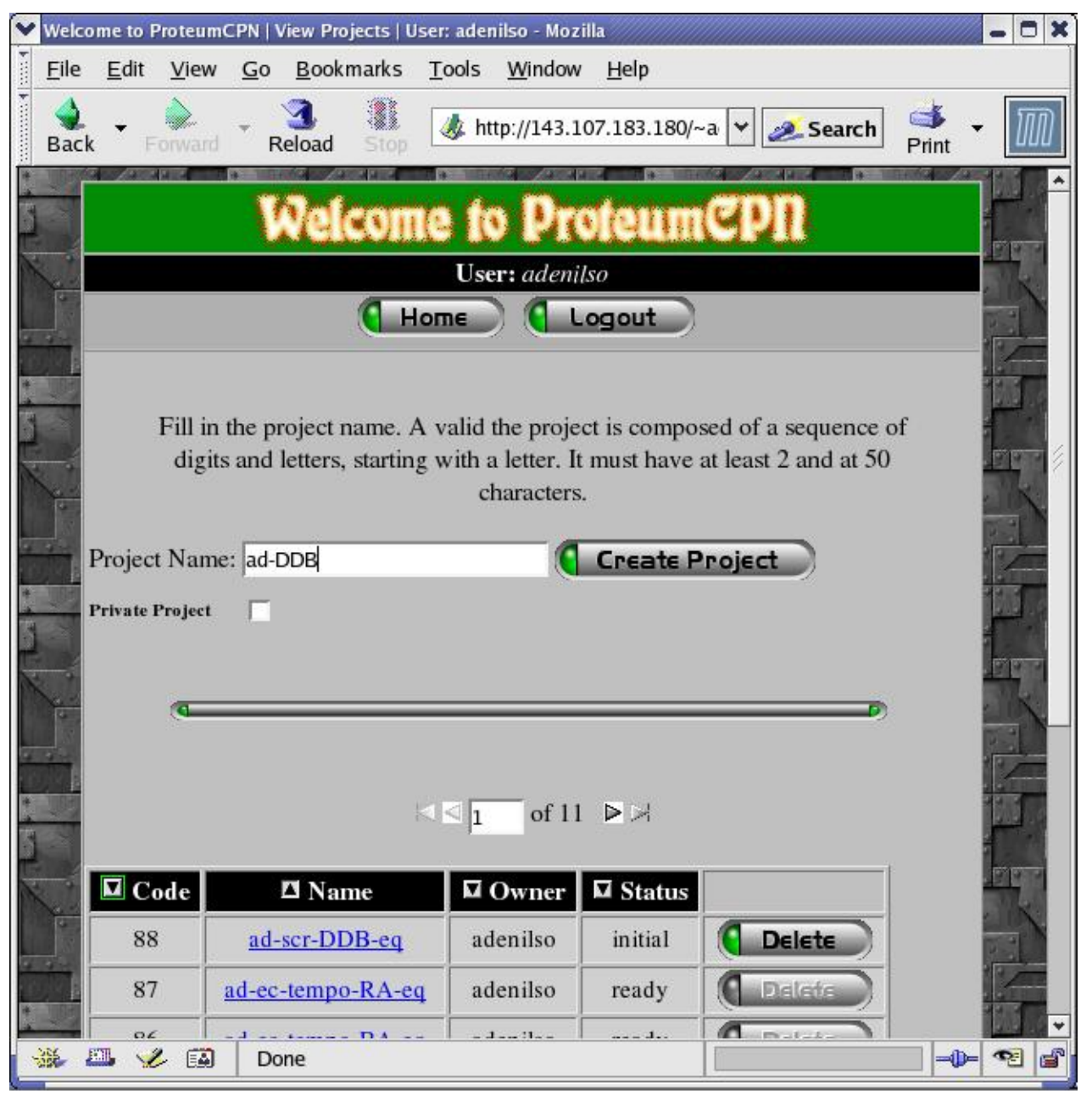

Figura 5.26: Página de Criação de Projeto.

Os projetos não privados e os projetos pertencentes ao usuário são listados numa tabela de projetos, encontrada na parte inferior da página apresentada na Figura 5.26, em que pode-se observar o código, o nome, o proprietário e o status dos projetos, como também se pode removê-los, quando não possuem sessões, pelos botões Delete. Se ainda não foram selecionados os operadores de mutação e o código fonte, o status do projeto é dito inicial (initial), caso contrário, é dito finalizado (finished) ou em processamento (processing), no caso de os mutantes do projeto estarem em processo de geração.

A tabela que lista os projetos é dividida em páginas. O número de linhas varia de acordo com o valor determinado em Settings do menu principal. Esse navegador permite ir diretamente para a primeira e última página da tabela bem como pode-se entrar com o número da página desejada. A Proteum/CPN mostra sempre primeiramente a página 
visitada mais recente pelo usuário. Também existem navegadores similares para as tabelas que listam as sessões, os mutantes e os casos de teste.

\subsubsection{Inclusão dos Operadores de Mutação}

Os operadores de mutação são selecionados na opção Operators do menu principal. Na Figura 5.27 é apresentada a página de seleção dos operadores. Nessa página, existem duas listas de operadores de mutação. Na lista da esquerda, encontram-se os operadores incluídos no projeto. Na lista da direita, encontram-se os operadores que ainda podem ser incluídos. Para incluir, selecionam-se os operadores da lista direita e clica-se em "<<". Inversamente, para remover, selecionam-se os operadores na lista esquerda e clica-se em " >>".

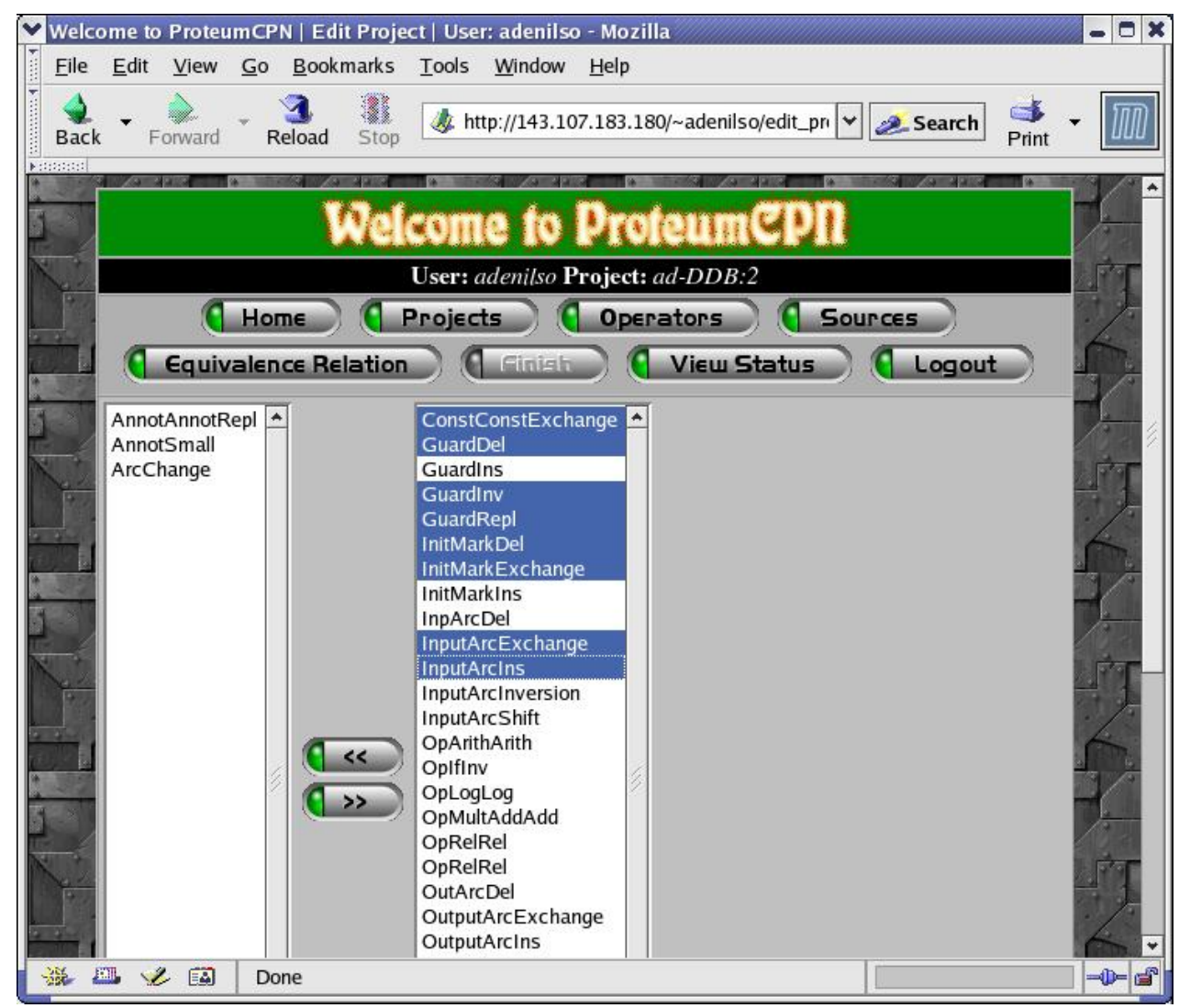

Figura 5.27: Página de Seleção de Operadores de Mutação.

\subsubsection{Inclusão da Rede a Ser Testada}

A importação da rede a ser testada é feita na página acessada pela opção Sources do menu principal, sendo apresentada na Figura 5.28. Ao clicar em Browse é aberto uma janela de diálogo para selecionar os arquivos que contêm o código fonte desejado. Para o projeto ad- $D D B$, é selecionado o arquivo DistributedDataBase.xml cujo conteúdo é a representação em Extensible Markup Language (XML) da RPC a ser testada. Esse 
arquivo XML segue o DTD definido para a ferramenta Design/CPN (Jensen, 2002). Atualmente, a Proteum/CPN não oferece recursos para a construção desse arquivo XML. No entanto, o XML pode ser obtido a partir da exportação em formato de intercâmbio da ferramenta Design/CPN. Após incluir o arquivo, pode-se visualizar seu conteúdo (como apresentado na Figura 5.29) ou removê-lo, clicando em View ou Remove, respectivamente.

Ao se incluir uma rede hierárquica, cada página é fornecida como um arquivo XML separado. É necessário indicar qual é a página primária (e, respectivamente, qual o arquivo XML). Essa é a página a partir da qual todas as demais serão incluídas. A forma mais simples de se fazer isso, é incluir primeiramente a página primária, e depois as demais páginas.

Internamente, a Proteum/CPN converte o conjunto de arquivos XML em um único arquivo em um formato CPN-ML (Simão e Maldonado, 2004), o qual inclui apenas as informações relevantes a simulação/execução da RPC.

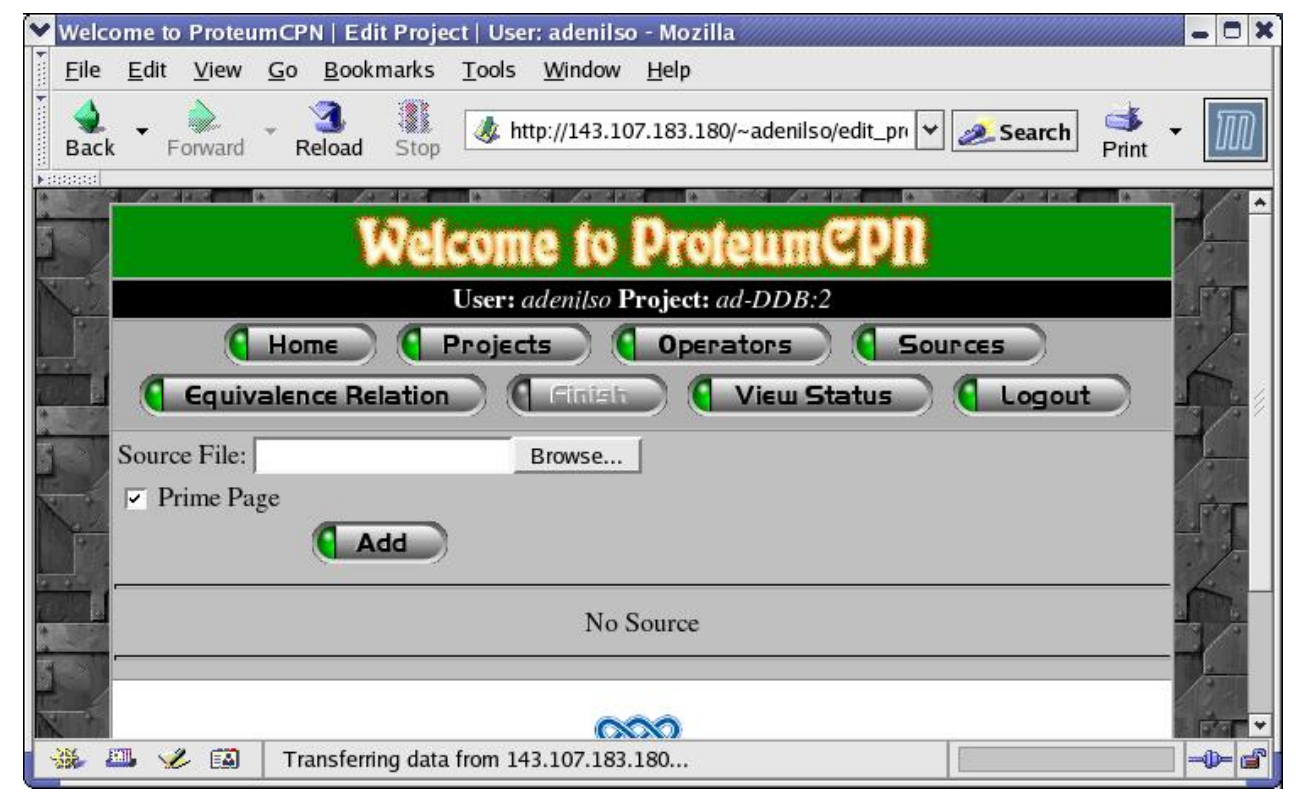

Figura 5.28: Página de Inclusão do Código Fonte.

\subsubsection{Definição da Relação de Equivalência}

Como discutido na Seção 3.3, dependendo da RPC a ser testada, pode-se escolher entre diversas noções de equivalência, tanto no que se refere aos lugares da rede quanto às transições. A ferramenta permite que seja escolhido qual função deve ser utilizada para avaliar o conteúdo de cada lugar da rede nas marcações resultantes da execução de um caso de teste. Na Figura 5.30 é apresentada a página na qual a escolha é feita. Por default, para todos os lugares da rede está selecionada a função Equality, definida na Seção 3.3.1.

Deve-se ressaltar que, atualmente, a ferramenta não possibilita a escolha de como lidar com os casos de ligações não habilitadas. Caso uma seqüência de ligações não esteja 


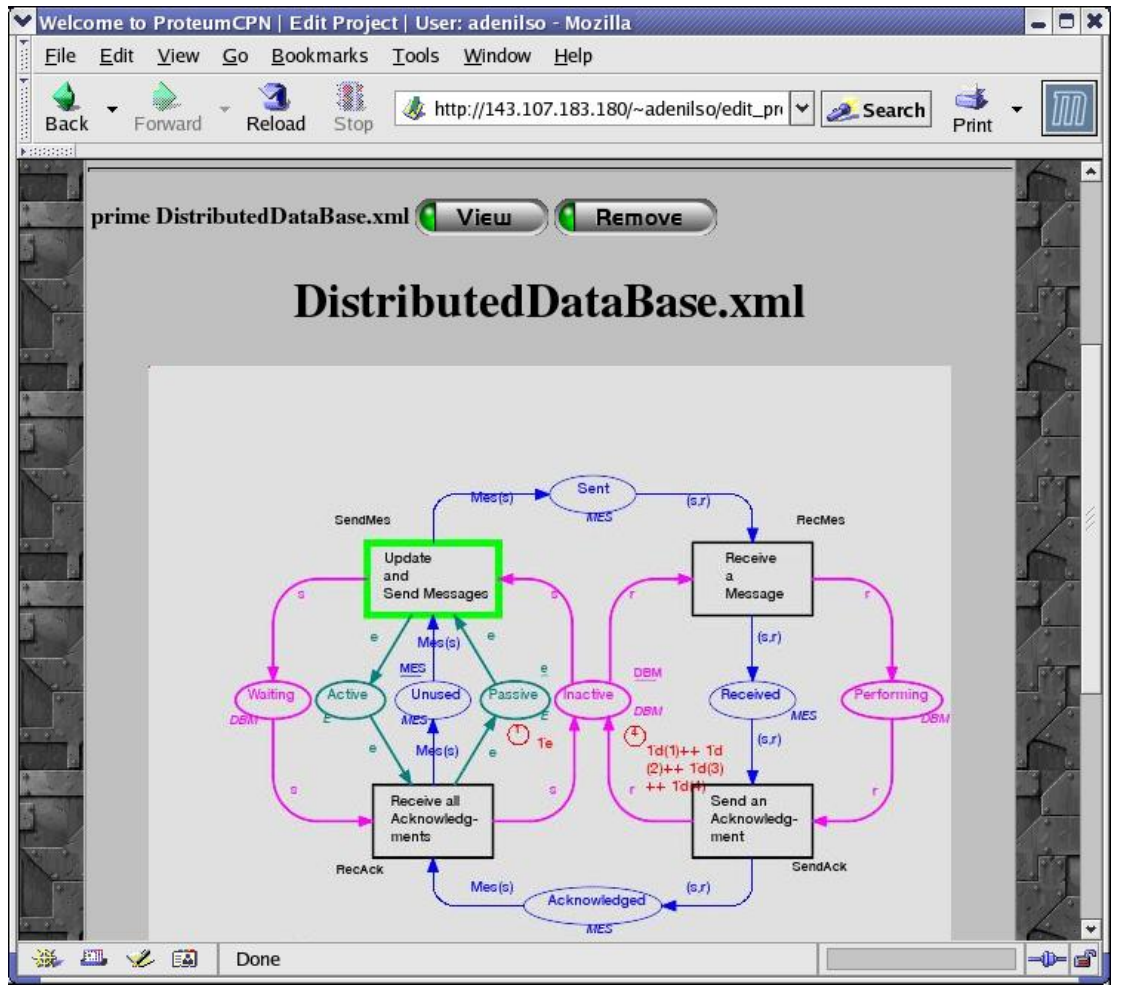

Figura 5.29: Visualização do Fonte.

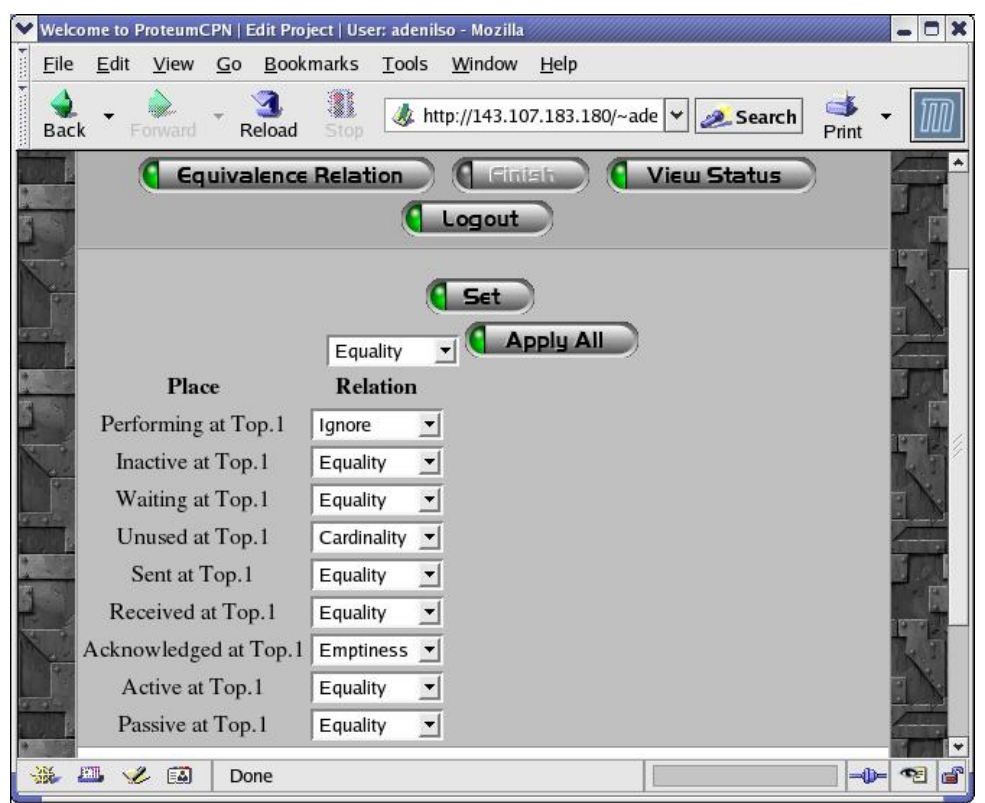

Figura 5.30: Definindo a Relação de Equivalência para Lugares.

habilitada a disparar a partir da marcação inicial, o mutante será considerado morto. No entanto, para possibilitar a condução de estudos empíricos, uma melhoria importante a ser realizada na Proteum/CPN é a inclusão de funcionalidades que permitam escolher outras possibilidades para lidar com seqüências não habilitadas, como discutido na Seção 3.3.2. 


\subsubsection{Finalização de Projeto}

Para finalizar um projeto, clica-se no botão Finish do menu principal. Esse torna-se habilitado, após a seleção dos operadores de mutação e a importação do código fonte. Ao finalizar um projeto, o código fonte é analisado e os mutantes são gerados. A partir de então, não se pode mais alterar o projeto, seja incluindo outro código fonte, seja modificando o conjunto de operadores de mutação do projeto. O processo de geração de mutantes é, em geral, demorado, dependendo do tamanho RPC e do número de mutantes a serem gerados. O progresso de geração pode ser observado pela página de status do projeto, que indica quais operadores de mutação já foram aplicados e quantos mutantes foram gerados por cada operador. Na Figura 5.31(a) é mostrado o status parcial de geração de mutantes do projeto ad-DDB e na Figura 5.31(b) o status final.

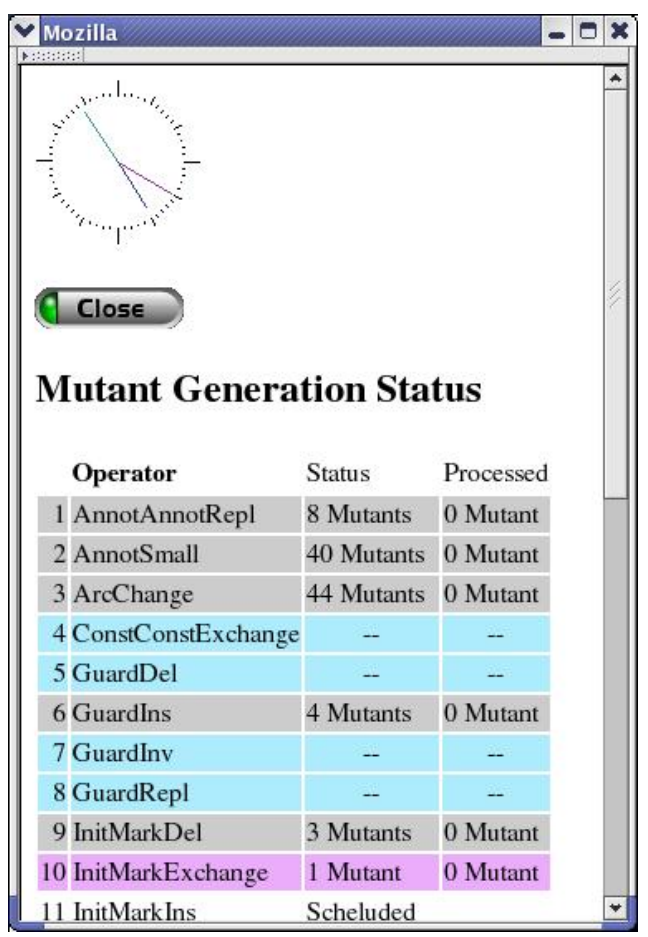

(a) Status Parcial

\begin{tabular}{|c|c|c|c|}
\hline$\checkmark$ Mozilla & & & 8 \\
\hline 10 InitMarkExchange & 6 Mutants & 6 Mutants & $A$ \\
\hline 11 InitMarkIns & 6 Mutants & 6 Mutants & \\
\hline 12 InpArcDel & 10 Mutants & 10 Mutants & \\
\hline 13 InputArcExchange & 22 Mutants & 22 Mutants & \\
\hline 14 InputArcIns & 50 Mutants & 50 Mutants & \\
\hline 15 InputArcInversion & 10 Mutants & 10 Mutants & \\
\hline 16 InputArcShift & 22 Mutants & 22 Mutants & \\
\hline 17 OpArithArith & - & - & \\
\hline 18 OpIfInv & - & - & \\
\hline 19 OpLogLog & - & - & \\
\hline 20 OpMultAddAdd & - & - & \\
\hline 21 OpRelRel & - & - & \\
\hline 22 OpRelRel & - & - & \\
\hline 23 OutArcDel & 10 Mutants & 10 Mutants & \\
\hline 24 OutputArcExchange & 22 Mutants & 22 Mutants & \\
\hline 25 OutputArcIns & 50 Mutants & 50 Mutants & \\
\hline 26 Arclnversion & 10 Mutants & 10 Mutants & \\
\hline 27 OutputArcShift & 22 Mutants & 22 Mutants & \\
\hline 28 VarSmall & 40 Mutants & 40 Mutants & \\
\hline 29 VarVarExchange & 12 Mutants & 12 Mutants & \\
\hline Total & 391 Mutants & 391 Mutants & \\
\hline
\end{tabular}

(b) Status Final

Figura 5.31: Status de Geração de Mutantes.

\subsubsection{Criação de Sessão}

Para se criar uma sessão de teste em um projeto, é necessário ser o proprietário do projeto ou ter sua autorização. No caso do usuário não ser o proprietário do projeto, deve-se pedir autorização ao proprietário. Por exemplo, na Figura 5.32, o usuário Thaise pede autorização para criar uma sessão no projeto ad-DDB ao usuário adenilso, propri- 
etário do projeto. Ao clicar em Request Authorization, aparece a página apresentada pela Figura 5.33 em que deve-se descrever o propósito da requisição. Feito isso, o usuário adenilso recebe um e-mail informando que existe um pedido de autorização aguardando para ser analisado. O pedido é analisado pela página mostrada na Figura 5.34 e pode-se conceder ou negar a autorização. O usuário que requisitou a autorização recebe um e-mail informando se foi aceito ou não.

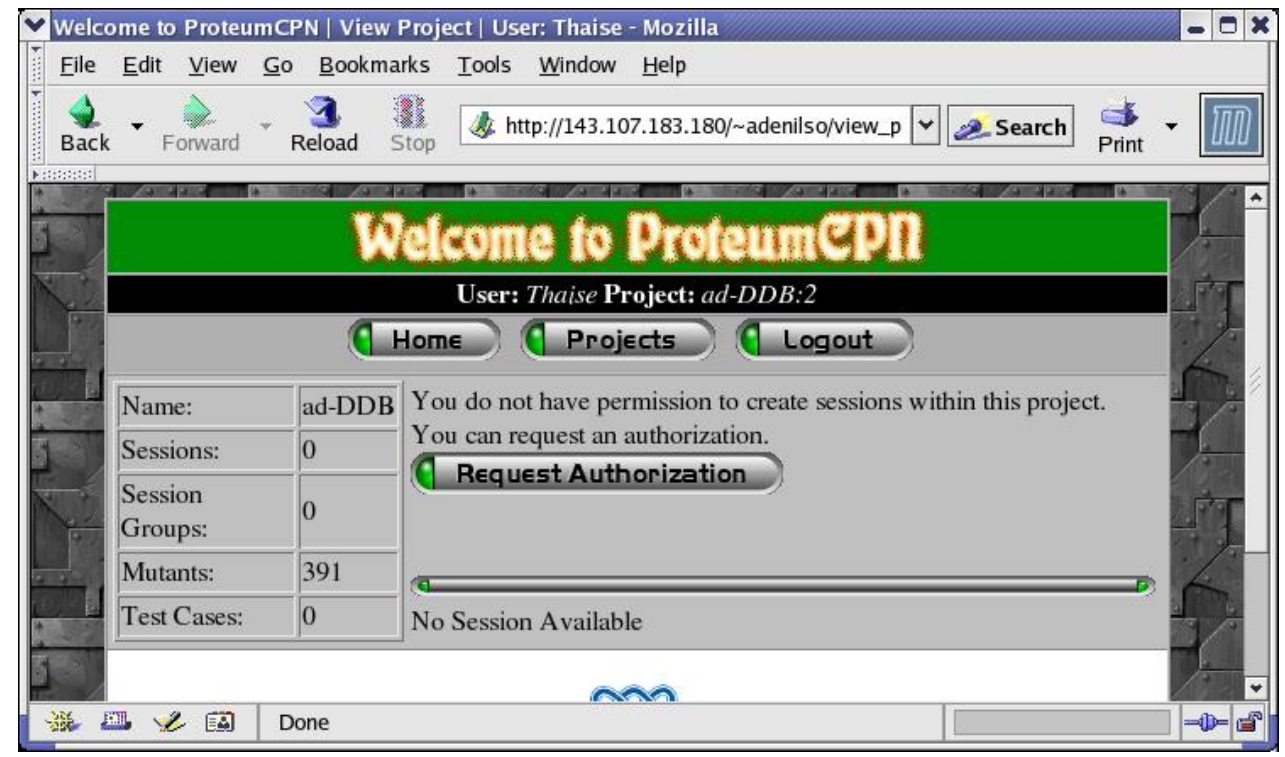

Figura 5.32: Requisição de Autorização.

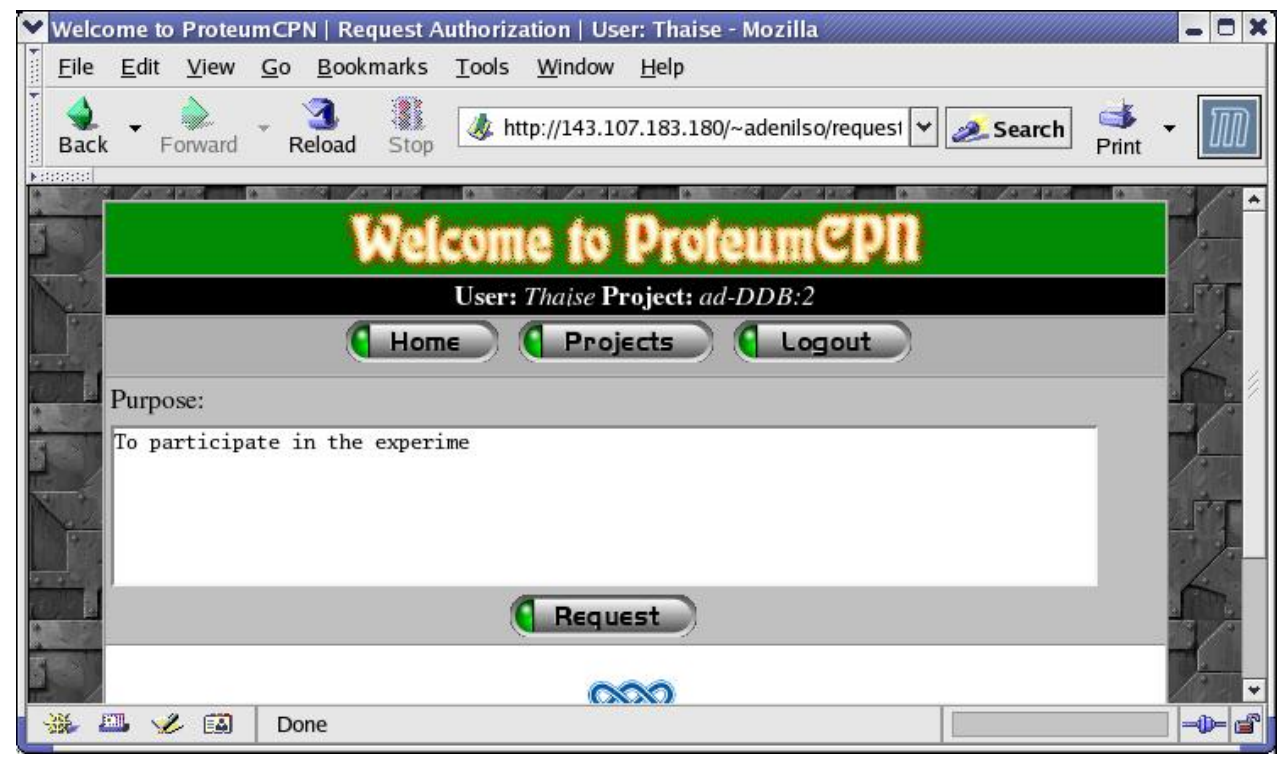

Figura 5.33: Propósito da Requisição de Autorização.

Na Figura 5.35 é apresentada a página para a criação de sessão, no caso do usuário ser o proprietário do projeto. Informam-se o nome, o grupo, o número máximo de 


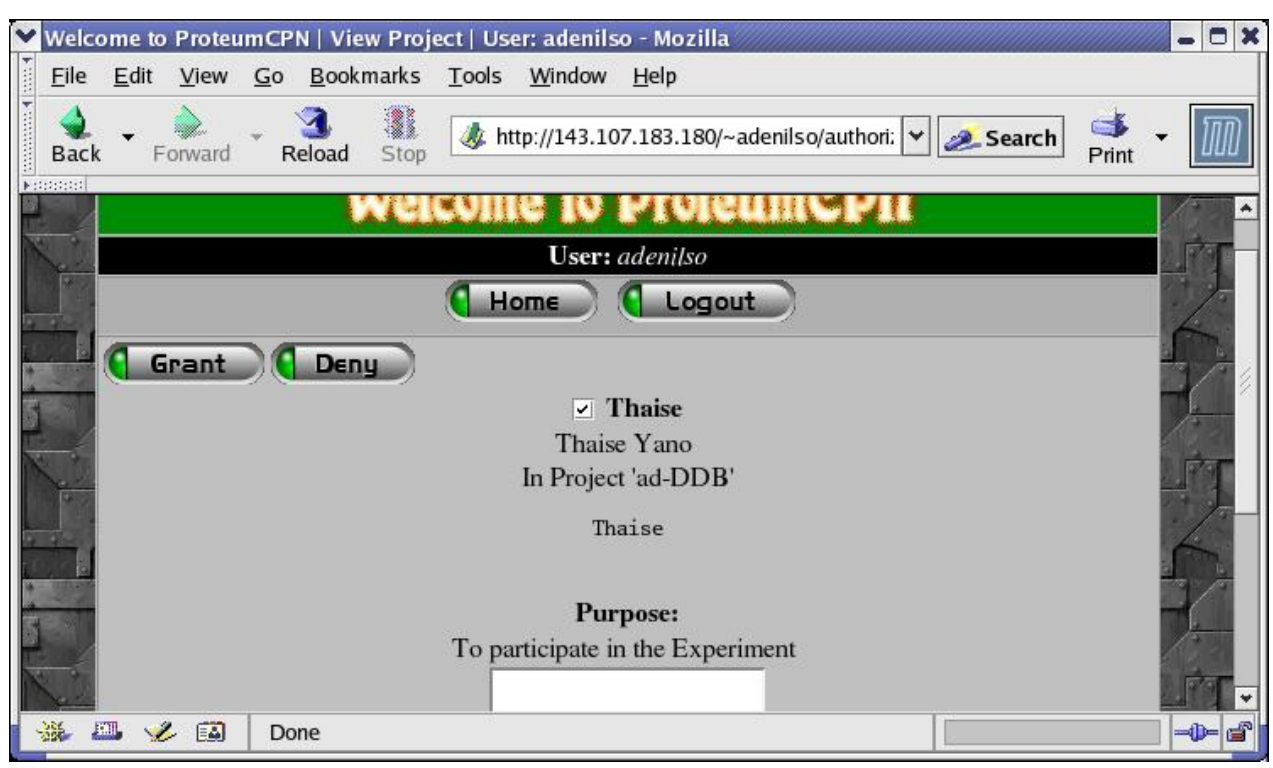

Figura 5.34: Página de Autorização para Criação de Sessão.

mutantes e o proprietário da sessão. Também é possível marcar a sessão como privada e com a permissão de incluir ou remover mutantes. Os valores default dessas opções são:

- o grupo é singleton (ou seja, a sessão não faz parte de nenhum grupo);

- a sessão não é privada;

- pode-se incluir/remover mutantes;

- não há limitação ao número máximo de mutantes; e

- o proprietário da sessão é yourself (ou seja, o próprio dono do projeto).

Se um usuário tem permissão para criar uma sessão em um projeto no qual não é proprietário, apenas aparecerá a opção de dar nome à sessão e marcá-la como privada. Considerando o usuário adenilso, as opções para a criação de suas sessões são as de proprietário de projeto. Por exemplo, é criada uma sessão cujo nome é sess1, dentro do projeto ad-DDB, com grupo denominado de $G 1$ e sem limite máximo no número de mutantes. Outra sessão, sess2, é criada pelo usuário adenilso com limite máximo de 50\% dos mutantes gerados no projeto e também pertencente ao grupo G1.

Após a criação de uma sessão, essa é incluída na tabela de sessões, parte inferior da Figura 5.35, na qual pode-se observar o nome, o proprietário, o número de casos de teste, o número de mutantes, o grupo e escore de mutação de cada sessão. Se houver grupos de sessões no projeto, são apresentadas linhas na tabela que sumarizam as informações de cada grupo. Além disso, por meio dessa tabela, pode-se remover uma sessão, com o botão Delete. Outra tabela, que se encontra no lado inferior esquerdo da página, mostra um resumo das informações do projeto, contendo o nome, o número de sessões, o número de grupos de sessões, o número de mutantes e o número de casos de teste do projeto. 


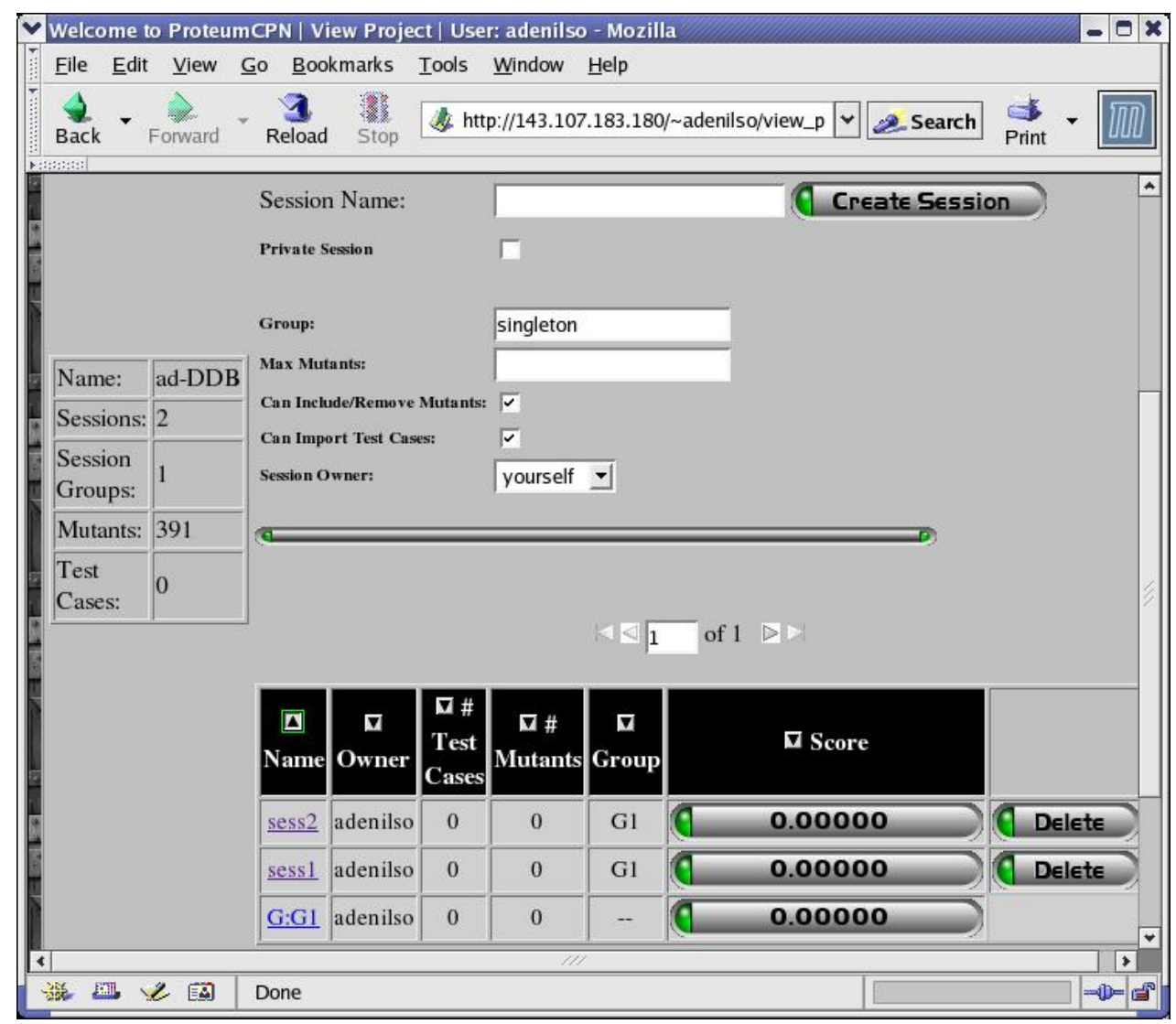

Figura 5.35: Página de Criação de Sessão.

\subsubsection{Inclusão dos Mutantes}

Uma sessão pode importar/remover qualquer subconjunto de mutantes gerados no projeto ao qual pertence, conforme apresentado nas Figuras 5.36, 5.37 e 5.38. Os mutantes podem ser selecionados informando-se a porcentagem ou a quantidade de mutantes que se deseja incluir/remover. A palavra all pode ser utilizada para selecionar todos os mutantes. Isso pode ser feito das seguintes maneiras:

Por operador: Selecionam-se quais operadores serão incluídos/removidos (Figura 5.36).

Apresenta-se uma lista com todos os operadores de mutação do projeto bem como o número de mutantes gerados para cada operador;

Por linha de código: Informa-se um intervalo dos números de linhas de código (Figura 5.37). O código fonte é mostrado por linhas de código numa área de texto em que se pode selecionar as linhas desejadas;

Por número de mutante: Informa-se um intervalo de números de mutantes (Figura 5.38). 


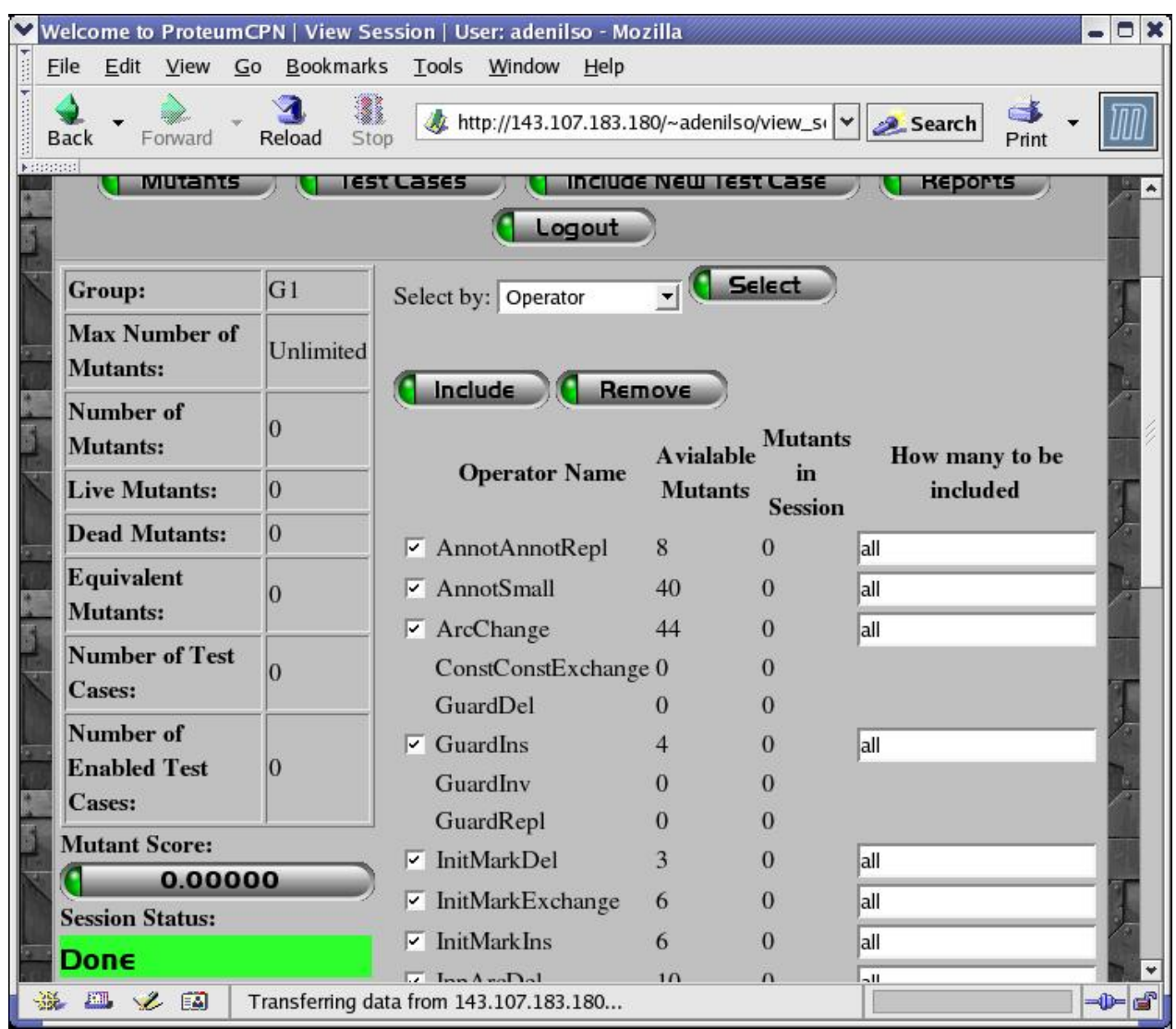

Figura 5.36: Inclusão de Mutantes por Operador.

\subsubsection{Inclusão de Casos de Teste}

Em uma sessão, pode-se incluir casos de teste tanto interativamente quanto por importação. Na importação, os casos de teste são importados de outra sessão a qual o usuário tenha acesso. Na inclusão interativa, o usuário fornece o caso de teste por meio da simulação interativa (Figura 5.39). Se o caso de teste já existir na sessão, o resultado é mostrado e o botão de confirmação é desabilitado. Ao inserir um caso de teste $t$, todos os mutantes do projeto em questão são executados com $t$. Os casos de teste inseridos na sessão são listados em uma tabela que contém o código e a entrada de cada caso de teste, bem como botões para habilitar/desabilitar e remover os casos de teste. 


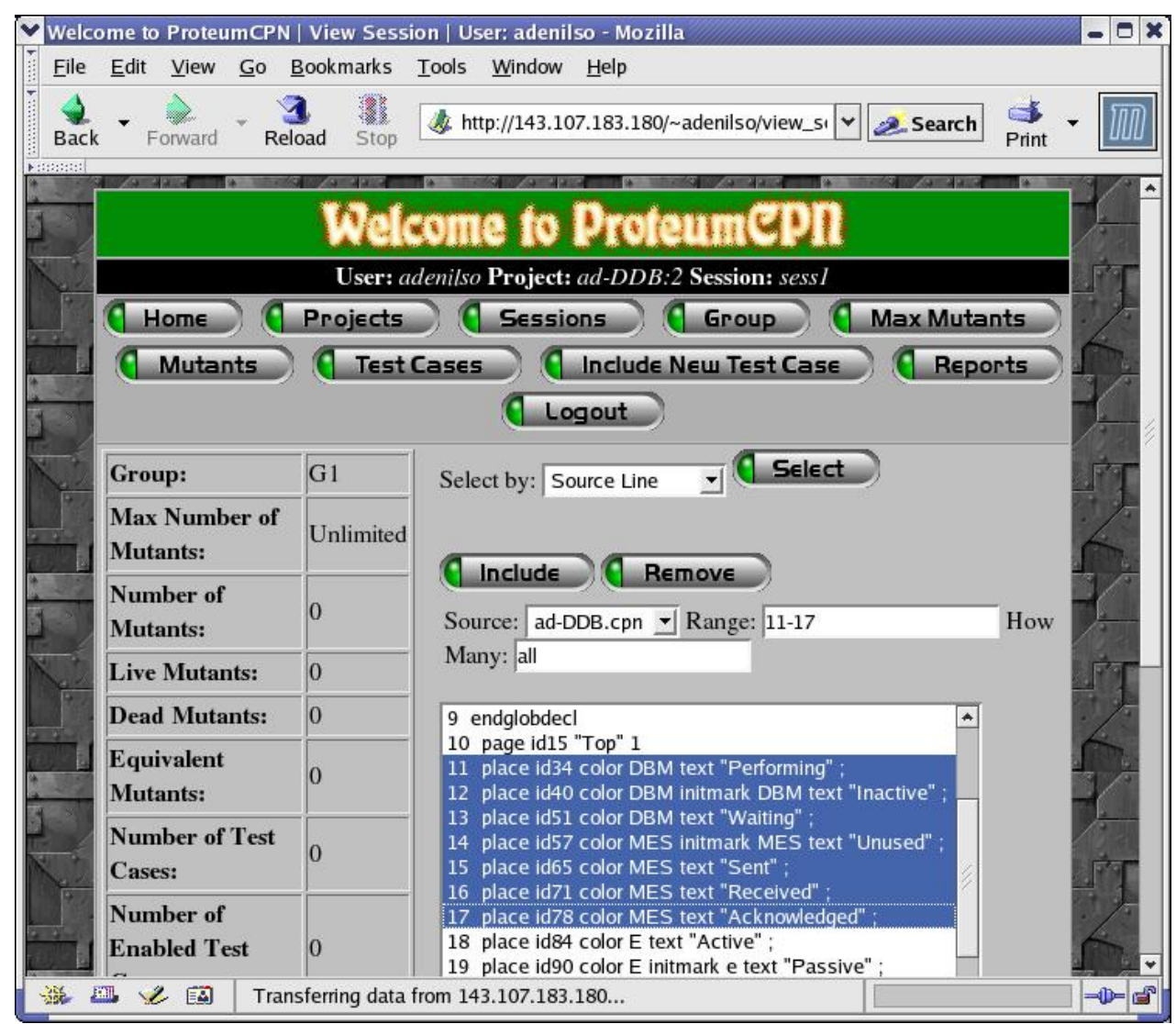

Figura 5.37: Inclusão de Mutantes por Linha de Código.

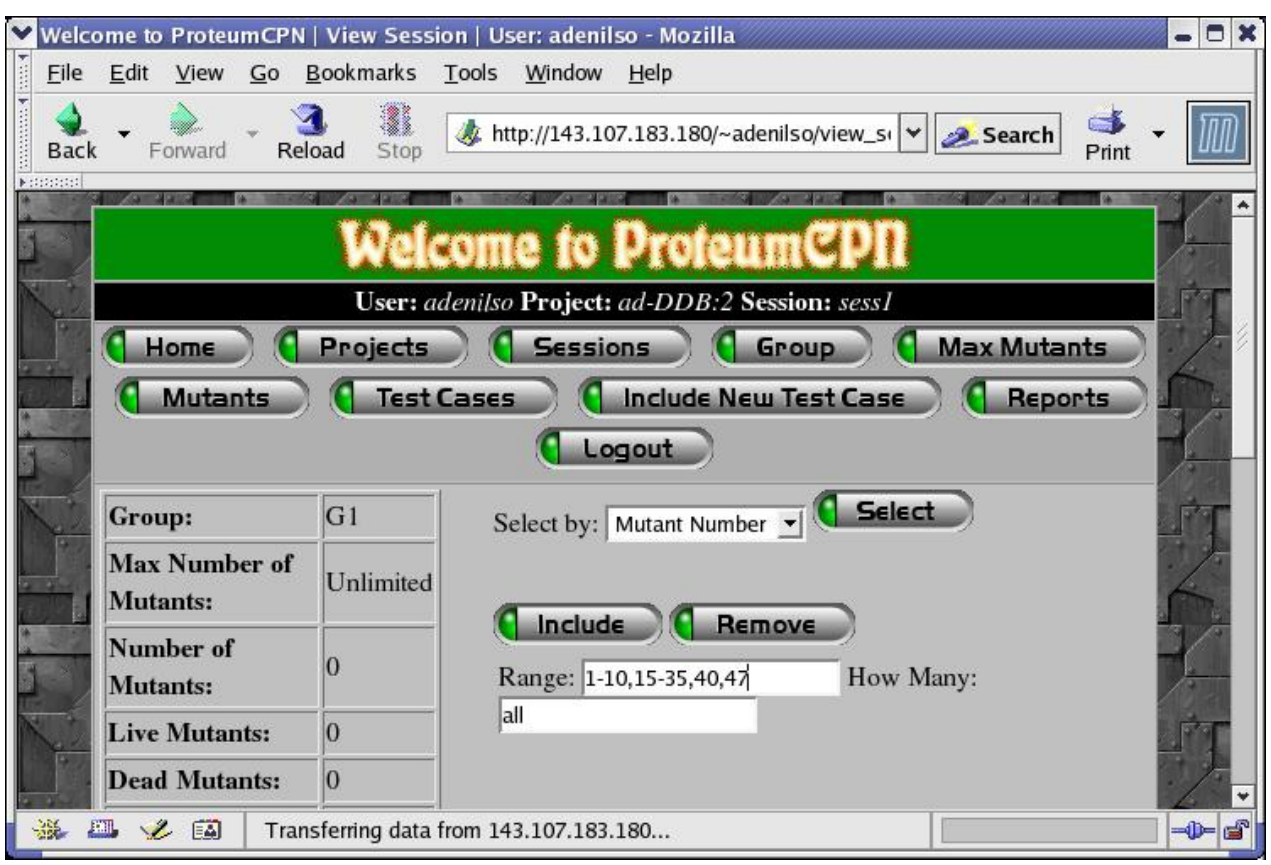

Figura 5.38: Inclusão de Mutantes por Número de Mutantes.

\subsubsection{Inclusão Interativa de Casos de Teste}

Na Figura 5.39 é apresentado um exemplo da página Web que permite a simulação da RPC e, dessa forma, a inclusão interativa de casos de teste. As figuras que aparecem 
nessa página, assim como as informações sobre as ligações habilitadas e a marcação atual, são produzidas por simulador de RPCs desenvolvido neste trabalho, o qual é descrito na Seção 5.4.2. Essa página ilustra as principais informações que são exibidas durante a simulação:

1. Hierarquia de Páginas: Nessa parte, a hierarquia das páginas é apresentada na forma de uma árvore que relaciona uma página com as instâncias de páginas que ela inclui (Jensen, 1997b). A página que está atualmente sendo apresentada é representada por um elipse, ao passo que as demais são representadas por retângulos. O usuário pode selecionar outra página clicando sobre o elemento que a representa. As páginas que possuem ao menos uma transição habilitada são destacadas.

2. Página da RPC: Nessa parte da página Web, a página da RPC que está atualmente selecionada é apresentada. As transições que possuem ao menos uma ligação habilitada são destacadas. O usuário pode clicar sobre uma transição para selecioná-la e atualizar a lista de ligações habilitadas que aparece na parte 3.

3. Ligações Habilitadas: Nessa parte, são apresentadas as ligações da transição atualmente selecionadas que estão habilitadas na marcação atual. Cada ligação é apresentada como um link. Um clique em um desses links irá requisitar o disparo da ligação correspondente, atualizando toda a página Web para refletir a nova marcação alcançada. Existem também links para permitir que o usuário acesse à marcação inicial (anulando toda a seqüência de ligações disparadas até o momento) e à marcação anterior (removendo a última ligação disparada).

4. Seqüência de Ligações Disparadas: Nessa parte, é apresentada a seqüência de ligações disparadas até a marcação. Existe também um botão para a inclusão dessa seqüência de ligações como um caso de teste. Se essa seqüência já foi utilizada como caso de teste nessa sessão de teste, esse botão aparece desabilitado. Se o caso de teste em questão matar o último mutante visualizado, a Proteum/CPN inclui um sinal de '*' no botão. Dessa forma, facilita-se a inclusão de casos de teste com o propósito de matar um determinado mutante.

\subsubsection{Análise dos Mutantes}

Após serem executados com o conjunto de caso de teste, os mutantes que permaneceram vivos devem ser analisados para verificar se são equivalentes ou não à RPC em teste. A análise pode ser feita observando-se os elementos nos quais a mutação ocorreu. Para tanto, a ferramenta permite a visualização lado a lado da RPC original e de um mutante, destacando-se os elementos mutados, como ilustrada na Figura 5.41. Também se pode observar a mutação por meio da tabela que lista todos os mutantes da sessão, 


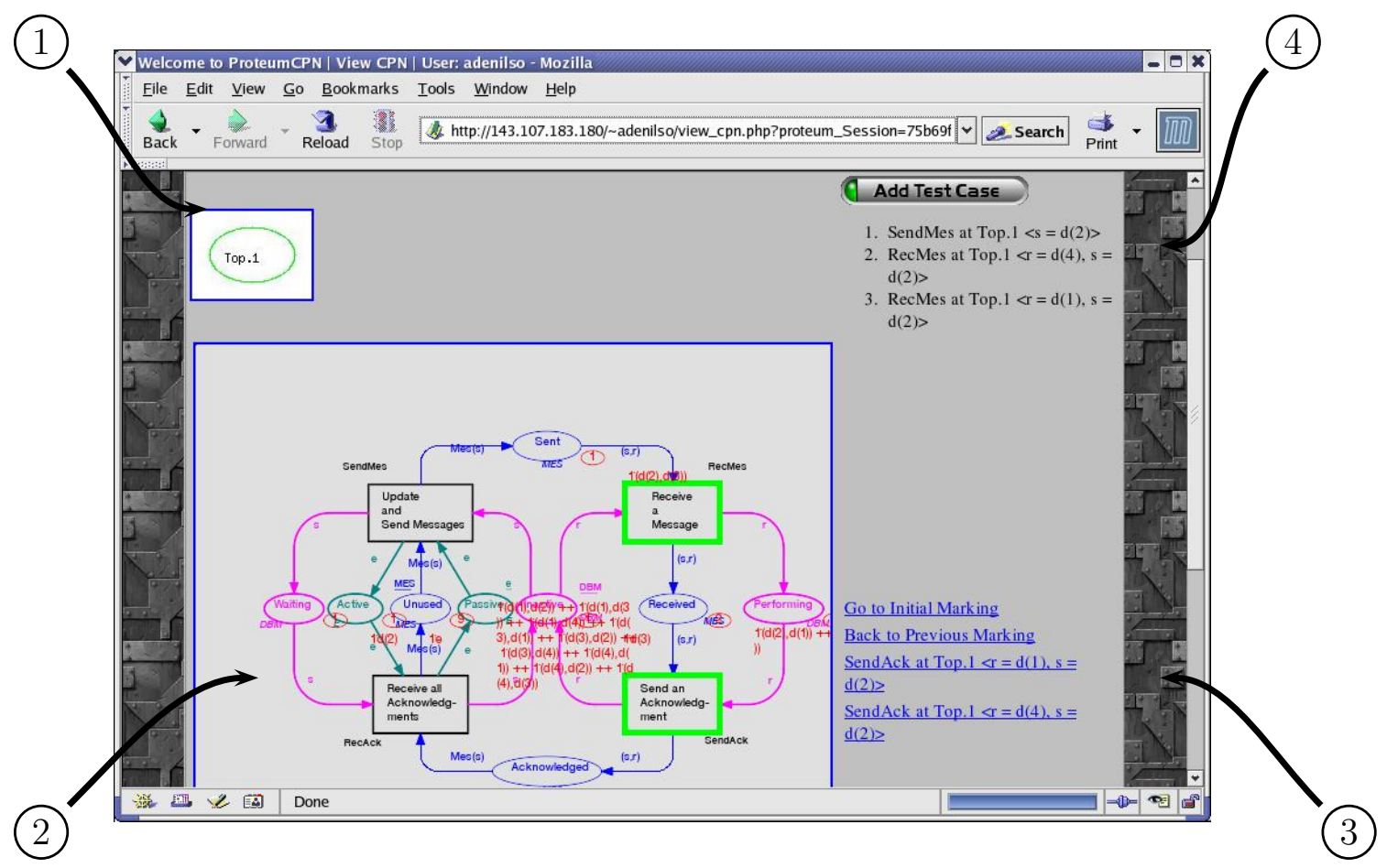

Figura 5.39: Simulação da Rede de Petri Colorida.

conforme apresentada na Figura 5.40. Essa tabela possui o código, o operador de mutação, o status de cada mutante, a diferença entre o código CPN-ML da RPC original e do mutante, bem como botões para marcar se o mutante como equivalente e para abrir a página de visualização lado a lado.

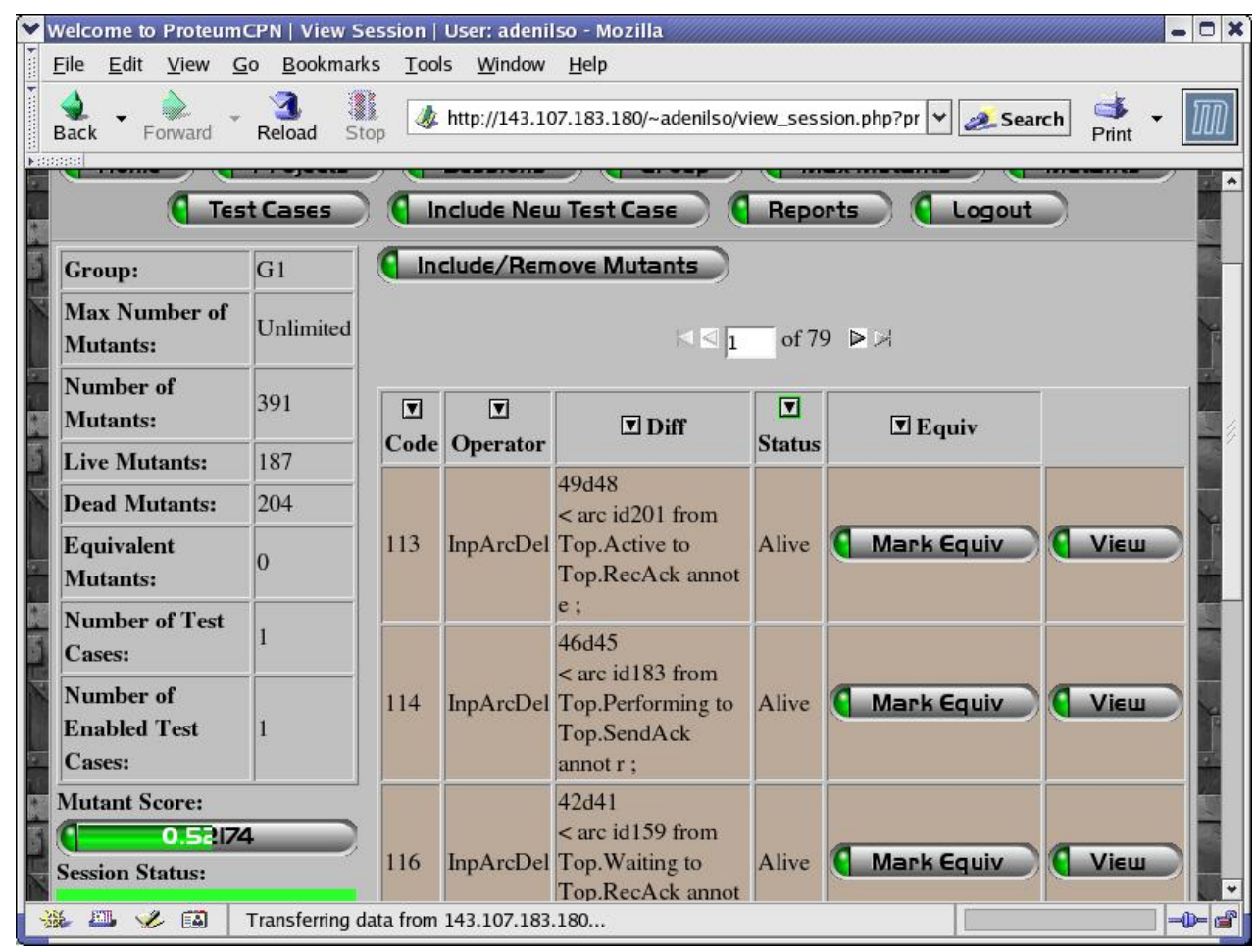

Figura 5.40: Mutantes de uma Sessão. 


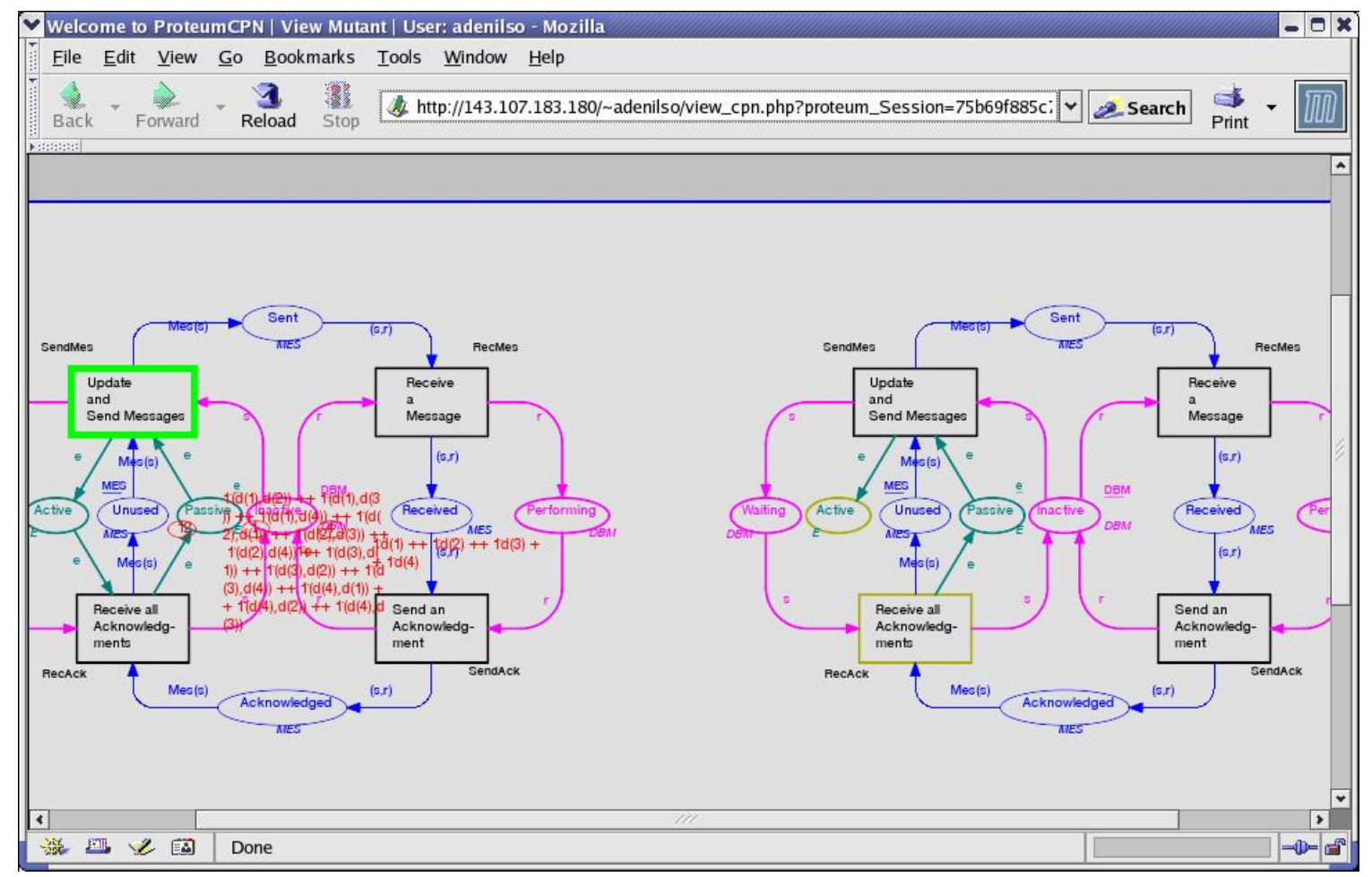

Figura 5.41: Visualização Lado a Lado da Rede Original e da Mutante.

\subsubsection{Configuração de Exibição}

A Proteum/CPN permite ao usuário utilizar diferentes skins para exibir a ferramenta. Isso pode ser configurado clicando-se no botão Settings do menu inicial. A página que aparecerá, após o clique, é apresentada na Figura 5.42. Pode-se selecionar o skin que se deseja, sendo exibida uma figura que ilustra a aparência da ferramenta com o novo skin. Além disso, pode-se selecionar a quantidade de mutantes que será mostrada em cada página. O valor escolhido também valerá para o número de linhas das tabelas que listam os projetos, as sessões e os casos de teste. Para aplicar tais configurações, é necessário clicar no botão Apply correspondente. Outro modo de exibição possível em Proteum/CPN é apresentado pela Figura 5.43. 


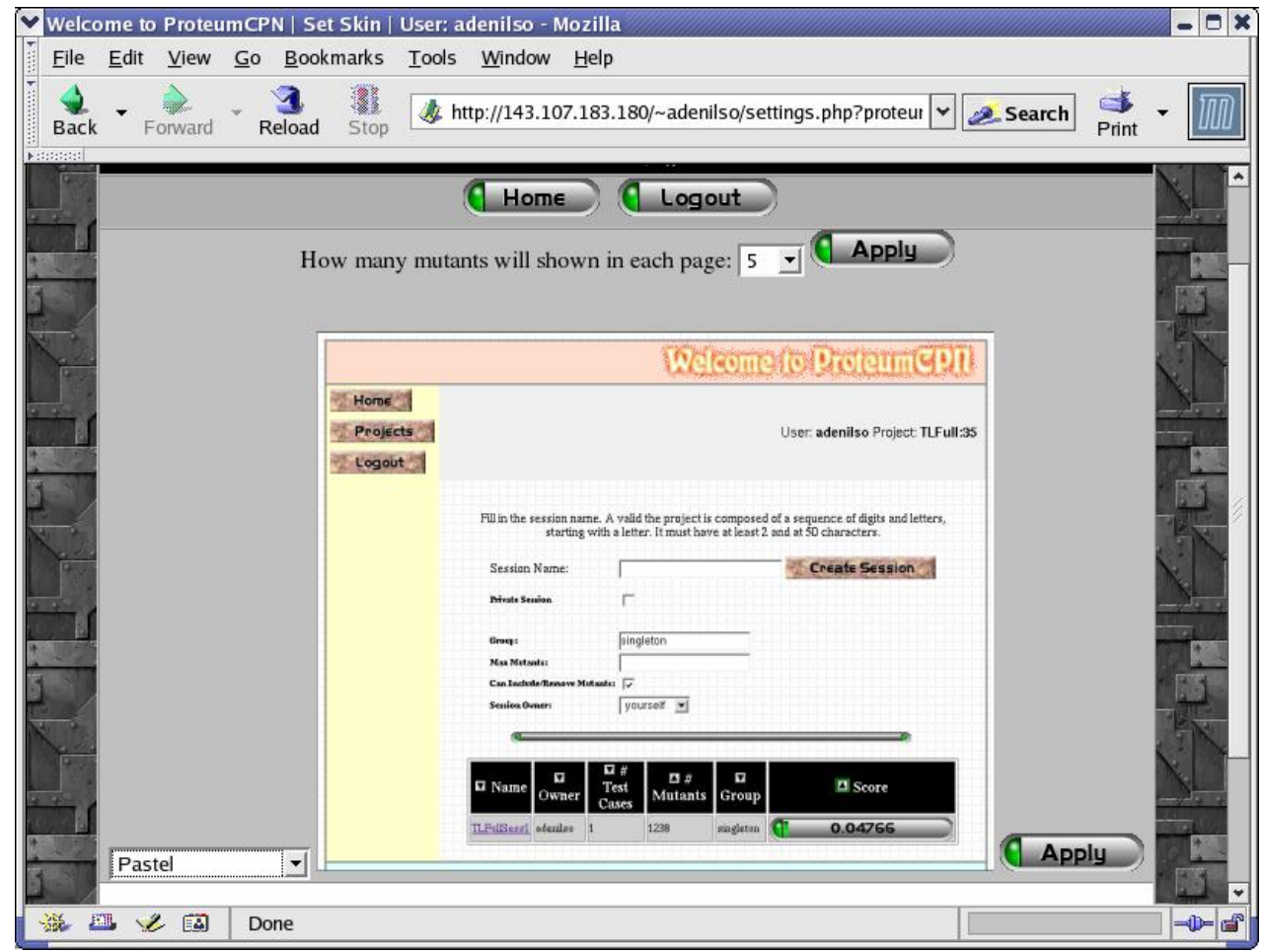

Figura 5.42: Página de Configuração de skins.

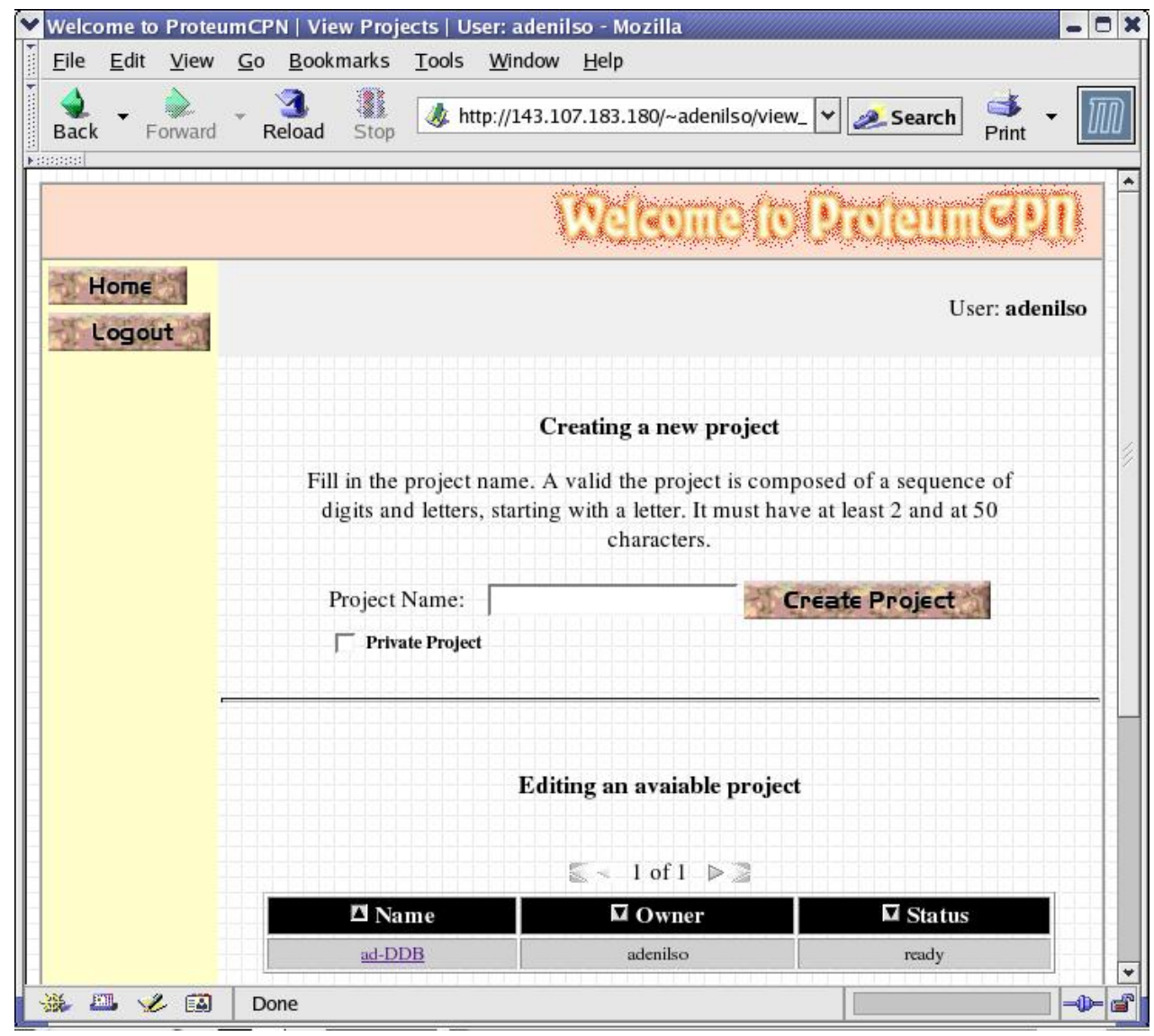

Figura 5.43: Outro Modo de Exibição Possível da Proteum/CPN. 


\subsection{Aspectos Relevantes da Implementação}

A ferramenta Proteum/CPN foi desenvolvida como uma aplicação Web, de forma a permitir sua utilização a partir de uma grande variedade de plataformas. Dessa forma, a Proteum/CPN pode ser acessada e manipulada utilizando-se um navegador Web.

A ferramenta executa sobre uma plataforma Linux, distribuição RedHat 7.3, com kernel versão 2.4.20-18.7, utilizando o Apache 1.1 como servidor de Web e o MySQL 3.23.56 como servidor de banco de dados. A ferramenta Proteum/CPN foi desenvolvida na linguagem PHP 4.1.2. De uma maneira geral, as escolhas referentes às linguagens e ferramentas utilizadas foram feitas com base em razões pragmáticas. Por exemplo, a utilização de PHP e não JSP foi motivada pela familiaridade com a linguagem. Contudo, uma diretriz que norteou as escolhas foi a utilização de softwares não proprietários.

O PHP é uma linguagem de script que permite a criação de aplicações $W e b$ dinâmicas e possibilita a interação dos usuários por meio de formulários, parâmetros de URL e ligações. A vantagem do PHP em relação aos scripts CGI escritos em C ou Perl deve-se ao fato de que seu código é embutido no próprio código HTML, enquanto que os scripts CGI precisam gerar todo código HTML. Como o código PHP é processado no servidor, não é necessário que nenhum recurso adicional seja instalado nos clientes.

O Apache é um servidor $W W W$ baseado no protocolo HTTP, que pode ser executado em máquinas com os sistemas operacionais Windows, OS/2, Netware e com a maioria das versões do Unix e do Linux. Sua distribuição é totalmente livre e seu código é aberto.

O MySQL, que é um gerenciador e servidor de banco de dados relacional, possui as vantagens de ser multi-plataforma, podendo ser executado sobre sistemas operacionais como Linux, Unix e Windows, e de possuir código aberto, podendo ser modificado e adaptado pelos desenvolvedores de acordo com suas necessidades. Uma característica bastante útil do $M y S Q L$ é a possibilidade de criação de usuários com diferentes níveis ou privilégios de acesso aos dados e de execuções das funcionalidades oferecidas pelo servidor. Isso garante, em parte, que as informações armazenadas somente serão acessadas e modificadas por pessoas autorizadas. Na Figura 5.44 é apresentado o modelo entidade-relacionamento da Proteum/CPN.

Os operadores de mutação foram descritos com a linguagem $\mathcal{M} u \mathcal{D} e \mathcal{L}$. Para a geração dos mutantes a partir das descrições, utilizou-se o sistema mudelgen, desenvolvido no contexto deste trabalho e descrito na Seção 5.4.1.

Para possibilitar a simulação da RPC, buscou-se identificar um simulador que atendesse aos seguintes requisitos:

(i) Permitisse, de alguma forma, que a RPC fosse exibida em uma página Web; 


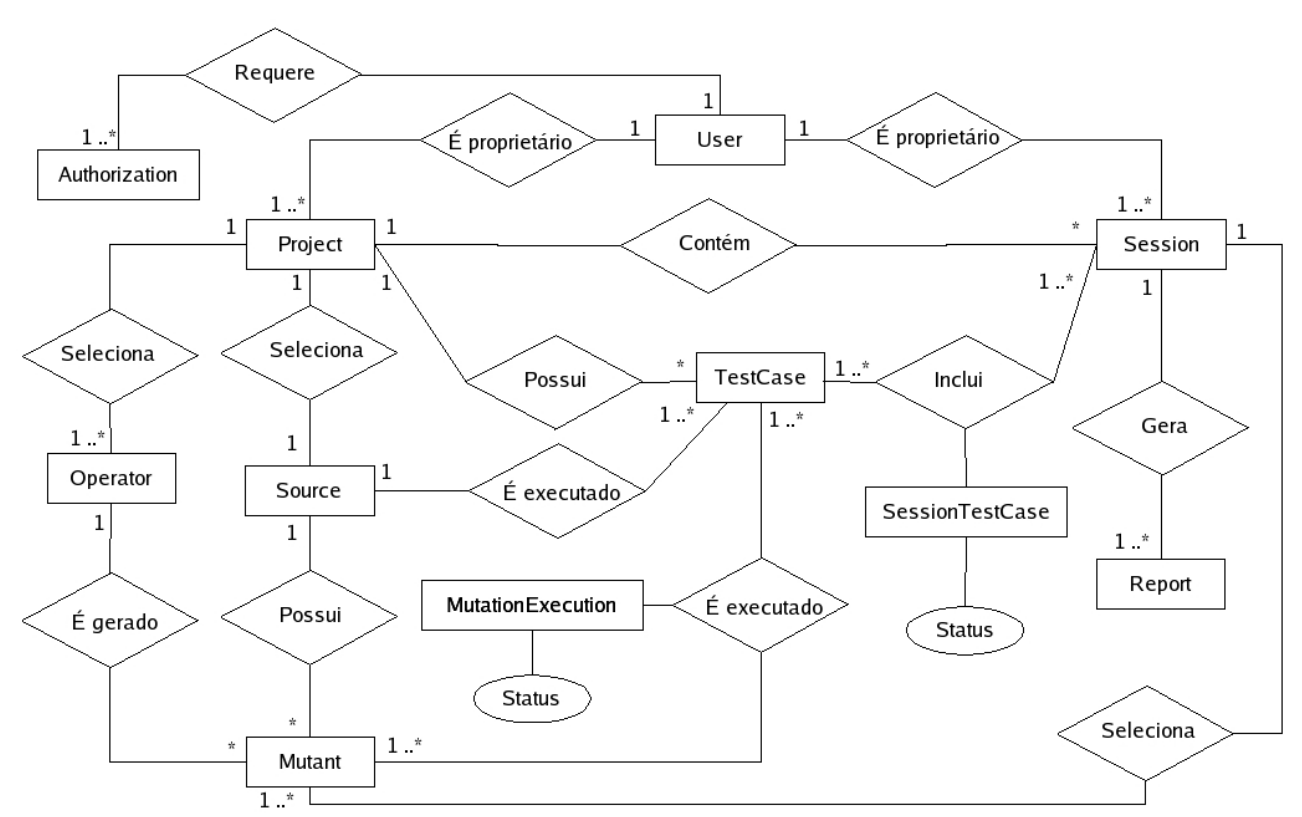

Figura 5.44: Modelo Entidade-Relacionamento da Proteum/CPN.

(ii) Permitisse que a execução ocorresse em lote, sem a necessidade de interação. Ou seja, que o simulador pudesse ser manipulado por linha de comando.

Nenhum dos simuladores encontrados atendia a ambos os requisitos, de forma que se optou por implementar um simulador, denominado SIM/CPN, que pudesse ser utilizado pela Proteum/CPN. Esse simulador é descrito na Seção 5.4.2.

\subsection{1 mudelgen}

Nesta seção serão discutidos os principais aspectos de implementação do sistema mudelgen, que foi desenvolvido para apoiar a utilização da linguagem $\mathcal{M} u \mathcal{D} e \mathcal{L}$. Quando lhe é fornecida uma gramática $G$ da linguagem alvo para a qual os operadores serão descritos, o sistema mudelgen produz um programa mudel.G. Esse programa pode, então, ser executado com uma descrição de operador de mutação $O D$ e um produto $P$. Após verificar se tanto $O D$ quanto $P$ são sintaticamente corretos em relação à gramática $G$, um conjunto de mutantes $M$ é gerado.

Para manipular a gramática de entrada do sistema mudelgen, foram utilizados os programas utilitários flex e bison, os quais são os programas de software livre similares ao YACC e lex (Mason e Brown, 1990). Apesar de esses programas facilitarem a manipulação das gramáticas, eles, por outro lado, limitam a classe de gramáticas que o mudelgen pode tratar a gramáticas LALR(1) (Aho et al., 1985; Mason e Brown, 1990; Salomaa, 1973). De forma semelhante ao que ocorre com esses programas, a gramática de entrada do mudelgen é fornecida em dois arquivos: um arquivo .y com as regras de produção e um arquivo . 1 com as informações sobre a análise léxica. O arquivo ·y é escrito em um subconjunto da 
sintaxe aceita pelo YACC (Mason e Brown, 1990), com uma sintaxe especial para as ações semânticas que permite definir a manipulação dos atributos da gramática (como descrito na Seção 3.5.2.2). De forma análoga, o arquivo . 1 é escrito em um subconjunto da sintaxe aceita pelo lex (Mason e Brown, 1990), sem as ações semânticas.

O sistema mudelgen pode ser dividido em duas partes: uma parte com os elementos que dependem da gramática de entrada; e outra parte com os elementos que não dependem. Na Figura 5.45 é ilustrado como essas partes interagem entre si e como é o esquema geral de execução do mudelgen. A parte dependente da gramática é composta por três módulos, os quais são programas executáveis: treegen, opdescgen e linker. A parte independente da gramática é incorporada em uma biblioteca de objetos. A maior parcela da biblioteca de objetos é responsável pela interpretação da descrição do operador de mutação e pela manipulação da árvore sintática, formando o $\mathcal{M} u \mathcal{D} e \mathcal{L}$ Kernel. As demais unidades da biblioteca de objetos são utilizadas para permitir a comunicação entre o $\mathcal{M} u \mathcal{D} e \mathcal{L}$ Kernel e os módulos externos $\mathcal{M} u \mathcal{D} e \mathcal{L}$ Animator e DS Oracle.

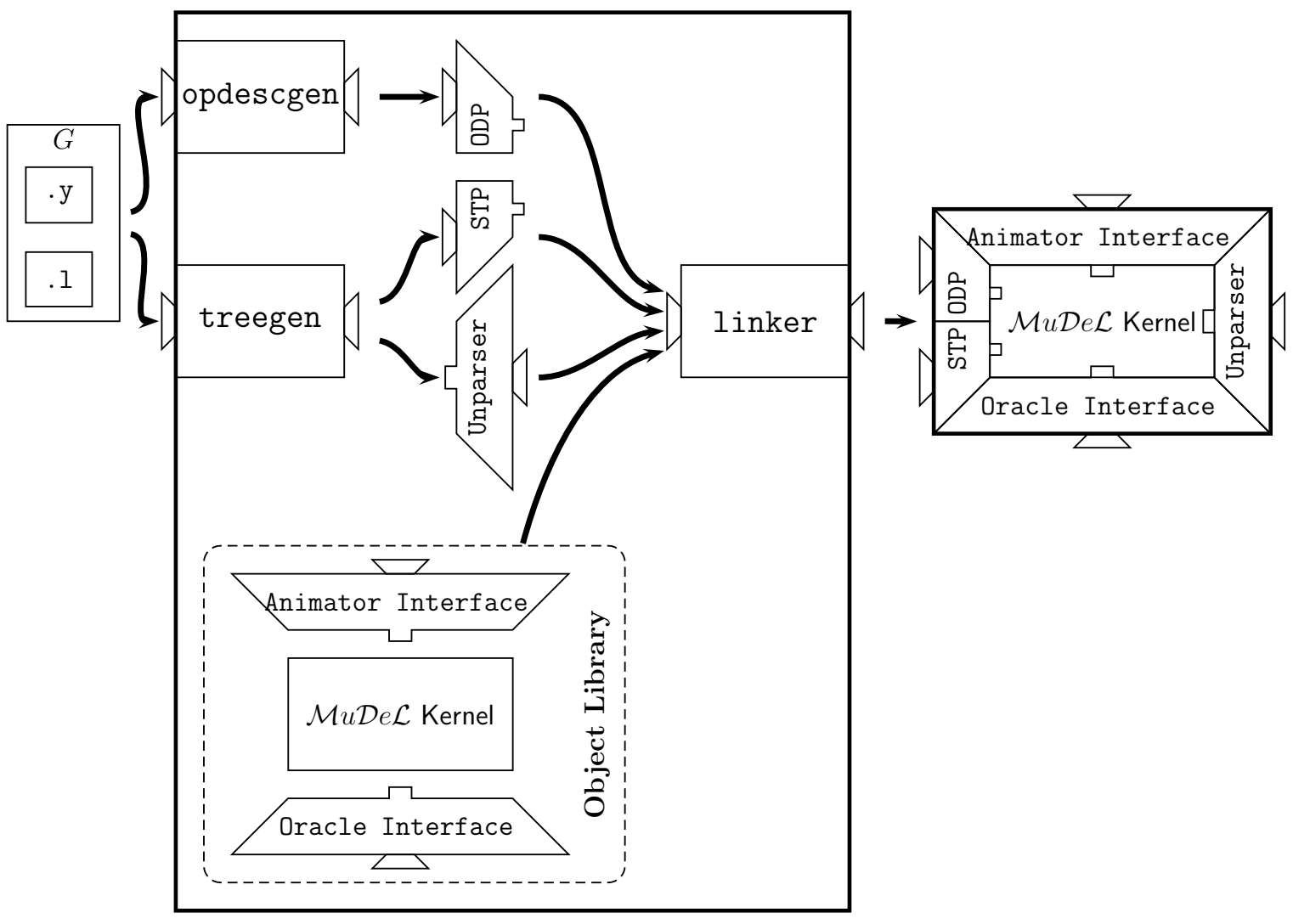

Figura 5.45: Esquema de Execução do mudelgen.

As unidades que dependem da gramática são construídas pelos módulos treegen ou opdescgen. O módulo treegen analisa a gramática $G$ e gera as seguintes unidades:

1. STP (Syntax Tree Processor), que é responsável por analisar sintaticamente o produto $P$ e gerar sua árvore sintática; e 
2. Unparser, que é responsável por converter a árvore sintática mutante no mutante.

O módulo opdescgen analisa a gramática $G$ e gera a unidade ODP (Operator Description Processor), que analisa a descrição do operador de mutação $O D$ em relação a $G$ e gera uma representação abstrata de como manipular a árvore sintática para produzir os mutantes. Finalmente, o módulo linker liga todas as unidades dependentes da gramática e a porção apropriada da Object Library e gera o programa mudel.G.

O programa mudel.G é executado utilizando o produto $P$ e uma descrição de operador $O D$ como entrada. Esses dados de entrada são processados por STP e ODP, respectivamente, e manipulados pelo MuDeL Kernel. Durante sua execução, o MuDeL Kernel gera uma ou mais árvores mutantes, que são processadas pelo Unparser para gerar os mutantes. Os mutantes produzidos por Unparser podem ser manipulados das seguintes formas:

(i) enviados para o dispositivo de saída padrão;

(ii) armazenado em bases de dados SQL (por exemplo, MySQL); e

(iii) escrito em arquivos texto (cada mutante em um arquivo separado).

Opcionalmente, o DS Oracle pode ser utilizado para validar se os mutantes foram corretamente gerados (como descrito na Seção 5.4.1.1). Além disso, a execução do programa mudel.G pode ser inspecionada com o $\mathcal{M} u \mathcal{D} e \mathcal{L}$ Animator (como descrito na Seção 5.4.1.2). O esquema geral de execução do mudel.G é apresentado na Figura 5.46.

\subsubsection{Uso de Semântica Denotacional como Oráculo}

O número de mutantes gerado é geralmente muito grande e verificá-los manualmente é um processo oneroso e passível de erros. Dessa forma, a validação do mudelgen é uma tarefa difícil, devido principalmente à quantidade de saída produzida. Para resolver esse problema, foi adotada uma abordagem que pode ser resumida em dois passos (Simão et al., 2002a):

- primeiramente, a semântica da linguagem foi formalmente definida utilizando-se a Semântica Denotacional (Allison, 1986). A semântica é apresentada no Apêndice B.

- em um segundo passo, com base no fato de que a Semântica Denotacional é baseada em Cálculo Lambda, utilizou-se a linguagem SML (Hansen e Rischel, 1999), que também é baseada em Cálculo Lambda, para "codificar e executar" a semântica da linguagem $\mathcal{M} u \mathcal{D} e \mathcal{L}$.

Implementou-se um módulo externo DS Oracle que pode ser executado em paralelo com mudel.G. Quando executado, o módulo DS Oracle recebe a informação sobre um operador de mutação $O D$ e deriva uma função denotacional $\mu$ que formalmente define a semântica 


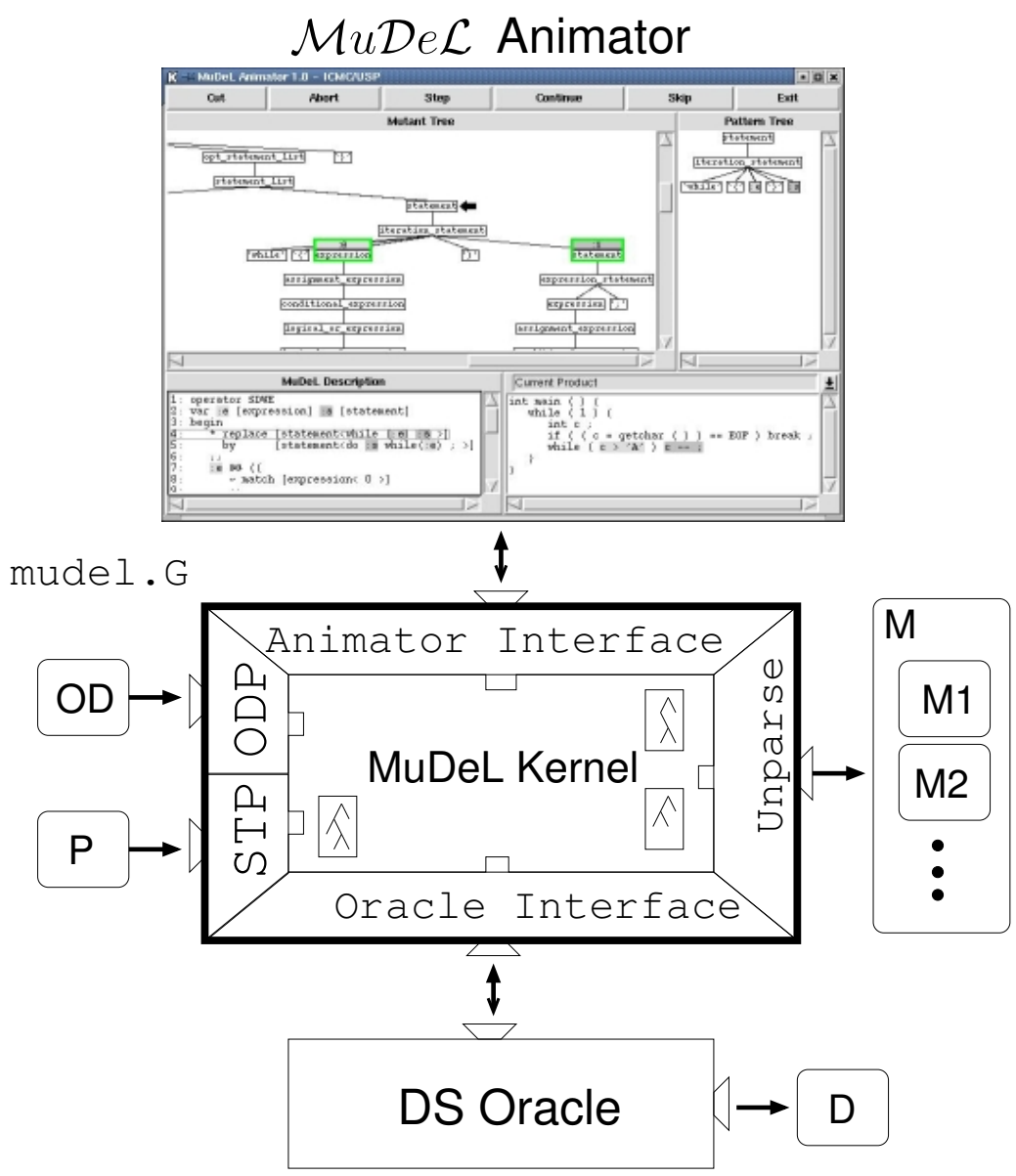

Figura 5.46: Execução de mudel.G.

de $O D$. Então, o módulo DS Oracle lê as informações sobre o produto $P$ e o conjunto de mutantes gerados $M$. Os mutantes em $M$ são comparados com os mutantes definidos por $\mu$. Qualquer diferença identificada é relatada no relatório de discrepância $D$.

É importante comentar que a execução em modo de validação não é útil para o usuário interessado na funcionalidade do mudelgen, uma vez que ela não traz benefício visível. No entanto, a execução em modo de validação é muito útil para o propósito de validação da ferramenta em si, uma vez que aumenta a confiança de que os mutantes estão sendo gerados corretamente. Teoricamente, existe uma possibilidade de um defeito na implementação não ser descoberto, devido ao fato de que a implementação SML também pode possuir defeitos que a façam produzir os mesmos resultados incorretos. Contudo, a probabilidade de que isso ocorra é muito pequena, visto que as duas linguagens de implementação são muito diferentes uma da outra. Além disso, o algoritmo e a arquitetura de ambas as implementações são consideravelmente distintas. Enquanto a implementação original foi realizada em $\mathrm{C}++$ no paradigma imperativo, a implementação em SML é extensivamente baseada em mapeamentos e continuações (Allison, 1986). Conseqüentemente, não é trivial induzir o mesmo tipo de desvio de comportamento simultaneamente em ambas as implementações. Em outras palavras, ainda que nenhuma 
delas seja livre de defeitos, o tipo de defeitos que elas provavelmente possuem são distintos. Com essa consideração, pode-se concluir que o uso de semântica denotacional e SML é um mecanismo importante para a validação do mudelgen.

\subsubsection{2 $\mathcal{M} u \mathcal{D} e \mathcal{L}$ Animator}

Foi implementado um aplicativo - o $\mathcal{M} u \mathcal{D} e \mathcal{L}$ Animator - que permite a visualização da execução de um operador de mutação (Simão et al., 2002b). O $\mathcal{M} u \mathcal{D} e \mathcal{L}$ Animator foi implementado em Perl/Tk. Ele possui algumas características que permitem inspecionar a execução, sem, contudo, permitir que se interfira no processo. Na Figura 5.47 é apresentada a janela principal do $\mathcal{M} u \mathcal{D} e \mathcal{L}$ Animator. No topo da janela estão os botões que controlam a execução do animador, tais como Step, Exit, etc. O restante da janela é dividido em quatro áreas:

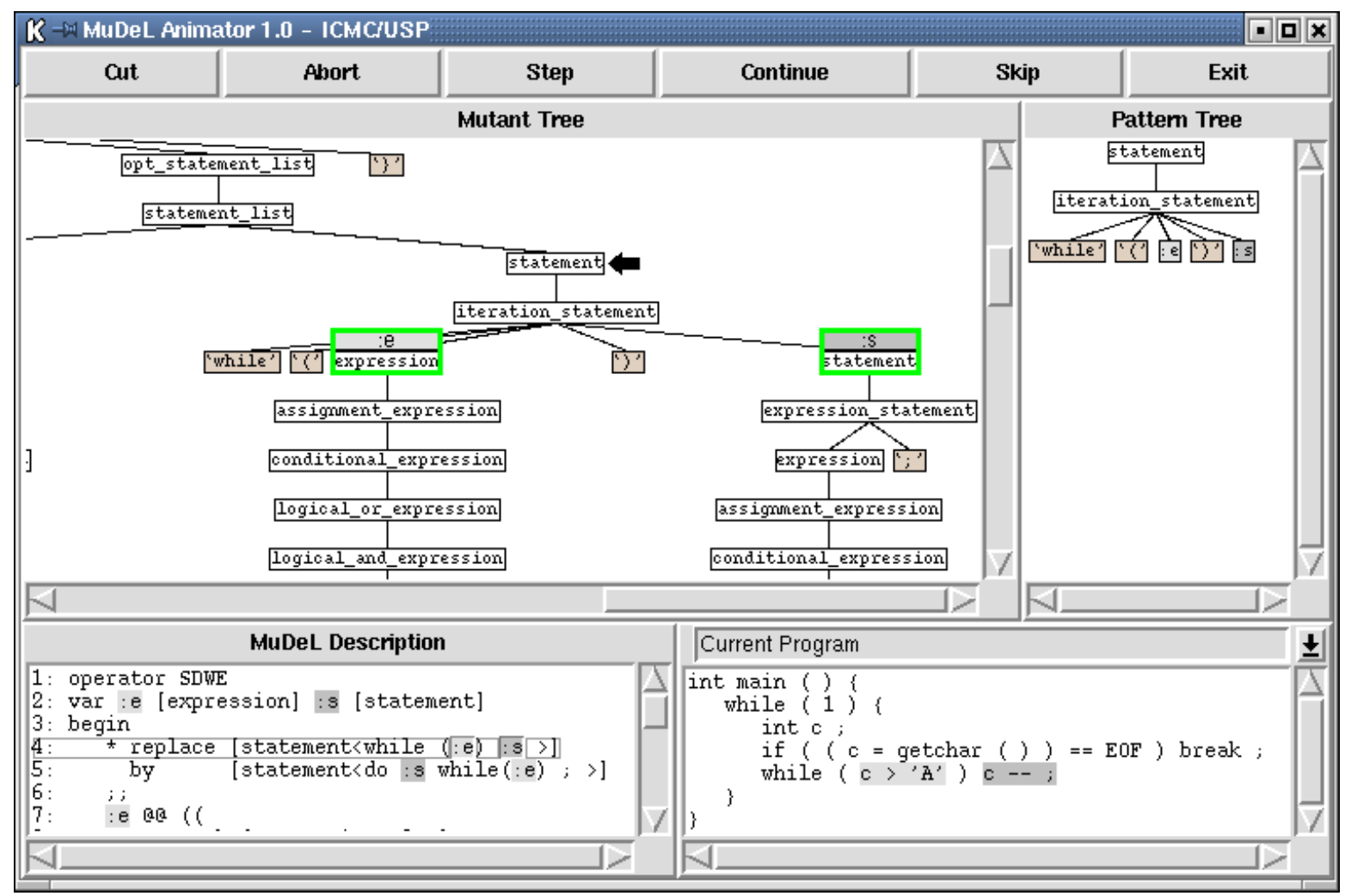

Figura 5.47: $\mathcal{M} u \mathcal{D} e \mathcal{L}$ Animator.

Descrição $\mathcal{M} u \mathcal{D} e \mathcal{L}$ : $\mathrm{Na}$ área inferior esquerda, o $\mathcal{M} u \mathcal{D} e \mathcal{L}$ Animator apresenta a descrição do operador de mutação. Um retângulo indica a linha que está sendo atualmente executada. Cada meta-variável é destacada com uma cor específica. A mesma cor é usada sempre que a mesma meta-variável aparece em todas as demais áreas.

Árvore Mutante: Na área superior esquerda, o animador mostra a árvore sintática do produto, refletindo qualquer mudança que ocorreu até o momento na execução. Uma seta indica qual nó é a raiz da árvore de contexto. As ligações de meta-variáveis são 
apresentadas incluindo-se o nome da meta-variável acima do nó correspondente da árvore.

Produto Corrente: Na área inferior direita, é apresentado o estado atual do produto, obtido percorrendo-se a árvore mutante. Os trechos no mutante que correspondem aos nós ligados a meta-variáveis são destacados com a respectiva cor.

Padrão de Árvore: Na área superior direita, o $\mathcal{M} u \mathcal{D} e \mathcal{L}$ Animator apresenta o padrão de árvore atualmente ativo (ou seja, que está na linha corrente da descrição).

\subsubsection{Sim/CPN: Um Simulador para Redes de Petri Coloridas}

O Sim/CPN é um simulador para RPCs, que é composto por um conjunto de módulos utilitários que fornecem as funcionalidades básicas necessárias para a Proteum/CPN. O simulador aceita como entrada um conjunto de arquivos XML, que descrevem tanto os elementos estruturais (tais como os lugares, transições e arcos) quanto os atributos gráficos (tais como o cor, posição e dimensão de cada elemento) da RPC. Basicamente, os módulos existentes são divididos em dois grupos:

Draw O grupo Draw é formado por scripts escritos em Perl que analisam os arquivos XML, sendo capazes de convertê-los para outros formatos. Por exemplo, o script generateFig.pl gera uma figura em formato PNG a partir dos atributos gráficos da RPC, ao passo que o script generateHier .pl gera uma figura em formato PNG com a hierarquia de páginas da RPC. Esses módulos foram desenvolvidos com o pacote de manipulação de imagens ImageMagick ${ }^{1}$.

cpn-ml2sml O módulo cpn-ml2sml é um compilador que gera um programa SML que é responsável por simular o comportamento da RPC.

Na Figura 5.48 é apresentado o esquema geral de execução do simulador. Para poderem ser utilizados, os arquivos XML são processados pelo cpn-ml2sml (Passo a), que os compila e gera o código SML para a simulação. O código SML é, então, ligado a um código SML genérico (Passo b), que é responsável por implementar os mecanismos para calcular as ligações habilitadas e as marcações resultantes (Passo c). O programa SML resultante, denominado $C P N_{\mathrm{SML}}$, é um driver que oferece funcionalidades tanto para a simulação iterativa quanto para a simulação em batch.

Os arquivos XML também são processados pelos módulos do DraW (Passo d), para produzir os arquivos com as figuras a partir dos atributos gráficos. Esses arquivos de figuras serão utilizados para compor as páginas da Proteum/CPN, quando necessário.

Deve-se ressaltar que, em função dos objetivos deste trabalho, atualmente, o simulador pode ser acessado apenas por meio da Proteum/CPN. Como um trabalho futuro, sugere-se a disponibilização do simulador como uma ferramenta autônoma.

\footnotetext{
${ }^{1}$ Disponível em http://www.imagemagick.org/.
} 


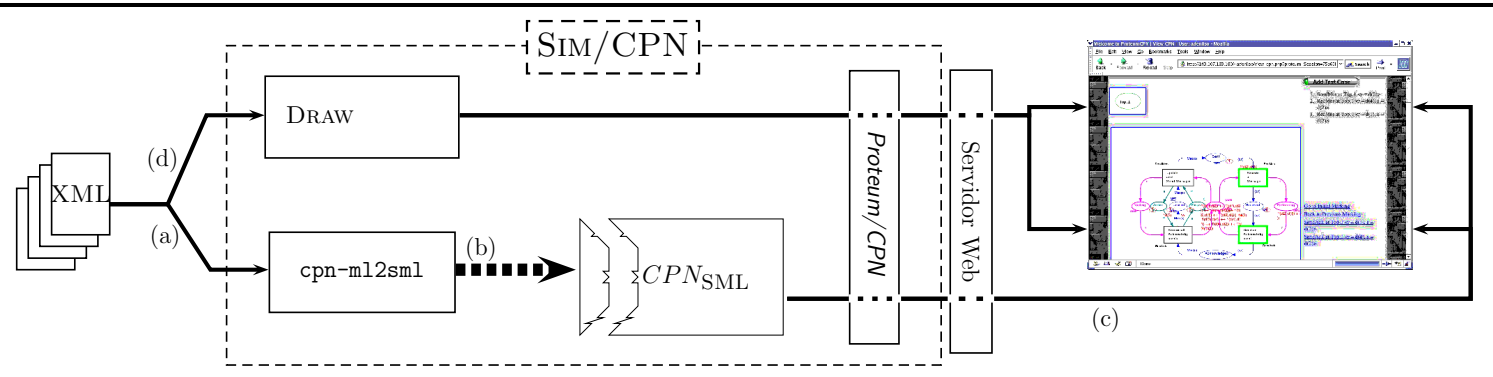

Figura 5.48: Sim/CPN: Esquema Geral de Execução.

\subsection{Considerações Finais}

Neste capítulo, foram apresentadas as contribuições deste trabalho no que se relaciona à automatização da atividade de teste. Foi apresentada a ferramenta Proteum/CPN, desenvolvida para apoiar a aplicação do critério AM no teste de especificações baseadas em RPC. Foram descritos os principais aspectos arquiteturais e de implementação, bem como a modelagem da ferramenta. A estrutura da ferramenta Proteum/CPN, baseada em projetos e sessões, minimiza o número de gerações de mutantes e execuções de casos teste. Isso é um aspecto interessante para o critério AM, pois reduz seu custo de aplicação. Além disso, a noção de grupo de sessões permite facilitar o trabalho cooperativo entre um grupo de testadores.

Foram também apresentadas as funcionalidades da Proteum/CPN, que permitem realizar o tratamento de casos de teste, tratamento de mutantes e a análise da adequação da atividade de teste. Além disso, foi descrito um exemplo do uso da ferramenta.

Buscou-se conduzir a especificação e a implementação da Proteum/CPN de forma a facilitar o reúso. Identificaram-se quais são as funcionalidades que são gerais a qualquer ferramenta baseada em mutação e quais são as funcionalidades específicas da linguagem alvo. Dentro desse esforço, foi desenvolvido um trabalho de mestrado no qual a ferramenta Proteum/CPN foi utilizada como ponto de partida para o desenvolvimento de uma ferramenta para apoiar a aplicação do critério AM em programas SML. O resultado obtido evidenciou a possibilidade de se generalizar tanto o código da ferramenta como a especificação, construindo um framework para ferramentas de teste.

No Capítulo 3, discutiram-se os diversos aspectos relativos a aplicação da AM para o teste de RPCs. A Proteum/CPN oferece apoio a todos os conceitos apresentados, exceto para a seleção das opções para a avaliação do mutante quando o caso de teste não está habilitado a disparar. Essa funcionalidade será implementada em versões futuras da ferramenta.

Neste capítulo, também foram apresentadas algumas ferramentas de apoio utilizadas, direta ou indiretamente, no desenvolvimento da Proteum/CPN, tais como o mudelgen (para gerar os mutantes a partir das descrições em $\mathcal{M} u \mathcal{D} e \mathcal{L}$ ), o $\mathcal{M} u \mathcal{D} e \mathcal{L}$ Animator (para visualizar dos operadores) e o Sim/CPN (para simular as RPCs). Deve-se ressaltar que, 
cada uma dessas ferramentas de apoio representa uma contribuição e um tema de pesquisa futuro.

No próximo capítulo são apresentados alguns estudos de caso conduzidos para avaliar os conceitos propostos neste trabalho e observar sua aplicabilidade. 


\section{Estudos de Caso}

\subsection{Considerações Iniciais}

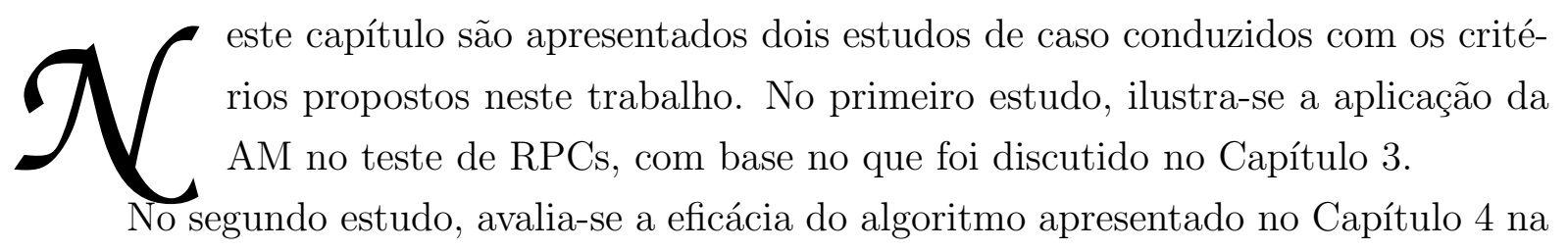
geração de casos de teste para RPs e na determinação de mutantes equivalentes.

Deve-se ressaltar que os estudos de caso conduzidos foram estudos observacionais, de forma que não é possível a obtenção de resultados estatisticamente válidos. Dessa forma, um trabalho futuro relevante é a condução de experimentos para avaliar a eficácia dos critérios e a usabilidade das ferramentas de apoio.

Cada um dos estudos de caso é caracterizado com base na nomenclatura proposta por (Wohlin et al., 2000). Inicialmente, apresentam-se o propósito do estudo, o contexto de aplicação e as medidas a serem coletadas. Em seguida, descreve-se a execução do estudo e apresentam-se os resultados obtidos. Ao final, faz-se uma análise dos resultados.

\subsection{Estudo de Caso I: Aplicação da Análise de Mutantes a Redes de Petri Coloridas}

Neste estudo de caso, a aplicação da AM a RPCs, tal qual apresentada no Capítulo 3, é realizada com seis RPCs, sendo quatro provenientes da literatura (Jensen, 1997a,b,c) e duas desenvolvidas no contexto de outros trabalhos do Grupo de Engenharia de Software do ICMC/USP. O objetivo deste estudo de caso é a avaliação da quantidade de requisitos de teste (ou seja, de mutantes) gerados pelos operadores propostos. De forma a avaliar o custo da aplicação, foram obtidos conjuntos de casos de teste adequados para cada RPC. 


\subsubsection{Definição}

- Analisar a aplicação da Análise de Mutantes

- Para o propósito de observação

- Com respeito ao custo de aplicação

- No contexto de Redes de Petri Coloridas

\subsubsection{Materiais}

Nesta seção, descrevem-se sucintamente as características mais relevantes de cada uma das RPCs utilizadas nesse estudo de caso. Destacam-se também as características estruturais, que permitem confrontar o "tamanho" da rede com o número de mutantes gerados (apresentado na Tabela 6.2). As RPCs provenientes de (Jensen, 1997a,b,c) são as quatro primeiras (DDB, RA, TL e HP), ao passo as duas últimas (BA e CP) foram desenvolvidas dentro do contexto de outros trabalho do grupo. As características estruturais dessas redes são apresentadas na Tabela 6.1. As RPCs utilizadas são sucintamente descritas a seguir. A título de ilustração, no Apêndice E, são incluídas as figuras referentes a essas redes.

Banco de Dados Distribuído (DDB): Essa rede foi utilizada neste documento para exemplificar os conceitos desenvolvidos (Figura 2.4).

Alocador de Recurso (RA): Descreve como dois tipos de processos (chamados de p-processo e q-processo) estão compartilhando três tipos de recursos (chamados de r-recurso, s-recurso e t-recurso). Cada processo é cíclico e durante as partes individuais de seu ciclo, o processo precisa ter acesso exclusivo a uma quantidade variável de recursos. Os processos podem estar em cinco estados distintos, representados pelos lugares $A$-E. Cada marca de um desses lugares representa um p-processo ou um q-processo e também a quantidade de ciclos inteiros que o processo completou. Os recursos são representados pelos lugares $R-T$. Essa RPC é representada na Figura E.1.

Sistema Telefônico (TL): Descreve como o sistema de telefone público é conhecido pelo usuário (e não pelo técnico de telefone). São ignorados time-out e serviços especiais tal como chamada de conferência.

O sistema telefônico possui uma única página principal Phone\#1, na qual existem três transições de substituição: Establishment of a Connection, Breaking of a Connection by the Sender e Breaking of a Connection by the Recipient. Os telefones podem estar em dois diferentes estados: Inactive e Connected. A troca de telefone (telephone exchange) (os eletrônicos do switch do telefone) é representado 
por um único lugar, Connection. Cada marca neste lugar representa uma conexão estabelecida entre o sender (telefone no qual a chamada foi feita) e o recipient (telefone que foi chamado). Essa RPC é representada nas Figuras E.2, E.3, E.4, E.5, E.6 e E.7.

Protocolo Hierárquico (HP): Representa um protocolo de rede simples para o envio de mensagens entre um emissor e dois receptores. O protocolo é representado por uma RPC hierárquica. Basicamente, o protocolo consiste em enviar as mensagens com um contador, indicando o número dessa mensagem na seqüência de mensagens enviadas. O receptor da mensagem envia um acknowledgement para o emissor com esse número, de forma a indicar que a mensagem foi recebida adequadamente. Tanto as mensagens quanto os acknowledgements podem ser perdidos, exigindo uma retransmissão. Essa RPC é representada nas Figuras E.8, E.9, E.10 e E.11.

Protocolo Bit-Alternante (BA): O protocolo Bit-Alternante é uma representação mais simples do "protocolo de janela deslizante", com uma janela de tamanho 1 (Tanenbaum, 1989). Esse protocolo fornece comunicação confiável em um serviço de rede não confiável, usando uma seqüência de 1-bit (que alterna entre 0 e 1) em cada mensagem ou acknowledgement para determinar quando as mensagens devem ser retransmitidas. Essa RPC é representada na Figura E.12.

Protocolo Conferência/Cotê de Resyste (CP): O protocolo conferência (Belinfante, 2003) fornece comunicação entre usuários que podem participar de "conferência" com outros usuários. Nesse protocolo, um usuário pode cadastrar-se em uma conferência e a partir de então, enviar mensagens, as quais serão transmitidas aos demais usuários dessa conferência. Além disso, o usuário pode receber mensagens dos outros usuários que estão na mesma conferência e sair da conferência. O protocolo garante a transmissão de mensagens apenas para os membros da mesma conferência, mas não garante que todas as mensagens serão efetivamente recebidas ou serão recebidas na mesma ordem do envio (ou seja, o meio de comunicação não é confiável). Contudo, o protocolo provê mecanismos para corrigir alguns problemas decorrentes disso, tais como a perda de uma mensagem de cadastro. Essa RPC é representada nas Figuras E.13, E.14, E.15, E.16, E.17 e E.18.

\subsubsection{Procedimento}

Cada uma das RPCs foi modelada de forma a obter uma descrição XML de suas páginas. Para isso, foi utilizada a ferramenta Design/CPN, uma vez que a ferramenta Proteum/CPN, empregada no restante do estudo de caso, não possui funcionalidades de edição. Foram criados projetos de teste para cada RPC, solicitando-se a geração de 
Tabela 6.1: Características das Redes de Petri Coloridas.

\begin{tabular}{|c||c|c|c|c|c|c|}
\hline & DDB & RA & TL & HP & BA & CP \\
\hline \hline Páginas & 1 & 1 & 6 & 4 & 1 & 6 \\
\hline Lugares & 9 & 8 & 32 & 25 & 8 & 25 \\
\hline Transições & 4 & 5 & 19 & 10 & 5 & 19 \\
\hline Variáveis & 2 & 2 & 2 & 10 & 7 & 8 \\
\hline Constantes & 0 & 4 & 3 & 18 & 5 & 1 \\
\hline
\end{tabular}

todos os mutantes para todos os operadores. Em seguida, nas sessões de teste criadas para esses projetos, foram inseridos casos de teste capazes de matar todos os mutantes não-equivalentes. Nesse passo, os casos de teste foram incluídos, buscando-se sempre matar algum mutante específico. Mais precisamente, escolhia-se um mutante vivo e derivava-se um caso de teste capaz de matá-lo. Os mutantes eram ordenados por operador de mutação e, dentro de um mesmo operador, pela ordem de geração. O mutante escolhido para guiar a geração do caso de teste era o primeiro mutante vivo não-equivalente. Nesse estudo de caso, foi utilizada a relação de equivalência para lugares definida como "Equality", apresentada na Seção 3.3, ou seja, o conteúdo de todos os lugares era considerado, e para que o mutante se mantivesse vivo, era preciso que os conteúdos na RPC original e na mutante fossem iguais. Com relação à relação de equivalência de transições, atualmente a Proteum/CPN implementa apenas uma das possibilidades apresentadas na Seção 3.3. Portanto, foi utilizada a relação de equivalência disponível, na qual, se a seqüência de ligações não é habilitada a disparar na marcação inicial, o mutante é considerado morto. Os mutantes equivalentes foram determinados manualmente.

\subsubsection{Coleta de Dados}

Nesse estudo de caso, foram coletados os seguintes dados:

- O número de mutantes gerados para cada operador.

- O número de mutantes equivalentes gerados para cada operador.

- O número de casos de teste dos conjuntos adequados obtidos conforme o procedimento apresentado na Seção 6.2.3.

\subsubsection{Resultados}

\subsubsection{Número de Mutantes Gerados}

Na Tabela 6.2 é apresentado o número de mutantes gerados para cada uma das redes utilizadas nesse estudo de caso. 
Tabela 6.2: Número de Mutantes Gerados para cada Operador.

\begin{tabular}{|c||c|c|c|c|c|c||c|c|}
\hline Operador & DDB & RA & TL & HP & BA & CP & Total & $\%$ \\
\hline \hline OpMultRelRel & 0 & 0 & 0 & 0 & 0 & 0 & 0 & $0.00 \%$ \\
\hline OpLogLog & 0 & 0 & 0 & 1 & 0 & 2 & 3 & $0.06 \%$ \\
\hline GuardInv & 0 & 1 & 0 & 0 & 2 & 3 & 6 & $0.13 \%$ \\
\hline GuardExchange & 0 & 5 & 0 & 0 & 2 & 0 & 7 & $0.15 \%$ \\
\hline OpMultArithArith & 0 & 0 & 2 & 8 & 0 & 0 & 10 & $0.22 \%$ \\
\hline OpIfInv & 0 & 4 & 0 & 7 & 0 & 3 & 14 & $0.30 \%$ \\
\hline OpRelRel & 0 & 5 & 0 & 4 & 2 & 4 & 15 & $0.32 \%$ \\
\hline InitMarkDel & 3 & 5 & 1 & 8 & 6 & 3 & 26 & $0.56 \%$ \\
\hline InitMarkIns & 6 & 6 & 8 & 5 & 1 & 1 & 27 & $0.58 \%$ \\
\hline OpArithArith & 0 & 10 & 0 & 10 & 10 & 0 & 30 & $0.65 \%$ \\
\hline GuardIns & 4 & 4 & 19 & 10 & 7 & 16 & 60 & $1.29 \%$ \\
\hline InitMarkExchange & 6 & 10 & 26 & 16 & 3 & 1 & 62 & $1.34 \%$ \\
\hline OutputArcExchange & 22 & 30 & 5 & 6 & 10 & 4 & 77 & $1.66 \%$ \\
\hline InputArcExchange & 22 & 30 & 16 & 6 & 10 & 4 & 88 & $1.89 \%$ \\
\hline OutputArcInversion & 10 & 9 & 26 & 14 & 20 & 36 & 115 & $2.48 \%$ \\
\hline OutputArcDel & 10 & 9 & 26 & 14 & 20 & 36 & 115 & $2.48 \%$ \\
\hline InputArcDel & 10 & 10 & 35 & 13 & 20 & 37 & 125 & $2.69 \%$ \\
\hline InputArcInversion & 10 & 10 & 35 & 13 & 20 & 37 & 125 & $2.69 \%$ \\
\hline VarExchange & 12 & 0 & 61 & 30 & 8 & 96 & 207 & $4.46 \%$ \\
\hline OutputArcShift & 22 & 36 & 50 & 8 & 72 & 52 & 240 & $5.17 \%$ \\
\hline InputArcShift & 22 & 40 & 63 & 10 & 69 & 52 & 256 & $5.51 \%$ \\
\hline VarSmall & 40 & 30 & 150 & 28 & 50 & 0 & 298 & $6.42 \%$ \\
\hline AnnotSmall & 40 & 38 & 122 & 26 & 28 & 80 & 334 & $7.19 \%$ \\
\hline AnnotExchange & 8 & 54 & 70 & 18 & 66 & 135 & 351 & $7.56 \%$ \\
\hline InputArcIns & 50 & 150 & 153 & 41 & 102 & 94 & 590 & $12.70 \%$ \\
\hline OutputArcIns & 50 & 150 & 153 & 41 & 102 & 94 & 590 & $12.70 \%$ \\
\hline ConstExchange & 0 & 54 & 24 & 726 & 64 & 5 & 873 & $18.80 \%$ \\
\hline \hline Total & 347 & 700 & 1045 & 1063 & 694 & 795 & 4644 & $100.00 \%$ \\
\hline
\end{tabular}

Pode-se observar que todos os operadores geraram mutantes para pelo menos uma RPC, com exceção do operador OpMultRelRel. Esse operador é aplicado sobre os operadores relacionais sobre multi-conjuntos. Uma vez que nenhuma das RPCs utilizadas possui um desses operadores, o OpMultRelRel não foi aplicado.

A maioria dos operadores geraram mutantes para todas as RPCs. Apenas os operadores que se aplicam sobre elementos que não aparecem comumente nas RPCs deixaram de gerar mutantes para alguma das RPCs. São eles os operadores OpLogLog, GuardInv, GuardExchange, OpMultArithArith, OpIfInv, OpRelRel, OpArithArith, VarExchange, VarSmall e ConstExchange.

Pode-se observar que os operadores que geraram o maior número de mutantes são os operadores VarExchange, OutputArcShift, InputArcShift, VarSmall, AnnotSmall, 
AnnotExchange, InputArcIns, OutputArcIns e ConstExchange. Somados esses 9 operadores geraram mais de $80 \%$ dos mutantes. Esses resultados estão em conformidade com a complexidade apresentada na Seção 3.4, uma vez que esses operadores possuem complexidade quadrática em relação aos elementos da rede.

Uma consideração especial pode ser feita a respeito do operador ConstExchange. Esse operador troca as constantes presentes na RPC para cada uma das demais constantes. Assim, o número de mutantes depende diretamente da quantidade de constantes da RPC. A RPC HP possui 18 constantes, de forma que o número de mutantes gerados pelo operador ConstExchange para essa RPC é relativamente alto, fazendo com que gere a maior porcentagem de mutantes.

\subsubsection{Mutantes Equivalentes}

Na Tabela 6.3 é apresentado o número de mutantes equivalentes gerados para cada uma das RPCs, divididos pelo operador que os gerou. O número de mutantes equivalentes não é elevado, representando em torno de $1.21 \%$ dos mutantes gerados. Vale lembrar que a relação de equivalência utilizada influencia os mutantes que são considerados equivalentes.

Tabela 6.3: Número de Mutantes Equivalentes.

\begin{tabular}{|c||c|c|c|c|c|c||c|c|}
\hline & DDB & RA & TL & HP & BA & CP & Total & $\%$ \\
\hline \hline AnnotExchange & 0 & 4 & 2 & 0 & 4 & 3 & 13 & $3.54 \%$ \\
\hline AnnotSmall & 8 & 10 & 0 & 0 & 0 & 0 & 18 & $5.52 \%$ \\
\hline GuardIns & 0 & 0 & 5 & 4 & 0 & 5 & 14 & $20.89 \%$ \\
\hline GuardRepl & 0 & 1 & 0 & 0 & 2 & 0 & 3 & $42.57 \%$ \\
\hline InputArcIns & 0 & 8 & 0 & 0 & 0 & 0 & 8 & $1.25 \%$ \\
\hline OutputArcIns & 0 & 8 & 0 & 0 & 0 & 0 & 8 & $1.25 \%$ \\
\hline VarSmall & 0 & 2 & 0 & 0 & 0 & 0 & 2 & $0.63 \%$ \\
\hline VarExchange & 0 & 0 & 0 & 2 & 0 & 1 & 3 & $1.42 \%$ \\
\hline \hline Total & 8 & 33 & 7 & 6 & 2 & 9 & 65 & $1.26 \%$ \\
\hline
\end{tabular}

Como discutido na Seção 6.2.3, um mutante é considerado morto em uma das seguintes situações:

1. A marcação final da RPC original é diferente da marcação final do RPC mutante; $\mathrm{Ou}$

2. A seqüência de ligações correspondente ao caso de teste não estava habilitada a disparar.

Na Tabela 6.4 é apresentada a porcentagem de vezes que os mutantes foram considerados mortos para cada uma dessas situações. 
Tabela 6.4: Porcentagem da Causa da Morte dos Mutantes.

\begin{tabular}{|c||c|c|}
\hline RPC & Diferença na Marcação & Seqüência não Habilitada \\
\hline \hline DDB & $42.25 \%$ & $57.75 \%$ \\
\hline RA & $55.72 \%$ & $44.28 \%$ \\
\hline TL & $38.82 \%$ & $61.18 \%$ \\
\hline HP & $46.58 \%$ & $53.42 \%$ \\
\hline BA & $27.14 \%$ & $72.86 \%$ \\
\hline CP & $30.34 \%$ & $69.66 \%$ \\
\hline \hline Total & $38.48 \%$ & $61.52 \%$ \\
\hline
\end{tabular}

Pode-se observar que, em mais de $60 \%$ dos casos, a causa da morte do mutante foi devida ao fato de a seqüência não estar habilitada na marcação inicial. Um ponto a ser investigado é o comportamento do escore de mutação quando outras relações de equivalência são utilizadas.

\subsubsection{Conjuntos de Casos de Teste}

Para cada RPC, foi gerado um conjunto de casos de teste que obtém escore de mutação 1.00. Na Tabela 6.5 é apresentado o número de casos de teste nos conjuntos adequados para cada uma das redes apresentadas anteriormente.

Tabela 6.5: Número de Casos de Teste nos Conjuntos Adequados.

\begin{tabular}{|c||c|}
\hline RPC & \# de Casos de Teste \\
\hline \hline DDB & 7 \\
\hline RA & 9 \\
\hline TL & 17 \\
\hline HP & 11 \\
\hline BA & 18 \\
\hline CP & 17 \\
\hline
\end{tabular}

A cardinalidade dos conjuntos é relativamente pequena, indicando que o custo de aplicação do critério não é elevado. Contudo, deve-se ressaltar a necessidade de condução de novos estudos para comprovar essa indicação e, principalmente, para avaliar a qualidade desses conjuntos em relação a outras formas de validação, assim como os aspectos complementares entre eles.

O procedimento utilizado para a geração dos casos de teste permitiu observar que os mutantes apresentam um comportamento típico, no qual uma grande quantidade de mutantes é morto pelos primeiros casos de teste. Por exemplo, o primeiro caso de teste mata, em alguns casos, mais de $50 \%$ dos mutantes. Esse comportamento pode ser 
explicado pelo fato de que muitos dos mutantes gerados são, de algum modo, fáceis de serem mortos. Esse comportamento pode ser observado nas Figuras 6.1, 6.2, 6.3, 6.4, 6.5 e 6.6, nas quais são apresentados os gráficos comparando a evolução do escore de mutação em função dos casos de teste incluídos, respectivos a cada RPC. Em cada figura, destaca-se a evolução do escore de mutação a partir do caso de teste que obteve um escore maior ou igual a 0.90 .

Na Figura 6.1 é apresentada a evolução do escore de mutação para a RPC DDB. Pode-se observar que os três primeiros casos de teste obtiveram um escore de mutação igual a 0.968 , sendo necessária a inclusão de mais quatro casos de teste para obter o conjunto adequado.
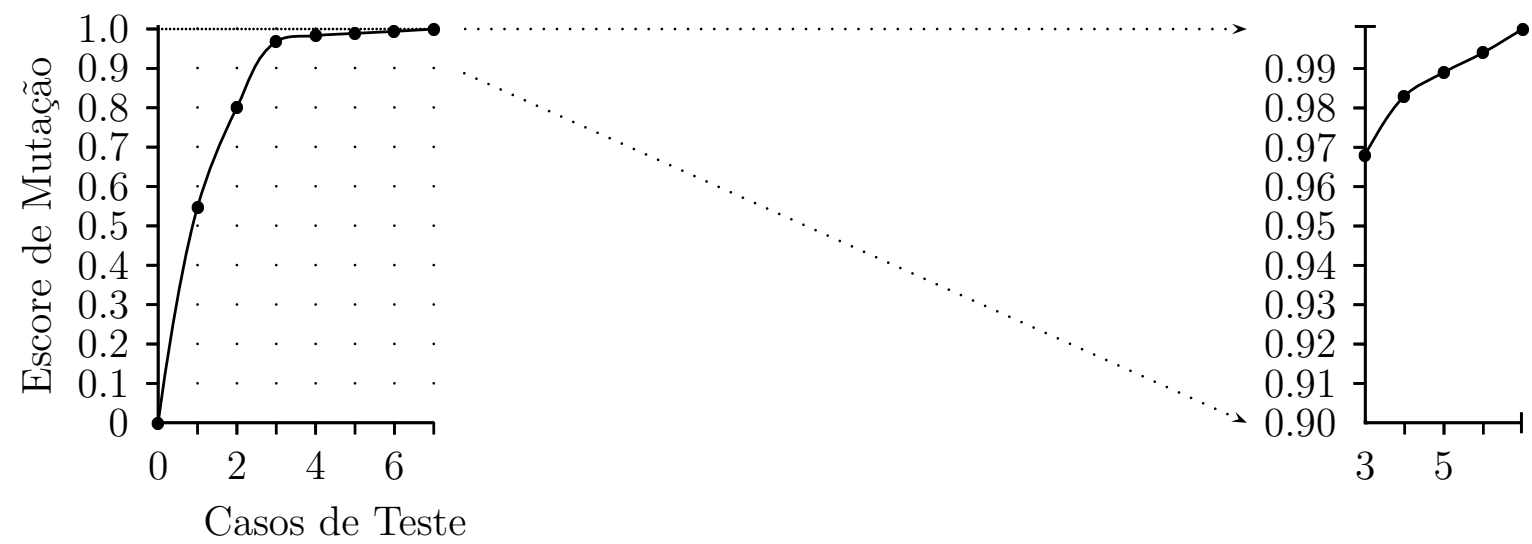

Figura 6.1: Evolução do Escore de Mutação para a Rede de Petri Colorida DDB.

Na Figura 6.2 é apresentada a evolução do escore de mutação para a RPC RA. Os três primeiros casos de teste obtiveram um escore de mutação igual a 0.975. Para a obtenção de um conjunto adequado, incluíram-se outros seis casos de teste.
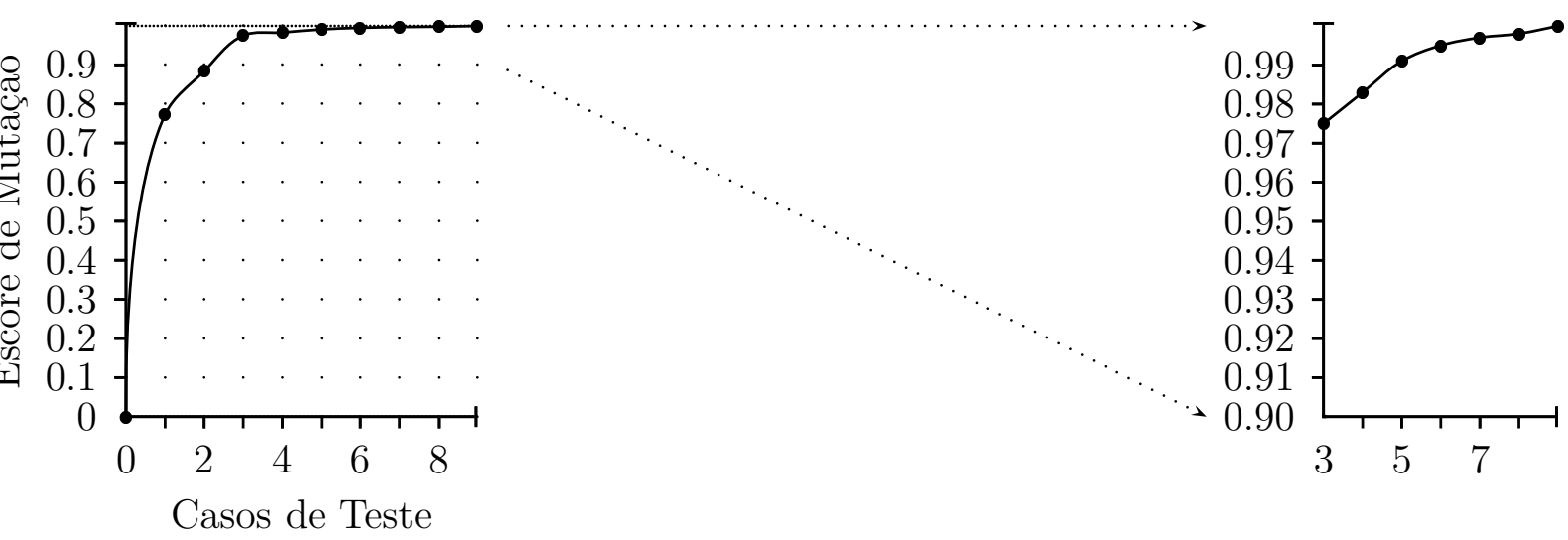

Figura 6.2: Evolução do Escore de Mutação para a Rede de Petri Colorida RA.

Na Figura 6.3 é apresentada a evolução do escore de mutação para a RPC TL. Os 10 primeiros casos de teste obtiveram um escore de mutação igual a 0.909. Foram 
incluídos outros sete casos de teste para obter um conjunto adequado. Pode-se observar que a evolução do escore para essa rede foi um pouco distinto dos apresentados pelas redes DDB e RA. Trata-se, como pode ser observado na Seção 6.2.2 e na Tabela 6.1, de um exemplo mais complexo.
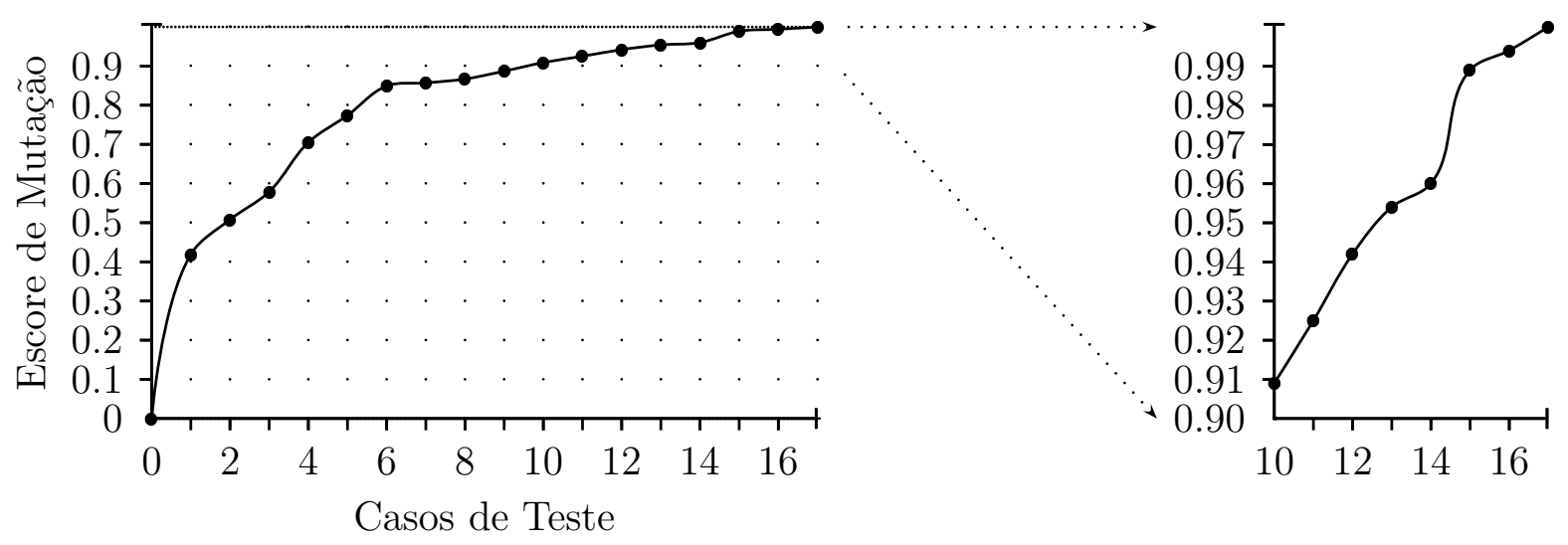

Figura 6.3: Evolução do Escore de Mutação para a Rede de Petri Colorida TL.

Na Figura 6.4 é apresentada a evolução do escore de mutação para a RPC HP. Pode-se observar que os quatro primeiros casos de teste obtiveram um escore de mutação igual a 0.937 , sendo necessária a inclusão de mais sete casos de teste para a obtenção de um escore igual a 1.00 .
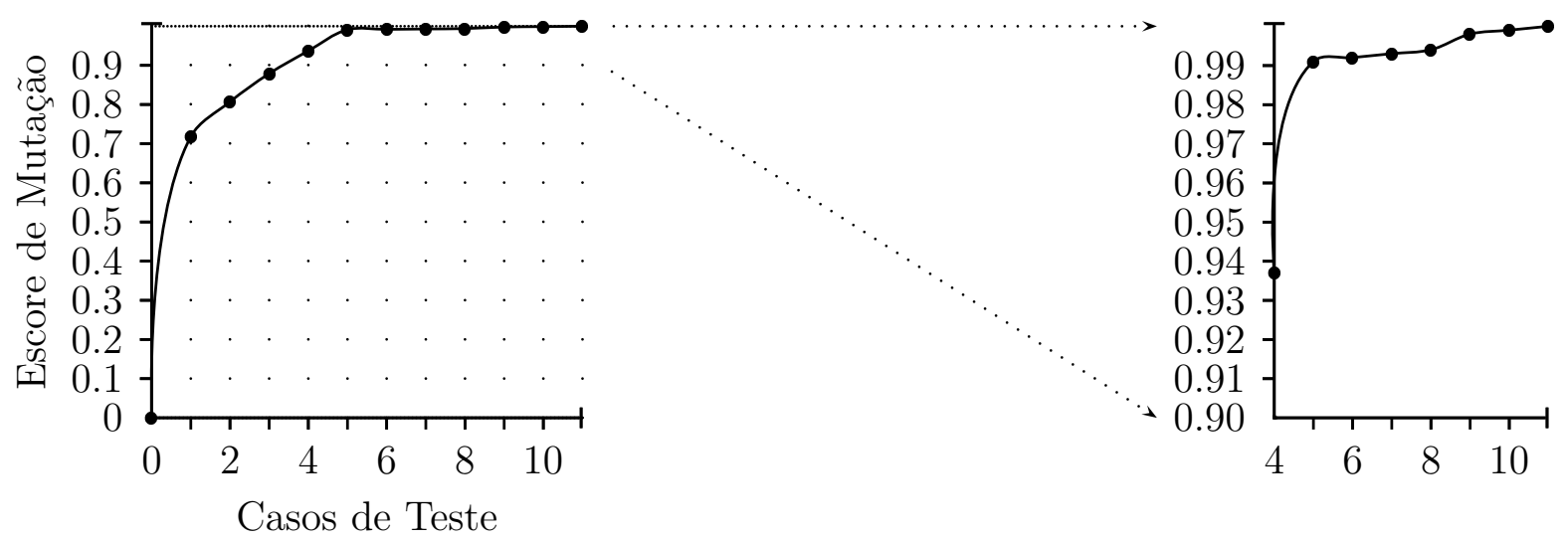

Figura 6.4: Evolução do Escore de Mutação para a Rede de Petri Colorida HP.

Na Figura 6.5 é apresentada a evolução do escore de mutação para a RPC BA. Os sete primeiros casos de teste obtiveram um escore de mutação igual a 0.922. Foram necessários outros 11 casos de teste para obter-se um conjunto adequado.

Na Figura 6.6 é apresentada a evolução do escore de mutação para a RPC CP. Os oito primeiros casos de teste obtiveram um escore de mutação igual a 0.908 , sendo necessários mais nove casos de teste para obter-se um conjunto adequado. 

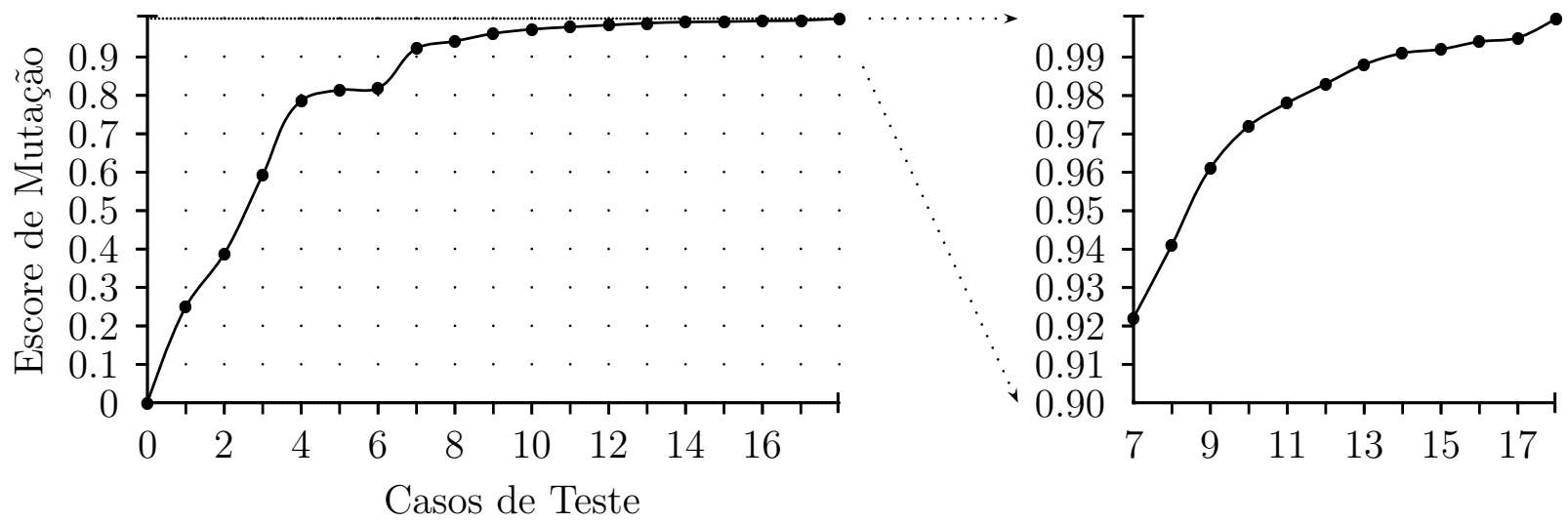

Figura 6.5: Evolução do Escore de Mutação para a Rede de Petri Colorida BA.
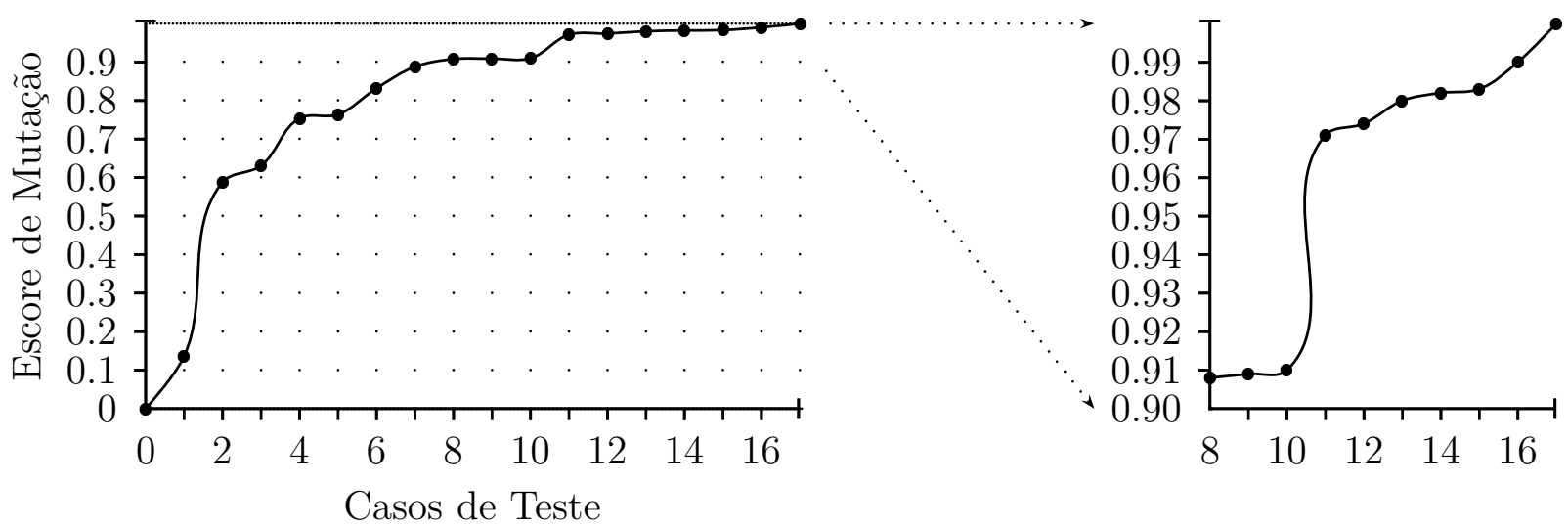

Figura 6.6: Evolução do Escore de Mutação para a Rede de Petri Colorida CP.

Pode-se constatar visualmente nos gráficos apresentados que o escore de mutação apresenta um comportamento assintótico, com um crescimento rápido para os primeiros casos de teste, passando, a partir desse certo ponto, a crescer de forma aproximadamente linear. Esse comportamento está em conformidade com o que já foi observado na aplicação da AM no teste de programas (Barbosa et al., 2001, 1998; Budd, 1981). Em nível de programa, esse fato foi explorado para definir abordagens alternativas para aplicação da AM, apresentadas na Seção 2.3.1.1, tais como a Mutação Aleatória, a Mutação Restrita, a Mutação Seletiva e a definição de Conjuntos Essenciais de Operadores. A observação de resultados semelhantes no nível de especificação, motiva a investigação dessas abordagens no contexto de RPCs. Por exemplo, o procedimento definido por Barbosa (1998) pode ser aplicado para se estabelecer um conjunto essencial de operadores de mutação para RPCs.

\section{Utilização da Proteum/CPN}

Como este estudo de caso foi conduzido com o apoio da ferramenta Proteum/CPN, ele também permitiu coletar informações sobre a usabilidade da ferramenta. Vale lembrar 
que os operadores descritos na linguagem $\mathcal{M} u \mathcal{D} e \mathcal{L}$ e que o sistema mudelgen foi utilizado para a geração dos mutantes. Assim, pôde-se também verificar a aplicabilidade desses mecanismos. Contudo, um ponto importante é o fato de que a utilização foi realizada pelo autor da ferramenta, de forma que os resultados não podem ser generalizados para outros contextos.

De uma maneira geral, o desempenho da ferramenta foi adequado, considerando-se as funcionalidades descritas no Capítulo 5. Entretanto, foram verificadas alguns pontos da ferramenta que devem ser melhorados, dentre os quais pode-se citar:

- Em algumas situações, o modelo navegacional torna difícil a busca de informações específicas.

- Em operações demoradas, seria importante a existência de mecanismos que permitissem interromper ou suspender o processamento de uma sessão em particular, retomá-lo posteriormente, caso desejado.

\subsection{Estudo de Caso II: Algoritmo de Geração de Casos de Teste para Redes de Petri}

Neste estudo de caso, o algoritmo apresentado no Capítulo 4 é aplicado a um conjunto de cinco RPs provenientes da literatura. O objetivo principal desse estudo de caso é a observação do número de casos de teste gerados pelo algoritmo e do escore de mutação obtido por esses casos de teste.

\subsubsection{Definição}

- Analisar a aplicação do algoritmo de geração de casos de teste

- Para o propósito de observação

- Com respeito à eficácia

- No contexto de Redes de Petri

\subsubsection{Materiais}

Esse estudo de caso foi conduzido com cinco RPs encontradas na literatura. Esse conjunto de RPs é o mesmo utilizado no trabalho de Simão (2000). As redes utilizadas foram extraídas de:

Rede-I (Reisig, 1985, Figura 70) Essa rede corresponde à modelagem de um sistema emissor/receptor em um canal com no máximo $n$ mensagens (escolheu-se $n=3$ ). 
Rede-II (Tanenbaum, 1989, Figura 4-22) Essa rede é correspondente à rede apresentada na Figura 4.1 e utilizada como exemplo no Capítulo 4. Corresponde ao Nível 3 do Protocolo OSI.

Rede-III (Macial et al., 1996, Figura 2.21) Essa rede é correspondente à modelagem do problema do jantar dos filósofos (Tanenbaum, 2003), com 3 filósofos.

Rede-IV (Baer, 1986, Figura 2.4) Essa rede corresponde à especificação de um pipeline para arquitetura de computadores pessoais.

Rede-V (Peterson, 1981, Figura 3.36) Essa rede corresponde à modelagem do fluxo de trabalho necessário para construção de uma casa.

Na Tabela 6.6 são apresentadas as características estruturais das RPs utilizadas nesse estudo de caso, assim como a quantidade de mutantes gerados e de mutantes equivalentes.

Tabela 6.6: Resultados do Estudo de Caso II

\begin{tabular}{|c||c|c|c|c|c|}
\hline $\mathrm{N}^{o}$ da Rede & Lugares & Transições & Arcos & Mutantes & Mutantes Equivalentes \\
\hline \hline $\mathrm{I}$ & 13 & 9 & 32 & 879 & 0 \\
\hline $\mathrm{II}$ & 7 & 11 & 33 & 623 & 0 \\
\hline $\mathrm{III}$ & 12 & 9 & 30 & 782 & 0 \\
\hline $\mathrm{IV}$ & 8 & 9 & 25 & 488 & 0 \\
\hline $\mathrm{V}$ & 26 & 17 & 50 & 2943 & \\
\hline
\end{tabular}

\subsubsection{Procedimento}

O algoritmo apresentado no Capítulo 4 foi implementado em Mathematica (Wolfram, 1996), utilizando-se o pacote desenvolvido para apoiar a aplicação da AM na validação de RPs, descrito em (Simão, 2000), e acoplado à ferramenta Proteum-RS /PN. Para a resolução do problema de programação linear inteira foi implementado o método Branch and Bound (Plane, 1971).

Para cada RP, foi criada uma sessão de teste, na qual foram gerados todos os mutantes definidos pelos operadores de mutação para RPs (Fabbri et al., 1994b; Simão, 2000). Em seguida, os mutantes equivalentes foram manualmente identificados, para possibilitar que a eficácia do algoritmo na determinação de mutantes equivalentes fosse avaliada. Em seguida, o algoritmo foi aplicado a cada mutante. O conjunto formado por todos os casos de teste gerados dessa forma foi aplicado a todos os mutantes. 


\subsubsection{Coleta de Dados}

Nesse estudo de caso, foram coletados os seguintes dados:

- O número de mutantes para os quais o algoritmo foi capaz de gerar um caso de teste.

- O número de casos de teste distintos gerados pelo algoritmo.

- O escore de mutação obtido pelos casos de teste.

- O número de mutantes equivalentes identificados pelo algoritmo.

\subsubsection{Resultados}

Na Tabela 6.7 são apresentados os resultados desse estudo de caso com relação à geração de casos de teste. Apresenta-se a porcentagem de mutantes para os quais o algoritmo conseguiu gerar um caso de teste. Além disso, indicam-se a quantidade de casos de teste distintos que foram gerados e o escore de mutação obtido por esses casos de teste. O número de mutantes equivalentes identificados manualmente é apresentado, assim como a porcentagem desses mutantes que foram identificados pelo algoritmo. $\mathrm{O}$ número de mutantes gerados também é apresentado a mérito de ilustração.

Tabela 6.7: Resultados da Aplicação do Algoritmo de Geração de Casos de Teste para Redes de Petri.

\begin{tabular}{|c|c|c|c|c|c|c|}
\hline & $\begin{array}{l}\text { \# Mutan- } \\
\text { tes }\end{array}$ & $\begin{array}{l}\# \text { Mutan- } \\
\text { tes Equi- } \\
\text { valentes }\end{array}$ & $\begin{array}{l}\text { Mutantes } \\
\text { Mortos }\end{array}$ & $\begin{array}{l}\text { Mut. Eq. } \\
\text { Identifica- } \\
\text { dos }\end{array}$ & $\begin{array}{l}\# \text { Casos } \\
\text { de Teste }\end{array}$ & $\begin{array}{l}\text { Escore de } \\
\text { Mutação }\end{array}$ \\
\hline Rede I & 879 & 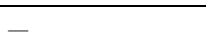 & $97.2 \%$ & 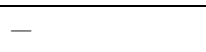 & $\overline{10}$ & 1.000 \\
\hline Rede II & 623 & - & $83.7 \%$ & - & 12 & 0.993 \\
\hline Rede III & 782 & - & $98.2 \%$ & - & 10 & 1.000 \\
\hline Rede IV & 488 & 27 & $92.9 \%$ & $74.07 \%$ & 6 & 0.995 \\
\hline Rede V & 2943 & - & $95.6 \%$ & - & 19 & 1.000 \\
\hline \multicolumn{3}{|r|}{ Média: } & $93,56 \%$ & & & \\
\hline \multicolumn{3}{|c|}{ Desvio Padrão: } & $5,21 \%$ & & & \\
\hline
\end{tabular}

Pode-se observar que o algoritmo foi capaz de gerar casos de teste para uma grande quantidade de mutantes. Para três das RPs (Redes I, III e V), geraram-se casos de teste para mais de $95 \%$ dos mutantes. Apenas para a Rede II o algoritmo gerou casos de teste para menos de $85 \%$ dos mutantes. Observa-se que, para as redes utilizadas nesse estudo de caso, o desempenho do algoritmo foi adequado.

Pela própria característica determinística da busca na Árvore de Caracterização utilizada no algoritmo, para muitos mutantes, gera-se o mesmo caso de teste. Pode-se 
observar que o número de casos de teste distintos gerados é, por esse motivo, relativamente pequeno, oscilando entre 6 casos de teste (para Rede IV) e 19 casos de teste (para a Rede V), com média 11.4.

Mesmo na situação em que o algoritmo não é capaz de gerar um caso de teste para matar um mutante específico, pode ocorrer que outro caso de teste gerado o mate. Assim, o conjunto de casos de teste foi aplicado a todos os mutantes e foi calculado o escore de mutação obtido. Pode-se observar que, para três redes, obteve-se um conjunto de teste adequado (ou seja, com escore igual a 1.000). Para os demais casos, verifica-se que o escore de mutação foi superior a 0.99 .

Das redes utilizadas nesse estudo de caso, apenas para a Rede IV foram gerados mutantes equivalentes. Para as demais redes, nenhum dos mutantes gerados foi identificado como equivalente. Com relação à determinação dos mutantes equivalentes, dos 27 mutantes equivalentes gerados para a Rede IV, o algoritmo foi capaz de identificar 20, correspondendo a $74 \%$.

De uma maneira geral, nesse estudo de caso foi possível observar que o algoritmo automatiza consideravelmente a aplicação da AM para RPs.

\subsection{Considerações Finais}

Neste capítulo foram descritos os estudos de casos nos quais AM foi aplicada no contexto de RPC. Foram oferecidas evidências da viabilidade de aplicação, com a obtenção de conjuntos de requisitos de teste e a geração de conjuntos de casos de teste adequados.

No primeiro estudo de caso, seis RPCs foram identificadas e utilizadas para observar a quantidade de mutantes gerados pelos operadores de mutação definidos neste trabalho. Pôde-se também avaliar a cardinalidade de conjuntos de casos de teste adequados para cada rede. Por meio da análise visual dos gráficos que confrontam os casos de teste com o escore de mutação, observou-se que o escore de mutação cresce muito rapidamente com a inclusão dos primeiros casos de teste, passando a comportar-se de forma quase linear a partir de certo ponto (em torno 0.90). Assim, indica-se que o escore de mutação não deve ser utilizado de forma linear. Um ponto a ser investigado, é a determinação de como normalizar o escore de mutação de forma a torná-lo um indicativo mais preciso da qualidade do conjunto de casos de teste. Pode-se conjecturar que tal comportamento também esteja presente na aplicação da AM em outros contextos.

Com a condução do Estudo de Caso I também foi possível observar a usabilidade da ferramenta Proteum/CPN, a qual foi utilizada para apoiar a geração dos mutantes (com o sistema mudelgen), e avaliação dos casos de teste. $\mathrm{O}$ desempenho da ferramenta mostrou-se satisfatório. Alguns problemas, assim como possibilidades de melhorias, foram observados, permitindo identificar direcionamentos para futuras evoluções da ferramenta. 
No Estudo de Caso II, cinco RPs foram utilizadas para avaliar a eficácia do algoritmo de geração de casos. O algoritmo foi implementado com o Mathematica e acoplado à ferramenta Proteum-RS/PN. Os resultados mostraram que o algoritmo reduz consideravelmente o custo da aplicação, gerando conjuntos de casos de teste que obtiveram escore de mutação próximos de 1.00. Embora somente uma rede possuísse mutantes equivalentes, o desempenho do algoritmo na determinação dos mutantes equivalentes para essa rede foi bom, identificando mais de $70 \%$ deles.

Ressalta-se que outros estudos empíricos devem ser conduzidos, buscando-se investigar os pontos em aberto identificados e, além disso, almejando-se obter resultados com validade estatística.

No próximo capítulo as principais contribuições deste trabalho são sumarizadas, algumas limitações são discutidas e as perspectivas de trabalhos futuros são apresentadas. 


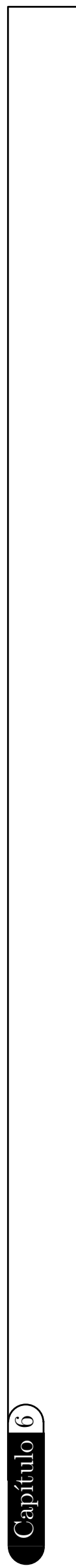




\section{Conclusão}

Conforme caracterizado anteriormente, as contribuições na área de Teste de Software podem ser classificadas em estudos teóricos, estudos empíricos e de automatização. Este trabalho apresentou contribuições nessas três perspectivas, investigando-se abordagens de teste para RPCs. Em particular, foi investigado o critério AM. Definiu-se um conjunto de operadores de mutação para RPCs. Para permitir a avaliação desses operadores, fez-se necessário o desenvolvimento de um ferramental que permitisse aplicá-los. Em primeiro lugar, definiu-se a linguagem $\mathcal{M} u \mathcal{D} e \mathcal{L}$. Para apoiar a aplicação do critério AM para o teste de RPCs, foi desenvolvida a ferramenta Proteum/CPN. Um algoritmo para automatizar a geração de casos de teste para RPs foi desenvolvido. Definiram-se abordagens para possibilitar a aplicação do algoritmo para RPCs. Foram conduzidos estudos de caso para evidenciar a aplicabilidade e eficácia dos conceitos propostos neste trabalho.

A seguir, apresentam-se em mais detalhes essas contribuições. Também são apontadas algumas limitações e dificuldades encontradas, assim como possibilidades de trabalhos futuros.

\subsection{Contribuições}

As principais contribuições podem ser divididas em estudos teóricos, estudos empíricos e automatização.

Nos estudos teóricos, investigou-se a adequação do critério de teste AM para o teste de especificações baseadas em RPCs. A partir da análise da experiência obtida no contexto de outras técnicas de especificação e de linguagens de programação, um conjunto de operadores de mutação foi definido. Avaliou-se a complexidade desses operadores, em termos do número de mutantes gerados.

Outra contribuição do ponto de vista teórico é a definição da linguagem $\mathcal{M} u \mathcal{D} e \mathcal{L}$ para a descrição de operadores de mutação. A $\mathcal{M} u \mathcal{D} e \mathcal{L}$ é um primeiro passo na direção 
de estudos que sintetizem os esforços despendidos com a AM em diversos contextos, identificando os pontos em comum e fatorando-se em mecanismos genéricos. A linguagem $\mathcal{M} u \mathcal{D} e \mathcal{L}$ foi utilizada com sucesso neste trabalho e em outros trabalhos do grupo de Engenharia de Software do ICMC/USP (Vincenzi, 2004; Yano et al., 2004).

No contexto de automatização, uma contribuição é o desenvolvimento do sistema mudelgen para a compilação dos operadores definidos em $\mathcal{M} u \mathcal{D} e \mathcal{L}$. Utilizaram-se técnicas do paradigma transformacional. Foram também investigados e desenvolvidos mecanismos para a visualização da execução dos operadores e para a validação da implementação com base na semântica formalmente definida, utilizando-se Semântica Denotacional.

Outra contribuição do ponto de vista da automatização é o desenvolvimento da ferramenta Proteum/CPN para apoiar a aplicação da AM no teste de especificações baseadas em RPCs. Visando a possibilitar sua utilização a partir de uma grande variedade de plataformas, a ferramenta foi desenvolvida como uma aplicação Web. Buscou-se modularizar a ferramenta de tal forma a isolar as características relacionadas a RPCs das características que são genéricas para qualquer ferramenta de apoio a mutação. A ferramenta foi utilizada como base para o desenvolvimento das ferramentas Proteum/SML (Yano et al., 2003) e Proteum/IM [WEB].

Ainda no contexto de automatização, desenvolveu-se um algoritmo para a geração de casos de teste para RPs, assim como para a determinação de mutantes equivalentes. Alternativas para aplicação do algoritmo para RPCs foram investigadas. Descreveram-se duas abordagens para a conversão de uma RPC em uma RP e posterior aplicação do algoritmo.

No contexto de estudos empíricos, conduziu-se um estudo de caso para observar a aplicabilidade dos conceitos relativos à adequação da AM a RPCs. A partir dos resultados, pôde-se observar, ainda que não conclusivamente, que a aplicação é viável e pôde-se apontar a direção de novos estudos a serem realizados tanto no contexto de RPCs quanto da AM em geral. Esse estudo de caso permitiu também avaliar as funcionalidades da ferramenta Proteum/CPN, com a qual foi conduzido. Foi conduzido também um estudo de casos para observar o desempenho do algoritmo de geração para RPs.

\subsection{Dificuldades e Limitações}

Pela própria natureza da AM e das RPCs, os tipos de erros inseridos por boa parte dos operadores de mutação introduzem erros estruturais na RPC. Tais erros, no entanto, são pouco prováveis e, mesmo que ocorram, poderiam ser identificados por meio da análise estrutural da rede. Em especial, caem nessa categoria os operadores de arco. Dessa forma, deve-se investigar se operadores com essa característica contribuem para a qualidade dos casos de teste e, se necessário deve-se propor novos operadores de mutação. 
Por oferecer recursos para a descrição de operadores a linguagem $\mathcal{M} u \mathcal{D} e \mathcal{L}$ pode auxiliar nesse processo.

Em relação à linguagem $\mathcal{M} u \mathcal{D} e \mathcal{L}$, a proposta inicial, apresentada em (Simão e Maldonado, 2002), permitia apenas a descrição de operadores livres de contexto. Contudo, observou-se que para a descrição de muitos operadores para RPCs e para linguagens como $\mathrm{C}$ e $\mathrm{C}++$, eram necessárias construções que permitissem a utilização de informações sensíveis ao contexto. Novas construções para lidar com essas características foram incluídas na linguagem. No entanto, ainda não está evidente que tais construções sejam genéricas o suficiente para lidar com todos os tipos de casos de operadores sensíveis ao contexto.

Em relação à ferramenta Proteum/CPN, era necessária a capacidade de simulação da RPC original, assim como das RPCs mutantes. Além disso, a simulação deveria ser feita de forma a permitir a apresentação dos resultados na Web. Dentre as ferramentas disponíveis para a simulação de RPCs, nenhuma fornecia as funcionalidades necessárias para a Proteum/CPN. Optou-se pela implementação de um simulador para RPC que pudesse ser utilizado na ferramenta. O simulador é capaz de entender as descrições CPN-ML de uma RPC e aceitar uma seqüência de ligações a serem disparadas, fornecendo a marcação resultante. A sintaxe e a semântica da CPN-ML utilizada foram baseadas na Design/CPN. Contudo, não foram incluídos todos os comandos e recursos que a Design/CPN oferece. Por se tratar de uma implementação complexa, buscou-se manter o simulador com as funcionalidades que foram julgadas como as mais importantes. Tais funcionalidades foram avaliadas nos estudos de caso apresentados no Capítulo 6.

O simulador implementado realiza a compilação da descrição RPC em código SML, baseado no qual foi definida a linguagem CPN-ML. O código SML gerado é então executado para permitir a simulação da RPC. Uma dificuldade encontrada a esse respeito é a relativa lentidão no processo de compilação do código SML obtido. Para que não seja necessário compilar a RPC original e as redes mutantes todas as vezes que um caso de teste é gerado, a Proteum/CPN compila todos os mutantes tão logo esses sejam gerados. Assim, conseguiu-se agilizar o processo de execução dos mutantes, em detrimento dos processos de geração e preparação dos mutantes, que ficaram mais demorados. No entanto, houve um ganho geral de desempenho, pois a geração e preparação é realizado uma única vez.

\subsection{Trabalhos Futuros}

Como dito anteriormente, durante o desenvolvimento da ferramenta Proteum/CPN, buscou-se identificar formas de generalizar as funcionalidades oferecidas, de maneira a poder ser utilizada no contexto de outras ferramentas de apoio à AM. Assim, delineou-se a possibilidade de definir um framework para o desenvolvimento de ferramentas de apoio. Um passo nessa direção foi o desenvolvimento das Proteum/SML e Proteum/IM [Web], 
no contexto de outros trabalhos do Grupo de Engenharia de Software do ICMC/USP. A experiência obtida com essas ferramentas deve ser sintetizada em um trabalho de continuidade desta tese.

Além de permitir a automatização da aplicação da AM a RPCs, proposta neste trabalho, a definição da linguagem $\mathcal{M} u \mathcal{D} e \mathcal{L}$ foi contribuição importante por si mesma. Ela pôde ser utilizada também na descrição de operadores para outras linguagens. No entanto, é preciso avaliar a expressividade da linguagem $\mathcal{M} u \mathcal{D} e \mathcal{L}$, com o objetivo de identificar precisamente quais operadores (e para quais linguagens) podem ser efetivamente definidos. Além disso, é necessária uma revisão das operações propostas. Por exemplo, em nenhum dos operadores descritos, a operação cut foi utilizada. Portanto, deve-se analisar se ela é realmente útil. Assim, um trabalho de continuidade desta tese é a análise e possível evolução da linguagem $\mathcal{M} u \mathcal{D} e \mathcal{L}$.

Os estudos de caso conduzidos neste trabalho permitiram observar algumas características referentes à aplicação da AM no contexto de RPs e RPCs. No entanto, um ponto importante não abordado nesses estudos de caso é a avaliação da eficácia do critério AM em relação a técnicas de análise. Dessa forma, uma linha de investigação relevante é condução de estudos experimentais para obter evidências da contribuição da AM nesse contexto. Esses estudos devem ser planejados cuidadosamente de modo a obter resultados estatisticamente válidos, a exemplo do que têm sido realizado em outros trabalhos do Grupo de Engenharia de Software do ICMC/USP, no contexto do projeto Readers (Readers, 2003). Esses estudos devem envolver diversos indivíduos com níveis diferentes de conhecimento da técnica RPC, além de utilizar RPCs com erros previamente conhecidos.

Como dito na Seção 4.1, em uma outra abordagem para a geração de casos de teste, desenvolveu-se uma família de critérios de cobertura baseados no GO (Simão et al., 2003a). Assim, um trabalho futuro relevante é a condução de estudos comparativos entre o critério AM para RPCs e os critérios dessa família.

No que diz respeito à automatização, a exemplo do que ocorre com outras ferramentas de teste, é importante a disponibilização da Proteum/CPN para a execução via scripts, facilitando a condução de estudos empíricos. Deve-se observar que, os esforços despendidos nessa direção podem ser reaproveitados no framework a ser desenvolvido com base na Proteum/CPN.

Na Seção 3.6, é delineada uma abordagem para a utilização da AM na Análise de Risco. Como um próximo passo nessa linha de investigação, deve-se identificar um exemplo de sistema modelado com RPC, no qual a abordagem possa ser aplicada. Deve-se também definir operadores de mutação para a Análise de Risco. Dessa forma, pode-se conduzir estudos teóricos e empíricos para avaliar os benefícios dessa abordagem, em complemento a outras técnicas de Análise de Risco. 


\subsection{Publicações}

A seguir, são apresentados os trabalhos publicados e em fase de revisão, que foram resultantes das atividades desenvolvidas durante o trabalho de doutorado. São incluídos também os trabalhos publicados em linhas de pesquisa que, apesar de relacionadas a essa tese, não foram incluídas como contribuições principais. As publicações diretamente relacionadas às contribuições desta tese aparecem numeradas.

\subsubsection{Periódicos}

- (1) Simão, A. S.; Maldonado, J. C. MuDeL: A language and a system for describing and generating mutants. Journal of the Brazilian Computer Society, v. 8, n. 1, p. 73-86, 2002.

- Simão, A. S.; Sugeta, T.; Maldonado, J. C.; Monard, M. C. Prolog \& TXL: A case study for prototyping structural testing supporting tools. CLEI Electronic Journal, v. 5, n. $1,2002$.

Além disso, estão em fase de revisão os seguintes artigos:

- (2) Simão, A. S.; Maldonado, J. C.; Bigonha, R. S. MuDeL: A transformational formal language for mutant description. ACM Transactions on Programming Languages and Systems, 2004.

- (3) Simão, A. S.; Maldonado, J. C.; Fabbri, S. C. P. F.; Wong, E. Mutation testing applied to the validation of Petri nets. Software Testing Verification and Reliability, 2004.

- Simão, A. S.; Vincenzi, A. M. R.; Maldonado, J. C.; Santana, A. C. L. A language for the description of program instrumentation and the automatic generation of instrumenters. CLEI Electronic Journal, 2004.

\subsubsection{Congressos com Arbitragem}

- (4) Simão, A. S.; Maldonado, J. C. Mutation based test sequence generation for Petri nets. In: Proceedings of III Workshop of Formal Methods, João Pessoa, PB, 2000, p. 68-79.

- $\quad$ Simão, A. S.; Sugeta, T.; Maldonado, J. C.; Monard, M. C. Prolog \& TXL: um estudo de caso para prototipação de ferramentas de apoio para o teste estrutural. In: Anais das $1^{a}$ s Jornadas Iberoamericanas de Ingeniería del Software e Ingeniería del Conocimiento, Buenos Aires, Argentina, 2001, p. 15-22. 
- (5) Simão, A. S.; Maldonado, J. C. MuDeL: A language and a system for describing and generating mutants. In: Anais do XV Simpósio Brasileiro de Engenharia de Software, Rio de Janeiro, Brasil, 2001, p. 240-255.

- Indicado como um dos três melhores artigos do evento.

- Simão, A. S.; Vincenzi, A. M. R.; Maldonado, J. C.; Santana, A. C. L. IDeL: A language for software instrumentation. In: XXVIII Latin-American Conference on Informatics - CLEI'2002, Montevideo, Uruguay, artigo em CD-ROM, 2002, p. 96.

- (6) Simão, A. S.; Maldonado, J. C.; Bigonha, R. S. Using denotational semantics in the validation of the compiler for a mutation-oriented language. In: Proceedings of $V$ Workshop of Formal Methods, Gramado, RS, 2002, p. 4-19.

- Simão, A. S.; Souza, S. R. L.; Maldonado, J. C. A family of coverage testing criteria for coloured petri nets. In: XVII Simpósio Brasileiro de Engenharia de Software, Manaus, AM, 2003, p. 209-224.

- (7) Simão, A. S.; Maldonado, J. C. Coloured Petri Nets: Safety analysis using mutation testing. In: Workshop on Safety of the First Latin American Symposium on Dependable Computing, São Paulo, 2003, p. 151-154.

- (8) Yano, T.; Simão, A. S.; Maldonado, J. C. Estudo do teste de mutação para a linguagem standard ml. In: Solar, M.; Fernández-BaCA, D.; Cuadros-Vargas, E., eds. 30ma Conferencia Latinoamericana de Informática (CLEI2004), Sociedad Peruana de Computación, iSBN 9972-9876-2-0, 2004, p. 734-744.

\subsubsection{Sessões de Ferramenta}

- Candolo, M. A. P.; Simão, A. S.; Maldonado, J. C. MGASet - uma ferramenta para apoiar o teste e validação de especificações baseadas em máquinas de estado finito. In: Anais do XV Simpósio Brasileiro de Engenharia de Software, Rio de Janeiro, RJ, 2001, p. 386-391.

- Premiado como o segundo lugar na sessão de ferramentas do evento.

- (9) Simão, A. S.; Vincenzi, A. M. R.; Maldonado, J. C. mudelgen: A tool for processing mutant operator descriptions. In: Anais da Sessão de Ferramentas do XVI Simpósio Brasileiro de Engenharia de Software, Gramado, RS, 2002, p. 426-431.

- Premiado como a melhor ferramenta do evento.

- Vincenzi, A. M. R.; Delamaro, M. E.; Simão, A. S.; Maldonado, J. C.; Wong, W. E. JabÁ - a Java bytecode analyzer. In: XVI SBES - Simpósio Brasileiro de Engenharia de Software, Gramado, RS, Brasil, 2002, p. 414-419. 
- Domingues, A. L. S.; Simão, A. S.; Vincenzi, A. M. R.; Maldonado, J. C. Evaltool: Um ambiente de apoio à avaliação e seleção de ferramentas de teste para programas orientados a objetos. In: Anais da Sessão de Ferramentas do XVI Simpósio Brasileiro de Engenharia de Software, Gramado, RS, 2002, p. 384-389.

-(10) Yano, T.; Simão, A. S.; Maldonado, J. C. Proteum/SML - uma ferramenta de apoio ao teste de mutação para a linguagem Standard ML. In: Sessão de Ferramentas do XVII Simpósio Brasileiro de Engenharia de Software, Manaus, AM, 2003, p. 67-72.

- Indicado como uma das cinco melhores ferramentas do evento.

\subsubsection{Outras Publicações}

-(11) Simão, A. S.; Maldonado, J. C. Mutation-based test sequence generation for Petri nets. In: Nunes, M. G. V.; Arenales, M. N.; Traina, A. J. M.; Maldonado, J. C., eds. Cadernos de Computação, ICMC/USP, 2001, p. 181-198.

- Simão, A. S.; Vincenzi, A. M. R.; Maldonado, J. C.; Santana, A. C. L. Software product instrumentation description. Relatório Técnico 157, ICMC/USP, São Carlos, SP, Brazil, 2002. 


\section{Referências Bibliográficas}

Acree, A. T. On Mutation. Tese de Doutoramento, School of Information and Computer Science, Georgia Institute of Technology, Atlanta, Georgia, 1980.

Acree, A. T.; Budd, T. A.; Demillo, R. A.; Lipton, R. J.; Sayward, F. G. Mutation analysis. Relatório Técnico GIT-ICS-79/08, Georgia Institute of Technology, Atlanta, GA, 1979.

Agrawal, H. Design of mutant operators for the C programming language. Relatório Técnico SERC-TR-41-P, Software Engineering Research Center/Purdue University, 1989.

Agrawal, H.; Alberi, J. L.; Horgan, J. R.; Li, J. J.; London, S.; Wong, W. E.; Ghosh, S.; Wilde, N. Mining system tests to aid software maintenance. IEEE Computer, v. 31, n. 7, p. 64-73, 1998.

Aho, A. V.; Sethi, R.; Ullman, J. D. Compilers: Principles, techniques and tools. Reading, Mass.: Addison-Wesley, 1985.

Alexander, R. T.; Bieman, J. M.; Andrews, A. A. Towards the Systematic Testing of Aspect-Oriented Programs. Relatório Técnico, Colorado State University, Fort Collins, CO, 2004.

Allison, L. A practical introduction to denotational semantics. Cambridge, U. K.: Cambridge University Press, 1986.

Ammann, P.; Black, P. A specification-based coverage metric to evaluate test sets. In: Proceedings of Fourth IEEE International High-Assurance Systems Engineering Symposium (HASE 99), IEEE Computer Society, 1999, p. 239-248.

Ammann, P.; Black, P.; Majurski, W. Using model checking to generate tests from specifications. In: Proceedings of $2^{\text {nd }}$ IEEE International Conference on Formal Engineering Methods, Brisbane, Australia: IEEE Computer Society, 1998, p. 46-54. 
BAer, J. L. Modelling architectural feaures with Petri nets. In: Goes, G.; Hartmanis, J., eds. Petri Nets: Applications and Relationships to Other Models of Concurrency, Berlin: Stringer, 1986, p. 258-277 (Lecture Notes on Computer Science, v.255).

Barbosa, D. L.; Andrade, W. L.; Machado, P. D. L.; Figueiredo, J. C. A. SPACES - uma ferramenta para teste funcional de componentes. In: XI Sessão de Ferramentas do Simpósio Brasileiro de Engenharia de Software, Brasília, DF, 2004, p. 55-60.

Barbosa, E. F. Um ambiente para a análise e simulação de sistemas modelados por redes de Petri. Dissertação de Mestrado, Universidade Federal de Santa Catarina, Florianópolis, SC, 1990.

BArbosa, E. F. Uma contribuição para a determinação de um conjunto essencial de operadores de mutação no teste de programas C. Dissertação de Mestrado, ICMC/USP, São Carlos, SP, 1998.

Barbosa, E. F.; Maldonado, J. C.; Vincenzi, A. M. R. Toward the determination of sufficient mutant operators for C. Software Testing, Verification and Reliability Journal, v. 11, n. 2, p. 113-136, john Wiley \& Sons, 2001.

Barbosa, E. F.; Vincenzi, A. M. R.; Maldonado, J. C. Uma contribuição para determinação de um conjunto essencial de operadores de mutação no teste de programas C. In: XII Simpósio Brasileiro de Engenharia de Software, Maringá, PR, 1998, p. $103-120$.

Barendregt, H. Lambda calculi with types. In: Abramsky, S.; Gabbay, D. M.; Maibaum, T. S. E., eds. Handbook of Logic in Computer Science, v. 2, Oxford University Press, p. 4-183, 1992.

BARnARD, J. COMX: A design methodology using Communicating X-Machines. Information and Software Technology, v. 40, n. 5-6, p. 271-280, 1998.

Baroni, A.; Borchardt, M.; Maziero, C.; Burnett, R. ASPeN - um ambiente para edição, análise e simulação de redes de Petri. In: Caderno de Ferramentas do XIII SBES - Simpósio Brasileiro de Engenharia de Software, Florianópolis, SC, 1999, p. $45-48$.

Disponível em http://www.ppgia.pucpr.br/〜maziero (Último Acesso em 20/01/2002)

BArrocA, L.; MCDermid, J. A. Formal methods: Use and relevance for the development of safety-critical systems. The Computer Journal, v. 35, n. 6, p. 579-599, 1992.

BeIZER, B. Software testing techniques. 2 ed. New York: Van Nostrand Eeinhold, 1990. 
Belinfante, A. Torx - côte de resyste software test tool - conference protocol case study. [On-line], World Wide Web.

Disponível em http://fmt.cs.utwente.nl/tools/torx/confcase.html (Último Acesso em 01/11/2004)

Bergadano, F.; Gunetti, D. Testing by means of inductive program learning. ACM Transaction on Software Engineering and Methodology, v. 5, n. 2, p. 119-145, 1996.

Bernardinello, L.; Cindio, F. D. A survey of basic net models and modular net classes. In: Rozenberg, G., ed. Advances in Petri Nets, Springer-Verlag, 1992, p. 304-351 (Lecture Notes on Computer Science, v.609).

Bieman, J. M.; Ghosh, S.; Alexander, R. A technique for mutation of java objects. In: 16th IEEE International Conference on Automated Software Engineering (ASE'2001), San Diego CA, 2001, p. 26-29.

Binder, R. V. Testing object-oriented systems: Models, patterns, and tools, v. 1. Addison Wesley Longman, Inc., 1999.

Black, P. E.; Okun, V.; Yesha, Y. Mutation of model checker specifications for test generation and evaluation. In: Mutation 2000 - A Symposium on Mutation Testing for the New Century, San José, California, 2000a, p. 24-30.

Black, P. E.; Okun, V.; Yesha, Y. Mutation operators for specifications. In: Proceedings of $15^{\text {th }}$ IEEE International Conference on Automated Software Engineering (ASE2000), 2000b, p. 81-89.

Bochmann, G.; Petrenko, A. Protocol testing: Review of methods and relevance for software testing. In: ISSTA'94, 1994, p. 109-124.

Borges, K. N.; Ramos, F. S.; Maldonado, J. C.; Chaim, M. L.; Jino, M. Poke-tool versão clipper - uma ferramenta para suporte ao teste estrutural baseado em análise de fluxo de dados. In: Anais do IX Simpósio Brasileiro de Engenharia de Software, Recife, PE, 1995, p. 483-486.

Bratko, I. Prolog programming for artificial intelligence. 2 ed. Wokingham, England ; Reading, Mass.: Addison-Wesley, 1990.

Browning, R. L. The loss rate concept in safety engineering. Marcel Dekker, 1980. BudD, A. T. Mutation analysis: Ideas, examples, problems and prospects. Computer Program Testing North-Holland Publishing Company, p. 129-148, 1981.

Budd, T. A.; Angluin, D. Two notions of correctness and their relation fo testing. Acta Informatica, v. 18, n. 1, p. 31-45, 1982.

Budkowski, S.; Dembinski, P. An introduction to estelle: a specification language for distributed systems. Computer Network and ISDN Systems, v. 14, n. 1, p. 3-23, 1987. 
Bueno, P. M. S.; Jino, M. Automated test data generation for program paths using genetic algorithms. In: 13th International Conference on Software Engineering 8 Knowledge Engineering - SEKE'2001, Buenos Aires, Argentina, 2001, p. 2-9.

Cardoso, J.; Valette, R. Redes de petri. Série Didática. Editora da Universidade Federal de Santa Catarina, 1997.

Chaim, M. L. Poke-tool - uma ferramenta para suporte ao teste estrutural de programas baseado em análise de fluxo de dados. Dissertação de Mestrado, DCA/FEEC/UNICAMP, Campinas, SP, 1991.

Chen, T.; Yu, Y. Constraints for safe partition testing strategies. Computer Journal, v. 39, n. 7, p. 619-625, 1996.

Chiola, G. Simulation framework for timed and stochasic petri nets. International Journal in Computer Simulation, v. 2, n. 2, 1991.

Choi, B. J.; DeMillo, R. A.; Krauser, E. W.; Mathur, A. P.; Martin, R. J.; Offutt, A. J.; Pan, H.; Spafford, E. H. The mothra toolset. In: Twenty-Second Annual Hawaii International Conference on System Sciences, HI, 1989a.

Choi, B. J.; Mathur, A. P.; Pattison, A. P. pmothra: Scheduling mutants for execution on a hypercube. In: 3rd Symposium on Software Testing, Analysis and Verification, Key West, FL, 1989b, p. 58-65.

CHow, T. S. Testing software design modeled by finite-state machines.

IEEE Transactions on Software Engineering, v. 4, n. 3, p. 178-187, 1978.

Chung, A.; Sidhu, D. Fault coverage of probabilistic test sequence. In: Proceedings of the IFIP TC6 Third International Workshop on Protocol Teste Systems, North-Holland, 1991, p. 305-316.

Clarke, E.; Wing, J. Formal methods: State of the art and future directions. $A C M$ Computing Surveys, v. 28, n. 4, p. 626-643, 1996.

Cohen, D. M.; Dalal, S. R.; Parelius, J.; Patton, G. C. The combinatorial design approach to automatic test generation. IEEE Software, v. 13, n. 5, p. 83-88, 1996.

Corporation IBM, D. P. D. Hipo: A design aid and documentation technique. New York, white Plains, 1974.

Coward, P. A review of software testing. Information and Software Technology, v. 30, n. 3, p. 189-198, 1988.

Daran, M.; Thévenod-Fosse, P. Software error analysis: A real case study involving real faults and mutations. In: ISSTA'96, San Diego, CA, 1996, p. 158-171.

DAvis, A. M. A comparison of techniques for the specification of external system behavior. Communications of the ACM, v. 31, n. 9, 1988. 
Delamaro, M. E. Proteum - um ambiente de teste baseado na análise de mutantes. Dissertação de Mestrado, ICMC/USP, São Carlos, SP, 1993.

Delamaro, M. E. Mutação de interface: Um critério de adequação interprocedimental para o teste de integração. Tese de Doutoramento, IFSC/USP, São Carlos, SP, 1997.

Delamaro, M. E.; Maldonado, J. C. Uma visão sobre a aplicação da análise de mutantes. Relatório Técnico 133, ICMC, São Carlos, SP, notas do ICMC, Série Computação, 1993.

Delamaro, M. E.; Maldonado, J. C. Proteum: A tool for the assessment of test adequacy for C programs. In: Conference on Performability in Computing Systems (PCS'96), Brunswick, NJ, 1996, p. 79-95.

Delamaro, M. E.; Maldonado, J. C. Interface mutation: Assessing testing quality at interprocedural level. In: Proceedings of XIX SCCC - International Conference of the Chilean Computer Science Society, Talca, Chile, 1999, p. 78-86.

Delamaro, M. E.; Maldonado, J. C.; Mathur, A. P. Interface mutation: An approach for integration testing. IEEE Transactions on Software Engineering, v. 27, n. 3, p. 228-247, 2001.

DeMillo, R. A. Mutation analysis as a tool for software quality assurance. In: COMPSAC80, Chicago, IL, 1980.

DeMillo, R. A.; Guindi, D. S.; King, K. N.; McCracken, W. M.; Offutt, A. J. An extended overview of the Mothra testing environment. In: Second Workshop on Software Testing, Verification and Analysis, Baniff, Canadá, 1988.

DeMillo, R. A.; Lipton, R. J.; Perlis, A. J. Social processes and proofs of theorems and programs. Communications of the ACM, v. 22, n. 5, 1979.

DeMillo, R. A.; Lipton, R. J.; SAyward, F. G. Hints on test data selection: Help for the practicing programmer. IEEE Computer, v. 11, n. 4, p. 34-41, 1978.

DeMillo, R. A.; Mathur, A. P. A grammar based fault classification scheme and its application to the classification of the error of TeX. Relatório Técnico SERC-TR-165-P, Software Engineering Research Center and Department of Computer Science, Purdue University, 1995.

DeMillo, R. A.; Offutt, A. J. Constraint-based automatic test data generation. IEEE Transactions on Software Engineering, v. 17, n. 9, p. 900-910, 1991.

Denney, R. Test-case generation from Prolog-based specifications. IEEE Software, v. 8, n. 2, p. 49-57, 1991.

Desel, J. Model validation - a theoretical issue? In: Esparza, J.; LAKos, C., eds. Application and Theory of Petri Nets'2002, n. 2360 in Lecture Notes on Computer Science, 2002 (Lecture Notes on Computer Science, ). 
Desel, J.; Oberweis, A.; Zimmer, T.; Zimmermann, G. A test case generator for the validation of high-level petri nets. In: IEEE International Conference on Emerging Technologies and Factory Automation, Los Angeles, 1997, p. 371-332.

Drath, R. Visual object net ++ . [On-line], World Wide Web.

Disponível em http://www.systemtechnik.tu-ilmenau.de/ drath/visual_E.htm (Último Acesso em 01/11/2004)

Duran, J. W.; Ntafos, S. C. An evaluation of random testing. IEEE Transactions on Software Engineering, v. 10, n. 4, p. 438-444, 1984.

FABbri, S. C. P. F. A análise de mutantes no contexto de sistemas reativos: Uma contribuição para o estabelecimento de estratégias de teste e validação. Tese de Doutoramento, IFSC/USP, São Carlos, SP, 1996.

Fabbri, S. C. P. F.; Delamaro, M. E.; Maldonado, J. C.; Masiero, P. C. Proteum/FSM : Especificação de uma ferramenta para apoiar a validação de Máquinas de Estado Finito pelo critério análise de mutantes. In: $12^{\circ}$ SBRC - Simpósio Brasileiro de Redes de Computadores, Curitiba, PR, 1994a, p. 284-304.

Fabbri, S. C. P. F.; Maldonado, J. C.; Delamaro, M. E.; Masiero, P. C. Proteum/FSM : Uma ferramenta para apoiar a validação de máquinas de estado finito pelo critério análise de mutantes. In: IX Simpósio Brasileiro de Engenharia de Software, Recife, PE, 1995a, p. 475-478.

Fabbri, S. C. P. F.; Maldonado, J. C.; Delamaro, M. E.; Masiero, P. C. Proteum/FSM: A tool to support finite state machine validation based on mutation testing. In: XIX SCCC - International Conference of the Chilean Computer Science Society, Talca, Chile, 1999a, p. 96-104.

Fabbri, S. C. P. F.; Maldonado, J. C.; Masiero, P. C.; Delamaro, M. E. Análise de mutantes baseada em máquinas de estado finito. In: $11^{\circ}$ Simposio Brasileiro de Redes de Computadores, Campinas, SP, 1993.

Fabbri, S. C. P. F.; Maldonado, J. C.; Masiero, P. C.; Delamaro, M. E. Análise de mutantes na validação de especificações baseadas em redes de Petri. In: $8^{\circ}$ Workshop de Qualidade de Software, Curitiba, PR, 1994b.

Fabbri, S. C. P. F.; Maldonado, J. C.; Masiero, P. C.; Delamaro, M. E. Mutation analysis testing for finite state machines. In: Fifth International Symposium on Software Reliability Engineering, Monterey, California, USA, 1994c, p. 220-229.

Fabbri, S. C. P. F.; Maldonado, J. C.; Masiero, P. C.; Delamaro, M. E.; Wong, E. Mutation testing applied to validate specifications based on Petri nets. In: FORTE'95 - 8th International IFIP Conference on Formal Description Techniques for Distributed Systems and Communications Protocol, Montreal, Canada, 1995b. 
Fabbri, S. C. P. F.; Maldonado, J. C.; Sugeta, T.; Masiero, P. C. Mutation testing applied to validate specifications based on statecharts. In: ISSRE - International Symposium on Software Reliability Systems, 1999b, p. 210-219.

Fonseca, R. P. Suporte ao teste de programas fortran no ambiente Poke-Tool. Dissertação de Mestrado, DCA/FEEC/UNICAMP, Campinas, SP, 1993a.

FonseCA, R. P. Suporte ao teste estrutural de programas fortran no ambiente poke-tool. Dissertação de Mestrado, DCA/FEE/UNICAMP, Campinas, SP, 1993b.

FrankL, F. G. The use of data flow information for the selection and evaluation of software test data. Tese de Doutoramento, Universidade de New York, New York, NY, 1987.

Frankl, P.; Weyuker, E. A data flow testing tool. In: Proceedings of IEEE Softfair II Conference on Software Development Tools, Techniques, and Alternatives, 1985, p. 46-53.

Frankl, P. G.; Weyuker, E. J. A formal analysis of the fault-detecting ability of testing methods. IEEE Transactions on Software Engineering, v. 19, n. 3, p. 202-213, 1993.

Frankl, P. G.; Weyuker, E. J. Testing software to detect and reduce risk. Journal of Systems and Software, v. 53, n. 3, p. 275-286, 2000.

FURBACH, U. Formal specification methods for reactive systems. Journal of Systems and Software, v. 21, n. 2, p. 129-139, 1993.

Gall, P.; Arnould, A. Formal specifications and test: Correctness and oracle. In: Haveraaen, M.; Owe, O.; Dall, O. I., eds. Recent Trends in Data Type Specification, Springer, 1996, p. 342-358 (Lecture Notes on Computer Science, v.1130).

Gane, C.; SARson, T. Structured system analysis: Tools and techniques. New Jersey: Prentice-Hall, 1979.

Gansner, E. R.; North, S. C. An open graph visualization system and its applications to software engineering. Software - Practice \& Experience, v. 30, n. 11, p. 1203-1233, 2001.

Genrich, H. J. Predicate/transition nets. In: Advances in Petri Nets, 1987, p. 207-247 (Lecture Notes in Computer Science, v.254).

Gerrard, C. P.; Coleman, D.; Dallimore, R. M. Formal specification and design time testing. IEEE Transactions on Software Engineering, v. 16, n. 1, p. 1-12, 1990.

GILL, A. Introduction to the theory of finite-state machines. New York: McGraw-Hill, 1962.

Goodenough, J. B.; Gerhart, S. L. Toward a theory of test data selection. IEEE Transactions on Software Engineering, v. 1, n. 2, p. 156-173, 1975. 
Gotlieb, A.; Botella, B.; Rueher, M. Automatic test data generation using constraint solving techniques. In: ISSTA'98, 1998, p. 53-62.

Grahlmann, B. The PEP Tool. In: Tool Presentations of ATPN'97 (Application and Theory of Petri Nets), 1997.

Gupta, N.; Mathur, A. P.; Soffa, M. L. Automated test data generation using an iterative relaxation method. In: Proceedings of the ACM SIGSOFT Sixth International Symposium on Foundations of Software Engineering, ACM Press, 1998, p. 231-244.

Gutjahr, W. J. Partition testing vs. random testing: The influence of uncertainty. IEEE Transactions on Software Engineering, v. 25, n. 5, p. 661-674, 1999.

Hamlet, D. Implementing prototype testing tools. Software - Practice and Experience, v. 1, n. 1, p. 1-4, 1988.

Hamlet, D.; TAYlor, R. Partition testing does not inspire confidence. IEEE Transactions on Software Engineering, v. 16, n. 12, p. 1402-1411, 1990.

Hammer, W. Handbook os system and product safety. Prentice-Hall, 1972.

Hansen, M. R.; Rischel, H. Introduction to programming using sml. Addison-Wesley, 1999.

HAREL, D. Statecharts: A visual formalism for complex systems. Science of Computer Programming, v. 8, n. 3, p. 231-274, 1987a.

HAREL, D. Statecharts: On the formal semantics of statecharts. In: The 2nd IEEE Symposium on Logic in Computer Science, Ithaca, New York, 1987b, p. 54-64.

HAREL, D. Bitting the silver bullet - toward a brighter future for systems development. IEEE Computer, v. 25, n. 1, p. 8-20, 1992.

HARrold, M. J. Testing: A roadmap. In: Future of Software Engineering, 22 ${ }^{\text {nd }}$ International Conference on Software Engineering, 2000, p. 61-72.

Heiner, M. Ped - a hierachical Petri net editor. [On-line], World Wide Web.

Disponível em http://www-dssz.Informatik.TU-Cottbus.DE/ ${ }^{\text {Wwwdssz/software/ }}$ ped.html (Último Acesso em 01/11/2004)

Herbert, J. S.; Price, A. M. A. Data test generation strategy based on symbolic and dynamic program analysis. In: XI SBES - Simpósio Brasileiro de Engenharia de Software, Fortaleza, CE, 1997, p. 397-411.

Herman, P. M. A data flow analysis approach to program testing. Australian Computer Journal, v. 8, n. 3, 1976.

Hoare, C. A. R. How did software get so reliable without proof? In: Gaudel, M. C.; Woodcock, J., eds. Formal Methods Europe - FME'96, Springer, 1996, p. 1-17 (Lecture Notes on Computer Science, v.1051). 
Holzmann, G. J. The model checker spin. IEEE Transactions on Software Engineering, v. 23, n. 5, p. 279-295, 1997.

Horgan, J. R.; Mathur, A. P. Assessing testing tools in research and education. IEEE Transactions on Software Engineering, v. 9, n. 3, p. 61-69, 1992.

Howden, W. E. Methodology for the generation of program test data. IEEE Transactions on Computers, v. 24, p. 554-560, 1975.

Howden, W. E. Weak mutation testing and completeness of test sets. IEEE Transactions on Software Engineering, v. 8, n. 4, p. 371-379, 1982.

Howden, W. E. Software engineering and technology: Functional program testing and analysis. New York: McGrall-Hill Book Co, 1987.

Howden, W. E. Validating programs without specifications. In: Proceedings of the ACM SIGSOFT'89 Third Symposioum on Software Testing, Analysis, and Verification, 1989, p. 2-9.

Hu, T. C. Integer programming and network flows. Massachusetts: Addison-Wesley, 1969.

Huang, C. M.; Hsu, J. M. An incremental protocol verification method. The Computer Journal, v. 37, n. 8, p. 698-710, 1994.

IEEE IEEE standard glossary of Software Engineering terminology. Padrão 620.12, IEEE, 1990.

ISO/TC97/SC21/WG1/DIS9074 Estelle: A formal description technique based on an extended state transition model. 1987.

ITU CCITT Specification and Description Language - recommendation z.100 (03/93). 1993.

JACKSOn, M. System development. New Jersey: Prentice-Hall International Englewood Cliffs, 1983.

JALOte, P. Testing the completeness of specifications. IEEE Transactions on Software Engineering, v. 15, n. 5, p. 526-531, 1989.

Jantzen, M.; VAlK, R. Formal properties of place/transition nets. In: Brauer, W., ed. Net Theory and Applications, Proc. of the Advanced Course on General Net Theory of Processes and Systems, Berlin, Heidelberg, New York: Springer-Verlag, 1980, p. 165-212 (Lecture Notes in Computer Science, v.84).

Jeng, B.; Weyuker, E. J. Some observations on partition testing. In: Proceedings of the ACM SIGSOFT'89 Third Symposioum on Software Testing, Analysis, and Verification, 1989, p. 38-47.

Jensen, K. Coloured Petri nets. In: Application and Theory of Petri Nets, Berlin: Springer, 1986, p. 248-299 (Lecture Notes on Computer Science, v.254). 
Jensen, K. An introduction to the theoretical aspects of coloured Petri nets. In: Rozenberg, G.; De Roever, W. P.; De Bakker, J. W., eds. A Decade of Concurrency, Berlin: Springer, 1994, p. 230-272 (Lecture Notes on Computer Science, v.803).

Jensen, K. Coloured petri nets: Analysis methods. 2 ed. Berlin: Springer, 1997a.

Jensen, K. Coloured petri nets: Basic concepts. 2 ed. Berlin: Springer, 1997b.

Jensen, K. Coloured petri nets: Practical use. 2 ed. Berlin: Springer, 1997c.

Jensen, K. Cpn-ml reference. [On-line], World Wide Web.

Disponível em http://www.daimi.au.dk/designCPN/man/Reference/Reference. Main3.CPN.ML.pdf (Último Acesso em 01/11/2004)

JiRAChiefPATtanA, A.; LAI, R. EVEN: A software environment for Estelle specification verification. Journal of Systems Software, v. 39, p. 119-143, 1997.

Kemmerer, R. A. Testing formal specifications to detect design errors. IEEE Transactions on Software Engineering, v. 11, n. 1, p. 32-43, 1985.

Kim, S.; Clark, J. A.; Mcdermid, J. A. The rigorous generation of Java mutation operators using HAZOP. In: 12th International Conference on Software \& Systems Engineering and their Applications (ICSSEA'99), 1999.

Kindler, E.; Weber, M. The petri net kernel. In: Mortensen, K. H., ed. Tool Demonstrations of International Conference on Applications and Theory of Petri Nets, Aarus, Dinamarca, 2000, p. 71-75.

Disponível em http://www.informatik.hu-berlin.de/ ${ }^{\sim m w e b e r / P o s t s c r i p t / p n k}$ pn2000.ps (Último Acesso em 01/11/2004)

King, S.; Hammond, J.; Chapman, R.; Pryor, A. Is proof more cost effective than testing? IEEE Transactions on Software Engineering, v. 26, n. 8, p. 675-686, 2000.

KIT, E. Software testing in the real world :improving the process. Wokingham, England: ACM Press, 1995.

Kordon, F.; Paviot-Adet, E. Using cpn-ami to validate a safe channel protocol. In: International Conference on Theory and Applications of Petri Nets - Tool presentation part, Williamsburg, USA, 1999, p. 13-18.

Korel, B.; Laski, J. W. A tool for data flow oriented program testing. In: Proceedings of Softfair II, San Francisco, CA, 1985, p. 34-38.

Kotik, G. B.; Markosian, L. Z. Automating software analysis and testing using a program transformation system. In: Proceedings of the ACM SIGSOFT'89 Third Symposium on Software Testing, Analysis, and Verification, 1989, p. 75-84. 
Kovács, G.; Pap, Z.; Viet, D. L.; Wu-Hen-Chang, A.; Csopaki, G. Applying mutation analysis to sdl specifications. In: REED, R.; REED, J., eds. SDL 2003: System Design - $11^{\text {th }}$ SDL Forum, Stuttgart, Germany: Springer-Verlag Heidelberg, 2003, p. 269-284 (Lecture Notes on Computer Science, v.2708).

Krichen, M.; Tripakis, S. Black-box conformance testing for real-time systems. In: Model Checking Software: 11th International SPIN Workshop, n. 2989 in Lecture Notes on Computer Science, Barcelona, Spain, 2004, p. 109-126 (Lecture Notes on Computer Science, ).

Kristensen, L. M.; Valmari, A. Finding stubborn sets of coloured petri nets without unfolding. In: Desel, J.; Silva, M., eds. 19th International Conference on Application and Theory of Petri Nets, ICATPN'98, Lisbon, Portugal, June 1998: Springer-Verlag, 1998, p. 104-123 (Lecture Notes in Computer Science, v.1420).

Kunn, D. R. Fault classes and error detection capability of specification-based testing. ACM Transaction on Software Engineering and Methodology, v. 8, n. 4, p. 411-424, 1999.

Kumar, D.; Harous, S. Distributed simulation of timed petri nets: Basic problems and their resolution. IEEE Systems, Man and Cybernetics, v. 24, n. 10, p. 1498-1510, 1994.

LAKos, C. Object oriented modelling with object Petri nets. In: AGHA, G. A.; Cindio, F. D.; Rozenberg, G., eds. Concurrent Object-Oriented Programming and Petri Nets, 2001, p. 1-37 (Lecture Notes on Computer Science, v.2001).

LAski, J. W.; Korel, B. A data flow oriented program testing strategy. IEEE Transactions on Software Engineering, v. 9, n. 3, 1983.

LEITÃo, P. S. J. Suporte ao teste estrutural de programas cobol no ambiente poke-tool. Dissertação de Mestrado, DCA/FEE/UNICAMP, Campinas, SP, 1992.

Leveson, N. G. Software safety: Why, what, and how. ACM Computer Surveys, v. 18, n. 2, p. 126-163, 1986.

Leveson, N. G.; Harvey, P. R. Analyzing software safety. IEEE Transactions on Software Engineering, v. 9, n. 5, p. 569-579, 1983.

Leveson, N. G.; Stolzy, J. L. Safety analysis using petri nets. IEEE Transactions on Software Engineering, v. 13, n. 3, p. 386-397, 1987.

Lindquist, T. E.; Jenkins, J. R. Test-case generation with IOGen. IEEE Software, v. 5, n. 1 , p. $72-79,1988$.

Liu, S.; MCDermid, J. A. A model-oriented approach to safety analysis using fault trees and its support system. The Journal of Systems and Software, v. 35, n. 2, p. 151-164, 1996. 
Lopes, W. S. Estelle: uma técnica para a descrição formal de serviços e protocolos de comunicação. Revista Brasileira de Computação, v. 5, n. 1, p. 33-44, 1989.

Macial, P. R. M.; Lins, R. D.; Cunha, P. R. F. Introdução às redes de Petri e aplicações. In: $10^{a}$ Escola de Computação, Departamento de Informática, Universidade Federal de Pernambuco, 1996.

Maldonado, J. C. Critérios potenciais usos: Uma contribuição ao teste estrutural de software. Tese de Doutoramento, DCA/FEEC/UNICAMP, Campinas, SP, 1991.

Maldonado, J. C. Critérios de teste de software: Aspectos teóricos, empíricos e de automação. (Trabalho de Livre Docência), ICMC/USP, São Carlos, SP, 1997.

Maldonado, J. C.; Chaim, M. L.; Jino, M. Arquitetura de uma ferramenta de teste de apoio aos critérios potenciais usos. In: Anais do XXII Congresso Nacional de Informática, São Paulo, SP, 1989.

Maldonado, J. C.; Delamaro, M. E.; Fabbri, S. C. P. F.; Simão, A. S.; Sugeta, T.; Vincenzi, A. M. R.; Masiero, P. . C. Proteum: A family of tools to support specification and program testing based on mutation. In: Mutation 2000, San Jose, California, 2000, p. 146-149.

Maldonado, J. C.; Fabbri, S. C. P. F. Verificação e validação de software, cáp. 3.4 Prentice Hall, p. 66-73, 2001.

Maldonado, J. C.; Vincenzi, A. M. R.; Barbosa, E. F.; Souza, S. R. S.; Delamaro, M. E. Aspectos teóricos e empíricos de teste de cobertura de software. Relatório Técnico 31, ICMC/USP, São Carlos, SP, notas Didáticas do ICMC, Série Computação, 1998.

MARICK, B. Classic testing mistakes. [On-line], World Wide Web.

Disponível em http://www.testing.com/writings/classic/mistakes.pdf (Último Acesso em 01/11/2004)

Martins, E.; Sabĩ̃o, S. B.; Ambrosio, A. M. Condata: a tool for automating specification-based test case generation for communication systems. In: Proceedings of the $33^{\text {rd }}$ Hawaii International Conference on System Sciences, Maui, Hawaii, 2000, p. $1-20$.

Masiero, P. C.; Maldonado, J. C.; Boaventura, I. G. A reachability tree for statecharts and analysis of some properties. Informations and Software Technology, v. 36, n. 10, p. 615-624, 1994.

Mason, T.; Brown, D. Lex $\&$ yacc. O’Reilly, 1990.

Mathur, A. P.; Wong, W. E. Evaluation of the cost of alternative mutation strategies. In: VII Simpósio Brasileiro de Engenharia de Software, Rio de Janeiro, RJ, Brazil, 1993, p. 320-335. 
Mathur, A. P.; Wong, W. E. An empirical comparison of data flow and mutation based test adequacy criteria. The Journal of Software Testing, Verification, and Reliability, v. 4, n. 1, p. 9-31, 1994.

Maurer, P. M. Generating test data with enhanced context-free grammars. IEEE Software, v. 7, n. 4, p. 50-55, 1990.

McDermid, J. A.; Pumfrey, D. J. A development of hazard analysis to aid software design. In: Compass'94: 9th Annual Conference on Computer Assurance, Gaithersburg, MD: National Institute of Standards and Technology, 1994, p. 17-26.

Michael, C.; McGraw, G. Opportunism and diversity in automated software test data generation. Relatório Técnico RSTR-003-97-13, RST Corporation, 1997.

Morell, L. J. A theory of fault-based testing. IEEE Transactions on Software Engineering, v. 16, n. 8, p. 844-857, 1990.

Mortensen, K. H. History of Petri nets. [On-line], World Wide Web.

Murata, T. Modeling and analysis of concurrent systems. In: Handbook of Software Engineering, New York: Van Nostrand Reinhold Electrical, 1984.

Murata, T. Petri nets: Properties, analysis and applications. Proceedings of the IEEE, v. 77, n. 4, p. 541-580, 1989.

Myers, G. The art of software testing. New York: Wiley, 1979.

MÄKELÄ, M. Maria: Modular reachability analyser for high-level petri nets. In: International Conference on Theory and Applications of Petri Nets - Tool presentation part, Williamsburg, USA, 1999, p. 59-64.

Nakagawa, E. Y.; Maldonado, J. C. Software-fault injection based on mutant operators. In: Anais do XI Simpósio Brasileiro de Tolerância a Falhas, Florianópolis, SC, 2001, p. 85-98.

Nemhauser, G. L.; Wolsey, L. C. Integer and combinatorial optimization. New York: Wiley-Interscience Publication, 1988.

Nicholson, T.; Foo, N. A denotational semantics for prolog. ACM Transactions on Programming Languages and Systems, v. 11, n. 4, p. 650-665, 1989.

NTAFos, S. On random and partition testing. In: ISSTA'98, 1998, p. 42-48.

Ntafos, S. C. On required element testing. IEEE Transactions on Software Engineering, v. SE-10, p. 795-803, 1984.

NTAFos, S. C. A comparison of some structural testing strategies. IEEE Transactions on Software Engineering, v. 14, n. 6, p. 868-873, 1988.

Offutt, A. J. The coupling effect: Fact or fiction. In: Proceedings of Symposium on Testing, Analysis, and Verification, ACM Press, 1989, p. 131-140. 
Offutt, A. J. Investigations of the software testing coupling effect. ACM Transactions on Software Engineering Methodology, v. 1, n. 1, p. 3-18, 1992.

Offutt, A. J.; Haeys, J. H. A semantic model of program faults. In: International Symposium on software Testing and Analysis, ACM Press, San Diego - CA, 1996.

Offutt, A. J.; Lee, A.; Rothermel, G.; Untch, R. H.; Zapf, C. An experimental determination of sufficient mutant operators. ACM Transactions on Software Engineering Methodology, v. 5, n. 2, p. 99-118, 1996.

Offutt, A. J.; PAn, J. Automatically detecting equivalent mutants and infeasible paths. The Journal of Software Testing, Verification, and Reliability, v. 7, n. 3, p. 165-192, 1997.

Offutt, A. J.; Rothermel, G.; Zapf, C. An experimental evaluation of selective mutation. In: 15th International Conference on Software Engineering, Baltimore, MD: IEEE Computer Society Press, 1993, p. 100-107.

Oliveira, K. A.; Andrade, P. D. L. M. W. L. Casltest - test case, test oracle and test data generation from casl specifications. In: Sessão de Ferramentas do XVII Simpósio Brasileiro de Engenharia de Software, Manaus, AM, 2003, p. 73-78.

ÖZDEMIR, K.; URAL, H. Protocol validation by simultaneous reachability analysis. Computer Communications, v. 20, n. 9, p. 772-788, 1997.

PENG, W. Deadlock detection in communicating finite state machines by even reachability analysis. Mobile Networks and Applications, v. 2, n. 3, p. 251-257, 1997.

Peterson, J. L. Petri nets. Computing Surveys, v. 9, n. 3, p. 223-252, 1977.

Peterson, J. L. Petri net theory and the modeling of systems. New Jersey: Prentice-Hall, Englewood Cliffs, 1981.

Petrenko, A. Technical correspondence comments on "a reduced test suite for protocol conformance testing". ACM Transaction on Software Engineering and Methodology, v. 6, n. 3, p. 329-331, 1997.

Petrenko, A.; v. Bochmann, G.; Yao, M. On fault coverage of tests for finite state specifications. Computer Networks and ISDN Systems, v. 29, n. 1, p. 81-106, 1996.

Petri, C. A. Kommunication mit automaten. Tese de Doutoramento, Universität von Bonn, 1962.

Pettersson, P.; Larsen, K. G. UPPAAL2k. Bulletin of the European Association for Theoretical Computer Science, v. 70, p. 40-44, 2000.

Plane, D. R. Discrete optimization: Interger programming and network analysis for management decisions. New Jersey: Englewood Cliffs, 1971. 
PREssman, R. S. Software engineering - a practitioner's approach. 5 ed. McGraw-Hill, 2000.

Probert, R. L.; Guo, F. Mutation testing of protocols: Principles and preliminary experimental results. In: Proceedings of the IFIP TC6 Third International Workshop on Protocol Test Systems, North-Holland, 1991, p. 57-76.

RAPps, S.; Weyuker, E. J. Data flow analysis techniques for program test data selection. In: 6th International Conference on Software Engineering, Tokio, Japan, 1982, p. $272-278$.

RAPPs, S.; WeyUKer, E. J. Selecting software test data using data flow information. IEEE Transactions on Software Engineering, v. 11, n. 4, p. 367-375, 1985.

ReAders NSF-CNPq Readers Project: A Collaborative Research to Develop, Validate and Package Reading Techniques for Software Defect Detection. [On-line].

Disponível em http://www.labes.icmc.usp.br/readers/ (Último Acesso em $01 / 11 / 2004)$

Reisig, W. Petri net: An introduction. New York: Springer-Verlag, 1985.

Reisig, W.; Rozenberg, G. Informal introduction to Petri nets. In: Lecture Notes on Petri Nets I: Basic Models, 1998, p. 1-11 (Lecture Notes on Computer Science, v.1491).

Ritchey, R. W. Mutating network models to generate network security test cases. In: Mutation 2000, San Jose, California, 2000, p. 101-108.

Roch, S.; Stark, P. H. Ina - integrated net analyzer. 2.2 edInstitut für Informatik, Humboldt-Universität zu Berlin, 1999.

Rossi, G. Um método orientado a objetos para o projeto de aplicação hipermídia. Tese de Doutoramento, PUC, Rio de Janeirio, RJ, 1996.

Rozenberg, G.; Thiagarajan, P. S. Petri nets: Basic notions, structure, behaviour. In: De Bakker, J.W.; De Roever, W.P.; Rozenberg, G., eds. Current Trends in Concurrency, Springer-Verlag, 1986, p. 585-668 (Lecture Notes in Computer Science, v.224).

SalomaA, A. Formal languages. New York: Academic Press, 1973.

Sharon, D.; Anderson, T. A complete software engineering environment. IEEE Software, v. 14, n. 2, p. 123-125, 1997.

Simão, A. S. Proteum-RS/PN: Uma ferramenta para a validação de redes de Petri baseada na análise de mutantes. Dissertação de Mestrado, ICMC/USP, São Carlos, SP, 2000.

Simão, A. S. Teste e validação de redes de petri coloridas usando análise de mutantes. Qualificação de doutorado, ICMC/USP, São Carlos, SP, 2002. 
SimÃo, A. S.; Maldonado, J. C. Mutation based test sequence generation for Petri nets. In: Proceedings of III Workshop of Formal Methods, João Pessoa, PB, 2000a, p. 68-79.

Simão, A. S.; Maldonado, J. C. Proteum-RS/PN: Uma ferramenta para apoiar a edição, simulação e validação de redes de Petri baseada no teste de mutação. In: Caderno de Ferramentas do XIV Simpósio Brasileiro de Engenharia de Software, João Pessoa, PB, 2000b, p. 376-379.

Simão, A. S.; Maldonado, J. C. MuDeL: A language and a system for describing and generating mutants. In: Anais do XV Simpósio Brasileiro de Engenharia de Software, Rio de Janeiro, Brasil, 2001, p. 240-255.

Simão, A. S.; Maldonado, J. C. MuDeL: A language and a system for describing and generating mutants. Journal of the Brazilian Computer Society, v. 8, n. 1, p. 73-86, 2002.

Simão, A. S.; Maldonado, J. C. Mutant operators for coloured petri nets. Relatório Técnico, (in preparation), 2004.

Simão, A. S.; Maldonado, J. C.; Bigonha, R. S. Using denotational semantics in the validation of the compiler for a mutation-oriented language. In: Proceedings of $V$ Workshop of Formal Methods, Gramado, RS, 2002a, p. 4-19.

Simão, A. S.; Maldonado, J. C.; Fabbri, S. C. P. F. Proteum-RS/PN: A tool to support edition, simulation and validation of Petri nets based on mutation testing. In: Anais do XIV Simpósio Brasileiro de Engenharia de Software, João Pessoa, PB, 2000, p. $227-242$.

Simão, A. S.; Souza, S. R. L.; Maldonado, J. C. A family of coverage testing criteria for coloured petri nets. In: XVII Simpósio Brasileiro de Engenharia de Software, Manaus, AM, 2003a, p. 209-224.

Simão, A. S.; Vincenzi, A. M. R.; Maldonado, J. C. mudelgen: A tool for processing mutant operator descriptions. In: Anais da Sessão de Ferramentas do XVI Simpósio Brasileiro de Engenharia de Software, Gramado, RS, 2002b, p. 426-431.

Simão, A. S.; Vincenzi, A. M. R.; Maldonado, J. C.; Santana, A. C. L. A language for the description of program instrumentation and the automatic generation of instrumenters. CLEI Electronic Journal, (Submitted), 2003b.

SouzA, S. R. S. Avaliação do custo e eficácia do critério análise de mutantes na atividade de teste de software. Dissertação de Mestrado, ICMC/USP, São Carlos, SP, 1996.

Souza, S. R. S. Validação de especificações de sistemas reativos: Definição e análise de critérios de teste. Tese de Doutoramento, Instituto de Física de São Carlos/USP, São Carlos, SP, 2000. 
Souza, S. R. S.; Maldonado, J. C. Uma estratégia de minimização de conjuntos de casos de teste para o critério análise de mutantes. In: Workshop do Projeto, Validação e Teste de Sistemas de Operação, Águas de Lindóia, 1997, p. 95-102.

Souza, S. R. S.; Maldonado, J. C.; Fabbri, S. C. P. F. Fcce: Uma família de critérios de teste para validação de sistemas especificados em estelle. In: Anais do XV Simpósio Brasileiro de Engenharia de Software, Rio de Janeiro, Brasil, 2001, p. 256-271.

Souza, S. R. S.; Maldonado, J. C.; Fabbri, S. C. P. F.; Lopes de Souza, W. Mutation testing applied to Estelle specifications. Quality Software Journal, v. 8, n. 4, p. 285-301, publicado também no $33^{\text {rd }}$ Hawaii Internacional Conference on System Sciences, 2000, 2000a.

Souza, S. R. S.; Maldonado, J. C.; Fabbri, S. C. P. F.; Lopes de Souza, W. Mutation testing applied to Estelle specifications. Software Quality Journal, v. 8, n. 4, p. 285-301, 2000b.

Souza, S. R. S.; Maldonado, J. C.; Fabbri, S. C. P. F.; Masiero, P. C. Statecharts specifications: A family of coverage testing criteria. In: CLEI2000 Conferiência Latino Americana de Informática, Cidade do Mexico, Mexico, 2000c.

von StaA, A. Programação modular: Desevolvendo programas complexos de forma organizada e segura. Rio de Janeiro, RJ: Campus, 2000.

Stoy, J. E. Denotational semantics: The scott-strachey approach to programming language theory. Cambridge, Massassuchits: MIT Press, 1977.

Sugeta, T. Proteum-rs/st : Uma ferramenta para apoiar a validação de especificações statecharts baseada na análise de mutantes. Dissertação de Mestrado, ICMC-USP, São Carlos, SP, 1999a.

Sugeta, T. Proteum-RS/ST: Uma ferramenta para apoiar a validação de especificações statecharts baseada na análise de mutantes. Dissertação de Mestrado, ICMC/USP, São Carlos, SP, 1999b.

Sugeta, T. Teste e validação de sistemas reativos com base no teste de mutação: Aspectos teóricos e empíricos. Tese de Doutoramento, ICMC/USP, São Carlos, SP, 2002.

Sugeta, T. Uma contribuição para o teste de especificações SDL: aspectos teóricos e empíricos. Tese de Doutoramento, ICMC/USP, São Carlos, SP, 2004.

Sugeta, T.; Maldonado, J. C.; Fabbri, S. C. P. F. Proteum-RS/ST - uma ferramenta para apoiar a validação de especificações statecharts baseada no critério análise de mutantes. In: Caderno de Ferramentas do XIII SBES - Simpósio Brasileiro de Engenharia de Software, Florianópolis, SC, 1999, p. 41-44. 
Sugeta, T.; Maldonado, J. C.; Masiero, P. C.; Fabbri, S. C. P. F. Proteum-RS/ST - A Tool to Support Statecharts Validation Based on Mutation Testing. In: $4^{\text {th }}$ Workshop Iberoamericano de Engenharia de Requisitos e Ambientes de Software IDEAS'2001, Santo Domingo, Costa Rica, 2001, p. 370-384.

Sugeta, T.; Maldonado, J. C.; Wong, W. E. Mutation testing applied to validate SDL specifications. In: HiErons, R. M.; Groz, R., eds. $16^{\text {th }}$ IFIP International Conference on Testing of Communicating Systems - TestCom2004, Oxford, UK, (To be published), 2004.

SzE, L. Atacobol: A cobol test coverage analysis tool and its applications. In: ISSRE'2000 - International Symposium on Software Reliability Engineering, San Jose, CA, (Aceito para publicação), 2000.

Tanenbaum, A. S. Computer networks. 2 ed. Prentice Hall, 1989.

Tanenbaum, A. S. Sistemas operacionais modernos. 2 ed. Prentice Hall, 2003.

Telcordia Technologies - USA xSuds Toolsuite. [On-line], World Wide Web.

Disponível em http://xsuds.argreenhouse.com/xsuds-demo-intel.exe (Último Acesso em 01/11/2004)

Trompedeller, M. Petri net classification. [On-line], World Wide Web.

Disponível em http://www.daimi.au.dk/PetriNets/classification/ (Último Acesso em $01 / 11 / 2004)$

Untch, R. H.; Offutt, A. J.; Harrold, M. J. Mutation analysis using mutant schemata. In: ISSTA'93, 1993, p. 139-148.

Ural, H.; Saleh, K.; Williams, A. Test generation based on control and data dependencies within system specifications in SDL. Computer Communications, v. 23, n. 7, p. 609-627, 2000.

URAL, H.; YANG, B. A structural test selection criterion. Information Processing Letters, v. 28, p. 157-163, 1988.

URAL, H.; YANG, B. A test sequence selection method for protocol testing. IEEE Transactions on Communications, v. 39, n. 4, p. 514-523, 1991.

Varpanalemi, K.; Halme, J.; Hiekkanen, K.; Pyssysalo, T. Prod reference manual. Digital Systems Laboratory, Department of Computer Science, Kelsinki University of Technology, Otaniemi, Finlândia, 1995.

Vergílio, S. R.; Maldonado, J. C.; Jino, M. Uma estratégia para geração de dados de teste. In: Anais do VII Simpósio Brasileiro de Engenharia de Software, Rio de Janeiro, RJ, 1993, p. 307-319. 
VILELA, P. R. S. Uma ferramenta para auxílio visual ao teste e depuração de programas. Dissertação de Mestrado, DCA/FEE/UNICAMP, Campinas, SP, 1994.

Vincenzi, A. M. R. Subsídios para o estabelecimento de estratégias de teste baseadas na técnica de mutação. Dissertação de Mestrado, ICMC/USP, São Carlos, SP, 1998.

Vincenzi, A. M. R. Orientação a objeto: Definição e análise de recursos de teste e validação. Tese de Doutoramento, ICMC/USP, São Carlos, SP, 2004.

Vincenzi, A. M. R.; Maldonado, J. C.; Barbosa, E. F.; Delamaro, M. E. Operadores essenciais de interface: Um estudo de caso. In: 13th Simpósio Brasileiro de Engenharia de Software, Florianópolis, SC, 1999, p. 373-391.

Vincenzi, A. M. R.; Nakagawa, E. Y.; Maldonado, J. C.; Delamaro, M. E.; Romero, R. A. F. Bayesian-learning based guidelines to determine equivalente mutants. In: 13th International Conference on Software Engineering $\mathcal{G}_{3}$ Knowledge Engineering - SEKE'2001, Buenos Aires, Argentina, (Aceito para publicação em um edição especial do International Journal of Software Engineering and Knowledge Engineering - IJSEKE), 2001, p. 180-187.

Vincenzi, A. M. R.; Wong, W. E.; Delamaro, M. E.; Maldonado, J. C. JaBUTi: A coverage analysis tool for Java programs. In: XVII SBES - Simpósio Brasileiro de Engenharia de Software, Manaus, AM, Brasil, 2003, p. 79-84.

Vladimir, D. Formal languages and automata theory. Computer Science Press, 1989.

WAH, K. S. H. T. A theoretical study of fault coupling. Software Testing, Verification and Reliability, v. 10, n. 1, p. 3-45, 2000.

WANG, C. J.; LiU, M. T. Generation test cases for EFSM with given fault model. IEEE INFOCOM'93 - 12 $2^{\text {th }}$ Annual Joint Conference of the IEEE Computer and Communications Societies, p. 774-781, 1993.

WeIss, S. N.; FleyshgakKer, V. N. Improved serial algorithms for mutation analysis. In: ISSTA'93, Cambridge, MA: ACM, 1993, p. 149-158.

Weyuker, E. J. On testing non-testable programs. Computer Journal, v. 25, n. 4, p. $465-470,1982$.

WEYUker, E. J. Axiomatizing software test data adequacy. IEEE Transactions on Software Engineering, v. 12, n. 12, p. 1128-1138, 1986.

WEYUKER, E. J. Using failure cost information for testing and realiability assessmant. ACM Transactions on Software Engineering and Methodology, v. 5, n. 2, p. 87-98, 1996.

Weyuker, E. J.; Jeng, B. Analyzing partition testing strategies. IEEE Transactions on Software Engineering, v. 17, n. 7, p. 703-711, 1991. 
Weyuker, E. J.; Ostrand, T. J. Theories of program testing and the application of revealing subdomains. IEEE Transactions on Software Engineering, v. 6, n. 3, p. 236-246, 1980.

White, L. J.; Cohen, E. I. A domain strategy for computer program testing. IEEE Transactions on Software Engineering, v. 6, n. 5, p. 247-257, 1980.

WING, J. M. A specifier's introduction to formal methods. IEEE Computer, v. 23, n. 9 , p. 8-22, 1990.

Wohlin, C.; Runeson, P.; Höst, M.; Ohlsson, M. C.; Regnell, B.; Wesslén, A. Experimentation in software engineering: an introduction. Kluwer Academic Publishers, 2000.

Woller, S. Programação linear com variáveis inteiras: Algoritmos e aplicações. Tese de Doutoramento, Escola Politécnica da Universidade de São Paulo, São Paulo, SP, livre Docência, 1968.

Wolfram, S. The mathematica book. 3 ed. Champaign, Illinois: Wolfram Media, 1996.

Wong, E.; Maldonado, J. C.; Delamaro, M. E.; Mathur, A. P. Constrained mutation for C programs. In: $8^{\circ}$ Simpósio Brasileiro de Engenharia de Software, Curitiba, Brasil, 1994, p. 439-452.

Wong, W. E. On mutation and data flow. Tese de Doutoramento, Department of Computer Science, Purdue University, W. Lafayette, IN, 1993.

Wong, W. E.; Maldonado, J. C.; Souza, M. E.; Souza, S. R. S. A comparison of selective mutation in $\mathrm{C}$ and Fortran. In: Anais do Workshop do Projeto Validação e Teste de Sistemas de Operação, Águas de Lindóia, SP, 1997, p. 71-84.

Wong, W. E.; Mathur, A. P. Fault detection effectiveness of mutation and data flow testing. Software Quality Journal, v. 4, n. 1, p. 69-83, 1995a.

Wong, W. E.; Mathur, A. P. Reducing the cost of mutation testing: An empirical study. Journal of Software and Systems, v. 31, n. 3, p. 185-196, $1995 \mathrm{~b}$.

Wong, W. E.; Mathur, A. P.; Maldonado, J. C. Mutation versus all-uses: An empirical evaluation of cost, strngth and effectiveness, cáp. 40 London: Chapmann \& Hall, p. 258-265, 1995.

YAno, T. Estudo do teste de mutação em programas funcionais. Dissertação de Mestrado, ICMC/USP, São Carlos, SP, 2004.

Yano, T.; Simão, A. S.; Maldonado, J. C. Proteum/SML - uma ferramenta de apoio ao teste de mutação para a linguagem Standard ML. In: Sessão de Ferramentas do XVII Simpósio Brasileiro de Engenharia de Software, Manaus, AM, 2003, p. 67-72. 
Yano, T.; Simão, A. S.; Maldonado, J. C. Estudo do teste de mutação para a linguagem standard ml. In: Solar, M.; Fernández-Baca, D.; Cuadros-Vargas, E., eds. 30ma Conferencia Latinoamericana de Informática (CLEI2004), Sociedad Peruana de Computación, iSBN 9972-9876-2-0, 2004, p. 734-744.

ZEIL, S. J. Testing for perterbation of program statements. IEEE Transactions on Software Engineering, v. 9, n. 3, p. 335-346, 1983.

ZHU, H. A formal analysis of the subsume relation between software test adequacy criteria. IEEE Transactions on Software Engineering, v. 22, n. 4, p. 248-255, 1996.

Zhu, H.; Hall, P. A. V.; MAY, J. H. R. Software unit test coverage and adequacy. Computer Survey, v. 29, n. 4, p. 367-427, 1997.

Zimmermann, A. Modellierung und Bewertung von Fertigungssystemen mit speziellen Petri-Netzen. Tese de Doutoramento, Technische Universität Berlin, 1997. 


\section{Gramáticas Formais e Linguagens}

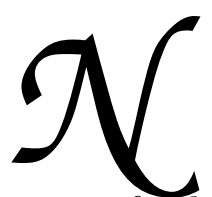

este apêndice, são apresentados os conceitos básicos necessários para a descrição da linguagem $\mathcal{M} u \mathcal{D} e \mathcal{L}$ apresentada no Capítulo 3. Apresenta-se uma introdução sucinta às teorias de gramáticas e linguagens formais, necessária para a facilitar discussão que se segue. Uma apresentação detalhada pode ser encontrada em Salomaa (1973).

Gramáticas formais são dispositivos finitos para descrever linguagens geralmente infinitas. Dada uma gramática $G$, denomina-se $L(G)$ ao conjunto de todas as sentenças que podem ser geradas pelas produções em $G$. Gramáticas livre de contexto são geralmente descritas em BNF Vladimir (1989). Uma gramática BNF $G$ é formada por uma tupla $G=(N, T, S, R)$, onde

- $N$ é o conjunto de símbolos não-terminais;

- $T$ é o conjunto de símbolos terminais;

- $S$ é o símbolo inicial; e

- $R \subseteq N \times(N \cup T)^{*}$ é o conjunto de regras de produção.

Uma regra de produção da forma $(n, \alpha)$ estabelece que o símbolo $n$ (chamado de lado esquerdo) pode ser substituído por uma seqüência $\alpha$ de símbolos terminais e não-terminais (chamada de lado direito) sem infligir a gramática. Geralmente, os símbolos não-terminais são escritos entre $\langle$ e $\rangle$, enquanto os símbolos terminais são escritos entre ‘ e '. Uma produção $(n, \alpha)$ é representada na forma $\langle n\rangle::=\alpha$. Quando várias produções possuem o mesmo símbolo à esquerda, essas podem ser expressas empregando-se o símbolo '|' para separar os respectivos lados direitos. Por exemplo, a expressão a seguir

$\langle n\rangle::=\alpha_{1} \mid \alpha_{2}$

é equivalente a

$\langle n\rangle::=\alpha_{1}$ 
$\langle n\rangle::=\alpha_{2}$

Será adotada a convenção de que para definir uma gramática BNF serão listadas apenas suas regras de produção. Os conjuntos de símbolos terminais e não-terminais são calculados a partir dos símbolos que ocorrem nas regras de produção e o símbolo inicial é o símbolo à esquerda da primeira regra. Na Figura A.1(a) é apresentada uma gramática BNF simples que define uma linguagem de expressões formadas por números, identificadores, adições e multiplicações, preservando a precedência matemática usual da multiplicação sobre a adição e o agrupamento de parênteses.

$$
\begin{aligned}
& \langle S\rangle::=\langle A\rangle \\
& \langle S\rangle::=\langle S\rangle \text { '*' }\langle A\rangle \\
& \langle A\rangle::=\langle B\rangle \\
& \langle A\rangle::=\langle A\rangle^{\prime}+{ }^{\prime}\langle B\rangle \\
& \langle B\rangle::=\langle\text { number }\rangle \\
& \langle B\rangle::=\langle\text { identifier }\rangle \\
& \langle B\rangle::='('\langle S\rangle \text { ')' } \\
& \langle\text { number }\rangle::=' 1 \text { ' } \\
& \langle\text { identifier }\rangle::=\text { 'a' }
\end{aligned}
$$

(a)

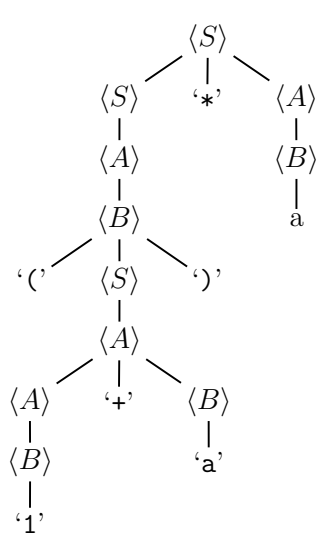

(b)

Figura A.1: (a) Uma Gramática BNF Livre de Contexto para Expressões Simples.(b) Árvore Sintática para ' $(1+a) * a$ '.

Os demais elementos da gramática são definidos da seguinte forma:

- os símbolos não-terminais $N=\{\langle S\rangle,\langle A\rangle,\langle B\rangle,\langle$ number $\rangle,\langle$ identifier $\rangle\}$;

- os símbolos terminais $T=\left\{{ }^{\prime}{ }^{\prime}\right.$, '+', ' (', ')', '1', 'a' $\}$; e

- o símbolo inicial $S=\langle S\rangle$.

De uma seqüência $\gamma\langle n\rangle \delta$, pode ser derivada outra seqüência da forma $\gamma \alpha \delta$, pela aplicação da regra de produção $n, \alpha$. Isto é representado por $\gamma\langle n\rangle \delta \Rightarrow \gamma \alpha \delta$. A linguagem $L(G)$ definida por $G$ é o conjunto de seqüências de símbolos que podem ser derivados a partir do símbolo inicial $S$ com as produções em $R$. Em outras palavras, $\varphi \in L(G)$ se, e somente se, $\varphi \in T^{*}$ e $S \Rightarrow \ldots \Rightarrow \varphi$.

A árvore sintática é uma árvore cujos nós não-folhas são rotulados com símbolos não-terminais; os nós folhas são rotulados com símbolos terminais; e o nó raiz é o símbolo inicial de $G$. Se um nó $\langle n\rangle$ tem nós-filho com os rótulos $\alpha_{1}, \alpha_{2}, \ldots, \alpha_{k}$, então existe uma produção da forma

$\langle n\rangle:=\alpha_{1} \alpha_{2} \ldots \alpha_{k}$ 
Se após realizar um percurso, da esquerda para direita, de uma árvore sintática $t$ de uma gramática $G$ e coletar os símbolos terminais for obtida a seqüência $\varphi$, então $t$ é uma árvore sintática de $\varphi$ com respeito à $G$. Em realidade, $\varphi$ pertence a $L(G)$ se existe uma árvore sintática $t$ para $\varphi$. Na Figura A.1(b) é apresentada uma árvore sintática para a expressão ' $(1+a) * a$ '. Se existem mais de uma árvore sintática para uma seqüência $\varphi \in L(G)$, então a gramática $G$ é denominada ambígua. No caso de uma gramática ambígua, serão consideradas as árvores sintáticas obtidas com as derivações mais à esquerda.

Seja $\pi$ uma função que toma uma gramática $G$ e uma seqüência $\varphi$ e retorna uma árvore sintática de $\varphi$ com respeito à gramática $G$. Seja $\delta$ uma função que toma uma árvore sintática e gera a seqüência de terminais percorrendo a árvore e coletando os símbolos terminais. Então, pode-se demonstrar que $\delta(\pi(G, \varphi))=\varphi$. Como afirmado anteriormente, um operador de mutação $\mu_{G}$ é uma função que toma um produto original e gera um conjunto de mutantes. Isto pode ser redefinido pela construção de uma função $\mu_{G}^{\prime}$ que satisfaz a seguinte equação

$$
\mu_{G}(p)=\left\{m \mid \exists t \in \mu_{G}^{\prime}(\pi(G, p)) \wedge \delta(t)=m\right\}
$$

onde $p$ é o produto original.

A linguagem $\mathcal{M} u \mathcal{D} e \mathcal{L}$ pode ser definida com uma linguagem para descrever funções do tipo $\mu_{G}^{\prime}$, isto é, para descrever como a árvore sintática do produto original deve ser transformada nas árvores sintáticas dos mutantes. Contudo, a linguagem $\mathcal{M} u \mathcal{D} e \mathcal{L}$ também incorpora tanto $\pi$ como $\delta$, que são as funções de parser e unparser. 


\section{Apêndice B}

\section{Definição Formal da Linguagem $\mathcal{M} u \mathcal{D} e \mathcal{L}$}
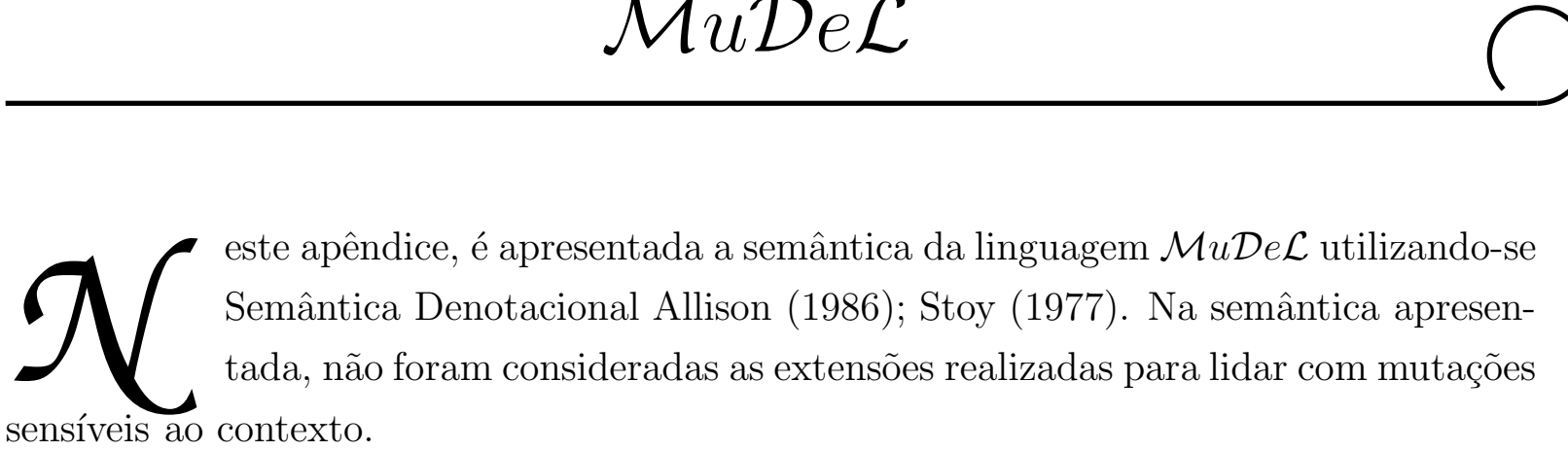

\section{B.1 Domínios}

Nesta seção são apresentados os domínios usados para especificar a semântica da linguagem.

\section{Domínios Básicos}

O domínio das localizações Loc é um domínio infinito e totalmente ordenado. Cada localização está associada a um nó da árvore. Uma possibilidade para definir Loc é utilizar os números naturais. Dessa forma

$$
\operatorname{Loc}=\{0,1, \ldots\}
$$

O domínio dos símbolos não-terminais NonTerm é o domínio finito cujos elementos estão em correspondência unívoca como símbolos não-terminais da gramática em consideração. Analogamente, o domínio dos terminais Term é o domínio finito cujos elementos estão em correspondência unívoca com os símbolos terminais da gramática.

Os elementos do domínio Rec são compostos por uma seqüência de localizações e um não-terminal e representa um nó interno da árvore sintática.

$$
\operatorname{Rec}=\operatorname{Loc}^{*} \times \text { NonTerm }
$$


O domínio Free representa o valor de uma meta-variável livre e possui um único elemento free associado com o não-terminal.

$$
\text { Free }=\{\text { free }\} \times \text { NonTerm }
$$

O domínio Undef possui um único elementos undef, que representa todas localizações não alocadas.

$$
\text { Undef }=\{\text { undef }\}
$$

Um estado que ocorrer durante a execução de um operador de mutação consiste basicamente de uma configuração particular da árvore sintática e dos padrões de árvore, assim como nas associações de meta-variáveis. As meta-variáveis estão associadas a localizações, de tal forma que pode-se formalmente representar os estados como uma função que mapeia localizações a

i) um valor não-definido (que representa que a localização não é utilizada),

ii) um símbolo terminal (que representa um nó folha na árvore),

iii) outra localizações,

iv) um valor livre (que representa uma meta-variável não ligada) ou

v) um nó interno da árvore sintática (que representa um símbolo não-terminal e seus nós filhos)

$$
\text { State }=\text { Loc } \rightarrow(\text { Undef }+ \text { Term }+ \text { Loc }+ \text { Free }+ \text { Rec })
$$

Com essa modelagem, pode-se modelar qualquer árvore sintática ou padrão de árvore. Dessa forma, uma árvore pode ser identificada pela localização de seu nó raiz.

Um mutante consiste de uma lista de símbolos terminais. Dessa forma,

$$
\text { Mut }=\text { Term }^{*}
$$

O resultado da execução de um operador de mutação é definido como uma lista de mutantes, como se segue:

$$
\text { Ans }=\text { Mut }^{*}
$$




\section{Domínios de Continuação}

Na terminologia da teoria da semântica denotacional, uma continuação é uma função que representa o efeito de executar os restante do programa. Na linguagem $\mathcal{M} u \mathcal{D} e \mathcal{L}$, existem dois tipos de continuação:

Continuação Alternativa Uma continuação alternativa mapeia um resultado parcial contendo os mutantes gerados até o momento em outro resultado. Uma continuação alternativa representa um ponto no qual a execução pode continuar, seja por que um mutante foi gerado e outro será tentado, seja por que a execução da alternativa corrente falhou. Dessa forma,

$$
\mathrm{Ka}=\mathrm{Mut}^{*} \rightarrow \text { Ans }
$$

Continuação Normal Uma continuação normal representa a execução normal até o final de um operador de mutação. Ele toma com argumento:

(i) um estado (o estado corrente),

(ii) uma continuação alternativa (a ser tentada no caso de falha),

(iii) uma continuação alternativa (que define como continuar se uma operação cut for executada), e

(iv) um resultado parcial (com os mutantes gerados até o momento).

Dessa forma,

$$
\mathrm{Kn}=\text { State } \rightarrow \overbrace{\mathrm{Ka}}^{\text {retry }} \rightarrow \overbrace{\mathrm{Ka}}^{\text {cut }} \rightarrow \mathrm{Mut}^{*} \rightarrow \text { Ans }
$$

$\mathrm{Ou}$

$$
\mathrm{Kn}=\text { State } \rightarrow \mathrm{Ka} \rightarrow \mathrm{Ka} \rightarrow \mathrm{Ka}
$$

\section{B.2 Sintaxe Formal}

A sintaxe formal abstrata da linguagem $\mathcal{M} u \mathcal{D} e \mathcal{L}$ é apresentada para permitir a denotação de sua semântica. Assume-se que a análise sintática já foi realizada de tal forma que tantos as árvores sintáticas quanto padrões de árvore podem ser identificadas univocamente por seu nó raiz. Além disso, assume-se que cada meta-variável foi substituída por uma respectiva localização livre. Dessa forma, os elementos sintáticos primários de um operador de mutação são árvores e operações. Na Figura B.1 é apresentada a sintaxe abstrata de um operador de mutação, na qual $r, b, m \in$ Loc e $o p_{1}, o p_{2} \in \mathbf{O p}$. 


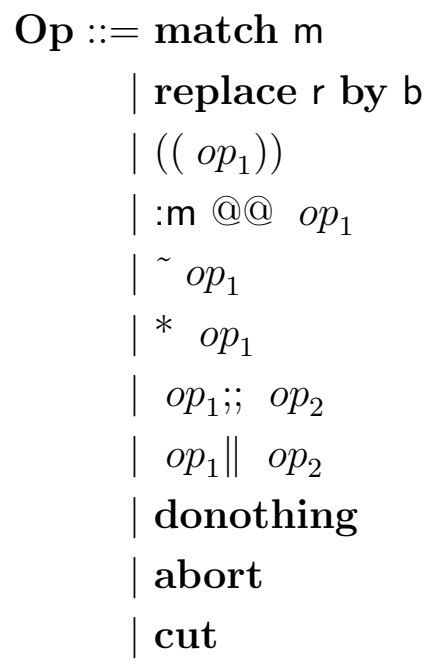

Figura B.1: Sintaxe Abstrata da Linguagem $\mathcal{M} u \mathcal{D} e \mathcal{L}$.

\section{B.3 Funções de Valoração Semântica}

A função de valoração semântica $\mathcal{A}$ atribui semântica a cada operação. Para definir o resultado, devem ser fornecidos:

(i) uma localização (que representa a árvore de contexto),

(ii) a continuação normal (que representa a próxima operação a ser executada),

(iii) o estado corrente,

(iv) a continuação retry (que é uma continuação alternativa e representa o próximo ponto a ser tentado),

(v) a continuação cut (que é uma continuação alternativa e representa o que será a continuação retry quando uma operação cut for executada), e

(vi) um resultado parcial (com os mutantes gerados até o momento).

Dessa forma,

$$
\mathcal{A}: \mathrm{Op} \rightarrow \mathrm{Loc} \rightarrow \mathrm{Kn} \rightarrow \text { State } \rightarrow \mathrm{Ka} \rightarrow \mathrm{Ka} \rightarrow \mathrm{Mut}^{*} \rightarrow \text { Ans }
$$

$\mathrm{Ou}$

$$
\mathcal{A}: \mathrm{Op} \rightarrow \mathrm{Loc} \rightarrow \mathrm{Kn} \rightarrow \mathrm{Kn}
$$




\section{Operação de Casamento de Padrão}

A semântica da operação de casamento de padrão consiste da função unify . Deve-se observar que a função unify (definida na Seção B.5), toma duas localizações representando as árvore a serem unificadas e altera o estado de forma a refletir os efeitos de qualquer unificação de localizações livre que venham a ocorrer.

$\mathcal{A} \llbracket$ match $\mathrm{m} \rrbracket l=$ unify $l \mathrm{~m}$

\section{Operação de Substituição}

A operação de substituição consiste do casamento das localizações do contexto e do padrão $r$, continuando no estado atualizado no caso de sucesso $^{1}$

$$
\mathcal{A} \llbracket \text { replace } \mathrm{r} \text { by } \mathrm{b} \rrbracket l k_{n} s=\text { unify } \mathrm{r} l \overbrace{\left(\lambda s^{\prime} \cdot k_{n} s^{\prime}[\mathrm{b} / l]\right)}^{\text {cont.normal }} s
$$

\section{Agrupamento}

A semântica de um agrupamento é semântica da operação interna com os ajustes necessários para limitar o escopo da operação cut. Deve-se observar que a continuação normal da operação interna é fixada pela função lambda.

$$
\mathcal{A} \llbracket((\mathrm{op})) \rrbracket l k_{n} s k_{r} k_{c}=\mathcal{A} \llbracket \mathrm{op} \rrbracket l \overbrace{\left(\lambda s^{\prime} k_{r}^{\prime} k_{c}^{\prime} \cdot k_{n} s^{\prime} k_{r}^{\prime} k_{c}\right)}^{\text {normal } \text { cont. }} s k_{r} k_{r}
$$

\section{Declaração de Contexto}

A semântica de uma operação modificada por uma declaração de contexto é a semântica da operação modificada com a localização correspondente à meta-variável associada.

$$
\mathcal{A} \llbracket: \mathrm{m} @ @ \mathrm{op} \rrbracket l=\mathcal{A} \llbracket \mathrm{op} \rrbracket(l o c: \mathrm{m})
$$

onde loc :m é a localização associada com a meta-variável :m.

\footnotetext{
${ }^{1} \mathrm{O}$ mapeamento $s[\mathrm{~b} / l]$ é idêntico a $\mathrm{s}$, exceto que $l$ é mapeado em b.
}

$$
s[\mathrm{~b} / l]\left(l^{\prime}\right)=\left(l=l^{\prime} \rightarrow b, s\left(l^{\prime}\right)\right)
$$




\section{Negação}

O modificador de negação inverte as continuações da operação modificada; a continuação retry é usada como continuação normal, e vice-versa.

$$
\mathcal{A} \llbracket^{\sim} \mathrm{op} \rrbracket l k_{n} s k_{r} k_{c}=\mathcal{A} \llbracket \mathrm{op} \rrbracket l \overbrace{\left(\lambda s^{\prime} k_{r}^{\prime} k_{c}^{\prime} \cdot k_{r}\right)}^{\text {cont. normal }} s \overbrace{\left(k_{n} s k_{r} k_{c}\right)}^{\text {cont. retry }} k_{r}
$$

\section{Modificador *}

Para definir a semântica de uma operação que possui o modificador *, emprega-se a função de valoração $\mathcal{G}$ (definida na Seção B.5), que recursivamente aplica a operação modificada em cada subárvore da árvore de contexto. Dessa forma, a função $\mathcal{G}$ gerará várias continuações alternativas.

$$
\mathcal{A} \rrbracket^{*} \mathrm{op} \rrbracket l k_{n} s k_{r} k_{c}=\mathcal{A} \llbracket \mathrm{op} \rrbracket l k_{n} s \overbrace{\left(\mathcal{G} \llbracket \mathrm{op} \rrbracket l k_{n} s k_{r} k_{c}\right)}^{\text {cont. retry }} k_{c}
$$

\section{Seqüência de Operações}

A semântica de uma operação composta por duas operações combinados por combinador ;; é a semântica da primeira operação usando a segunda operação como continuação normal.

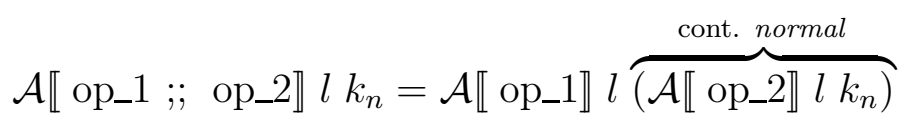

\section{Lista de Alternativas}

A semântica de uma operação composta por duas operações combinadas com o combinador || é a semântica da primeira operação usando a segunda operação como continuação de retry.

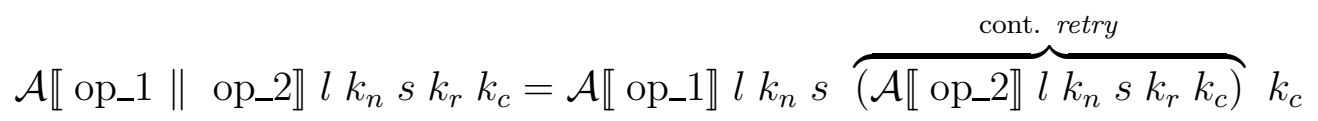

\section{Operação donothing}

A semântica da operação donothing é igual a continuação normal.

$$
\mathcal{A} \llbracket \text { donothing } \rrbracket l k_{n}=k_{n}
$$




\section{Operação abort}

A semântica da operação abort é igual a continuação retry.

$$
\mathcal{A} \llbracket \text { abort } \rrbracket l k_{n} s k_{r} k_{c}=k_{r}
$$

\section{Operação cut}

A semântica da operação cut é igual a continuação normal invocada com a continuação cut como continuação normal.

$$
\mathcal{A} \llbracket \mathbf{c u t} \rrbracket l k_{n} s k_{r} k_{c}=k_{n} s k_{c} k_{c}
$$

\section{B.4 Função $\mathcal{S}$}

A função de valoração semântica $\mathcal{S}$ define a semântica de um operador de mutação. A semântica de um operador de mutação consiste da semântica da operação usando a função addmut como continuação normal, a função print tanto como continuação retry quanto como continuação cut e uma lista vazia como resultado parcial. Deve-se observar que a função $\mathcal{S}$ toma como parâmetros a operação (possivelmente composta) que forma o operador de mutação, o nó inicial da árvore sintática do produto original e o estado inicial, os quais são obtidos pelo pré-processamento do produto original e do operador de mutação.

$$
\mathcal{S} \llbracket \mathrm{op} \rrbracket l s=\mathcal{A} \llbracket \mathrm{op} \rrbracket l(\text { addmut } l) s \text { print print }\langle\rangle
$$

A função addmut toma uma localização e retorna uma continuação normal que adiciona o mutante corrente (obtido percorrendo-se a árvore com raiz na localização $l$ ) ao resultado parcial e invocando a continuação retry para tentar uma alternativa.

$$
\text { addmut } l s k_{r} k_{c} m=k_{r}((\text { traverse } s l) \bullet m)
$$

onde traverse percorre, em ordem, a árvore e • é o operador de concatenação de listas.

A função print é a função identidade e simplesmente concluir a execução com os mutantes gerados até o momento.

$$
\text { print } m=m
$$




\section{B.5 Funções Auxiliares}

\section{Função $\mathcal{G}$}

A função de valoração semântica $\mathcal{G}$ possui a mesma assinatura da função $\mathcal{A}$.

$$
\mathcal{A}: \mathrm{Op} \rightarrow \mathrm{Loc} \rightarrow \mathrm{Kn} \rightarrow \mathrm{Kn}
$$

A função $\mathcal{G}$ verifica o valor associado à localização de contexto no estado corrente. Se esse valor for um elemento de Rec, então a função $\mathcal{G}$ aplica a operação a cada elemento da lista, usando a função de valoração semântica $\mathcal{R}$. Caso contrário, a função $\mathcal{G}$ tenta uma alternativa, invocando $k_{r}$

$$
\mathcal{G} \llbracket \mathrm{op} \rrbracket l k_{n} s k_{r} k_{c}=\text { isRec }(s l) \rightarrow \mathcal{R} \llbracket \mathrm{op} \rrbracket(e l 1(s l)) k_{n} s k_{r} k_{c}, k_{r}
$$

onde el $n d$ é o $n$-ésimo componente da lista $d$ Stoy (1977).

\section{Função $\mathcal{R}$}

A função de valoração $\mathcal{R}$ possui a mesma assinatura da função $\mathcal{A}$, exceto que uma lista de localizações é utilizada, em vez de apenas uma localização.

$$
\mathcal{R}: \mathrm{Op} \rightarrow \text { Loc }^{*} \rightarrow \mathrm{Kn} \rightarrow \text { State } \rightarrow \mathrm{Ka} \rightarrow \mathrm{Ka} \rightarrow \text { Ans } \rightarrow \text { Ans }
$$

Se a lista de localizações está vazia, a função $\mathcal{R}$ simplesmente invoca a continuação retry. Caso contrário, a função $\mathcal{R}$ aplica a função $\mathcal{A}$ ao primeiro elemento da lista, usando a invocação recursiva da função $\mathcal{R}$ aos demais elementos como continuação retry.

$$
\begin{aligned}
\mathcal{R} \llbracket \mathrm{op} \rrbracket r k_{n} s k_{r} k_{c} & =\text { isnull } r \rightarrow k_{r}, \\
& \mathcal{A} \llbracket^{*} \mathrm{op} \rrbracket(h d r) k_{n} s\left(\mathcal{R} \llbracket \mathrm{op} \rrbracket(t / r) k_{n} s k_{r} k_{c}\right) k_{c}
\end{aligned}
$$

\section{Função Unify}

O algoritmo de unificação empregado pela função unify é baseado no algoritmo da linguagem Prolog Bratko (1990); Nicholson e Foo (1989).

$$
\text { unify }: \mathrm{Loc} \rightarrow \mathrm{Loc} \rightarrow \mathrm{Kn} \rightarrow \text { State } \rightarrow \mathrm{Ka} \rightarrow \mathrm{Ka} \rightarrow \text { Mut }^{*} \rightarrow \text { Ans }
$$

A definição da função unify é apresentada na Figura B.2. Para esclarecer a semântica dessa função, a seguir são comentados as partes relevantes da definição. Após verificar 


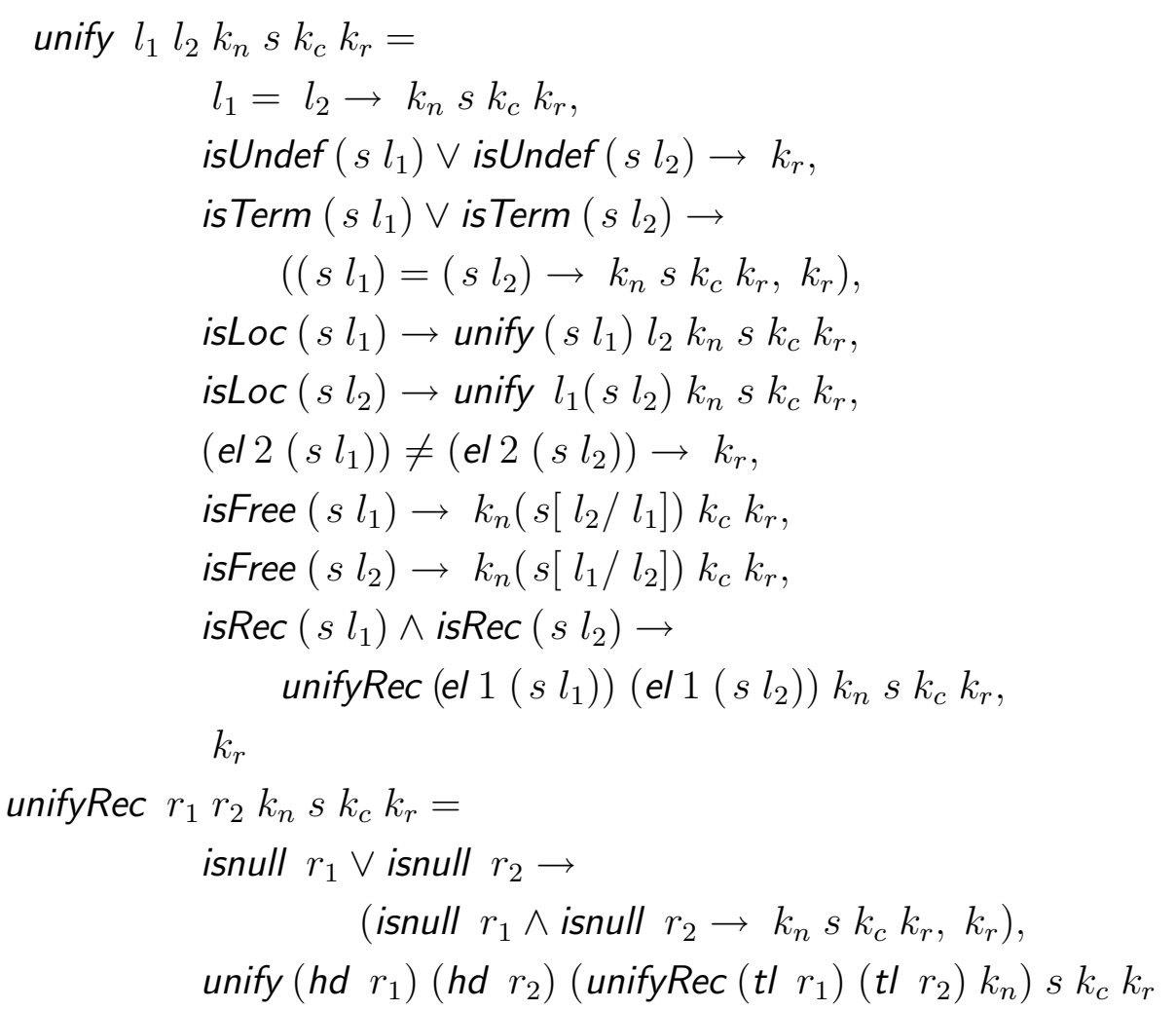

Figura B.2: Definição da Funções unify e unifyRec.

um série de condições, a função unify invoca ou continuação retry ou a continuação normal. Essas possibilidades serão referenciadas como retry e continue, respectivamente.

(B.1) Se as localizações a serem unificadas são as mesmas, então continue.

(B.2) Se uma das localizações estiver associada ao valor undef, então retry.

(B.3) Se uma das localizações estiver associada a um terminal, então continue se os valores forem iguais, e retry, caso contrário.

(B.4) Se $l_{1}$ está associada com outra localização, unifique esta outra localização com $l_{2}$.

(B.5) Análogo a (B.4), com respeito a $l_{2}$.

(B.6) Nesse ponto, pode-se garantir que os valores associados a $l_{1}$ e $l_{2}$ são elementos ou do domínio Free ou do domínio Rec. Em qualquer um dos casos, cada um desses valores é um par ordenado cujo segundo elemento pertence a NonTerm. Dessa forma, se os tipos de ambos os valores não forem o mesmo, então retry.

(B.7) Se $l_{1}$ é igual a free, então continue em um novo estado no qual $l_{1}$ é associado com $l_{2}$. 
(B.8) Análogo a (B.7), com respeito a $l_{2}$.

(B.9) Se ambos os valores pertencem a Rec, invoca-se a função auxiliar unifyRec com as respectivas listas de localizações.

(B.10) Se nenhum dos casos acima se aplicam, então retry.

A função unifyRec tentará unificar duas listas de localizações, aplicando unify aos respectivos pares de elementos.

(B.11) Se uma das listas é vazia, então, continue se ambas são vazias. Caso contrário, retry.

(B.12) Caso contrário, a função unify é invocada para os respectivos primeiros elementos de cada uma das listas, usando como continuação normal a aplicação recursiva de unifyRec dos elementos restantes. 
Apêndice

\section{Descrição $\mathcal{M} u \mathcal{D} e \mathcal{L}$ dos Operadores de Mutação para RPCs}
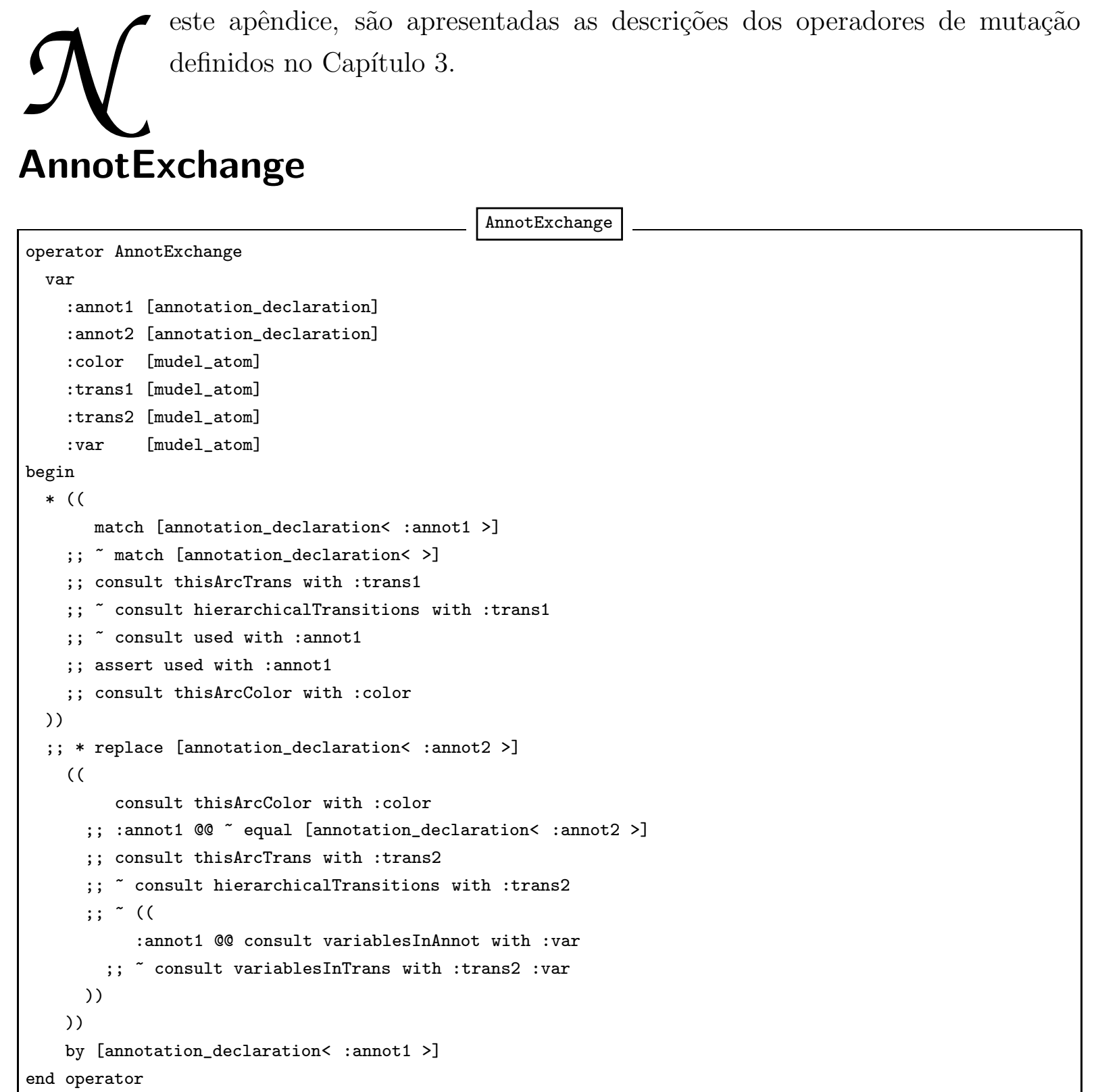


\section{AnnotSmall}

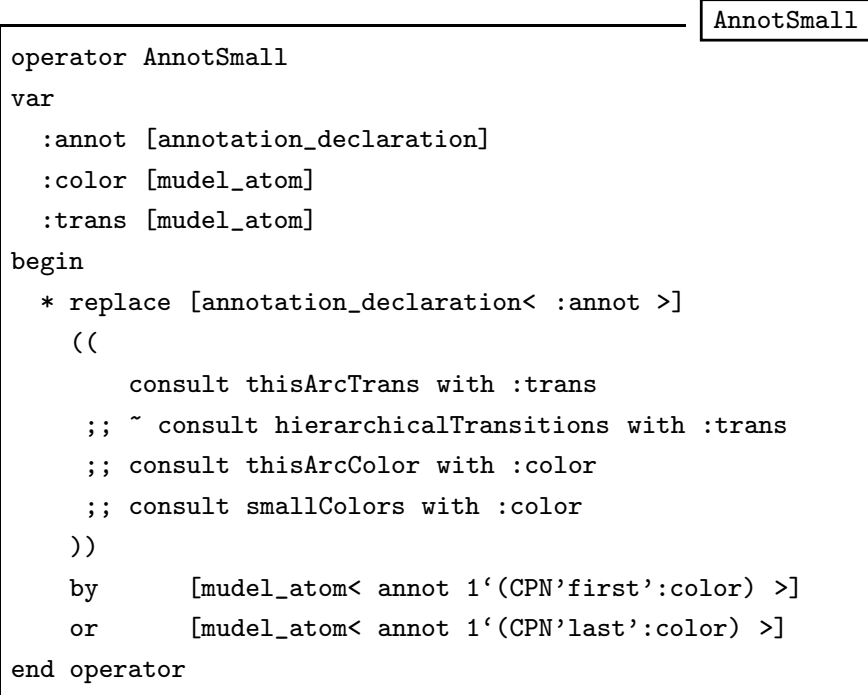

\section{ConstExchange}

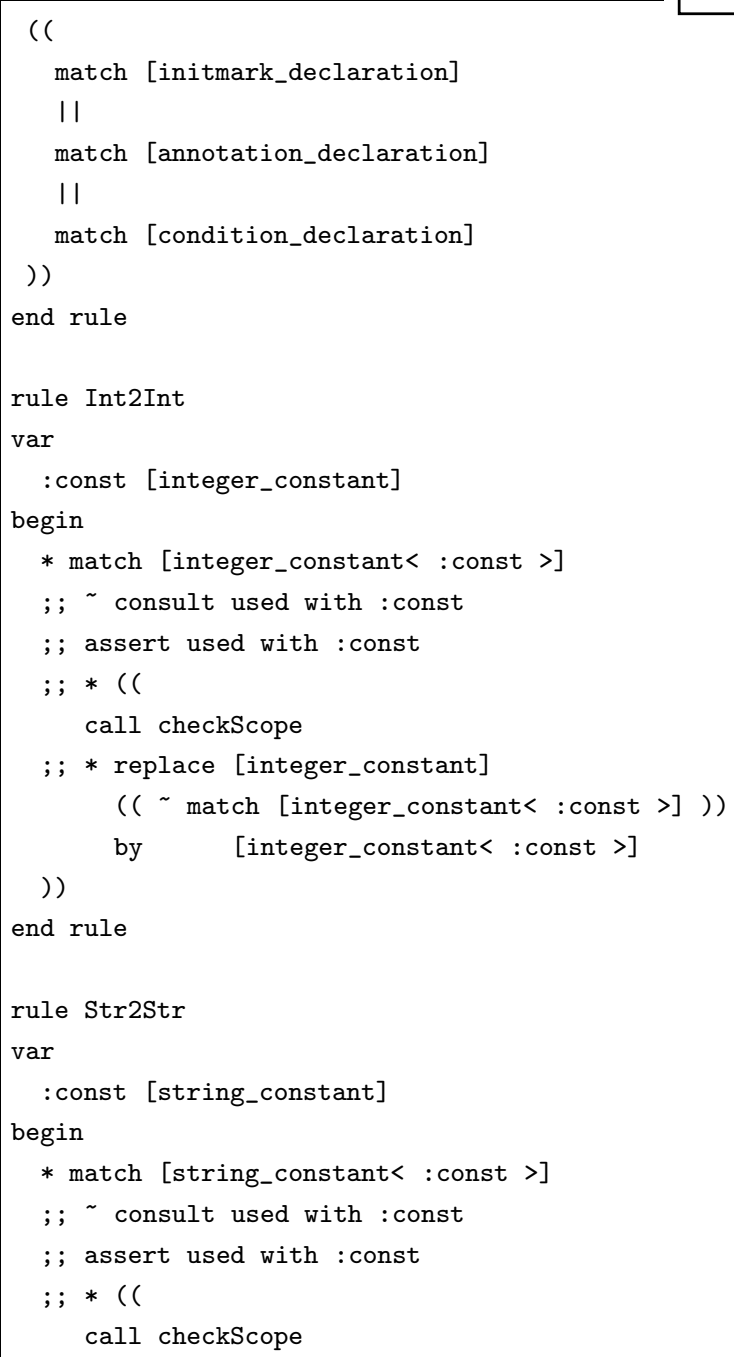




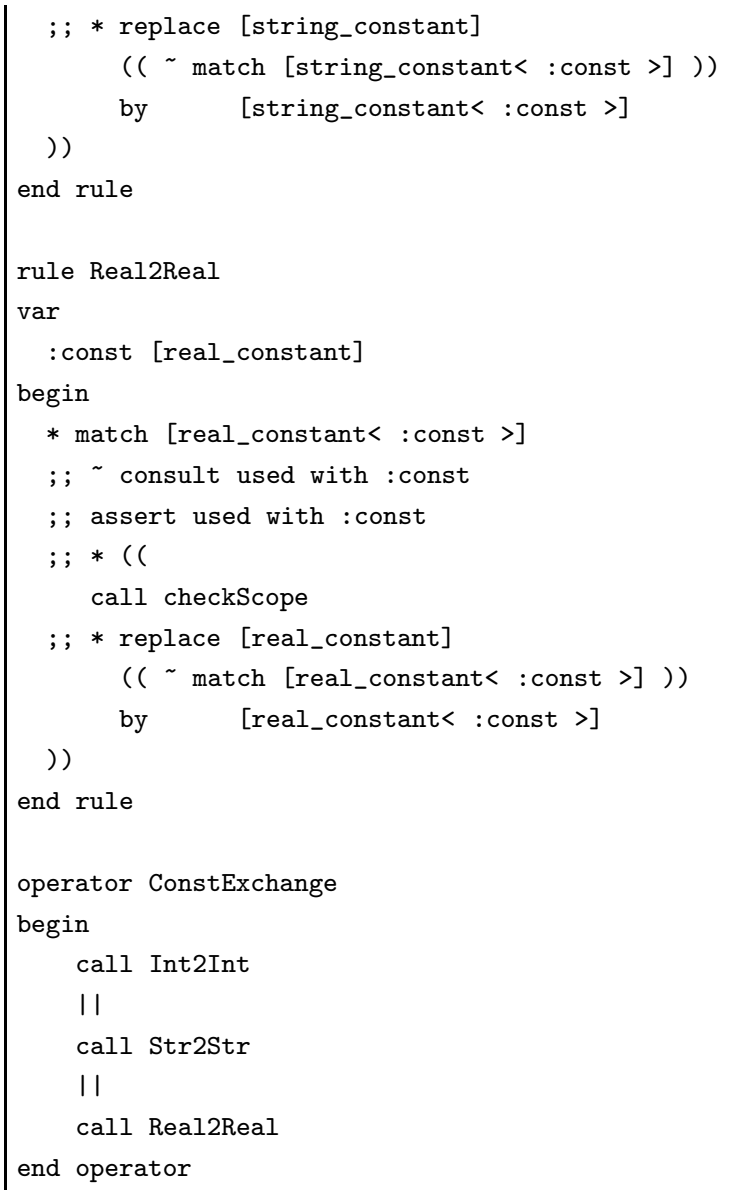

\section{Guardlns}

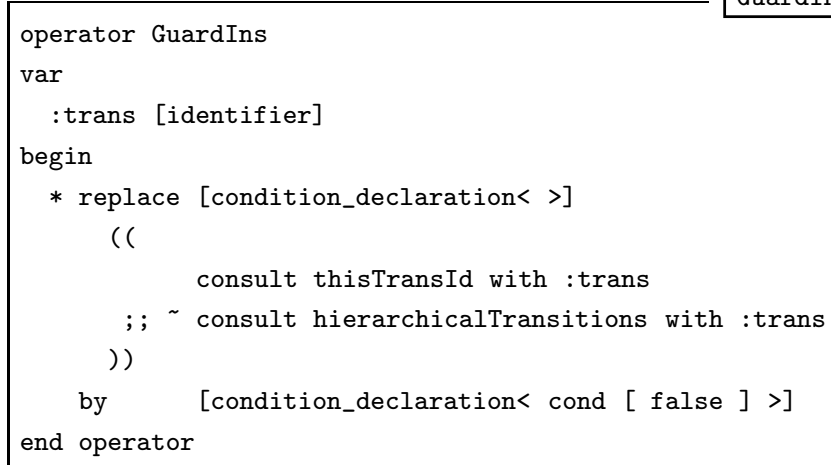

\section{Guardlnv}

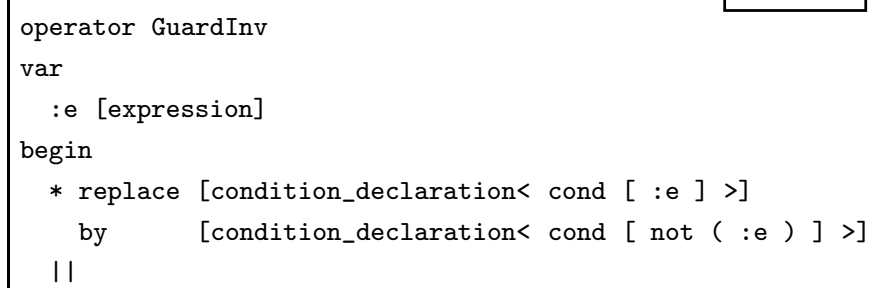


* replace [condition_declaration< cond :e >]

( ( :e @Q match [expression< [:[expression] ] >] ))

by [condition_declaration< cond not $(: \mathrm{e})>$ ]

end operator

\section{GuardExchange}

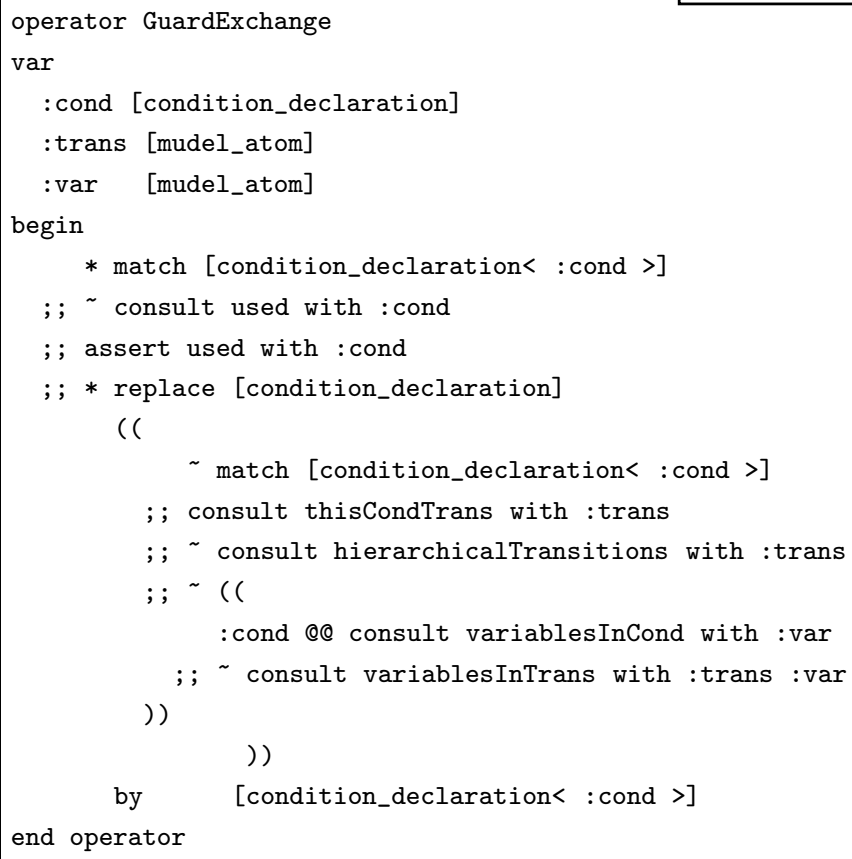

\section{InitMarkDel}

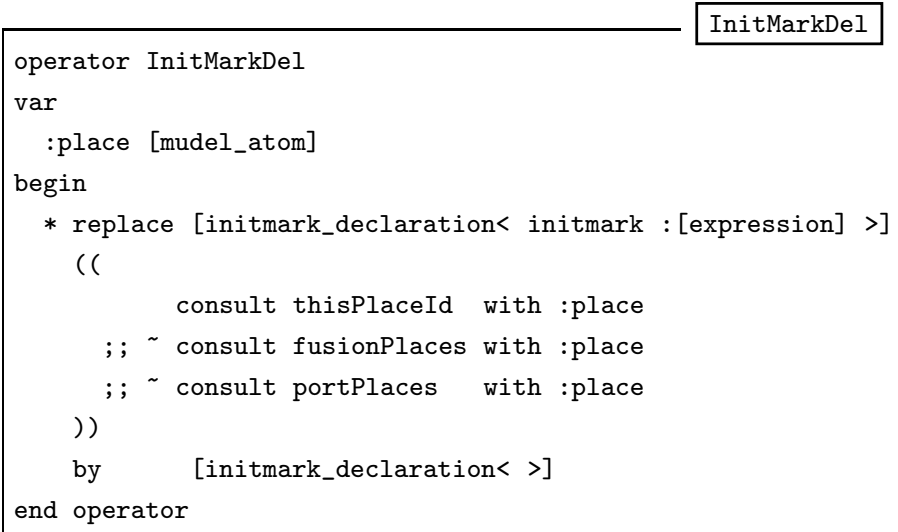

InitMarkDel

\section{InitMarkExchange}


:init2 [initmark_declaration]

:color [mudel_atom]

:place [mudel_atom]

begin

* replace [initmark_declaration< :init1 >]

( (

consult thisPlaceColor with :color

; ; assert used in [place_declaration]

))

by [initmark_declaration< : init2 >]

; ;

* replace [initmark_declaration< :init2 >]

$(($

consult thisPlaceColor with :color

;; consult thisPlaceId with :place

;; consult fusionPlaces with :place

;; consult portPlaces with :place

;; consult used

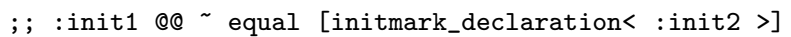

))

by [initmark_declaration< : init1 >]

end operator

\section{InitMarkIns}

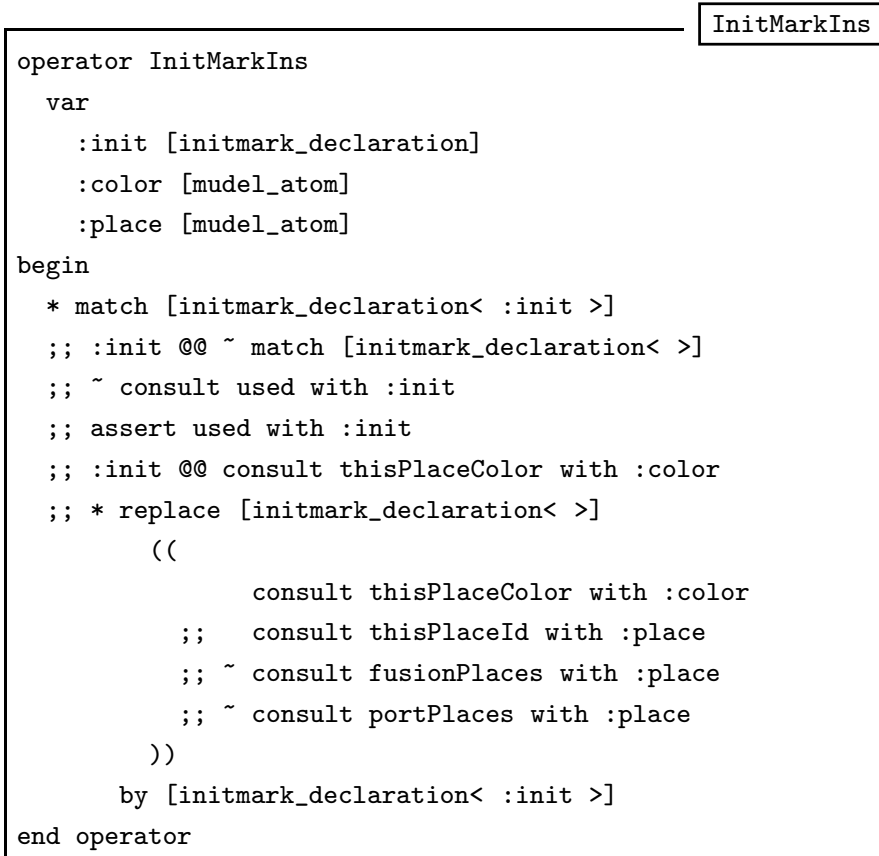

\section{InputArcDel}

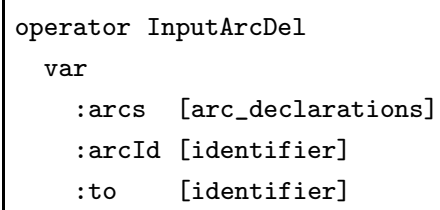




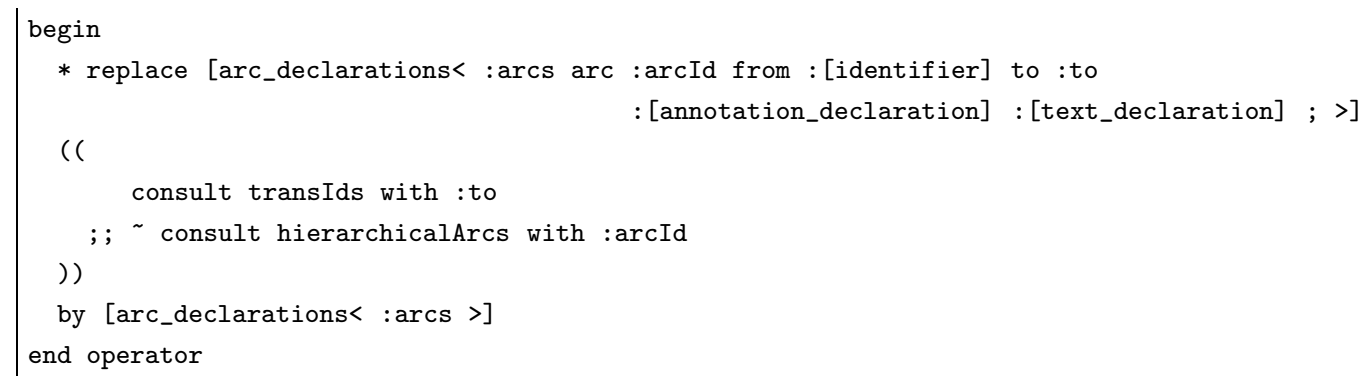

\section{InputArcExchange}

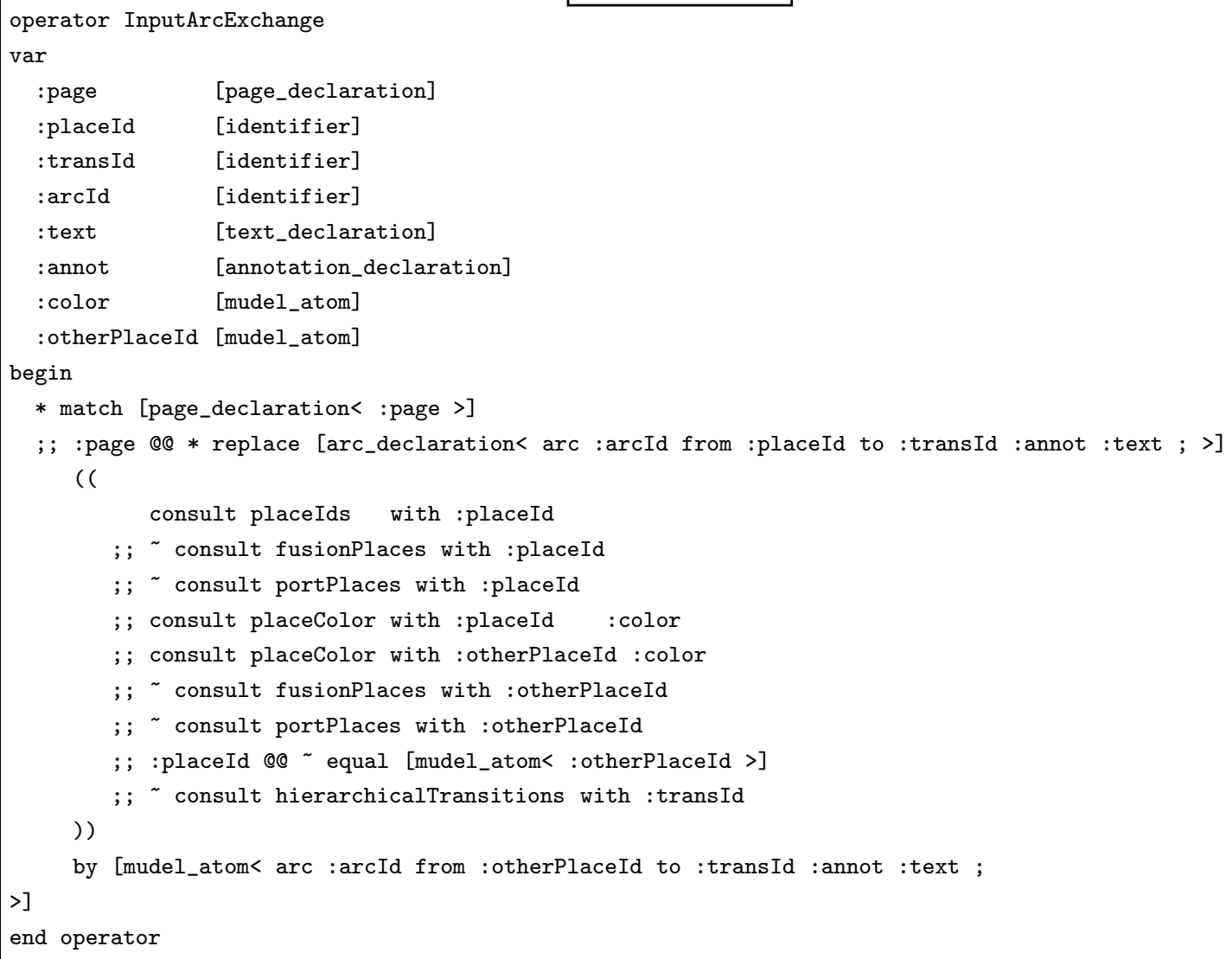

\section{InputArclns}

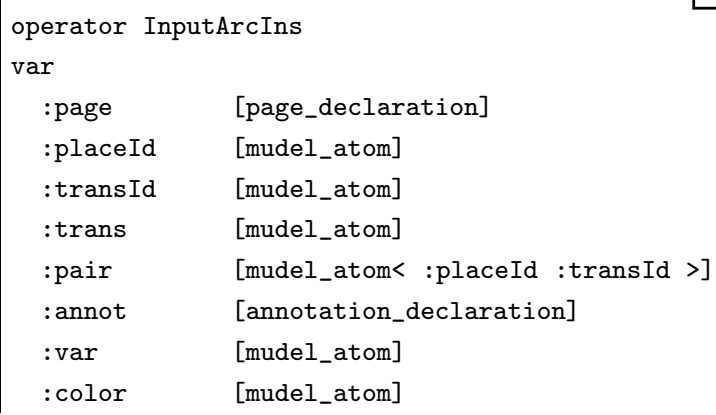




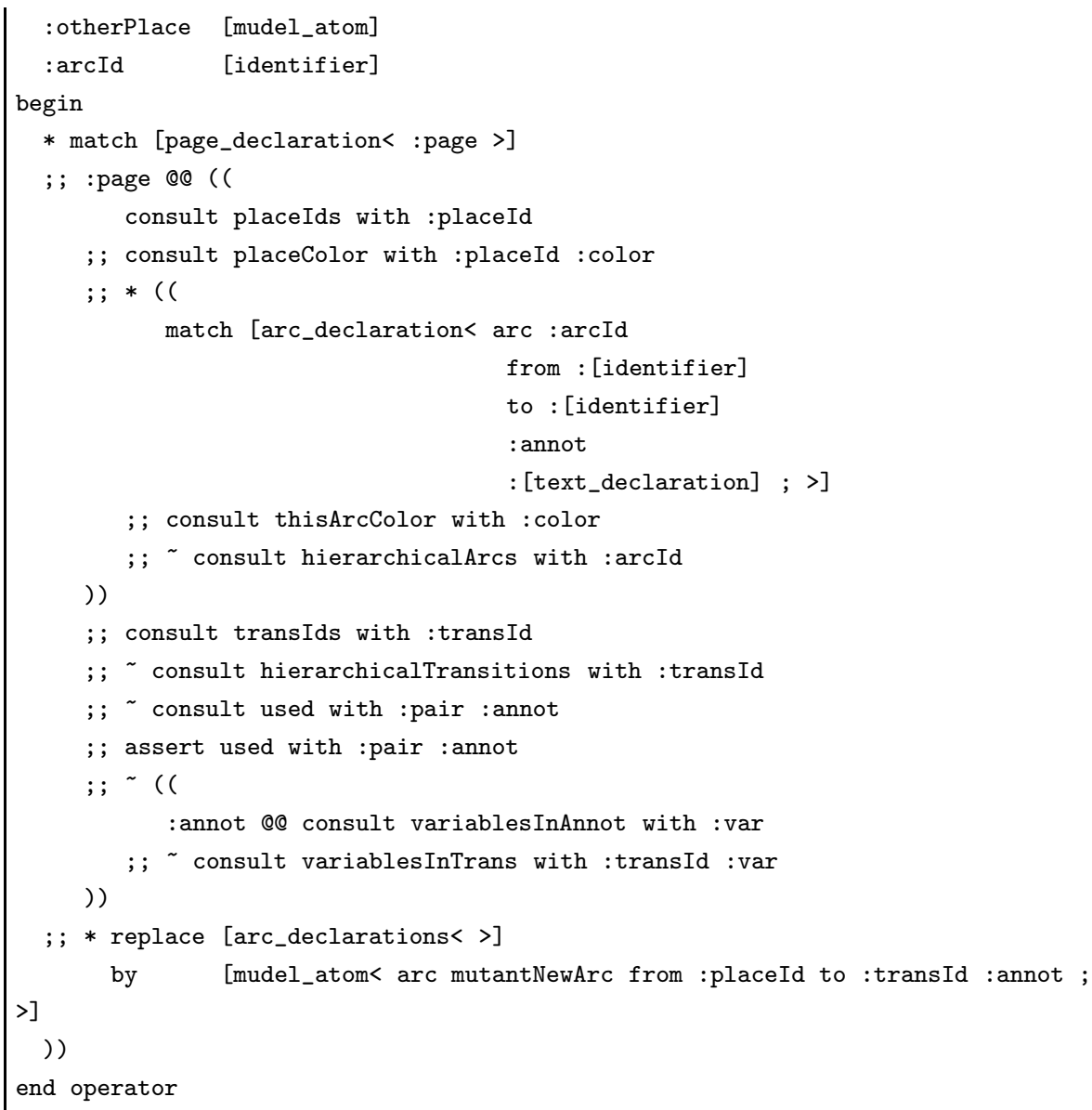

\section{InputArclnversion}

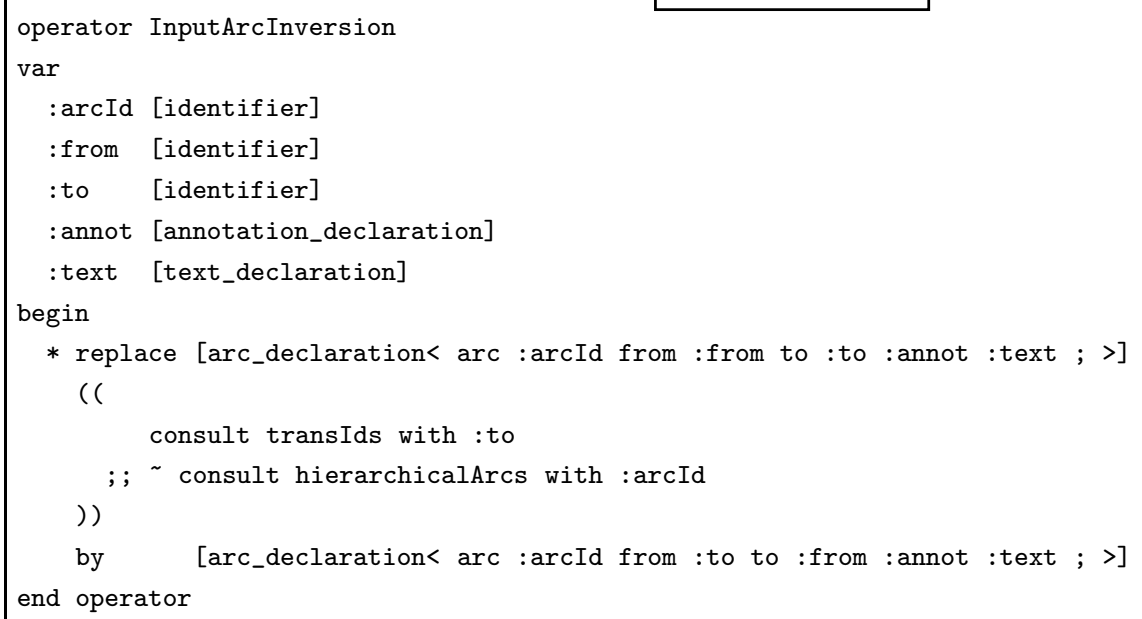

\section{InputArcShift}




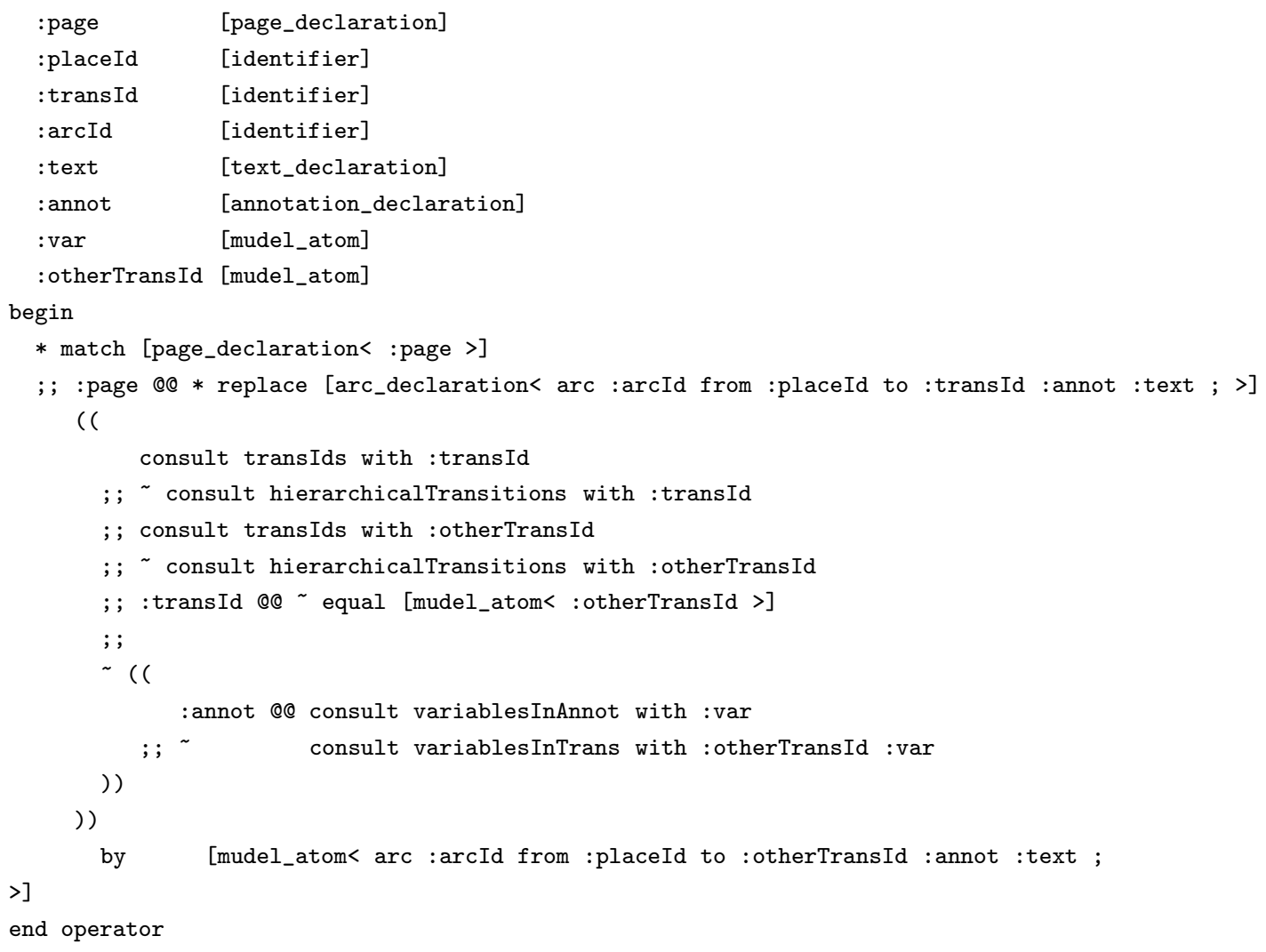

\section{OpArithArith}

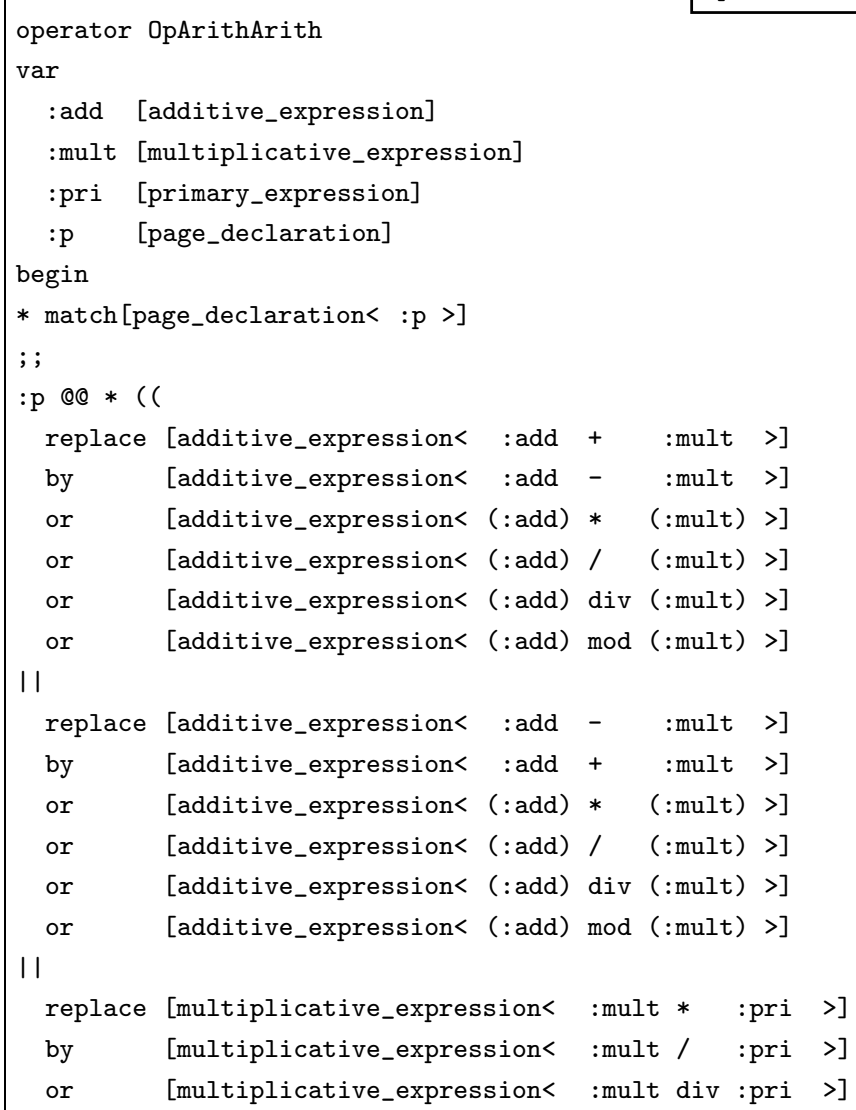




\begin{tabular}{|c|c|c|c|c|c|}
\hline or & [multiplicative_expression< & :mult & $\bmod$ & :pri & $>$ ] \\
\hline or & [multiplicative_expression< & $(:$ mult & + & :pri) & $>$ ] \\
\hline or & [multiplicative_expression< & $(:$ mult & - & :pri) & $>$ ] \\
\hline \multicolumn{6}{|c|}{11} \\
\hline replace & [multiplicative_expression< & :mult & I & :pri & $>$ ] \\
\hline by & [multiplicative_expression< & :mult & * & :pri & $>$ ] \\
\hline or & [multiplicative_expression< & :mult & div & :pri & $>$ ] \\
\hline or & [multiplicative_expression< & :mult & $\bmod$ & :pri & $>$ ] \\
\hline or & [multiplicative_expression< & (:mult & + & :pri) & $>]$ \\
\hline or & [multiplicative_expression< & $(: \mathrm{mult}$ & - & :pri) & $>$ ] \\
\hline \multicolumn{6}{|l|}{11} \\
\hline replace & [multiplicative_expression< & :mult & div & :pri & $>$ ] \\
\hline by & [multiplicative_expression< & :mult & I & :pri & $>$ ] \\
\hline or & [multiplicative_expression< & :mult & * & :pri & $>$ ] \\
\hline or & [multiplicative_expression< & :mult & $\bmod$ & :pri & $>$ ] \\
\hline or & [multiplicative_expression< & $(:$ mult & + & :pri) & $>]$ \\
\hline or & [multiplicative_expression< & $(:$ mult & - & :pri) & $>$ ] \\
\hline \multicolumn{6}{|c|}{ II } \\
\hline replace & [multiplicative_expression< & :mult & $\bmod$ & :pri & $>$ ] \\
\hline by & [multiplicative_expression< & :mult & I & :pri & $>$ ] \\
\hline or & [multiplicative_expression< & :mult & $\operatorname{div}$ & :pri & $>$ ] \\
\hline or & [multiplicative_expression< & :mult & $*$ & :pri & $>$ ] \\
\hline or & [multiplicative_expression< & (:mult & + & :pri) & $>$ ] \\
\hline or & [multiplicative_expression< & $(:$ mult & - & :pri) & $>$ ] \\
\hline
\end{tabular}

\section{OplfInv}

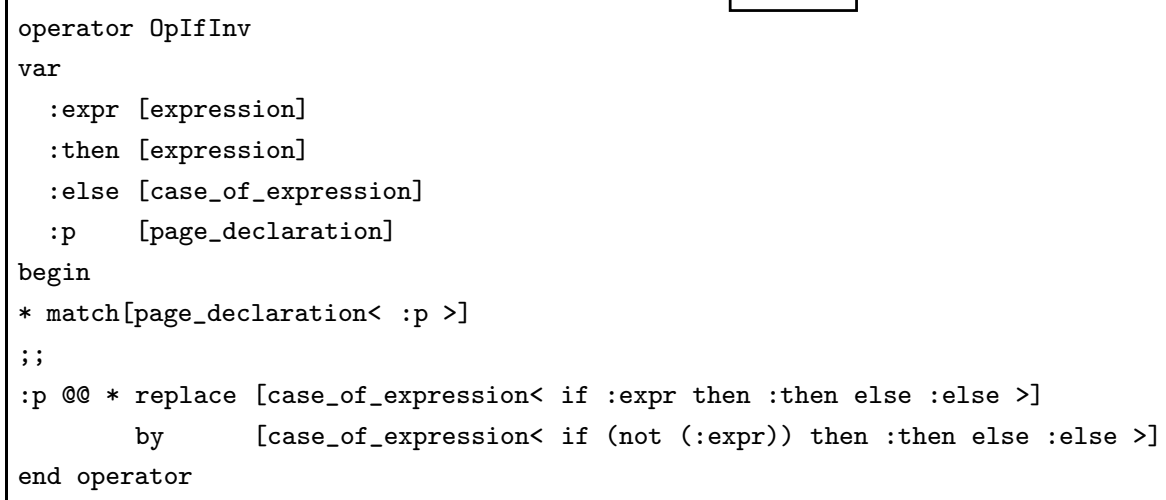

\section{OpLogLog}

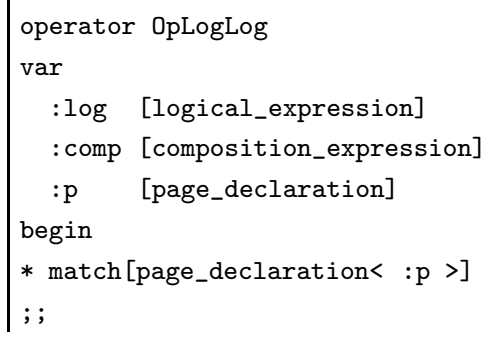




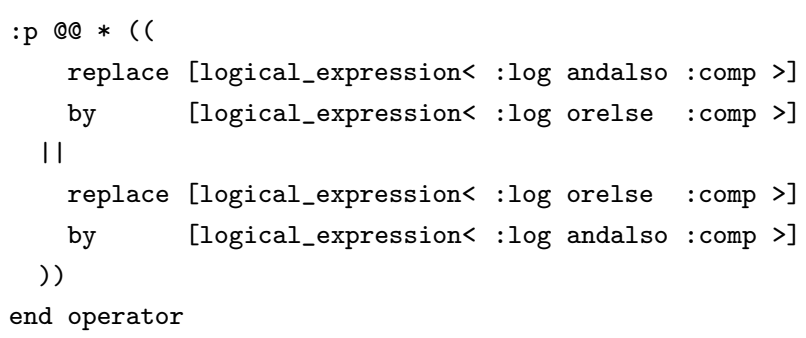

\section{OpMultArithArith}

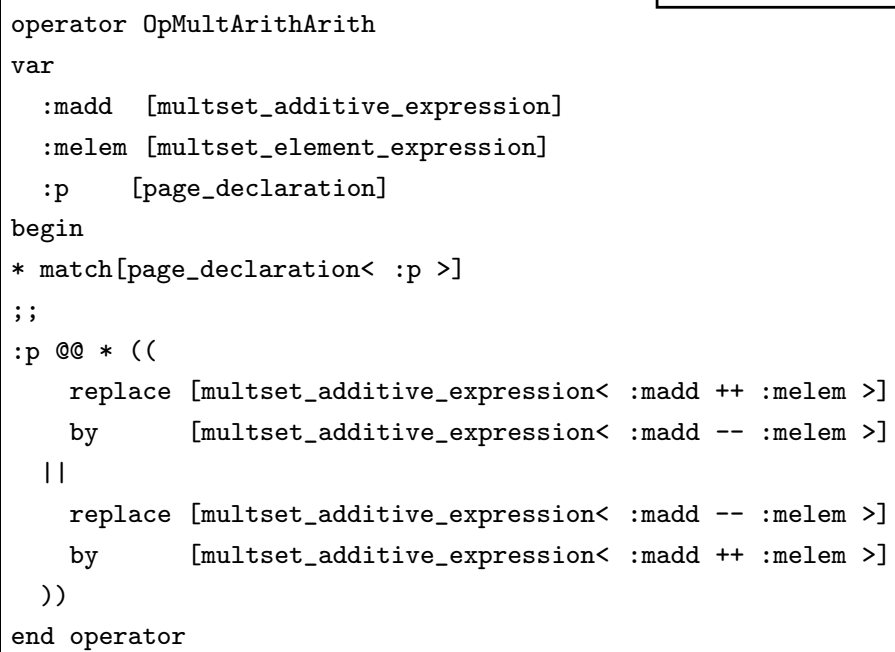

\section{OpMultRelRel}

operator OpMultRelRel

var

:mrel [multset_relational_expression]

:madd [multset_additive_expression]

$: p \quad$ [page_declaration]

begin

* match[page_declaration< :p >]

; ;

$: \mathrm{p}$ @Q * (

replace [multset_relational_expression $<$ :mrel == :madd $>$ ]

by [multset_relational_expression $<$ :mrel $\longleftrightarrow\langle>$ :madd $>$ ]

or [multset_relational_expression< :mrel $\gg$ :madd $>$ ]

or [multset_relational_expression $<$ :mrel $<<\quad$ :madd $>$ ]

or [multset_relational_expression< :mrel $\gg=$ :madd $>$ ]

or [multset_relational_expression $<$ :mrel $\ll=$ :madd $>$ ] II

replace [multset_relational_expression $<$ :mrel $\langle><>$ :madd $>$ ]

by [multset_relational_expression $<$ :mrel $==$ :madd $>$ ]

or [multset_relational_expression< :mrel $\gg$ :madd $>$ ]

or [multset_relational_expression $<$ :mrel $<$ :madd $>$ ]

or [multset_relational_expression $<$ :mrel $>>=$ :madd $>$ ]

or [multset_relational_expression $<$ :mrel $\ll<$ :madd $>$ ] 
11

replace [multset_relational_expression $\langle$ :mrel $>>$ :madd $\rangle$ ]

by [multset_relational_expression< :mrel $\langle>\langle>$ :madd $>$ ]

or [multset_relational_expression $<$ :mrel $==$ :madd $>$ ]

or [multset_relational_expression $<$ mrel $<<$ :madd $>$ ]

or [multset_relational_expression $\langle$ :mrel $>>=$ :madd $>$ ]

or [multset_relational_expression $<$ :mrel $<<=$ :madd $>$ ]

II

replace [multset_relational_expression $<$ :mrel $<$ :madd $>$ ]

by [multset_relational_expression $<$ :mrel $\langle><>$ :madd $>$ ]

or [multset_relational_expression $<$ mrel $\gg$ :madd $>$ ]

or [multset_relational_expression $<$ :mrel $==$ :madd $>$ ]

or [multset_relational_expression $\langle$ :mrel $\rangle\rangle=$ :madd $\rangle]$

or [multset_relational_expression $<$ :mrel $\ll<=$ :madd $>]$

11

replace [multset_relational_expression $\langle$ :mrel $\rangle\rangle=$ :madd $\rangle$ ]

by [multset_relational_expression $<$ :mrel $\langle>\langle>$ :madd $>$ ]

or [multset_relational_expression $\langle$ :mrel $\gg$ :madd $\rangle]$

or $\quad$ [multset_relational_expression $<$ :mrel $<$ :madd $>$ ]

or [multset_relational_expression $<$ :mrel $==$ :madd $>$ ]

or [multset_relational_expression $<$ mrel $<<=$ :madd $>$ ]

II

replace [multset_relational_expression $<$ :mrel $<<=$ :madd $>$ ]

by [multset_relational_expression $<$ :mrel $\langle><>$ :madd $>$ ]

or [multset_relational_expression $<$ :mrel $\gg$ :madd $>$ ]

or [multset_relational_expression< :mrel $\ll$ :madd $>$ ]

or [multset_relational_expression< :mrel $>>=$ :madd $>$ ]

or [multset_relational_expression $<$ :mrel $==$ :madd $>$ ]

))

end operator

\section{OpReIRel}

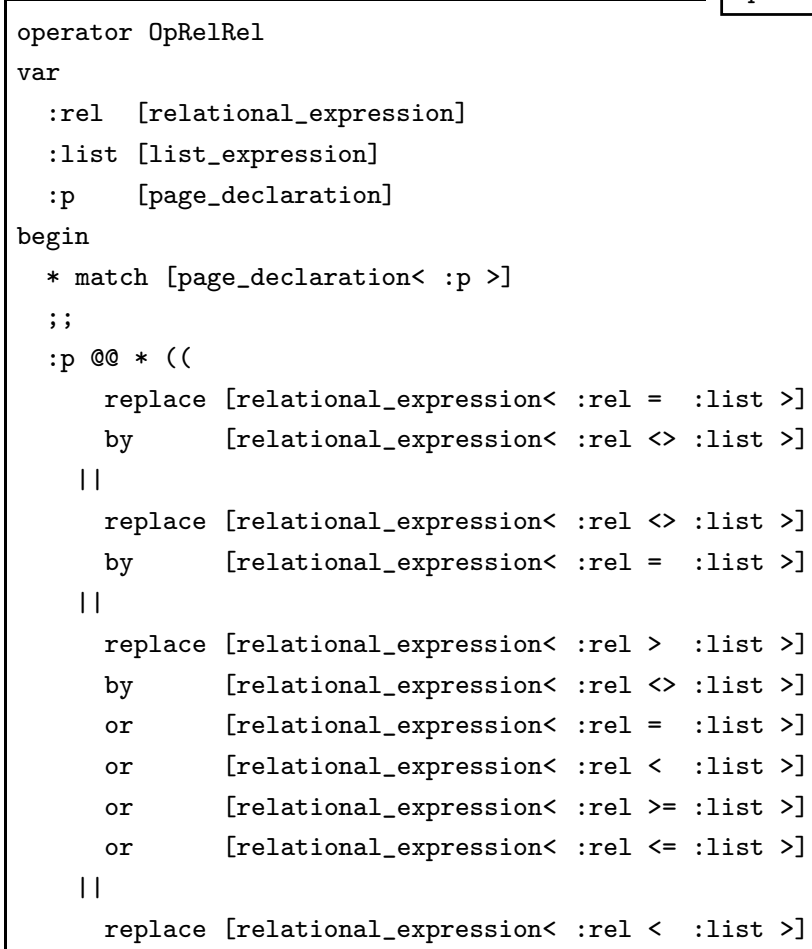




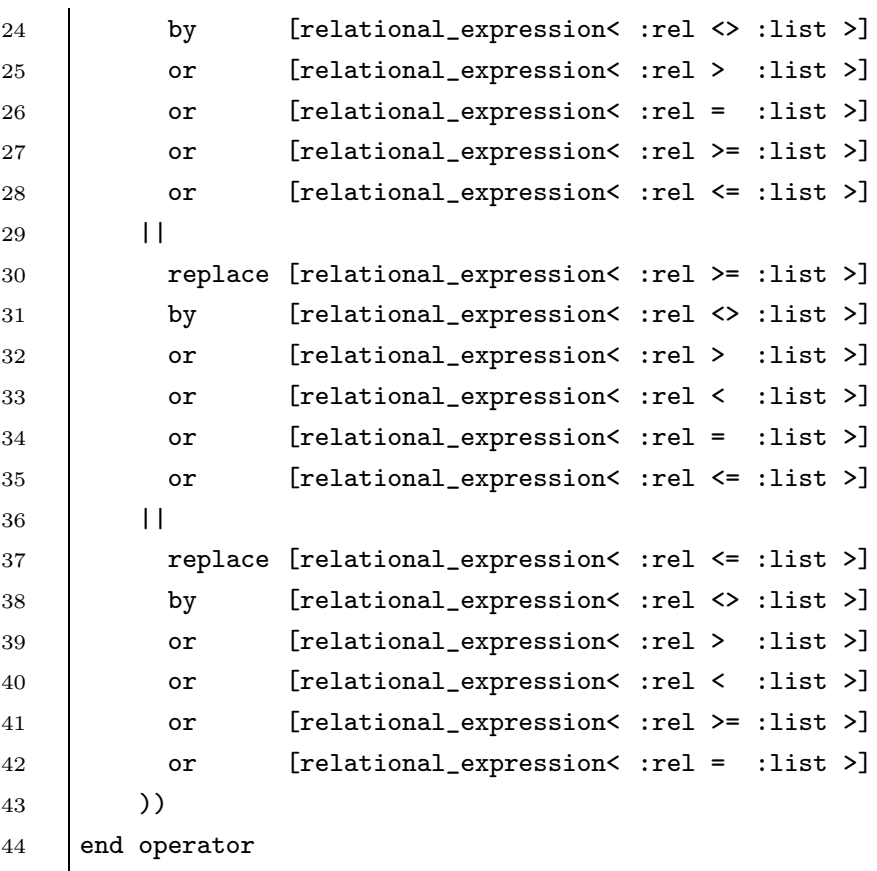

\section{OutputArcDel}

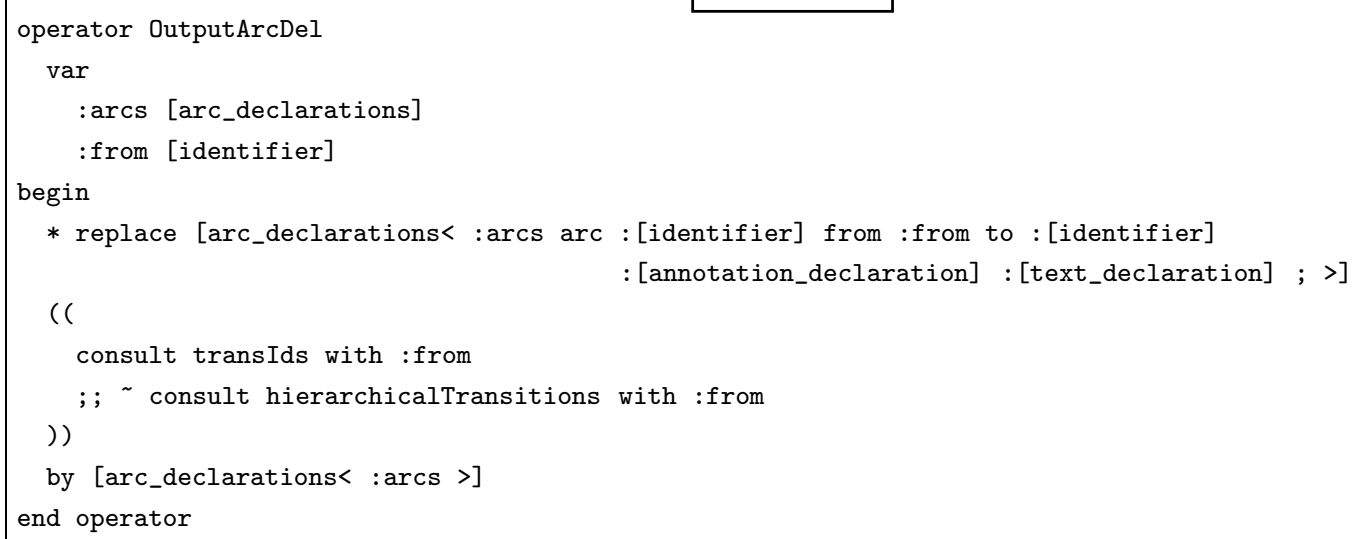

\section{OutputArcExchange}

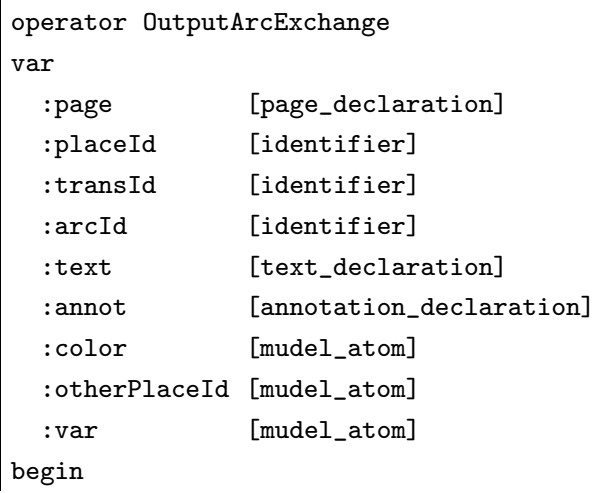


* match [page_declaration< :page >]

; ; :page @@ * replace [arc_declaration< arc :arcId from :transId to :placeId :annot :text ; >] $(($

consult placeIds with :placeId

;; consult fusionPlaces with :placeId

;; consult portPlaces with :placeId

;; consult placeColor with :placeId :color

;; consult placeColor with :otherPlaceId :color

;; consult fusionPlaces with :otherPlaceId

;; consult portPlaces with :otherPlaceId

; ; :placeId @Q equal [mudel_atom< :otherPlaceId >]

;; consult hierarchicalTransitions with :transId

))

by [mudel_atom< arc :arcId from :transId to :otherPlaceId :annot :text ; $>]$

end operator

\section{OutputArclns}

OutputArcIns

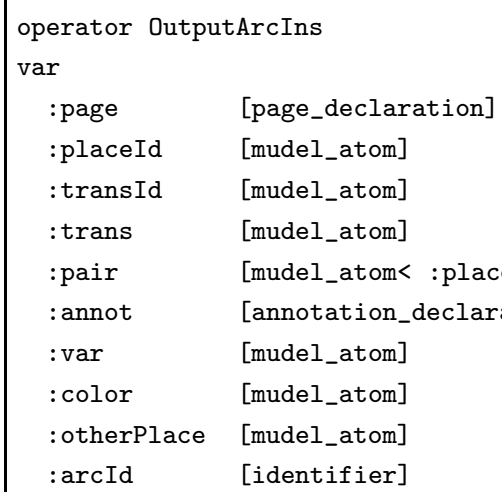




\section{OutputArclnversion}

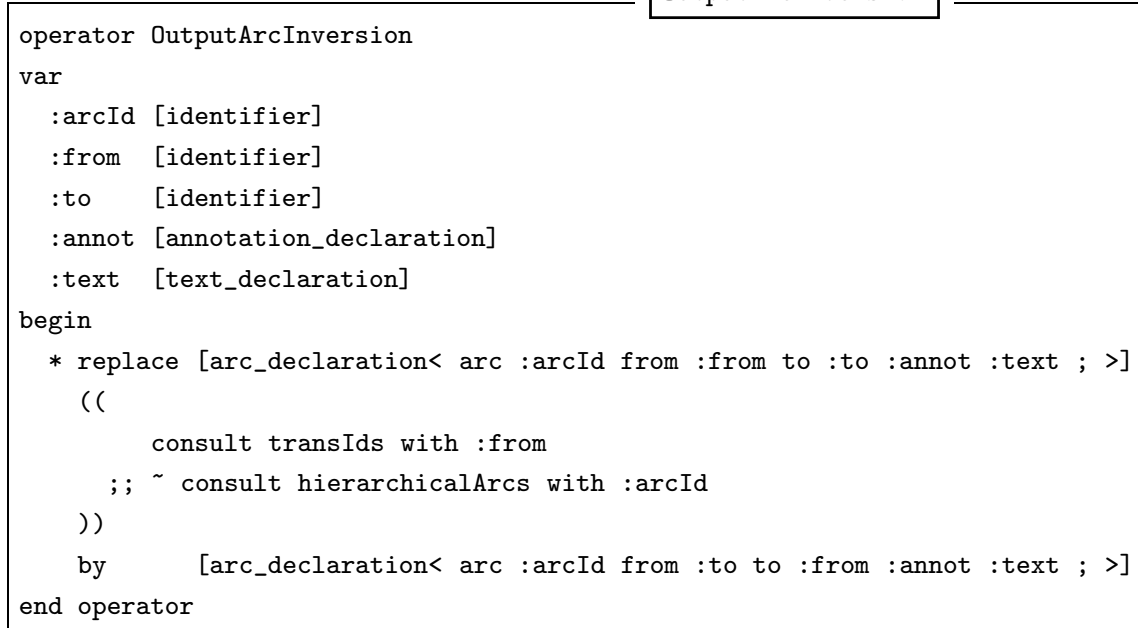

\section{OutputArcShift}

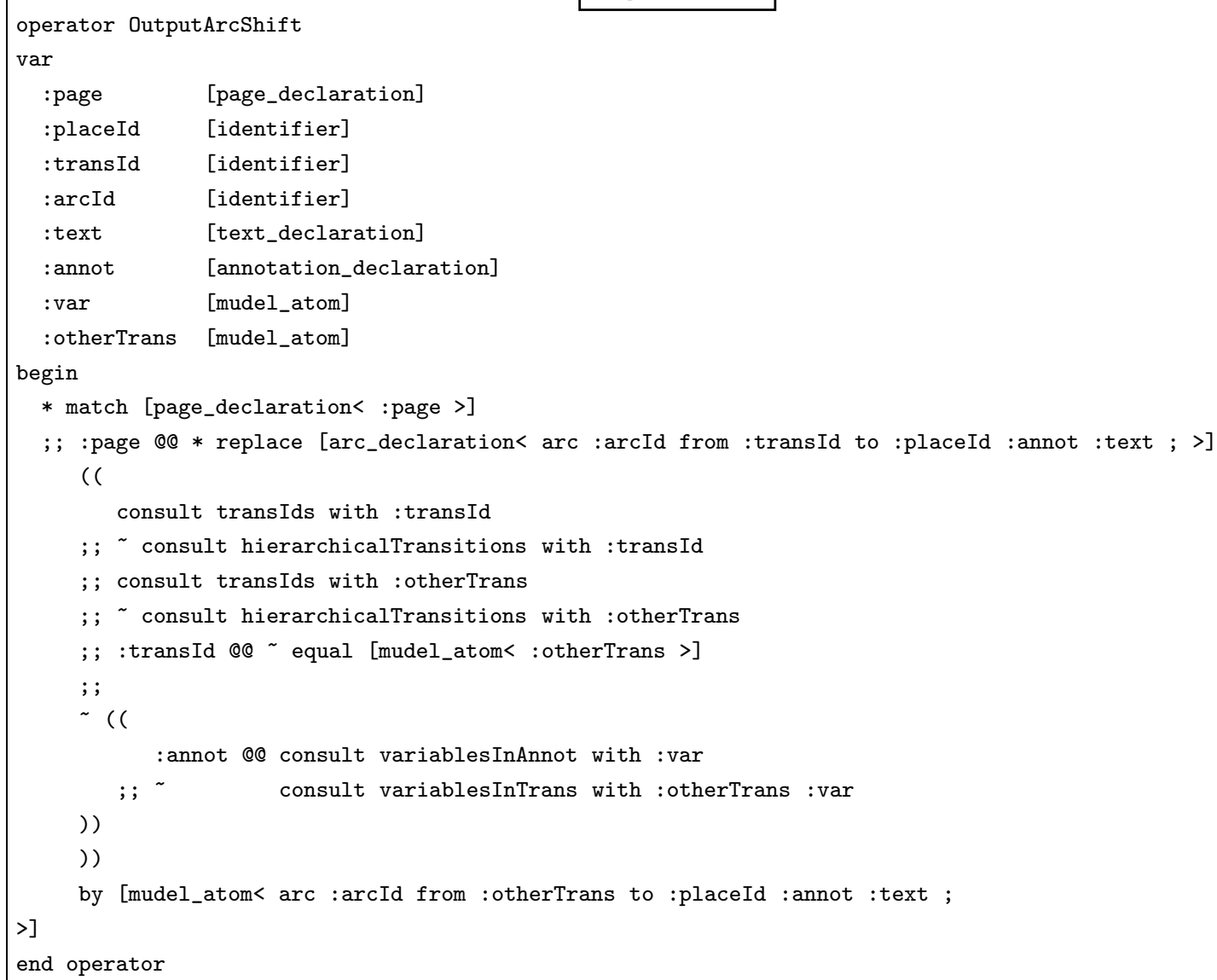




\section{VarSmall}

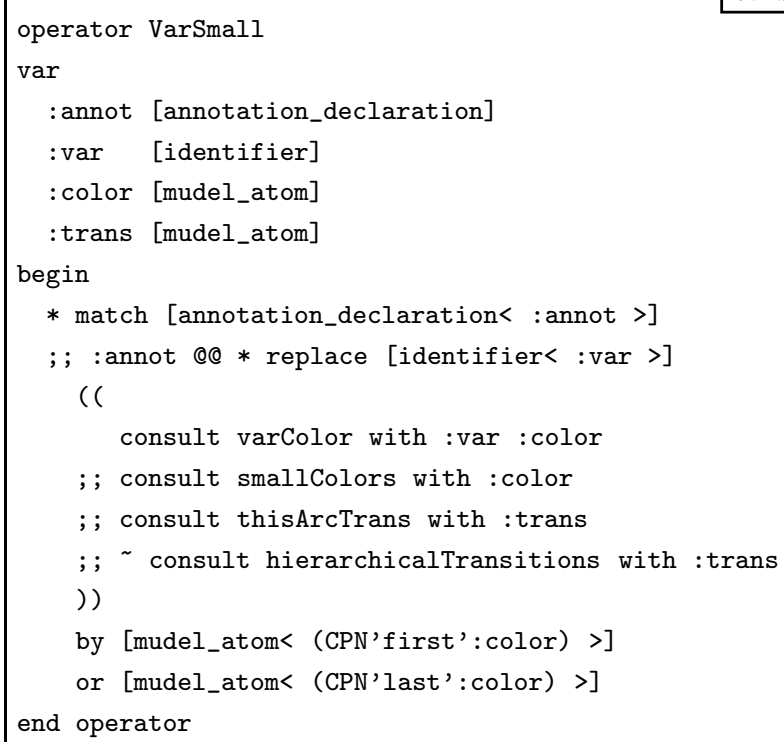

\section{VarExchange}

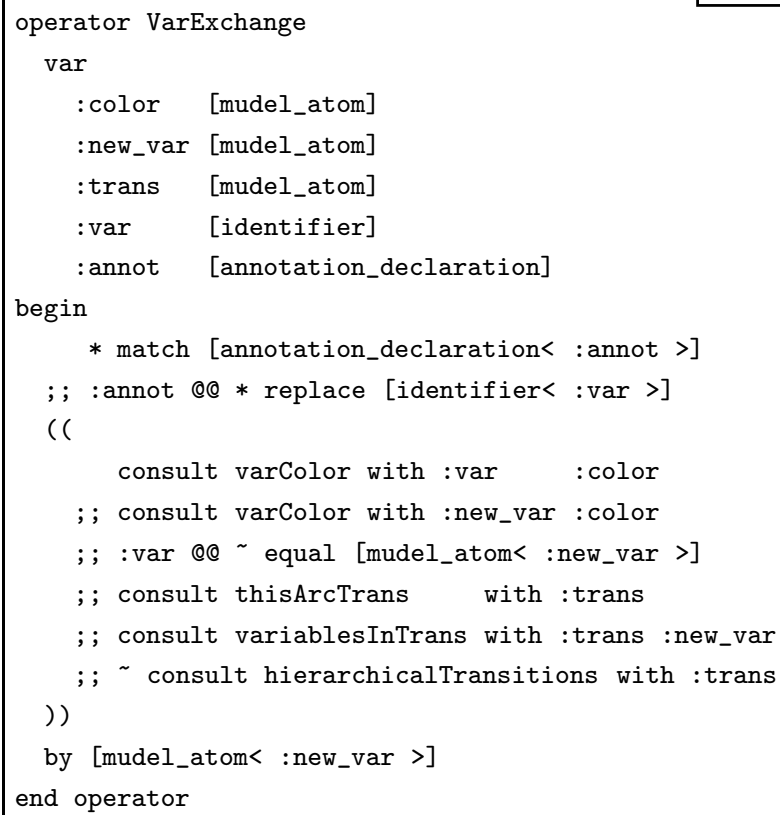




\section{D.1 Considerações Iniciais}

ma questão crucial na atividade de teste é o estabelecimento de uma estra-
tégia de teste para ser aplicada durante o desenvolvimento e a manutenção
que leve em consideração a relação custo/benefício na revelação de erros críticos. No contexto do teste de software em geral, uma forma de quantificar a qualidade de um conjunto de casos de teste (e, dessa forma, a atividade de teste) são as medidas de cobertura baseadas em um critério de teste. Assim, de forma complementar a aplicação da AM, apresentada no Capítulo 3, e as abordagens atuais de validação de RPCs, propõe-se uma família de critérios de cobertura para a validação de especificações baseadas em RPCs. Esses critérios fornecem mecanismos tanto para avaliar seqüências de teste (por exemplo, seqüências geradas por simulação) como para guiar a geração de seqüências de teste adequadas por construção. Esses critérios fornecem uma medida de cobertura para quantificar a atividade de teste e, dessa forma, contribuir para melhoria da qualidade dessa atividade no contexto de especificações. A aplicação desses critérios de cobertura é feita usando uma representação comportamental de RPCs conhecida como GO Jensen (1997a). O GO mostra os possíveis estados globais e os caminhos - seqüências de configurações - que podem ocorrer em uma RPC.

\section{D.2 A Família de Critérios}

A eficácia das atividades de teste e validação depende principalmente da qualidade do conjunto de casos de teste utilizado. Como mencionado anteriormente, desse ponto de vista, existem duas importantes questões:

- Como selecionar casos de teste?

- Como garantir que a especificação ou o programa foi suficientemente testado? 
A última questão é geralmente abordada levando em consideração medidas de cobertura baseadas em critérios de teste.

Um critério de teste permite a sistematização da atividade de teste, fornecendo mecanismos tanto para selecionar um conjunto de casos de teste quanto para medir a adequação de um dado conjunto. Alguns pesquisadores têm explorado a definição de critérios de teste para validar especificações, mapeando conceitos de critérios definidos em nível de programa para o nível de especificação Fabbri et al. (1994c, 1995b); Probert e Guo (1991); Souza et al. (2001, 2000c); Ural e Yang (1991). Fabbri et al. (1994c, 1995b) e Probert e Guo (1991) exploraram os conceitos de AM, ao passo que Ural e Yang (1991) exploraram o uso de conceitos de fluxo de dados. Souza et al. (2001, 2000c) propõem critérios de cobertura para Statecharts e Estelle. Sugeta (2004) propõem critérios de cobertura para SDL. Na mesma linha, propõe-se a CPNCCF para a validação de especificações baseadas em RPCs. Esses critérios enfatizam as características intrínsecas da técnica RPC. CPNCCF é baseada em critérios de fluxo de controle Beizer (1990); Rapps e Weyuker (1985) e fornecem mecanismos para avaliar se uma especificação satisfaz os requisitos do sistema. Por exemplo, usando-se esses critérios, pode-se analisar as seguintes questões:

- Todos os possíveis interleavings de marcações foram alcançados?

- Todos os possíveis paralelismos entre marcações foram ativados?

- Todas as dependências (e independências) causais foram exploradas?

A seguir, definem-se alguns conceitos que serão usados para definir os critérios da CPNCCF:

Caminho Um caminho é uma seqüência finita de marcações $P=\left\langle m_{0}, \ldots, m_{k}\right\rangle$, com $k>1$, tal que a primeira marcação é a marcação inicial $m_{0}$, e para cada par de marcações $\left(m_{i}, m_{i+1}\right)$, com $0 \leq i<k$

Caminho Simples Um caminho simples é um caminho $P=\left\langle m_{0}, \ldots, m_{k}\right\rangle$, tal que todas as marcações são distintas, com a possível exceção da primeira e da última. Isto é, $\forall j \forall i, 0<i \leq k \wedge 0 \leq j<k$, tem-se que $i \neq j \Longrightarrow m_{i} \neq m_{j}$.

Caminho Livre de Laço Um caminho livre de laço é um caminho $P=\left\langle m_{0}, \ldots, m_{k}\right\rangle$, tal que todas as marcações são distintas. Isto é, $\forall j \forall i, 0 \leq i<k \wedge 0 \leq j<k$ tal que $i \neq j \Longrightarrow m_{i} \neq m_{j}$.

A cobertura mínima desejável para sistemas especificados com RPC é o exercício de todas as marcações e todas as transições. Dessa forma, são definidos dois critérios de cobertura:

Definição 5. O critério todas-marcações requer que todas as marcações de uma RPC seja alcançada ao menos uma vez por uma seqüência de teste. 
Deve-se observar que, para o caso de RPCs não-limitadas, esse critério é impraticável, uma vez que podem existir infinitas marcações.

Definição 6. O critério todas-transições requer que todas as transições de uma RPCs sejam disparadas ao menos uma vez por uma seqüência de teste, sem se levar em consideração a ligação.

Adicionalmente, como uma mesma transição pode ser disparada com distintas atribuições (ou seja, com distintas ligações), o próximo critério é definido para considerar essa situação.

Definição 7. O critério todas-ligações requer que todas as ligações sejam disparadas ao menos uma vez por uma seqüência de teste.

Deve-se observar que, para o caso de RPCs com variáveis cujas cores são infinitas, esse critério é impraticável, uma vez que podem existir infinitas ligações.

Chow (1978) demonstrou que, para o caso de especificações baseadas em MEFs, critérios semelhantes aos propostos nas Definições 5, 6 e 7 não são suficientes. De forma análoga, pode-se concluir que tais critérios também devam ser complementados para o caso de especificações baseadas em RPCs. Dessa forma, a seguir, são definidos outros critérios que podem ser considerados mais "fortes".

Definição 8. O critério todos-caminhos requer que todos os caminhos sejam percorridos ao menos uma vez por uma seqüência de teste.

Deve-se observar que, em geral, o critério todos-caminhos não é aplicável, pois podem existir infinitos caminhos. Assim, as Definições 9, 10, e 11 introduzem critérios mais rigorosos do que os critérios todas-marcações, todas-transições e todas-ligações, porém, menos onerosos do que o critério todos-caminhos. Esses critérios estabelecem algumas restrições na seleção de caminhos e estabelecem uma hierarquia entre o critério todos-caminhos, de um lado, e os critérios todas-marcações, todas-transições e todas-ligações, de outro.

Definição 9. O critério todos-caminhos-simples requer que todos os caminhos simples sejam percorridos ao menos uma vez por uma seqüência de teste.

Definição 10. O critério todos-caminhos-livres-de-laço requer que todos os caminhos livres de laço sejam percorridos ao menos uma vez por uma seqüência de teste.

Definição 11. O critério todos-caminhos-k-marcações requer que todos os caminhos contendo no máximo $k$ repetições (com $k \geq 2$ ) para cada marcação sejam percorridos ao menos uma vez por uma seqüência de teste.

Esses critérios estabelecem requisitos de teste para precisam ser exercitados por um conjunto de casos de teste para ser considerado adequado com relação a um dado critério. Um conjunto de seqüências de teste $T$ é adequado em relação a um dado critério de teste $\mathcal{C}$ (denotado por $\mathcal{C}_{\text {adequado }}$ ) se $T$ satisfaz ou executa todos os requisitos impostos por $\mathcal{C}$ Zhu et al. (1997). 


\section{D.2.1 Análise de Propriedades da CPNCCF}

Existem três parâmetros que podem ser utilizados para a comparação de critérios de adequação:

1. Custo;

2. Eficácia; e

3. Força (do inglês, Strength).

De um ponto de vista teórico, a força pode ser analisada por meio da relação de inclusão (do inglês, subsumption relation). Nesta seção, com base na relação de inclusão Rapps e Weyuker (1985), é apresentada a hierarquia entre os critérios CPNCCF. De acordo com Zhu et al. (1997), a relação de inclusão é provavelmente a propriedade que é mais conhecida a respeito dos critérios de adequação, apesar de que nem todos os critérios possam ser colocados facilmente na hierarquia, especialmente critérios baseados em especificações. Os autores mostram também que, em algumas circunstâncias, a relação de inclusão pode fornecer informações para comparar a eficácia dos critérios. Um critério $\mathcal{C}^{\prime}$ inclui um critério $\mathcal{C}^{\prime \prime}$ se todo conjunto de caminhos $P$ que é $\mathcal{C}_{\text {adequado }}^{\prime}$ também é $\mathcal{C}_{\text {adequado }}^{\prime \prime} \mathcal{C}^{\prime}$ inclui estritamente $\mathcal{C}^{\prime \prime}$ se $\mathcal{C}^{\prime}$ inclui $\mathcal{C}^{\prime \prime}$ mas $\mathcal{C}^{\prime \prime}$ não inclui $\mathcal{C}^{\prime}$. $\mathcal{C}^{\prime}$ e $\mathcal{C}^{\prime \prime}$ são incomparáveis se $\mathcal{C}^{\prime}$ não inclui $\mathcal{C}^{\prime \prime}$ e $\mathcal{C}^{\prime \prime}$ não inclui $\mathcal{C}^{\prime}$.

Teorema 5. Considerando os critérios propostos neste trabalho, as relações apresentadas a seguir são válidas:

(i) todos-caminhos inclui estritamente todos-caminhos-k-marcações;

(ii) todos-caminhos-k-marcações inclui estritamente todos-caminhos-simples;

(iii) todos-caminhos-simples inclui estritamente todos-caminhos-livres-de-laço; $e$

(iv) todas-ligações inclui estritamente todas-transições.

Demonstração. Todas essas relações podem ser demonstradas de forma semelhante. A seguir, é apresentada a prova da relação (iii).

Seja $P_{1}$ um conjunto de caminhos que satisfaça o critério todos-caminhos-simples, ou seja, $P_{1}$ é todos-caminhos-simples adequado. Dessa forma, por definição, $P_{1}$ contém todos os possíveis caminhos cujas marcações são todas distintas, com a possível exceção da primeira e da última. Seja $P_{2}$ um conjunto de caminhos que satisfaça o critério todos-caminhos-livres-de-laço. Dessa forma, por definição, $P_{2}$ contém todos os possíveis caminhos cujas marcações são todas distintas. Assim, pode-se verificar que $P_{2} \subseteq P_{1}$. Pode-se concluir que $P_{1}$ também satisfaz o critério todos-caminhos-livres-de-laço. Portanto, o critério todos-caminhos-simples inclui todos-caminhos-livres-de-laço. Por outro lado, $P_{2}$ pode não satisfazer o critério todos-caminhos-simples. Seja $p$ um caminho cujas primeira e últimas marcações são iguais. Assim, $p \notin P_{2}$ e, portanto, $P_{2}$ não é adequado ao 
critério todos-caminhos-simples. Logo, todos-caminhos-livres-de-laço não inclui o critério todos-caminhos-simples.

\section{D.2.2 Estabelecimento dos Requisitos de Teste}

Os requisitos de teste estabelecidos pelos critérios CPNCCF são obtidos por meio do GO Jensen (1997b).

Um problema que torna difícil a utilização de GO é a explosão de estados. O problema da explosão de estados ocorre quando o número de nós cresce de forma exponencial, em função do aumento do comprimento das seqüências. Em alguns casos, o número de nós pode ser infinito, especialmente com RPC não-limitadas, ou com RPC cujas cores possuem um número infinito de elementos. Para superar o problema da explosão de estados, existem algumas abordagens que reduzem o GO, tais como a utilização de classes de equivalência e conjuntos stubborn. As classes de equivalência empregam o conceito de que algumas marcações são, em algum sentido, similares. Essas marcações podem ser consideradas como equivalentes. Em vez de construir um GO cujos nós são todas as marcações alcançáveis, os nós do GO representam apenas as classes das marcações equivalentes. Para poder aplicar essa abordagem, é necessário definir uma relação de equivalência para o conjunto de marcações e uma relação de equivalência para o conjunto de ligações. Tais relações são dependentes tanto da RPC em particular quanto das propriedades que o usuário/testador possa querer levar em consideração. Deve-se observar que a relação de equivalência pode ser definida de tal forma que um número infinito de marcações (e analogamente, de ligações) seja representado por uma única classe de equivalência. Dessa forma, o problema de RPCs não-limitadas (ou seja, RPCs cujo conjunto de marcações alcançáveis é infinito) pode ser resolvido com a definição de relações de equivalência adequadas.

Os conjuntos stubborn são conjuntos de ligações que são mutuamente independentes. Em outras palavras, são ligações que podem ser disparadas em qualquer ordem, atingindo a mesma marcação. Nessa abordagem, ao invés de considerar todas as possíveis combinações dessas ligações, apenas um elemento, chamado de conjunto stubborn, é incluído no grafo.

Na Figura D.1 é apresentado ${ }^{1}$ um GO da RPC da Figura 2.4 com $n=3$.

Para ilustrar o uso do GO para implementar os critérios CPNCCF, serão considerados os critérios todas-marcações e todos-caminhos-livres-de-laços. Os requisitos estabelecidos para o critério todas-marcações correspondem ao conjunto de marcações na GO (ou seja, o conjunto de nós). Para o critério todos-caminhos-livres-de-laços, os

\footnotetext{
${ }^{1}$ Nessa figura é apresentado o mesmo GO da Figura 2.7 e foi incluída também aqui para facilitar a referência.
} 


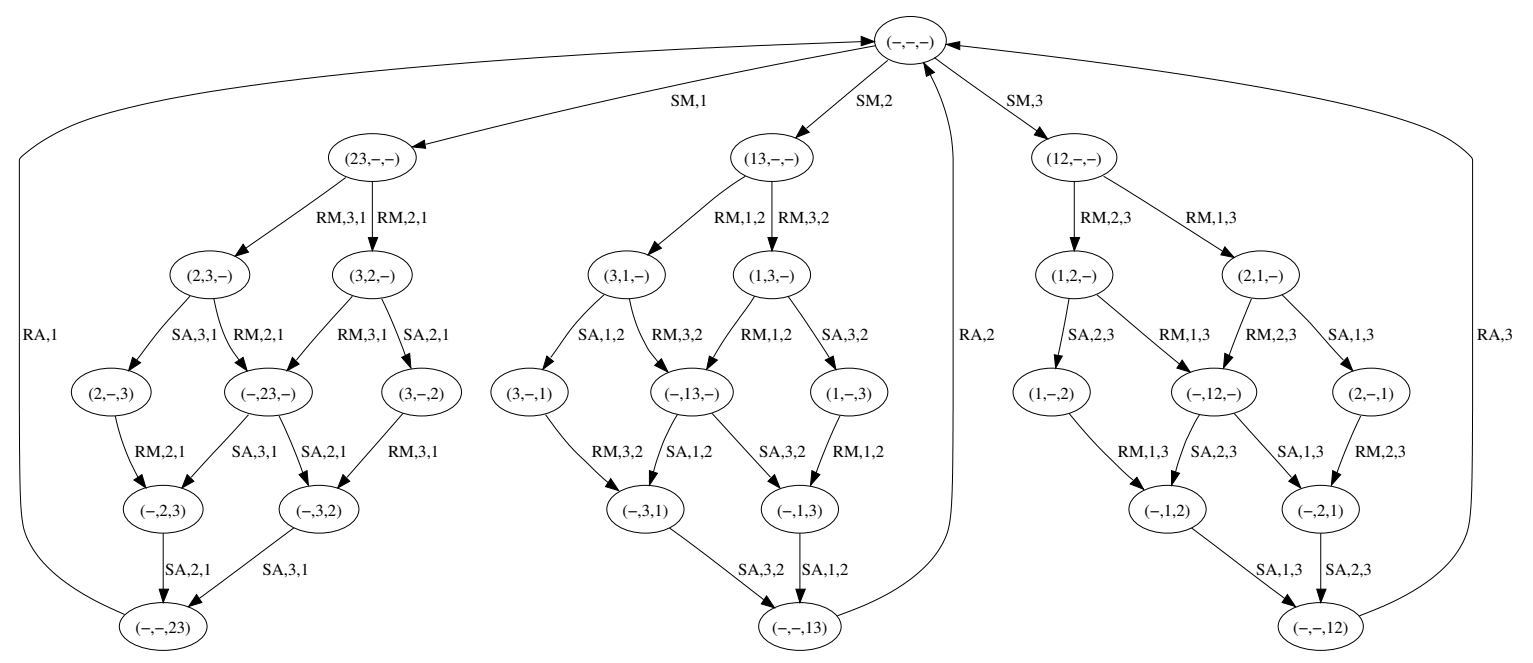

Figura D.1: Grafo de Ocorrência da Rede de Petri Colorida da Figura 2.4.

requisitos de teste são obtidos percorrendo o GO e coletando todos os caminhos que são livres de laço. Os demais critérios podem ser implementados de forma similar.

Na Tabela D.1 é apresentado o número de requisitos de teste estabelecidos para cada critério de CPNCCF para a rede da Figura 2.4, assim como alguns exemplos desses requisitos. Esses requisitos podem ser verificados em relação ao GO da Figura D.1.

Tabela D.1: Subconjunto dos Requisitos de Teste para a Rede de Petri Colorida da Figura 2.4 .

\begin{tabular}{|c|c|c|}
\hline Critérios & \multicolumn{2}{|r|}{ Número de Requisitos de Teste e Alguns Exemplos } \\
\hline todos-caminhos & $\infty$ & $\begin{array}{l}t r=\{\langle(-,-,-),(12,-,-),(1,2,-),(-, 12,-),(-, 1,2),(-,-, 12),(-,-,-), \\
(13,-,-),(1,3,-)\rangle,\langle(-,-,-),(23,-,-),(3,2,-),(3,-, 2)\rangle, \ldots\}\end{array}$ \\
\hline $\begin{array}{l}\text { todos-caminhos- } \\
-k \text {-marcações, } \\
\text { com } k=2\end{array}$ & 1102 & $\begin{array}{l}\operatorname{tr}=\{\langle(-,-,-),(23,-,-),(3,2,-),(3,-, 2),(-, 3,2),(-,-, 23),(-,-,-), \\
(23,-,-),(3,2,-),(3,-, 2),(-, 3,2)\rangle,\langle(-,-,-),(23,-,-),(3,2,-),(-, 23,-), \\
\left.(-, 3,2),\left({ }^{-},-, 23\right),(-,-,-),(13,-,-),(3,1,-),(-, 13,-),(-, 1,3),(-,-, 13)\right\rangle, \\
\ldots\}\end{array}$ \\
\hline $\begin{array}{l}\text { todos-caminhos- } \\
\text {-simples }\end{array}$ & 76 & $\begin{array}{l}t r=\{\langle(-,-,-),(23,-,-),(3,2,-),(3,-, 2),(-, 3,2),(-,-, 23),(-,-,-)\rangle, \\
\langle(-,-,-),(23,-,-),(2,3,-),(-, 23,-),(-, 3,2),(-,-, 23)\rangle, \ldots\}\end{array}$ \\
\hline $\begin{array}{l}\text { todos-caminhos- } \\
\text {-livres-de-laço }\end{array}$ & 58 & $\begin{array}{l}\operatorname{tr}=\{\langle(-,-,-)(23,-,-)(2,3,-)\rangle,\langle(-,-,-)(13,-,-)(3,1,-)(3,-, 1)(-, 3,1) \\
(-,-, 13)\rangle,\langle(-,-,-)(23,-,-)(3,2,-)(3,-, 2)\rangle, \ldots\}\end{array}$ \\
\hline todas-transições & 4 & $\operatorname{tr}=\{S M, R M, S A, R A\}$ \\
\hline todas-ligações & 18 & 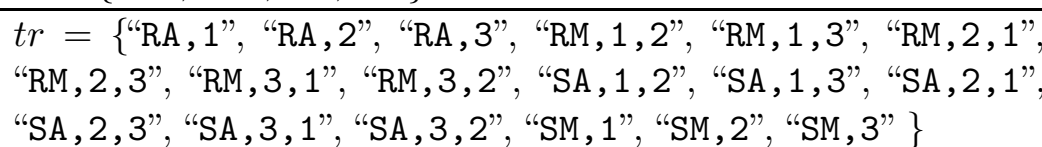 \\
\hline todas-marcações & 28 & $\begin{array}{l}\operatorname{tr}=\{(-,-,-),(23,-,-),(13,-,-),(12,-,-),(3,2,-),(2,3,-),(3,-, 2), \\
(-, 23,-),(-, 3,2),(-,-, 23),(-, 2,3),(2,-, 3),(3,1,-),(1,3,-),(3,-, 1), \\
(-, 13,-),(-, 3,1),(-,-, 13),(-, 1,3),(1,-, 3),(2,1,-),(1,2,-),(2,-, 1), \\
(-, 12,-),(-, 2,1),(-,-, 12),(-, 1,2),(1,-, 2)\}\end{array}$ \\
\hline
\end{tabular}

Para ilustrar como o GO pode ser reduzido e o impacto dessa redução nos requisitos de teste, considere a aplicação da abordagem de classes de equivalência para esse exemplo. 
A relação de equivalência para as marcações é definida de tal forma que duas marcações são consideradas equivalentes se, e somente se, existe uma função bijetora $\varphi: D B M \rightarrow D B M$ que possa "converter" uma marcação na outra. Por exemplo, a marcação $(2,3,-)$ é equivalente à marcação $(1,2,-)$, uma vez que a última pode ser obtida a partir da primeira por meio da "tradução" de sites definida pela função bijetora $\varphi:\left\{d_{1} \mapsto d_{3}, d_{2} \mapsto d_{1}, d_{3} \mapsto d_{2}\right\}$. A relação de equivalência para as ligações é definida de forma análoga. Intuitivamente, essas relações de equivalência implicam que duas marcações são equivalentes se elas diferem apenas com relação aos "nomes do sites". O GO reduzido é apresentado na Figura D.2. Pode-se observar que esse grafo é consideravelmente menor que o grafo apresentado na Figura D.1.

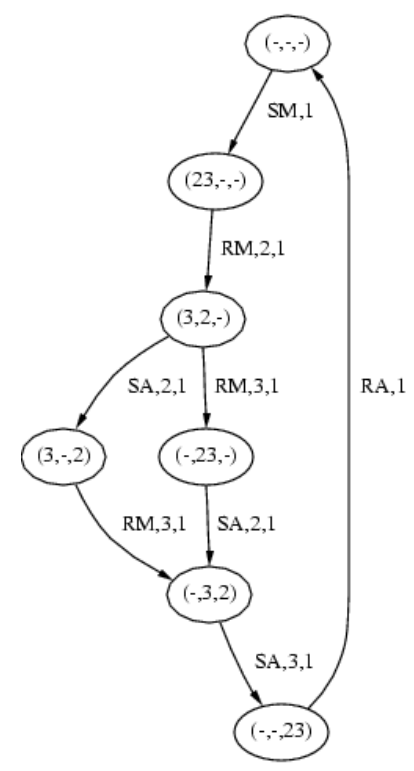

Figura D.2: Grafo de Ocorrência Reduzido com a Utilização de Classes de Equivalência.

Na Tabela D.2 é apresentado o número de requisitos de teste, levando em consideração as classes de equivalência. A cardinalidade do conjunto de requisitos é sensivelmente menor do que no caso em que nenhuma relação de equivalência é considerada. Entretanto, o GO pode não ser sensível a possíveis erros que possam ser dependentes de um site particular.

\section{D.2.3 Análise de Adequação e Geração de Conjuntos de Teste}

Os requisitos de teste podem ser usados para dois propósitos distintos, porém relacionados:

i) Guiar a geração de seqüências de teste; ou

ii) Avaliar a adequação de um conjunto de seqüências de teste em relação ao critério de cobertura em questão. 
Tabela D.2: Subconjunto dos Requisitos de Teste para a Rede de Petri Colorida da Figura 2.4 com Classes de Equivalência.

\begin{tabular}{|c|c|c|}
\hline Critérios & & Número de Requisitos de Teste e Alguns Exemplos \\
\hline todos-caminhos & $\bar{\infty}$ & $\begin{array}{l}\operatorname{tr}=\left\{\left((-,-,-),(12,-,-),(1,2,-),(-, 12,-),(-, 1,2),(-,-, 12),()^{-,-,-)},\left(13,,^{-,-}\right),\right.\right. \\
(1,3,-)\rangle,\langle(-,-,-),(23,-,-),(3,2,-),(3,-, 2)\rangle, \ldots\}\end{array}$ \\
\hline $\begin{array}{l}\text { todos-caminhos- } \\
\text {-k-marcações, } \\
\text { com } k=2\end{array}$ & 27 & $\begin{array}{l}\operatorname{tr}=\{\langle(-,-,-),(23,-,-),(3,2,-),(3,-, 2),(-, 3,2),(-,-, 23),(-,-,-),(23,-,-), \\
(3,2,-), \quad(3,-, 2), \quad(-, 3,2)\rangle,\langle(-,-,-),(23,-,-),(3,2,-),(-, 23,-),(-, 3,2), \\
(-,-, 23),(-,-,-)\rangle, \ldots\}\end{array}$ \\
\hline $\begin{array}{l}\text { todos-caminhos- } \\
\text {-simples }\end{array}$ & 11 & $\begin{array}{l}\operatorname{tr}=\{\langle(-,-,-),(23,-,-),(3,2,-),(3,-, 2),(-, 3,2),(-,-, 23),(-,-,-)\rangle,\langle(-,-,-), \\
(23,-,-),(2,3,-),(-, 23,-),(-, 3,2),(-,-, 23)\rangle, \ldots\}\end{array}$ \\
\hline $\begin{array}{l}\text { todos-caminhos- } \\
\text {-livres-de-laço }\end{array}$ & 9 & $\operatorname{tr}=\{\langle(-,-,-)(23,-,-)(2,3,-)\rangle,\langle(-,-,-))(23,-,-)(3,2,-)(3,-, 2)\rangle, \ldots\}$ \\
\hline todas-transições & 4 & $\operatorname{tr}=\{S M, R M, S A, R A\}$ \\
\hline todas-ligações & 6 & $\operatorname{tr}=\{" \mathrm{RA}, 1 "$, "RM , 2, 1", "RM , 3, 1", "SA , 2, 1", "SA , 3, 1", "SM , 1" $\}$ \\
\hline todas-marcações & 7 & $\begin{array}{l}\operatorname{tr}=\{(-,-,-),(23,-,-),(3,2,-),(2,3,-),(3,-, 2),(-, 23,-),(-, 3,2),(-,-, 23), \\
(-, 2,3),(2,-, 3)\}\end{array}$ \\
\hline
\end{tabular}

Neste trabalho, os critérios de CPNCCF foram utilizados como um critério de cobertura. Foi desenvolvido um protótipo, chamado $\mathcal{T}_{\text {es }} \mathcal{C C}_{C P N}$, para apoiar essa tarefa. $\mathrm{O}$ esquema geral de execução da $\mathcal{T}_{\text {esCC }} \mathcal{C}_{C P N}$ é apresentado na Figura D.3. Antes de poder

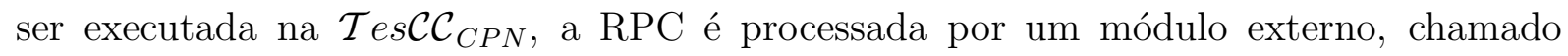
cpn-ml2sml (Passo a), que a compila, gerando código SML Hansen e Rischel (1999) para a simulação/execução da rede (Passo b). O código SML da RPC é uma representação intermediária da RPC que incorpora a semântica da execução. O código SML gerado é, então, ligado à $\mathcal{T}_{\operatorname{esC}} \mathcal{C}_{C P N}($ Passo c).

Uma funcionalidade da $\mathcal{T}_{e s} \mathcal{C C}_{C P N}$ é a geração do GO (Passo f). O GO é empregado internamente para calcular os requisitos de teste. A $\mathcal{T}_{e s \mathcal{C}} \mathcal{C}_{C P N}$ pode ser solicitada a escrever o GO de forma que possa ser manualmente inspecionado. Atualmente, a

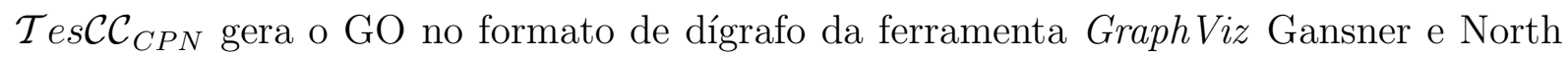
(2001). A GraphViz é uma ferramenta para o desenho de grafo e é capaz de gerar vários tipos de arquivos de imagem (por exemplo, JPEG, PNG e EPS) ${ }^{2}$. A $\mathcal{T}_{\text {es }} \mathcal{C C}_{C P N}$ pode ser controlada (Passo d) com dados sobre os critérios de teste de interesse, assim como as relações de equivalência, se necessário. A relação de equivalência deve ser fornecida com funções SML que determinam se duas marcações (respectivamente, duas ligações) são ou não equivalentes. Existem dois possíveis modos de execução:

(i) O conjunto de seqüências de teste é fornecido (Passo e) e os dados sobre a cobertura obtida são produzidos (Passo h). Tais dados incluem quantos requisitos de teste foram definidos para um dado critério, quantos requisitos de teste foram executados pelas seqüências de teste, e, se requerido, quais requisitos de teste não foram exercitados.

\footnotetext{
${ }^{2}$ Os GOs apresentados nas Figuras D.1 e D.2 foram gerados dessa forma.
} 


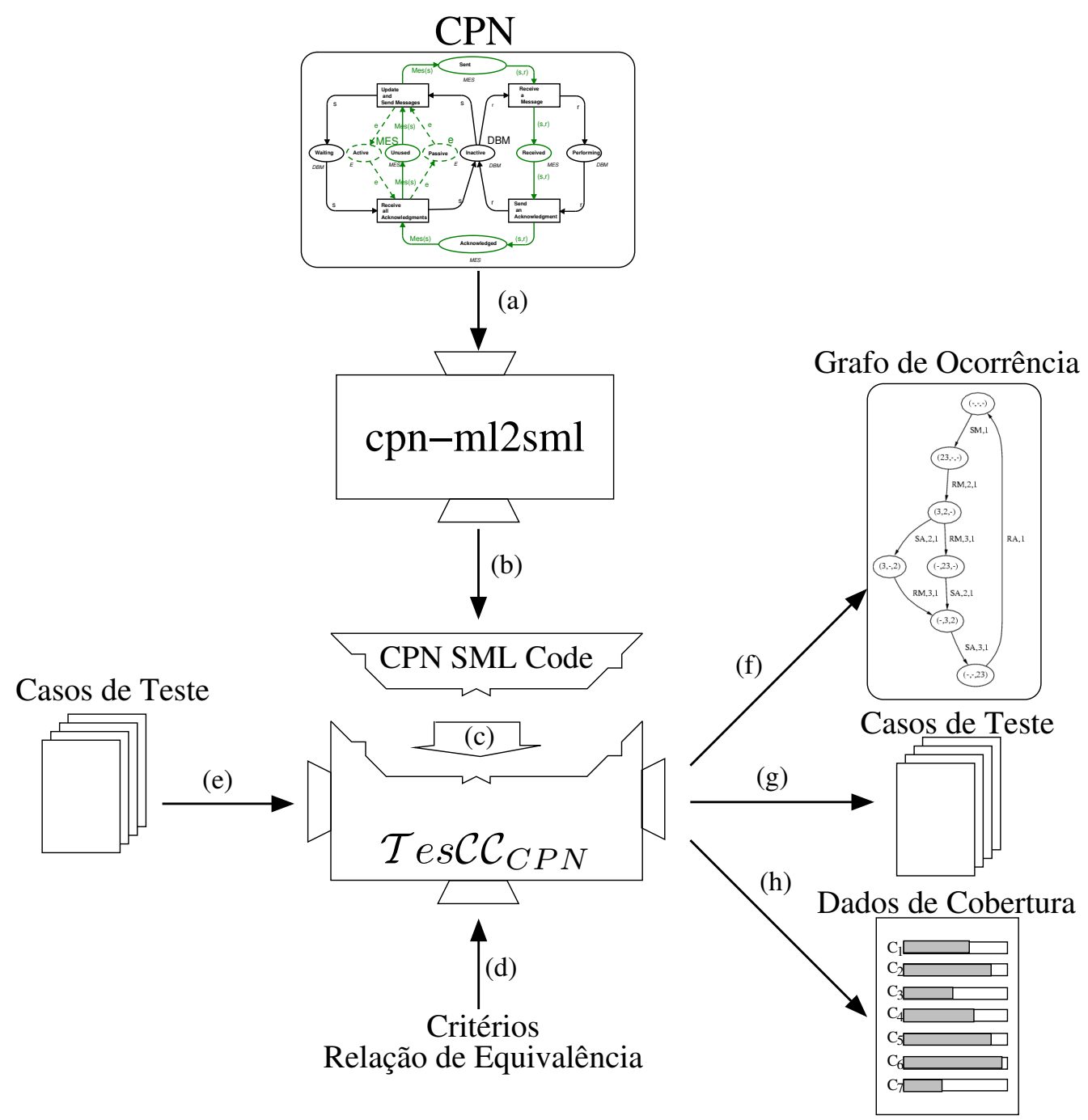

Figura D.3: Esquema Geral de Execução da $\mathcal{T}_{\operatorname{esC}} \mathcal{C}_{C P N}$.

(ii) Um conjunto de seqüências de teste é produzido (Passo g). Nesse caso, a $\mathcal{T}$ es $\mathcal{C C}_{C P N}$ produzirá um conjunto que é, por construção, adequado para um dado critério.

\section{D.3 Considerações Finais}

A contribuição principal nessa linha do trabalho é a definição de uma família de critérios de cobertura para RPC. Esse é o primeiro esforço nessa direção que pode ser identificado na literatura. A relação de inclusão entre os critérios foi determinada, fornecendo informações para o estabelecimento de uma estratégia de teste incremental para especificações baseadas em RPC.

Os requisitos de teste da CPNCCF foram derivados com base no GO. Essas informações podem ser utilizadas para avaliar, para um dado critério, quão completo é o conjunto de seqüências de teste pela comparação do número de requisitos de teste que foram derivados com número de requisitos que foram exercitados. 
Deve-se observar que o conjunto de seqüências de teste obtidos para testar e validar a especificação é, na realidade, um mecanismo para conduzir o teste de conformidade para uma implementação. Nesse cenário, é importante a investigação do relacionamento entre o teste nesses dois níveis: especificação versus implementação. 


\section{Apêndice E}

\section{Redes de Petri Coloridas do Estudo de Caso I}

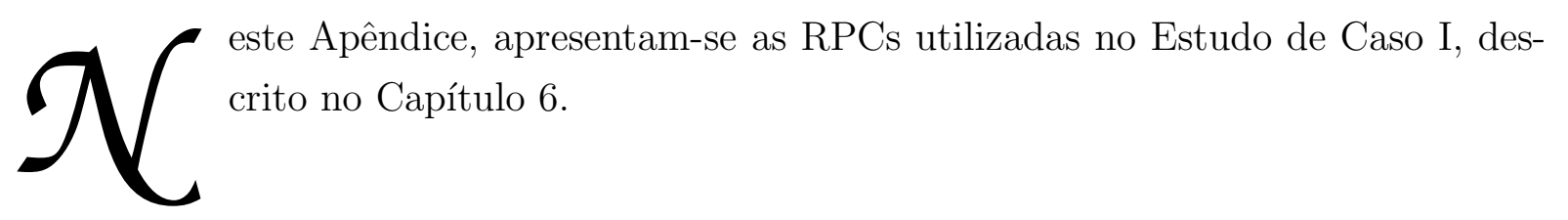

\section{E.1 Alocador de Recursos (RA)}

Essa RPC descreve como dois tipos de processo (chamados de p-processo e q-processo) estão compartilhando três tipos de recursos (chamados de r-recurso, s-recurso e t-recurso). Cada processo é cíclico e durante as partes individuais de seu ciclo, o processo precisa ter acesso exclusivo a uma quantidade variável de recursos. Os processos podem estar em cinco estados distintos, representados pelos lugares $A$-E. Cada marca de um desses lugares representa um p-processo ou um q-processo e também a quantidade de ciclos inteiros que o processo completou. Os recursos são representados pelos lugares $R-T$. 


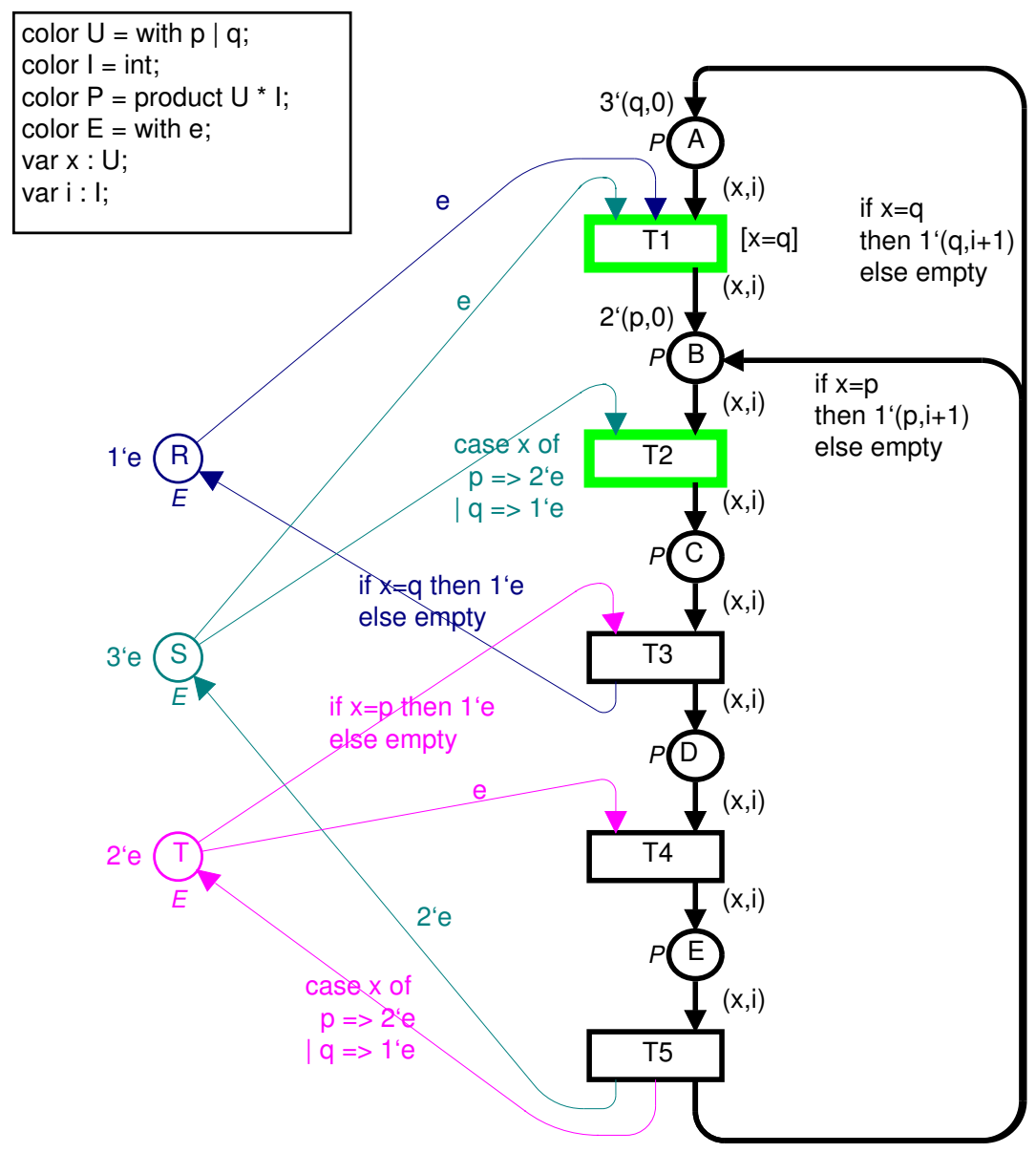

\section{Resource Allocation Example}

Figura E.1: Rede de Petri Colorida RA.

\section{E.2 Sistema Telefônico (TL)}

Essa RPC descreve como o sistema de telefone público é conhecido pelo usuário (e não pelo técnico de telefone). São ignorados time-out e serviços especiais tal como chamada de conferência.

O sistema telefônico possui uma única página principal Phone\#1, na qual existem três transições de substituição: Establishment of a Connection, Breaking of a Connection by the Sender e Breaking of a Connection by the Recipient. Os telefones podem estar em dois diferentes estados: Inactive e Connected. A troca de telefone (telephone exchange) (os eletrônicos do switch do telefone) é representado por um único lugar, Connection. Cada marca neste lugar representa uma conexão estabelecida entre o sender (telefone no qual a chamada foi feita) e o recipient (telefone que foi chamado). 


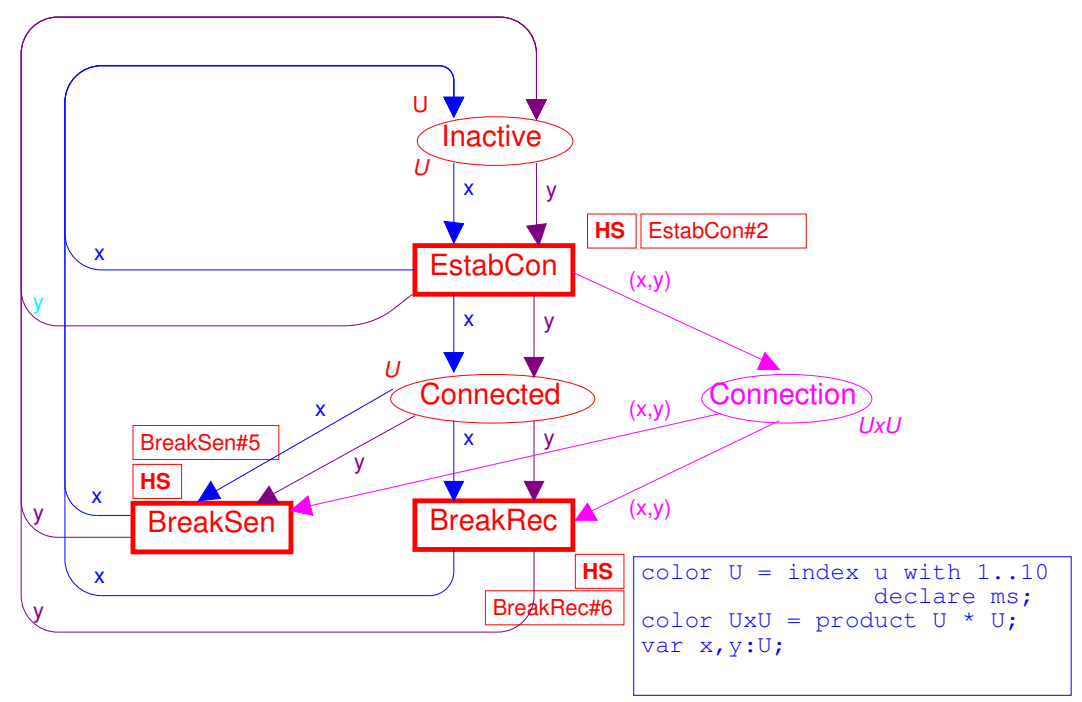

Figura E.2: Rede de Petri Colorida TL - Página Phone.

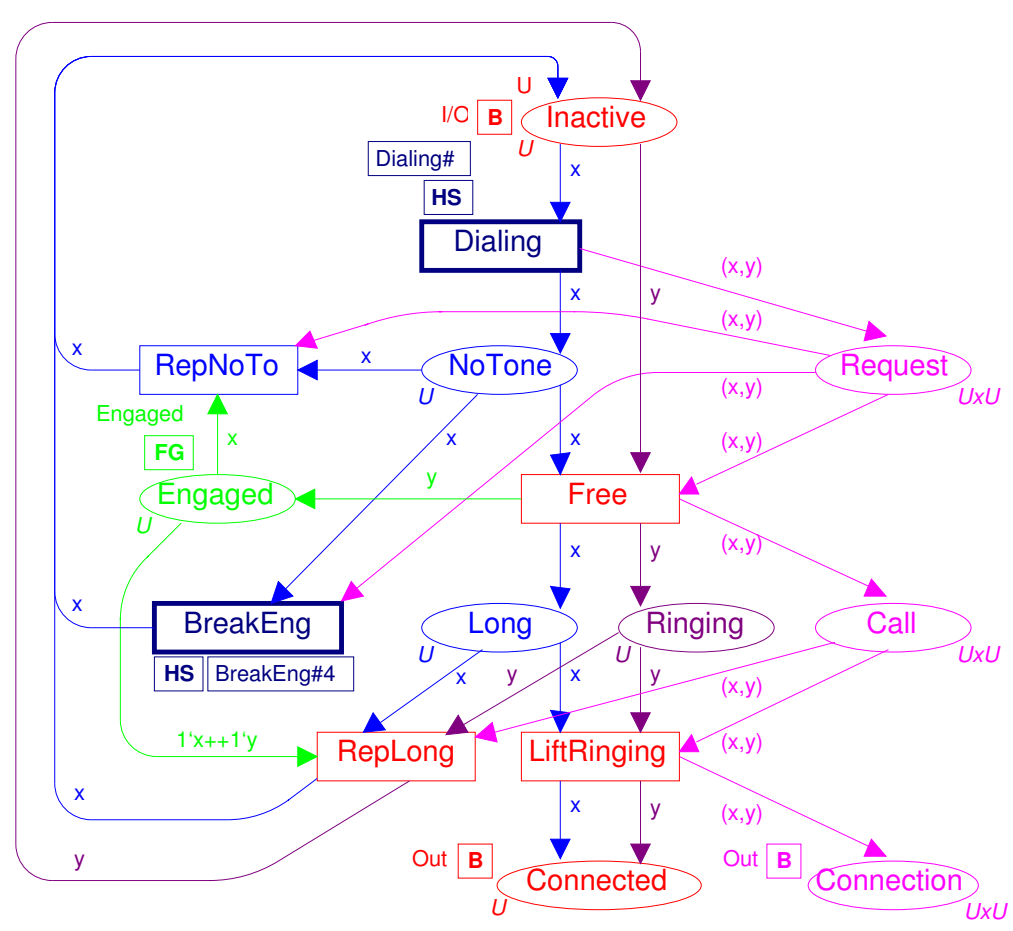

Figura E.3: Rede de Petri Colorida TL - Página EstabCon. 


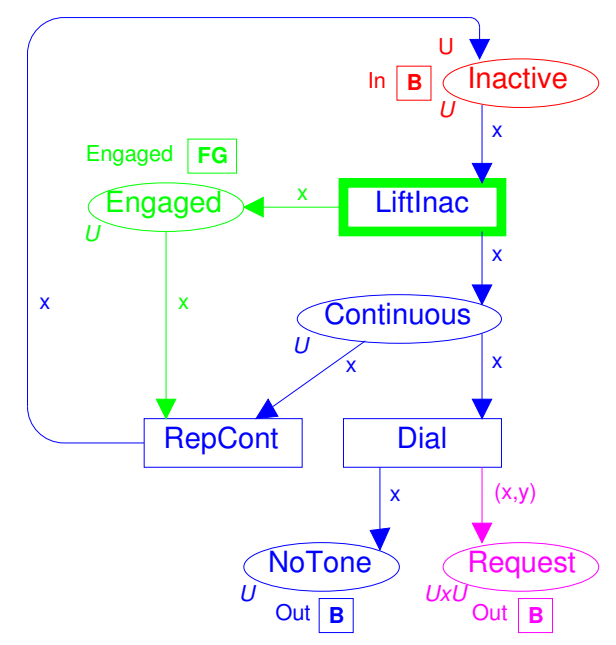

Figura E.4: Rede de Petri Colorida TL - Página Dialing.

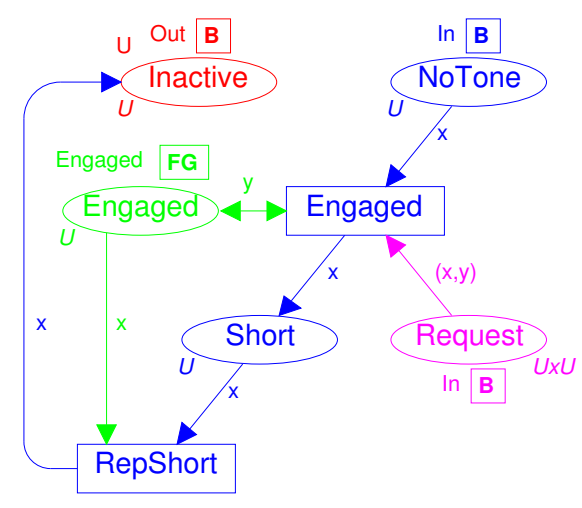

Figura E.5: Rede de Petri Colorida TL - Página BreakEng. 


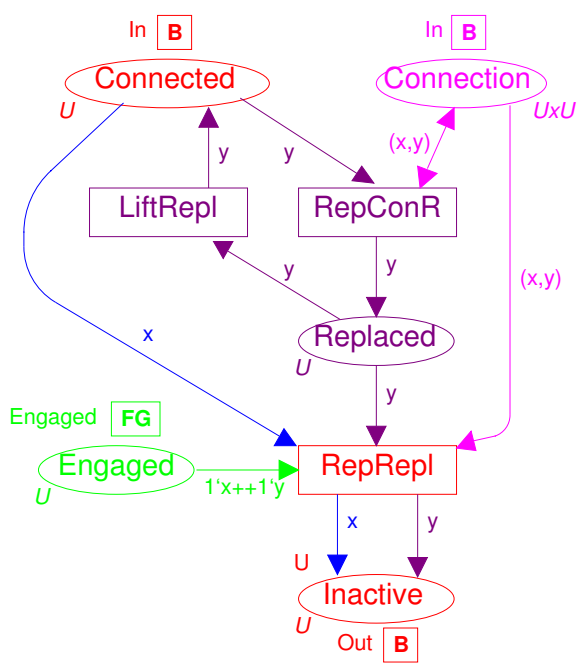

Figura E.6: Rede de Petri Colorida TL - Página BreakRec.

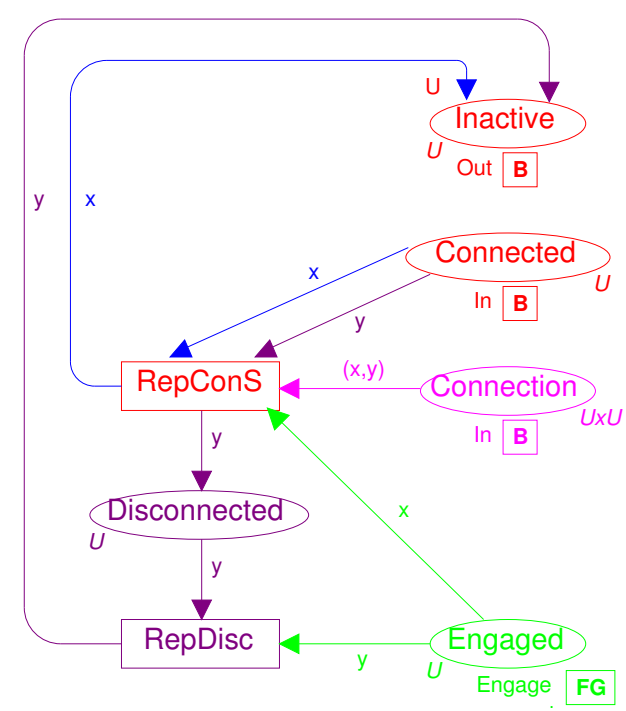

Figura E.7: Rede de Petri Colorida TL - Página BreakSen. 


\section{E.3 Protocolo Hierárquico (HP)}

Essa RPC representa um protocolo de rede simples para o envio de mensagens entre um emissor e dois receptores. O protocolo é representado por uma RPC hierárquica. Basicamente, o protocolo consiste em enviar as mensagens com um contador, indicando o número dessa mensagem na seqüência de mensagens enviadas. O receptor da mensagem envia um acknowledgement para o emissor com esse número, de forma a indicar que a mensagem foi recebida adequadamente. Tanto as mensagens quanto os acknowledgements podem ser perdidos, exigindo uma retransmissão.

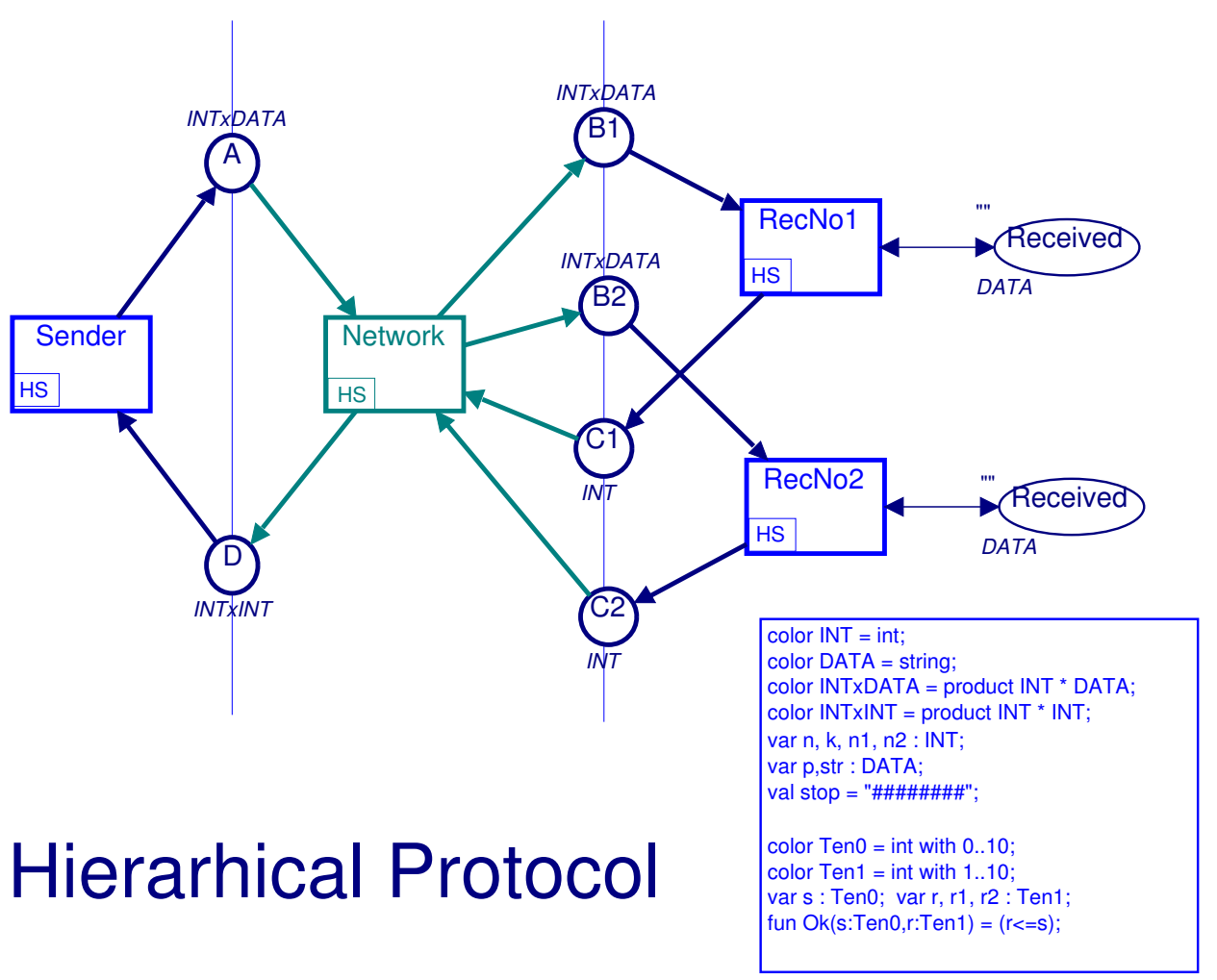

Figura E.8: Rede de Petri Colorida HP - Página Top. 

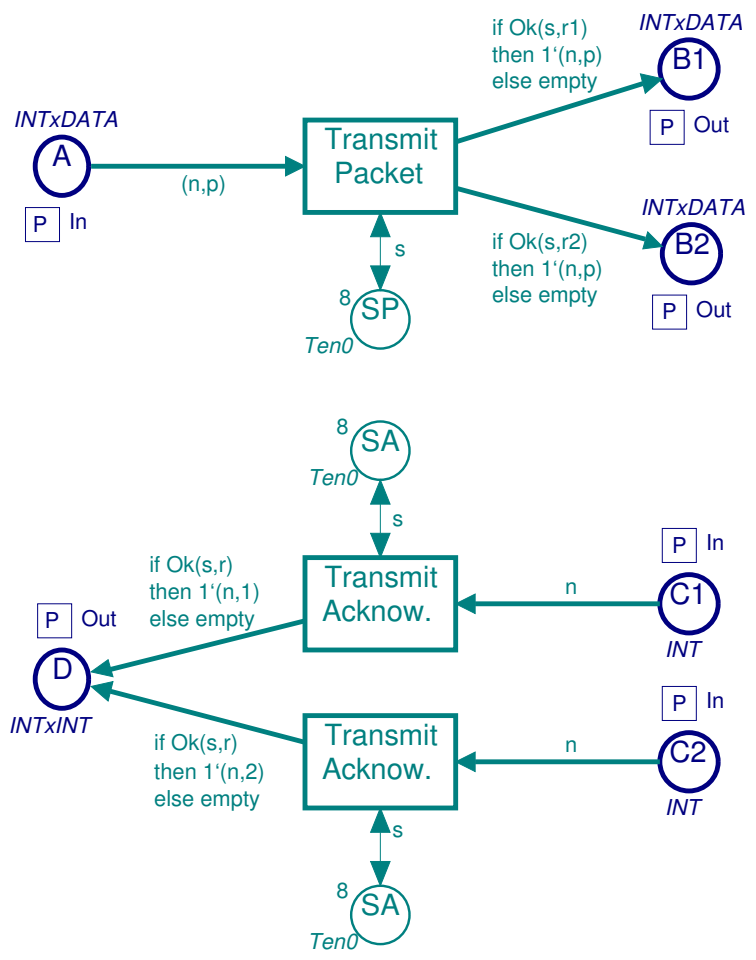

Figura E.9: Rede de Petri Colorida HP - Página Network.

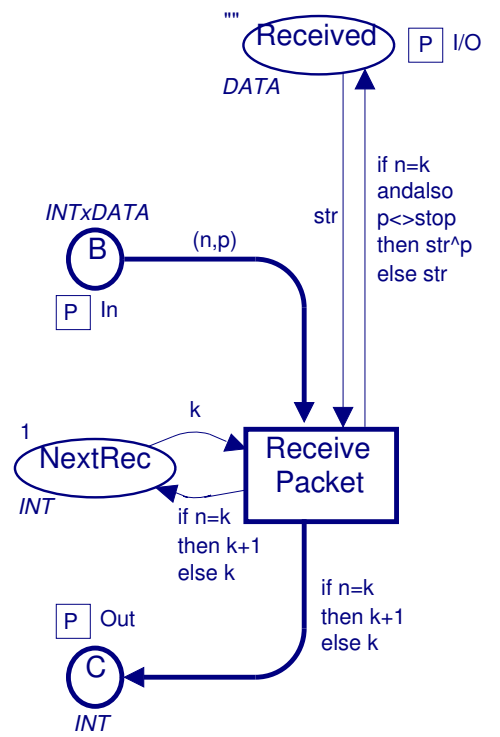

Figura E.10: Rede de Petri Colorida HP - Página Receiver. 


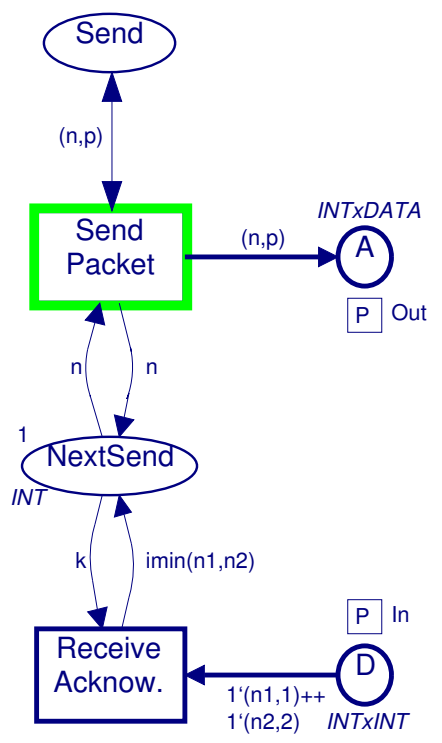

Figura E.11: Rede de Petri Colorida HP - Página Sender. 

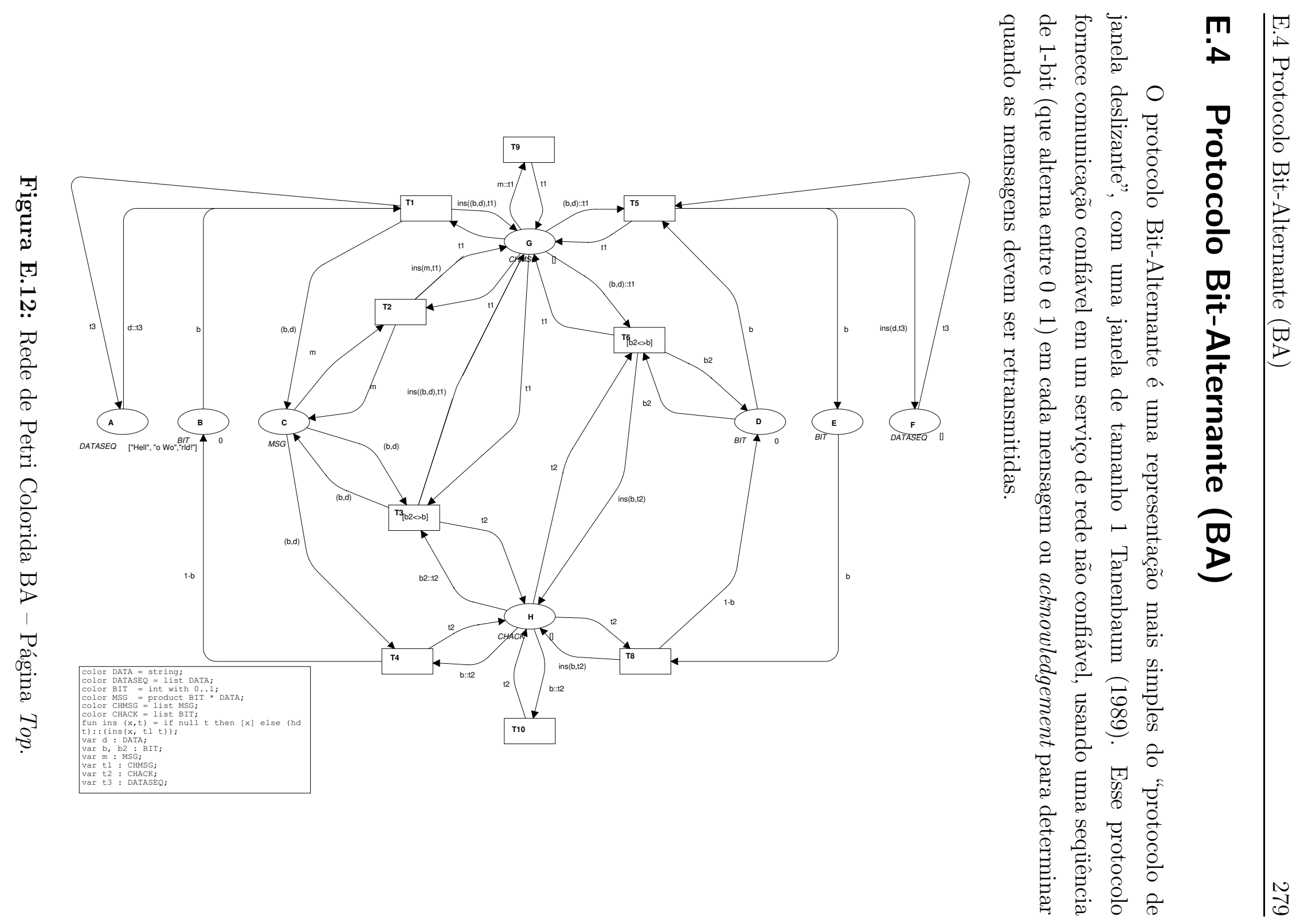


\section{E.5 Protocolo Conferência/Cotê de Resyste (CP)}

O protocolo conferência Belinfante (2003) fornece comunicação entre usuários que podem participar de "conferência" com outros usuários. Nesse protocolo, um usuário pode cadastrar-se em uma conferência e a partir de então, enviar mensagens, as quais serão transmitidas aos demais usuários dessa conferência. Além disso, o usuário pode receber mensagens dos outros usuários que estão na mesma conferência e sair da conferência. O protocolo garante a transmissão de mensagens apenas para os membros da mesma conferência, mas não garante que todas as mensagens serão efetivamente recebidas ou serão recebidas na mesma ordem do envio (ou seja, o meio de comunicação não é confiável). Contudo, o protocolo provê mecanismos para corrigir alguns problemas decorrentes disso, tais como a perda de uma mensagem de cadastro.

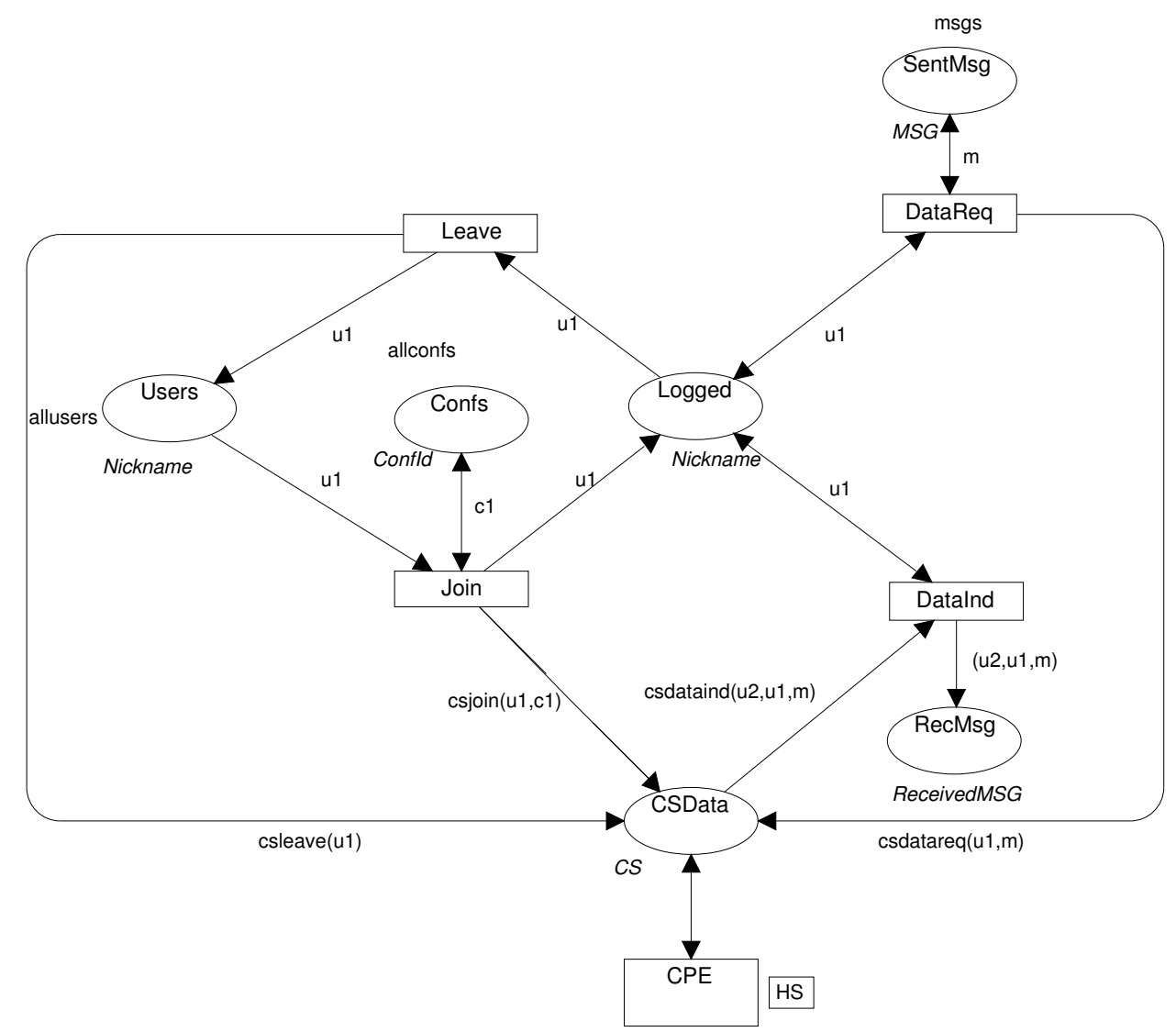

Figura E.13: Rede de Petri Colorida CP - Página CSAP. 


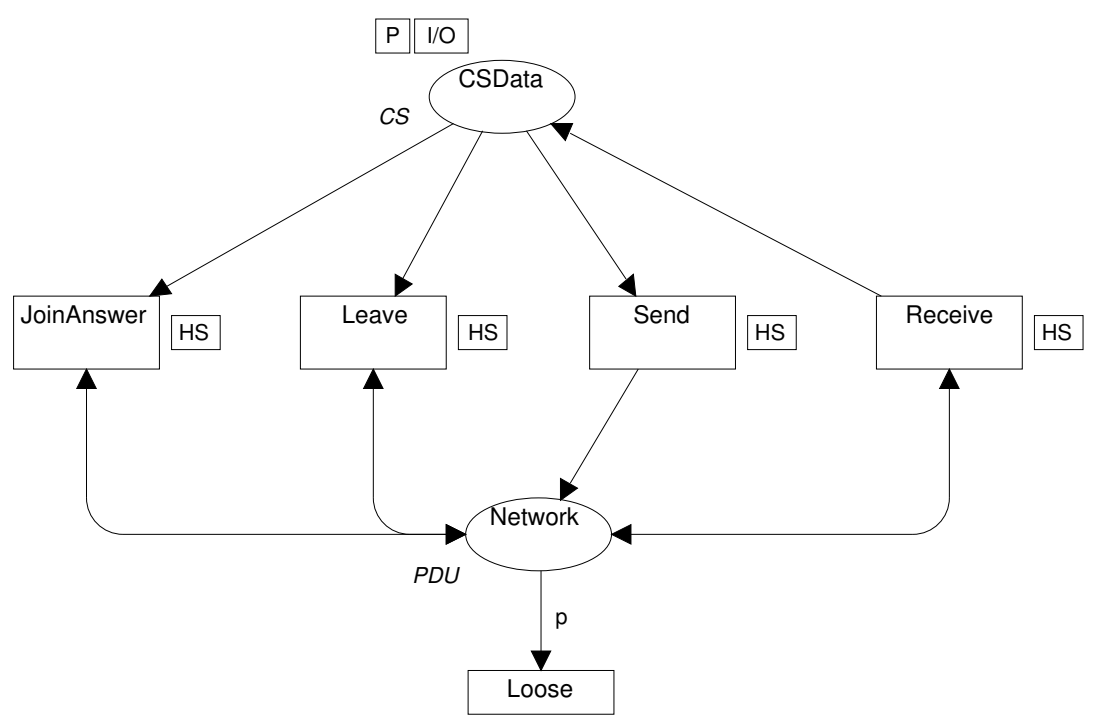

Figura E.14: Rede de Petri Colorida CP - Página CPE.

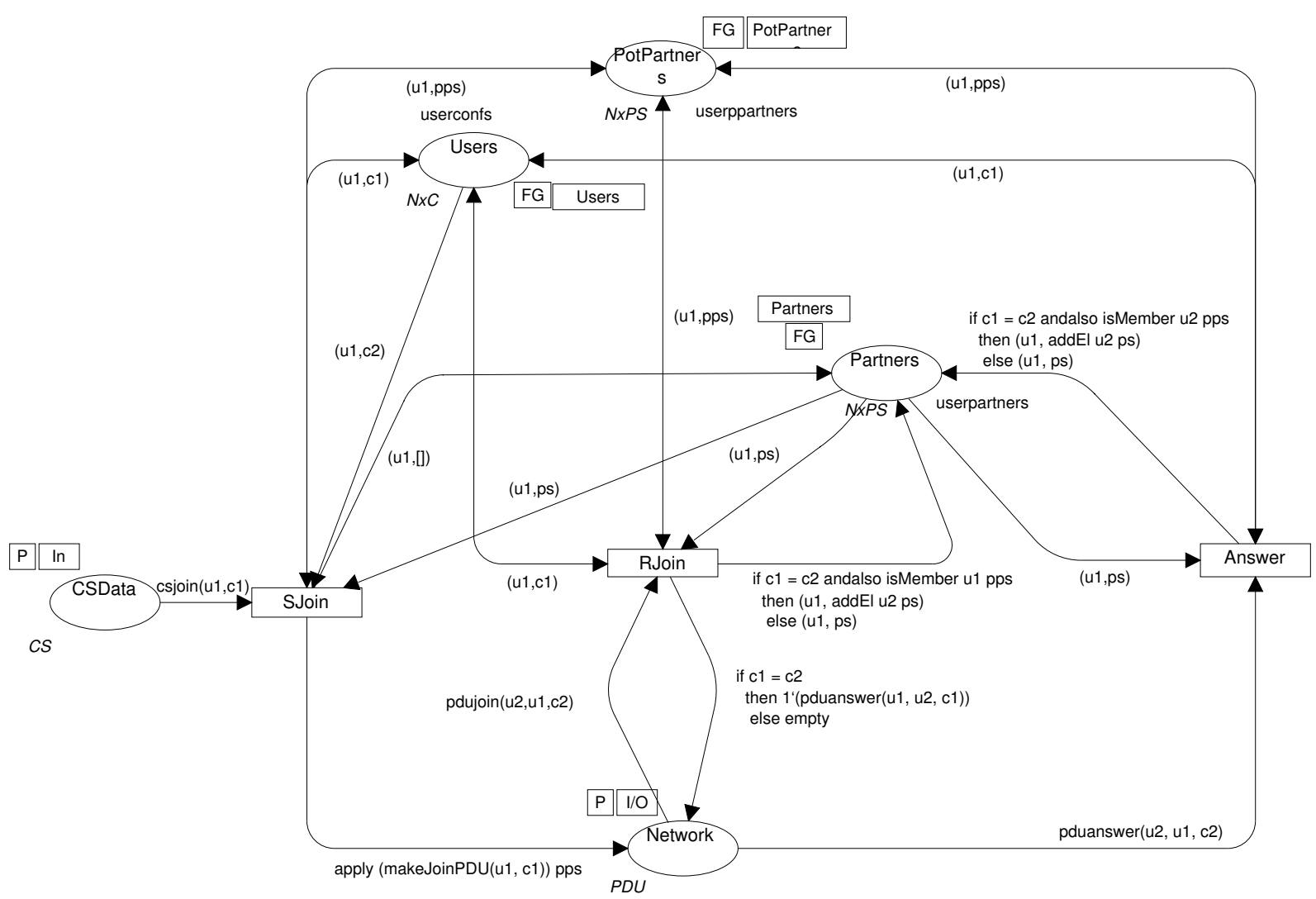

Figura E.15: Rede de Petri Colorida CP - Página JoinAnswer. 


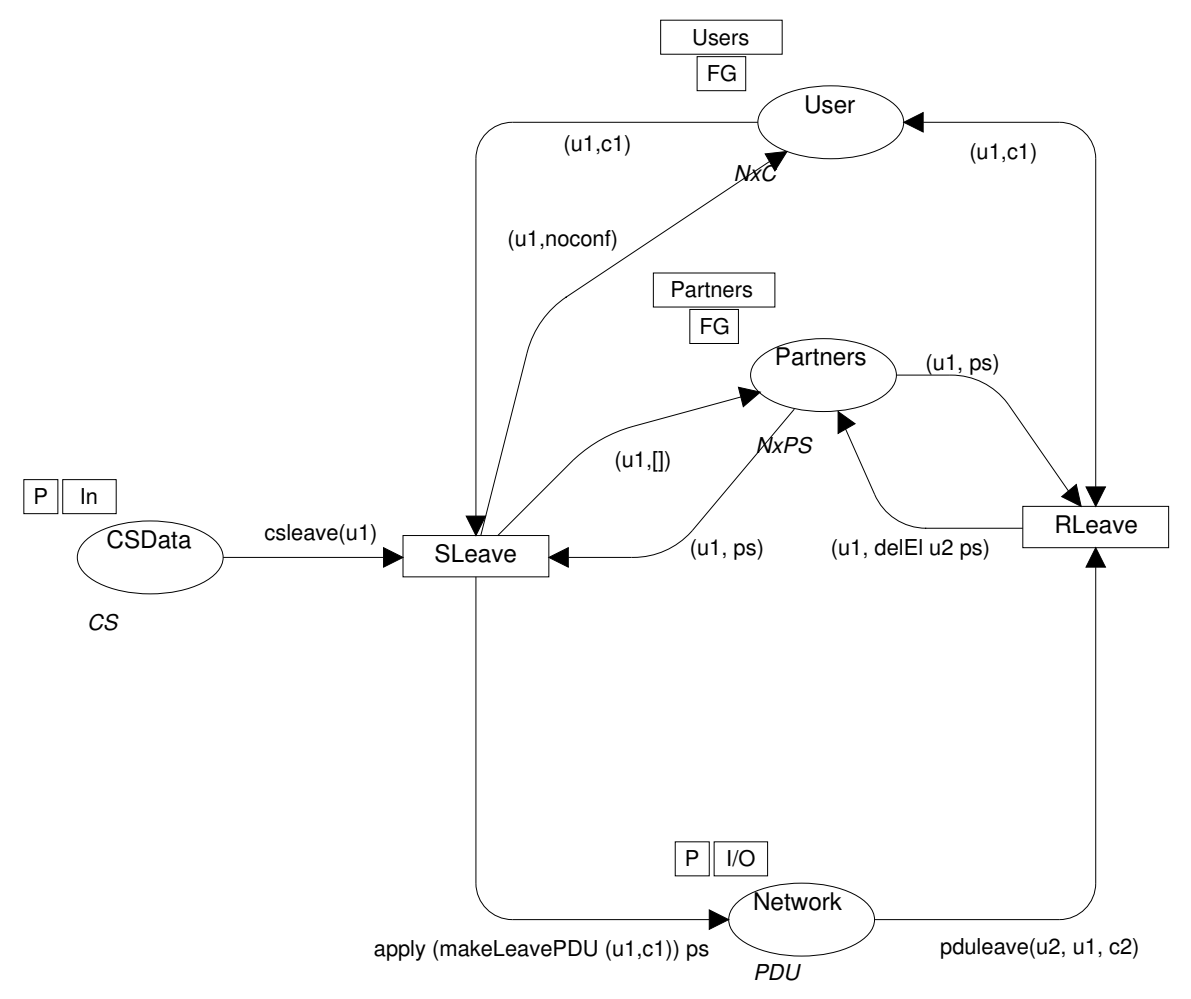

Figura E.16: Rede de Petri Colorida CP - Página Leave.

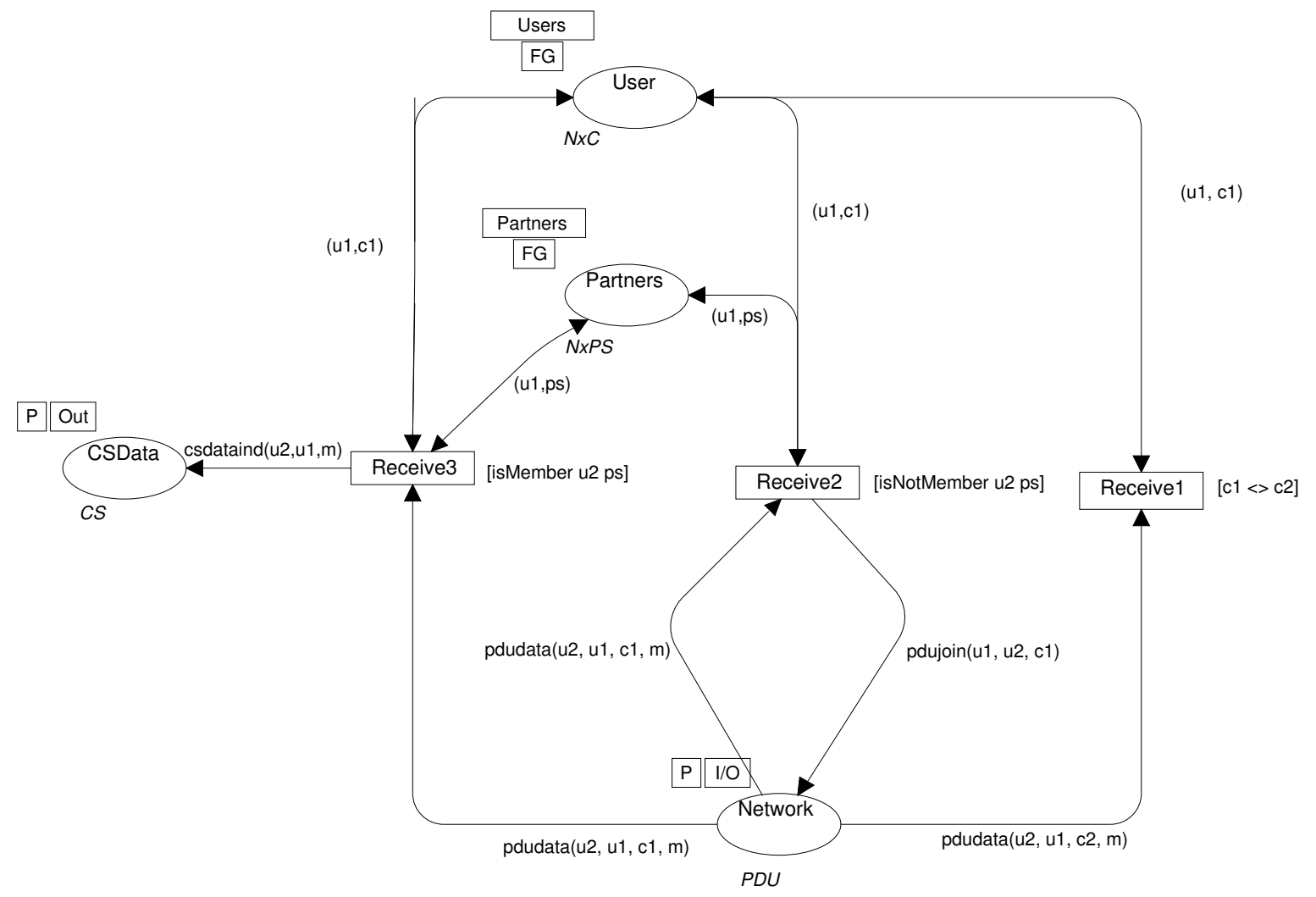

Figura E.17: Rede de Petri Colorida CP - Página Receive. 


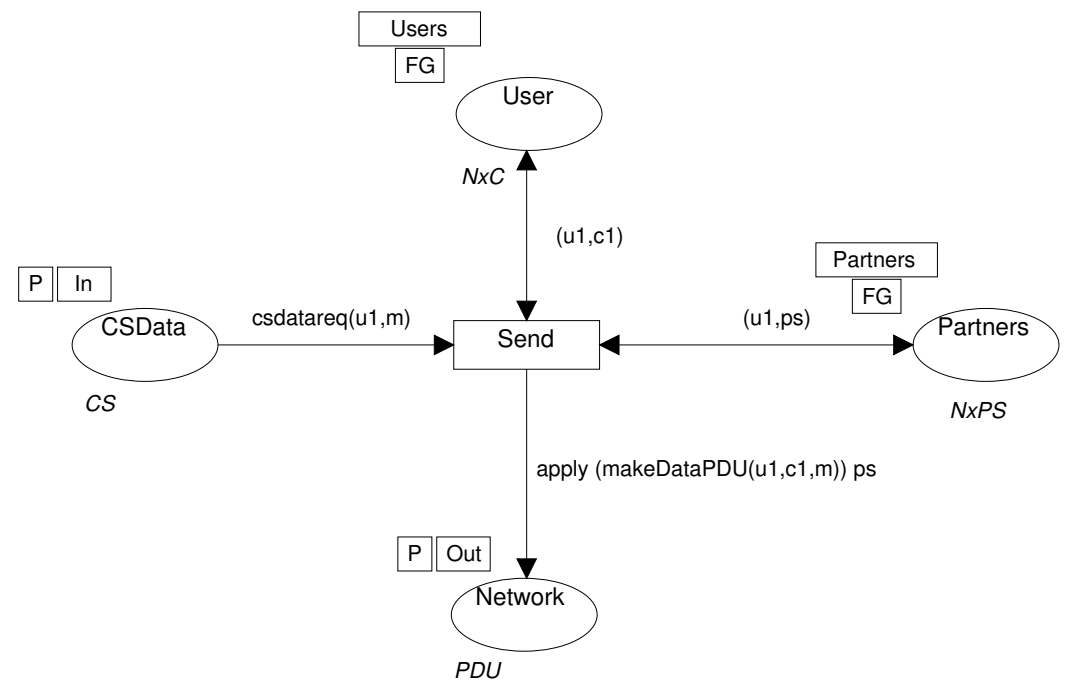

Figura E.18: Rede de Petri Colorida CP - Página Send. 
